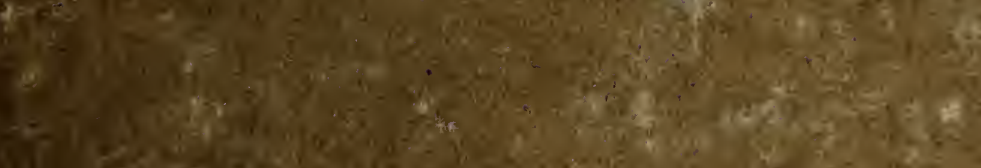

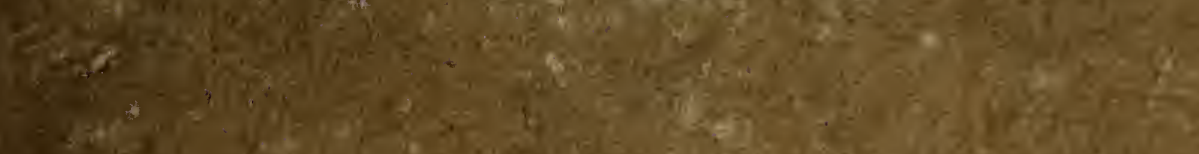

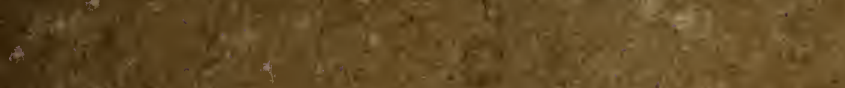

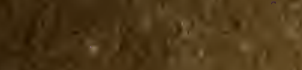

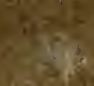

46

te

\title{
$2 x-4$
}

$2 x+2=$

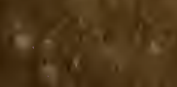

\section{if 8}

8 




\section{Digitized by the Internet Archive in 2017 with funding from Getty Research Institute}

- https://archive.org/details/promtuariumrerum00kund 


\section{PROMTUARIUM}
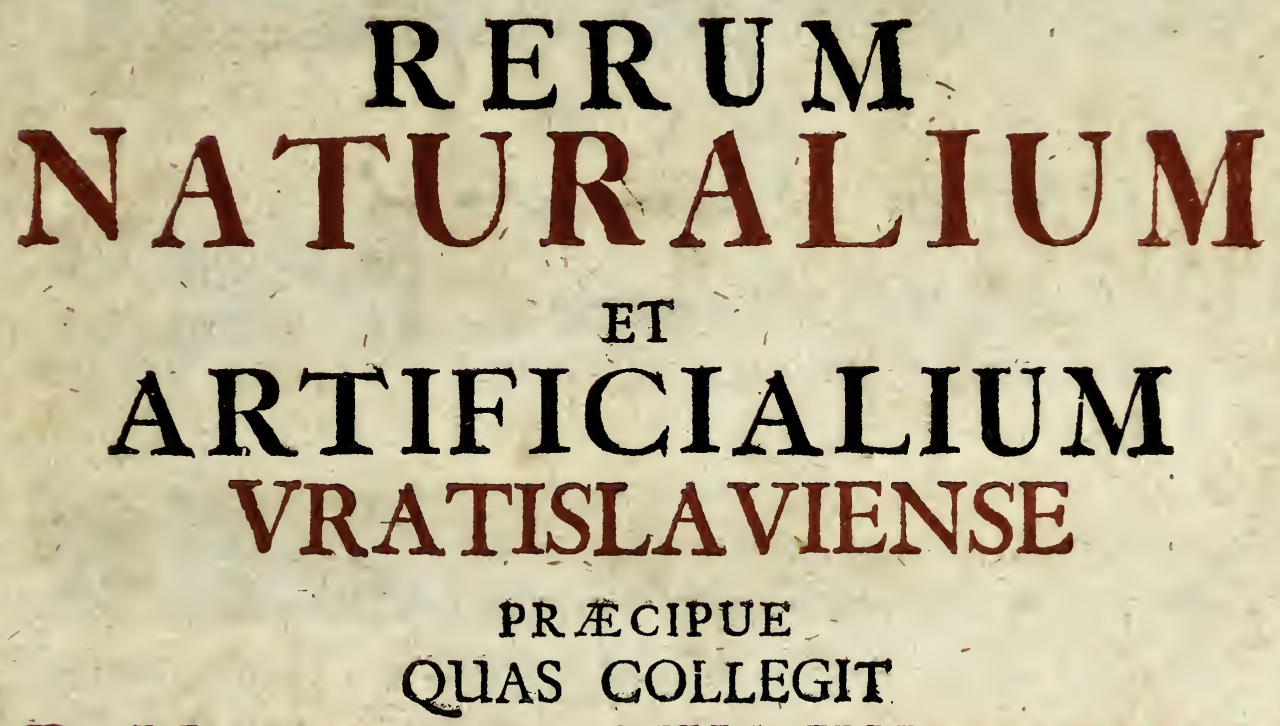

D. 1O. CHRISTIANUS KUNDMANN - MEDICUS VRATISLAVIENSIS.

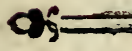

VRATISLAVIIE APLID MICHAELEM HUBERTLM, M DCC XXVI. 
INUSUI

9. Fr. Bhemenbach itys.

20176TWLTRAOA

WuPRAgY

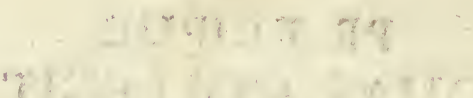




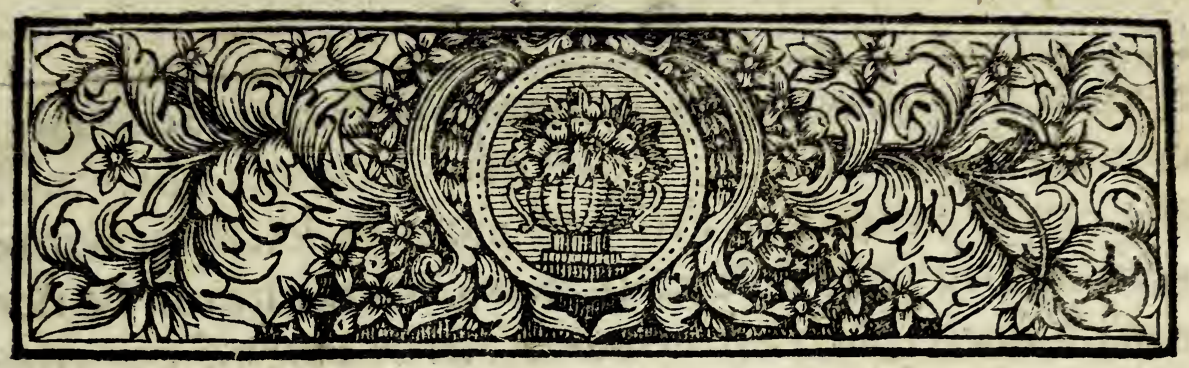

\section{B. L. S.}

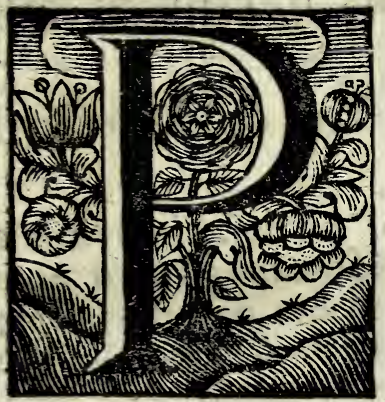

Zomtuarium hoc typis exfcribere non fuiffet animus, nifi petitis amicorum abfentium fatisfacturus; aut qux bis, \& pluries posfiderem, iis gratificari; aut ex apparatu aliorum, defectus Collectionis mex fupplere intendiffem; aut qux hic $V$ ratislavis curiofa extent, ipfis notificare, animo ftaret fententia.

Tuque etiam, qui omnia fugitivo oculo perfpexifti, habeas quo memorix tux fuccurratur, prexcipue cum au. ctores allegaverim, ubi pleraque hæc aut defcripta, aut ære incifa reperiantur; quod defiderandum in omnibus $\mathrm{Ca}$ talogis, huc usqae editis, aut a Michaele Bernbardo Valentini in A ppendice Mufei Mulcorum collect is, aut poftmodum publicatis, $\left.{ }^{*}\right)$ ubi non raro rem vilisfimam \& vulgatisfimam, pro pretiofisfima \& rarisfima, venditatam legas.

Cxterum fi qux hic offenderis, tibi melius cognita \& per(pecta, rogo, ut tuas nobiscum communices accu- 
ratiores denominationes, defcriptiones, obfervationesque dabitur forfan occafio ea addendi, \& omnia uberibus locupletandi; precipue delineationem \& defcriptionemearum rerum, nullibi \& raro alias obvenientium \& notarum adjunxi in Collectione Vratislavienfi eventunm Phyfico-Medicorum fingulis annis obtingentium; item adjungam pluribus, in Examine Fos filum E Lapidum figuratorum proxime prodituro. Vale interim \& fate

\section{Auctori \& Collectori.}

(*) Ita prodiit Mufeum Gotnoaldianum Gedani An. 1714. in 8vo. Mta. feum diluvianum quod posfidet job. Fac. Scheucbzerus Tiguri Anno 1716. in 8vo. Catalogus zahlreicher nüızlicher und fonderbarer von Narur und Kunft gebildeten Seldenheiten in Regno Animali, Vegetabili \& Minerali D. Cbrifiani Maximiliani Speneri Berol. Anno 3718 8vo. Catalogus rerum Minerdlum \& Metallicarum quas collegit, Giorgius Gothofredus Ricbter, Fribergx Anno 1719.800. Willem d'Orville Paftoris Harlemenfis Caralogus van een Uytmuntend Rabinet, beftaande in Hoorns, Scheipen, en rare zee gewallen, fchone Agare, Carneolyne, Boom en andere edele Gefteendens Amftelodami An. 1722. 8vo. Qux Mufea omnia preter Scbeuzemias. masm lectu dignisfimum, publicx auctioni expofita fuerunt.

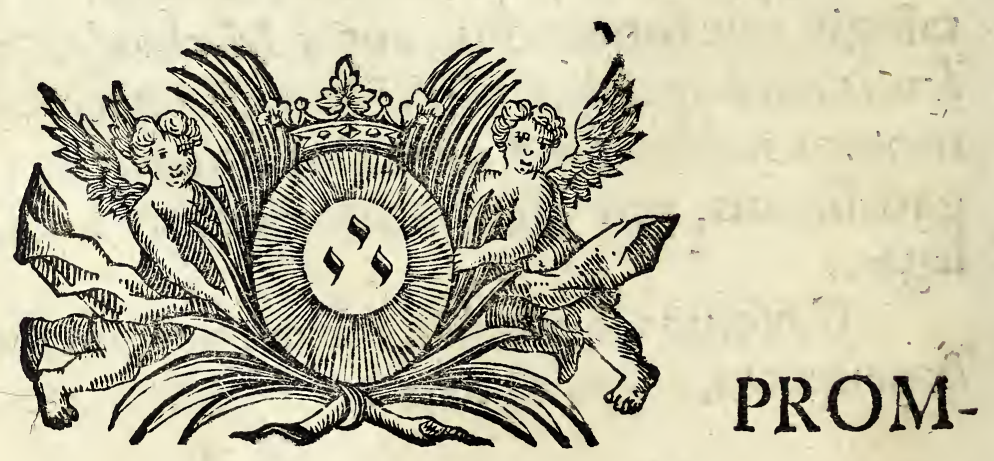




\section{PROMTUARIUM \\ RERUM NATURALIUM ET \\ ARTIFICIALIUM VRATISLAVIENSE。}


Acte tuis opibus num fis maneasque Budorgis,

Quas tacitụs donat mundus, quasomnia vincens

Collegit ftudium. Tibi, Præftantisfime KUNDMANN,

Qui primus mores naturæ hos mittis in auras,

Devinctos credas antiquis moribus aptos.

His paucis

Communem Eruditorum plaulum è longinquo comitabatur

N. $\mathbf{N}$. 
tor

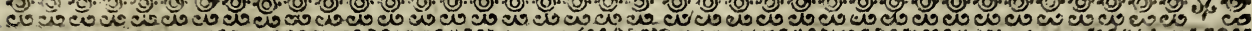

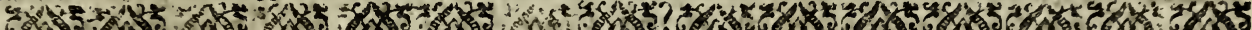
5. 10 250 S

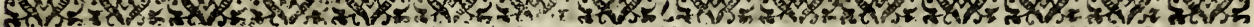
๓⿴囗十 ๓

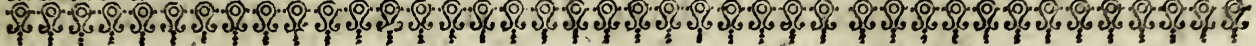

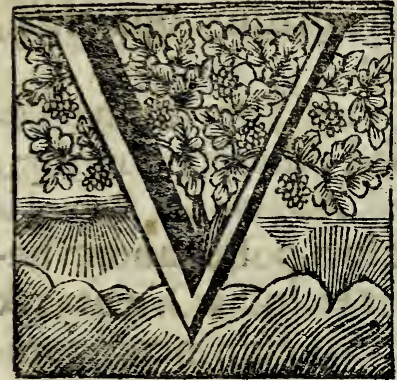

Ratislavie in Muleis Kret chmarianum, D. Laures, Vollgnadiorum, D. Scboltzii, Kalenbergeri, Crufii \& D. Sacbfii de Lewenbeimb, effe pracipua, teftatur Foh. GuilielmusMollerus in Differt de Tecbnopbyfiotameis Altorffiante XX. annos habita; \& poit eum Mich.Bernh. Valentini in fecunda Mufei Mufeorum parte, annis ab hinc fere $X$. edira,idem confirmat At vero jam A.M. DC. LXXIX. adeoque ante XLVI. annos nullum ex his omnibus amplius, fed longe alia extitiffe, fequens oftendit Progxamma fcholafticum, quod M. Georgius Wendius, Prof. Gymnafii Mar. Magdalenai celeb dicto anno publicavit, cujus titulus eft: Vratislavienfum quorundam Patronorum, E Civium fudium colligendi nummos; In hoc vero non folum Nummophyläcia recenfuit, led commemoravit etiam, quorum collectio ulterius extenditur, in fequentibus: Vratislabia in privatis Summorum, \& Nobilium yirorum Scriniis Numos, vel cum optimis Germano-," rum componendos, aliquibus etiam anteferendos, grate exhibet:,, Illuftr. Vir Dn. Fridericus, Maximilianus a Retbel E Hennersdorff, in, Scbmiedefeld E Elgut, S.C.M. Confli. E Afe for apud Capitaneatum Ducatus," Vratislav. Comes Palatinus Cafareus, Eques Auratus, quemadmodum, nupero hoc tricennali intervallo abfolutiffimum quoddam Mufeum,, fibi comparavit, ita in eodem prater fexcenta alia curiofa, quod-,", cunque ex Numifmatibus rarum aut charum judicatur, mira fo-," lertia, nec minore fumtu depofuit. Magnificus $D n$. Fo. Sigifnundus, ab Haunold in Sacberwitz,Incluti Senatorii Collegii Senior E'c. in recentio-,, ribus imprimis : Incomparabilis Dn. Daniel Cafpar a Lobenfein in, Kütlau, Reyfau E Roskowitz, S. C. M. Confil. E Reipubl. Vratisl. Proto-Syn-," dicus, in antiquioribus apprime, qux non ubivis obvia fpectantium, offerunt oculis. Nec laude fua defraudandi veniunt, Nobiliff. $D n$., Georgins Mauritius ab Hoffmanswaldaw in Arnoldsmüble, \& Nobiliff. Dn., 
Daniel i Reufch, Mercatorum, quos Vratislavia alit, facile primarius ac, Senior. Ille enim, fi juftam Cæfarum Teriem defideres a Julio Cæare, usque ad Gallienum in æreis dabit: Hic, five ex antiquioribus, frve, recentioribus felectiora Numifmata efflagites, quantum ex $\mathrm{Hol}_{-, \text {, }}$ landiæ provincia ante biennium felix afportavit, profua, qua erga, bonos humanitate fertur, libens communicabit.

Cum igitur \& hi Virilaudatiad unum omnes diem futum obie. rint; ex Mufeis vero, nalli fua conftiterint, fed diftrakta fuerint. omnia; dum fcilicet Rötbelianum Tit. Pleniff. Job. Adriano Lib. Baroni a Plencken, Regio Suprema inSilefia Curia Cancellaria, hic loci, poftea autem heredibus ipfus ceffit; Haunotdianum, qua Nummos ex India Orientali \& Occidentali allatos Arnfladium, (id quod nunc una cum incomparabiliapparatu nummario Gotha vifitur, quaNummos modernosalios in Bibliothecam Elifabetbanam urbis noftra, \& ad proximos agnatos pervenit; Labesfeinianum, in quo fimul Gemmæ antiqua multo elegantiffmæ fuerunt obviæ, Generofa Dn: a Rebdiger fumma 4000 . Imperialium emit, unde poftea pleræque omnes in manus Judaorum inciderunt; Reufcbianum vero \& Hoffmannswaldavianum Dn. Ecclefiaftes Godofr. Hanckius hic loci maxima ex parte emtionis lege fibi vendicavit; ex pofteriori Mufeum Conchyliorum Bibliothecæ Eliffabethan teftamento legatum; apparatus autem picfarum tabularum præftantiffimarum magnam partem divenditus eft, exceptis illis, quas Gener, Generofiffimus Dn. Carolus Ludovicus a Cotnoitz, Senator Civitatis noftra Ampliffimus, adbuc poffidet: Ego quidem Promtwarizm rerum Naturalium E Artificialium, uti hoc tempore Vratislanis, partim in locis publicis, partim in Mufeis multorum Procerum \& quorundam privatorum affervantur, breviter delineare ; defcriptionem vero copiofrorem \& meditationem de fingulis inftituendas, in aliud tempus refervare volui.

Locis quæ Divino cultui funt facra, nitet quam plurimis isque magnificis Iratislabic noltra : In quibus dignitate atque opere primum eft Templum Catbedrale D. Fohannis in infula, inter primas Germaraia bafilicas citra injuriam cenfendum. Exordia hujus templi madueta redistawiam fede Epifcopali, quæ smogrowia primum, dein. 
de Bicine fuerar, pofuit Cafimirns Polonia Rex circa annum falutis 1052. - Id quod, cum initio ligneum tantum effet, fub $\mathbb{W}$ altbero Epifcopo circa medium Seculi XII. de latere, \& feeto per artem lapide exfru\&um, fubindeque inftauratum, nunc vero ferme totum marmoreum factum, in formam magnificentiffimam excrevit.

Et quidem furntibus Tit. Pleniff. Dni Sigismundi Leopoldi Comitis de Franckenberg E Ludwigsdorff, Ecclefia bujus Catbedralis Pralati, Decani, \& Caronici; quippe qui omnia Altaria Templi \& Sacellorum ex præftantiffimo marmore Pribornenfi, colorisalbi ceruleo rnixti, effingi, lapideis ftatuis fulgidius inauratis, aliisque ornamentis inftrui, in Sacello etiam Manfionariorum B.Virgini facro illa erigi, ejusmodi marmoreis loricis Sacella, in primis Presbyterium vulgo Chorum. communiri, ac quatuor ejusmodi lapideis ftatuis inauratis, Patres ecclefiafticos St. Gregorium, Ambrofium, Hieronymum, Es Auguftinum ad virilis ftaturæ magnitudinem repræfentantibus, exornari curavit. In hifce Altaribus fumtuofiffimæ picturæ Italorum, aliorumque artificum excellentiffimorum confpiciuntur: In quibus $S t$. Barbara an. te columnam ftans marmoream, gladio ad pedes ejus jacente (tanquam figno, quod $a b$ ipfo patre fuo fuerit decollata, ) proeffigie pla. ne eximia, cum St. Catbarina fuperius ereeta, qux Brandelium habuere artificem, in hoc templo funt habendx: Nifi quod Tit.Pl. Dn. Fob. Wenceslaus Zierowsky de Zierova, Cathedralis bujus ecclefie Pralatus Scbolaficus Es Prafidens Inclyti Regiminis Epifcopalis Niffenfis, it. Pl.Tit. Dn. Job. Francifcus Lib. Bar. de Hoffmann, Cathedralis \& Collegiate Vratisl. Ecclefiarum Prelatus, Cantor E Cuffos, item Prafidens ejusdem Regiminis Nifenfis, finguli fingula ejusmodi Altaria in parte meridionali proxime Sacrarium erigi curaverunt, in quorum ordine IX. tabulam mediam Rottmayerus a $R o$ fenbrunn St. Fofepbum depinxit, tenentem ulnis Chriftum puerum, cui ab Angelo corona I pinea, aliaque cruciatuum inftrumenta oftenduntur. De catero in tabulis Altarium aliis depicta confpiciuntur feqq. ut in ImoSt.Anna a Schmiedio pietore Viennenfi præeftantiffmo: In IIdo St. Fobannes Evangelifta ab eodem : In IIItio St. Carolus Borromeus \& fuperius St. Salcfius, Rome: In IV to Quatuordecim Patroni in afflietionibus, ab Ambrof. Mainardo ibidem: In Vto St. Michael Arch-angelus ab eodem: (De VIto vid, fupr.) In VII. St. Petrus \& Paulus ab eodem Mai- 
nardo: In VIII. St. Fobannes Baptifta Chrifum in Jordano baptizans, cum fupra exftante Zacharia \& Elifabetha itidem Roms: (De IX vid. fupr.) In X.St.Wenceslaus: In X1. St. Maria Major Rome: In XIl. St. Hedvoigis, Glogovie maj: In XIII. St. Leopoldus \& fuperius St. Sigismundus Roma: In XIV.St.Foh. Nepomucentis a Mainardo; qui itidem in Choro, ut vocant, minoriafcenfionem St Marie fcitiffime expreffit. Prope Presbyteriurn pro pietura Altaris vifitur ingens \& incomparabilis fere Tabula ex metallo, adfcriptis verbis: Viftoriæ \& Gloriæ St. Vincentii Francifcus Vr/snus, Epifcop. Nicopol. Præpofitus \& Suffragan. Wratislavienf, H.M. F. F. qui St. Vincentium in craticula reprafentat, ab Adriano de Fries fufa: Eregione autem fimilis exftat Tabula St. Maric Afcenfionem exhibens, opere cælato argenteo, quam Tit Pl. Canonicorum olim Prepogatus, Dn. Comes Gotthard a Scbaffgott che dictus, huic templo donavit.

Similiter Altare fublimius conftat ex argento folido, ne cardinibus quidem \& antepagmentis forium exceptis : $\Lambda \mathrm{d}$ hoc Epifcopus Andreas Ferinus 10000 . thalerorum fumtus expendir, illudque Anno 1591. d. 4. Maji, poltquam Paulus Nitfcbius, Civis \& Aurifaber urbis noftræ, affabre confeciffet, confecravit: In medio extat Cbrifli effigies cruci affixi argentea ingenti magnitudine, ftellis multis argenteis inauratisque cinda, una cum St.Maria \& fohanne ad crucem adftantibus; in foribus aurem comparent St. Fobannes Baptifta, st. Fobannes Evangelifta, St.Vincentius, St. Hedbvigis ; infra imago expreffa Jerini E. pifcopi, atque è regione infignia ejusdem, omnia illa quidem ex argento inaurato, a Bernbardo Edero hujus Bafilicæ Canonico inventa ac efficta: Subfcriptio habet: Andreas Epifcopus Wratislavienfis, Silefi fupremus Capitaneus, Altare hoc ex puro argento conflatum, ut pietatis fux in Deum \& munificentiæ in Ecclefiam monimentum exftaret, proprioære F.F. A. C. M. D. XC. Solet autem in hoc Altari variis diebus feltis, ac primis quorumvis menfium Dominicis confpici Velamen perquam artificiofum opere cælato argenteo Augufte Vindelicorum confeetum, quod pro Antipendio Altariobducitur. Inprimis in eodem videre licer fumtuofum \& belle fatis factum Tabernaculum, etiam omnino ex argento exftructum, quod opusfuperiori anno fuit abfolutum a fofepho Wolffg. Feffenmayero, Dicalterii Aug. Affeff.nec non Colonienfis Electoralis \& Saltzburgenfis Aulæ Argyropola, Cive \& fabro 
fabro aúrario argentarioque $\Lambda$ uguftano, cujus fumtus ad 14890 . florenorum afcendunt, \& maximam partem ex legatis Canonicorum Baltbafar. Lifcbii ab Hornau Suffraganei \& Ferdinandi Leopoldi Ducis Holfatis Cathedr.hujusEcclefixDecani provenerunt; cujus rei gratia etiam eorundem Infignia in parte fuperiori apparent : Cæterum vero in medio imago Salvatoris, five Ecce Homo; \& e transverfo st Jobannes Baptifta \& St. Jobannes Evangelifta, multis cum Angelis in ftatuis ex argento fufis; cælatura vero eminenti, St.Vincentius \& St.Hedobigis exhibentur, omnes illi quidem fole inaurato colluftrati, \& umbella argentea tecti. Et diebus feftis Apoftolorum aliisque confpiciuntur IV.ingentes ftatuæ argentex, fupra dietos tres Patronos \& Patronam Templi repræfentantes: Nec non effigies $S t$. Vincentii thoracetenus expreffa, quam foh.Klinge, Aug. Vindelicorum oriundus, hic loci ante biennium fabricavit, cujus pondus II2. marcas habet, \& pretium 1792. florenorum fummam efficit : huic inclufum eft caput St. Vincentit, quod Hieronymus Epifcopus numero feptimus, vel quinomen Epifcori Vratislavienfis geffit primus, quique Epifcopatum huc transtulit, ex Italia attuliffe perhibetur, cujus reliquum corpus Lisbone in templo Cathedrali colitur: adhæc pars capitis St.Fobannis Baptiftx patinæ aureæ inclufa oftenditur, quæ Husfitis in Bobemia tumultuantibus, Vratislaviam in Templum St. Fobannis deportata fuit, unde Pragam ron rediit. De digito autem indice, quo St. Johannes Baptifta Salbatorem noftrum f. Agnum Dei demonftravit, lcribir Tit. Pl. Micbael Jofeph Fiebiger Prælatus \& Magifter ad St. Matbia in Silefiographia renovata Heleniana Part. II Cap. VIII. 5. 8. pag. 33. „Digitum porro, qui reli„quas inter reliquis facras in hac Cathedrali oftenditur, St. Joban,nis Baptift $x$ effe humana quidem fide credimus; quin ramen in„dex ille fit, quo Cbrifum generis humani Servatorem tanquam $\mathbf{A -}$ "gnum Dei demonftravit, dubium nobis movet citatus R.P. Crugerius, „qui facrum hunc indicem dexteræ manus $S t$. Jobannis cryftallo in"clufum, \& auro exornatum in Offecano Monafterio ad fines Bohe„miæ a Ciftercienfibus Religiolis fibi oftenfum fuiffe afferit.

Habetur præterea in hac Batilica Johannaa-lapis, ut dicunt, miraculofus, in quo pedum plantæ St. Adalberti Epifcopi \& Martyris fat profunde impreffe videntur. 


\section{PROMTVARIVM RERVM NATVRALIVM}

Utalia pretiofa \& arte facta ornamenta ecclefiaftica, e. gr. argenreas nec non gemmis diftin tas monftrantias, (ut vocant) cruces, lituos, infulas, veltes facrificas, calices, cantharos, lychnuchos pen. files aliosque \&c. taceam : in quibus fingulari opere eft Infula, ex ftramine a Monacho Capucino Romæ mira arte confeeta ; \& alia, quam Regii Polonorum Principis facobi Ludovici conjux Sereniff. Hedvvig Elifabctha Amalia, una cum Principibus filiabus manu fua Olabie ingeniofe acu pinxir,infertis margaritis præftantisfimis e prada acceptis, quas Turcarummagnus (ut vocant) Vezirius in obfidione Viennæ in veftitu fuogeftaverat.

Suggeftus ornnino ex cæruleo marmore Pribornenfia fob. Ada. mo Karingero hic loci, quemadmodum ante memorata Altaria exfulptus eft. Supra exftat effigies Ecclefiæ militantis cum VI. fici'lis, uti ApocalypC.VI. præfiguratur, a foh. Georgio Urbansky hic loci fabricata, qui \& ibidem cælatura eminentiori st. Fohannem Baptifam in deferto, ejusque obtruncationem in carcere, porro in afcenfu $I V$. Ev. angeliftas, omnes illos quidem ex alabaftro inauratosque expreffit. Chriftum vero Salvatorem in fuggeftu depinxit Rome Ambrofius Mai\#ardi, ficut \& grandiores imagines XII. Apofolorum ad pilas templi appenfas, fumtum hisomnibus ferente Illuftriff. Comite deFranckenberg.

Adhæc magni æftimanda in parte templi feptentrionali in facello VIII. Mater virga cum fefulo in filvula quadam abietum a Lucs Cranacbio depicta: it. Johannes Baptifta cum Agno, pofk Tabulam Ara St.Vinceratii mediam ex metallo fufam, a Wilmanno effigiatus, Maximum huic Templofplendorem conciliant duo facella fpatiofa, magnis excitata fumtibus, \& pulcherrimis ftatuis infigniter exornata.

Primum fuis impenfis, dum adhuc in vivis effet, exfrui curavit, atque etiam corpus fuum polt mortem, quæ An.M.DC.LXXXIL. eft fecuta, ibidem tumulo inferri jusfir, FRIDERICUS Sacrs Roma ne Ecelefse Cardinalis, Hafse Landgravius, Epifcopus Vratislabienfis, Ordinis Militaris St. Jobannis Hierofolymitani in Provinciis Germanis Magnus Magifter, Princeps in Hertzfolden, Comes in Catzenellenbogen, Dietz, Ziegenbeimb, Nidda, Scbauenburg, Ijeriburg ES Budungen E.c. Sacri Romani Imperiinatio. nis Teutonick, E Regnorum Arragonis Ė Sardinie Protecter, nec non Ducatus utrins- 
utriusque Silefre fupremus Capitaneus. Atque hoc Sacellum conditum \& d. V.Sept. An. M. DCC. aperturm eft, in honorem St. Elifabethe, qua fuit Andree Regis inferioris Hungarie filia An. M. CC.VII. nata; An. M. CC. XXI. Ludobico Landgravio Haffia nupta; An. M. CC. XXXl. defuncta; \& An. M. CC. XXXV. a Papa GregoriolX. in numerum Sanetorum relata : Quamobrem fupra aram, nixa genibus, ftaturam jufz habens magnirudinis in nube confpicitur, VI. Cherubinis \& III. Angelis, puerorum fpeciem pra fe ferentibus ftipata tanquam miniftris, quorum unus dextra marfupium, finiftra panem geftat, ad fignificandam ipfius in pauperes mifericordiam; alter oftentat pileum Ducalem, ana cum fceptroRegio; tertius librum cum corona duplici renet, ad indicandam faftigii Regii depofitionem. Hæ omnes quidem, ficut \& fequentes ftatuæ, ex pulcherrimo: marmore Genuenfi candido $\mathbb{E}$ Mafta Carara, exfculptæ funt. In utroque Altaris tarere columnæ marmoreæ excelfæ colore cæruleo eminent,e quibus dependent II. Angeli volantes, infigni magnitudine: quax opera omnia Roma a celeberrimo artifice, Hercute Ferreti fabricata fuerunt. Et fub Altari oftenduntur offa. St. Clementis Marty ris, quæ ftatim poft feftum St. Elifabetbe ipfo Clementis die nominali folenniter accenfis lucernis publice coluntur.

Monumentum fepulchrale fequentibus rebus \& rationibus eft exornatum: fuper eə genibus nixus cernitur fupra laudatus Cardialis, elevatis complicatisque manibus, purpura amia us cardinalitia, mira fimilitadine effigiatus : fupraillum pendent Infignia, \& fuperius adhuc ruber, \& genuinus itle quidem ex ferico factus Galerus Cardinalitius. Ad dextram inferius confiftitmulier, longe fupra humanam magnitudinem, dextra folem tenens, finiltra fpeculum, $\mathrm{Ve}$ ritatem fignificans: hæc pedibus calcat Invidiam ad frmilicudinem vetulæ efformatam, cujus capilli multis implexi funt ferpentibus, quæque libros aliquot manibus tenet: In altero latere pari modo confiftit mulier ejusdem magnitudinis : hæc dextra geftat ferpentem, capite \& cauda in circulum coëuntibus, finiltra vero fipicas maturas ex hordeo ; qua muliereadumbratur Eternitas.

Supra Infcriptionem fepulchralem in medio exitat Calvaria coronata, fub qua Nummus lapideus ex aurei coloris marmore pulcherri- 
cherrimo cernitur; hic a duobustenerur leonibus marmoreisex ejus: dem generis lapide effictis; atque in illo ipfoFides fub feemin $x$ forma leoni infidet, qux dextra calicem, finiftra crucem tenet, cum Cardinalis Symbolo infcripto: Pro Deo, \& Ecclefia: Juxta pendent ex Ophite facta ornamenta; utrinque vero fedent duo pueri, quorum alter Pileum Cardinalitium, alter Biretum tenet. (Hoc opus a Statuario infigni Dominico Guidi fabrifaetum eft.)

Supra fores Sacelli comparet effigies Cardinalis thoracetenus, ab equite toto orbe celeberrimo Bernini expreffa.

Hxe ftatux folx, fumma multo majori quam 20000 . Imperialium conftiterunt: de quarum magnicudine \& corpulentia ut judicari poffit, tingularum pondus adjicio, \& ad modulum quidem ponderum Romanorum habet: Sta. Elijabetba 3600. libras: duo Angeli in columnis marmoreis 4350. libras: 3. Angeli in Altari 1700. libras: Cardinalis 3805. libras: Veritas 3956. libr. Conftantia 4259. libr. duo Leones juxta Nummifina 1500 . libr. duo pueri utrinque ftartes 3548. libr.

Summa eft : 26718 . Librarum.

Præterea totum opus ab imo ad fuperiorem projecturam usque ex cœruleo \& candido marmore ordine Corinthiaco eftexftruetum, ubi paffim per pieturas Vitæ \& miracula St. Elifabetbe adumbrantur: Fornix medius vero, \& teftudo, Italis Cupola it.laterna,cœleftem gloriam omniüm Sanctorum repræfentant, quæ a Piftore artificiofifimo facobo Scanzy in recentem calcem depicta fuit. In Sacrario ibidem oftenditur Scipio ligneus Stæ. Elifabethæ, quo ufa fuit ipfa; cui Cardinalis bracteas argenteas induci, \& quomodo ipfe ab illa defcendat, \& quxipfe fuerit, inferibi curavit: item veftitus ejus facrificus \& Cardinalitius.

Secundum, magnis fumtibus, exftrui fecit FRANCISCUS LUDOVICUS Archi-Epifcopus Trevirenfis, Sacri Rom. Imperii per Galliam E Regnum Arelatenfe-Archi-Cancellarius \& Elector, Generalis Militio Hierofolymitane Ordinis B. M.V. Teutonicorum in Pruffia Adminifrator, 6 Ejusdem per Germaniam, Italiam, partesque Transmarinas Supremus Magi. Aer, Episcopus Wormattenfis, E Vratislabienfis, Prapofitus Principi Ellbacenfl, 
Adminiffrator Prumienfis perpetuus, Comes Palatinus Rheni, Bavarie, Julix, Clivie E Montium Dux, Princeps Mörfe; Coadjutor Arcbi. Epifcopatus Moguntini, Comes Veldentia, Sponbeimii, Marchie E Ravenfpurgi, Dominus in Ravenfein, Freudentbal E Eulenberg Efc. Magnitudine præcedens Sacellum exfiperat, \& a Celeberrimo Architecto Cæfareo Dn. Lib. Bar. 3ob. Bernbardo Fifchero ab Erlach defignatum, fuperiori anno abfolutum, \& die Mofis confecratum eft. Opus itidem omnino ex cæruleo marmore Pribornenfi, usque ad projecturam factum, fex ejusmodi columnis XVI. pedalibus fine ulla adminicula ftantibus innititur, quas candide inaurata capitula \& pedes exornant, fimiliter ordine Corinthiaco. Altari impofita cernitur Arca foderis cum Sole Juititix oriente, \& omnia illa quidem ex metallo \& igne inaurata: hujus abuno latere eft Mofes, ab altero Aaron, ex candido marmore Tirolenfi ab Ferdinando Brokkoff, celeberrimo Pragenfium artifice, Viennæ fabricati: e regione vero Vecus \& Novum Teftamentum, prius quidem per Mofen velata facie, baculumque æneo ferpente circumftrictum manibus tenentem, pofterius imagine Chrifi crucifixi repræefenta um. Supra portas ab eodem artifice, ex eodem marmore,cælatura eminentiori, quatuor Noviffima, Mors, Judicium, Beatitudo \& Damnatio perquam eleganter expreffa confpiciuntur: fupra primam hane portam, duo fedent pueri, quorum alter clepfammy dium, alter calvariam tenet : fupra fecundam puer unus tubam inflat, alter urnam aperit ex diverficolori marmore Salisburgenfi eoque pulchro faßtam, cujusmodi fupra fingulas portas in medio cernere licet: fupra tertiam puer unusfub brachio tenet agnum, alter vero coronam ftellatan: fupra quartam puer unus fimiliter geftat hircum, alter ingentem librum five peccatorum indicem apertum, qui inprimis artificis ingenium concelebrant.

In Teftudine r.Cupola, Præcipitatio Luciferi per Archangelum Michaëlem; nec non IV. Evangeliftæ \& IV. Patres Ecclefix fupra nominati infra in fornice facelli a praftantiffimo pietore C. F.Carloni depieti funt: Utrinque vero Sacrificium Melchifedeci \& Cœnam Domini pietor Gallicus expreffic, fupradieto diverficolori marmore Salisburgenfi circumdata : Extrinfecus fupra aditum Sereniffimi Eleetoris Infignia ex marmore inaurato, \& e transverfo Serenitatis 
fuæ poreftas Ecclefiaftica \& Politica, prior Pedo Epif́copali, pofterior gladio reprefentatur: Infra autem facellum cœruleo \& candido marmore eft diftinctum, commiffuræ vero metallo eleganter expletæ funt.

Diverforum Epifcoporum \& Canonicorum hujus templi Monumenta etiam fpectatu funt digniffima : inprimis Precislai de Pogrella, qui ab An. M. CCC. XLI. usque ad An. M. CCC. LXXVI. Epifcopus fuit, \& cum chorum minorem, f. Capellam Manfionariorum, B. Virgini facram exftruxerit, ibidem etiam fepeliri voluit: Jacet, forma, virilem ftaturam longius excedente, habitu Epifcopali indutus, cum libro, quem manu tenet, \& cum leone ad pedes decumbente, ex candido eoque pulcherrimo marmore, arteficiofe omnino pro genio illius feculi excifus fupertabula marmorea coloris albi badio permixti, cum fequenti Infcriptione ex metallo fata: sinno Domini M. CCC. LXXVI die menfis Aprilis obiit Reverendiff. in Cbrifo Pater $E^{\circ}$ Dom.Dom. Preceslaus de Pogrella Epifcopus bujus Ecclefie E Fundator Ca. pelle, Orate pro eo Deum. Sub Infignibus autem legitur: Precesla de Pogrella Epijcopus Wratislabienfis temporum fuorum felicitas. Juxta Precislaum in Choro Manfionariorum cineres reconditi Johannis IV. Roth ditti, Epifcopi ab An. M. CCCC. LXXXII. usque ad An. M.D. VI. ubi imago ejus confpicitur in tabula metallica eleganti ereeta, quæ V.ulnas excedit, cum hoc Elogio: fobannes IV. Epifcopus Wratisla. sienfis vera piorum Pontifcum imago. Ad latus Aræ primarix eodem modo ex metallo fufæ jacentes cernuntur, $a b$ una parte effigies $E$ pifcopi Petri II Novack dieti, qui An.M. CCCC. LVI. defunetus eft, ab altera, Rudolphi, qui An. M. CCCC. LXXXII. \& in Choro Henricus, qui An. M. CCC. XIX. ibidem fepultus fuit. In Sacello primo feptentrionem verfus jacet Epifcopus Johannes V. Thurzo dictus, forma ftaturam virilem exæquante, e faxo, \& juxta Aram argenteam, quam ipfe, ut fupra dictum eft, exftruxic Epifcopus andreas Ferinus ex rubro marmore An. M. D.XCVI. excifus: proxime Sacrarium vero Sebaftianus Epifcopus Roftock diêus. Præterlapfo anno, honoris caufa, primo Epifcopo Godofredo, \& e regione Epifcopo Nanm kero pulcherrima Monimenta e marmore nigro Cracovienfi \& caruleo Pribornenfi, lapideisque ftatuis inauratis erecta funt; infra au- 
tem cælatura eminentiori a prædicto urbansky in alabaftro Stolbergenfi, fub primo (monimento) efformatus cernitur Epifcopus Godofredus, finiftra Dagonem evertens, dextra vero Aram Chriftianam demonftrans :' fub altero monumento Nankerus repræientatur, Jobannem Bohemiæ Regem excommunicans, de cujusrei caufa dignus eft, qui evolvatur Dn. Prælatus Fiebiger in Silefiographia Heneliana renovata Part. II. Cap. VIII. pag.90.

Ex Canonicis fplendidiffima \& artificiofiffima Epitaphia habent: Adamus Wreiskopf, qui Suffraganeus fuit, quapropter etiam folenni amictu ornatus cum infula \& pedo Epifcopali ex rubro \& candido marmore forma fupra humanam auguftiori e regione fugge. fus jacet: Et Baltbajar Lifcb ab Hornau, qui paucis ab hinc annis, quia præcipue fundationibus plurimis optime de hoc templo fuit meritus, pulcherrimum Monumentum ex candido \& cœruleo marmore accepir. Alia e vario marmore erecta Epitaphia Canonicorumaliorumque funt fequentia, ut: Ferdinandi Leopoldi Heredis Norwegiæ, Ducis Sleswici \&Holfatiæ, Cafp. Henr. ab Oberg, Caroli Neasdri de Petersheidau, Francifci Stanislai Baucke a Roftock, Antonii Erasmi a Reitlinger, Francifci Engelberti Barbi, Abrab. Ignatii Kircbneri de Lilienkirch, Jobannis a Leuderode, Job. Wenceslai Zierowsky de Zierova, Joh.Franeifci Lib. Bar. de Hoffmann; \& denique Chriftiani Hæredis Norwegiæ \&. Holfatia. Ducis, qui An. M. DC. XCI. in prœlio Salankemenfi contra Turcas gloriofe occubuit, cujus heroicum cor hic conditum fuit.

II. Templum ad Stam Crucem in eadem Infula. Affervatur in Thefauro hic Radix, quam Dn. Dr. Philippus facobus Sacbs a Lewenbeimb in Ephemeridibus Nature Curioforum Decur. I. An. I. Obfervar. CXVI. pag. 269, ita defcr. Radicem hanc An. M. CC. LXXXIIX. , in Infula hac inventam fuiffe, cum Henricus Probus Dux Silefix fun-," damenta quæreret pro exftruendo Templo St. Bartbolomeofacran-", do, itaque ob inventam hànc radicem permotus Dux ifte, aliud, Teinplum fuperius inferiori huic fuperædificavit, in honorem Cru., cis. Superiorem raaicis partem ferunt repræentaffe crucifixum, fed," quod argento hæc pars effet circumdata, in direptionibus detrun-,, cata eft, nifi quod aliqua pedum fuperfint quafi veftigia. Ex me-s 
,dia Trunci radicis parte ab utroque latere bine Icuncule exfurgunt, ea ,in figura, quam xre delineare curavi, a dextra quidem quafi fexus ,fœminini cum mammis, a finiftra parte quafi masculini, ubi aliquor „parvæ \& prætenues radices barbæ fpeciem exhibent; quales te„nues Radices in fuperiore parte in capite quafi capillorum quorun"dam fparforum figuram, non minus quoque fimiles aliæ Ciliorum „pilos, aliosque in partibus inferioribus monftrant. Inferior trunci "pars in radicum olim corpus unita, pariter in iftis depradationibus "refecta fuit, nunc mutilam exhibet Radicem : ipfa vero tota Radix ,hinc inde cariola eft \& a vermibus exefa, mollis tamen, ut certo vi"deri pollit, non lignum efle, fed radicem, illamque cum Dn. D. Hen"rico Vollgnadio Collega Curiofo aliquoties probe perluftrare concef"fum fuir. Ruditer quidem omnia figuram exhibent, ita tamen "ut membra ad eum modum, quo delineata funt, diftingvi po. "tuerint.

In Templo ipfo, Septentrionem verfus, in tabula magna cernitur pi̊tura vetulta, modo dietum Templi conditorem, Ducem Henricum Probum, exhibens, qui dexira gladium, finiftra clyseum cum Aquila Silefiaca tenet.

Ante primum Templiaditum in cadena pendet pars cflis, quod pro giganteo venditatur: Hoc idem Georgius Antonius Volckmann in Silef Subterran. Tab. XXV. num. 2. æri incifum delineavit, \& „Parte 1. Cap. V. pag. 1 46. ita defcripfrt: Diefen Knochen halte ich „vor ein os femoris, der auf dem Dohm zu Breslau in der Creutz "Kirche gezeiget wird; die länge if zwey Schu, weniger ein halben "Zoll, die obere und dicke breite ein halber Schu, die mittere fünff "und ein halber Zoll, und die unterfte vier und ein halber Zoll, wie"wol es, wie man an beiden Enden, alwo es abgebrochen oder ab„gefaulet, noch länger gewefen.

III. Templum D. Virginis, quod in Arena Infula Regularium Ordinis $D$ Augufini Canonici inhabitant, Altaribus plane novis eo. dem modo \& Organo pnevmatico omnino fere arite paucos annos exornatum eft, in quibus preftantifimæ Altarium picturæ funt illæ, quæ proxime Aram primariam cernuntur; ut St. Apollonia, quomodo dentes ei forcipe effringuntur, fupra hanc vero St. Petrus, \& e regio. 
regione decollatio St. Barbara cum Difma l. dextro iatrone fupra exftante, a celeberrimo Willmanno depicta.

Ceterum Templi hujus Turris admodum excelfa eft, præclara arte conftrusta, \& triplici ambitu inftrufta.

IV. D Facobi conobium ab Henrico Pio, D. Hedivigis filio a Tartaris cæfo atque iftic humato, conftrufum avorum memoria $D$. Vincentii nomen induit: Infra Tabulam Aræ mediam, effigies Ejus in Iaxo cernitur, quomodo Tartari cervicem pedibus calcat. Altaria, Suggeftus, Podia, Organum pnevmaticum \&c. itidem eandem præ fe ferunt itructuram, atque Tabulæ Ararum mediæ, item parietibus affixæ, ferme omnes a Willmanizopictæ funt, in quibus quæ Chorum proxime tangunt, arificem maxime laudant.,

Nunc temp ris Pralatus, quiadhuc in vivis eft, Tit. Pleniff.Dn. Dn. Ferdinandus Comes de Hobberg, facellum exftrui curat prorfus incomparabile, quod ab Ignatio Provifore Marmorario Viennenfi undique gyplo marmorato obducitur; quis vero, \& quibus picturis telfudinem $\int$. Cupolam exornare debear, de eo nondum eft conftiturum.

Ex magnificis Templis Parochialibus in quibus Ebangelicorum facra fiunt, eit:

I. Templum D. Elifabetbe, ab Henrico III. circa medium Seculi XIII. ædificatum: Juxta ftat Turris præcelfa, cum hiltoria ruinæ, quæ in templo depieta, \& extrahoc in tabula turri affixa cernitur.

Infignem eadem turris habet Companam An. M.D. XII. fufam, cujus ambirus eft XIV. ulnarum Vratislavienfium \& inferior craffitudo ulnæ fere dimidiæ, pondus vero CCXXIV. Centenariorum.

Tabula Aræ primariæ media, Cœnam Domini repræfentans, etiam artificem habuic præftantiffimum Willmannum: \& in Pila, facrario proxima, luftrari meretur antiquum Epitaphium Magda lens Kromajeris de An. M. D. LXIV. in quo refurreetio, quemadmo. dum Ezechielis XXXVII. defcribitur, perquam belle depicta elt; quo addendum Henr. Ribifibii J. U. Doet. \& Conf. Car. Monumen- 


\section{4

tum ex rubro \& candido marmore, it. Fob. Cratonis de Kraff theim III. Imperatorum Medici celeberrimi, ex alabaftro albo, refurreetionem mortuorum eleganter exprimens.

Tum porro attentionem meretur defuneti haud ita pridem Proto - Camerarii noftri Tit.Dn.Georgii a Wolff Monumentum, quod poft fuggeftum, qui totus ex nigro marmore Cracovienfi conftat, rubris candidisque columnis ex Salisburgenfi marmore exornatum, in facello eft erectum.' Hoc ipfum ergo fundamento ex lapidibus, qui tanquam faxum nativum fuerunt excifi, innititur; huic impofita eft bafis quadrata ex cœruleo marmore Pribornenfi, in illa vero ingens confpicitur tabula, enigro marmore Cracovienfi, cum Inferiptione. Huic bafi quadratæ innititur ingens Pyramis ex eodem marmore Pribornenfi, cujus apex vero nubibus corufcis, quibus nomen JEHOVAH infcriptum, vel Gloria (ut vocant) tegitur. In bafi Pyramidis exftat effigies thoracetenus ftatura jufta expreffum, infra ipfam Infignia Wolfiana eminent, utrumque opus ex candido marmore pulcherrimo f. Maffa Carara factum. Áb uno latere mu. lier confiftit cum alis \& flamma in capite, Divinum amorem repræfentans, quxe effigiem una manu fvaviter amplectitur, oculos ad Gloriam dirigens. Ab altero autem latere paulo fuperius Angelus comparet, qui cor in fublime ad Gloriam effert. Infra utrinque duo fedent pueri, quorum alter prunas ferme extinetas fufflare conatur, alter vero manu calvariam tenens \& ad pedes clepfamydium videns everfum dejequmque plorat. Omnes hæeffigies a fupradiEto Ferdinando Brokkhoffio fact $æ$, univerfum vero opus a ftatuario urbis noftræ Job Adamo Karingero erectum eft. Inventor \& Direetor fuit Architectus Cæearius haud ita pridem defun tus, Dn.Lib.Bar. Joh. Bernbardus Fijcberus ab Erlach.

I1. D. Mar. Magdalenæ Templum variis Conotaphiis ex marmore confpicuum: In his fingulari quadam forma effulget Monumentum Arzatianum, cujus ftatuæ alias quascunque arte exfinerant. Fabricatori illius nomen fuit Mattbias Raucbmüllerus, isque c Tirolenfi Comitatu ortus eft. Continet autem monumentum illud fe- 
quentia: Sarcophago ex marmore nigro Cracuvienfi, quod ambitu ejusdem lapidis depreffiori circumdatum eft, infidet Gloria, palmam dextra, finiftra infignia tenens Arzatiana, cui fpes Coronam porrigit querneam ; Fama vero tenet Infcriptionem ex ejusmodi nigro marmore, mira arte concinnatam, fcriptura candida immiffa. Sarcophago nummus albus marmoreus eft affixus, vultum Dni ab Artzat exprimens, omnia illa quidem ex candido marmore Salisburgenfi, eoque pulcherrimo excifa. E regione autem in Sacello confpicitur ab ejusdem artificis manu aliud Epitaphium memorix Juvenis generofi a Pefaluzy dedicatum; fupra exftat ipfius effigies thoracetenus expreffa, quam fuperne puerulus manipulo florum obumbrat, infra autem juxta Nobilitatis Infignia puerulus alius fedet plorans, ex ejusmodi candido \& cœruleo Salisburgenfi \&c Pribornenfi marmore.

Suggeftum infuper habet eximii operis a Friderico Grosfio ftatuario perito An.M.D.LXXXI. ex alabaftrite translucenti in Polonia, \& marmore viridi ad Zabothum montem eodem auctore primum foffo, fculptum, \& variis hinc inde imaginibus exornatum. Adhæc in hoc ipfo Templo fub finem fuperioris anni abfolutum fuit artificiofiffimum \& dulcifimum omnino Organum pnevmaticum, pofteaquam Job. Reederus Berolinenfistres annos cum quadrante illi conftruendo impendit. Externa tibiarum difpofitio eft plane fingularis, cui demum multifaria ornamenta fculptoria fepe laudati Urbansky majorem fplendorem addiderunt: In medio eminet Gloria (quam vocant) cum vitreo fole rutilante five omnituente Dei oculo, \& paulo fuperius Eternitas. Summum locum occupat $a b$ uno latere Regius Vates Davidescum cithara, $a b$ altero Afraphius forma fupra humanam auguftiori ; aliquanto inferius utrinque 2. eminent Tympana, quæ a ligneis puerulis arte flexilibus pulfantur, \& Clavibus aliquot fupra Pedale conftruetis calcantur, quemadmodum item per pedale movetur Syftema quoddam campanularum, ubi campanulx numero XXVI. a totidem puerulis, qui encarpis funt implexi, \& una manu campanuiam, altera maleolum ex metallo tenent, pulfantur. 
Ceterum hoc Organon conftat LIII. argues fonorum choris, LXVI. Regulis, III. Clavium ordinibus, Pedali, X. magnis follibus, IV. epiftoniis, fanneis metallicis \& ligneis fiftulis MMM. CCC. XLII. cum in celebratiffimo Gorlicenfium Organo nonnifi MMM. CC. LXX. tibiæ fonoræ deprehendantur. Fiftula maxima in hoc noftro Organo ftannea, fub Clave $\mathrm{G} \cdot 3^{\frac{2}{2}}$. Centenarios gravitate exequa.: $5,12 \frac{2}{4}$. Ulnas longa, \& in diametro 14 digitos lata, capit 8. modios vel I2. amphoras, \& 64. fextarios. Fiftula fequens, A, circiter 3. centenarios gravitate continens $10 \frac{1}{2}$. ulnas longa, in diametro $\frac{1}{2}$. ulnam lata, capit 5. modios, cum quadrante vel 8. amphoras cum 4 . fextariis.

Difpofitio Chororum Vocalium eft fequens:

In Organo primario XIV. Vocum chori:

I. Regula primaria, extrinfecus confpicua XVI. pedes e ftanno. 11. Quintitenens

III. Octava

IV. Tibia Salicet dicta

V. Quintitenens

VI. Tibia lenior

VII. ORtava -

VIII. Quintá

XI. Canna

X. Super-Ofava

IX. Quinta ftrepera

XII. Tibia acuta

XIII. Mifcella

XIV.Tuba

XVI. pedes. ] ex metallo, VIII. i.e. partim

VIII,

VIII. ftauno par-

tim plum. VIII. ped. e ligno IV.

III.

IV.

II.
duplici ferie
quadruplici ferie octuplici ferie

VIII. ped. 


\section{In fecundo Clavium ordine funt XIII. Vocum}

\section{Chori.}

I. Regula primaria

II. Cornu Damx

III. Carina

IV. Ostava

V. Tibia Salicet dieta

VI. Coni

VII. Quinta

VIII.Super. OEtava

IX. Tibia fylveftris

$\mathrm{X}$. Quinta

XI. Cymbalum

XII, Mifcella

XIII.Vox humana
VIII. pedes.

VIII.

VIII.

IV.

IV.

IV.

III.

II.

II.

I. \& dimid.

ferie triplici

fextuplici

VIII. ped.

exmetalla.

In tertio Clavium Ordine XII. Vocum Chori.

1. Regula primaria in confpectu

II. Viola di Gamba

III. Pileata

IV. Oetava

V. Tibia lenior

VI. Quinta pileata

VII. Super. OAtava

VIII.Quinta

IX. Sedecima

$X$. Sefqui altera

XI. Cymbalum

XII. Lituus
VIII. pedes, ex ftanno. VIII. ex metallo. VIII.

IV.

IV.

III.

II.

I. \& dimid.

I.

ferie duplici. ferie triplici. ex ligno. ex metallo. ex ligno.

1<smiles></smiles>

Sexmetallo:

VIII.ped.a b usque $\overline{\overline{\mathbf{C}}}$

Hæ XII. Vocum Ordines ad Tonum utrumque, tam Chori, quam Gameræ, ut vọcant, accommodari poffunt. 


\section{- In Pedali XIV. Vocum Chori.}

1. Regula primaria in confpefu pofita,

II. Bafis-Oftavæ

III. Quintitenens

IV.Pileata maxima

V. Oelava

VI.Quinta

VII. Super - Octava

Vili. Canna

IX. Cornu vigilium

X. Mifcella

XXXII.ped.ex ftanno.

XI. Buccina

XII Fagotto

Xlli. Tuba

XIV.Buccina

Huc accedunt

XVI. ex metallo.]

$X V I$. ex ligno.

XVI. ex ligno.

VIII. ex metallo.

VI. ex metallo.

IV. ex metallo. Toni pro

VIII.

II.

decemplici in fene.

Choro \&

XXXII ped.e ligno.

XVI.

VIII.

XVI.

Camera.

XV. Sÿftema Campanularum.

XVl. Tympana.

III. In Templo St. Barbara exftat vulgare quidem Epitaphium ligneum, quod memorix Francifci Hoferi civis \& alutarii Vratislavienfis An.M. D. LVIII.dedicatum ; attamen ideo confideratu dignum, quod virille cum barba depietus eft, toram reliquam ipfius ftaturam excedente: qui tunc temporis ea fuit celebritate, ut ipfe Imperator CAROLUS $V$. hunc virum ob prolixàm barbam Viennam accerfere non fit dedignatus, gratiofum ei munus etiam pollicitus, ubi quidem bonus ille vir nil aliud petiit, quam ut, fe olim defuneto, univerfus Vratislavienfurm Magiftratus funus comitaretur. Et prope Januam templi majorem firus eft Wenceslaus Dux Saganienfis An. M. CCCC. LXXXVIII. defunetus, cujus Sepulcrum Tabula me. tallica contectum eft.

I.In Curia Cælaris, Barg dieta, quæ Sigismundi Imperatoris opus (tefte Henelio in Breslographia) exiftimatur, \& ubi antea Camera 
Silefiac $¥$ Collegium confeffum fuum $\&$ conventum habuit, Patres Societatis $\mathcal{F} \subseteq$ fu, ex jpfo fundamento magnum \& praclarum Tem. plum inde ab An. M. DC. LXXXIX. exftrui curaverunt; Aravero.primaria longe elegantiffima, demum hoc anno abfoluta eft. Inventor illius eft, Frater Cbriftopborus Taufcbius, qui difcipulus celeberrimi Frat. Pozzi fuit, ficut \& Circumcifionem in hoc Altari artificiofe depinxit. Conftat autem Altare ipfum ex lapidibus lateribusque gypfo marmorato, a fupra dicto Marmorario Ign. Probifore artificiofe obductum, ita ut colore \& politura marmori præftantiffimo rubro, flavo, candido, ccruleo \&c. longe fimillimum videatur:Supremæ ftatuæ albæ ex gypfo, calce \& carbonibus perquam belle fabricatæ, repræfentant Cceleftum Gloriam cum Ángelis ; imæ vero majores lapideæ a dextris Fidem, quomodo colitur, a finiftris vero Incredulitatem, quomodo in infernum detruditur. Cum igitur hoc Templum nomini JESU fit confecratum, idcirco fuperne hxc fcriptura exitat, literis metallicis \& igne inauratis: In nomine JESU flectatur omne genu : fupra Coleftium; prope Fidem, Terreftrium; \& prope Incredulitatem, Inferorum. In toto vero templo non nifi Acta \& Fa\&ta IESU, item Patrum fefuitarum, a Celeberrimo pictore Fob. Micbaele Rottmayero a Rofenbrunn JOSEPHII. Imperatoris PiAtore domeftico undique in recenti albario depicta fuerunt, quem laborem An. M. DCC. VI. abfilvit. Supra in fornice, proxime Aram primariam depictum eft nomen JEHOVAH cum fidelibus Vereris Teftamenti, in illo JESUM adorantibus : In majori circulo, \& quidem intermedio, Principes \& Domini omnium IV. Inundi partium, populique comparent, quibus nomen JESU eft communicatum, quamobrem in medio, St. Francisci Xaberii celeberrimi Miffionarii e Soc. Fefii ad gentes præcipue, ficut \& aliorum, e. gr. St. Ignatii Lojole \& præcipuorum Fundaturum Sacri cujuscunque Ordinis, quorum opera nomen JESU propagatum fuit, inprimis $S$. $S$. Apofolorum Facta expreffa funt; In medio autem Nomen I. I I. S: cum Matre Virgine, St. Fofepbo \& Fobanne Baptifta, \& Archangelis St.Mi. sbaële \& Rapbiële \&c. inferiptum eft. In circulo poftremo cœleftis apparet Gloria omnium Beatorum cum Infcriptione adpofita, ad 
primum : A Solis Ortu : ad poftremum : Usque ad Occafum: conjunction in Medio: A Solis Ortu usque ad Occafum laudabile Nomen Domini.

Supra in Choris confpiciuntur fata pracipua quæ JESU in carne acciderunt: fcilicet $\mathcal{F}$ fus Gaudium Angelorum, quomodo ab. Angelis puer colitur: Fefus pauperrimus, in Nativitate in Itabulo: fofus Lumen Confelforum, in remplo in ulnis Simeonis: fefus Sapientia æterna, ibidem exacta XII. annorum xtate in medio Doftorum : Fefus filius Dei vivas, in Baprismo per Fobanenem : Fefus fplendidior fole, in Glorificatione: Fefus miriffimus, in ingreffu ad Palfionem : Fefus exemplar virtutum, in pedilavio: Fefus patientiffimus, in flagellatione: Fefus obedientiffimus, in crucifixione: Fefus gloriofiffimus, in refurrectione: Fefus mediator Dei \& hominum, in afcenfrone: fofus fortitudo Martyrum, in lapidatione $S t i$ Stepbani - Fefres fponfus virginum, inter V. virgines prudentes; \& denique e transverfo majoris feneftra, $\mathcal{F} f$ fus emtores $\&$ venditores, ana cum vendentibus columbas flagello e templo ejiciens:- Infra proxime Aram primariam, quia ibi Sacra Communio celebratur, st. Fobannes Baptifta Chriftum Agnum Dei demonftrans cum fubfcriptione: Ecce qui tollit peccatum mundi, Joh.1,29 \& e regione fefus cum Centurione Capernaitico, \& fubficript. Domine non fum dignus, Matth. VIII, 8. effigiatus cernitur.

In Sacellis vero fata \& miracula Sanctorum, quibus confecrata illa funt, fimul in tabulis Altarium mediis depicta confpiciuntur: at in primo, St. Ignatii Lojola Fundatoris hujus Ordinis: e regione St. Francisci Xaverii: intertio, St. Mariz Virginis: in quarto, St. Jofe2bi.: in quinto, St. Anne: infexto, St. Michaelis Archangeli : in feptimo, St. Erancisci Borgie.: in oftavo st. Hedroigis.: in nono, St. Jude Tadkdiai : in decimo, st. Sebaftiani. in undecimo, Purgatorium.

Infra Organum pnevmaticumeres comparent pi\&ur $x_{\text {, Adora }}$ cionem JESU: in Cotis, Phil. II, 10, in Terra, A\&tor.IV,12. \& fub Terra, Marc. X VI, 17. exhibentes: In aditu vero Petrus Claves regni ecelorum a JESU accipiens, \& e regione Paulus, claudum hominem Liftræ fanans, Actor. XIV, 8: 9. 10. Superne autem fejüs cum Samaritide actaetu fimbria vefimenti ejus fanatx confpicitur. Ne- 
que hoc loco prætereundun eft tilentio, quod in media fere fornicis fummitate, Rottmayerus fe ipfe perfecta fimilitudine, in hujus vero rei fignum infra fe canem funm per loricam tranflientem de. pinxerit.

11. Templum Albertinum a Eaurentio Epifcopo Vratislavienfi An. M. CC. XXIII fundatúm, Dominicani inhabitant, ibi Ceslao precibus \& lacrymis Dei mifericordiam implorante, Tartaros ab arcis Vratislavienfis obfidione, flammis de cœlo delapfis, repulfos, Polonicarum reram Scriptores tradunt: Paucis ab hinc annis hajus B. Ceslai honoribus Sacellum pulcherrimum cum teftudine \& laterna hi Patres exftrui curaverunt, quod in recenti albario pictum, ad projectum vero usque ex pulcherrimo marmore W' ederizenfi maculis nigris candidisque perfperfo, havd longe a Zabotho monte effoflo, erectum eft. In Altari ex eodem marmore, in albo Sarco. phago ex Alabaftrite Stollbergenfi facto, ofla ejus quiefcunt. Et transverfo duæ Tabula majores erigentur, in quarum altera hic Prior puerum Tartaricum baptizat; in altera vero puerum Tartaricum refufcitat; a Celeberrimo Antwerpienfium, nunc vero hic loci degente Pietore Joh. Francifro de Backer confecta.

III. Templum D Dorotbee Caroli IV. Imperatoris fumtibus conditum; ubi inter reliquas piquras fatis bellas praftantiflima eft ea, qua St. Wencestaum refert a Willmanni manu profecta. Et qua

IV: in Templo Commendiataris Corporis Cbrift vifuntur.

Porro V.apud Fratros Mifericordie five in Templo S:S. Trinitati confecrato, in fuburbio Olavienfi:Steinel Viennenfis Aram admodum elegantem invenit, Thom. vero.W eifsfeld ftatuarius hic loci fabrica vit, Tabulamque illius mediam Celeberrimas Pietor Viennenfis Schmied picturis illuftravit.

In conobiis Virginum ad st. Claram vetufta effigies, Annan Hew sici Pii Uxorem Ottocari Bohemiæ Regis filiam repræfentans, qua An. M. CC. LXXV. Henricus vero V1. ultimus Vratislavienfium Dux An. M. CCC. XXXV. eo fepultus fuit, in effigie lapidea Bux gladium dextra, finiftra vero clypeum cum aquila Silefiaca tenet, atque ctiam alix fatis elegantes pifturæ minime funt omittendx.

Imprimis autem apud Virgines ad st. Urfulam IV. majores ef- 
figiés perquam egregia memoratu digniffimæ funt, ut: St. Xaverius orans, \& St. Urfula a Willmanno, SS. Trinitas vero, \& Cruciffxio Cbrifti a Rotimayero depißtæ: Et tum deinde in omnibus Templis etiam extra illosimago St. Nepomuceni, ex quibus in templo Cathedrali st. Fohannis una ex marmore, ad St. Mattbiam vero altera, ex faxo arenario a fæpe laudato Urbanskio hic loci per quam belle fabricata ef: ut alia Artis Opera fpectatu digniftima, quæ in reliquis illisque plurimis templis notari poterant, nec non Cœnobia magno artificio \& fumtu exitrueta, e.gr. in Infula Arena, ad St. Vincentium, ad St. Mattbiam item Minoritarum ficco pede prætereamus.

In 1 dificiis publicis meritiffimo jure, primo loco laudanda mihi Curia, memorandumque eft, in Erario vitreum urceolum \& vitrum antiqui operis elegantiffimi, quæ ufibus St. Hedwigis quotidie inferviiffe dicuntur ; \& porro filii ipfius Ducis Henrici Pii gladi. um \& cingulum fingulari forma, affervari.

Multo plura jam dicenda funt de præclariffima Bibliotbeca Elifebethana, qua prope Templum ejusdem nominis in priftino Auditorio Theolngico eftrecondica. Orta vero illa eft An. M. D.LXXVI. ex Legato lautifimo Tit. Dr. Thome a Rebdiger Es slifa: fiquidem is in peregrinatione fua XV. annis per Galliam, Belgium, Angliam, Germaniam, Heluetiam, E Italiam inftiruta, non modo libros pretiofisfimos \& MSta rarisíma, ied etiam nummos antiquos \& piłas tabulas prorfus incomparabiles conquifivit, inque coëmendis 17000 . Ducatorum longe majorem impendit: Atque etiam An. M. DC. LXXXIX. infigni accesfione librorum \& aliquor MStorum illam ipfam Bibliothecam adauxit Tit. Dn. Albertus a Sebifch, Cohortis rubrx apud nos Capitaneus, eidemque apparatum Conchyliorum non contemnenduin, \& peculiarem veterum figurarum ænearum $\&$ rariorum quidem collectionem, copia tanta, quanta non facile alibi occurrerit, adjunxit : quæ omnia Celeberrimus hoc tempore $\mathrm{Re}$ etor ejusdem Gymnafii \& Bibliothecæ illius Præfectus nec non Infpector Scholarum Vratislavienfium Dn. Gottlob Krantzius in Dramate publico pertraktavit, \& deinceps edidit, fub Tit. feqq. Memo. rabilia Bibliothecæ Elifabethanæ Vratislavienfis (Vratislav.An.1699. in fto public.) Cum vero poft feripti hujus publicationem multa fingu- 
fingulariter curiofa llluftris Dn. Job. Sigismundus ab Haunold E' Rbumberg, S. Cæl. Maj. Confiliarius \& Reipublicæ Vratislavienfis Præfes, it. Generofus Dn. Georgius Mauritius ab Hoffmannswaldau Capitanei olim locum tenens apud Cohortem rubram hujus loci, Mufeum Conchyliorum perluftratione dignum huic Biblicthecæ legaverit: A Dn. Vincentio vero Amflelodamo apparatus quidam Conchyliorum elegănter politorum, una cum curiofis Infectis exoticis, amicis quibusdain fumtum fuppeditantibus, emtionis lege accefferit: ex Scripto paulo ante laudato huc pertinentia breviter excerpere \& quibus poltea rebus hæc Bibliotheca fit locupletata, paucis adjicere volui :

Præcipue autem æftimanda ingens Tabularum lignearum copia, quibus Heroum, Fœminarutnque illuftrium capita, ante fefquifeculum fere depieta, fiftuntur, tanta vultuum \& linearum concinnitate, tanta colorum conftantia, ut vix unius anni atatem præ fe ferre videantur. Maxime vero dolendum ignota efle artificis nomina, \& quamvis plurima ab una eademque manu profe 9 a videantur, attamen nec fedula inquifitione adhibita, quicquam monumenti reperire potui, ex quo piftoris, celebre fine dubio nomen colligere licuiffer. Non tamen dubito, Antverpienfi alicui hæc ornamenta deberi, cum facies Principum eo tempore in Belgio verfantium vel maxime ad vivum expreff $x$ videantur.

Præcipue videnda hic Auftriacæ magnitudinis decora: ut Maximilianus I. Imperat; Pbilippus, primus ex Auftriacis Hifpaniz Rex; Carolus V.Imper, Max; Pbilippus II. Hifpania Monarcha; item hujus filius Carolus pramaturo \& infelici exitu peremptus; Maxi. milianus II. Imperator. Ex Galliæ Regibus Francifus I. Hesricus II. \& Carolus IX. Sequuntur. Heroum Icones, qui belli Belgici turbis immixti, five Hifpanicæ dominationis feu Belgicæ libertatis augmenta forti manu propugnavere, ut: Ferdinandus Toletanus, Dux Albanus, Antonius Perenottus Cardinalis, Fobannes a Cerda, Dux Medina Cali; Emanuel Pbilibertus Sabaudus \& Ericus junior Dux Brunfvicenfis, contra Gallos, ad Quintini Fanum Itrenui defenfores.

Apparent porro prima libertatis Belgicæ victima, ipfis etiam holtibus laudati Heroes, ut: Lamoralius Comes de Egmont, \& Pbilippus 
Momorantius Horne Comes, \& qui horum fanguinem armorum felicitate vindicavit, Guilielmus Naffovius, Princeps Araufionenfis. Sequuntur Pbilippus Crajus, Dux Arefchotanus, diu Regis,pofeaConfederatorum amicus; Johannes Glimeus, Marchio Bergenfis, præcipuus Granvellani holtis ; Maximilianus Henninius, Boffunii Comes, polt navale prelium \& corpore \& animo a çonfoederatis captus; Antonius Lalinius, Comes Hocbftratenfis, ex Albani manibus fuga elapfus; Carolus Brimeus, Comes Meganus Regia parti addiAtisfimus; \& Henricus Brederodius, Dux conjurationis in Albanum.

Ex Belgio in Galliam me vocat Herorum feries; Siftuntur trium fratrum celeberrimorum paria, Antonius Borbonius \& Ludovicus Condeus Reformatorum per Galliam capita, hisque confilio \& auxilio juncti Cafpar É Adelottus, Colinii, ille Francia Admiralis, hic uni. verfo peditatui præfeetus. Hoftes horum infenfisfimi adduntur, fratres Franciscus Guifus \& Clavidius Aumatius, ille in Aurelianenfi, hic Rupellenfi obfidione globis trajecti ; necomiffus fobannes Poltrotus, Francifci Guifii interfector, in ipfa imagine crudelitatem fpirans; \& ut in vita aulicorum cetibus, fic hic Heroum vultibus fe immifcuit prudentis fultitia Confultus Clemens Marotius.

Spectare quoque licet Carolum Audacem Burgundum, fobannem Fridexicum Saxoniæ Eletorem in Smalcaldico bello infelicem, item Erasmum Roderodamum; Omitto Pontificum quorundam \& Cardinalium eadem manu \& artificio paratas effigies; taceo $R$ bedigerorum Nicolai ES Thome, Lutberi, Melancbtbonis, Calvini, \& Theologorum Vratislavienfium quorundam monimenta, item prolixam illuftrium fominarum feriem, \& venuftate facierum, \& cultus elegantia oculos oblestans;

Videndæ quoque picturæ non paucæ, membranaceis codicibus infertæ, quæ trium, vel etiam quatuor feculorum atatem referunt, \& in iis fi non exactam delineandi perfectionern, facierum tamen fvavitatem, \& colorum accurate tritorum, \& commixtorum conftantiam præfeferunt: Præcipue mentem afficiunt IV.majoris formæ codices, mira pickurarum copiofisfimarum fubrilitate refer$t i$ quarum exacta contemplatio aliquot dierum confiderationem pofcit. 
Continent hi Codices Jobannis Froiffardi, Canonici Chimacenfis, Hiftoriam fui temporis, qua non modo res, $a b$ an. 1326. per LXXIII. annos in orbe geftæ fideliter exprimuntur, fed \& Arcium \& AEdificioruın ftatus, ritus publici, veftes, aliaque ftatum Seculi XIV. illuftrantia picturis artificiofis ante oculos ponuntur. Altius quidem afcendiffe in Catagraphis \& umbræluminisque obfervatione feculum noftrum non repugno; fed qui in imaginibus hifce ædificiorum accuratisfimam delineationem, fylvarum \& montium fvavisfimos tractus, aêris, nubiumque jucunda fpeetacula, operofis. fimas prœliorum mixturas, \& in his omnibus linearum du\&tus, exaetamque fubtilitatem examinabit, facile fatebitur, Artificem hunc fi vel hoc folum totius vitæ opus effet, perpetuam hoc uno nominis celebritatem meruiffe.

Aliquam confiderationem etiam meretur Codex mémbranaceus Bibliorum, formæ maximæ, ubi mater virgo Jefulum recensnatum finiftra, cruci affixum vero dextra tenet.

Cum admiratione videnda exigua Dominicæ pasfionis delineatio, quæ fpatio vix oboli magnitudinem excedit, quod tamen CHRISTUM inter duos latrones crucifixum, aditantes fobannem \& Mariam, militum tam equeftrium quam pedeftrium, aliorumque hominum haud exiguam copiam, aream vacuam fatis amplam, urbem Hierofolymorum in dextra latere appietam, eaque omnia, diftinete videnda exhibet.

Demonftratur hic quoque CHRISTUS fub hortulani fpecie Mariæ Magdalenæ apparens, item IV. Evangelifts fcite elaboratæ piEturæ; præc. Capita Sti Petri \& Pauli Apoftolorúm, ex filis fericeis artificiofe acu pieta, ex donatione fohanne Sufanne de Obi \& Adlerscron, natx de Ridel \& Lewenftern. Ars pyroboliftica integra, volumine ingenti, magna figurarum affabre elaboratarum copia expreffa.

Effigies CHRISTI \& Maria vitro artificiofe appię, it. fpecimina piêur $x$ Rusficæ \& Helena Antonia Leodienfis puella barbata.

Volumen florum iconibus plenum, quorum plurimæ fpecies ad vivum delineatx, tam colorum Ivavitate, quam artis pertectione fe fpectatorum oculis fatis commendant. 
Figurarum in $æ$ incifarum plusquam 20000 .inveniuntur 104. voluminibus comprehenfa: ubi vix quisquam artificum feu antiquorum feu recentiorum, cujus hic opera non inveniantur quædam. Vix aliquid Alberti Düreri artificiofa manus, five ligno, feu æri incidit, quod hic non appareat; nec defunt Martini Scbonii, primi omnium Chalcographi labores; item figuræ ligno infculptæ fob. Scheif. felini, exactisfimi imitatoris Diireri; Sculpturæ Luca Leydenfis, Alberti Aldegrafii, Bartbolomai E Jobannis Sebaldi Böbmiorum, Alberti Altörferi, Georgii Penfii, facobi Binkii \& Virgilii Solis \&c." Imo nec Jacobi Bros. bameri opera defunt, quæ maximus Chalcographorum indagator, Joacbimus a Sandrart, fe non vidiffe conqueritur. Serpens alatus, qui Luce Cranachii nomen indicat, item aliorum figna \& monogrammata, inter hæc Cimelia fæpe occurrentia. Imo etiam nomina niEtorum Italorum, ut: Rapbaelis Ulrbinatis; Antonii Corregienfis, Mich. Angeli Bonarotte, Titiani llccelli, Facobi Tinctoretti, Frid. Barotii, Urbinatis, Pauli Caliarii, Veronenfis, Jacobi Palms, Veneti, Facobi de Ponte Baffano, Jofepbi Arpinenfis, Pauli Farinati, Annibal Caraccii $\sigma_{c}$. Adfunt \& celebria feculi noftri quædam decora, Guido Renus Bononienfis, Petrus Tefta, infelici exitu \& arte fua indigno, Tiberi fubmerfus, Petr. Beretinus, Cortonenfis, Francifcus Albanus, Bononienfis aliique, quorum opera æri infculpta curiofum fpectatorem mirum quantum afficiunt.

Nec eft quod Sculptorum Italorum artificia defideres, cum Marci Antonii, Imitatoris Düreri non infelicis, fulii Bonafonii, cæli \& artis fvavitate celebris, Enea Vici, Parmenfis eruditione clari, fulii Fontane, Veronenfis, Pbilippi Thomafini, fulii Sanute, Petri Sanctii Bar. tboli, Ferdinandi Bertelii, Fob. Fac de Rubeis, Caroli Cafii, Stepbani de la Bella aliorumque non paucorum opera copiofe fatis appareant.

Ex pietoribus Gallicis, Tbeodori Bernardi, Caroli Brunii, Nicolai pitonii, Fobannis Coffierii, Samuelis Bordoni, Nicolai Pufswii, Ifraelis Sylvefris, aliorumque multorum opera fe perfectæ delineationis artificio commendant. Ex Sculptorum operibus, Nicolai Pereilii, Cornelii Galli, fob. Morini \& aliorum Campi Sylvæque admiranda fvavitate infignes, Gerb. Laire/Jii, Job. Potrii \& Gregorii Hureti Sacræ Profanæque hiftoriæ artis perfectione mirabiles, Facobi Callotti, Abrabami Bofjii, \& 
aliorum abfoluta erofionis fpecimina; Francifci E Nicolai Poilliorum, Nicolai Bonartii, multorumque aliorum perjucundæe imagines fpeetatorum oculos alliciunt.

Belgicorum artificum non exiguus eft numerus: Antwerpia fola provocare reliquum Orbem valet, cujus artificies hic ingenti numero in operibus fuis fe fpectandos præbent. Petri Pauli Rubenii miranda fpecimina hic aliquot volumina complent. Antonii de Dyk, Martini de Vos, Bartbolomai Sprangeri, Gerbardi Segeri, Jacobi Fordani, Facobi de Gheyn, Erasmi Quellini, Agidii Coninxloo of c. Hic Pauli Brillis. \& Jacobi Foquierii camporum fylvarumque jucunditas, hic Adriani Broweri \& Petri Brengelii, inter rufticos nati actiones rufticorum mira. arte expreffæx, hic Davidis. Terierii induftria colleeta variorum artificum Specimina apparent. Sic Huberti Golzii eruditisfimi pietoris \& fculptoris ubertas, Rolandi Saverii jucunditas naturæ penicillo expreffa, Pauli Morcelfenii facierum perfectio, Petri de Laer maxima artis minutiæ, Davidis Vinckbomii delineationum elegantia, Abrabami Diepeiabeckii fedulitas, Abrabami Blamart florigisfima artificia aliaque plurima admirationem merentur. Sola Rembrandi de Rbyn opera contra artis fere regulas mira perfeetionis laude digna, aliquot ho. rarum contemplationem pofcere videntur.

Nicolai Bruynii fumma in arboribus montibusque exprimendis fuavitas, linearumque fubtilitas; Jacobi Matbam \& Job. Sanredam, in affe Rtibus exprimendis felicitas, Pauli Pontii, Michael. Natalis, Luce Vorfermanni, Petri de Fode, Henrici Hondii, Job. Sommeri, Bolfwertiorum, multorumque aliorum opera laudatiffima, hic curiofiffimo cuique fatisfaciunt. Quid Cornelius Blocmart, \& Antonius W Waterloo, in camporum ædificiorum,que delineatione, quid Nicolaus \& Cornelius Vifheri, quid Fridericus Wittius, aliique variarum rerum defignatione præltiterint, optime videndum. Afficiunt præcipue fpecimina artis jucundiffimæ, quæ inverfo umbrarum ordine nigro fundamento candidas imagines imponit, curioforum oculos, quæ hic Guil. Vaillantii, Blotelingii, Petri Schenckii, aliorumque artificiofa manu facta, copiofe fatis exhibentur.

Lucent hic copia minime contemnenda artis noftræ ex Germanis lumina; ex quibus præter fupra laudatos, Dürerum, Cranacbi- 
um, alinsque hic fob. Holbeinium, fohannem Aqbisgranenfem, Crifpinum Pafeum, cum Magdalena, filia multosque alios in operibus fuis vivere. deprehendi; Idem de Fob. Feldii, Adami Elsheimeri \& fob. Henrici Scboenfeldii artificiofis inventis dicendum, qux aque ac 7ofepbi Heinzii, Chriftaphori Scbioartzii, \& præ cæteris, Joachimis Sandrart opera hic copiofe videnda: Adde Agidii \& Raphaëlis Sadlerorum, Bartbolomsi Ev LuGa Kilianorum, Georgii Andr. Wolffgangi, Melcbioris Kufelii, Jeremise Valckii, multorumque Germanorum Sculpturas, omnibus numeris abrolutas. Solus Wencesl. Hollar, Bohemus æris per aquam fortem erofione, cujus copiofa fpecimina hic apparent, omnes alienigenas longo intervallo poft fe reliquit.

Ad Plalticen quæ fpestant, inter Cimelia Bibliothecæ multa \& eximia artis hujus fpecimina inveniuntur: $\Lambda d$ funt Thecæ XX. e corio ductibus aureis exornato, quæ imagines e cera fiotas vultuum fimilitudinem fumma faavitate referentes in fe continent, quaruni plurimæ ad aulam Gallicam fuperioris feculi fpectant, ut Henricus II. Rex, cum fratre Carolo Aurelianenfi, \& quatuor filiis Francifco II. Ca. rolo IX. Henrico III. E Francijfo Alenzonio; it. Cabbarina Medicea quatuor filiorum jam citatorum mater, Maria Albretana Navarræ \& MariaScotix Regina : Videntur \& Cardinalium Borbonit, Lotbaringi, Oliverii \& Senonenfis, item Francifci Guifii, ipfius etiam Clementis Marotti, \& aliorum vultus. Imo \& hac arte effictæ quædam Theologorum Evangelicorum facies, Martini Lutberi, Pbilippi Melancbtbonis \& præcipue Luc. Pollionis. Item 3I7. figna numerantur e plumbo, tantam fymmetrix artisque perfectionem præ fe ferentia, ut vix eorum afpectu curiofi faturari queant; Inter 47 . Heroum fimulacra eminent, Caroli V. Cæel, Pbilippi II. Hifpani, Caroli filii, Ferdinandi I. \& Maximiliani II. Imperatorum; Sigismundi Augufi Poloniarum \& Erici Svec. Regum effigies. Emanuelis Pbiliberti, Sabaudi, Alexandri, Fransifci, \& Cofmi II. Mediceorum, Octavii, Parmenfis, Alpbonfi, Ferra. rienfis; præcipue'Turcorum flagella, Zobannes de Vaiette, Maltenfium Magifter, \& Andreas Toria Genuenfium reftitutor, hic fefe fpe. Etandos præbent: Item 72. foeminarum illuftriam lcones, Paparum, Cardinalium, aliorumque virorum, literis aut virtute illuftrium 59. capita. Pracipue autem eminet genuinæ antiquitatis opus five Caput Livo ex are fufum.

Gulta- 
Guftaphus Adolphus ex offe fepiæ. Ciftula a Georgio Duce Bregenfi ex ebore tornata.

S ALV ATORIS e cruce pendentis, altera ex ebore, alterae fuccino effigies, affabre elaborata; infans e corallio fculptus, copiofre metallifofforum imagines; lignum exiguum, fubtiliffima fculptura multas Icones facras cum crucifixi effigie repræfentans.

Tabulæ æneæ XXVII. a Phil. Kiliano fculptæ, in quibus Præfes, \& Senatores urbis hujus inclytæ.

Summus inter curiofa hujus Bibliothecæ locus monetis tribuendus, fiquidem quatuor fere millia hic cuftodiuntur.

EX GR IECIS: Pbilippus, aliquoties in auro \&argento, Alexan. der in argento \& ære, Ptolomaus in auro, Lyfmacbus in auro \& ære, $A r-$ finoe uxor in ære, Demetrius itidem in ære deprehenditur. Nec ævi Alexandrini literis decus Arifoteles deeft, ære expreffus; Confervatur \& in ære Artemifia cum Maufoleo affabre, lice irecentiori ævo elaborata; imo \& Mithridates cum cervo, Regum Ponticorum fymbolo in argento \&ære hicinvenitur.

Præter alios Atbenienfium nummos noctua notatos, etiam Heroum Athenienfium, Themifoclis \& Thrafybuli monumenta exftant: Videndi hic funt Epbefiorum, ThefJalonicenffum, Pbocenfium, Etolorum (quibus forfan \& Timarcbi memoria accenfenda) Heracleenfium, Dyrrbacbiorum, Apollonistarum, Neapolitanorum, Thafiorum, \& e magna Gracia Thuriorum, Syracufanorum, Velienfium, \& aliorum nummi, varia antiquorum Symbolorum ncbilitate confpicui.

Nummorum Romanorum CONSULARIUM XCIV. familiæ ex argento \& numero CCCCXXII. cuftodiuntur.

In nummis Emilis familiæ multa curiofa videntur. Rex Arabum Aretas e Camelo defcendens in genua provolutus, \& ramum Olivæ porrigens, pacis defiderata fignum, addito fupra nomine $M_{0}$. Emil. Scauri. Ad eandem familiam fpeetat, Pauli smilii nummus, Trophxum cum adftante Paulo filisque \& voce TER. exhibers, it. P. Lepidi Triumviri nummus, qui in averfa parte Puteal Scriborii $\mathrm{L}_{1-}$ bonis oftendit. squilia familia nummus memcrabilis, in quc $M$. Aquilius armatusSiciliam iervorum tumul u rebellem in terran; profternit. In nummis Carifii Dea Moneta \& inftrumenta monetaria 
antiquiratem oftentant; imo \& Sphynxin ejusdem nummo alio expreffa, contemplationem meretur. Sic in Casfii Longini nummo judex calculum in urnam immittens; Virgo Veftalis in nummo $C$. Clo. dii fedens, Caftor \& Pollux in Ruf Triumviri nummo, Martisultoris templum in nummo L. Cinna aliaque plurima fatis curiofa videntur. Ad urbis Romanx faciem declarandam fpectat C. Confidii Noniani nummus, in quo Veneris Erycinæ templum ad portam Collinam in colle elatiori pofitum, cum muri Romani parte, \& ipfa porta Collina, eleganti artificio exhibetur. In M. Cordii Ruf nummo, Cupido alatus natanti Delphino infidens, eumque fræno regens; Vix aliquis fculpturæ artificio commendabilior eft nummo \& Fabii Maximi, - cujus calvi fenis caput in averfa V. fafces, in memoriam Tarenti receptæ pofiti fpeetari merentur. Sic \& libertatis caput in familiæ Junix nummo,\& in averfa $L$. Jun. Brutus cum III. fociis ad Reges urbe pellendos properans. In L. Hoftilii nummo DianæE Ephefia fimulacrum elegantiffimum; Cancelli Comitiorum, cum fuffragiorum ciIta in nummo P. Nerve; Ulyffes pileatus cum cane Homerico, a quo agnitus dicitur, ad Mamilia gentis originem indicandam, nummo impeffus; Ceres fedens cum annotato Cerealium ludorum initio, a C Memmio facto; fafces in C. Carbonis elegantiffimo nummo optime expreffi; Romulus \& Remus a lupa nutriti fub ficu ruminali, cui picus Martius infidet, \& Fauftulus Paftor adftat, in $S$. Pompeji nummo.

Aquæ Martiæ aquæductus cum Anci Martii effigie in Pbilippi Martii nummo, \& Jugum boum Coloniam forte Eporedianam a C. Mario juniore deduetam indicans, imo \& Cancelli Comitiorum in foro Romano, cum Veneris cloacinæ memoria, \& viris faffragia in urnam conjicientibus, in quodam Mufidii Longi rummo.

C. Marii torva facies \& Trophæum de Cimbrica vietoria ere: Etum; Baccbius fudaus Arabiæ Regulus ad Cameli pedes genibus flexis olivam porrigens. Sacra Romana a Numa Pompilio inftituta egregie nummus L. Pomponii Molonis exprimit, ubi vir capram ad Juronis aram, cui augur lituum tenens adftat, adducit, Numæ nomine fubfcripto; Varia facra ludorum fecularium A. Po ftbumii nummi exprimunt; Bacchi Sacra in Caji Vibii nummo optime delineantur, ubi tigris pedibusanterioribusaram confcendit, cuilarva $\&$ Thyrfus ad-. jacent; 
jacent; Mater Deum Cybele leonibus veeta in M.Volteji nummo, Arufpex ceremoniali fcientia lupx, Romuli \& Remi nutrici, affidens, duasque aves advolantes obfervans, in incertæ familix nummo.

IMPERA:TORVM quoque ex auro, argento \& are non exiguus eft numerus; qui ab ipfo fulio Cafare coeptus,per IV. fecula extenditur, \& paulo poft Theodofium M. definit, paucis quibusdam ultra IV. Seculum additis: Non feriem recenfere placer, hoc tantum cito, paucos ex Imperatorum ordine deeffe, imo \& rariores 0 thonis nummos in argento \& ære, Tyrannorum etiam tertii Seculi, Póflbumorum, Tetricorum, Vietorini, Caraufii numifmata. Sic \& Auguftarum in nummis exiftentium pauce defunt, quarum plurimas rarioribus annumerare curioti folent.

Antiqua Gentilium Religio fere tota e nummis explicari poteft: Jobis tot hic fimulacra proftant, ut vix plura defiderare poffes. $f u$ piter Confervator, in Domitiani, AlexandriSeveri \& Gordiani, Jupiter Cuflos in Neronis \& Vefpafiani, Salutis defenfor in Sept. Severi, Propu. gnator in Alexandri Severi, Olympicus in L. Aurelii Veri, Stator in Gordiani, Victor in Domitiani nummis exhibetur. Apollinis variæ effigies in Augufti, Antonini Pii, \& Caracallæ numifmatibus fpectantur, hujusque filium Afculapium Caracallæ nummi tenent. Neptunum Auguftus \& Sept. Severús fuis, Mercurium Hadrianus Antinoi nummis infculpi curarunt. Martis tot hic fimulacra fivefolo, five Gradivi, ul. toris, Victoris nomine infignita, ut nummos recenfere tædiofum effet. Baccbum cum Hercule elegantiffimus, fatisque rarus Sept. Severi nummus fiftit; Herculem folum multi, peculiari vero elegantia Trajanus \& Hadrianus exhibent. Serapis in eleganti Caracalla nummo, sol DEUS in Heliogabali, Genius in Neronis Vefpafiani \& Maximini nu, mifmatibus apparent.

Dearum quoque copiofifima fimulacra fpectanda: Cybele fupra in Confularibus citata, hic in elegantisfimo Juliz Severi uxoris num. mo fiftitur. Junonis icones hic copiofe five folo, five Monets aut Re. gine nomine addito videntur; fed curiofior eft Punica funo leonibus veeta, in Sept Severi nummo expreffa. Venus vario habitu fefe fpe. Etandam prabet, jam coleffis, jam felix, jam genetrix, jarn victrix dieta, yel XX, autulterius nummis expreffa; Palladem $\mathrm{X}$, diverfi nummi exhi- 
exhibent, hafta, cly peo \& noetua fua inftruetam; imo exigua Palla. diola copiofiflima videntur. Cererem fpicas gerentem, vel face Proferpinam quærentur, Claudii, Neronis \& aliorum monetæ continent. Diana venatrix in Hadriani, Lucifera in Julii Severi nummis exftat. Vefam Caji \& Vefpafiani, Templum Vefte Neronis nummi tenent. Hebe five fuventus in Aurelii Cæefaris, Fortuna \& Victoria ut Deæ, in copiofiffimis plurimorum nummis videntur.

Rerum ad Religionem fpectantium hic tantus apparatus eft, ut quid primo citem, vix conftet: Templa Deorum varia eleganti ftruetura in nummis expreffa, Ara five folx, feu Jovis fulmine inftruetz; Tripus five Cortina Delphica cum cornice \&Delphino Appollini facris, in nummis præcipue Vitellii \& Domitiani. Caduceus Mercurii paffim obvius, Pegafus in Antinoi præcipue nummo confpicuus, Sacrificia var ria,totum facrificandi ritum fcire exhibentia præcipue in Caji \& FauAtinæ junioris elegantiffimis nummis; Signa Pontiffcalia, Albogalerus, Appergillum, securis, Capeduncula, in Cæa aris pracipue nummis æreis; Signa Auguralia, Lituus, Guttus cum Afpergillo \& Capeduncula in Cæfaris \& Marci nummis. Qux ad Confecrationem five Apotbeofin fpectant, hic ad naufeam apparent; Řogi eleganter ftrueti, ut Alii \& A ntoninorum, Pii \& Marci; Apotbeofis Augusti rara \& curiofiffima, Carpenta five Tenfa in Auguftarum Liviæ filicet \& Agrippinæ confecratione, Aquile Deitatem fignificantes \& alia non pauca.

Nihil dicam de aliis Imperii \& Victoriarum ornamentis, Fafcibus, /ggnis militaribus, Labaris, Hafiis, Clypeis votibis, coronis variis apertis, Laureis, radiatis, guernis, aliisque; nihil de Triumphalibus ornamentis, Tropheis curiofiffimis, Bigis, Quadrigisque triumphalibus, nihil itidem de publicarum Solennitatum memoriis, sellis curulibus, Congiariis \& Suffimentis populo datis, qux præcipue in Neronis, Domitiani, Nervæ, Hadriani \& Antonii Pii nummis apparent.

Aliquam Hiforie partem declarant, ut: 2uindecim viri facris faciendis, Frumento Prafecti, Triumviri monetales, Duum biri municipales, 2uefores, imo \& Trium viri Reipublice conftituends, in nummis notati; quorfum \& ipfa Tribunitia poteftas fpectat, ubique in Imperatorum nummis obvia. Publicarum Solennitatum monumenta habemus, in Ludis quinquennalibus, decennalibus, Jecularibus egregie expreffis; in 
Votis publicis, Lufrationibus, Decurfronibus, Donativis aliisque rebus copiefa elegantia confpicuis. Quot quæfo hic Allocutiones cobortium, Pro. fectiones \& Adnentus Auguftorum. Tropha, Arcusque Triumphales ereEti, aliaque viftoriarum monumenta apparent? Fani templum clau. fum de pace reflituta teltatur, Adoptiones curam pro Succelforibus Imperatorum, Propago Imperii in filiis Ixtitiam oftendunt, aliaque curiofa \& Hiltorico fcitu necelfaria hic occurrunt.

Gograpbiain five etiam Topographiam juvantiafunt: Roma fub decora foeminæ armatæ fpecie, quam \& refurgentem Vefpafiani, fa. crificantem Commodi nummi exhibent. Ex ornamentis Urbis Romanæ Colifeum five Ampbitheatrum in Vefpafiani, Circus in CaracalIæ nummis, Colums tam in Trajani, quam Antonini Pii, Aqueductus in Trajani, Pons Alius in Hadriani, imo ipfe Portus ofienfis inelegantisfimo Neronis nummo exhibentur. Huc \& Tiberis fpegtar, Rortui Oftienfi, fub fimulacro fenis additus, via itidem Appia a Trajano reftituta. Ex aliis Orbis terrarum fluviis, Nilus, Crocodilo \& Hippoporamo fignatus, in numino Hadriani ; \& Danubius a Trajano ponte fubaqus exhibentúr. Cupiofam Coloniarum deduftionem Boum Juga pasfim in nummis occurrentia defignant, ut: Calagurris Fulia in Tiberii, Nemaufus in vexato illo Augulti nummo, in quo verba dimidiata COL. NEM. I. Colonia Nemaufienfis. Forfan \& Diana benatrix in Hadriani nummis Coloniam Hadriani in Myfia, SeptaVenaticá dictam, denotat.

Regiones Orbis defignantia fimulacra hic copiofe fatis inveniuntur; Oriens capite crinito \& radiato, \& Africa Eleptiantis probofcide virtata, feorpion emque gerens, in Hadriani nummis exftant; Egyptum cum Siftro \& lbi, Mauretaniam equum ducentem, idem $\mathrm{Ha}$ drianus exhibuit ; Judam fub Palma lugentem Vefpafianus, Cap. padociam rupem, \& Vexillum gerentem Hadrianus fiftit; Achajam urceolo \& palmæ ramo infignitam Hadrianuse terra elevat, Dacism vero arcu fracto triftem Trajanus exhibet. Italia turrito capite in Antonini Pii \& aliorum nummis globo infidet; Sicilia per Neptunum acroftolium gerentem in nummo Augufti defignatur; $\mathrm{Ger}$ mania in Domitiani nummo, fcuto infidens, fagitta fraeta luget; $G a l-$ liam \& Hufpaniam depreflas e terra elevat \& reftituit Hadrianus; P an- 
nonia cornu copiæ gerens L. Elio fedenti Palladiolum five falutem fuam tribuit ; Britanniam haftatam \& clypeatam Hadrianus oftendit.

Ex urbibus fola quidem præter Romam Alexandria,; fpicis fertilem ubertatem indicans in Hadriani nummis apparet, indicantur tamen paffim Delpbi per Delphinum tripodi impofitum, Garthago per leonibus vectam Junonem, aliæ initialibus literis, 'quarum officinæ monetariæ varios nummos ad nos miferunt; in quem cenfum præcipue Conftantinopolis, Antiocbia, Lugdunum, Trejeris, aliæque ve. niunt.

Populorum præfertim devietorum' copiofa hic memoria eft. Non prolixe fcribam de expeditionibus Germanicis hic expresfis Domitiani, Trajani, Marci, Caracallæ; Partbicis Augufti, Trajani, Marci Sept.Severi, Caracallæ, Opilii Macrini; Arabica Trajani; BritannicisClaudii,Commodi \& Caracallæ; Marcomannicz \& Sarmatica Marci, aliisque; Memorabilia tamen funt/fgna tam a Parthisquam Germanis recepta, in Augufti \& Caji Cæfaris nummis; \& Armenis Rex datus M. Aurelius Soæmus, in curiofffimo L. Aurelii Veri nummo exhibitus.

Ad ufum Moralem five Emblematicum fpeetant: Fortuna gubernaculo inftrueta \& cornu copix, in plurimorum Imperatorum nummis videtur, quam reducem multi, obfequentem fibi folus Antoninus Pius in eleganti nummo exhibuit. Felicitas caduceum' \& cornu copiæ tenens pasfim obvia eft, imo nummi quidam felicitatem temporum, alii Seculi alii publicam vocant; fuam felicitatem Auguftus Capricorno, Cornu copix in tergo gerente fcite quidem, fed fuperftitiofe expreffit. Bonus eventus patellam \& fpicas gerens; Hilaritas velum Capitis præ gaudio attollens; Latitia per Juvenem fpicam, \& puellam globum gerentes, qui fe invicem ampleetuntur, in Pii nummo defignata; Salus pateram gerens, copiofiffimis nummis impo. fita. Seruritas haftata \& cubito innixa ad aram quiefcens; Tranquillitas gubernaculum \& fpicas tenens, harumque omnium gubernatrix Probidentia, globum fuppofitum fceptro protegens, elegantia fane fpeetacula fiftunt, hic quidem fxpisfimerepetita. His jungi merentur, variæ felicitatis caufe, $P a x$, nummis fatis numerofis impo. Gita, ramum Olivæ \& Caduceum portans, cujus fe fundatorem Sept. 
Severus in quodam nummo vocat; Libertas, Pileum manu porrigens; Honor, Lauri ramo ornatus; Annona abundans five Cereris fi. mulacro, feu Calatho, frugibus pleno defignata; frecunditas, infantulis cincta, aliaque varia publicam felicitatem juvantia ; imo ip $\left\{\begin{array}{l}\beta \\ \beta e s \\ \text { cre. }\end{array}\right.$ berrime apparens, herbam trium foliorum, primum fcilicet planta. rum germen oftendit. Virtus mulieris armatæ effigie fe etiam creberrimam exhibet, longam filiarum feriem fecum ducens. Pietas thura igni injiciens, Equitäs Cornu copix \& bilancem geftans, $\mathfrak{f u}^{u}$ fitia pateram baculumque tenens, fides jam publica, jam militum, jam Exercituum dieta, mox cornu copiæ \& pateram,jam figna militaria monftrans, Concordia, manibus junctis plurimum defignata, Amor mucuus, eodem figno expreffus, Clementia Lauri ramo \& hafta inftruEta, Indulgentia manum expanfam porrigens, Liberalitas cornu copiæ effundens, Confantia galeata \& haftata, indicem verfus faciem propriam dirigens, Pudicitia peplum fronti obtendens; Nec facere poffum monitum Augufti, feftina lente, Emblemate eleganti in nummis Vefpafiani expreffum, ubi Delphinus, celeritatis fignum, anchora circumvolutus a veloci curfu detinetur. Ipfa Eternitas folem dextra, finiftra lunam gerens, non inelegans Emblema fiftit.

Catalogum vero Imperatorum, pracipue in qua forma, \& ex quo metallo nummi cufi, fequens exhibet Tabula:

In Auro.

Julius Caf
Auguffus

- -

6

Tiberius

Cáligula

Claudius

Nero

Galba

Otbo

3

$--$

7

4
In Argento.

9

23

$\because$
9

3

I

2

8

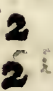

In Ere.

maj. \& med. form. 7 . .. min. 2.

maj:\& med. min.

maj. \& med. maj. \& med. maj: \& med. maj. \& med. min.

maj. \& min. maj. \& med.

2.

I.

4.
24.

17.

7.

12.

15. 


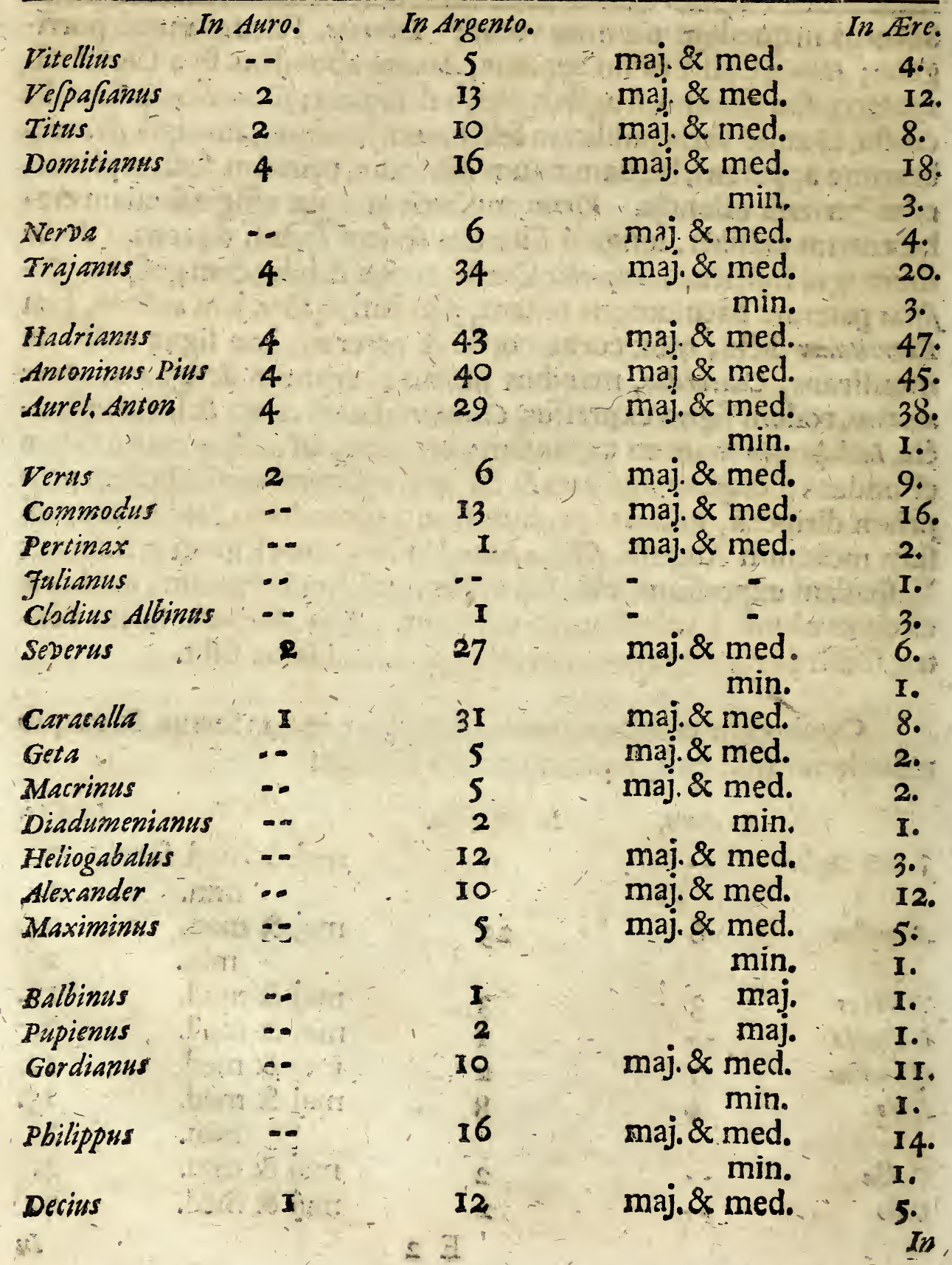




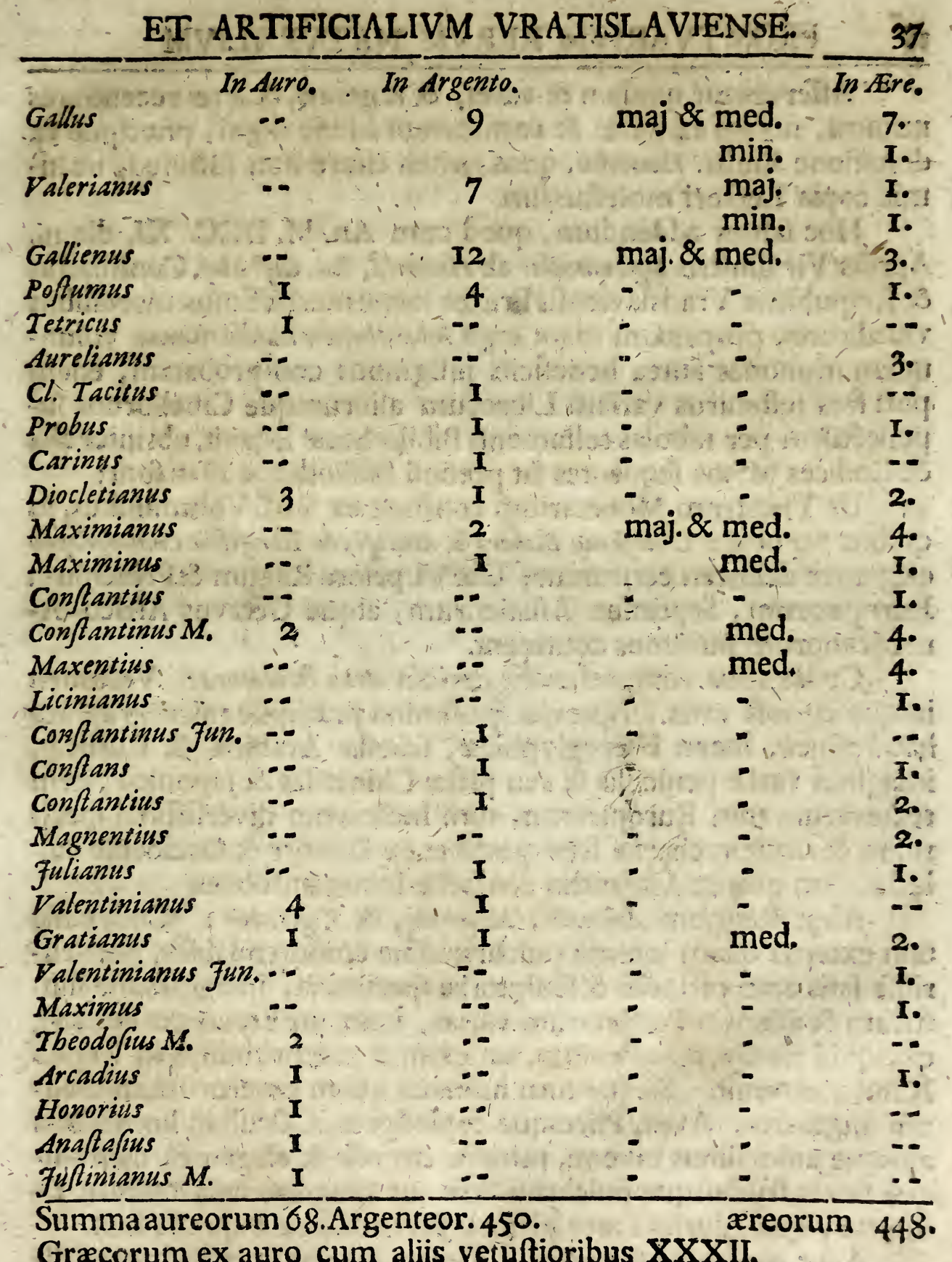

Græccrum ex auro cum aliis vetuftioribus XXXII. 
Affervantur quidem \& aurei, \& argentei, \& ærei recentiores nummi, notatu ex parte \& commemoratione digni, præcipue ex dohatione Illuitr. Haunoldi, quos tamen citare non fuftineo, ne nimia copia Lectori moleftus fim.

Hoc faltim addendum, quod cum An. M. DCC. XI. die 16. Aprilis Vir Illuftris sigismundus ab Haunold, Sac. Cas. Maj. Confiliarius \& Reipublicæ Vratislavienfis Præfes longe meritiffimus mortalibus valediceret, propenfam fuam erga Bibliotbecam Elifabethanam voluntatem multoties antea beneficiis infignibus comprobatam, etiam poft fata teftaturus variam Librorum aliorumque Cineliorum fupelleetilem per tabulas teftamenti Bibliotheca legavit, ubi interalia \& Codices MStos fequentes fat pretiofi Bibliothecæ illati funt:

Ut Theatrum Monetarium conftans ex VIII. Voluminibus, in quibus nummi a Godofredo Biebero \& Godofredo Bartfchio Chalcograpbo eleganter delineati cernuntur; Ubi VI. priora Regum \& Principum Europæorum, Septimus Afiaticorum, atque Oetavus Africo-Americanorum nummos continent.

Codes alius comprehendit curiofa Artis \& Nature: Volumen in quo curiofa artis fcriptoriæ fpecimina præcipue micrographica hâud pauca, literæ Hieroglyphicæ, fchedæ Arabicæ \& Rufficæ, imagines variæ penicillo \& acu piłtæ Chinenfes \& Japonicæ, item texturarum tüm Europæarum tum Indicarum diverfiffima fpecimina, \& tandem chartæ fere quælibet ex Oriente \& Occidente col. lect $x$, item quæ ex Amiantho confecta incombuftibiles.

Alius Régnum Animale, Minerale, \& Vegetabile: Codex hic tam externa quam interna pulchritudine commendabilis, poft curiofa fatis artis pictoriæ \& fculptoriæ fpecimina, imaginesque illu. ftrium \& aliarum Perfonarum varias, juxta tituli tenorem exhibet; quicquid rarum, monftrofum, aut eximiæ pulchritudinis in Regno Naturæ obvenit. Sicque tum humana quam cæererom animalium fingularia, Aves, Pifcesque copiofiores, Calculi in hominibus aliisque animalibus inventi, mineræ curiofæ \& elegantes, demum: que flores fructusque pulchritudinis aut magnitudinis eximiæ fi: ftuntur, quæ plurima arte pictoria jucundiffime expreffa funt.

Alius Herbarium Impreffum : Codex hic continet herbarum diverfif- 
verfisfimarum folia fingulari artificio ad vivum expreffa, foliis ipis colore typographorum atro tinctis, ficque chartæ impresfis, ita ut fingulæ foliorum fibræ \& venulæ accuratisfime exhibeantur. Alius Herbarium bivum exoticum : Codex hic curiofiffimus colleetus eft manu Celeberrimi -Viri Syldii Bocconis Nobilis Panormitani Monachi Ciftercienfis \& Mi. Hetruria Ducis Botanici, qui per omnes maris Mediterranei oras navigans, multorum annorum induftria collegit, tandemque cum in Boruffiæ cœenobium Olivam tendens Wratislaviz ad tempus moraretur, Illuftri Haunoldo vendidit: Continet ille Herbas exficcatas \& Chartæ affixas quafcunque, five per Africæ, Siciliæ, Italiæ, aliasque maris Mediterranei littora, five in io pfo mari fcopulisque colleetas invenit,qui fingulis tam nomina quam locum fua manu adfcripfit.

Volumina alia vocantur Recreatio Mentis \& Oculi Botanica: Hac continent herbas fere quaslibet $\&$ flores, quos Silefia tam in planitie, quam in montibus Giganteis gignit, exficcatos chartisque affixos, additis paffim papilionibus aliisque infeetis a facobo $W$ illifio, Collega Elifabethano, in hac arte fatis perito, plurimum collectis.

Ex Regno Animali Conchyliorum tantus apparatus a Sebiffo colleEqus, ut vix detur aliqua concharum fpecies, cujus non hic multa cuftodiantur fpecimina; præcipue cum ex liberalitate llluftr. Dni.Præefidis Haunoldi \& Generofi Dni. Georgii Mauritii ab Hoffmannswaldau maxime auftus fuerit: nec oblivifcenda nitide politorum Conchylio. rum collectio, qux a Vincentio mercatore Amftelodamenfi Patroni aliqui compararunt, cum fcatulis in quibus Folia ambulantia, Scorpiones Javani, Aranea Brafilienfes, Abes Colybri item varix Papilionum \& Infectorum Indix Orientalis \& Occidentalis fpecies, inclufx.

Plura animalium marinorum genera funt: Stella marina maxima, item alia reticulata feu cancellata \& tuberofa, admirando artificio a natura elaborata, Ecbinorum diverfe fpecies, Aftacorum marinorum variæ fpecies, Xipbiaf. Pifcis gladiatus, Raja, quarum altera minor in Draconis f. ut creditur Bafilifci formam efformata, oftra. sius pifis mire in fuperficie cancellatus, Hippopotamus, Crocoditus, Tefurs. dines marine, eleganti teftarum variegatarum ornatu decoratæetc.

Topbus maximus albus, qui equo Rofenthalii prope Vratislaviam inteftinum reftum difrupit, Ovum in Ovo Gallinaseo etc.

Silt- 
Siltitur porro Elephas turritus f. onultus, qui varia Mineralium genera tergo impofita gerit, copiofiora vero pedibus fubltrata jacent: Ex Lapidibus oculos afficiunt quinque Gloḅi politi e marmore diverfi coloris, ubi maximus horum fere terreftris globi faciem mentitur, quem Natura (ur ita loquar) furço cingulo quafi Equatore quodam in medio dittinxir, raliquas partes vero provinciarum quafi fluminibus fuis interftingarum diverfitate ornavit. Ambiunt porro elephanti dorfum varia Cryfalli curiofioris genera. Ame*byfus puriflima ultra cava manus magnitudinem fe extendens, Turcois Hungarica, Sardonychis \& Chalcedonie gemmæ fragmenta, lapidis Lazuli particulæ, smaragdus Occidentalis in tenebris fulminans aliaque talia.

Videndum \& fragmentum non exiguum lapidis ex vario gemmarum genere compofiti, quem foffores Freibergenfes, ubi non exigua ejusdem copia reperitur, lapidem Corallinum vocant; in quo Ebrenfried Wraltherus a Tfcbirnbaus admirandam fuam poliendi artem applicavir.

Item Liapides Sciffles Mansfeldici, pifcium figuras exastiffime referentes, Arboris petrefact e cavernis Vallis Joachimica frufta, Lapi. a'es Violarum odorem fpargentes, - Fungite elegantifimi albi etc.

Auri argentique mineræ, ut dixi, elephantis tergo impofitæ funt, pretiofiores tamen, non procul diffita alia pyramis inclufas fervat, ex Hungaria fodinis maximam partem petitas, ut: Argentum rude, coloris rubei, candidum in mamore metallico, aliud plumbei coloris, aliud capillare, aliud Cadmie metallice mixtum etc.

Minera aris f. cupri hominis robur excedens, quæ venis argenteis mixta, e fodinis Nefolienfibus, Placenta aris e Suecia cavernis eruta.

Cupri camentati Neofolienfis aliquot pecimina, five foleam ferream, five crucem Hungaricam duplicatam referentia.

Floris ferri elegans fpecimen. Marcaftarim, Cadmia, Cirnabaris, Sazdarache, Aruginis, aliarumque mineralium jucunda fpectacula.

Varia terrarum fpecies.

Minera Salis cryjtallini maxima, ex meris cubis concreta,\& Wilicum prope Cracoviam effolfa. 
Precum Turcicarum volumen capfulæ argentex inclufum; Globuli Turcarum precatorii \& Amuleta varia.

Particulæ quædam Lapidis fciflilis \& Amiantbi uftoriis fpeculis Tfcirnhaufianis ex parte in vitrum converfa.

Corallii veri arborefcentis fingularis magnitudinis arbufculæ etc.

Neque parvum Templo Magdaleneo decus adjuncta conciliat Bibliotheca, quæ Ampliffimi Senatus \& privatorum munificentia adornata, \& publicis ufibus an. 1601 . confecrata fuit; continet vero fecundum Defcriptionem a Celeberrimo Dno.M. Chriftiano Stieffio Rectore adjacentis Gymnafii \& Bibliothecario hujus Bibliothecæ meritiffimo transmiffam feq. res Naturales \& Artificiales.

Bibliothecam Vratislavienfem publicam, quæad ELdem D. Marie Magdalene facram, fingulis Martis ac Veneris diebus, horis pomeridianis ordinarie, ac fi neceffitas urgeat, ex promtiffima $\mathrm{Bi}$ bliothecarii benevolentia, tam Indigenis quam Extraneis quotidie ad ufus litterarios \& fatiandam curiofitatem pater, primus in hac urbe Paftor Evangelicus, $D$. Fobannes Heffus fupellectile fua libraria, quæ pro ratione illius temporis exigua fuit, per modum legati teftamentarii, ante bina propemodum Secula quafi fundavit,alii poft eum Illuftres,-Magnifici, Litterati ac Civici Benefaetores infigniter auxerunt; Chriftophorus deinde colerus, Eloquentiæ Profeffor Elifabetanus \& Bibliothecarius Magdaleneus, Oratione aufpicali An. M. DG.XLIV. defcriplit, \& brevi polt Geo. Schafrichen Indice operofisfime confecto ftudiofe inftruxit; cujus tamen partem Onomafticam penitus abfolvere morte præventus haud valuit.

$\mathrm{Ab}$ illo tempore multis acceffionibus mirum in modum auQtam, \& non Libris tantum, fed etiam Picturis, Sculpturis, Numifmatibus, Reliquiis, Naturalibus \& Antiquaris egregie dotatam Magnificus Reipubl. Wratisl. Senatus poft obitum B. Küpfenderi An. M. DCC. X VIII. Chriftiano StieffióReetori \& Profeffori Gymnafii Magdalenei felemniter conftituto, fub expreffa juramenti formula cuftodiendam commifit: qui eam non modo recentibus Patronoruin donationibus hactenus locupletavit, fed infatigabili quoque opera in novum plane ordinem exactiffimum redegit, \& in novo infuper Catalogo conficiendo nunc defudat. Quo facto, fi Dcus 
vires ac otium concefferit, Labóris peracti rationes Scripto publico exponere, \& ampliffimam Memorabilium, quæ ibi colliguntur; recenfionem inftituere, in animum induxit.

Extant in ea omnium Facultatum, Difciplinarum \& Linguarum, quibus eruditi folent inclarefcere, quatuordecim mille propemodum Volumina: Codices autem membranacei \& manu exarati admodum pauci comparent; quoniam ex tumultuariis ac infeparatis plerumque largitionibus integrum iftud Syftema Bibliothecarium concrevit, \& novam indies Benefactorum liberalitatem expectat. Cui etiam non nullos Codices Hebraicos, Chaldaicos, Turcicos, \& Arabicos, nec non chronicas rerum patriarum com. pilationes, \& Adami Pufchmanni Opus de Pbonajcis Germaniæ (oon Denen Neifter=Sängern uno ibren Sbönen) debemus.

Extant Inftrumenta quædam Mathematico-Aftronomica, a Celeberrimo Hebelio Dantifcano profeeta; Sphæræ duæ armillares Copernicanæ; Automaton muficum minoris formæ; Mineralia indigena \& exotica; Lithoxyla in Silefix montanis prope Landisbutiam reperta; Panis \& Cafeus petrefacti; Foffilia Maslenfia; Mumia Fgyptiaca, ex famofiffima hæreditate Laurentii Scholzii a Rofenau, Poliatri olim Breslenfis clariffimi, ad Cbriflophorum Craufium Pharmacopolam emtionis titulo delata, \& tum cultro anatomico per nobiliffimum Andream Grypbium an. 1662. examinata, tum doetiffima Commentatiuncula per eundem Orbi erudito defcripta.

Extant Urnæ fepulchrales veterum gentilium Silefiorum, in pago Ranfern, qui uno a Wratislavia milliari diftat, occafione eluvionis Viadrinæ An. M. DC. XIV. d. XV. Aprilis detectæ; quarum deinde numerum pluribus aliis, Lignicio, Lubena, Raudena, Pilgramsdorfio, Wiltfchizio, Maffilia, Smigelio, Pilsnizio \& aliunde ad fe miffss auxit modernus Bibliothecæ Præfectus Stieffius : qui non folummodo An. M. DCC.IV. de Urnis in Silefia Lignicenfibus ac Pilgramsdorfienfibus Schediafma Epiftolicum publicavit; verum \& de fuis, quas ipfe per annos triginta paffim collegit, Ollis funsbribus $\mathcal{F}^{2}$ Reliquiis antiguariis infra fpecialius acturus eft.

Extant Lothi cum filiabus Convivium inceftum, \& Salomo. nis Regis Judaici de duabus meretricibus Judicium ex alabaftro, an- 
te duo jam Secula, nefcio quo artifice perquam accurate fculptum; Chrifti porro inter duos latrones crucifigendi per quatuordecim figuras ligneas exquifita reprafentatio, a quo autore, qualiscunque fuerit, quatuor etiam Evangeliftarum effigies \& Vita Chrifti duodecim Tabulis ligneis figurata confpectui advenarum fiftitur.

Extant Scripturæ, aut cara\&teribus minutiffimis, aut figuris hieroglyphicis, variorum manibus exaratæ; immo \& fine manibus humanis, fola pedum dexteritate confectr ab illis, quibus infelicitas nafcendi monftrolum corpus fine brachiis tribuerat: quales furerunt An. M. D.LIV. Thomas Scbweicker Halenfis Suevus; An. M. DC. LI. Magdalena Rudolpbia Thuinbuja mulier Holmienfis Sveca; \& An. M. DC. LIV. Theodorus Steib Viennenfis Auftriacus; noftro autem hoc Seculo ineunte Mattbias Buchinger Francus, qui fortaffe adhuc in vivis eft, ac panis lucrandi caufa paffim divagatur.

Extant infuper variorum Autorum Sculpturæ \& Pifuræ: Ad sculpturas ære fingulariter expreffas, quarum alias nonnulla Volumina inter reliquos fimilis argumenti libros reponuntur,pertinent Iconifmi Virorum litteris \& armis illuftrium, reprefentationes Flo. rum, Hortorum, Templorum, Arcium, Diftrictuum, Geftorum Biblicorum \& bellicorum, Sectiones Anatomicæ, Currus velifer Batavicus, Navis aëria Lufitanica, Sarcophagus D. Jofephi Imperatoris, Organa Pnevmatica, Maúfolea \& Tumuli honorarii.

Inter Picturas coloribus vivis \& figura plerumque augulta adumbratas eminent Divus Leopoldus Cæfar, \& Margareta Hifpanica veltitu nuptiali; Rudolpbus II. \& Mattbias I. Impp. Erneftus \& Albertus Archiduces Auftriæ; Stephanus Batborius RexPoloniæ; Georgius Fridericus Marchio Brandeburg. El.; Cardinalis Grimanius Venetus, qui Pro-Rex Neapolitanus Auftriacus noftra ætate deceffit; Annas Dux Mommorantius Par, \& Comes Stabuli in Francia; Marchefe del Gafto; Don Juan Manriquez de Lara; Carolus L. B. de Zierotin, Cæfareus Pro-Marchio in Moravia, Mæcenas eruditorum \& Bibliothecæ hujus benefactor fuperiore feculo eminentiffimus; Scbivemlerus \& Riembergius, Proto-Syndici Wratislavienfes \& Confiliarii Cæfarei immortaliter meriti; Foannes Acolutbus. S. S. Theol. D. \& Prof. Paftor Elifabetanus, Ecclef, \& Schol. Aug. Confeff. Infpector Wra- 


\section{PROMTVARIVM RERVM NATVRALIVM}

tislavienfis; Omnes ac finguli Paftores Evangelici Maria-Magdalenei; Joh. Kretfchmerus Civis \& Mercator primarius nec non Templi Magdalenei per annos bene multos Curator vigilantiffimus, Vir dè Patria, de Litieratis, de Bibliotheca noftra meritiffimus.

Georgius Scbabelius a Rofenfeld, generalis olim Bibliothecarum Wratislavienf. Infpector, poftea Canonicus \& Thefaurarius ad St. Sebaftianum Magdeburgi, qui in gratiam urbis patrix Germanum Wratislabie Decorem iconifmis Senatorum \& principum Virorum notabilem fuis fumtibus edidit; Albertus Durerus, Titianus Michael Angelus Banerota, Rembrandus, Pietores clarifimi; Henricus Clofus primus Reetor Gymnafii Magdalenei; Andreas Duditbius; fobannes Heffus; Georgius Logus; Socrates \& Afopus; Joachimus Georgius Senator Wra. tislavienfis cum barba quadrata; Henricus $I V$. Borbonius Gallix Rex; Helena Antonia virgo Leodienfis barbata; Adamus a Döbfcbiiz Capi. taneis W Watislavienfis; Lutberus E Melanchtbon per Lucam Kranacbium in tabula lignea depieti; D. Maria Etbiopica \& Czenftochovienfis Polona; Quatuor Hermanni Theologi Wratislavienfes cum Epigraphe fepulchrali; Francifcus \& Mattbias Virlingit; Martinus Ratgius Cives Wratislavienf. qui huic Bibliothecx vix colligi cœptæ-centum Joachimicos five Vallenfes folidos in Teftamento An. M.D. LiII. reliquerat, \& alii.

Ne dicam de St. Hieronymo nudo, de Capite Chrifti in area de: aurata; de FEnea, Patrem Anchifen ex incendio Trojano deportante; de duobus vultibus monftrofss; de Cimone filiabus mam. mis lactato, quem nonnulli pietores falfo Charitatem Romanam socant; de una ex hydriis fex nuprialibus Canæ Galilæx, quam ad archetypum Viennenfem fob Mufelius Med.D. An. M.D. XCIII. depingi, Laur. autem Scholzius Poliater Wratisl. in æream formam incidi curavit; de Lucretia per Titianum affeeta, fed non perfe. eta; de TemploSalomonis, calamo per Adamum Reufnerum An. M. D. LV. delineato, \& per Generofif Nicolaum Rbedingerum An. M. D. LXXI. in hanc fedem librariam illato; dé faciebus llluftris Haus: noldi Præfidis \& Fanifi Med. Do\&t. \& Proto-Phyfic. Wratislavient. ex cera formatis; de Imagine Chrifti acu pictoria expreffa; $\&$ qux hujus generis alia funt, Hiftoriam Artium \& Patriæ non levi; ter illuftrantia.

Extat 


\section{ET AR TIFICIALIVM VRATISLAVIENSE.}

Extat denique Nummorum tam Veterum quain recentium in. fignis apparatus, tribus arculis multisque capfulis inclufus. Confularium, Civitaticorum, Regiorum, \& Imperatoriorum ex argento bina circiter millia varii inoduli, æreorum aliquot centuriæ numerantur, qui tamen omnes novam ordinis fui difpofitionem flagitant, \& confequi, Deo favetite, poterunt, quamprimum emendatior librorum catalogus, multis voluminibus, propter opufculorum \& materiarum mulcitudinem conftiturus, ad umbilicum deduetus fuerit. Proftant interillos duo etiam coriacei Leidenfes; alii ex variis metallis; brafteati quidam; obuli minutiffimi complures; e lypi rariorum aliquot ex materia mixta conformati \&c.

Fternam vero in hoc Bibliothecariorum Ornam torum genere-gloriam habebit Munificentia noftro ævo valde: as infolita, Johan. Kretfchmeri fupra laudati; qui quadringentos Ur. ciales argenreos rarioris obfervantia, \& nonaginta Nummos memoriales ftanneos, fingulari fudio delectos, \& nobiliffími cujusdam litteratoris manu breviter defcriptos, vivus adhuc \& valens armariis noftrisintulit, atque fic memoriam Kret/chmeriani Nominis, quæ præmaturo duorum Filiorum fine mafcula prole morientium fato commori videbatur, ab omni Pofteritatis fepius ingratæ oblivione vindicavir.

Hæc \& fimilia ftrictim modo \& primis quafi labiis memorata, cum orbe litterato communicare potuit modernus Bibliothecæ Præfectus : qui quæ de uberiori Memorabilium explanatione fuprapollicitus fuit, prafentibus, qux ipfi magno numero incumbunt, negociis feliciter expeditis, in diem aclucem exponere nullatenusgravabitur.

Armamentaria Vratislavia duo, tam infigni copia tormentorum, mortariorum, lithobolorum, colubrorum, bombardarum, fcloporum, fpingardarum multitudine, romphearum, lancearum, fariffarum, haftarum, gladiorum, loricarum, aliarumque municionum \& armorum omnis generis thefauro rerum ordine, facili ufu, promtaque ad omnes neceffitases expeditione, ut cum quibusvis Ger. maniæ urbium armamentariis conferri poffine, præcipue notanda Tormenta IV. ubi maximum CXX: Centenarios æris babet, atque 
globeos ferreos LX. librarum capic, In Armamentario Burgfeldenfi repofita eft in fuperiori illius parte ingens antiquarum fagittarum copia, An. M. CC. XLI, a Tartaris in urbem miffarum: factx funt illæ omnino e ligno querno excepta armatura ferrea, qux fupra trium unciarum pondus habet : ibidem quoque reperiuntur aliquot arcus eo pertinentes, cum clavibus fuis fingularibus, item clypei Tartarici, \& alia ejus generis inftrumenta plura. Speciatim huc referendum eft Technopbylacium ad portam arenariam in Armamentario inftitutum, cui fupra memoratus Tit. Dn. Albertus. a Sebifcb curiofiffimum armorum Germanicorum, Hifpanicorum, Turcicorum aliorumque Exoticorum apparatum, una cum variis exemplaribus tormentorum celeriter glandes ejicientium, nec non inAtrumenta plurima ad Architecturam militarem \& artem pyrobolicam facientia, teftamento legavit: Polonicus autem Princeps $L u-$ bomirsky Cataphractam livefcentem \& obauratam, una cum reliqua armatura fua præftantiflima, quaipfe eft in præliis ufus, aliique ejus genéris talia donaverunt.

In armario quodam ibi affervantur XXIII. enfes, quibus At. M. CCCC. XIX. cives XXII. cum I. muliere in Burgo (uti vo. catur) Cæfareo, præfente hic Vratislaviæ Imperatore Sigismundo fuerunt decollati, utpote qui anno præcedente tumultu contra Magiftratum hujus loci excitato Senatores partim trucidaverant, partim de feneftra præcipitaverant, partim obtruncari curaverant.

Machinarum varia proplafmata funt notabilia, ut : Stateræ quibus onera majora ponderantur; plauftra feeno vehendo apta, in quibus etiam funt Lipfienfia; variæ machinæ tractoriæ \& impulforiæ cum sohleis perpetuis; variæ cochlex aquaticæ \& machinæ fuetoriæ, item machinæ quibus aqua vel fitularum ope hauritur, vel elevatur alio modo, inter quas etiam habentur rofaria; varii generis molæ vento agitabiles, quibus pulvis pyriusatque frumenta teruntur \& afferes fimul formantur; molæ omnino teetx in caftellis \& munimentis tempore belli adhibend $x$; mola equin $x$ \&c. Sipho tribus cylindris inftructus, qui rota agitatur; it. machina Ala artificiofistima quæ Dantisci fuit adhibica ad montem, munitia- 
ni urbis infeftum, amovendum, nec non multifaria artis fpecifnina, qux Fabri lignarii ex more efformant, artem fuam publica aucto. ritate exercitaturi.

Non oculis prætereunda receptacula f. Cafella aquaria, in quibus aqua ex Viadro \& Olava derivata, magnis verfatilibus rotis aliisqu machinis artificiofis furfum attrahitur in locum, indeque per fub. terraneas tubas in remotisfimas urbis partes large difpenfatur; - ut, quos negavit natura, fontes, ars abunde fuppeditet, rarasque adeo urbe tota reperias domos, fine antleis, e quibus aquam prona facilique quisque volet, etiam puer hauriat manu, \& in aliquibus per. omnes contignationes premitur: Speciatim maximam omniumi aqua vim fuppeditat Magnus, qui ita nominatur, bydraulicus, in quo præcelfa \& perquam valida rota movetur, diametri altitudine XXIII. ulnas \& VII. digit. habente, cui utrinque CXXIV. hydriæ funt affix $x$, infra e Viadro aquam haurientes, \& fupra in canales effundentes, unde in alveum, \& porro per tubos in omnes aquxduEtus urbis influit. Hydraulus ad St. Matthie eft Antlia, ubibeneficio rotæ aqua in XXVII. ulnarum altitudinem per tubos VIII. afcendit, perque alios in aquæduetus defcendit. In Hydraulo ab hareticis nomen trahente, (vulgo Ketzel-five Ketzer Kunft, ) in urbe per ro. tam aqua in alrum premendo evehitur, vel Ola aquarum penuria laborante, ut rota agitari nequeat, idem ope perpendiculi continuo ventilati peragitur.

Ut incendiis invalefcentibus cito mora injiciatur, non Magi. fratus modo Vratislarienfis fuo fumtu multos eximix magnicudinis sipbones in promtu fervat, inter quos \& una eft cum 2. canalibus, qui aquam continuo ejicit, item fipho unusferpentinus (vulgo dictus ). Sed pleræque etiam tribus fodalitatesque civium fuos quxque habent fiphones tubis metallicis \& æneis labris inftructos, quibus \& premendis dirigendisque certi homines perpetuo officio funt conftituti : Inprimis Mercatorum Zythopolarumque fiphones incendiarii, vi fua \& magnitudine, cum quavis presfione prior LX. pofterior XL. fextarios aquæe ejiciat, plurimum efficiunt, \& prior quidem aquam ulcra centum ulnas afcendentem, emittere valet. 
Nunc deveni $\delta$ ad váriorum Magnatum \& aliorum Privatorum peculiares hortos, effigies, porticus, conclavia, mufea, nummophylacia \& alia, qux ad Promtuarium rerum Naturalium \& $A$-tificialium Vratislavienfe adhuc pertinent.

Inter omnes hortos, quanquam complures hic loci lectiffima malorum aureorum copia aliisque plantis ex utraque India allatis abundent, maxime numero aliorum fe excerpit fitus ad Olavam bortus. Tit. Plenif. Dn. Dn. Joacbimi. Willbelmi Sac. Rom. Imp. Comitis de Malzan, Liberi Baronis de Wartenberg \& Penzlin, Domini Hareditarii Libera Dynaffie Milicenfis in Silefia, Domini in Militfch, Fregban, Gros-Petenvitz, Pinxen, Proskowa $\mho_{c}$ c. atque Augufitsfimo Imperatori a Conflitis fecretioribus: Is tribus fuperciliis, in extremo autem profpectu Amphitheatro inftructus eft, cujus ambulacra, atque in extremis quatwor diverfx contignationes, ubique lapideis inauratifque ftatuis, nec non ejusdem generis itemque marmoreis urnis five vafis coloris cærulei, \& pulcherrima malorum aureorum copia funt adornata, ita ut in extremo Amphitheatro arbores ultra XIII. ulnarum altitudinem affurgant. Ceterum in fingulis quatuor angulis horti difpofitx funt citri auratæ, fingulari craffitie \& magnitudine, quarum cacumen XIX: ulnas ambitu \& ftirpes ulnam craffitudine tranfcendunt: quin \& integra feries ejusmodi Citrorum adhuc craffiorum ex Sardinia allatarum ibi conficicitur, qux omnes urnis ex ære majoribus (quarum fingularum pretium excedit fummam 250. florenorum), \& minoribus, item porcellaneis Berolinenfibus infite continentur. Auftrum verfus cernuntur arbores parieti affixa, que jam ultra VI. ulnarum altitudinem excreverunt,quartum hortus patet in longitudinem; funtquæ illæx ipfa meræe Citri aureolæ, quæ in tellure perpetuo manent infitæ, quam ob caufam hiemistem. pore feneftris vitreis contra frigus muniri illas neceffe eff. In ineditullio horri eft magnumaqua receptaculum, cujus in centro deprehenditur aquæ ejaculatio in haftæ prælongæ (qux Gallis Pique dicirur, ) altitudinem; ubi fimul varii anates peregrini \& aves aquaticæ exoticx natant, alix volucres autem ex utraque lindia adveetre is horto difeurrunt. Introitus in hunc hortum patet per vefibulutu \& fatiofum Periftylium colore cum oleo permixto Trium: phum 
phum Bacchi, item e regione Triumphum A pollinis cum Minerva \& novem Mufis depictum reprefentans; in quo fimul fpeculum ingens ex multis vitris compolitum IV. ulnas altitudine exæquans, erętum eft, quod totius horri profpectum reprafentat. Siniftram verfus autem inveniuntur quinque conclavia nitidiffima, quippe ferico damafceno auro argentove pratexto, panno holoferico \& fplendidiffimis texturæ Belgic $x$ tapetiis exornata, medium vero un. dique fpeculis expletum eft, \& omnia paritar argenteis tychnuchis penfilibus, itemque parieti affixis, aliisque inftrumentis, nec non grandioribus fpeculorum vitris 3 ulnas \& 2. pollices altis, 3.ulnas vero\& 1. pollicem latis inftruefa funt.

Ex Palatiis Magnatum illud Illufriffimi Comitis Hatzfeldii in platea St. Alberti recens exltruetum tine controverfia magnificentiffimuin fpectatisfimumque eft; fiquidem non folum architeeturx artificio, fed etiam aliis ibi obviis picturis fane rariffimis pretiofisfimisque infigniter enitet : Porta princeps cum duplici Xyfto inftruEta ftatuis quæ multis lapideis columnis \& ftatuis giganteis tine adminiculo ftantibus innituntur, his ædibus foris, nec non expofita partibus fuperioribus, trophæa, vafaque; intus autem artificiofe excogitatæ, fublimi teftudine \& laterna obtectæ fcalæ duplicatæ magnum decus conciliant. Speciatim Periftylium majus nihil fimile aut fecundum habet in Silefia : Id nimirum usque ad projecturam undique marmore glaucino diftingvitur, gypfoque marmorato exornatur; pilæ inauratis epiftyliis \& pedibus décorantur, \& fuperius effigies media colore oleo permixto depieta eft a manu fæpe laudati Rottmayeri, inferius vero omnes pieturæa foh. Rudolpbo By/s Aulæ Eleetoralis Moguntinæ Pietore pulcherrime funt expreffx, repræfentantes, Compenfationem Deorum gloriofis illuftrisfimæ. Domus factis convenientem. In conclavibus, in quibus unumquodque fingulare quiddam habet, invenitur maximus tabularum pietarum pretiofisfimarum apparatus, a manu præftantisfimorum artificum profectus,' ex quibus non nifi fequentes nominatim recenfeo:

XIII. Tabulx a Rubenio, five Vultus Chrifi \& XII. Apoftolorum. I. Árcentio scarie, a Cornelio Scbutt. 
II. Tabulæ Florum, a Mignonio.

II. Tabulæ imaginum thoracetenus expreffarum, a Rembrando.

1. Tabula Familix Chrifli, a Florifro.

I. Tabula talis, a Kayo.

II. Tabulæ Bachanaliorum, a Rottmayero de Rofenbrumm.

I. Regio, a Saverio.

III. Tabulæ Regionum, a Peclenburgio.

1. Sertum floreum, a Gerbardo Segers.

I. Tabula florum, a Brïgelio.

I. Tabella Samfonis \& Delilæ, auctore de $\mathbb{W}$ erff f $_{\text {. }}$

V. Tabula Regionum, a Coffrano.

VI. Tabulæ Regionum, a Bendlero.

IV. Prælia, \& Rugendafio.

II. Tabulæ pecudum, a Rofio.

1. St. Franciscus, a Wilmanno.

1. Tabula magna Hubertus, a Lifchea.

1. Caput St. Jobannis, ab Alberto Dürero.

1. Juditb cum Holoferne, a Lica Cranacbio.

1. Chriftus inter gregem puerulorum, ab eodem.

I. Maria effigies; a Carolo Maratta.

II. Regiones cum militibus \& rufticis, a Brügelio feniore.

1. Tabula Andromedæ, auctore Libri.

II. Tabulæ rerum quiefcentium, a Feytio.

II. Tabulæ florum, auctore Huifum.

II. Tabulæ florum, auctore Mari de Fiori.

II. Tabulæ cum multis figuris, a feniore Frankkio.

I. Lepus, ab Hamillono.

I. Lepufculus, a Röslero.

1. Tabella Encæniorum rufticorum, a Bautio.

1. Maris effigies cum variis Sanctis, a Dominicbino.

1. Venatio Leonum, a Rubenio.

1. Prælium, auctore Burgognion.

II. Effigies, a Kupezgio.

Infignem quoque picturarum aliorumque curiofarum prorfis excellentium apparatum goffidet, Tit. Plen Dn. Dm. Cbrifopba- 
rus Comes de Profskaus Dominus Horeditarius Dynaftis Pimbkenavien fis, Dominus in Petersdorff, Lauterbach, Krampf. Weiff, Wolffersdorff E Hertwigwalde, S. C. Maj. Camerarius Ec. Confignatio manu iplius illuftrisfima mihi tradita, ita habet: Ex Tabulis pict is præftantiffimæ funt: IV. PiEturæ in tabulis æneis $\frac{6}{4}$. altis \& $\frac{2}{4}$. longis, a Jobanne Hartmanno

IV. Elementa in regionibus reprælentantes, cum innumeris fere figuris.

XII. Vultus, a Rembrandio XII. Philofophorum.

I. Bacchus, a Rubenio.

I. Andromeda, ab eodem.

I. Regio, a Rolando Savery.

1. Tabula optice pi\&ta, a Felderio, Templum Jefuitarum Antverpienfe fimul effingens.

1I. Tabulx primis coloribus adumbrata, a Calloto.

I. Chrifli nativitas, a Jobanne de Werff.

VI. Opera architectonica, auctore Sayts.

1. Tabula magna, Juftitiam Salomonis exhibens, auftore de Vos.

Delineationes Pietorum complurium celeberrimorum \& figuræ æneæ, item alia diagraphica opera $\mathrm{f}$. picturæ lineares minime defunt: fpeciatim in his comparet opus magnilaboris \& momenti ex M. DCC. foliis \& amplius conttans, in quo Erneftus Anton. a Lebmann ex præltantisfimis MStis \& Libris Mathematicis calami ope variis coloribus in univerfam Mathefin figurationes defcripfit, figurarum ænearum variegato colore expreffarum fpeciem præ fe ferentes: quo in opere Auctor ultra XII. annos continuo defudavit, \& iple dum effet in vivis 8000 . florenorum fumma aftimavit atque plus fimplici vice nactus eft, qui dimidian iftius pretii partem licitarentur.

Et a M. Cbrifiano Hempelio Volumen formæ majoris, in quo pulcherrimos rarisfimosque flores ad vivum depinxit, 500. foliis conftans.

A Maria Sibylla Greffin natalibus Meriana, quæ ea de caufa peregrinationem in Indiam Orientalem fufcepir, ut Surinamenfes erucas, papiliones, infecta \& conchylia varia manu propria in æs incideret, ubi ad vivum ab illa ipfa coloribus mira arte illuminata, hic confpiciuntur. 
Ludovici Renarii pifces, cancri \& aftaci fingulares, quos Auctor, in Infulis Moluccis offendit, pulcherrime in æes incifi \& illuminati. $\Lambda$ le Blong Londinenfi præftantiffimæ figuræ æneæ, picturarum coloribus oleo mixtis expreffarum fpeciem exacte referentes.

Ex multis aliis curiofis memorabile eft Horologium manuale \& repetitorium ab Antonio Milloegg Jun. Viennæ fabricatum, quod horas, femihoras, quadrantes $\&$. femiquadrantes proprio moru fonando indicat, menfem, diem, lunæ ætatem, item incrementa \& decrementa, motum Planetarum etc: demonftrat, aut fi quis illius fonum audire nolit, dirigendo inhibere poteft, quo minus fonicum edat: hoc horologium eft aureum, vitreo rubineo adamantibusque diftinctum. Artifex \& auctor illius Viennæ 1000. florenorum pretium pro eo accepit: Quod vero maxime omnium notari meretur, horologium idem, etfi tani multa ac varia demonftrat, tamen horologio manuali, media magnitudinis majus non eft, \& unica tantum in ipfo rota amplius, quam in aliis vulgaribus, invenitur.

Multa Matbematica \&o Optica, in quibus eminet eximius plane difcus diviforius, ufibus fabrorum automatariorum inferviens, auAore Tampion: multi circini proportionales eximia magnitudinis, circini ovales; Antlia pnevmatica, Barometron \& Thermometron in capfula, ejusdem cum capfula, in qua recondi folent dentifcalpia, magnitudinis, ex argento.

Armamentarium, in quo præftantiffima præftantiffimorum arificum Germanicorum \& Hifpanicorum arma affervantur; atque in his Tormentum pnevmaticum, miranda artis opus, quod Kelnerus Norimbergx fecit, eoque Serenif. Principem Eugenizm dona. re voluit, nifi mors confilium intercepiffet.

Multa Numifmate antiqua $\sigma^{\circ}$ moderna, ubi in pofterioribus longiflima omnium Imperatorum \& Pontificum habetur feries, a Clorifopboro Wermutbio Gothx cufa.

Egregium plane Concbyliorum Mufeum ultra 4000. conchas continens.

Varia petrefacta, in quibus Cochlea cum cancello, longe pulcherrime \& luculentifime confervata.

Pra. 
Præter ea adhuc apud alios Viros magnæ Dignationis fparfim, \& extra collectionis cujusdam fyftema, præftantiffima inveniuntur pieturæ; ut apud Tit. Pleniff. S. C. M. Conflitarium intimum E' Pr\&fidem Camere Vicarium, Dn. Dn. Antonium Cbriftopborum Comitem ES De. minum a Proskau, etc.

IV. Tabulæ Regionum cum multis figuris, a Brïgelio.

Tabulæ florum, a Thammio.

VI. Tabula Regionum; a Greffierio.

Tabülæc cum pugnis navalibus, ab codem.

II. Tabulæe, a Scbnautio.

VI. Tabulæe, ab Heiffio.

Hercules in juventute, auctore sayts.

Quædam opera architectonica, a Pierfio.

Effigies pietorum præftantiffimorum opere miniato elegantiffime expreffa.

A pud Tit.Pleniff. Dn. Dn. J.B. Sacr, Rom,Imp. Com. a N, ex multis Tabulis eminent:

FEfus puerulus in cruce recumbens, auctore Maratto.

Lapidatio St. Stepbani, a Procacino Romano.

Regio minuta in ære, a Brïgelio.

1I. Tabulæ præliorum, auetore Burgonion.

St. Magdalena, a Raphaële.

Crucifixio Cbrifli cum Maria \& Fobanne, a Micbaële Angelo Buonarots. Tabula belliffima pecudem exhibens, ab' offerbeckio.

Mars \& Pallas, a Paulo Veronenfo.

Clorinda, a Strudelio.

Prælium, ab Eyfenmayero.

IV. Tabulæ majores pecudem repræfentantes, a $R o \int_{A}$.

Caput fenile, a Davide Teniers.

Regio, a Fabricio.

2. Regiones, a Momberto Romano.

2. Tabulæ Zaleucus \& Stratonica, ab Haintzio.

A pud Tit. Plenif. Dr. Dn. Fobannem Emericum S. R. I. Comitem A Berg, Supreme Curia Regia Confliarium, inter alia præclara celeberrimorum artificum opera: 


\section{4 PROMTVARIVM RER VM NATVRALIVM}

Inventio artis pietorix, fcil. Cupido facem ardentem manu tenens, cujus lux umbram in parietem immittit, hanc vero Nympha adumbrando imitatur, a fobanne de Re: (Hanc pieturam preftantisfimam Ludovicus XIV. Rex Gallix, Gobanni sabieskio Regi Poloniæ olim dono dederat, a quo ad Principem Regium facobum Ludovicum Olaviam, \& tandem donationis titulo, ad Illuffriff. Comitem a Berg tranfiit.)

1I. Gigantes faxum levantes, auktore Trevifane.

Venus recubans, eodem auetore: cujus comitem, videlicet Venerem Cupidini oculos obvelantem, fob. Francifcus a Backer pinxic,

Sequitur nunc infigne Mufeum Tit. Dn. Ernefti Benjamini a Lö. wenffüdt $\&$ Ronneburg, quod intra XXIV, annorum fpatium, partim in peregrinationibus fuis, partim in hac urbe noftra magno ftudio fumtuque collegit; \& quidem uti recenfionem ex ipfius manibus acceptam, lingua vernacula publicare juffus fum:

Der_Catalogus von denen Schildereyen ift folgender: Aingrofjen Stücken.

1. Ein Stiick worauf eine Weibes-Perfon mitFrüchten, van Rofa. 2. Eine Weibes.Perfon mit einem Stroh-Hutte, wobey ein ZiegenBock, von Rofa.

3. Die Heiligen drey Könige Cbriflo opffernde, von einen Welfchen Meifter.

4. Die Römirche Liebe, von Baro Strudel.

5. Loth mit feinen Töchtern Wein trinckende, von eben denfelben.

6. Sufanna mit zweySufanna-Briidern, von einenWelfchenMeifter. 7. Wie Cain den Abel todt fchläget, von Carl Screta.

8. Ein Knabe wie er einen Kopf abzeichnet, von Vaillant, (der Jun. ge ift fein Sohn nach dem Leben gemahlet.)

9. Ein Jäger als ein Portrait, von Hr. von Löwvenfädt, von Heinitz. 10. Ein Pfau mit einer Pfauin, und allerhand Enten, von Hondecouter (eines der beften Stücke.) 


\section{Mittlere Stücke.}

II. Ein See-Stücke wo ein Thurm nebIt allexhandSchiffen, von seemann.

12. Ein anderes, von eben denfelben.

13. Eine Bataille.

14. Ein anderes wo ein Schlos belagert wird, Compagnon,

15. Eine Sufanna mit den fogenennten Sufanna. Brïdern, vonRoltmayern.

16. Ein Teppicht worauf ein Todten-Kopff nebft Mufcheln, von Sauerland.

17. Ein Haafe nebft einen Hirfch-Fänger, von Tbam.

18. Die Cleopatra wie fie fich mit Schlangen ums Leben bringet; von 2uido Reno. .

19. Ein Trapp liegende nebft einer Wayde-Tafche, wo ein Vorfteh-Hund, fehr wohl gemahlet auf der Seite lieget, von Fetti.

20. Eingefallene Ruinen, wo Vieh weidet, von Ficbter.

21. Ein anderes wo Jäger von der Jagd mit Hunden kommen, Compagnon.

22. Der Hr. Cbriftus wo er das Creutze fchleppet, von Cocce, aus Italien.

23. DieZeit wie fie die Jugend crönet, von de Moor.

24. Das Lafter wobey ein Frauenzimmer einem Tieger Trauben giebet, von de Moor, Compagnon.

25. Ein Stück worauf ein Hahn nebft Auer-Hünern, von Heinietztbal.

26. Ein anderes wo Enten im Waffer fchwimmen, die ein Hund im Rohr aufjagt, vơn eben denfelben, Compagnon.

27. Ein Stück worauf allerhand Kupfer-Gefchirr gemahlet, nebft einen Bauer-Jungen.

28. Ein anderes mit Kupfer-Gefchirr, vvobey ein Bauer-Mägdchen, nebft allerhand griin Zeug, Compagnon.

29. Ein Hirfch vvelcher von Hunden gebiffen, aus der Schule des Schneiers.

30. Ein vvildes Schvvein von Hunden zerriffen, Compagnon. 
3i. Ein Hahn hangénd an der Wand, vvobey allerhand Vögel liegen.

32. Ein hangend Frucht-Stück, vvo ein Affe nach der Traube greiffet, unten liegen allerhand Mufcheln und See-Gevvächfe, vvo die Mufcheln vortrefflich gemahГet, Compagnon.

33. Eine Juden-Schule, vvo vielerley Juden in Lebens-Gröfle, mit vvunderlichen Gebehrden gemahlet.

34. Der Heil. Sebafian mit Pfeilen durchfchoffen.

35. Des Hr. von Läzpenfä̈dt, Conterfait von Kopetzky.

36. Ein Korb mit Epffeln und Wein-Trauben, vvobey ein Krebs, item, Porcellain, nebft zwey Meer-Schweinen von Gillmanns.

37. Ein Korb mit allerhand Früchten, wobey ein weiffer Papagoy, von Gillmanns, Compagnon.

38. Eine Landfchafft in einem Eich-Walde, von Berchem.

39. Ein Blumentopff, auf einen grïnen Teppicht ftehend mit allerhand Blumen, von einem unbekannten Meilter aus Welichland.

40. Ein anderer Blumentopff; Compagnon.

41. Eine Landfchafft vvo das Waffer zwifchen den Bergen flüffet, nebft vielen Dörffern, Schiffen und 10o. Figuren aufHoltz gemahlet, von Sacbtleben, unvergleichlich, (und ift diefes Stiick vor Carl. I. König in Engelland gefchildert, und von Cromweln verkauffet worden.)

42. Eine Bataille, von Huchtenberg.

43. Ein See-Sturm, von Backbuifen.

44. Ein fchönes Gebäude mit einem Garten, von Hucbtenberg.

45. Ein fchönes Gebäude mit einem Profpeet, wo allerhand Pfer. de und Wagen zu fehen.

46. Ein Krantz mit allerhand Früchten und Blumen, von Son aus Braband.

47. Ein Hahn hangend an der Wand, nebft einer Goldammer, von eben denfelben.

48. Ein Profpeet von einem Marckte, wo allerhand Kauff-Leute und Juden feil haben, von alten Bredal.

49. Eine Synagoge wo mehr den 50. Juden gemahlet, von éen denfelben, Compagnon.

50. Ein 
50. Ein Frucht-Stiick wo Wein-Trauben und Pomrantzen und allerhand Früchte, von Cornel. ban Heem.

51. Ein ftehender Pfau, von Botbfchilt.

52. Allerhand Ruinen von rothen Marmor, vvobey Manns-und Weibs-Volck von der Jagd kommen, mit Hunden und Pferden, von einen Wellchen Meifter.

53. Eine Wayde-Tafche mit allerhand dabey liegenden Vögeln.

54. Der Heil. Sebaftian von Callot.

55. Ein hangend Frucht-Stücke, von Pfirfchken, Feigen, Pflaumen, von Gillmanns.

56. Ein anderes von eben denfelben, Compagnon.

57. Ein Vorfteh-Hund bey einem Reb-Huhn und Wayde-Zeug, von Fetti.

58. Allerhand Blumen auf einen Spring-Brunn liegende.

59. Auf einem Stein liegende Blumen von einem Scholar von $\mathrm{Ca}$ rol. Fiori, Compagnon.

6o. Ein Garten und Landrchaffr, von Bloom.

6I. Eine Landfchafft mit Kühen, und einen Hirten, von Rofa aus Franckfurth.

62. Vulcanus von einen unbekannten Welfchen Meifter.

63. Ein Teppicht worauf Blumen und ein Papagoy, nebft allerhand Früchten.

64. Ein Trapp nebft unterfchiedenen liegenden Vögeln an einem Baume.

65. Ein Phafan mit allerhand Vögeln.

66. Ein Hafel-Huhn nebft einer Mandel-Kräh.

67. Eine Ente an einem Baum liegende, mit allerhand Vögeln, (diefe IV. Stiicke gehören zúfammen.)

68. Allerhand Vögel und liegende Thiere in das Kleine auf Holtz.

69. Ein Conıpagnon von einem unbekannten Meifter aus Holland.

70. Das Urtheil Paridis von Mieris vortrefflich gefchildert, (ift von einem groffen Herrn 1000. Ducaten gebothen worden.) 


\section{Kleine Siücke.}

71. Ein Fleifcher vvie er Fleifch hauet, von Brawers. 72. Ein Reuter auf einem Schimmel, von Peter Wowormann.

73. Neptunus mit einem Kruge.

74. Ein Blumen-Stiicke, von Weninx.

75. Ein anderes Compagnon.

76. Die Venus und Cupido, vvie er vveinet, dafs ihm der Pfeil von der Venus genommen vvorden.

77. Eine Spiel-Gefellfchafft, vvo die Magd einen Spiegel vorhält, um die Karten zu fehen, von Metzu.

78. Ein See-Stiicke.

79. Ein dick bevvachfener Wald, vvo der Heil. Euflachius vor dem Crucifix niederfället, vvelches dem Hirfch zvvifchen dem Ge. viveyhe ftehet, von Rofenboff:

80. Eine Landfchaffi von der Gräffin von Oppersdorff ftaffiret, von Frantz Ferch aus. Wien.

81. Compagnon.

82. Eine Landrchafft von Backers.

83. Eine Landfchaffr, nach dem Brïgel.

84. Der Compagnon darzu.

85. EineSchiff-Flotte in einem Sturn, von Peter Nolpes

86. Eine Landfchafft, von Feifenberger.

87. Der Compagnon darzu.

88. Ein Profpeet von Schövelingen bcy Haag.

89. Eine Landfchafft von einem unbekannten Welfchen Meifter.

90. Eine See-Fatirt.

9r. Ein eingefallen Gewölbe, von Schmies und Agricola ftaffiret.

92. Zwey Soldaten geharnifche die Taback rauchen, von Schuit.

93. Allerhand Welfche Früchte mit Johannis Beren in einer Porcellainen Schale nebft cirem Glafs Weine, von Gillmanns.

94. Kirfchen und Wein. Trauben nebft einem Becher, von eben denfelben, Compagnon.

95. Eine Bataille, von Hucbtenberg. 
96. Maria mit dem Kindlein jEfu und folepb nebft zvvey Engeln, von Titians.

97. EineFrau vvelche Fliegelvverek feil hat,nebit 2. beyftehenden Jungen.

98. Ein Weib vvelche ein Kind auf der Schoos hat, nebft ihrem Manne mit einer betrübten Mine, von Brackenbourg, Compagnon.

99. Diana und Endimion.

100. Venus und Adonis, Compagnon von einem unbekannter Meifter aus Holland.

10I. Eine Landfchaffr von Bemmel, vvie er zu erft gemahlet.

102. Ein Compagnon.

103. Ein Glafs mit Blumen auf einem Marmorfteinernen Tifch mit allerhand Infeeten, von Jungfer Reuefch.

104. Ein fchöner Kopff mit der Hand, von Rembrand.

105. Eine Weibes-Perfon vvie fie aus dem Bade kommt, von Titian.

106. Ein Fuder Heu darein das Wetter fchlägt, vvobey die Pferde durchgehen, den Mittag vorftellende.

107. Eine Landrchaffe vvo der Mond fcheinet, und bey dem Feuer fich Leute vvärmen, die Nacht vorftellende.

108. Eine Landfchafft mit einer Brücke, vvo der Hirte das Vieh austreibet, den Morgen vorftellende.

109. Eine Landfchaffe vvie die Sonne untergehet, mit einem Welfchen Palatio, den Abend vorftellende, (diefe vier Tags-Zeiten find von Agricola auf Kupfer gemahlet.)

IIo. Die Hiftorie Tomyris, vvie fie das Haupt Cyri ins Blut tauchet, auf Holtz gefchildert, von einem Scholar von Rubens.

III. Die Hiftorie Jofephs, vvie er fich feinen Brüdern zu erkennen giebet, von Lairefe auf Holtz.

I12. David mit dem Kopffe Goliaths vor dem Saul kniende, vvo er mit einem Lorber-Krantz gekrönet vvird, von einem Brabanter.

II3. Eine Grotte vvo einem Heidnifchen Götzen geopffert vvird mit vielen Prieftern. 


\section{PROMTVARIVM RERVM NATVRALIVM}

114. Eine Landfchaffr, von einem Hollär,difchen Meifter.

15. Eine Küche mit allerhand Küich-Werck auf Holtz, von Sachtleben.

116. Eine Landfchaffr nach der Natur gefchildert, von Ruysland. 117. Diane und Califte auf Holtz fehr fchön gemahlet, von Mieris. 118. Ein alter Mann vvelcher bey dem Licht ftudiret, von Ifean $\mathrm{Li}$ Dens.

119. Ein Nacht-Stüick vvo eineFrau in einer Maus.Falle eine Maus gefangen, und ihrem Sohne zeiget, von Scbalcken.

120. Eine Landfchaftt fehr fein gemahlet, van der Heyden.

121. Ein Nacht-Stück Maria Magdalena, vvie fie bey der Lampen liefer, und zu dem Fenfter der Mond hinein fcheinet, um zvveyerley Licht anzudeuten, von Scbalcken.

122. Ein Frauenzimmer vvelches die Laute fpielet bey einem Tifche, vvorauf ein Teppicht vortrefflich gemahlet auf Holtz, von Peter van der Werff.

123. Ein alter Mann vvelcher in einem Buche liefet, von Gerh. Dawni.

124. Das Conterfait von Hr. Kopetzky," vvie er den Hrn. von Lötwenfädt abfchildert, von Fijchern Kayferl. Hoff-Mahler, von Elffenbein.

125. Ein Wein-Röhmer, da durch das Fenfter die Häufer fcheinen, fehr künftlich gemahlet, aus König Carl I. Gallerie, von Cromwol'verkauffe.

126. Ein Crucifix auf Holtz fehr fein gemahlet, in Miniatur. 127. Ein kleines Conterfait von einer Welfchen Dame, von Rofalba aus Venedig.

Verzeichnüfs der Statuen aus Bronzo, fo vool Antiquen als Modernen, voelche meift aus Italien.

1. Ein Saltator bachans.

2. Ein Pugil.

3. Ein Gladiator. 
4. Ein Römifcher Raths. Herr, cum fago.

5. Cibele cum Cornu Copia.

6. Die Venus auf einer Mufchel fitzend.

7. Die Venus ftehende.

8. Mercurius vvie er einen Brief in der Hand hat.

9. Mercurius den Kopff Polyphemi in der Hand haltend.

Io. Ein Satyr vvelcher tantzet, fehr künftlich gebildet.

II. Antinous einèn Schu lang.

12. Hercules vvie er die Schlangen zerreilt.

13. Die kniende Venus, vvie fie aus dem Bade fich abtrocknet.

14. Die Venus ftehende mit einem Delphin, und einem Apfel in der Hand, bald zwey Schu hoch.

15. Meleager den Schweins-Kopff in der Hand, und einen WindHund bey fich.

16. Pan auf einer Flöthe pfeiffend.

17. Eine Sibylla.

18. Sibylla Cumana.

19. Hercules wie er mit den Lövven ftreitet.

20. Mafaniello von Neapolis einen Fifch-Korb in der Hand haltend.

21. Ein Hund fich kratzend.

\section{Cabinet von Kupfer - Stichen und Zeich- nungen.}

Darinnen befitzet Er eine Collection von den zierlichften Handriffen der beften Mahler, wie auch die vollftändigen Wercke Laireffens, Petri Beretini de Cortona, Fagens, Rubens, Albrecbt Durers; Theils auch a parte Kupfer - Stiche, von den berühmten Callot, Rembrand, Stepbano della Bella, Ifrael Sylbefter, und anderen, wie er denn infonderheit des Rembrands faft alles was er radiret, und fehr viele mit Farben gedruckte Kupfer gefammlet: Aus der Schwartzen-Kunit aber Smitbs, Som, scbenck \&c. 
Wie nun die Bildhauer - Kunft eine Schwefter der Mahlerey kan genennet werden, als befitzet $\mathrm{Er}$ davon folgendes:

I. Das Portrait Leopoldi M, aus Holtz von ihm felbft ged ech. felt.

2. Ein Zahn-Stecher - Büchslein aus Elffenbein von dem Printz Jacob auf der Feftung Pleiflenburg zu Leipzig gedrechfelt.

3. Ein kleiner Pocal von Hertzog George von Brieg.

4. Carl XI. König in Scbweden von Carlftein aus Elffenbein.

5. Der Schwedifche Cantzler Wölfel aus Elffenbein von Cart. Aein.

6. Ein Becher wo 50. Becher hinein gedrechfelt.

7. Der Ring der Heil. Dreyfaltigkeit aus einem Stück Elffenbein gedrehet.

8. Ein Meifter - Stück von einen Drechsler aus Wien, wo ein Dutzend Teller fo dinne dafs man durchfehen kan, und $\frac{i}{2}$. Dutzend Schüffeln eben fo gedrehet.

9. Ein paar Löffel von Holtz in einer Ketten, aus einem Stücke Holtz, von einem Bauern in Ungarn gefchnitten.

10. Ein gantzes Thee-Zeug aus Elffenbein, von dem Hrn. von Löwenfläd gedrehet.

Gantz was fonderbares hat Er in Oft - Indifchen Porcellain ge. fammlet von allerhand Farben; infonderheit befitzet Er über 100 . Stück groffe Schalen, Teller und andere Gefäffe von Preufslern in grau in grau gemahlet; Ja Er hat felbften es fo weit gebracht, dafs Er unterfchiedliche Porcellaine Becher vergolden und doch noch darauf mahlen laffen: Worzu er gantzer VII. Jahr gedachten Preufsler gehalien.

Er befitzet auch Gewehr und Rüfungen von unterfchiedenen $\mathrm{Na}$ tionen: Als Türckifche Sebeln, Röhre, Caffee - Kannen, Schreibzeuge, Meffer, unterfchiedene Kleidungen, wie auch einen fchönen Alcoran; die meilt zu Temefwar und Belgrad erobert vvorden.

Er hat antique und moderne Grichifche und Römifche Müntzen in originalien und welche manquiren die Copien davon: von Aller. 


\section{Allerband andern Curiofis aber}

1. Einen Perfianifchen Krug von Meffing und vergoldet, vvelcher mit einer gevviffen Materie ausgegoffen, die abfpringet vvenn Giffe hinein kommet.

2. Ein Perfianifches Tinten-Fafs, von auffen lacciret, invvendig von Silber, mit allerhandZugehör, als Feder-Meffer,Schreib-Feder; und Indianifcher Tinte.

3. Ein Wind-Fächer aus China mit unterfehiedenen Pofituren, und kan man ihn aufmachen, dafs auch alles vveifs ift, und richts zu fehen.

4. Von Porcellain ein Krebs aus Japan.

5. Die Göttin lfis von einem grünen lafurten Thone aus Egypten; vvelche fie denen Todten über den Kopff legen.

6. Eine Murchel zum Trincken von Florentiner Steine.

7. Eine Mufchel von vreiffen Alabafter.

8. Ein Granat - Apffel von Rubin-Flufs, vvelches zur Probe von Hrn. Kunckelin gemacht vvorden.

9. Ein Garavin von Rubin. Flüs.

10. Ein Trinck-Gefchirr aus einem Steine, mit rothen Zacker; vvortiber der Stein-Schneider ein gantzes Jahr gearbeitet aus der Schvveitz, (da das Arbeit-Lohn über roo. Rthli gekoltet.) fi. Eine Mufchel von Topafs.

12. Ein Brech-Becher vom Vitro Antìmonii.

13. Eine Wurtzel vvie eine Wurft gevvachfen.

14. Ein Stein v vie ein Käfe.

15. Ein Stein vvie ein Brodt.

16. Ein Stíck von dem Horn eines Einhorns, vivelches differiret von dem unicornu foffli, und von dem Horne des Fifches Narval.

17. Malabarifche Schrifft und Glaubens.Bekännenifs der Chriftlichen Religion, von einem bekehrten Malabaren.

18. Piedro del Porco von ungemeiner Grölfe, vvelcher vvieder den Giffs 


\section{PROMTVARIVM RERVM NATVRALIVM}

Gifft ift, und zahlet man in Holland vor einen folchen Stein 100. Ducaten.

19. Eine Kugel vvelche einem Hirfch in dem Magen gefunden vvorden, die invvendig voll Haare.

20. Ein grofs Stïcke Leder, das einem Bocke im Magen geftecker.

2I. Eine von dem Donner zerfchmeltztezinnerne Kanne, in vvelcher vier Siebenzehn - Creutzer Kayfer-Geld, in Leinvvand eingevvickelt, vvelche auf dem Boden zu fehen, und die Leinvvand unverfehrt; auf der andern Seite find noch die Halmen Stroh, vvorauf fie geftanden, verhanden, vvelches vor ein rechtes Wundervverck des Donners zu halten, und hat diefe Kanne in der Trachenbergifchen Herrfchafft in Schlefien auf einem Fen. fter geftanden.

22. Eine Schale von Eifen, vvelches zu Kupfer vvorden, vergoldet.

23. Ein Löffel mit Meffer und Gabel von vveiffen Carniol, darinnen einegroffe Ameiffe von Natur gevvachfen; (ein fürtrefflich Stiick, fo auf 200. Ducaten æftimiret vvird.)

24. Ein Löffel von Perlen-Mutter, vvo der Stiel von rothen Corallen.

25. Ein groffer Stock, vvorauf die Corallen - Bäume einen Schu lang gevvachfen, nebft unterfchiedenen Neftern von SeeWürmen.

Da Er nun die meiften Berg - Wercke Teut cblandes, infonderheit bey dem Geheim. Rath Scbomberg in Freyberg; bey dem Geheim. Rath Pufcb auf dem Hartz; vveiter in Ober - Ungarn, Scbemnitz, Crem. nitz, Neufol, Scbmelnitz, Eperies, Leutfcbau, Tockay, befuchet, hat er viele fchöne Minern herrausgebracht: Befonders aber zu Tockay das Glück gehabt, dafs er von einem gemeinem Manne etvvas Gold, fo vvie Haare fich um einen Weinftock und deffen Trauben gevvunden, ungefehr 3. Ducaten fchvver, erlanget, doch lieber gevvünfchet den Stock, vvovon es diefer Einfältige abgenommen, felblt zuhaben. Ferner ift $\mathrm{Ihm}$ auch von einem Kayjerlichen 
Cammer - Rath eine Weinbeere, um welche gediegen Gold gewachfen, als eine fonderbare.Curiofitæt verehret worden: Auch hat lhm ein Kauffmann in Schemnitz in einer cryftallenen Druhe gediegen Gold gefchencket, welches einer Henne, die in ihrem Nefte fitzet, gleichet. In Neufohl hat Er von Hr. Doct. Mollern ein aus der Erde gewachfenes Stiicke goldenen Drath empfangen. Allermaffen Er nun nicht allein eine groffe Menge von Gold-Stuffen, derer bis 106. fondern fo gar darunter welche mir gediegenem gewachfenen Gold, aus Peru, Mexico, Guinea, Ormus, aus Perfien, wie auch aus Cbina, Fapan, aus Africa von Capo de bon Efperance und andern entfernten Orten zufammen gekauft von Leuten die daher kommen.

Von Silber - Staffen könten derer mehr als 300. in den Catalogum gebracht werden, worunter einige fehr koftbare Stücke verhanden, als da find etliche von gediegenem Silber, fo bifs 21. Loth fchwer; Roth und weifs giilden Ertz ift auch im ziemlichen Uberflufs bey Ihm zu fehen: Abfonderlich auch hat Er vielerley Sorten von Ungarifch gewachfenen Kupfer, und ift vornehmlich ein kleines Bäumchen auf einen grauen Stein ftehend anfchauenswürdig: Uber diefesfo verwahret Erauch eine Stuffe mit Mercurio Virgineo 2. th. fchwer, fo Er bekommen, als Er durch Idria in Italien gereifet,in welcher der Mercurius fehr wohl zu fehen ift; weiter befitzet $\mathrm{Fr}$ auch von gewachfenen Eifen eine fchöneStuffe aus Schweden, und ift diefesum defswillen zu bewundern, vveil fonft das Eifen niemahlen fo zu vvachfen pfleget : Endlich findet man auch von vveiffen und grünen Bley-Ertz, und unterandern auch ziemlich groffe vveiffegevvachfene Zinn-Graupe aus Cornvval in Engelland, vvelche etliche 20. Loth vvieget, und vor vvas fonderbar rares zu halten: DerZinnober -Stuffen aus Cremnitz, Scbemnitz, Siebenbuirgen, aus, Idria, von HobesElb aus Böbmen, aus Peru, Cbina, Mexico find an der Zahl 25.

So hat Erauchnoch ein ander Cabinet von allerhand Orientalifchen Gemmis, theils roh vvie fie gevvachfen, als auch vvie fie durch die Hand des Künftlers gefchnitten und polirt vvorden: Als Diamant, Rubin,Smaragd,Hyacinth, Saphir, Opal, Prafius, Aquamarin, Ame- 


\section{PROMTVARIVM RERVM NATVRALIVM}

thilt, Chalcedon, Carnol, Jafpis, Katzen-A ugen, Schlangen-Augen; Und find unter diefen Steinen etliche fehr notabel; als vornehmlich einer, vvorinnen ein Körbchen mit Blumen von der Natur abgebildet: vviederum ein kleinerStein, in vvelchem eine Diftel, vvie fie blïhet,zu fehen ; in einem andern aber ein Bruft-Bild, und noch in einein andern ein Mafquen-Gefichte verhanden. Auch ift noch fonderbar merckvviirdig der vveiffe Carniol, vvoraus ein Löffel gemacht vvorden, mit der A meiffe (deffen oben gedacht) und ein Chalcedon, in vvelchem faft eben eine dergleichen Ameiffezu fehen. Fernerhat Erauch einen unreiffen dem Diamant gleichenden Stein, in vvelchen alle Farben fiehlen : vveiter fiehet man auch ein Stück von Topafs, darinnen Silber gevvachfen, in einem andern vvo Moofs; Auch zvveyCryftallen, da die eineHelffre die Tinctur von einemHiacynth, die andere aber die Farbe von einem Smaragd bekommen: Sonften hat Er auch noch unterfchiedene Gefchirre von Gemmis, fo oben fpecificiret; $Z u$ diefen kommt noch eine Sammlung von vielerley Börnftein, in I velchen Fliegen, Miicken, Gefäme, Tropffen. Waffer, in einem auch eine Spinne zu fehen; das curiölte aber ift ein Stiick Börnftein, in vvelchem ein Frofch fich præfentiret.

\section{Verzeichnüss der Petrificirten Mufcheln, und ande- ren Steinen.}

Als: Eine zu Stein gevvordene Aufter.Schale, Piltz, Peeten, Venus. Hertz, Schnecken, Mufcheln, kleiner Petten, grofs-und kleiner Nautilus,zvvey Mufcheln; Ein Kinnbacken aus der Baumanns-Höhle mit einem Zahn; ein ander Zahn aus der Baumanns. Höhle, petrificiret Holtz; Beine aus der Schartzfelder Höhle im Hartz; petrificirt Linden - und Eichen - Holrz, Rohr,daran man das Gevvächfe fiehet; Nautilus, darinnen dieStrix zu fehen von Zenftochau; Kiefer-Baum, daran man die Rinde noch fiehet, Holtz von Landeshut, Holtz von Joachimsthal in Böhmen, davon ich ein kniendes Berg - Männchen fchnitzen laffen: 10. Sorten von den gröften bis kleineften Echinis Marinis, Kröten oder Knopff-Steinen; Pectines, mit unterfchiedenen 
Striis6. Stück; 2. Mytulos; Ein Drachen-Zahn aus der Schvveitz; Eine groffe Welfche Nufs; Zvvey an einander gewachfene Aprico. fen Kerne, gefunden bey dem Clofter Oliva bey Dantzig; Ein zu Stein gew ordenes Ey, vvelcheszu Wizin in Böhmen gefunden, ein zu Stein gevvordener Fufs mit allen 5. Nägeln von einem groffen $\mathrm{Pa}$ viran, vvelcher in Schlefien gefunden worden, (diefes ift ein curiöres Stuck, vvelches man in keinem Cabinet finden vird, vveil auch fo gahr man das Blut oben noch fiehet, das zu Steine worden.) Ein zu Stein gevvordenes Waffer, welches in einem Brunnen in dem Zipfer Lande unweitKáfemarck zu Steine vvorden; In einem Feuer-Steine ein Pecten, welcher vortrefflich gevvachfen, das man allekleine Striasfehen kan; Eln zuStein gevvordenes Waffer, vvelches gantz durchfichrig vvic Cryftall ausfieher, aus einem Brunn in China ; Ein Krebs, vvelcher zu Stein vvorden; Eine kleine petrificirte Schlange, vvel. che fich rund in einen Ring gedrehet.

\section{Verzeichnüfs der Petrificirten Früchte.}

Rothe Mandeln aus Oft-Indien; Mandeln und Linfen invvendig vveifs von Landeshut; Erbfen eben daher, Erbfen aus dem Carlsbade; Eyer mit Carlsbad Topho überzogen; Petrificirter Moofs und Spähne mit diefem Topho überzogen, vvie auch Holtz und Rinde.

\section{Von Lapidibus figuratis.}

Ein Feuer-Stein vvie eine Taube gevvachfen; Ein Feuer-Stein vie ein Todten -Kopff; it. ein anderer vvie eine Semmel; Ein FeuerStein vvie ein Portrait gevvachfen; vvie ein Ohri,Steinerner Priapus, Rothes Hertz, Confect von Tivoli, Dattenftein; Ein Stein vvie gelber candirter Zucker, vvie Ingvver, vvie Bezoar, ein Bienenftein, ein Stein vvie ein Nieren; Ein Feuer-Stein, vvodurch ein Loch ift, ein Stein mit einem Circul, einer mit Puneten, einer, vvie ein,MufcatenNufs. 


\section{Baumfteine von Neuftadt.}

Mit Fahren-Kraut, mit Grafs, mit Schilff, mit allerhand Kräutern, mit allerhand Bäumchen; Schifer aus dem Mannsfeldifchen mit einem Perfcke,einer Karpe,einem Weisfifch ; zvvey Adler Steine aus Tyrol, ein Stein mit Circuln, drey Stück Mufcheln in Sand-Stein, ein Stïck Mufchel mit feinerMutter inSand. Stein von Landshut,ein Mufchel-Stein gedoppelt gevvachfen;zufammen gevvachfene Mufcheln in einer eifenhaligenGïlbe ; drey zufammen gevvachfene Kugeln.

\section{In einem vouiffen Letten.}

Ein Blat von einer Erle, Weide, Buche, Efche,Efpe; ein grofles Blat von einem unbevvuften Baume; noch ein groffes Blatt von einer Weide; Ein kleiner Fifch, vvo man alle Græten fieher, noch ein an. derer groffer Fifch, fehr fchön abgebildet; noch 2. kleine Fifche auf einem Steine; vorreinem kleinen Firche der Rückegrad; Ein Regen-Wurm, ein Cornu Ammonis, in einem vveiffen Sand.Steine.

\section{In einem braunen Letten.}

Ein Blat von einer Weide; noch VII. Blätter von Weiden auf VII. Steine; ein länglicht unbekanntes Blatt, Grafs \&c.

Letzlichift noch zugedencken desMufchel-Cabinets; Da Er denn in zvvey groffenSchrancken von mehr als XXX. Schübladen auf Taffend die Mufcheln, nach ihren Arten und Sorten, paarvveife geleget,darunter vvenig manquiren fo Bonannus und Rumpbius befchrieben,aber auchvvelche, deren fie keine Meldung gethan.

Unter andern ift auch eine quantitæt allerhand raren Corallen und See - Gevvächfe, vvie denn ein gantzer Stock, vvoraus viele Corallen-Bäume gevvachfen.

Da viele Thiere, infonderheit dieVögel leicht vonMotten verzehret vverden, fo hat Er über Ioo.Stück von einem Mahler, fo lange Zeit in Perfien und Indien gelebet,und fie, dafelbit abgemahlet.

Was aber die rareften Bücher, die dergleichen curiofa anbelanget, betriffe, hat Er einen fchönen Vorrath davon, und derer über 200. beyfammen.

Tit. 
Tit. Dn. M. Godofredi Hanckib Eccleliaftx ad St. Elifaberhæ, Affefloris Confiftorii \& Profefforis Theologiz in vicino Gymnafio meritiffimi, Nummophylacium primardia!duxit e Colleetione B. Dn. Parentis ejus Martini Hanckiz, Rectoris Elifabethani \& Infpectoris Scholarum Vratislavienfum longe celeberrimi; infigniter vero auctum elt acceffione Mufeorum Reufchiani \& Hoffmannswaldasiani, ut nihil dicamus de iis, quae fparfim multis ab hinc annis, operofa \& ingenti fumtu collegit.

Speciatim Thefaurus quidam Nummorum antiquorum e. gr. Gracorum \& Romanorum longe praftantiflimus in promtu eft, quod ex calculo fequenti patet:

Nummi aurei foli antiqui inveniuntur 102. pulcherrima fors ma \& fpecie fervati; cum tamen Abbas Molanus in Nummophy. lacium fuum celebratiffimum \& numerofiffimum, non amplius quam 50. colligere potuerit (vid Tentzelii Colloquia Menftrua An. 1692. Menf. OAtobr. pag.790.)

\section{In Auro.}

Ex Gracis funt numero 14 . in quibus maxime notabiles: Timotbei Atbenai, \& Afandri Bofphori \& Thracia Regis Nummi præAtantiffimi.

Reliqui numero 88. ad Imperatorum feriem pertinent; atque in his fingulari fefe raritate commendant Nummi fequentes: $C$. $\mathcal{F u}$ lius Cefar maximi moduli five ponderis X. Ducatorum (vid. Job. Vaillantius in Numifmat. Imperator. praftantior. Tom. I. pag. I. ubi fulii Cafaris Nummi inter praftantiffimos collocantur) Agrippina ejusdem ponderis, de quo ob raritatem Eccardi peculiarem Epiftolam (An. 1722. Lipfiæ in 4to) publicavit. Tiberius Chaudius, cum Infcriptione: Imperio recepto, qui a Vaillantio pro rariffimo laudatur L. C. pag. 59\% Nero cum figuris duabus ftantibus, \& Infcr. Auguftus Augufta. Otbanum z. funt diverfi Nummi, qui ex auro a Vaillantio pag.82. pro raris habentur. Trajanus cum Bafilica VIpia, de quo Vaillantius pag,122. ita fcribit: Hic Nummus aureus fingu- 


\section{PROMTVARIVM RERVM NATVRALIVM}

laris \& eximiæ raritatis eft, Hadrianus cum Lupa, Romulum \& Remum lactans, Cos IV. Helvius Pertinax, de quo idem Vaillanțius pag.203. Fulii Severi, cum fex figuris facrificantibus coram templo rotundo, cum Infcr. Vefta Mater, de que Vaillantius ita judicat pag, 249. Hic Nummus aureus raritate \& elegantia inlignis eft. Trajanus Decius in quo duæ figuræ muliebres cum figno militari \& Infer. Pannonia, quem Vaillantius pag.336. pro rariffimo habet. Pofumorum num. Il, five Pater \& Filius, cum Infcr. Claritas Augu. Atorum; vid. Laurent. Begenus in Thefauro Brandenburgico feleeto pag. 749. it. Vaillantius L. C. ubi Paftumorum nummifmata aurea rariffima effe deprædicat.

Ex Conftantinopolitanis, Confans \& Confantius maximi moduli notandi, qui rariffimis annumerantur in eleganti Opere $\mathrm{Ca}$. roli du Frefne c. tit. Hiftoria Byzantina Tom.II. C. Defcriptione Urbis Conftantinopolitanx. Tab. III. pag. 18. it. Phocas cum Infcr.Vi. Etoria Auguftorum, id. du Frefne L. C. pag.109.

Ex Gothicis aureis cum aliquibus Sinicis adfunt num. 20. qui fummatim 300. Ducatorum pondus habent.

\section{In Argento.}

Sunt ex Gracis num. LXXII. (plurimi nummi maximi moduli): Ex quibus notabiles Atbenienfis maximus. Ptolomais num. 2 . diverfæ fignaturæ, Leucas Corinthiorum Colonia, vid. Begerus L.C. pag. 448. - Ifria Milefiorum Colonia, Idem pag. 488. Turinenffum Athenienfium Colonia. Id. pag. 33l. Biatia Hifpaniæ Infula. Id. pag. 522.

Ex Romanis Confularium num. CCCXVII. in quibus funt nonnulli, qui in ipfo Caroli Patini Opere defiderantur. Ad feriem Imperatorum fpectantes num.1043. ubi XI. Otbomes diverfae fignaturæ, non ubivis obvii, Vaillant. L.C. Tom. II. pag.82. Plotina Martiana non ubique occurrens, Antoxinorum num. LX V II. diverfi. Didii fuliani num. 2. optime confervati rariffimi, fecundum Vaillant. 
Tom. II. pag. 206. Pertinacis num. 2. quos idem Vaillantius Tom.Il. pag.202. elegantioribus adfcripfit.

Nummorum Gotbicorusm num. XVI.

Bracteatorum maximi moduli num.3. \& minorum Halberfta. dienfiuın, Magdeburgenfium \& aliorum fupra 150. Notandus quo. que nummus Sammaritanus fingularis elegantix \&

Spignei Ducis Bohemiæ; ex mediis Seculis.

\section{In Are.}

Ex Gracis num. LXVII.

Ex Confularibis num.XXIX.

Seriem Imperatorum tam eleganti fpecie haud facile in ullo alio invenias Nummophylacio; Nummorum maximi modulifunt num. 647 minorum, num. 474. non legibilium, num. 56. vel in Summa 1228. quo numero etiam Tyrannorum Illtii Seculi numifmata comprehenduntur, quia parum argenti continent.

Ex Imperatoribus in promtu funt VI. diverfi Otbonum Eetypi longe elegantiffimi. Item Plotine Martiane \& Matidie, Trajani Conjugum rariffimus nummus, fecundum Vaillantium Tom.1. pag. 53 . feqq. Antinous Hæres. Pefcesnii Nigri num. I V diverfæ fignatura. Didii fuliani num. Il. diverfi, cum conjugibus, Manlia Scantilla \& Didia Clara. id Vaillant. Tom. I. pag. I06. Summa omnium ex auro, ar. gento E are 3093 .

Ex Modernis \& Thaleris quidem rarioribus lequentes, nec non longiffimos Principum completa prorfus ferie collestorum ordines, notavi, unde judicari poteft, quanta copia Thalerorum alios Reges, Eleetores, Principes, Comites \& Dominos atque etiam Cardinales \& Epircopos etc. repræfentantium fuppeditat, ut: 1 . Nummus fcutatus Sixti $V$. Pontificis Romani; Nummus fcutatus Clementis VIII. fequentiumque Pontificum omnium usque ad ultimum proxime defunctum.

Thalerus rariffinus Matibei Cardinalis de An.1522. ir. Nisolazi Epifcopi Sedunenfis Thalerus rariffimus de An. 1498. Et deinde 
Thalerus Theodoli Epifcopi Sedunenfis cum diabolo \& campana de An. 1501 .

Fobannis Epifcopi Vratislavienfis, cum Johanne Baptifta, \& Infer. Sancte Johannes Baptifta ficcurre.

Sigismundi Imperatoris Thalerus dimidius de An 1484. a Maxia miliano autem (cujus folius adfunt VII. diverfæ fignaturæ) feries, usque ad Imperatorem noftrum Augufiffimum.

Ex Anglicanis \& Scoticis: Elifabethe Reginx Anglix Thalerus cūm Infcriptione: Pofui Deum adjutorem meum; facobi Regis Scotiæ Coronatus $\mathrm{f}$. Thalerus cum enfe, \& Infcr. Pro me, fi mereor in me; Supremæ curix (Parlamentum vocant,) Thalerus, cum Infeript. God with us C. Deus nobifcum; Cromvelli Coronatus integer,dimidius \& quarta pars illius, it. folidus (qui vocarur Schilling, ) cum Infcript. Pax quaritur bello.

Ex Regiis Danicis feries a FridericoII. de An. 1572, in cujus Thalero eft Infcriptio: Deus refugium \& fiducia mea; it. Chriftiani Ir. cum Infer, Quid non pro religione? item alius cum Infcr. Benedietio Domini divites facit.

Regum Svecicorum feries incipit a Thalero Guftavi T. de An. 1535. \& definit in Thalero Caroli XIr. fatis raro, in memoriam Tractatus Altranftadienfis cufo, cum Infcr. Collapfam fortiter reftituit; in quibus nec illi defiderantur qui in Guffavum Adolpbum fuerunt fignati, ut Thalerus $\Lambda \mathrm{n}$. 163r. in vietoriam Lipfienfem, cum Infer. Dextera tua Domine, percuffit inimicum, cum fignis $\hat{\alpha} \& \not ;$ it. alius cum Symbolo militari: GOtt mit uns; it. alius de An.1633. cum Infcr. Joh. X. Ein guter Hirt, läffet fein Leben für dieSchaafe.

Vladislai Regis Hungarix integer \& dimidius Thal. de An. 1506. cum equite Matrem Virginem hafta percutiente.

Petrifilii Alexii Mofcorum Monarchæ integer \& dimidius Tha. lerus (quem vocant Rubel,) de An.1709. in Prælium ad Pultavam curus. 
Friderici Electoris Saxonia cum verbis peetori infcriptis: JEfus Maria; alius de An. 1522. cum Infcript. Verbum Domini manet in xternum; alius Friderici cum Alberti nomine, jr. Joh. Georgiill. cum Infcr. Deo, \& Patrix, Deo ad caput \& caudam equi.

Thaleri funebres Electorales Saxopici ab Augufto de An.x586. us-: que ad Johannem Georgium $I V$. in quibus V1. nummi diverfae fignaturæ exitant in mortem Cbriftiani 1. Electoris.

Thalerus Fehrbellinenfis Friderici Wilhelmi EleAoris Branden: buingici, de An 1675. cum verbis Infer. addit. fundit feptimeftres pradones.

Wolffgangi Palatini, cum Infcr. Date Carari, quæ funt Cæraris etc.

Variarum Matronarum Principum Ele toribus Ducibusve nuptaruin, Thaleri funebres, numero $\mathrm{XX}$.

Ex Brunfoicenflbus adfunt integri \& dimidii Thaleri no. diverfæ fignaturæ, in quibus Chrifiani Ducis Brunfvicenfis Thalerus invenitur, cum gladio vibrante, de An:1622. GOttes Freund der P. Feind; \& afius cum enfe, quadrato facerdorali infixo, cum eadem Infcriptione, it. Augufti Thalerorum feries cum campanis de Anno 1643. Ernefti Augufi florenus, cum fanguine e naribus ftillante de An. 1693. item alius cum equo cornuto, de An.1694.

Pbilippi Landgrav. Hafjis de An.1552. eum Infcr. Befl. Land und Lud verlorn, als en falfch aid gefchworn.

Ex Silefiacis Lignicenfibus \& Bregenfibus feries integrorum ac dimidiorum Thalerorum a Friderico de An. 1541. usque ad Georgium Wilbelmum An. 1675. LXXII1. diverfæ fignaturæ.

- Ex Munfterberga Olsnenfibus XXIII. dimidii \& integri Thaleri. Ex IV allenfteinianis f. Alberto D. Mega. Fridl. \& Sagàn. Thaleri feptemplicis fignaturæ.

Comitum de Mansfeld Thaleri num. XVIII cum St. Georgio it. Infcript. Bei GOtt ift Rath; und That; nec non groffus argenteus cum eadem Infcriptione. 
Comitum de Scblick XXI. diverfe fignature.

Ex civitatum dimidiis \& integris Thaleris LXXXVIII. fignaturæ, in quibus eft Hamburgenfis cum urticx folio, \& Infcr. Fiat mihi fecundum verbum tuum; Imprimis Luneburgen/s cum Luna, aurem habens, de An.1547. \& Infcr. Vifitavit nos oriens ex alto.

Jobannis Huff Thalerus, vel potius Numifma, cum ipfius vaticinio: Centum revolutis annis Deo refpondebitis \& mihi. In Librum Interim cufus Thalerus cum Infcr. Packe di Sathan du Interim; In feedus Smalcaldicum Thalerus; Argentoratenfis, Magdeburgenfis, it. Islebienfis Thalerus jubilaus cum Infir. GOttes Wort und Luthers Lehr, vergeht nun und nimmermehr. Anabaptifarum Thalerus; Thom. Miinferi Thalerus; Jobanzis a Leyden Thalerus.

Thalerus triplex in Peftilentiam Wittembergenfem etc.

Magnam collectionem Ducatorum rariorum; ut \& Numifmatum aureorum argenteorumve propter copiam ficco pede prætereo; id tantum memorans, quod Vir ille Doctiffimus in ipfum Jubilaum Lutberanum An.1717. celebratum 50. nummos diverfimode fignatos poffideat. Ex cæteris duorum Numifmatum fane rariffimorum mentionem faciam; alterum cufum eft An.1686. in decollationem civium Hamburgenfium, Court. Faftrami \& Hieronymi Scbnitgeri; alterum in Principem haud ignotum, cujus imago in una parte comparet thoracetenus expreffa, ita ut ex pectore D. Lutherus profpiciat, in altera parte, fcilicet averfa brachium cum ftricto gladio ex quo fphærulæ precatoriæ, (vulgo Pater nofter) dependent, cum Epigraphe: Sacra fic fulminat ira.

Quod privatam Reliquiarum, Antiquitatis, Naturæ, vel Artis colleetionem a me infra $7^{8}$. dem nec mole nec raritate præcellit: nunquam enim fingulares in illam fumtus impenfi fuerunt, licet animus ac oculus ex contemplandis aut Providentiæ Divinæ, aut Induftria humanæ monimentis delectationem capiat. Merentur tamen horum, qui ejus. 
modi curiofitates amant, adfpectum Minerze quedam ex Tranfylvaria \& Silefia auriferæ, nec non aliis metallis imprægnatæ; Mineralia item varii generis, coloris \& loci, $\mathfrak{B e r g}=$ Drufen, Dovarke, Eraupen, Sinner uno 3 lúthen; Lapides conchis minufculis petrefaEtis refertiffimi, atque in Silefia paffim reperti; Lapides porro Florentini, Mansfeldici ac Silefiaci variarum Plantarum, Arborum, Ruderumque Civitaticorum figuris elegantiffime infigniti; Ligna petrefaeta in altioribus Silefix montanis hoc Seculo effoffa; Sal cryftallinum Vielicenfe prope Cracoviam in varias figuras transformatum; Eleetri feu Succini femilibris portio, ex agro Illuftris in Ducatu Jaurovienfi Silefiaco Familiæe forte fortuna eruti; EleEtrum araneis \& foliis arborum inclufis perfpicuum, \& Vanitatis Hieroglyphicum ex triplici eleeti fpecie affabre conglutinatum, uti \& multa Naturalia Maslenfia, de quibus in Viri Clar. Leonhardi Davidis Hermanni Maslograpbia, Brigæ anno I7 Ir. 4. edita diffe. ritur.

Inter res, qux $\mathrm{ab}$ induftria humana proficifcuntur, eminec fimulachrum -Veneris ex ligno peregrino fcitiffime fculptum; Caput Ciceronis verfatile ex ligno; Conchitæ Maslenfes inftar Gemmarum lævigati; Gemmæ provinciales indigenæ perpolitæ; Tubi Optici, Telefcopia \& Microfcopia; Vitra quædam ex cinere Nicotiano; Chartæ papyracex ex asbefto feu lino incombuftibili Hungarico confeetx; Ova Pafchalia Mofcovitica \& Kiovienfia admirabiliter pieturata; Culter facrificatorius Turcicus fuaveolentia notabilis, \& alius litteratura Saracenico-Damafcena confpicuus; Cingulum Pergamenum ex Corio humano cum verbis amuleticis; Scopula fetacea venticularis, (PRagen = Bürrfte;) Ligamertum variis coloribus ac diftinetis vocabulis magnitudinem Divæ Virginis Lauretanæ, \& infantuli JEfuli exacte referens, etc.

Inter Nummos veteres occurrunt Græeci quidam, Romani; Gothici \& Bracteati complures ex argento, quorum pofteriorum multi in Silefia cafu effoffi, vel ab imbribus detecti func. 1 cce- 
dun Cupreus Hekna, Jingenbogen=G duptimgc, cbuli extranei - indigenæ; amule a ex tere merallo Chemico; nec non incogriti \&rariores ex prioribus Seculis; cum uncialibus \& mnemoneuricis ahquor, quibus precium affectionis in Obfervarion bus Hamburgenfibus hiftoricis adjudwacur.

Omnium vero admirationem, credo, merebitur Centuria Urnarum sepukhralium, in Silefia noftra \& vicina Polonia repertarum. Quum enim ab annistriginta circiser in eo defudaverim, ut hanc An iquitatis Silefiacæ fupellectilem ab alis ante me vel peninis intatam, vel obier tantummodo memoratam illuftrarem, fedulo vicos $\&$ locos complues perveffigavi, in quibus hujus generis aliquid cafu plerumque fortuito detectum audivi, \& ea quidem in re tanta felicirate gavifus furm, ut aut me prafente, aut ipfis manibus meis, tria ferme ollarum gencilium millia effoffa fuerine, ita tamer plerumque in ipfis arenarum ftras jamjam confrasta, ut ne vix decima quidem pars illarum integra extrahi, vel fragmenta fedulo colle ta refarcinari, \& in ufus litterarios reponi potuerint. Cauffe fractionis partim in aratra arvis arenariis fuperindufta, partim in humores a nive pluviaque in porofam tellurem perietrantes, parrim quoque in radices arborum per medias urnas dehifcences fefe intinuantes, arque in fofforum, ligones incurio. fe immittentium ruditatem, conjiciendx: quamobrem multa præftantiores in minuriflima fragmenta diffolvuntur. His tamen difficultatibus non obftantibus pervenerunt in manus meas egregia - plane Offuaria, Cineraria, Phiala ac Patella fine dubio facrificaroriæ, Lacrymatoria falfo fic dista, Grepitacula figuræe penitus infolita, interque illa porcellus quidam ineger, Acerra nonnulla, Iucerna unica fictilis, \& alia variarum formarum vafcula, anfata, ftriata, punctata. Omnium materia eft argillacea, color vel flavus, vel nigricans ac cinericius, aliquando $a b$ extraneo latere maculis rubicundis in fectus, aliquando ab intrinfeca parte encaulto figulino inductus: de quibus circumftantiis omnibus jam olim in Epiftolico Schediafmate, Lipfix an. 1704. typis impreffo differui, 
8 , ti Deus vires ac otium ulterius concefferit, ampliori fcripto in pofterum commentabor:

Minores Unulas perpetuo non alia quapiam re quam arena vel terra adimpletas offendi; Majores ex dimidia parte fuperiori arenam habent; intus autem circa fundum Offium concrematorum copia conftipata deprehenditur. - Inter illa interdum FibuIas æreas \& ftylos encaufto viridr fpectabiles, cultra facrifica. torial ferrea, duo calçaria ferrea, ferta duo ferrea, annulos majufculos areos; imo ante biennium Globulos perforatos minufculos varie picturatos, ex materia incognita fabrefactos, \& alias mundi muliebris reliquias in veni : quarum tamen accuratior confideratio fpectatores quoscunque literacisfimos in ftuporem absipuit

Nummi, quod fcram, in iplis ollis nunquam reperti. Servo tamen unum, qui fine dubio ignem paffus fuir, \& alterum, ubi duo numifmata argentea flammis prædominantibus tam arete conflata funt, ut a fe invicem absque violentia mallei feparari nequeant.

Servo etiam duas Icunculas Ifidis, pollicis longitudinem \& erasfitiem vix excedentes; ex antiquo marmore, alreram coronatam, vittatam alteram, quæ ex famofisfimo IEgyptiorum emporia Cairo in Europam per curiolum peregrinarorem an-

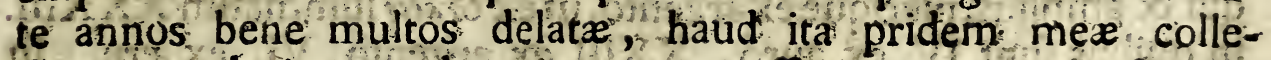
ctioni ac juri per donationem accefferunt Nominabantur in adibus prioris Poffefforis Diaboli five Lares domefict, ex cavernis Piramidum per Muhammedanos fublati ac venditi: unde, fi commodior occafio affulferit, originem, figuram ac cultum dilucidius explicabo. mo to the why

Reliqua curiofa, $\nabla$ gr. Codices quosdam Nanuferiptos, iconifmos ari incilos florum \& plantarum rariorum picturas, Gemvistia K 3 
PROMTVARIVM RERVM NATVRALIVM

mas veteres annulares, \& nonnulla hujus fortis alia, minoris momenti exiftima: quoniam in aliorum ditiorum Gazophylaciis \& Dactyliothecis vel fimilia, vel præftantiora magno numero eru. ditorum oculis fubjiciuntur, Scribeb. exeunte Majo A.C. I725.

\section{Chriltianus Stieff, $R$}

Tit. Dn. M. Michaëlis Liebentantzii Sublenioris Marize Magdalenæi vigilantisfimi Nummophylacium ortum eft ex collectione meritiffimi olim Infpectoris noltri Tit. Dn. Capparis Neumanni, qui feriem Electoralem Saxonicam inde a temporibus Reformationis, five ab Anno 1517. - 1617. eo produxit, ut fummam 800. Imperialium effecerit. Ab An. 1617.-1717. laudatus Dn. M. Libentantzius hanc feriem continuavit, eamque omnino completam in fcriniis fuis affervat: Infigne prorfus augmentum nactum eft hoc Mufeum accesfione Milicbiami Mufei, cujus Catalogus Amftelodami An. 1708. in 4to typis exfcriptus fuit, fequenti titulo præfixo: Numifmata aurea \& argentea antiqua \& nova, tam Gracorum Regum \& Civitatum, quam Romanorum, \& omnium fere Germanorum Imperatorum omniumque totius Europæ Regionum \& Civitatum, per multos annos fummo ftudio collecta a Theopbilo Valentino Milich Vratisl, quod quidem Mufeum Milichianum Rever. Licbencanteires fumma 3000 . Imperialium perfoluta fibi vindicavit.

Inveniuntur in eo quadringenti quinquaginta Nummi Antiqui \& amplius, plerique ex argento, ut ex Grecis fummatim XXXIII. in quibus funt IV. ex auro, XXIII. ex argento, VI. ex ære. In argento præcipui nO $\triangle \triangle A M A N T$. cum capite barbato \& crifpato, \& alea tabula:

In Ere IøITENeia aramemnon. cum quatuor perfonis, quarum una capreolum tenet pateram effundens. (vid. Sambersus de Sacrificiis pag. 518.

Confularium num. IO2. ut. I. in auro, XCVI. in argento, \& V. in zre; exquibus notandum in argenso Caputhonoris laureatum cum sileno 
sileno caudato utrem hircinum in dorfo gerente, dexira elevanie, pone columna cum lcuncula. c. cenfor.

In Ere M. Portius Cato Cenf. rev. Roma clypeis infidens dextra bilancem, finiftra cornu copix tenens.

Imperatorum num.CCCXXXI.ut 5. aurei,176.argentei,150. ærei.

Ubi inter rariores numerandi in auro: Trajani nummus, cum Abuudantia Cornu copix effundens.

In Argento Caput Julii Cefaris, it. Neronis Claudii Druf. German. \&in averfa parte, Arcus triumphalis, fupra Nero equitans, inter duo Trophæa in ejus periftylio, cum Infer. De Germanis; Caput Caligula laureatum \& corona quercea ; Caput Otbonis laureatum, cum fermina dextra fertum, finiftra haftam tenente, Infcr. Securitas P. R. Caput Helvidii Pertinacis laureatum, Rev. figura muliebris, dextra bilancem, finiftra Cornu copix tenens. Infcript. Atquitas Auguft. TR. P. COS.1I. Præcipue Caput Pefcennii Nigri, cum Victoria, dextra coronam, finiftra palmam geftante, \& Infcript. Vietoria Aug. Caput Clodii Albini, in quo Minerva, dextra ramum, finiftra clypeum \& haftam ferens; Caput Diadumeniani nudum cum figura mu. liebri ftante inter IV. figna militaria \& Infcr. Princeps Juventutis, (fecundum Vaillantium LC. Tom. II. pag. 283. eft nummus eximiæ raritatis \& elegantix.) Capita Balbini \& Pupieni, cum Hercule; Caput Gordiani cum Liberalitate.

In Are:- Julii Cafaris nummus cum capite laureato, ad fron: tem ftella, pone lituus \& Infcr. C. Cafar Dictator. in averfa parte, corona laurea Infer. Veni, vidi, viét. (qui fuppofititiis accenfendus.) Augufi nummus maximi moduli cum Templo Martis plurimis columnis fuffulto. Tiberii Caput \& Ara cum vietoriis hine \& illine cippo impofitis, (qui inter rariffimos collocatur a Vaillantio Tom. 1. pag. 9. ) Neronis Claudii Drufi Germanici. Caput, Rev. Arcus Triumphalis cum ftatua equeftri \& Germanorum fpolis; Infer. De Germanis; alius in quo Germanicus palludatus ftans, dextra extenfa, funiftra haftam tenens, Infcr. Signis receptis deviatis Germa. 
nis; alius (fecundum Vaillantium L.C. pag. I8.) rariffimus, cúm figura muliebri, five Spe, dextra florem, finiftra togam prehendente; Infcr. Spes Auguft. Caput Neronis cuin portu Oltienti, in cujus medio plurimæ naves; cum Tiberi, fub fimulacrofenis decumben tis; Infreript. Port. Auguft (pro rariffimo habetur a Vaillantio Tom. I. pag. 2I.) Caput Galbs laureatum Rev. Imperator paludatus ftans in fuggeftu, adfiftente figura militari, alloquitur cohortes; Infcr. Adlocutio. (rariffimus fecundum Vaillant. Tom. I. pag.22.) Ejusdem, in quo figura muliebris ftolata ftans dextra pileum, finiftra haftam puram tenens; Infcr. Libertas. (idem rariffimis adfcribitur a VTaill. Tom. I. pag. 23.) Ejusdem cum figura galeata gradiente, dextro pede globo infiftente, cum vißtoriola \& hafta; Infor. Roma renafcens (inter raros collocatur a Vaillantio Tom. I. pag. 24.) Caput Vitellii laurearum Rev. Vietoria fcribens in clypeo, paimx arbori appenfo; Infer. Victoria Auguft. (rarioribus adfcribitur ab eodem Tom. I, pag. 28.) Caput Titi laureatum, Rev. Imperator paludatus Itans, finiftro pede galex impofito, dextra haftam, læva parazonium tenens fub palma arbore, Judæa mœelta fpoliis infider; Infcr. Judxa capra. Capur Marci Aurelii laureatum, Rev. in Clypeum appenfum trophao fcribit victoria, pede finiftro galex impofito, in imo trophæi captivus; Infcr. Vict Germanis; Ejusdem cum trophæo, fub quo duo captivi; Infer. de Germanis (hic nummus fuperiori paulo rarior eft tefte Vaillantio Tom. I. pag. 82.) Caput Alexandrí laureatum; InfCr. M. AVR. CEUH. AAEZANAPOC. CEB. Rev. Tabula fupra quam dux urnæ \& Capita Severi \& Mammex, fub menfa urceus, (Literæ Græcæ non legibiles.) Caput Gordiani Afr. Rev, figura militaris galeata itans dextra clypeum, finiftra haftam tenens, Infcr. Virtus Aug. (inter rariffimos habendus fec. Vaillantium Tom. I. pag. 155.) Caput Balbini Rev. Providentia ftans, dextra radium, finiftra Cornu copiæ ferens, pro pedibus globus; Infer. Providentia, Deorum (pro rariffimo habetur a Vaillant. Toin. I. pag. 157.) Caput Gordiani cum \& \&uitate dextra bilancem, finiftra cornu Copix tenens; Infcr. Equitas Augult. 
Ex Tbaleris rarioribus omnes fere illi hic reperiuntur, qui paulo ante nominatim funt recenfiti, exceptis Nummo fcutato Sixti V. it. Thalero Nicolai Epifcopi Sedunenfis, it. Thalero Johannis Epifcopi Vratislavienfis, nec non Thalero Fehrbellinenfi : E contrario hic inveniuntur nonnulli, qua in Mufeo præcedenti defiderantur: ut Mattbei Cardinatis \& Epifcopi Salisburienfis Thalerus rariffimus de An. 152 I. cum Infeript. Ora pro nobis Deum Sancta Virgo radiana: 70banneus quidam Epifcopalis hic loci cufus, groffi magnitudine, pondere Thaleri ; Secula II. integra Gloriofiffimorum Imperatorum Romanorum de fingulis fere annis, in quibus etiam comparet Caroli $V$ quem ipfe cudi jufit; item Auftria Archiduces pulcherrima ferie ; Friderici Regis, quem vocant, brumalis Thalerus; Ex folis Mansfeldicis St. Georgii, qui nominantur, Thaleris, quibus in plerisque ineft Infer. Bei Gott ift Rath, und That. XXV. fignaturæ differentes, in quibus nec ille defideratur de An. 1523. ubi in equi inftragulo verba luculenter expreffa leguntur, Ora pro; Friderici Electoris Saxonix Thalerus duplus, ubi in peetore legitur: Fefus Maria; In Peftem Wittembergenfem Thalerus fimplex \& duplex \&c.

Numifmata moderna ex impreffo Catalogo cognofci poffunt, quibus vero ingens copia accesfit; ut feries elegantisfima in Jubilaum Lutheranum. An. I7 17. in mortem Caroli XII. Regis Svecia XVIII. diverfa Numifmata, \& alia plura.

Gemmæ antiquæ numero LXIII. funt in promptu ; in Lapidem Lazuli, Jafpidem, Sardum, tam fabulæ poëticæ, quam varia Romana Capita incifa ; item annuli, ubi in Onyche, etiam in auro literæ Arabicæ infculptæ, it. Mater Dei in Turcoide opere eminenti incifa.

A pparatus, quem in oblectationem animi \& fuam \& amicorum posfidet Tit. Dr. Fohanines Georgius $P$ - - eft fequens: 


\section{Pictura.}

I. Archetypa præclara Imaginum humanarum, Regionum, Præliorum, Figurarum minutarum, Animalium, Fruetuum, Florum \& Rerum rureftrium: ut IV. genualia, Auctor. Lely, Rofalba, Heribaldo \& Agatba, van der Myn, Quellino, Welbero, Brandelio, Jordaëno, Perugino, Sachtleven, Heemskerkio, Bendlero, Antonio Polcke Erc.

2.) Aviarium Silefiæa a naturalem fere fimilitudinem expreffum, colore aqueo a, Bottengrubero.

3.) Diverfa inftructa vaforum porcellaniorum eleganter piEtorum \& encaufticorum a Bottengrubero.

4.) Arcbetypa imaginum fumms preftantie Ev dignitatis.

Bachanalia 2. integrarum \& 3. dimidiarum figurarum forma fupra humanam longe auguftiori, præftantisfimi opus generis, auctore Annibale Caraccio $3 \frac{1}{2}$. pedum altitudine, latitudine $4 \frac{1}{2}$. moduli Rhenenfis.

Magdalena in caverna ante Chrifti crucifixi effigiem genibus nixa, figura integra, auftore Francifco Florifio, 3. pedum altitudine, 2. latitudine.

Ecce Homo! cum duabus figuris aliis, pictura diligenter \& pulchre colorata, ab Alberto Durero de Ann. I512. I $\frac{2}{2}$. ped. altitud. \& 1. $\frac{i}{4}$. ped. latitudine.

Ejusdem generis cáput, a Jobanne Bellino.

Ejusdem generis figura integra perfecta pulchritudine a $\mathrm{Pal}$. $m a$ Sen, I. ped. altit. \& $\frac{2}{2}$. latitudine. 
Fobannis Baptiftx effigies dimidia ab Anton. van Dyk. latitudine.

Sancta familia integris figuris a Rubenio 2. ped. altit. \& $\mathbf{I}_{\mathbf{2}}^{\frac{2}{*}}$.

Dux Tabulæ Ferarum, fcilicet cervorum, leonum, pantherarum, \& tigridum, urforum, lyncium, \&c, fingulariter elegantes, a Carolo Rutbardo de Ann. 1666. $2 \frac{1}{4}$. ped. altitud. \& 3. ped. latitud.

\section{Caput parvum, a Francifco Hallio.}

Orpheus cum multis feris, a Saverio.

Tabula ovium \& gallinarum cum duabus figuris in Italia pieta, a Carolo Screta $3 \frac{3}{7}$. ped. altitudine \& $5 \frac{1}{4}$. latitudine.

Variæ fpecies fimiarum, miros \& ridiculos geftus præ fe ferentium cum fruetibus, vafis argenteis, præclare prorfus pietx, auetore Tbiel Brügel.

Regio cum figuris, a Davide Teniers.

Coronatio Chrifti cum multis figuris integris, a Simone de Vos.

Effigies Burry perquam belle expreffa, a Pi\&tore Italo.

Effigies van Dyckii folo capite expreffa.

St. Maria Virgo cum fefulo, a Willmanno.

Dux Tabulæ maxime, in quibus Charitas Romana, autho: re Halbaxio.

\section{Opera miniata.}

Effigies Henrici VIII. uno colore expreffa (vulgograu in grau) ab H. Holbeinio. 


\section{PROMTVARIVM RERVM NATVRALIVM}

Regio diligenter picta, a H. Bol. nagel.

X. Tabellæ cum floribus \& infectis, a Georgio Hoeff-

Effigies num:VI. fingulariter elegantes ab eodem.

In IV. Libris multa animalia \& pifces marini, item fructus, auctore eodem.

\section{Opera diagrapbica.}

I.) Ingens prælium ad exemplar Rapbaelis artificiofe expreffum a Petro van Lint.

2.) Collectio PiQturarum, monogrammarum majoris formx tam Hiftoriarum quam Regionum, autoribus: Fens, Fabentino, S. Rofa, Jac. Jordaëno, Blomarto, Saverio, Ecc.

3. Ejusdem generis collectio minor Hiftoriarum LXXX. \& amplius, \& quidem omnino felectarum, in quibus una eft a $R a-$ phaele, 2. a Polydoro, 1. a Maratto, 1. a Titiano, 2. a Fof Arpino, Dïsrero, Aldegrafio, Mart. Scbönio, Holbeinio, Luc. van Leyden f. Lugdu. nenfi Bat. multa a Wierixio, de Bray, oftadeno, Braunero, Bramero, 1. a Rubenio, 1. a Dan Dikio, r. a Fac. Fordaëno, Hollaro, multæa Willmanno, Rembrando, Blomiarto, Dreveto, Jac. Frey, \&c.

4.) Similis Collectio Regionum in archetypo \& quidem feleEisfimarum numero roo. ab Elsbeimero, C. Pouffino, Cl, Gill, Lorraine, Saverio, Brügelio, Svanefeldio, Sacbtleben, Waterloo, Willmanno, Tempefta, P. de Laer, Bril, Mompero, Vingboomio, Nyts, Velden, Seemanno, van Goyen, Rademakero, du Molins, Bendlero, \&c.

\section{Figura enea.}

(1.) Collectio magna Hiftoriarum facrarum \& civilium a ma- 
nu Veterum \& Recentiorum, Germanorum, Belgarum, Italorum \& Gallorum Artificum, multis voluminibus conftans.

(ubi Difpofitio \& ordinatio fecundum fcholas illorum falta eft.)

2.) Ejusdem generis Collectio Imaginum humanarum, in qua Collector non tam Hiftorias quam artem fpeetavit.

3.) Similis Collectio Ferarum \& Venationum.

4.) Similis collectio Regionum.

Colleetiones laudatæ praftantisfima \& rarisfima cujusque Artificis, \& integra:Opera præcipuorum Chalcographorum in arte fua excellentium complectuntur.

\section{$V$.}

Apparatus fatis inftruetus ichnographias munimentorum archetypas auetore Vaubanio, Beanben, Devillieres.

Inftrumenta egregia \& libros ad Sculpturam, Archireeturam antiquam \& modernam, Opticam facientes, comprehendens.

Tit. Dn. Fridericus Kalt fchmidius, Med. Doetor, Sac, Cær. Maj. Perfonæ \& Aulæ Medicus \& S. R. Imp. Academiæ Nat. Curiof. e liberalitate Haunoldi, D. Schröckii, D. Wolffi, D. a Rhoda, D. Bayeri, D. de Franckenau, Pr. Werneri, Pr. Pfeifferi Berolinenf. Prof. Franckii Hallenf. D. Volckmanni, D. Hambacberi, M. Buttneri, Hermanni \&c. Mufeum collegit Fosfilium \& Lapidum figuratorum, quod ante beatam analyfin per teftamentum filo natu min. Dno Ernefto Sigifmundo Kaltfcbmidio Juris Candidatolegavit; In quo affervantur:

\section{Gemma rudes Silefiacx, Saxonicx \& Hungaricx num.} LXX.

11. Gemmæ \& Fluores fcalpti \& politi num. LIX.

III. Lapides Cryftallini num. XXXIII. ex quibus cryftallu: viridis, ftriis Vitrioli fimilibus maxime confpicua. 
IV. Stalactitæ \& Tophi num. XLIV.

V. Lapides certa figura gaudentes num. LXIV. ex quibus eminet Aftroites albus, ftellis purpureis infignitus.

VI. Lapides qui referunt corpora Vegetabilium num. LVII. ex quibus notandi Pifolithus maximus, ex Thermis Carolinis; Corallinx tabularis fruftum infignis magnitudinis; item Lapides Den: droides Eyftädtenfes num. XV.

VII. Lapides qui referunt corpora animalium num. LXXVI. ex quibus Cornua Ammonis Querfurchenfia maxima in matrice, \& alia a matrice feparata, item alia polita, in quibus concamera: tiones apparent; \& Turbinites maximus in matrice Querfurtenfis cum Lapide cranium humanum referens.

VIII. Vegetabilia petrefacta num. XXXIV, ex quibus confidexationem meretur Fungites quercinus,

IX. Partes Animalium petrefaßta num. VII. ubi ex Specu: Baumanniano ftalactitæ fruftum maximum, in quo offa humana petrefacta ubique prominent; it. alius Lapis Querfurtenfis, in quo os fibulæ immenfum; item Dentes \& Offa varia Canftadienfia.

X. Ex Mineris metalliferis proftant Auri num. LVII, Argenti num. LII. Cupri num. LXXIII. ubi Cupri nativi arbufcula Epperienfis \& Minera Tyrolenfis egregia viridis, colore coeruleo diftincta non ubivis obvia; Stanni num. XVI. Plumbi num. XXXVI. Ferri num. XXVIII. Mineralia media \& Metallis affinia num. LXXXV. Scoriæ num.IV. Salia num. XXVI. Bitumina \& Sulphura num.XLVIII. Terre figillate \& Medicinales num.LXIHI. Quibus jungendæ Urnæ variæ fepulchrales Silefiacæ prc. Maslenfes\& Lignicenfes, item aliæ prope Wittembergam \& in Polonia erutæ.

Dn. Godofredii Aldii, Pannorum Infpectoris Cærarei in Silefia, Collectio Mineralium eft feqq.

Ex Auri mineris funt fpeetabiles V. ex Tranfylvania, item alia Bozenfis, Cremnicenfis \& Schemnicenfis, alia Bohemica, alia Mor fcovitica. 
Ex mineris Argentiferis crifpatis, capillaribus, afperis, rudibus fui coloris, rubris, nigris, cinereis, albis num. X L. ut Peruanæ, Norwegicæ, Hungaricæ, Bohemicæ, Moravicæ, Silefiacæ, Mifnicæ, Thuringicæ; ubi minera Peruana Hifpanis Aranna dicta, ex meris filis fubtiliffimis compofita maxime notabilis, item rubra Vallis Joachimicæe, ubi teffellulæ rubræ cryftallo albo infperf $x$.

Ex Stanni Mineris num. V. ubi rariffima Malaccenfis, \& alia Anglica Cornubienfis confpicua.

Ex Plumbi mineris num. XXXV. ut: Suecicæ,Polonicæ,Bohe. micæ, Moravicæ, Silefiacæ, Mifnicæ, Tyrolenfes, Palatinæ, ex montibus Hercynix, it. Anglica, pre raritate fe commendat minera plumbi ex monte Ararath, item alia alba Georgenftadienfis, alia Schwartzbergenfis Bohemica, alia Bleyftadienfis ejusdem Regni alba, ex meris tubulis compofita.

Ex mineris Aris num. XL. ut:Hungarice, Tyrolenfes, Bo: hemicæ, Silefiacæ, Moravicæ, Mifnicæ, Thuringicæ, Sueciæ, Norwegicæ, \& aliæ Sylvæ Hercyniæ, Mofcoviæ \& Sibericæ, ubi minera Norwegica \& alia Schwartzburgica variis coloribus; item alia Tyrolenfis maxima colore viridi \& cceruleo variegata.:

Ex mineris Ferri num XL. elegantiffimæ, ut: Suecicæ, Saxonicæ, Silefiacæ, Hungarica, Bohemicæ, Moravicæ, Byruthinæ, it, alia ex Styria.

Ex mineris Mercurialibus quadam Mercurio virgineo tument, prc. Schemnicenfis Hungarica.

Ex mineris Antimonialibus, Hungarica turrita ejusmodi non fæ. pe occurrit.

Ex mineris Bifmutbi, Cobalti, Talci \& aliis mineris metallis affi: nibus num.XLY. ubi fingularis pulchritudinis minera Cobalti ex meris cubis albis fplendentibus compofita, quæ floribus rofei coloris diftineta.

Ex Salibus num. VI, ubi Sal Vitrioli album lanuginofum. 
Ex Terris Medicinalibus num. XII. prc. Terra Sinenfis Tenfchee dicta.

Ex Lapidibus figuratis num.LV. ubi Lapides Dendroides \& Ichthyitæ Eyftädtenfes fingulari funt elegantia \&c.

Apud Dn. Jobannem Stenzelium Lingux Gallicæ Magifrum re. peritur Pieturarum, a Celeberrimo Regionum Pietore Bendlero hic loci expreffarum Colleetio ampla fatis \& copiofa, cum alias ipfius Tabulæ fingulares \& feparatæ difficulter, \& multo ære vix parabiles fint.

Conftat illa pulcherrimis LX. \& amplius, quarum pars dimidia admodum magna eft, Tabulis Regionum, quæ omnia anni tempora \& diei, itemque omnes mutationes venti, pluviæ, iridis, nebulæ, nivis, fulguris etc, repræfentant.

Præterea ibidem fpectandæ proponuntur III. Imagines humanæ, ut unius fœminæ \& 2. puerorum a Burbofro incomparabili arte pictæ.

Caput fenile a fordano, \& alia fatis pulchra artis fpecimina.

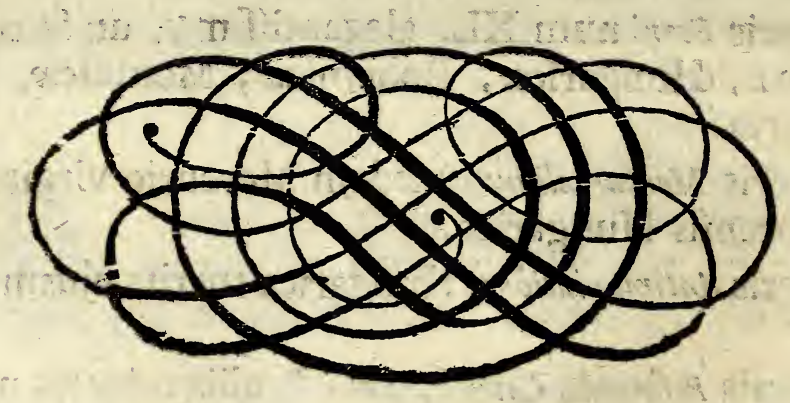




\section{PROMTVARIVM}

RERVM

NATVRALIVM ET ARTIFICIALIVM

QIOD POSSIDET

D. JOH. CHRISTIANVS KVNDMANN. MEDICVS VRATISLAVIENSIS. 


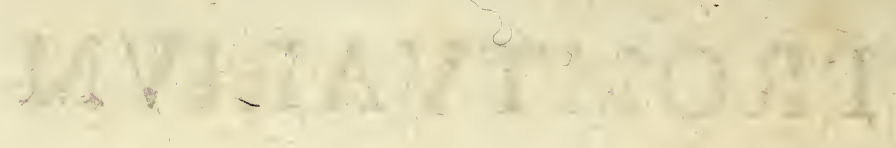

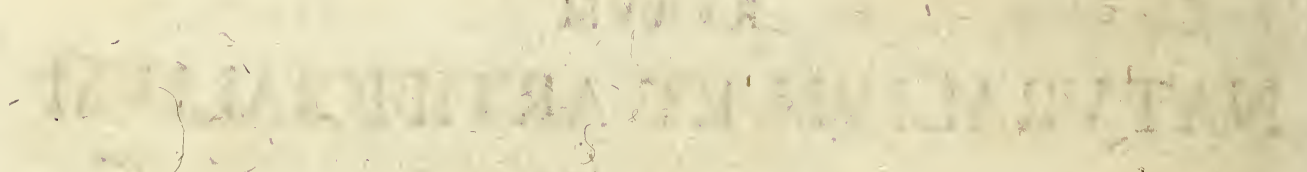

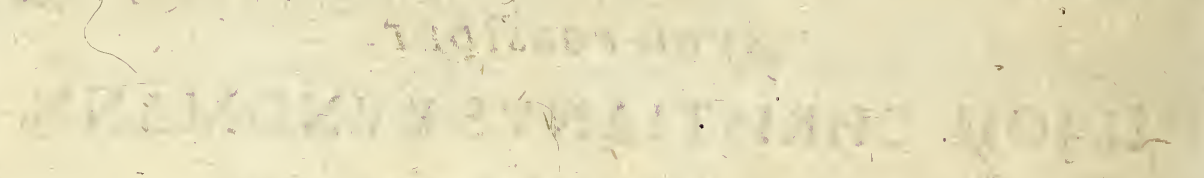

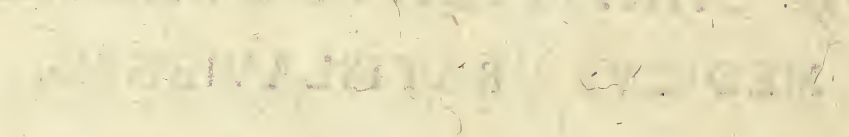




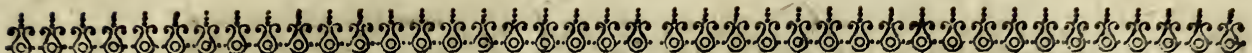

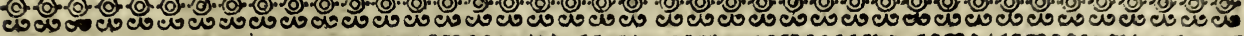

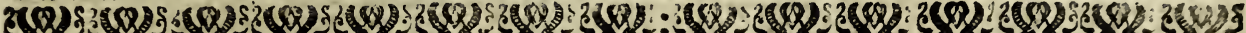

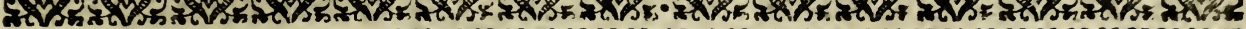

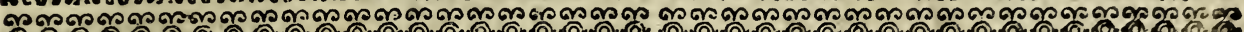

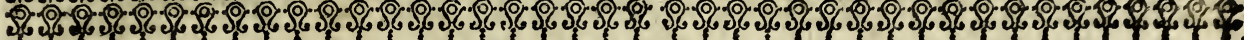

\section{SECTIO I. \\ Regnum Animale. \\ Claffis I.}

Animalia marina integra, itemque in äere Ev terris degentia, partesque c.x iis defumte, aut exficcata, aut in liquore balfamico confervata.

A. I. Abortus humanus unius menfis in liquore balfamico, talem delineavit \& defcripfit Tbeodorus Kerckringius in Anthropogenix Ichnographia, qux reperitur in Dan. Clerici \& J.J.Mangeti Bibliotheca Anatomica Part.IV. SeA, I. Cap. V. pag. $5 \bigcirc 8$.

A. 2. Abortus talis II. menfium

A. 3. - - - - - III. menfium

A. 4. - - - IV. menfium

A. 5. - - - - V. menfium

A. 6. - - - - VI. menfium

A. 7. - - - . VII. menfium

A. 8. - - - - Vill. menfium.

Omnium horum delineatio reperitur in Godefrid. Bidlco Anatomia humani corporis Tabul. XLVII. figur. III. IV.V. VI. \& VII. Abortum humanum cultro anatomicu fubjecit Olaus Borricbius in Thom. Bartbolini A\&t. Medic. \& Philolophic. Hafnienfibus an.16;3. Oblerv. XLIX. pag.ırr. feqq. A. 9. Abortus quinque menfium niger æthiopicus. De nigredine Eth:opum \& eorum cauld, vid. Fob. Ludov. Hannemanni Scrutinium nigredinis pofterorum Chnm five Athiopum, prc. Fob. Nicol. Pccblini de habitu \& colore Ærhiopun: Anatomen inftituit id. Pecblinus in Th. Bartbolini Act. Med. \& Phil. Hafn. Vol.IV. Obl. XVII. pag. 50. Multa etiam hue fpectautia collegit Andr. Libapius in Commentatiuncula de duplici Serum gente Æthiopica \& Scythica, quæ habetur in ejusdem Singularium Parr. IV. pag.690..-676.

A. IO. Sceletus abortus octimeltris albiffimus, vid. idem Bidloo L. C. 
Tab.100. it, Kerckringius L. C. Part. IV. Sect. I. Cэp.V. Tab.LXII. fig. I. pag. 523. Conficiendi, \& ofla dealbandi modum docuit Sim. Pauli in Mangeti Biblio. theca Anatomica Part. VI. Libr.V. pag.1075. \& 1084.

A. II. Sceletus partus monftrofi mafculi, una cum gemellis in oppido Militfch An. 1722. nati, inferius usque ad abdomen perfeeti, nifi quod vifcera in pectore \& caput deficeat, item infra protuberantiam umbiliciformem funiculus peculiaris abdomen penetraverit, \& in inteftinis craffis fe terminaveric. Monftum hoc defer. \& delin. in Bresl. Sammlungen von Natur. und Medicin. Gefibicbten XX. Verfuch, Anno 1722. Menf: Junio Clafe IV. Artic. XIV. pag. 626. feqq. convenit cum delineat. qqux reperieur in Fortunii Liceti de Monftris Libr. in Appendice pag.303. Monftra acephala alia del. \& defcr. in Gafp. Scbotti Phyfica curiofa Lib.V. Cap. I. pag. 573. feqq. in Ephemerid. Natur. Curiofor. Decur.I. An.III. Obferv. CCLXXII. pag.490. \& Dec.II. An.IX. Obf.CXLVIII. Fig.XXXIV. pag.258. it. in allegati Fortunii Liceti de Monftris Libr.II. Cap.II. pag. 88. \& Cap.XXX. pag.131. \& 132. In 7ob. Bin. bards Thüringifcher Chronica Libr.III. pag.192. ap. fob. Scbenekium Obf. de Monftris, pag. 39. Multa huc fpectantia quoque collegit' Job. Jacob Wepferus in Hiftorica Defcriptione Puellx fine cerebro natx, qux reperitur in Mangeti Bibliotheca Anatomica Part.IIt. pag. 339. it. in Ephemerid. Nat. Curiof. Dec. I. An. III. Obf. CXXIX. pag. 205. feqq. Puellam aliam fine cerebro natam vid, ap. Nicol.de Bleg$n y$ in Zodiaco Medico Gallico An.III. pag. 54 . Alium infantem talem XXIV, horas fuperftitem ap. Cornel. Stalpartum van der Wiel in Centur. Obfervationum Medico-Chirurgico-Anatomicurum rariorum Cent I. Obf.Il. Infanten fine capite per IV. dies viventem, defcr. Joh. Lovthorp, in Tranfactionibus \& Collectionibus Philofophicis, Vol. III. Part. I. it. Raygerus in Epbemerid. Nat. Curiof. Dec. I. An. VIII. Obf.LXIV. Alius cerebro, item cerebello \& medulla fpinali carens, poft VI. horas demum decedens, vid. ex Hiforia Academix Regix Scientiarum An. 1713. Alta Eruditor. Lipfienfia An.1718. Menf. Junio pag.242. It. An.1724. Menfo Novembr. pag. 50 r. ubi puella fine capite, brachiis, corde, pulmonibus, ventriculo, resibus, inteftinis tenuibus, hepate, veficula fellis, liene, pancreate nata mortua, cum alia adhuc viva integra \& fana defcr. Conf. de Monttris humanis ulyff. Aldrovandi de Monftris Hiftoriam, Jacob Rueffii Tract. de Conceptu \& Generatione hominis Libr.V. Cap.III, fol.4I. feqq. it. Forr. Lixeti \& Cafpar, Schotii Libr.fupr. alleg.

A. 12. Monftri hujus interna vifcera in liquore balfamico, vid. Breslauifcbe Samml. vion Natur - und Medicin - Gefchicht. L. fupr. cit. pag. 628. A. 13. Monftrum hoc ad vivum delineatum.

A. 14. Caput agni monftrofum. Agnos montrofos delin, Henrit. Oldesburgius 
burgius in Actis Societ. Reg. in Angl. An.1667. Menf. Junio pag.386. Monftrum aliud agninum vid. in Tb. Bartbolini AA. Med. \& Philor, Hafn, Vol.III. Obf.XXVII. pag.58. \& Obf.IX. pag.99. it, Vol.V. Obr.VI, pag.21.

A. I5. Sceletus muris monftrofi ex acervo formicarum defumtus. defer. Georg. Hieron. Velfcbius Obfervat. Phyfico-Medicarum Hecatoft. I. Obf. LXXVI. pag. 99. De Animalibus monftrofis alias evolv. Franc. Hernardez Rerum Medicar. Nov. Hifpanix f. Fob. Fab. Lynceus Expofit. pag.626. Fortunius Licetus de Monftris Lib. I. Cap. IV. pag. Is. feqq. Cafp. Schotius in Phyfica curiofa Libr. V. Cap.III. pag.580. feqq. it, Mich. Bernb. Valentini Muf. Mufeor. Part.II. Cap.XXXV. pag.157. feqq.

A. 16. Pes Pafferis monftrofus, talis defcrib. in Job. Hornungi Cifta Medica Epift. LXXVII. pag.2Ir. Aves monftrofas alias del. \& defcr. Cafp. Sibontus in Phyfica curiofa Part. I. Libr. V. Cap. XXVI. pag.616. feqq. Ulyjf. Aldrovandus de Avibus Libr. XIV. Cap. XVII. Fob. Fac. Leibnitzius in Defcript. F. Memorabilibus Bibliothecæ Norimbergenfis pag.18. Thom.Bartbolinus Cent.II. Epiftol.LXXXVIIt. Epbemerid. Nat. Curiof. Dec.II. An.IV. Obf.XLI. pag.IOI. M.B. Valentini in Muf. Mufeor. Part. II. Cap.XXXV. pag.158 feqq.

A. 17. Corii humani craffiffimi pars, f. Virginis annofæ.

A. 18. Cranium humanum, cum Ufnæa cruftacea, five Flos cranii. De comparatione vid. Ephemer. Nat. Curiof. Dec. I. An. Il. Obf.LIIl. pag.95. it. Micb. Bernb.Valertini Muf. Mufeor. Part.II. Cap.XXII. pag.94. De Ufu Médico \& fuperftitiofo vid. Ol. IV ormius Muf. Libr.III. Cap.XXVI. pag.342. Petr. Pomet im Materialiften-und Spezerey- Händler Part. II. Cap.I. pag.470.prc, Cbrift. Frid. Garmannus in Oologia curiofa Diff.I. \$. 103. pag. 103 . feqq.

A. 19. Officula auditus in homine. hxc delin. \& defcr. Thom. Bartbolinus Epiftol. Medicinal. Cent.I. Epift.LXIII. pag. 25s. feqq. it in Anatome Lib.IV. Cap. VI. Tab.III. pag.713. Julins Cafjerius Placentinus in Tabulis Anatomicis Tab. XII. Libr.X. Fig. VIII. IX. X. \& XI. pag. 27 I. ir. in Hiftoria Anatomia de Vocis Auditusque organis, Pbil. Verbeyen in Anatomia corporis humani Tab.XXIII. pag.410. prc. Guntberus Chriffopb. Scbellbammerns \& fofeph. du Verney in Tract. de Auditu \& ejusdem Organo, qui reperitur in Dan. Clerici \& Jac. Mangeti Bibliotheca Anatomica Part. III. pag.371...454. Isbrand. de Diemerbroeck Operum Anatomicorum \& Medicorum Libr.III. Cap.XVIII. Tab.XV. pag. 4Ir. fegq. aliique Anatomes fcriptores.

A. 20. Maxima pars offis brachii humani, quæ absque fractura poft ulcus inveteratum feceffit. vid. Obfervatio meia in Bresl. Samml. von Natu und Med. Gefch. XXIII. Verf. An.1723. Menf. Januiar. Clafr. IV. Art.X. pag. 99. fegq. it. Ludov. Pbil. Tbümmígs merckwürdigfte Begebenheiten der Natur Parc.IV. 


\section{4

num.V. pag.3I2. feqq. citant: Isbraind. de Diemerbroeck in Operibus Medicis \& Anatomicis, Anacomes de Oflibus Lib.IV. Cap.I. pag. \{19. it. Henr. von Roonbuyfens Hiftorifcher Heil-Kunt, Part. II. Obf, IX. pag.217.feqq.

A. 2I. Os humeri cum cubito, radio \& manu ruftici aliquoties fraCum \& iterum confolidatum, fubfecuta magna excrefcentia carnof, vid. Bresl. Samml. pon Natur- und Med. Gefch. XXVI. Verf. an. 1724. Menf. Jun. Cl.IV.

A. 22. Bafilifcus vulgo, five Draco alter ex Raja exficcata concinnatus. del, \& defcr. Georg. Woljgg. Wedelius in Ephemerid. Nat, Curiof. Dec. I. An. III. pag. 202. Ulyff. Aldropandus de Pifcibus Libr. III. Cap.XLVIII. pag. 343. Mufeum Calceolar. Veronenfe Sect. I. pag.90. Fob. Fonfonus in Hiftor. Natural. de Serpentibus Lib. I. Tab. XII. pag. 36. it. in Ejusdem de Pifcibus Tab. X. XI. \& XII. Cornel. Stalpart van der Wiel Cent. Obfervationum Medico - Chirurgico - Anatomicarum rariorum Cent. II. Obf.L. Fob. Henr. Locbnerus in Mufeo Besleriano Tab.XV. pag. 6. Conf. Cbriftiani Vateri Phyfiolog. experimental. Sect. VIII. Cap. V. Quxet. I. pag. 753. it. Mich. Ber. Valentini Muf. Mufeor. Fart, II. Cap. XXXVI. Tab.XXXXI. pag. 160. Fabulas ex authoribus de Bafilifco collegit \& refutavit Melch. Sebizius de cafiu adolefcentis cujusdam Argentinenfis mirabili, Wedelius L. fupr. c. Sim. Scbulszius in Epberm. Nat. Curiof. Dec. I. An.III. Obf. CXC. pag. 359. Cbrift. Francifc. Paullini in der Zeit. kürzzenden erbsul. Luft Part. III. Them. CXXVIII. prc. foh. $A d$. Geritz in Bresl. Samml. von Nat, u. Med. Gefcb. XVIII. Verf. An. 1721. Menf. Odt. Claff. IV. Art. V. pag. 382. feqq. Ex Ovo galli non excludi demonftr. Cafp. Bartholinus in Exercisationibus Mifcellaneis Exercit. II. Serpentem, fub nomine Bafilifci coronatam del. \& defcr. Conrad. Gefnerus Hiftor. Animal. Libr. V. qui eft de Serpentium Natura fol. 32. Conf. Sebizii Differt, paulo fupra allegatam.

A. 23. Pi cis alatus . Hirundo marina. del. \& defcr. in Rocbeforts Befchr. der Antillen Infuin in America Cap. XVI. pag. 264. 7ob. Albert. de Mandelsloo Murgenländifcher Reife Befchreib. Lib. II. Cap. XIII. pag. 106. Joh. Neubofii Befchreib. des Kayferthums S na pag. 206. George Anderfen Orientalifch. Reife-Refchreib. pag. 181. Erafm. Francifsi Oft - und Weft - Ind. Luft - Garten Part. I pag.zi. Job. Hug. Lintfchottani Ind. Oriental. Parc. IV, Sect. II. Cap. II. pag.92. Franc. Leguat. Reifen nach zuveyen Oft - Indifchen Infuln Part. I. pag. II. Guil. Pifonis Hiftor. Nat. \& Medic. Libr. III. fig. II. pag. 6I. Fac. Bontii Hift. Nat. \& Medic. Libr. V. Cap. XXIV. pag. 78. Fub. Lerii Hiftor. Navigat. in Brafil. Cap.III. pag. I6 Partheus Oft - Indianifch. Kriegs - Dienft. pre. evolvend Conr. Gefnerus Hiftor. Auimal. Libr.IV. quí eft de pifcium \&áquatilium animantium natura pag. \{14. Hypolibus Sal. vianus in Aquatilium Animal. Hiff. Hiftor. L.XVII, fol. 185. Guil. Rondcletirs de Picibus marinis Part. I. Lib. X. Cap. I. pag. 284. Fob. Jonfonus de Pifcibus Libr. I. Tab. 
Tab. XVII. num. VIII. pag. 65. Ol. Wormius in Mufeo Libr. III. Cap. X.pag. 266. Micb. Bernb. Valentini in Muf. Mufeor. Part. II. Cap. XXXVII. pag. 162. aliique.

A. 24. Armadillus f. Tatou Brafilienfis. del. \& defcr. fob. fonftonus de Quadruped. Tab. LXII. pag. 144. Georg. Marcgravius in Hift. Brafil. Libr. IV. pag. 23I. Guil. Pifo in Hiftor. Natural. \& Medic. Lib. VI, pag. IOr, fob. de Lat. in Novo Orbe f. Americx utriusque Defcript. Lib. V. Cap. V. pag. s\$2. Ol. Wormius in Mufeo Lib. III. Cap. XXIII. pag. 335. Ad. Olearius in Gottorphifch. Kunft . Kammer Tab. VI. pag. 7. Fob. Henr. Locbnerus in Muf. Besler. Tab. IX. pag. 40. De virtute fingulari Medica, vid. Caßß. Barlaus de Reb. geft. fub Comir. Mauritio in Bralifia pag. 369. Meras fabulas effe afferit, Fr. Redi in Experimentis circa res diverfas naturales, fpeciatim illas, qux ex Indiis adferuntur.

A. 25. Hippocampus Indiæ Orientalis major. del. \& defcr, Conr. Gefnerus Hiftor. Animal.Libr.IV. pag. 49r. it. Ad. Olearius in der Gottorpifch. KunftKam. Tab. XXVI. num. IV. pag. 48 .

A. 26. Hippocampus ex mari Mediterraneo minor; convenit cum del. \& defcript. Fob. Fonftoni Hiftor. Natural. de Infect. Libr. IV. Tab. XXVI. Cap. III. pag. 199. Guil. Rondeletii de Pifcibus marin. Part. II. Lib. II. Cap. III. pag. I08. 7oh. Pomet in Mater. und Specerey - Händl. Tab. LXII. fig. 374. pag. 589. it. Mich. Bern. Valentini Muf. Mufeor. Part. I. Cap.XXIV. pag. 470.

A. 27. Echinus marinus f. Carduus maris aculeis albis minutiffimis confpicuus. accedit ad delineat. Conrad. Gefneri Hiftor. Animal. Libr. IV. pag. 416. it. Fob.Lochneri Muf. Bes!erian. Tab. XXII. it. Guil. Rondeletii de Pifcibus Marinis Part.I. Lib.XV. Cap. XXX. pag. 579.

A.28. Echinus marinus maximus rutilus, aculeis minutiffimis armarus, fimulque aculeorum veftigia demonftrans.

A.29. Echinus efculentus tuberculofus cinereus paulo minor fpinis carens. Del. \& defcr. Mart. Lifterus in Hiftor. Animal. Anglix Tab. III. nun. 18. pag. 169. it. Georg. Everb. Rumphius Amboincfch. Rarit. Kam. Tab. XXIII.-Lit.B. fol. 30 .

A. 30. Echinus marinus maximus papillofus elegantiff. id. Rumpbius Amb. Rarit. Kam. Tab.XIV. Lit. B. fol. 32 .

A. 31. Echini marini albi papillofi fpecimen minimum.

A. 32. Echinus marinus albus minor, aculeorum veftigits parum aut nihil eminentibus. talem delineav. Locbnerus in Muf. Beslerian. Tab. XXII.

A. 33. Echinus marinus coloris fufciminor, f. Caftanea marina fpoliata 


\section{PROMTVARIVM RERVM NATVRALIVM}

liata fpinis. del. in Rocbefort Befchr. der Antillen-Infuln Cap. XIX. num. XIII, pag. 335. ic, in Olearii Gottorpifch. Kunt.Kam.Tab. XXX. num. 1. \& 2. pag.57. A.34. \& 35. Echini marini aculeis orbati interior mira facies, tam papillofi, quam tuberculofi. del. in Ephem. Nat. Curiof. Dec. II. An. VIII. pag. III. fig. 9.

A. 36. Echinus integer marinus aculeis totus horridus. del. \& defcr. Pbil. Bonannus in Recreatione mentis \& oculi Part. II. Claf. I. num. 17. pag.92. prc. 7ob. Jonftonus de Exanguibus Tab. XII. \& XIII. pag. 5I.

A.37. Echinometra f. Echinus marinus digitatus elegantis frueturæ, quinis lineis undulatis, quæ parvis foraminulis diffecantur, æqualiter a vertice ad bafin usque procedentibus, ubi fpatia papillis fupereminentibus adimpleta. del. \& defcr. Pbil. Bonannus in Recreat. ment. \& oculi, Part. It. Claff. Il. num. 18. pag. 92. Ad. Olearius in Gottorp. Kunft-Kam. Tab. XXX. num. I. pag. 17. it. Gearg. Everh. Rumphius Amboinfch. Rarit. Kam. Tab. XIII. num. 3. De ineffabili copia in mariAdriatico \& Tyrrheno, it. de ufu medicamentofo, vid. Francife. Placentia Mare Ægeum redivivum pag. 56.

A.38. Echinus fulcatus, cranio humano fimilis. conven. cum delin. ap. Valentinum in Muf, Mufeor. Part. II. Tab. III. Cap. II. fig. $7 •$

A.39. Echinometra plana ftellata difcoidæa. vid. Lifteri Hiftor. Animal. Anglix pag. 21. f. Echinus planus ftellatus Rumpbii Amboinfch. Rarit. Kam. Tab.XIV. Lit. E. pag. 36.

A. 40. 41. Aculei Echinometræ digitatæ purpurei coloris \& cinerei, in apice fafciis albis cincti, inferius fovea notati. Echinus defcr. \& delin. ap. Pbil. Bonannwm in Recreat. ment, \& ocul. Part. Il. num. 9. pag. 92. \& ap. Georg. Everb. Rumpbium Amb. Rarit. Kam. Tab. XIII. num. I. \& 2. pag. 35 . Pedes vel aculei itid. in Rumpbii Amb. Rar. Kam. Tab. XIII. Lit. D. \& in Epbem. Nat. Curiofor. Dec. II. An. I. \& II. Tab.III. pag. 56.

A. 42. Pedes f. Aculei Echinometræ Pelagii Ariftotelis, inferius fovea notati petrefacti, ubi papillis Echini marini adhæferunt. del. cum Echino Pbil, Bonannus in Recr. ment. \& Ocul. Part. II. Claff. II. num. 17. pag.92. Rumpbius Amboinfch. Rar. Kam. Tab.XIII. Lit. E. num.3. \& 4. pag.30. totum vero cum aculeis in lapidem mutatum del. Ferrand. Imperatus Hiftor. Natural. Lib. XXIV. Cap. XXVI. pag. 759.

A. 43. Os cum dentibus Echini marini, coronam Imperialem ropræfentans, fec.del.\& defcr. frepius cirati Rumpbii Amb. Rar. Kam. Tab. XIII.Lit. A. pag. 30. Batavis: OpegaandeZee-Tulpen, vid.Wil.d' Orville Catalogus van 
Kabinet pag. 25. Cum Echino defer. Conr, Gefnerus de Aquatilibus Libr. IV.pag. 416, it. Gaßp.Scbottus in Phyfica curiola Lib. X. Cap. XV. pag. Itr. prc. Pbil. BO. nannus in Recreat. ment. \& ocul. Part. III. Problem. XXIX.pag,244. feqq.

A. 44. Acus marina. del. \& defcr. in Conr. Gefneri Hiftor. Animal. Libr. IV. pag. II. Guil. Rondeletii de Pifcibus Marinis Part. I. Lib. VIII. Cap. IV, pag. 229. uliffs. Aldropandi de Pifcibus Lib. I. Cap. XXII. pag. IO5. Fob. Forffoni de Pifcibus Tab.XV. num. I4. pag. \$6. Ol. IVormii Muf. Libr. III. Cap. X. pag. 26G. Ad. Olearii Gottorp. Kunft - Kam. Tab. VIII, num. V. pag.8. Gaßp. Schotti Phyfica curiofa, Lib.X. cap. II. pag. I0\{3. Anatomen iftituit Ol. Borrichius in Th, Bartholini Act. Hafnienf. An. 1673. Obf. XXXVIII. pag. 149. leqq.

A. 45. Scolopendra Aldrovandi India Orientalis $f$. Regionis Coromandel. vid, ejusdem de Infectis Animalib. L,ibr. V, Cap. XV. pag. 635, it. Conr, Gefnerus Hift. Animal. Libr. IV. pag. 1009. \& Guil. Rondeletius de Pifcibus Marinis Part. II. qux eft univerfa Aquatilium Hiftoria Lib.II. Cap. III. pag. 108. Sive Hippocampus Moufetti \& Fonfloni H!nt. Nat, de Infeç. Libr, IV.Tab. XXYI. pag.I98. De fumma virulentia vid. Georg. Anderfen Oriental. Reis, Lib.I. Cup.XVIII. pag. 25. it. Libr.II. Cap.XV. pag. 76. Rochefort Befchr. der Antillen Infuln Cap. XIV. pag. 228. Will. Boffmanns Reife nach Guinea p3g. 236. it. Guil, Pifonis $\mathrm{H}$ ritor, $\mathrm{Na}$, tural. \& Medic, Ind. Occidental. Libr. V. pag. 286. Per microf copium examinavit Ant, de Leeuvenhoek in Continuatione Epiftolarum ad Reg. Soc. Londinenfem datarum Epift. VII. pag. 91 . it, in Anatomia beneficio microfçopiorum detecta Tab. CII. fig. XI. Sect. I. pag. III.

A.46. Cauda echinata maxima Rajx pifcis, vid, prc. Joí. Jonfonus de Pifcibus Libr, I. punâ, IV. Tab.X, XI. \& XII. pag. 33. Hyppolitus Salvianus in A. quatil, Animal. Hiftoria, Hift.XLIX. fol. I49. it. Authores qui fupra de Bafilifco; Anatomen Rajx vid, in Nic, Stenonis Specim, Obfervation, de Mufculis \& Glandulis in fine.

A. 47. Cataphraetus parvus defcr, \& del. Siephan. a Scboenfeld in Ichthyologia pag. 30. it. Fob. fonftonus de Pifcibus Tab. XLVI. num. 5.

A. 48. Teftudo Brafilienfis marina minima, pedibus pinnatis. del. \& defcr. ap. Fob. Fonftonum de Exangvibus Tab. VIlI. num. VIII. it. in Valentini Mu. feo Mufeor. Part, I. Libr. III, Cap. XXXXI. pag. 48 \%. Multo major, in Job. Henr. Lochneri Mufeo Beslerian. Tab. XVI. pag. 60. Petr. Pomet. Material. u. Spezer. Händl. Part. II. Tab.LXIII, fig. 377. pag. 595. Rocbefort Befchr. der Antill. Infuln Cap. XX. num. 2. pag.353. feqq. Leguat Reifen nach zvveyen Oft-Indifchen Infuln Part. II.

A. 49.' Tegumentum Teftudinis Brafilienfis terreftris ftellatum. conven. cum delin. ap. Conr. Gefnerum Hiftor. Animal. Libr. II. gui eft de Qua- 
drupedibus oviparis pag. Irz. defcr. \& del. in Guil. Pifonis Hifor. Natural \& Me. dic. Libr. III. pag. Io . in Erafm. Francifci Ont - und WW elt - Indifchen Luft-Gạten Part. I. Tab. X. num. 6. pag. 335. Gob. Henr. Seyfridii Medulla mirabilium Naturx Libr. II. Cap. II. pag. $564 . \& 567 . \quad$ Ol. Wormi Mufeo Libr. III. Cap. XXIII. p3g. 516.

A. 50 . Sceletus Teftudinis vulgaris aquatica. del. \& defcr. in Epbem. Nat. Curiof. Dec. I. An. IV. \& V. Obferv. CLXXXIII, pag. 240.

A. 5 I. Serra pifcis, roftro dentibus f. fpinis XXVIII. ab utroque latere munitus. del \& defcr. prxter Aldrovandum, Jonflonum Hif. Nat, de Pifilus \& Ceris Tab. XLIV. p. 220. Gefnerum Hifor. Animal Libr. IV. pag. 856. Carolus Clufins Exoticor. Libr. VI. Cap. XIX. pag. 135. Ad. Olearius Gotcorpifch. Kunf Kum. Tah. XXV. num. I. pag.38. Ol. Wormius in Mufeo Lihr. III. Cap XV. pag. 288. Frid. Martens in der Spitzbergilch. oder Gronländifch. Reife-Befch. Cap. VI. aum. VII. pag.95. Guil. Pifo Hift. Nat. \& Medic. Ind. Occidental. Libr.

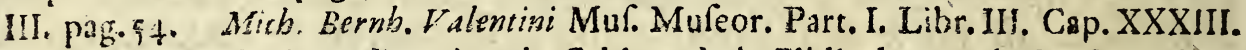
p.og. 490 Clatht. du Molinet dans le Cabinet de la Bibliotheque de St. Genevieve Part. II. Tab.IIl. prc. Hannans in Eph. Nat. Coriof. Dac. II. An. VIII. Obi. CVII. it. Job. H.:2r. Losknerus in Muf. Besl. Tab. XXVII. pag. 63. ubi plures fimul Authores nominantur.

A. 52. Radii ferrati Pallinacæ marinæ. defcr.in Guil. Rondeletii de Pifcibus

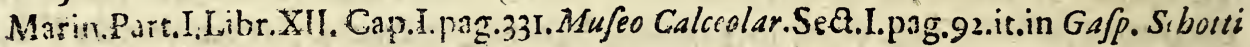
Phyfica curiofa Libr.X. Cap. XXXVI. pag. 1138. De Summa virulentia vid. Erafor. Francifci Oft-und Weft -Ind. Lun - Garten Part. II. pag.986.

A.53. 54. Pila marina \& fagnatiles diverforum colorum \& magnitudinis, vid. Ol. Wormius in Mufeo Libr. II. Cap.II. pag. 139. pre. Job. Mat's. Faber de Pile marinx Anatome Bontanolog. in Mifcell. Nat. Curiof. Dec. II. An.I. Ohl.XIV. pag. 32. it. An. X. pag.197. Conf. Dec. III. An. I. pag.313. it. Grorg. Hier. Velfsbii Obferv. Phyfic. Medic. Hecatof.1. Ob?. XVIII. pag. 29.

A.55. Natrix rubra maxima in rene lupi, cum aliis reperta. delor. in Brest. Samml. von Nat. und M.d. Gefch. XIV. Verf. An.1720. Meni. Nov. Clafi IV. Art. VI. pag. 547. feqq. conven. cum delineat. Amphisbanx in Piforis Comment. fupra Jac. Bontii Hiftor. Natural. Libr. V. cap. XXIII. pag. 77. \& Job. Jonftonide Serpentibus Tab. IV. pag 2I.

A.56. Natrix rubetaria ex montibus Riphxis.

A. 57 . Af is Egyptiaca I. Angvis Afculapii albus, fquamulis rotandis rubris in dorfo confpicuis.

A.53. Angvis Efculapii niger, fquamulis rotundis albis ita difpofitis, ibidem frequens. 
A.59. Zicatlinan f. Mater formicarum, ferpens Indiæ Orientalis, circulis albis \& nigris aliernatim cincta, del. in Ad. Oiearii Gottorp. Kunft-Kam. Tab. XI. num.I pag. 16.

A.60. Cœcilia marina nigra capite rubro punctato, in Guinea frequens. vid. Georg. Everb. Rumpbsii Amb. Rar. Kam. Libr. I. Cap.XXXVIII. pag.45. A.61. Serpens nigra Indiz Oriental. maculis oblongis albis notata. A. 62. Serpens minima albicans, in dorfo punctulis fufcis oblongis infignita.

A. 63. Serpens Americana elegantiffima, fquamulis in dorfo albis \& nigris alternantibus.

A.64 Serpens perexigua, qux capta prope Vratislaviam ranam maximam, \& triplolatiorem, vel craffiorem evomuit, cum rana. vid. Obfervatio mea in Bresl. Nat. u. Medic. Gefib. XXI. Verf. An. 1722. Menf. Jul. ClafT. IV. Art. V. pag. 67.

A.65. Serpens talis fingularis magnitudinis ex montibus Giganteis. A. 66. Exuvia ferpentis longifima Americana, ubi totà pellis (quamis tecta pulchre difpofitis, \& dorfum a capite ad extremam caudam coninuo ordine fecundum longitudinem nigricantibus quafi clypeiformibus maculis ornata. defcripfi in Bresl. Samml. XX. Verf. An. 1722. Cl.JV. Art. V. pag. 69. Serpentem ejusmodi delin. \& defcr. Carol. Clufus Exoticor. Libr. V. Cap. XVIII. pag. II. ir. Curar. Pofterior. pag. 66. Adam. Olearius in Gottorpifch. Kunt - Kam. Tab. XI. pag. 17. Exuviam Ol.Wormius in Muf. Libr. III. Cap. IX. pag. 263. Fob. Henr. Locbnerus Mur. Beslerian. Tab. XIV. pag. \{3. Andr. Cleyerus in Epbem. Nat. Curiof. Dec. II. An. II. Obr. VII. pag. I8. Maximas ferpentes Indix Orientralis \& Occidentalis, oves, homines, cervos, imo boves deglatientes defcr. Pbil. Baldaus in Befchreib. der Küften Malabar und Coromandel pag. 426. prc. Job. Ludolfius Hiftor. Airliopic. Lib. I. Cap.XIlI. Atbanaf. Kircberus Chin. illuftrat. Parc. IV. Cap.X. pag. 202. \& 203. Georg. Hier.Velfsbius de Vena Medinenfi pag. 214. Pbilipp. a St. Trinitate in Oriental. Reile - Befchro Libr. VII. Cap.IV. Pbilip. Pigafetta in Defcript. Regn. African. Part, I. Cap. XI. pag.23. Francifc. Leguat. in Reilen nach zvvey unbevvohnten Infuln Part. II. pag. 300. Wilb. Bofmanns Reifen nach Guinea Epia XVII. pag. 368. Cbriff. Eranc. P.aulini in der Zeit. kürtzenden erbaul. Luft Part. II. Them. XCIX. Onnem fidem fuperant, qux annotavit de portentufis Serpentibus ex Ol.Magni Libr. XXI. Cap.XLIII. Conr. Gefnerus Hiftor. Animal. Libr. IV. qui eft de Pifcium \& Aquatilium Animancium Natura pag. 1040. \& Libr. V. fol. 70. it. Gafp. Sibottus in Phyfica curiola in Append. Cap. VI. S. 3. pag. 1169. Conf. Obferpationem meam in Bresl. Samml. 


\section{PROMTVARIVM RERVM NATVRALIVM}

ton Nat. u. Med. Gefch.XXI. Verf. An. 1722. Menf. Jul. Claft. IV. Art. V. pag. 66. feqq.

A. 67. Cocilia Gefneri coloris flavefcentis. del. Ferrand. Imperatus Hift. Natural. Libr. XæVIII. pag. 916.

A. 68. Vipera Atinericana longisfima cinerea, colore nigro fafciata.

A.69. Vipera Italiæ, èx quibus Trochifci ibidem conficiuntur. Hanc cum Trochifcis del. \& defcr. ex Petr. Pometii Material, und Specerey. Händl. Part. II. Cap. XXVII. Tab. LIX. fig. 36I. 364. pag. 360. feqq. Mich. Bernb. Valen. tini in Muf. Mufeor. Part. I. Lib. III. Gapit. XXXIX. pag. 504. præcip. Marcus Aurel. Severinus in eleganti opere, de Viperxe Natura, Venetio, Medicina, it. Bal. dus Angelus Abbatius de aumirabil. Vipere Natura, \& de mirificis ejusdem facultatibus:- Varia experimenta cum Viperis inftituit Moyfes Cbaras in Continuatione novorum experimentorum circa viperas, una cum Differtatione de earum veneno, it. Bourdelot in Judicio \& Obfervationibus circa Viperas, Gallice fcript. \& Franc. Redi in Experimentis circa res diverfas naturales, fpeciatim illas; quæ ex Indis adferuntur in fue, it. in Obfervationibus de Viperis; Anatomen inftituit Oliger. Jacobaus in Th. Bartbolini Act. Medicis \& Phil. Hafn. Vol. V. Obf. C.pag.266. it. Edoard. Tyfjon in Viperx caudifonæ Anatomia. Fabulas de Vipera collegit Pbil. Fac. Sacbs a Lewenbeimb Gammatologix Cap.II. 5.7.pag. 25. De Congreffu \& Partu fabulofo \& vero multa reper, in Gotbofred. Voigtii Curiofitatibus Phy. ficis Cap. IV. pag. 108. - $15 \%$. De vano ufu in Medicina vid. Obfervatio mea in Bresl. Samml. Don Natur and Medic, Gefeb. XXI. Verf. Au, 1722. Menf, Jul, Glalf. IV. Art. V. pig. 74 .

A. 70. Ova Viperæe Italiæ botryformia.

A. 7 1. Serpentum diverfimode variegatarum non vulgarium $\mathbf{X}$. diverfe adhuc fpecies. De his evolv. ullyff. Adrobandis in Hift. Serpent. \& Dràcon. Conrad. Gefrnerus Hift. Animal. Libr. V. qui eft de Serpentium Natura, fob. Fonflonats in Hift. Natural. de Serpentibus, Guil. Pifo in Hift. Nat. \& Medic. Ind。 Orcidental. Libr. V. Cap. VIIt, pag. 274 . - 282, Conf, de Serpentum differentiis, fenecta, pártibus, fenfibus, veneno, ejusque remedio, Wolffg. Frantzii Hiftor. Animal، Part. IV. Cap. I.

A. 72. Coronæ Serpentum vulgo, r. Pars Chelæ Squillæ árenariæ Indix Orientalis. del. \& defcr. cum Squilla uly/f. Aldrovandus de Animalibus exangvibus Libr.II. pağ. I59. Pbils gac. Sacbs a Levenbeimb Gammarol. Cap.XIV. S. i5. pag. 304. Micb. Bernh. Valentini in Muf. Mufeor. Tom. I. Cap. XXXV. pag. 494. S. Squillæ lutaria Moddermans Rumpbii Amb. Rar. Kam。Tab. IIt. Lit. E. fol.G. 
A. 73. 74. Coronæ Serpentum ex dentibus porcellorum molaribus majores \& minores. del, \& defcr. Chrif. Warlitzius in Mufeo curiofo aucto Seĉ. III. Num. V. Part. II. Cap. XLI. pag. 176. Georg. Hier. Vellsbius Hecatof. I. Ob́ferv. Phyfic. Medic. XXVII. pag. 42. F. H. Locbnerus in Muf. Besler Tab. XXXI. pag. 93. Conf. Mifcell. Nat. Curiof. An. V. Dec. It, Obr. CVI. pag. 212. pr.. Schol. Dari tales coronas etiam aureas fuperftitiofe probat Fob. Lud. Hanemannus in $E$ pbem. Nat. Curiof. Dec. II. An. VI. Obr. LXXVIII. pag. 129. it. Rofinus Lentilius in Ephem. Nat. Curiof. Dec. III. An. 1V. Obf. XXII. pag. 48. De fabulofo ufu in Medicina vic. Conrad. Kbunratb in Medulla Deftillatoria \& Medica Part. II. Tratt. XXVII. pag.309.

A.75. Corona Serpentis ejusdem ftrueturæ potrefaeta minima nigra Maslenfis Silefix.

A. 76 . Squilla marina, cujus tegumentum calices maris ornant, ex quibus fquillæ minimæ proveniunt. De Calicibus vid. Fob. Fonftonus de Exangvibus Tab. V. pag. 24. feqq. Phil. Bonannus in recreatione mentis \& oculi Part. II. Claff. I. num. 14. pag. 92. precip. Pbil. Fac. Sacbs a Levenbeimb Gammarologix Cap. V. pag. 90. feqq. it. Mifcellan. Nat. Curiofor. Dec. I. An. II. Obf. C. pag.174. Bufoni fimile animal Americanum Pipa \& Pipal indigenis dictum cum foetibus e dorfo emergentibus del. \& defcr. ex Frid. Ruysbii Thefauro Animalium primo Ait. Erudit. Lipf. An. 17ro. Menf. Novembr. Tab. VII. pag. 484. Ana. tomen Squilly marine inflitưit Ant. a Leeulbenboeck in Epiftol. ad Societat. Reg. Angl. \& alios Illuftres Viros f. Continuatione mirandorum arcanorum Nature de. tectorum Epift. CXXV.

A. 77. Chela Cancri marini lævis Rumpbii, Amb. Rar. Kam. Libr. I. Cap. ViI. Tab. VI. Lit. P. fol.It.

A. 78. Aftacus fluviatilis cum tegumento \& chela monftrofa. Monftrofos cancros delcr. id. Levenbeimb in Gammarol. Cap. VII. pag. 115. feqq. A. 79. Chelæ Aftaci fluviatilis corniculatæ \& variæ monftrofæ. tales defcr. Georg. Hier. Velfcbius Obferv. Phyfic, Medic. Hecatoft. I. Obi. VII. pag. 9.

A. 80. Tegumentum Cancri Moluccani maximum. del. \& defcr. Car. Clufuis Exoticor. Libr. VI. Cap. XIV. pag. 127. Job. de Laet in Nov. Orb. f. Ind. Occidental. libr. II. Cap. XIX, pag. 56. Ol. WV ormius in Muf. Libr. III. Cap.V. pag. 249. Fob. Fonfonus de Exanguibus Tab.VII. num. I. \& 2. Ad. Olearius in der Goto torp. Kunft Kam. Tab. XXVIII. pag. \{0. Oliger. Jacobaus in Muf. Danic. Sect.III. pag. 17. prc. Pbil. Fac. Sacbs a.Lebenbeimb Gammarol. Cap. VI. pag I13. it. Marr. Bernb. a Bernitz in Epbem. Nat. Curiof. Dec. I. An. II. Obf. CII. pag. 176. \& Georg. Everbo Rampbiur Amb. Rarito Ksam. Libr. I. Sect. XXI. p. 23. Cancri Moluc. 
cani fragmentum follile lapideum del. \& defer. Joh. Jac.Schcucbzerus in Specim. Lithograph. Helvotica curiof. pag. 6̧. \& feqq.

A. 8r. Paranacare fpecies Cancrorum Brafilianorum, del. \& defer. foh. Jonfonus de Exangvibus Tab. XI. num, 15. pag. 35, it, Ad. Olearius Gottorp. Kunft-Kam. Tab.XXVIII, num. 5 , pag. $5 \mathrm{r}_{\text {。 }}$

A.82. Cancellusf.Paranacare Brafilienfis in Cochlea qux crufta tuberculofa obducta. Del. \& defcr. Conr. Gefnerus Hiftor. Animal. Libr. IV. pag. 189. Guil. Rondeletius de Pifcibus Marinis Fart. I. Lib. XVIII. Cap, XII. pag. 353. Fob. Fonftonus de Exangvibus Tab. VII, pag. 30.Thom, Bartbolinus Epiftol.Medicinal. Cent. IV. Epirt. XVI. pag. 65. it.Epift.XXXVI. pag. 212. Rocbefort in Befchreib. der Antillen-Infuln Cap.XIV. pag. 216. prc. Pbil. Jac. Sachs a Lewenbeimb Gammarol. Cap. V. pag. 102. Georg. Everh. Rumpbius Amb. Rar. Kam.Tab.XXVIII. num. I. Conf. Marcgravii Hiftor. Brafil Libr.IV. Cap. XXI. pag. 188. Petr. Pometii Material tund Specerey - Händler Part. II. Cap.XLII. Tab. LXV. fig.384. pag. 607. \& ex eo Mich. Bernb. Valentini Muf, Mufeor. Part. I. Cap. XXXVIII. pag. 502.

A. 83. Lapides ex Cancris albi \& cœrulei non vulgaris magnitudinis. defcr. Valvafor in der Ehre des Hertzogth. Crains Tom. I. Libr. III. Cap. XXXVI. pag. 453. it, Muf. Calceolar. Seet. III. pag. 368. Multa huc fpectantia collegit Pbil. Jae. Sacbs a Lewenbeimb Gammarol. Libr. I. Cap. XIV. pag. 289. it.309. feqq. Variis figuris infignitos defc. Thom. Bartbolinus Aat. Medic. \& Phil. Hafnienf. Vol. III. Obf, LXV. pag. 106. De ufu Medico idem Sachfus L. C. Libr. II. Cap.II. p:g. I66. feqq. conf. Unfere Samml.von Nat. und Medic. Gefcbicbt. VI. Verf. An. 1718 . menf. Dec. Clafr. IV. Art. XI. pag. 1999. feqq.

A. 84. Chela maxima monftrofa Aftaci marini. conven, cum delin, in Ephem. Nat. Curiof. Dee. I. An. II. Obf. CI. pag. 175. Conf, dé Aftaco marino Ul. Aldrovandi de Animal. Exangv. Libr. II. pag. I15. Conr. Gefneri Hift. Animal, f. de Aquatilib. Libr. IV. pag. 1rg. Fob. Fonfoni de Exangvibus Tab.II. num.2. pag. 17. It. Ephem. Nat. Curiof. Dec. I. An,II. Obf. Cl. pag. I75. Maximi Aftaci defcr. in Hiftorifch. Remarquen An. I7CI. pag. I23.

A.85. Folliculus mofchifer, fingularis magnitudinis. Mofchi folliculum pecul. Tract. defcripf. Lucas Scbrö́kius in Hiftor. Mofchi, cui jungendus Dan. Ludovicus in Ephem. Nat. Curiof. Dec. I. An.IV.\& V. Obf. CCV. pag. 286. Dec. I. An. VI. \& VIr. Obf. CXXVIII. pag. 166. it. Dec. I. An. VIIl. pag. 81. Muf. Calceolarian. Veronenfe Sect. VI. pag. 661. Animal. delin. pag. 666. it. Scbraeckius L.C. pag. 45. \& ex eo Mich. Bernh. Valentini Muf. Mufeor. Parr. I. Libr. III. Cap. XI. pag. 44 r. Conf. Atban. Kircheri Chin. illuftrat. Part. IV. Cap. VII. p?g. 191. Fob. Bapt. Tavernierii Reife-Befchr. Part. II. Cap. XXIV.pag. I4I. Ol. Dapperi Befchreib. 
von Africa pag.21. Ysbrant Ides Reife nach China Cap. VIII. pag. 76. P. Pumetii Material - und Spez. Händl. Part. II. Cap. IV. pag. 479. Tab. LIV. fig. 334. Gaß̨. S: botti Phyf. Curiof. Libr.VIII. Cap. XXVI. pag. 856 . De generatione Mofchi vid. Tb. Bartbolini Act. Medic. \& Philof. Hafnienfia an. 1671. \& 1672. Obr. L illl. pag. 116.

A. 86. Lapis Bezoar Orientalis maximus mire variegatus \& læviga. tus. Hunc peculiari Tractat. defcr. Caßpar. Baubinus, Job. Bapt. Sylvaticus, Nic. Monardes, Anion. Deufingius aliique, quibus jungend. del. et defer. ap. Conrad. Gefnerum de Figuris Lapidum Cap. XII, fol, 160. b. et ex eo ap. Anfel. Boctium de Boot in Hiftor. Gemmar. \& Lapid. Libr. II. Cap.CXCI. CXCIV. pag. 361. feqq. Conf. Pbil. BaldeiBefthreib. der Küften Malabar und Coromand. Cap.XXVI. pag. I62. Job. Bapt. Tavernierii Reife Befchreib.Part.II.Cap.XXIV.pag.I42. prc. Guernisri Rol. finckii peculiar. Differt. Jenx an. 1679. \& Juft. Vefti Differt. Erfurthi an. 1707. ba. bit. it. Engelbert. Kâmpferi Amœnitat. Exotic. Politico - Phyfico-Medic. Fafcifcul. II. 5. 3. pag. 398. feqq. Frans. Hernandez Rer. Medicar. Libr. IX. Cap. XIV. pag. 325. Fabie Columne Lyncei Annotat. in Nard. Anton. Reccbi Rer. Medicarum No. væ Hifpanix Volumen, it. Unfere Samml, pon Nat. und Medic. Gefchicbt. V. Verf. an. I718. Menf. Aug. Claff. IV. Artic. XII. pag. 1526. De raritate in ipfis Indiis, \& copia in Europa, it. de factitio vid. Jeb. Zwelfferus Pharmacopœjx Reg. reformatx in Appendic. pag. 92. it. Frider. Slare in Experiment. \& Obfervationibus circa Lapidem Bezoardicum in fine; conf. Anf. Bostium in Hift. Gemmar. \& Lapid. Libr. II. Cap. CXCIV. pag.37r. Gajpar a Rejes in campo Elyfio jucundarum quxitio. num, Quxft. LXVII. 24. Verum Lapidis Bezoardici Orientalis examen inftituir. Caßp. Kölicben in Th. Bartholini Act. Med. \& Phil. Hafnienfib. Vol. V. Obf. CXXX. f. in Appendice pag. 32 . Animal. defer. \& delin. Petr. Pomet im Material. und Spezerey. Händl. Part.II. Cap. III. Tab. LIII. fig. $333^{2}$. pag. 472 . \& ex eo Aich. Berrb. Valentini Muf Mufeor. Part.I. Libr. III. Cap. XII. pag. 444. Plures Authores congesfit Pbil. Fac. Sacbs a Lewenbeimb Gammarol. Cap. XIV. S. 13. pag.303. it. in. fer. fub A.102. ubi de Cornibus Capri Bezoardiciagitur.

A. 87. Lapis Bezoar Occidentalis $f$. Peruanus crufta alba obductus, obfcurioris coloris. Preter plerosque fupra allegatos vid. Frant. Hernandez Hiftor. Plantarum, Animalium \& Mineralium Mexicanorum pag. 325. Uly.j. Aldrovandus in Mufeo Merallico Libr.IV. pag. 8or. Cbrift. Viellberuer in Befchreib. frend. Materialien pag. 169. feqq. Georg. Marcgravius de Regione \& Incolis Brafilix nec non de Chilenfibus Cap. VI. Fojepb.a Cefta de Natura Novi OrbisLibr. I. Cap. XXI. it. Libr.IV. Cap. ult. Erafm. Franciffi im Of - und Weft - Indifchen Luft Garten Part. II. pag. 1200. feqq. prc. Volckammerus in Ephemer. Nat. Curio. for. Dec. II. An. II. Obf. CXXCIX, pag. 420, it, Mich. Bernb. Dalentini Mur. Mufeor. Part. I. Cap.XIIl. pag. 446. 
A.88.87. Bezoar fuillum album, \& aliud aurei coloris. del. \& defcr. Ll. Aldrovandus in Mufeo Metallico Libr.IV. pag.794. it, Pbil. Jac. Sachs a Lewenbeimb Gammarol. Cap. XIV. \$. 6. pag, 295. conf, Obfervationem meam in Bresl. Sanml. von Nat.und Med. Gefchicht, XXIV. Verf.An, 1723, Menf, Maj. Claf, IV. Art, III. pag. $\{23$.

A. 90, Bezoar Microcofmicum f. Calculus Veficæ humanæ coloris flavi, magnæ molis duriffimus, ex lameilis diverficoloribus compofitus, Geodem fimul referens, Calculum veficx globulo plumbeo \& alios tales lapides prægnantes defcripfit Joh. Capp. Baubinus Ephem. Natur. Curiofor, Dec. I. An. I, Obf. XXXVI, pag. 121, in Schol. it, Erafm, Francifci im GefchichtKunft - und Sitten - Spiegel auslä̈ndifcher Völcker, Libr. I, Cap. XXVIII. pag.2 $\$ 8$. prc. vid, Obferpatio mes in Bresl. Samml.von Nat, und Med. Gefcbicht. XXVII, Verfo an. 1724 , Menf. Januar. Cl. IV. Art.

A. 91. Calculus Veficæ humanæ cretaceæ fubftantiæ XII. Lotho. nes ponderans ex viro XXX. annorum. conven, cum delinear, in Ephemerid. Nat. Curiof. Dec, I, An. II. Obferv, CXLI. num, IV, fig.1I. pag. 224. it, Decur.I. Ann. VIII, Obfer, XI. pag, 18. Omnium maximus, mole capur infantis rę= cens nati fuperans XXV, Unciarum del. \& defcr. Fo . Gronevelt in Differt. Lithologica variis Obfervationibus \& figuris illuftrata pag. 128 . feqq. alium Mart. Bernb. 3 Bernitz in Ephem. Nat. Curiof. Dec. I. An, II, Obferv,CXL. pag, 224. Er alium Caput infantis æquans, nec multum ei disfimilem defer. Goodrick Act. Philofoph, Soc. Reg. in Angl. An. 1667. Menf. Junio pag.388. De Calculorum generatione vid. Fob. Bapt, Helmontii Tract. de Lithiafi, Tacbenius in Hippocrate Chym, Cap. XIV. prc. Georg. Ernef. Stablii.Diff, tradens novam Pathologiam Calculi,it, Obfervation. in Bresl. Samml. L, paulo fupr, citat,

A.92. Calculi Veficæ num. XVIII, ejusdem fubftantiæ avellanas æquantes, intra bihorium a J. G. G. viro feptuagenario, fine dolore excreti. vid. Obfervatio mea in Bresl, Samml, von Nat, und Medic. Gefcbicbt. XXI. Verf. An.1722. Menf, Aug. Clafr. IV. Art. XViIl. pag, 218. feqq. Conf. Ephemer, Nat. Curiof. Centur. III. \& IV.Obferv. XCII, pag, 228. Talia exempla in fequiori fexu recenf. Petr. Borellus Cent. II. Obferv. XXII. Thom. Bartbolinus in Act: Med. \& Phil. Hafn, Vol.IV. Obr. LXXXIII. pag. 193. Johan. Anton. Clozius in Ephem. Natur. Curiofor. Dec. I. An. II. Obferv. CXXIV. pag.205. Decur.II. An. II. Obferv. CLXXX. pag. 392. Dec.II. An. IV. Obferv, XIV. it. Centur. III. \& IV. Obferv. LXXIX. pag. I57. Unfere Samml. von Natur-und Medic. Gefcbicbt.V. Verf. An. I718. Menf. Sept. Clart, IV. Artic. XIV. pag. 1656. it, XX. Verfuch. Au. 1722. Clafi.IV. Artic. XVI, pag.517. 
A. 93. Calculi varii Renum. defcr. \& del. Fob. Kentmannus de Calculis in Corpore humano fol. 9. Mich. Daeringius de Calculo Renum pag. 418. Ml. Aldrovandus in Mul. Metallic. Libr. IV. pag. 98. it. Ephem. Nat. Curiofor. Dec.II. An. VIII. Oblerv. CXCIX. pag. foo. De Generatione Calculorum renalium vid.Zacutus in Tract. cui Titul. Calculos non gigni in fubftantia, fed cavitatibus renum, Frid. Hofmannus in Obfervat. Phyfic. Chymicis fele Aiotibus Libr. II. Obferv.XXV. pag. 229. it. Obfirvatio mes in Bresl.Samml. vons Nat, und Medic. Gefch. XXVII. Verf. An. 1724. Menf. Jan. Clan.IV.

A. 9.4. Lapillus ex pulmone hominis. convenit cum defor. quam dedit fob. Henr. Brecbifeld in AC. Med. \& Phil. Hafnienf, an. 1671. \& 1672. Obf. XCIX. pag. 192.

A. 95. Calculus in vificula fellea humana repertus fubflavus, qui vermen includit. De generatione \& fubftantia Calculorum talium vid. Bresl. Samml, von Natur. and Medic. Gefcbiche X. Verl. an. 1718. Menf. OA. Clafr. IV. Art. VII. pag. 495. Jeqq. Multa huc fpectantia evolv. in Ephem. Nat. Curiofor. Dec. 1. An. 1. Obferv. XLIV. prc. in Schol. it. in Pbil. J.x. Sacbfii Gammarolog. Lib.I. Cap. XIV. S.3. pag. 291. \& pag.901, in Appendice. prc. ap. F. G. Scbenckiuri in Lithogenel. fo de Microcolmi membr. petrefact. Cap.X.pag. 21. \& Gotbofr. Voigtium in Phyfical.Zeit-Vertrcih. Cent.II. Quxft. XLI. pag.316. fegq. Vermes:ales in meatu cyftico, it, ip fis calculis inclufús defcr. Guil. Fabrit. Hildanus in Operibus, C. Operationum \& Curationum Medic. Chiru'g. Ohf. LX. pag. 48. del. \& defcr. in unferen Sammlungen von Nat, und Med. Gefcb. III. Verf. an. 1718. Menf. Febr. Claff. IV. Artic, VIII, p3g.694. it. im X. Verf als. 1719. Menf. Novembr. Claft. IV. Art. X. pag. 596.

A. 96. Calculi II. pyramidales ex veficula fellea vervecina crocei coloris, laves. vid. Obfervatio mea in Bresl. Samml. von Nat. und Med. Gefot. XXIV. Verl. an. 1723. Menf. Maj. Claff. IV: Art. III. pag. 523.

A. 97. Bezoar bovium C. Lapis e felle tauri, defer. Georg. Hier. Velfchius Obferv. Phyfic. Medic. Hecatoft. I. Obferv. XCHI. it, in Muf. Calceolarian. Veronenfi Sect. III. pag.38I. \& Mich. Bernh. Valentini Muf. Mufeor. Part. I. Libr.III. Cap. VII. pag. 433. Maximos defer. Volgnadius \& Sacbs a Lewenheimb in Ephem. Nat. Curiof. An. I. in Schol. ad Obfervar. XLIV. pag. II8. delin. Fob. Henr. Locbnerus in Muf. Beslerian. Tab. XXXIX. pag. 107. Frequentiffimos in Saxonia vidit Rofinus Lentilius in Paralelifmo ad Obr. in An.I Dec. I. Annex. Mifcel. Nat. Curiofor. Dec. II. An. X. in Append. pag. \{I. Conf. Micb. Bernb. Valentini Differt. de Lapide porcino, vulgo Pedra del Purco Cap.IV. pag. 18. De Ufu Medico vid. lllyff. Aldropandus Libr. de Bifulcis Cap.I. it. Petr. Bellonius Obfervationum Libr. III. pag. 46.

O. A. 98 . 


\section{PROMTVARIVM RERVM NATVRALIVM}

A. 98. Lapilli rotundi pillulas argento obductas refer. ex vefica urinaria bovina. vid. Objervatio mea in Bresiauifeben Samml. von Nat. und Med. Gersb. XXIV. Verf: Ann, 1723. Menf. Maj. Claf.IV. Arr. III. pag.j23. de Calculis varis brutorum vid. 7. Gcorg. Scbenkius in Lithogenefia.

A. 99 . Concretio oblonga tophacea ex ulcere inveterato mufculo. rum abdominis extracta.

A. roo. Cornua Rupicapræ. del. \& defcr. ap. Job. Fonflonum de Quadrupedib. Tab. XXXII. num. 3. pag. 79. Ad. Olearium Gottorp. Kunit - Kam. Tab. IX. unum.III, pig. i2. G.Jp. Scbottum in Phyfica curiofa Libr. VIII. Cap. XXVI \$.2. Tab.

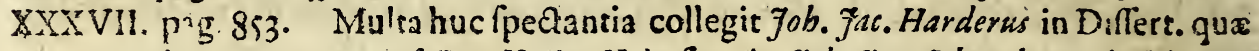
annexa Epheris. Nat. Curiof. Dec.II. An.II. in fine, it, Job. Jac. Stbeucbzerus in Itinerilius Alpinis Itin. III. pag. 7 .

A.10!. Cornu Afini \&gyptiaci Camphur diai. convenit delineat. \& deicript. Fob. Fonfonz de Quàdrupedib. Tab. XIL. Libr. I. Cap. III. pag. 27. Petr. Pometibim Miterialift, und Spez. Händl. Libr.II. Cэp.II. Tab. LIII. Fig. 329. pag. 471. \&2 ex co Mich. Bern. Valentini Muf. Mufeor. Part. II. Cap. XXVIII. pag. 141. Conf. Ysbrant Ides Reile nach China Cap.XVI. pag. 185.

A. I02. Cornua Capri Bezoardici circulis eminentibus obvoluta, intus cava. del. \& delcr. Ad. Olearins Gottorp. Kunft - Kamm. Tab. IX. num. VII. pag. 13. N.r.dus Ant. Recchus Rerum Medic. in Supplemento pag. 893. it. Libr.1X. C1;.XIV. pag. 325. Fob. Dim. Major in Ephem. Nat. Curiofor. Dec. I. An. VIII. Otferv. I. pag. 2. \& pag. 188. \& ex iis Micb. Bernb. Valentini in Muf. Mufeor. Part. 11. Cup XLV. pag. 193. Tab. XXXVI. it. Gob. Henr. Locbnerus in Muf. Beslerian. Ta'J.X nuin. III. pag. 38. Totum Animal, defc. Gwil. Pifo Hift. Nat. \& Med. Ind, Occidental. Libr. III. Sea. III. Ill. Aldropandus de Quadruped. Bifulcis Libr.I. Cop. XXII. F. E. Nicrembergius Hift. Natural. Libr. IX. Cap.LX. Gaf. Sibottus in Phyfica euriuf. Libr. VIII. Cap.XXVI.pag.885.

A. 103. Cornua Capreoli monftrofa numero tria, cranii particulx adhærentia, mire inflexa. Cornu tale monftrofum del. \& defer. in Bresl. Samm?. pon Nat, und Med. Gefib. XIX. Verf. An. i722. Menf. Febr. Claff. IV. Artic. V. pag. 180. Multa huc fpeetuntia collegit Micb. Bernb. Valentini in Mur. Mufeor. Part. II. Cap.XLV. pag. 193. feqq. it. J. H. Locbnerus in Muf.Besl. Tab.X. pag. 37. fenๆ.

A. ro4. Capreoli albi Cornua candidiffima. defcr. in Bresl. Samml.von Nat. and Med. Gefch. XVII. Veri. An. 1721. Ment. Sept. Claff. IV. Art. V. S. 2. pag. $28 \%$

A. ro 5. Unicornu marinum r. Pifcis Narval candidiffimum. defcr. \& del. Them. Bartbolinus in Obfervationibus novis de Unicornu, Of. Wormins in Mufeo 
Muleo pag. 282. Gafp. Scbotcus in Phyf. cur. Libr. XII. Cap. V. pag. 1373. feqq. Ad. Olearius in der Mofcowitifch-und Perfianifch.Reife. Befchr. Libr. III. pág. I7f. Ant. Deufingies de Monocerote, Micb. Bernb. Valentini in Muf. Mufeor. Part.I. Libr. III. Csp. XXX. pag. 482.

A. 106. Scorpio Ceylanicus niger maximus. conv. cum delin. ap. Valentinum Muf. Mufeor. Part. II. Cap. XXXVIII. Tab. XXXIII. pag. 168.

A.107. Scorpium cum ovis. del. \& defcr. uly]f. Aldrovandus de Infeais Animalibus Libr. V. Cap. XI. pag. 572 . \& 590. Job. Fonflonus H:\{t. Nat. de Infectis Tab. XVIII. Libr. II. Cap.II. Art.I. pag. 128. prc. Conr. Gefnerus Hiftosix Infector. in Libello quieft de Scorpione; De morfu \& foramine aculei fngularia collegit Ant. Vallisnerius in Ephem. Nat. Cariof. Cent. III. \& IV. Obf. XXXI. pag. \{8. it. varia obfervavit Oliger Gacobaus in Act. Med. \& Philof. Hafnienf. Vol, V.Obf.XCIX. pag. 262. Anatomen inftituit Ant. a Leewexboek in Epiltol.ad Soc. Reg. Angl. \& alios illuftres viros datis, $\mathrm{l}_{\text {. }}$ in Concinuarione mirandorum arcanorum Naturz detedorum Epiift. CXXII.

A. 108. Caput Vulpis Canadenlis crucifera. vid. rsbrands Ides Reife nach China Cap. IV. pag. 36.

A.109. Capput IRtis Brafilienfis.

A. IIO. Ovum Struthionis $\Lambda$ fricanum maximum flavelcens, totum punctulis nigris infperfum.

A. III. Ovum Struthionis tale candidiffimum, mire lævigatum, fine punctulis.

A.I12. Ovum Struthionis aliud album ftigmatibus leviffimis donatum. vid. Vielbeuers Befchr. fremd Materialien pag. 182, Marxii MazerialKam. pag. 187. Petri Pomet Material - und Spezer. Händl. Part. II. Cap. X XVII. pag. \{27. Tab. LIX. fig. 350. Ul. Aldrobandi Ornithol. Libr. IX. Cap.II. Micb. Bernb. Valentini in Muf. Mufeor. Part. I. Cap. XX. pag.460. Maximum, feptem hominibus fatiandis fufficiens, \& alia vid. apud Anton. Fureteriim in Distionario univerfali Struthí - Camelus pre. defcr. \& del. in Tbevonots Reifen Libr. Il, Cap.XXV. pag. 223. Relationem de Anatome Struthio. Cameli vid. in Eduard. Brown Colleat. Philofoph. Angl. Menf. Februar, an, 1682. No. V. pag. 147.

A. I13. Ovum gallinaceum caudatum. accedit ad defcr. \& del. in Bresl. Sammal. von Nat. und Med. Gefib. VIII. Verf, an. 1719. Menf, Maj. Claff. IV. Art. VI. pag. 587. it. XXIV. Verfuch. an. 1723. Menf. Maj. Claff. IV. pag \{26. feqq. A. II4. Ovum gallinaceum monftrofum aliud, cum appendicula oblonga. 


\section{-FO8: PROMTVARIVM RERVM NATVRALIVM}

A.115. Ovum gallinaceum monftrofum vermiculare. Ova alia nionfrofa \& portentofa evolvo in Ga/p. Sibotti Phyf. cur. Libr. V. Cip.XXI. Tab. XX. frg. XXXIV. \& XXXV. prag. 617. In Ephemerid. Nai.Curiof. Dec. I. An. II!. Obferv. CXC. pag. 354. feqq. it. Dec. II. An. I. \& II. ObI.XVI. pag. 36. feqq. in Mich. Bernb. Valentini Muf. Mufeor. Psrt. II. Cap. XXXVI. png. 159. feqq. in Bresl.Samml. von N.at. und Med. Gefch. If. Verf:an: 717 menf. Nov. Claft. V. Art, VII. pag. 328. ir. VIII: Verf. an. 1719. Menf.Mij. Clut.IV. Arr. VI. pag. $58.7 \%$

A. I 6. Ovum vulgo galli gallinacei, magnitudine nucem Mofchatæ: vix furperans, interne lapidem fluctuantem continens. vict. in $O 5$. Jervatione mea in Bres!. Samml, von Nato und Med. Gefchich. XX. Verf. An. i722. Menf. Jun. Caff.V. Artic.XV.pog.634. Silicem in ovulo gailinaceo defe. Georg. Wulfig. Wedelius in Ephem. Nat. Curiofor. Dec. I. An.IX. \& X. Obr.LXXXIII. pag. 220. de Ovo Galli alias Diflert. publicav, Eaurent. Siraufius, aliud nominavir Wíl, Bernb: Valentini im Bedencken von Kunft-und Naturalien-Kamnern Cap. X. p. 73. cirante Sim. Stbulazio in Ephem. Nat. Curiof. Dec. I. An.Ih. Obr.CXC. pag. 35. it. Bartbolinus in A ctis Med. \& Phit. Hafn an. 1673 Obf X. pag. 14. de Ovis multa quoque collegit Frit. Garmannus in Oologia curiofa. A.I17. Maffa nigra duriffma triangularis in ovo gallinaceo recens exclufo reperta, fimilis officulo ex corde cervi. defiripf in Brest. Samm . L. fup. cit.

A.113. Ovulum in ovo gallinaceo. tale defcr. Petr. Rivalieiz in Epiftol. ad Jac. Spoinium, qux una cum dabas Obfervationibus Medico Phyficis proct. \& excerpe. rep. in A\&t. Erudit. Lipfienf. An. 16,83. Menf. Jun. Pag. 219: Petr. Harrejus de Generat. Animal. Excrc. XI. pag. 85. Thom. Bartbolinus Epiftol. Medicinal. Cent. III. Epitt. XLII. \& Cent.IV. Epift. LXIII. it. in AË. Medic. E Pbilofoph. Haf-

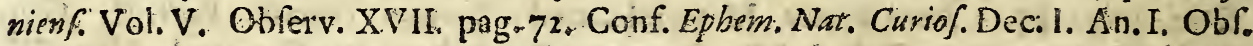
XXXVI. pag. 120. it. Obfervationem meam in Bresl. Samml. von Nat. und Thed. Gefcb. XXI. Verf. An. 1722. Menf. Aug Clafr. IV. Art. VI. pag. 173. feqq. it. Offervationem ibidem Menf. Ocrobr. Cl.IV. Artic. V. pag. 414. feqg.

A.II. Bufo quem vir Skarfchinæ in Ducatu Olsnenfi Silefix, una cum aliis, magnos poft cruciatus per vomitum ejecit. Defcr, \& deFin. in Brest. Simml von Nat. und Med. Gefobicht. XIV. Verf. An. 172C. Menf, OQt. Cl.IV. Art. V. pag. 437. feqq. ir. XV. Veri: An. I721. Menf. Jan. Claff. IV. Artic.IX. pag. 77. Hittorins fimiles recenfent Hinr. Volgnad ir Ephem. Nat. Curiof. Dec. 1. Ann.I. Obferv.CMI. pag. 236. feqq. it. Georg. Segerus E. C. Dec. I. An. II. Obf. LVI. pag. H3. Conf, Appendic Decur. II. An. VI. Obferv. L, pag. 66. Decur. III. An.IV. Obf.XXIIT, pag 5T. feqq. it. AdI. Med. E Pbilof. Hafnienf. An. 1673. ObErv. XXXIX. pag. 108. feqq. Andr. Libavium Singularium PartIV. f. Batrachiorum 
Libr.Il. Cap. XV. pag. 3iб. feqq. Pecr. Borellum in Hiftor, \& Obfervat. MedicoPhyficis Cent. III. ObI. XXXI. pag. 222. Kergerum de Fermentation. Voigtium im Phyficalifch.Zeit-Vertreib.Cent. IT. Quxeft. XLI. pag. 32 I. Nov. Lit. Mar. Baliic. An. 1700. Meirf. A pril. pag. 100. feqq. Hamburgifib. Kemarquen A11.1700. Menf. Mart. pag. 82. Uinfere Samml. von Natur-und Medic. Gefobicht. III.Verf. An. 1718. Cıafr. IV. Artic. IX. p.g.695. VI.Verf. An 1718. Meir. OQ. Clarr. IV. Artic. XV. pag. 17G. it. XIX. Verl. An. I722. Mef. Mart. Claff. IV. Art. X pag. 3or. feqq. prc. evolvend. Rofrnus Eentilius in Milcell. Med. Pract. Part. I. pag. 81. feqq. ubi ex Salmutbo, de Sorbait, Scbenkio, Rïverio Zacutbo Lufitano, Olig. Facobeo, Hildano, aliisque ejusmodi recenfet exempla, it. Mclcb. Sebizius de Calis adolefentis cujusdam Argentinenfis mirabili. Conf. Obfervatio mea in Breslo Samml. XXI. Verf. An.1722. Menf. Jul: Clarf. IV. Art: V. pag.72. it. XXV. Verf. Ann. 1723. Claf.IV. Artic. VHIt. pag.197.

A. 120. Sceletus ranæ viridis majoris $\Gamma$. Calamitidis, per nitedulas paratum. Multa huc fpectantia collegit Libavius loc. paul. fupr. citato pag. 350 feqq. Anatomen Ranx vido in AEt, Erudit. Lipfienf. An, 168\%. Menf. Mtij: Fui. VI. pag. 284.

A.12I. Rana peregrina colore fubcceruleo., vid. Andr. Libavius Singul. Part. IV. pag. 18I: feqq: aliique, prc. de Ranarum Ámericanarum mira magnitudine \& mugitu vid. Lud. Henepini Defcriptionem Eowifranam.

A. I 22. Bufo Indiz Oriental colore cinereo \&albo variegatus; ore parvo.

A. 123. Bufo peregrinus cinereus, crucibus albis in dorfo infignitus.

A. 124. Pennæ Hyftricis Africanæ゙ oblongæ. defcr. \& del.cum Hyftrice Micb. Bernb.Valentini in Muf. Mufeor. P’art. I. Cap. XIIX.pag.45\%.

A.125. Avis Paradifiaca f. Manucodiata. del. \& defc. ully. Aldrovandis in Oinithol. Carot. Cluffus Exoticor. Áuetar. pag. 359: Fob. fonflonus de Avibus Libr.VI. Cup. I. pag.169. Franc. Hernandez. Rer.Med. Nov. Hifpan. Libr. IX.Cap. V1. pag. 318. Mufeum Calceolar. Veronenfe Sedt.VI. pag. 673. Claude du Molinet dans le Cabiner de la Bibliotheque de Sit. Genevieve Part.11. Tab. I. Micb. Bernb. Valentini in Muf. Mufeor. Part. I. Lib. III. Cap. XXI. pag.463. Fob. Fenr. Losbne zus in Muf. Bester. Fab. XI. Fig. I. pag.32: Dian. Gï̈tzmannin Dif. de Avibus Pa. radifiacis harumque Rege. Varia fabulofa, pre. quod pedibus careane, collegir Pbil. Jacob. Sacbs a Leweinbeimb Gammar. Cap. II. pag. 28, it. Gafi. Scoutces it Phy. ñea curiofa Libr. IX: Cap.Ell. \$.3. pag.10Ir. An'aëre, vel rore vietitenc, vid, Bened. Hopfferi Differt.de inedia Chamxleontis S. T3.pag.9.

A. 126. Roltrum Hungum, $f_{8}$ Avis Rhinocerotis Aldrovaldi, vid, ejus\% 


\section{PROMTVARIVM RERVM NATVRALIVM}

dem Ornithologiz Part.I. Libr.XII. Cap. XX. pas. 805. del. quoque \& defer. Ol. Wormius in Muleo pag. 293. Ad. Olearius Gottorp. Kunt - Kam. Tab. XV. num. IV. pag. 24. Micb. Rup. Beslerus in Gazophylacio, Micb. Bernb. Valentini Mur. Mufeor. Part. I. Libr. IIf. Cap. LII pag. 425 . Fob. Henr. Locbnarus in Muf. Bisler. Tab. X. num. VII. pag. 57 . Cum Capite fub nomine Curvi cornuti, Jac. Bontius Hift. Natural. \& Medic. Indix Oriental. Libr. V. Cap. XI. pag. 6.t. Conf. Georg. Ax. derfen Oriental. Reifen Libr. I, Cap. IX. pag.Ir. it. Nebem.Grew Muf.Regalis Societatis pag. 45 .

A. 127. Roftrum dentatum Picæ Brafilienfis Toucam dicta, colore flavo, puniceo \& nigro ftriatum. del. \& defer. Ul. Aldrovandus Ornitholog. Part. I. Libr. XII. Cap. XX. pag. 80r. Fob. Fonflonus de Avibus Tab. LVI. pag. I7I. Ad. Olearius Gottorp. Kunt-Kam. Tab. XIII. num. 7. Nard. Ant. Reccbus Rer. Medic. Nov. Hifpan, pag. 697. it. Nebem. Grew in Muf, Regalis Societatis pag. $\{9$.

A. I28. Roftrum corvi Americani, inferius nigri, fuperius aurei co. loris. vid. Fac. Bontius Hit. Nat. \& Medic. Ind, Oriental. Libr. V. Cap. X. pag. 62.

A. 129. Roftrum Abardeolæ f. Pelicani Ornichologi Aldrovandi. vid. Ejusd. Ornithol, Tom.III. Libr. XX. Cap.XIII. pag.384 „. Roltrum Platyrinchi, fecund, Gcfnerum, Wormium \& Locbneram.vid. Mul. Besler. Tab. IX. pag. 36.ir. Ad. Olearii Gottorp. Kunft Kam. Tab. XIII. pag. 22. num.4. \& Galp. Scbotti Phyf. curiol. Libr. IX. Cap. LX. pag. I023. feqq. del. Tab.LIV. pag. 1029.

A.I30. Caput Pavonis non vulgare. Pavonem alias defcr. Colerus im HausBuch Lib. XIII. Cap. XLIIX. psg. 302. Job. Jonftonus de Avibus Libr.II. Cap. I. Tab.XXII, pag.56. it. Mi.b.Bernh.'Valentini Muf. Mufeor. Part.I.Libr. III. Cap.XXI. pag. 462. Anatemen publ. Casp. Bartbolinus in Thom. Bartholini Aat. Med, \& Phil, Hafnienf, an, 1673. Obf.CXIV. pag. 288.

A. 131. Vefpertilio cum auribus longiffimis monftrofis.

A.132. Caput Delphini juvenis, vel potius Phocænæ, dentibusinftruetum. del. \& defcr. Conr. Gefnerus Hift. Animal. Libr. IV. qui eft de Aquatilib. pag. 38r. Ul. Aldropandus de Cetis Libr. I. Cap. VII. Ad. Olearius Gottorp. Kunft.Kam. Tab. XXIII. num. I. pag. 34. Fob. Jonftonus de Pifcibus Tab. XLIV. pag.218. Fob. Henr. Locbnerus in Mur. Besler. Tab. XVII. pag.67. Anatomen Delphini vid. in Ephem. Nat. Cusiof. Dec. I. An. III. Obf. XX. pag. 25. plura qui legere defiderat, evolv. Steph. a Scboenfeld Ichthyol. \& Nomenclatur. Animal. ma. rinor. Holfatix. pag.77. Olig. Jacobai Muf. Dan. Ol. Wormii Muf. Libr.ill. Cap. XV. pag. 288. Gafp. Sibotti Phyf. Cur. Libr. X. Cap. XII. pag. 1085. feqq. aliosque, prc. Anatomen Tyfonis: Et fi quis fabulis fimilia amat, adeat Ariftotelem, Plini- 
um, Elianum, Ge'lium, aliosque qui de amore Delphinorum erga homines \& muficam plurima annotarunt.

A. 133. Dens Hippopotami. del. \& defcr. ex Gobi Ludolf Hift. Wthiopica Libr. I. Cap. II. num. 2. Micb. Bernb. Valentini in MuI. Mufeor Part. II. Cap. XXVI. psg. I36. conf. Tbevenors Reifen Part. II. Cap.LXXIl,it. Everb.Wilb.Happelii Theatrum Exoticorum pag. 84 .

A. 134. Monachus marinus. del. \& deícr. Ad. Olearius Gottorp. Kunft. Kam. Tab.XVI. num. I.

A. 135. Fœtus erinacei echinis duriffimis \& acutiffimis jam inftruEtus. Defcriprionem Anatonicam Erinacei noftratis, publ. Ol. Borricbius in Aat. Medic. \& Philofoph. Hafivienf. An.1671. \& 1672. Obf.XC. pag, 179. feqq. Siamenfrs, Ticbardus in Itinere altero Siamenfi Libr. VI. pag. 250. fegq.

A. 136. Fœtus equinus paucorum dierum.

A.137. Fœu caninus menfis.

A. 138. Scarabæus maximus Indiæ orientalis alis læviffimis.

A. 139. Scarabaus monoceros $f$. unico cornu in vertice capitis armatus. defcr. \& del. Ol. Wormius Muf. Libr. MI. Cap. II. pag. 242. Fob. Fonftonus de Infectis Libr. XV. num. 2. C. Scarabzus Rhinoceros Ferr. ImperatiHiftor. Nat.ral. Libr. XXIIX. pag. 924.

A. 140.141 . Scarabæus cervinus $\int_{0}$ bicornis vulgaris, mas \& fœmina. del. \& defer. id. Imperatus L.C. Nard. Ant. Reccbies de Animal. Nov. Hifpan. pag. 832. feqq. Fob. Fonflonus de Infeetis Libr. I. Tab. XIV. num. I. \& 2. pag. 95. Ad. Olearius Gottorp. Kunft-Kam. Tab. XVI. num. 5. pag. 25. Conf. Ol. Wor. mii Muf. Libr. III. Cap. II. pag. 242. it Muf, Calceolar. Veronenf. Seat. VI. pag. 668.

A. I42. Scarabæi cervini cornua, non vulgaris magnitudinis.

A. I43 Scarabæus buceros naficornis maximus. Olearius L. C.num. 1. T. Taurus volans Brafilienfis fonfoni Hil. Nat. de Infeetis Tab.XVI. fig. 1. Libr. I. Cap. V. pag. 100.

A.144. Scarabxi aquatici \& carabi variii. del. \& defcr. ul. Aldrodandus de Infect. Animal. Libr. IV. pag. 450 . feqq. it. Joh. fonfonus de Infectis.

A.145. Scarabxi picti colore rutilo \& albo variegati, hic Vratislariæ An.1716. Capti, r. Scarabxi majales Indix Orientalis. del. \& defer. in Ephem. Nat, Cariofor. Dec.I. An. VI. \& VII. pag. 348.

A.146. Scarabæi tales nigri notulis albis infigniti.

A. 147. Nidi avicularum edules Indiæ Orientalis f. Regionis Coro:

mandel 
mandel hemifpharicus, ofteocolla glutinofam fubltantiam referens. del. \& defcr. Ad. Oléarius Gottorpilch. Kunft. Kam. Tab. XIV. num. G. pag. 24. Chr. Fr.Paullini Zeic kürtzende erbauliche Luft, Parr.1. pag.837. it. Part.II. Them. XCVIII. Ol. Wormius in MuS. Libr.III. Cap. XXI. pag. alls. Pbil. Gac. Sacbs a Le. wenhb. Gammar. Lib.II. Cap.I. \$.8. pag.\$2. 7ob. Heinr. Seyfried in Medul, Mirabil. Natur. Libr.II. Cap,V. \$.30. pag. 617. Aviculam defcr, Joh. Matb. Faber in Pili marinx anatome, qux reperitur in Ephem. Nat. Curiof. Dec.II. An.X. pag.20I. in fine, \& cum nido Petr. Pomet in Mater. und Specerey Händl, Part.II. Cap.XXI Tab. XLIX. fig.354. pag.331. Gottfr. Foigtius im Phyfical.Zeit Vertreiber Cent.III. Quxft. XCVII. pag.800. Erafm. Franciffi in Ausländifch. Kunft-und Sitten-Spiegel Libr. 11. Scet. XXXIII, pag. 743 prc. Ath. Kircberus Chin. illuftrat. Part. IV. Cap. VIII. pag 191. Scopulos cum nidis adhærentibus, del, \& defcr. Jac. Bontius. Hiftor. Nat. \& Medic. Ind. Oriental. Libr.V. Cap.XIII. pag.66.

A. 148. Nidus Pfittaci ex goffypio compalus in Guinea frequens id. Olearius Gottorp. Kunft-Kam. Tab.XIV. pag.24.

A. 149. Tarantula Perfica venenatifima prope urbem Cafan frequens. del. \& defcr. Erafm. Francifi im Ausländifchen Kunt-und Sitten-Spiegel, Libr.IV. Sect.II. pag 1224. citante Ad. Oleario Mofcowitifch-und Perfianifch. Reife-Befchreib. Lib. IV. fol, 496 . it. Engllb. Kämpfer Amoenisat, Exoticar. Politic. Phyfic. Medic. $\$ .4$.

A. 150. Tarancula ex Apulia exficcata \& alix in liquore balfamico confervatæ deler. Herm. Grube de ICtu Tarantula \& vi Mufices in ejus curatione, 7. W. Sengverdus de Tarantula, Mufeum Calceolar. Veronenf, Sect. VI. pag. 666. Atb. Kircherus in Art. Mig. Lucis \& Umbrz Libr.III. Cap.II. pag.8. Fr. Tertius de Lazis in Magifer. Natur. \& Artis Tom.II. Libr.X. Cap.I. pag.431. feqq. prc. Georg. Baglipius Diflert.VI. de Anatome, morfu \& affectibus Tarantula, qux reperitur Operum pag.599.eqq. \& Lud. Valetta de Phalangio A pulo, in quo pleraque hifto- rice, plerague philofophice de hoc infecto, ejusque miro veneno enarrantur ac difcutiunzur; quedam quoque de Tarantulis earumque affectu \& cura fubiiciuntur in Wrolfg. Francii Hiftoria Animal. Part.IV. Cap.VIII. in fine, it. in Paul. Bocconis curiöfes Anmerckungen Obr. XV. De Morfu Tarantularum vid. Differtar. Fob. Mulleri \& Cbriftian. Andr. Scboengafts, de Morfu Tarantularum, it. Kircbmajeri Differt. de Araneis Wisteb. habit. quibus addendi Auctores quos Gotbofr. Voigtius in Phyficalifchen Zeir-Vertr. Cent.II. Quxt,XLVII. pag337. collegit, Confo. Ferrand. Im. perati Hilt Nat. Libr.XX VIII. pag.920. Ephem. Nat. Curiof. Dec.I. An. IX. \& X. Obf.CXVI. pag,28r. it Mich. Bernb. Valentini Muf. Mufeor. Part. I. Cap. XLIII. pag. 514 . Feqq.

1.. Is I. Aranea Regni Sardiniæ pedibus longiffimis. conv. cum del. \& defcr. 
defcr. Guil. Pifonis in Hift. Natural, \& Medic. Libr.V. Cap.X. num.2. pag.285. de fumma virulentia vid. Paul, Bocconir curiofe Anmerckungen fuber natiurliche Diage Obf.XVI. XVII, XVIII.

A. I 52. Arachnites verus f. Aranea exficcata lapillum referens. authores vid. huj. Libr. Claff.III. Artic.IIf, num.i.

A. 153. Aranea Brafilienfis maxima, ibidem Nhamdu-Guaca dieta, del, \& defcr. Car, Clufius Exoticor. Libr.V, Cap.XVIII. pag.46, \& II3. Ol. Wormius in Muleo Libr,III, Cap,IX. pag.263. Ad. Olearius Gottorpilch. Kunft-Kammer Tab.XVII, pag, 27. Rochefort Befchreibung der Antill, Inful, Cap.XIV. num.5. pag. 229. Foh. de Laet in Nov. Orb. f. Defcript. Ind. Oecidental. Libr. XV. Cap. XII. pag.507. Guil, Pifo in Hiftor, Nat. \& Medic. Brafil.Libr.V, Cap.X. pag.284. Georg. Marcgravius in Hift. Brafil. Erafm. Francifci im Ausländifchen Kunft-und Sitten.Spiegel Libr,IV. Sect.II. 'Tab.XXXIII. pag.1229. Andr. Cleyerus in Ephem.Nat. Curiof, Dec,II, An.II, Obf.VII. pag. 18. Conf. Rofini Lentilii Obferv, in Paralefilm. annex. Ephem. Nat, Curiof. Dec.UII. An.III, Obr.LXXXV. it. Obferp. meam in Bresl. Samml. von Nat. und Med. Gefcb, XXIV. Verfuch, An.1723. Menf. Maik Clafr.IV. Arr,III. pag. 523. Alia fingularis magnitudinis defcr. in $\mathbb{V}$ ilh. Boffmanni Reife nach Guinea Epift,XVII. pag.383.

A. 154. Afellarum lapides majores gibbof, f. Lapides D. Petri. Conveniunt cum Lapidibus Corvili \& Umbre pifcis, ap. Ul. Aldropandum in Muf.Metall. pag.796. del. \& defer. in Bresl. Sammlungen von Nat. und Med. Geftb. XVIII. Verf. An.1721, Menf. Dec. Claff.o. Art.VII, num,3. pag.612, de Ufu in Medicina vid. Georg. Hier. Velfchius Obferv. Phyf. Medic. Hecatoft.I. Obf. XXVIIf. Job, Heinr. Locbnerus Muf. Besler. Tab.XXXIX. pag.I06.

A. 155. Afellorum pif́cium lapilli minimialbi incurvi, laves, in limboleviter crenati, ex cerebro pifcis, accolis Dorfch dieti, refte Majore in Memorab. Anarum. Obl.V. de Animal. Littor. Kilonienf. \$.7. conf. del. \& defcr. ex Conr. Gefneri de Figur. Lapid. Libr.XIV. pag.182. Ol. Wormium Muf. Libr.I. Cap. VIII, pag.59, it. Jab. Heinr. Locbnerum Mú, Besler. Tab.XXXIX. pag.107.

A. 156. Eruca prope Vratislaviam an, 1720. arboribus prc. piceis peftifera, defcr, in Bresl. Samml, von Nat, und Mcd. Gefch. XII. Verfuch, An.I720. Menf. Juv. Clan.IV. Art.V. pag. 663. feqq. Convenit c. delin. quam dedit Johann Leonh, Frifcb in Befchreib, von allerley Infecten in Teutfchland pag. I4. Erucas tales in Saxonia frequentes defcr. in Bresl.Samml. von Nat. und Med. Gefcb. XI. Verf. An. 1720. Menf. A pril, Claff. IV. Artic. II. pag. 472. feqq. in Palatinatu Super. Ibid. XVI. Verf. An.i721. Menf. Jun. Clafr. IV. Art.XII. pag. 639. in Helvetia id. XIX. Verf. An.1722. Menf. Mart. Claft.IV. Art.V. pag.285. 
A. 157. Eruca peregrina longiffima. vid. ulyff. Aldrovandus de Infca.Libr. V. Cap.XV. num.7. pag.636.

A. 158. Chamæleon Amboinus fec. delin. Mich.Bern.Valentini Muf. Mufeor. Part.I. Libr.III. Cap.XXXI. f. Chamæleon Javenfis Bontii, vid. Hifor. Natural. \& Medic. Ind. Oriental. Libr.V. Cap.VI. pag. 58.

A. 159. Chamæleon coloris cinerei, dorfo ferrato. del. \& defcr. Nard. Ant. Reccbus de Animal. Nov. Hifpan. pog 72i. Fob. Jonfionus de Quadrupedib. Tab. LXXIX. Libr.IV. Cap.VII. pag.198. Petr. Bellunius Obf. Lib.II. Cap. LX. pag.125. qux reperitur in Clufii Exoticor. Opere, it. ex co Jac. Bontius loco paulo fupr. cit. Ad. Olearias Gottorp. Kunft-Kammer, Tab.VIII. num.2. pag.8. Muf. Calceolar.Veronenf. Sea.V1. pag. 658. feqq. Claud. di Molinet dans le Cabinet de la Bibliotheque de St. Genovieve Part.II. Tab.II. Ol. Dapper in Befchreib. von Africa pag.118. Joh. Heinr. Locknerus in Muf. Besler. Tab.XX. pag 44. Jac. Breuning in Oriental. Reif. II. Meerfarth Cap.XVII. p.130.\& Cap.XXVII. p.172. WVilb. Boffmarn in der Reife nach Guinea Epift. XIV. pag.205. Partes Chamxleoutis diffect. del. \& defcr. Anonymas in Anatomica defcriptione Chamxleontis, Caftoris, Dromedarii, Urfietc. qux excerpta legitur in AZ7. Pbilof. Soc. Reg. in Angl. An.1669. pag.830. it. Fob.Nic. Pecblinus in Obferv. Phyfico Medicis Libr.II. Obf.I.XX. De vietu aëreo, f. mirabili inedia, vid. Pbil. Pigafetta in Defcr. Regn. Afric. Part. I. Cap.XI. pag. 23. ir. Gob. Leo dfricanas, in Defer. Africa Part. II. pag. 765 . prc. Differt. Bened. Hopfferi Tuhingx 1681. hab. Multa huc fpectantia collegit Gotbofr. Vo: gtius in Cur. Phyf. Cap. V. pag.157-200. Cbrift. Franc. Paullini inZeit-kürtzend. erbaul.Luft. Part.1II. Them. CXXVIII. Pbil. Jac. Sacbs a Lewenbeimb in Gammárol. Lib.11. pag. 28. De Colorum mutatione, vid. Whelerus of Sponirus dans le Voyage de Dalmatie, de Grece, \& de Levant. Waltb. Sibultz in Oft Indifch. Reifen, Libr.IIl. Cap.XVI. pag.233. Borsius Libr. \& Loc. cit, it. Breuning L. C. conf. Mich. Bernb. Valentini Muf Mufcor. Part.I. Libr.III. Cap.XXXVIII. \$.9. pag. 904 . feqq. \& Obfervationem mesm in Breslo Sansml. von Nat. und Med. Gefch. XXIII. Verf. Clalf.IV. Art.VI. pag.305.

A. 160. Lacertus Cyprius Scincoides fonfloni Hiftor. Nar. de Quadruped. Tab. LXXVI. num. 12. feu Scincus maximus Locbmeri Mur. Besler. Tab. XII. pag. 44.

A. 16r. Scincus marinus Egyptiacus albus, fec. del. \& defcr. Hans gac. Breunings Oriental, Reif.II. Meerf. Cap.XVIII. pag.137. Job. Henr. Locbneri Muf. Besler. Tab.XII. pag. 44. it. Petr. Pometii im Materialift. und Spez. Händl. Part.1L. Cap.XXIX. pag.517. Tab.LVII. fig.369. C. Crocodylus terreftris minor BetJonii de Aquatil. Libr.I. it. Jonftoni de Quadrupedibus Tab.LXXVIII. pag.196. \& 1d. Olearii Gottorp. Kunft. Kammer Tab. VIII. pag. 8. num. I. T. Salamandra Wurffbainii Salamandrolog. Cap. VI. 5.8. pag. 57. De ufu fuperftitiofo vid. Of. Wermitrs in Mufeo Libr.tIL. Cap.XX. pag.3150

A.162. 
A. 162. Crocodylus terreftris Agyptiacus fquamis in Ipinam acutiffimam ubique definentibus. del. \& defcr. Fob. Henr. Locbnerus in Mur. Beslerian. Tab.XIII. pag.5:. Convenir cum delineatione Bufonis caudati, quam dedit Conr. Gefnerus Hiftor. Animal. Libr. II. pag.46. it. Fob. Jonßonus de Quadruped. Tab.LXXV.pag.186. \& I Lacertæ Chalcidicæ Eerrand. Imperati Hiftor. Natural. Libr.XXVIII. pag.919,

A. 163. Dracunculus $f$. Lacerta volans, expanfis alis, ingluvieque expanfa Indiæ Orientalis. del. \& defcr. Pctr. Belloniu Obferv. Oriental.Libr. II. Cap. LXX. prc. Jac. Ponitics Hihur. Nat. \& Med. Ind. Oriental. Libr.V. Cap. VII. pag. 99. it. ex Petiverii Gazophylaceo Nat. \& Art. Valentini in Muf. Mufeor. Part.II. Cap.XXVIII. Tab.XXXIII. fig.IV. pag.168.

A. 164. Lacerta domeftica nigra, maculis aureis depieta, C. Salamandra Indis Jecco dieta. del. \& defcr. Ferrand. Imperatus Hift. Nat. Libr. XXVIII, pag. 918. Atban. Kircberus in Chin. illuftrat, Part. IV. Cap.XI. pag. 20\%. 7ok. Ludolfus Hiftor. Etthiopic. Cap. XIII. pag. 167: Adam. Olearius in Gottorpilch. Kunft-Kam. Tab.VIII. num.IV. pag.8. Gearg.Anderfen Oriental. Reis.Libr. I. Cap.VII. pag.8. aliique. De fumma virulentia vid. Jac.Bontii Hiftor. Nat. \& Medic. Ind. Oriental. Libr.V. Cap.V. pag. 57 . Fabulas de Salamandra incombuftibili collegit Pbil. Jac. Sachs a Levenb. in Gammar. Cap. II. S. I. pag. I4. Feqq. Gafp. Scbostus in Phyfic, curiof. Libr.VII. Cap.VIII. pag.706.feqq. Cbrift. Eranc. Paulli$w i$, in der Zeit-kürtzenden erbaul. Luft, Part. III. Them. CXXVIII. it. Tilingius in Ephem. Nat. Curiof. Dec.II. An.II. Obf.LX. pag.170. De Salamandrefpeciebus diverfis, qux ignem fuftinere \& non fuftinere poffunt, vid. jam Arifoteles Hiftor. Animal, Libr.V. Cap.XIX. it. Plinius Hift. Natur. Libr.X. Cap.LXVII. \& ex Recentioribus Heinr. Oldenburgius in Act. Philofoph. Soc. Reg. in Angl. An.1667. Menf. Januar. pag.3II. Hier. Ambrof. Langenmantelius in Ephem. Nat. Curiof. Dec.II. An.VII. Obl. CXXXII. p3g. 439. pre. Fob. Paul. Wurffbainius Salamandrolog. pag. 116. \& fob. Sponius dans le Voyage Part.I. pag. 79. Anatomen Salamandrx inftituit Olig.jacobans in Act. Med, \& Phil. Hafnienf. Vol.IV. Obf.II. pag.s.

A. 165. Lacerta Indica tota coerulea maculis nigris triangularibus in dorfo confpicuis.

A. 166. Lacerta Indica colore fubnigricante, cauda longiffima. conven. cum delin. \& defcript. Job. Henr. Locbneri in Muf. Besler. Tab.XI. pag.42. A. 167. Lacerta mafculini generis peregrina, ex rubro \& fufco variegata, cum membrogenitali bifurcato prominente.

A. 268. Lacerta colore albo \& nigro eleganter diftineta \& punetata $\mathrm{P}_{2}$ Brafi- 


\section{I16 PROMTVARIVM RERVM NATVRALIVM}

Brafilienfis, convenit cum ea ap. Carol. Clufum Exoticor. Libr.V. Cap.XXI. pag. .IIs. it. Foh. Henr. Lochnerum in Mur. Besler, Tab.XI. pag.43.

A. 169.170. Lacerta Chalcidica major \& minor. del. \& defcr. in Mufeo Calccolar. Veronenf.Sect.VI. pag.656. I. Crocodylus terreftris $\mathbb{E g y p t i a c u s}$ Locbneri in Mur. Besler. Tab.XIII. pag. $\{1$.

A. 17I. Cordylus minimus coeruleus cauda ex dimidia parte fufca \& alba. vid. Conr. Gefnerus Hiftor. Animal. Libr. VI. qui eft de Pifcium \& Aquatilium Animantium Natura pag.357. Gob. Fonflonus Hift. Nat, de Quadrupedib. Tab.LXXVIII. Lib.IV. num.VI. Cap.VI. pag.197.

A. 172. Crabronum nidus mire ftructus. convenit cum delineac. ap. $\mathrm{Al}$ drovandum de Animalib. Infect. Lib. I. Cap. VII. pag.229. feq9. it. Fob. Fonftonum de Infect. Libr.I. Cap.IV. Tab.II. pag.34. Cunf. Guilo Pıfonis Hiftor. Nat. \& Medic. Ind. Orient. Libr.V. Cap.XI. pag.287.

A. 173. Pes alcis cum ungulis. vid. Petr. Pomet im Mater. und Spezerey. Händl. Part.II. Cap.VII. Tab.LV. fig 338. pag.495. 70b. Wigandus in Hift.Succini, ubi fimul de Alce Borufliaco, Cbr. Vielbeucr in Befchreib. fremd. Material. pag. 168. Galp. Scbottus in Phyfic. curiol. Lib. VHII. Cap.I. pag. 778. feqq. delin. Tab. XXIV. Ulidaricus Heinfus in Diff. de Alce. De ufu Medico, Apollonius Menabenus in Tr. de Alce, prc. Andr. Batcius de magna beflia ab antiquis Alce, Germanis Elend vocato, ejusque ungulæ pro Epilepfia abigenda viribus, ic. Scbottus L.C. rag. 782. Vanitatem hujus ufus demonftr. Martinierre in Reifen in die Nordifchen Landfchafften, Cap.III. pag.s. it. Commentatio mea de Intellectu hominis ante \& poft lapfum Libr.Il. Cap.III. S.6. pag. ed, novif. 235 .

A. 174. Ungula Lyncis maxima argento obducta.

A. 175, 176. Uva marina, Meer-Träubel, .. Ova fepiarum racematim compa\&a alba \& flava. defcr. \& del. Aldrovandus de Animalibus InfeEis Libr.VII. Cap.XVII. it. Fob. Fonflonus Hift. Nat. Libr.IV. Tab.XXVI. Cap.III. pag.199.

A. 177. Bugloffa Gefneri Hift. Animai. Libr.IV. pag. 784. it. Rondeletii de Rifcibus Marinis Part.I. Lib.XI. Cap.XV. pag.324. C. Lingula Aldrodandi de Picibus Libr.II. Cap, XLIII. pag. 237. I. Solea lingulata fonfoni de Pifcib. Tab. $\mathrm{XX}$. num.12.

A. 178. Thurus marinus $\mathrm{f}$. Pifcis quadrangularis cornutus et ftellatus Indiz Oriental. defcr. Ol. Wormius in Muf. Libr.III. Cap.XI. pag. 276. A. 179. Pifcis triangularis ftellatus non cornutus, prope Moluccas Infulas frequens, ibid. Guamajacu-A pe dictus. del. \& defcr. ul. Aldropandus de Pifcibus Libr.IV. Cap, ultim. Ol. Wormius in Mufeo Libr. III. Cap.XI. 
pag.274. Fob: fonfonus de PIfcibus Tab.XLV. Car. Clufuis Exoricor.Libr,VI:Cap. XXVII. pag. 142. Guil. Pifo it Hiftoria Naturali \& Medic. Ind, Oriental, Libr. V. Cap.XVİ. pag. 300.

A. 180. Pifciculus cornutus alius, $f$. Pificis triangularis minor, duobus cornibus armatus, Indize Oriental. vulgo, Columba marina. Id. Clufius L. C. it, Jac, Bontius Hift. Nat, \& Med, Ind, Oriental, Libr. V. Cap.XXVI. pag.79.

A. I81. Loculta Egyptiacæ caudatæ, \& Hon caudatæ. del. \& defcriAd. Olearius in der Gottorp. Kunft.Kam. Tab.XII. num.5. pag.20. Fob. Fonflonus Hift. Nat. de Infectis Libr.I. Cap. 1. Tab.X̀I. pag. 82. Cbriftoph. Henr. Loeberus in Beo fchreib. des Heufchrecken. Heers. Singularia collegit Leo Africanus in Defcr. Africx Part.II. pag.769. prc. Fobus Ludolfus Hiftor. Ethiopicx Libr.1. Cap.XIII. it. in Commentar, ejusd. pag.180. \& in Lib. de Locuftis, it. Bresl. Samonl, von Nat. und Medic. Gefch. XVI. Verf. An.1721. Menf. Maj, Claff.IV. Art.IX. pag.534.feqq. Detrimenta integris regionibus illata recenfentur in $W^{2}$ olff. Franzii Hiftoria Animal. Part.IV. Cap.IV. De locuftis immenfo agmine aëretn in Saxonia implentibus, \& quid portendere putentur exhib. Fob. Paulus Hebenftreit in Differt. Jenz habita, it. Ludov. Cbrift. Crellius in Diff. de Locuft is non fine prodigio in Germania, it. Pbil. Job. Treunerus in Difr. cui Tic. Phrenortiena Locuftarum. De Pratagiis Locuftarum incertis \& fallis Diff. publ. Fob. Cbrifopb. Ortlob. conf. Willb، Erneft. Tenzelii Monatl. Unterred. an.1693. Menf. OA. pag.838.feqq.

A. 182. Locultarum alæ literatæ, quæ An. 1693. per Bohemiam in Silefiam \& Saxoniam irruerunt. Alas literis hebraicis fimilibus inferiptas del. \& defcr. Job. Ignatius'Mufcbel de Mofcbau in Ëphem, Nat. Curiof.Dec. II. An. IX. Obf. CXX. fig. XXIX. pag. 204. Reqq. alias figuras exhibuit Lebmannus in Hiftorifch. Schau - Platz des Ertz-Gebürgifchen Meifnifch. Crayfles XI. Abcheil. Cap. VIIl. pag. 648. Conf. Chrift. Frid. Paullini Zeit-kürtzende erbaul. Luft Parr. II. Them. XII. \& CVII. Carol. Raygerus in Ephem. Nat. Curiof. Dec.III. An. II. Obr. XXII. pag. 29. Treunerus in Diff. Supr. alleg. Mich. Bernb. Valeñtini Muf. Mufeor. Part. II. Cap.XXXIX. pag. 169. Species XVI. Locuftarum defcr. Gob. Scbrammerdam Hift. Infectorum pag. (ed. Gallic.) 18, it, Bresl. Samml. Loc. paul. supr. cit.

A. 183. Locufta Indiæ Orientalis maxima fubviridis rariffima, collo \& cruribus longiffimis, \& duabus expanfis alis, qua folia arborum reprefentant, vulgo folium ambulans, Batavis Wandelnde Blaat. conven. cum Delineat. ap. Aldrovardum de Infeet tis Animalibus Libr.IV. Cap.1. Job. Fonftonum \& Monfettum de Infectis, fub nomine Mantes Tab. X1. num. 1. Georg. Marcgrà̃ium in Hilt. Naturale de Infeet. pag, 246. prc. ap. Mar. Sybil. $P_{3}$

Graffin 
Greffin nat. Merianin Differt. de Generatione \& Metamorphofibus Infecturum Surinamenfium Tab. LXVI. \& in obfervatione mea in Besl. Samml von Nat. und Med. Gefib. XXV. Verf. An, 1723. ClarT. IV. Art. IV. pag.304. Quod'pedes radices agant, \& ale in ipfas plantas convercanesr, demonttravit, fimulque infeaum delineavit Guil. Pifo in Hiftor. Nat. \& Medic. Ind. Occidental, Lib. V. Cap. XXI. pag. 317. Erafm. Frassifci im Oft - und Weft-Indifch. Luft-Garten pag.41. it. Joh.Henr. Seyfrid in Medulla mirabilium Naturx Libr. II. Cap. V. 5.34. pag.6 63. Conf. Ep.bem. Nat. Curiofor, Cent.III. \& IV. Obf. XXXV. Tab. I. pag. 81. Folia alia ambulantia defcr. Hier. Cardanus de Subtil. Lib.X. pag. 588. \& ex eo Jul. Cafar Sfaliger de Subtilitate Exercit. CXII. pag. 42I.

A.184. Locufta, Talpa Capenfis dieta, tota echinata nigra. del. \& defcr. Fob. Lutdolfus de Locuftis pag. 14. it. Retiner in Gozophilacio Naturre \& Artis Tab. XXIIl, fig. VII. conf. Bresl. Samml. XVI. Veri. An, I721. Menfo Maj, Claff. IV. Art, IX, pag. 546.

A. 185. Fgagropila 1. Pila Damarum fingularis magnitudinis odoris mofchiferi. Talem defer. Foh. Weicb. Valvafor in der Ehre des Herzogth. Crains Tom. I. Libr. III. Cap. XXXII. pag. 44z. it. in pecul. Tract. Georg. Hier. Vel. fobius \& in pec. Differt. 7ob. Fac. Harderses, qua reperitur ad finem Ephem. Nat. Cus viof. Dec.II. An.I. Conf. Cafp. Baubinum de Lapide Bezoardico Oriental. \& Occi* dental. Cap. XIII. pag. 67. Joh. Jac. Scheucbzeruss Hift. Nat. Part. I. pag. 165. Unn. fere Samml. von Nat. und Medic. Gefchicbi. An, 1718. Menf. Aug. Clafi.IV. Art.XII. pag. 1526. item Obfervationem meani in Bresl. Samml. XX. Verf. Aw. 1722. Menf. Mai. Clar, IV. Art. XI, pag. SOI. De Ufu medico vid. Hr. von tiosbbergs Adeliches Land.und Feld Leben Libr.XII, pag.73r.Maximam Indix Oriental, defcripf.Epherw. Nat. Curiof. Dec. I. An.III, Obr.XIX.pag. 45. feqq.

A.186. 187. Mus albus, \& alius maculis nigris infignitus, Vratisla. viæ capti.

A. 188. Mus albus Norwegicus. defer. Ol. Wormius Muf. Libr. III. Cap. XXIII. pag. 322. delin. Ad. Olearius in der Gottorpifch. Kuntt-Kam. Tab.XII. num. 6. pag. 20. alia defcr. in Brest. Samml. von Nat. und Medic. Gefchicbt. XVII. Verf. An. I72 r. Claft. IV. Art. V.pag. 284.

A. 189. Mures marini diverfæ magnitudinis f. Exuviæ murium marinorum. fec. Georg. Andr. Helving in Brest. Samml. von Nat. usnd Med. Gefcbicht. XIV. Verf. An. 1720. Menf. Dec. Claff.IV. Art.VII. pag. 646. Pifciculi cornuti Jacob. Bontii Hiftor. Ind. Oriental. Libr. V. Cap. XXVI. Exuviæ vel Qva Rajæ pifcis Conr. Gefneri Hiftor. Animal. Libr. IV. qui eft de Pifcium Natura, pag. 930. Guil. Rondelesti de Pifcibus marinis Part. I. Lib. XII. Cap. IV. pag. 342. Fob. Jongtoni de Pifcib. Libr. I. Tab. XII, num. 40 it. Job. Henr. Locbreri in Mus, Beller. 
ler. Tab.XV. pag. 57. \& Mub. Bernb. Valentini in Muf. Mufeor. Part. I. Libr.III. Cap.XXXIV. pag. 491. His non fubfcribit Nic. Steno in Epiftol. ad Nic. Steno. nem \& Olig. Facobeam in Muf. Reg. Dan, pag.17. de Ufu Medico vid. Unfere Samml. von Nat. und Medic, Gejcbicbt. VI. Verf. An. 1718. Menf. Nov. Claff. IV. Art. V. pag. 1867.

A. 190. Sturionis maximi fcutellæ, in dorfo prominentes. del. \& defcr. Sturionen Conr. Gefnerus Hiftor Animal. Libr. IV. qui eft de Pifcium \& Aquatilium animantium Notura pag. 7. Ll. Aldrovandus de Pifcibus Libr.IV. Cap. IX. Job. Fonftonus de Piccibus Tah. XXIII. num. IIX. Cap. VII. pag. III. prc. Hippolytus Salvianus A quatilium Animal. Hiftor. Hift. XXX. pag. I13. Conf. de raritate Unfere Samml. von Nat, und Ased. Gefcbicht. V. Verf. An. I718. Menf. Aug. Claff. IV. Art. XII. pag. IIZI.

A. 191. Capricornus infeetum in Scotia frequens. vid. Rob. Sibbaldi Sco. tix illuftrate Tab.XIIX. num. 4 .

A.192. Carpionum lopides fingularis magnitudinis ex fluvii Tibifci carpionibus, del. \& defcr. Anf. Boetius de Boot in Hiftor. Gemmar. \& Lapidum Libr. II. Cap. CLXXV. pag. 349. De ufu Medico vid. Ol. IVormius in Mufeo Cap. IIX. pag. 59. prc. Pbil. Jac. Sachs a Lelwenbeimb Gammar. Libr.XIV. S. 17. pag. 307. De Carpionibus fingularis magnitudinis evolvend. Ephem. Nat. Curiof. Dec. II. An. X. Obf. IX. pag. 28. it, Ad. Olearius Itinerarii fui MofcoviticoPerfici Libr.IV. Cap.XV. pag. 412.

A. 193. Rhombus aculeatus fonfoni. vid. de Pifcibus Tab. XXII. num. I2. pag. 89.

A. 194. Gobio capitatus id. Fonfioni. L. C. Tab. XXIX. num.2.

A. I95. Pennæ Galli Africani nigræx, notulis albis infignitæ. Gallinam del. \& defcr. Jonfonus de Avibus pag. 188.Tab. LVII. f. Galli Guineenfis Aldrovandi. vid. Ol. Wormius Muf, Libr. III. Cap. XIIX. pag. 297. it. Ad. Olearius Gottorp. Kunit. Kam. Tab. XV. num. 3. pag.24. f. Flamingos Wilb.Dampierii der Reifen nach Neu.Holland f. Reifen um die Wels UII. Theil. pag. 33. it. Gallus Numidicus Sylveftris in Brafilia frequens Guil. Pifonis in Hiftor. Natural. \& Medic. Ind. Occidental. Libr. Ill. pag. 92. A. 196. Stella marina maxinia f. quarta Rumphii tota tuberculofa, cujus diameter ulnam dimidiam \& tres pollices æquat. vid. Guil. Ron. deletius de Pifcibus Marinis Part. Ilt. qux eft de Infedis \& Zoophytis Hiftor. Cap. XI. pag. 122. Georg. Everb. Rsmpbius Amb. Rarit. Kam. Libr. I. Cap. XXXIV. Tab. XV. Lit. A. pag. 39. it, Rochefort in Befchr, der Antillen-Inf, Cap. XIX. num, XIV. pag. 336 . 


\section{PROMTVARIVM RERVM NATVRALIVM}

A. 197. Stella marina echinata dorfo fupereminenti.

A. I78. Stella marina Scolopendroides, id. Rumpbius L. C, Lit. C. pag. 40.

A. 199. Stellarum marinarum diverfe fpecies minores. has del. \& defcr. Conr. Gefnerus Hiftor, Animal, Lib, IV, Guil, Rondeletius de Pifcibus Marinis Part. III. qux eft de Infeetis \&Zoophyris Hiftoria Cap. XI, pag. I22. Ul. Aldro. pandus de Infeat. Animal. Lib. VII, Cap. XIIX. pag. 742, feqq. Ad. Olearius Gottorpifch. Kunft Kam. Tab, XIIX, num, IV, pag. গr. Gob, Jonfonus Hif, Nar, de InfeCas Tab.XV. Libr. III. Cap. II. pag. Igs. it, in Ejusd, de Exanguibus Tab. VIII, num, 9. Jub. Henr, Lochnerus in Muf. Beslerian, Tab, XXII, pag, 76. Georg, Everb, Rum. phius Amboinf. Rar, Kam, Tab, XV. fol, 39。

A.200. Inftrumentum auribus \& dentibus mundandis aptum, ex offe genitali \& ungue Canis, argento obductum, vid, ol, Wormius Mur, Libr. III. Cap.XXIII. pag, 32I.

A.201. Offa ex Corde Cervi, vid.Adami Differt, de Offe Cord, Cervi Giefa fe habita,

A. 202, Mumia f. Partes hominum conditæ $\mathbb{E g y p t i a c x , ~ d e f c r , ~}$ del. prater Struppium \& Kircberum, qui ex inftituto de Mumiis commentari funt, Andr. Libavius Singularium Part, III. Fo, de Bituminibus Libr, VIl, Cap.XV, pag, 9c7. feqq. Ulyf. Aldrobandus in Mufeo Metallic. Libr, III, pag. 399. Frid. Goutl. Kettnerus de Mumiis Agypriacis, Ol. Dapper in Befchr, von Africa pag. 93. feqq. Hans jac. Breuning, Oriental. Reif, II. Meerfahrt Cap, XXV, pag. Is8. Petr. della Valle Reife - Befchr. XI. Send - Schreib. pag.IO3, feqq. Tbevenotus der Reifen Part, I. Libr. II. Cap. VI. pag, 183. Job. Lanzonus de Bulfamatione Cadaverum. Gabr. Clauderas in Methodo balfamandi corpora humana. Petr. ab Hartenfels in Pro. grammate, quod annexum Differt. 7. Vefti de Pollinclura, Mattbaus Bayaus in fine Operum, Cbriff. Frid. Garmannus de Miraculis mortuorum Libr.III. Tit. II. \$. II9.- 193. Th. Bartbolinus Hiftor. Anatom, Cent, I. Hiftor, LXII. Theoph. Raynaudus de Cadaverum incorruptibilitate, Sebizius de Conditura Cadaver. Pomet im Materialift, und Spezer, Händl. Part.II. Cap.I. Tab. LII. fig. 322, -324. pag. 457. Cbriftian Hertzog in Mumiographia Medica oder Bericht von Agyptifchen Mumien, Micb. Bernb. Valentini in Mur, Mufeor, Part. I. Libr. III. Cap. I. pag, 417. De Mumia Vratislavienfi pecul. Schediafma public. Andr. Grypbius, qux nunc in Bibliotheca Mar. Magdalenea cuftoditur. De Balfamatione corporum peculiari, vid. Ludov. Bilfus in Epiftolis de Balfamatione corporum, prc. Fjusd. Specimina Anatomica; De Balfamatione ficca \& humida, item Mumiarum, vid. Georg. Wolffg. Wedelius Exercitationum Medico-Philologicarum, Sacrarum \& Profana: 
rum Dec. V. Programmat, VI, De Conditura per cochionem, vid, Nebem, Grew in Mufeo Regalis Societatis, pag. 2.

A. 203. Tophus Juvencæ plinit Hift, Natur, Libr, II, Cap, XXXVII. f. Pila exterius cortice nigricante veftita, interius tota ex pilis coflata, \& in ventriculo fecundo bovino reperta. vid, obferpatio mea in Bresl. Samml, von Natur-und Medic, Gefcbicbt. XX. Verf. An. 1722. Menf, Maj. Claff, IV. Artic. XI. pag. for, feqq. defcr. \& del, quoque Conr. Gefnerus de Fig. La. pid, Cap. XII. pag. 158. \& ex eo Ol. Wormius in Mufeo Libr, I. Cap. VIII. pag:60. Ciftidem pilofam ex bubulo del, \& defcr, Olig. Jacobaus in Aq. Hafnienfibus An. 1673. Obf. XLV. pag. 81. \& 140. prc. de earum generatione \& ufu Medico legendus Foh. Wierus de Preftigiis Dxmonum Libr. IV. Cap. XVI. pag. 446. Atban. Kirrberus in China illuftrata Part. IV. Cap. XI. pag. 206. F. G. Schenckius in Lithogener. \& quidem in Appendice, Guil. Pifo in Hiff. Nat. \& Med, Ind. Occidental. Libr. V. Cap. XXV, pag. 327, diffesta delin. in Ferr, Imperati Hiftor. Naturali Libr. XXVIII. Cap. I. pag. 928. Conf. Diony/f. Kay Befchreib. des Kayferth. China Cap, III. pag. 274. qux reperitur in 2 sbrand Ides Reife nach China pag. 757. fegq.

A. 204. Globus talis levis vitulinus. defcr. in Epbem. Nat. Curiof. Dec. I. An. II. Obf. CX. pag. I8I. feqq. prc. in Annotat. pag. 398. it. Dec. II. An. VII. Obf, XXI, pag. 47. conf, Bresl. Samml. von Nat. und Med. Gefib. VIII. Verf. An. 1719. Menf. Jun, Claff. IV. Art. XIV. pag. 740.

A. 205. Dens maximus Canftadienfis in terra repertus. vid. Conr. Gefneri Hift. Animal. Lib.IV. pag. 497. prc. Dav. Scbleuffii Differt. fub Titul. Oedipi Ofteolithologici, f, de Cornibus \& Offibus foffilibus Canftadienfibus Schaffhufx publ.

A. 206. Dens Canftadienfi fimilis albus $\mathrm{f}$. calcinatus in Urna fepulchrali repertus. conven, cum delin. \& defcr. Leonb. Dád. Hermanni in Maslographia Libr. II. Cap. XI. Tab. VIII. num. 9. S. 2. \& 3. pag. I34. Ieqq.

A. 207. Dentes ex mandibula f. rietu Canis marini vel Lamiæ pifcis ferrati, Gloffopetras amulantes. Pifcem cum rietu del. \& defcr. ul. aldrovandus de Pifcibus Libr. III. Cap. XXXII. Ga $\beta$. Scbottus in Phyfic. curiof. Libr.X. Cap. VIII. pag. I27r. Erafm. Francific im Oft - und Weft-Indianifch. LuftGarten Part, I. pag. 7o. Reqq. Ad. Olearius in der Gottorpifch. Kunft . Kam. Tab. XXIII. num. 5. \& 6. pag. 306. Job. fonfonus de Pifcibus Tab. VII. pag. 26. it. fob. Henr. Lochnerus in Muf. Besl, Tab. XVII. pag. 66. \& 67. \& Micb. Bernb. Valentini Mur. Mufeor. Part. I. Lib. I. Cap. XXIV. pag. 65.prc. die Bresl. Samml.von Nat. und Med. Gefib. XVI. Verf. An.1721. Menf. Jun. Claff. IV. Art. XI. pag. 635. feqq. 
Anatomen inftituic Noc. Sterio in Myologis fpecimine f. Mufculi Defcriptionegeo. metrica pag. 69.

A. 208. Lapis Malaccenfis verus f. Fiedra del Rorco. del. \& defer. Anf. Bootius de Boot in Hift. Gemm. \& Lapidum Libr. Il. Cap. LXXX11. pig. 3i5. Ull. Al.drovandus in Mufeo Metallico Libr.IV. pag. 798. Fac, Buntius Hitt. Nat. \& Med. Libr.IV. pag 48. Mich. Bernb. Valentini Muf. Mufeor. Part. I. Cap. XIIX. pag. 456. it. in Dill. de Lapid. Porcino, pre. Engelb. Kämpferus Amon. Exotic. Fafcicul. II. §.3. pag. 393. Conf. Georg. Everb. Kumpbii Amboinf. Rarit. Kam. Libr.III. Cap. LII. pag. 297.feqq. De arte facto f. adulterino \& efficacia Medica vid. Bresl. Samml. von Nat. und Med. Gefcb. XIX. Verf. An. 1722. Menf. Jan. Claff. IV. Att. IV. pag. 9 .

A. 209. Piedra della Cobra inftar Silicis duriffima. del. \& defcr. Pabil. Baldeus in Befchr. der Küften Malabar und Coromandel Cap. XXVI. pag. 16I. Athan. Kircberus Chinæ Illuttrat. Part. II. Cap. V. pag. 80. Mich. Bernh. Valentini Muf. Mufeor. Part. I. Cap. XL. pag. 507. Georg. Everb. Rumpbius Amb. Rarit.Kam. Libr. III. Cap. LVII. pag. 304. it. Georg. Bagliviss Operum Differt. VI. Cap. XI. pag. 630. prc. Engelb. Kampferus Amonit. Exotic. Fafcicul. Il. 6.3. pag.397. it. Fâfcicul. III. pag. 778. feqq. Serpentem delin。 Francife. Legunt in Reifen nach zwey Oft . Indifchen Infuln Part. II. pag. 300 . it. Erafm. Francifc. in Oft und WeftIndifchen Luit - Garten Part.II. Tab.XLI. fig.X.pag. 1212. De Ufu in Medicina vid. Henr. Oldenburgius in Act. Soc. Reg. in Angl. An. 1665. Menf. Nov. pag. 77. it. Paulo Boccone in Curiöfen Anmerckungen über natürliche Dinge Obi: XVI.

A. 210. Caviaro ex ovulis Sturionis pifcis in Barbaria paratus. defcr. Petr. Pomet in Material. und Spezer. Händl. Part. II. Cap. XLIV. pag. 6r4. prc. Wilbelm. Erne z. Terzelius in Colloq. Mentr. Ann. 1690. Menf. April. pag. 38r. citant. Georg. Ad. Stbleufingio in dem Neuentdeckten Sibyrien oder Siewerien Cap.I. Conf. Paul. Jac. Marpergers Kaufmanns-Magazin pag. 263.

A. 211. Cafeus peregrinus funium infar in circulum convo. Iutus.

A.212. Cafeus laviffimus Hungaricus literis Hebraicis infcriptus. de Cafeo vid. Job. Combacbirzs in Libr. de Homine, it.Petr. Loticbius in Tr. Medico Phyfiologico de Cafei nequitia, de Averfatione Cafei pecul, Tract。 fcr. Martin. Scboockitus.

A. 213. Lapis e cêrvo albus, flexuris nigris infignitus, Orientalis. defcr, Georg. Evork. Rumpbius Amb, Rar, Kam, Lib. III, Cap. LIII. pag. $299^{\circ}$ 
A. 214. Orbis maritinus fpinofus, f. Hyftrix pifcis maximus Cluffi, Exoticor. Libr. VI. Cap. XXII. pag. r38. Reqq. f. Orbis Muricatus Guil. Rondeletii de Pifcibus Marinis Part. I. Lib XV. Cap. IV. pag. 42I. it. Claud. du Molinet dans le Cabinet de la Bibliotheque deSt. Genevieve Part.II. Tab. III. del. \& difc. in Corrad. Gefneri Hift. Animal. Lib. IV. pag. I45. Ul. Aldrodandi de Pifcib. Lib. IV. Cap.XVII. \& ex eo 7ob. Fonfoni de Pifcibus Tab. XXIII. pum. X. Titul. II. Cap. V. pag. 124. it. Tab. XLV. num. 3. it. Muf. Calccolar. SeC. I. pag. gro prc. Guil. Pifo Fiffor. Animal. \& Medic. Ind. Occidental. Libr. V. Cap. XVI. pag. 390. \& Joh. Herr. Locbnerus in Muf. Besler. Tab. XVI. pag. 59.

A. 215. Vermis cucurbitarius, f. Gryllotalpa, C.Talpa Ferr. Imperati Hift. Natural. Libr. XXVIII. pag. $90 \mathrm{cr}$ \& 92 I. del. \& defcr. CaAß. Scbwench. feld de Infect. pag. $\{28 . \&\{29$. Th. Bartbolinus in Aqt. Hafuienf. Vol. IV. Obr. II. pag. 9. it. Wolf Heimbard von Hoibberg im Adlichen Land-und Feld - Leben Libr. V. Cap. XXII. Anatomen inftituit Georg. Hier. Velfcbius in Obferv. Phyfic. Medic. Hecatoft. I. Obr. XXVI. pag. 39. feqq. it. Olig. Jacobaus in Tb. Bartholini Act. Medic. \& Philor, Hofnienfibus Vol. IV. Obf. II. pag. r. Conf. Bresl. Samml. von Nat. und Mied. Gefch. V. VerI. An. 1718. Menf. Jul. Claff. IV. Art. VI. pag. 666.

A. 216. Colle collegit, delineav. \& defcr. Fob. Fonftonus de Infect. Tab. VII. VIII. \& IX. pag. १०. pre. Maria Sibyll, Graffina nat. Meriana in der Raupen - Vervvandelung und Blumen-Nahrung; Surinamenfes defcr. \& delin. id. Meriana in Metamorphofi Infęorum Surinamenfium; conf. preter Moufettum, Majum, \&c. Fob. Goedartiam de Infectis in Methodum redactus cum notularum additione opera Mart. Lifferi, Scbammerdamium, de illorum Metamorphofi, Redi de Ortu Infectorum, it. Stephanum Blancardum in de Schouburg der Rupfen, Wormen, Maden, en vliegende Dierkens $\uparrow$. Theatrum Erucarum, Vermium, Termicum, \& qux ex his oriuntnr beftiolarum, volatilium \&c. Alas Papilionum cum aliis infeets, per microfcopium examinavit: Pbil. Bonannus in Oblervationibus circa viventia, que in rebus non viventibus reperiuntur, cura

Mierographia curiofa f. Part. III. Conf. Bresl. Samml. von Natur - und Medic, Gefcbicbt. IX. Verf. An.1719. Menf. Septembr. Claf, IV. Art. V. pag. 35I. feqg. 


\section{Claffis II. \\ Teftaceorum univalvium,non turbinatorum.}

(Ei quidem fingularum fpecierum num, duo aut plura.)

\section{ARTICVLVS I. \\ Nautili : five}

Teftace marina univalbia Dalde vientricofa, Ev ita in fe transierfim contor$t a$, ut eorum circumaolutiones nulla ex parte promineant, $\sigma^{\circ}$ nul10 modo bel bix appareant, Germ. Sdifffuttel.

A. I. Nautilus Sinenfis maximus five craffus argentei fplendoris figuris ornatus, \& artificiofe perforatus. Hunc del. \& defer. Pbilippus Bo. nannus in recrestione mentis \& oculi in obfervatione animalium teft aceorum $\mathrm{Claff.I}$. Num.I. it. in Mufeo Kircberiano. Aldrodandus de Teftaceis Libró. Martinus Lifterus in Hiftoria Conchyliorum Libr.IV. Sect.IV. Georg. Everb. Rumpbios Amboin. Raric. Kammer Libr. II. Tab. XVII. fol.6z. Conf, Ephemerid. Nat. Curiof. Dec.II. An. VII. Obf.XIV. Ad. Olearii Gottorpifche Kunft - Kammer; Mich. Bernb. Valentini Mur. Mufeor Part.II. Tab.XXXX V. Cap.43. pag.180. Job. Henr. Locbneri Múf. Besler. Tab.XIX. ubi cum feledtioribus Nautilum noftrum delcr. \& delin. reperies. A. 2. Nautilus major a cortice liberatus fubftantiæ margaritiferæ eleganter politus. Bonannus L. C.

A. 3. Nautilus talis minor.

A. 4. Nautilus maximus totus figuris ornatus, in quo aperto latere interior fabrica, five concamerationes apparent. del. Bonannus L. C. Clan.1. num.2. it. Rumpbius Amboin. Rar. Kam. Tab.XVII. Lit. C.

A. 5. Nautilus minor, $C$. Carina tenuis alba dentibus in dorfo colore pallo afpera. del. \& defcr. in Mufeo Calceolariano, Sect. I. pag. 36. in Guilo Rondeletii de Pifcibus Marinis Part.I. Lib.XVII. Cap.IX. pag.\$17. Pbil. Bonanni L. C. Claf.I. num.13. Fob. Everb. Rumpbii Amb. Rar. Kam. Lib.II. Tab.XVIII. Lit. A. pag.66. 7ob. Henr. Lochneri MuS.Besl. Tab.XIX. pag. 70. it. in Ephem, Natur. Curiof. Dec.II. An. IV. Obf.III. pag. 210. Singularia de Nautilo noftro, cum fuo pife, prout in mari velificat \& remigat, vid. ap. Conr. Gefnerum Hift. Animal. qui eft de Pifc. Libr.1V. pag.734.feqq. Fac. Bontium in Hift. Nat. \& Medic. Inc.Oriental. Libr.V. Cap.XXVIIL. pag.80. in Ephem, Nat. Cur. Dec.II. An.VII. Obr.XIV. pag.8. \& ex iis in Mich, Bernb. Valentini Muf. Mufeor fo in fine Part. I. der Oft.In. diani. 
dianifchen Sendfchteibeu, Tab.I, fig. 21 pag. $\{9$. it, apud G. E. Rumpbium L. C. Libr.II. Tab.XVIII. num.2, fol. 66 .

A. 6. Nautilus minimus albus fluviatilis ferpentinus, C. Serpentuli Rumpbil Amb. Rar. Kam. Tab.XXVII. Lit. Y. pag.92.

A. 7. Nautilus marinus ita formatus interne fubftantiæ margaritiferæ, totus concamerationibus non perviis adimpletus. Conv, cum del. \& defcr. Rumpbii Amb. Rarit. Kam. Tab.XX, num.I. pag.67.

\section{ARTICVLVS II.}

Patellæ, five Teftacea unibalbia marina in forisam coni faftigiata non tur. binata, Ev in fe non contorta, nullo modo vel folummodo in apice tantillum incurvata, balva fuperius convexa, ac frequentius claufa,

fubtus bero concava Ev aperta mobili, Germ.

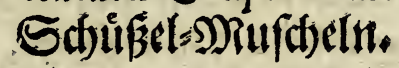

Spondyli, five Concbe marine anomale umbonate, afpera ac berrucofe tefta balidifimo ginglimo articulat, Germ. Etcitt=2(ufteth.

Aures marinæ, five Teftaced unibalbid, que auris figuram referunt, aper. tura omnium patentiffima perforata, Meel:Dbien.

Umbilici marini, five Opercula Cocblearum marinarum fubrotunda in fe contorta, umbilici figuram babentia, Germ. Miec: Mabel,

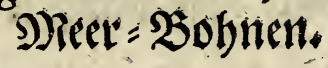

B. 1. Patella indica major pellucida maculis fangvineis-per album colorem diffeminatis.

B. 2. Patella ftriis multum eminentibüs diftincta.

B. 3. Auris marina maxima, annexis Balanorum teftis.

B. 4. Aures marinæ diverfæ magnitudinis num.VI. vid. Mart. Liferus in Hiftor: Animal. Angl. Tab.Ill. num.16. pag. 16\%, it. Guil. Rondeletius de Pif́ibus Marinis, Part.11. Lib.l. Cap.III. pag.f.

B. 5. Auris marina, adnatis innumeris cochleis parvis, iisque albis confpicua.

B. 6. Auris marina interne tuberculis referta, qua margaritas re. ferunt.

B. 7. Patella ftriata, colorị terrei. Bonannus L. C. Claffi, num.3.

Q3 B. 8. 


\section{PROMTVARIVM RERVM NATVRALIVM}

B. 8. Patella non ftriata ejusdem coloris.

P. 9. Patella validiffma fublutea.

P. 10. Umbilicus granofus colore vinofo. Rumpbius L. C. Tab.XX. Lit. D. pag.72.

P. II. Spondylus finuofus roftro ad. finiftrum. Bonan. Claff. II. num.20. P. 12. Patella lactea leviter fulcata.

P. 13. Patella eleganter ftriata, coloris fpadicei, dorfo albo.

P. I4. Patella alba tuberculofa in apice ferrata.

P. 15. Patella alba, in dorfo ftella nigra decorata, del. Mart. Liferus in Hirt. Animal. Angl, Tab.V. Tit.4r, pag.196.

B. I6. Patella alba oblonga maxima ftriis a bafeos modiolo ad verticem tendentibus, lineis circurnduetis aureis.

B. 17.18. Patella Canarienfis uberis papillam exhibens alba \& viridis. del. \& defcr. Rumpbius Tab.XX. Lit. B. pag.72.

B. 19. Úmbilici marini diverfæe magnitudlnis \& coloris num. $X$. vid. Ol. Wormius Mư, pag.72̂. Bonannus Cl.III, num.I4. Rumpbis \$ab.XX. pag. 72. Lit. C. \& E. aliique,

\section{ARTICVLVS III.}

Balanorum teftx . Calices, $\int$. Teflacea canaliculata recta brevia, frrbscture tenuis ore frequenter angufiore, adnata Jupra Jaxa $b$ oftrea.

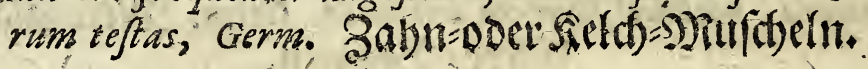

Tubuli Vermiculares, $f$. Teftacea univalvia intus cava, vermium in modum formata, varie incurvata, inflexa ac intorta, Germ. $2 B u m$ formige Micer = Robbricin.

C. I. Tubulus $f$. Siphunculus maris acutus \& ftriatus major, Dentalis difus, coloris viridis, Batav, Olyfantfande. vid. Wilb. d' Orville Catalogus van feen Kabinet pag.26. prc. Bonannus Cl. I. num.8. it. Rumpbius Tab. XLI. Lit. J. it, num.5.

C. 2. Tubulus $f$. Siphunculus maris non acutus albus.

C. 3. Tubulus f. Siphunculus maris minor, Antalis dictus. Bonass. Cl.t. num.9.

C. 4. Balanorum teftx virides, fupra aurem marinam pofitæ.

C. 5. Tubuli vermiculares, Patellæ, imprimis Buccinæ, L.9. Mu- 
ET.ARTIFICIALIVM KVNDMANN. VRATISLAV. 127

fculo ftriato D. 27. \& Purpuræ S.281. adhærentes. Bonann. Claff. II. num.20. pag.92.

C. 6. Balanorum teftæa albæ $\int$. Calices Neritis annexæ. Bonan. Cl.I. num.I4. Is. it. Conr. Gefnerius Hift. Animal. Libr. IV. qui eft de Aquatilibus pag. 122. \& Job. fonfon

C. 7. Balanorum teftæ maximæ colore amethyftino \& fufco variegatæ. del. G. E. Rumphius Amb. Rar. Kam. fol. 226. Tab.XLI. Liter. A.

C. 8. Tubulus vermicularis rofei coloris fpiraliter inflexus elegantiffimus, linea nigricante circumfcriptus, Batav. een heel feyn Schape darmtje. vid, wilb.d' Orville Catal. pag.26. del. Bonan. Cl.II. num.20. Lit. D. Rumpbius Tab.XLI. num.2.

C. 9. Tubulus vermicularis albus totus tuberculofus. id. Bonann. L. C. Lit. B.

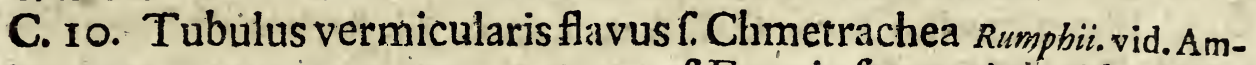
boin. Rar. Kam. Tab. XLI. num. I. fol.126. f. Exuvia ferpentis lapidea Loch. meri. vid. Muf. Besl. Tab.XXXVI. pag.IO3. del, Bonan. Claff,II. num.20. Lit. C.

\section{Claffis III. \\ Teftaceorum bivalvium. ARTICVLVS I.}

Conchæ, Oftrea, Mytuli, Pinnæ, Balani, Solenes:

Confant autem Conch $x$ valbis aqualibus aquilateris mediocriter vel le: viter umbonatis $E$ incurvatis, cardine denticulatim unito, tefla crafiore; Germ. Meer:Miifoldn.

Oftrea, sfuftern, vero cardine per fimplicem ginglimum unito.

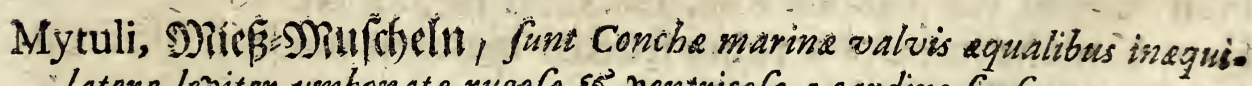
latere levitcr umbonate rugofes Ev bentricofe a cardine fenfome contracto $v$ acuminato ad oram fubrotundam E latam longe products.

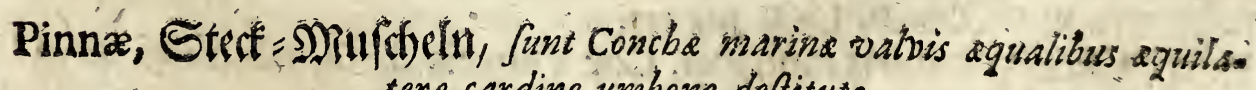
ters cardine umbone defitute. 
Balani, Diect: Eid)eln; pero Tefacea marina, unipaldia in fe non contosta nec incurbata, valva fuperius aperta $E^{5}$ concaba, inferius pero claufa so immobili,

Solenes, Magel:Miufdeln; funt conche marine valvis equalibus insquilatere non umbonate, recte a cardine tantillum profundiore ad oram angu. fiffime, atque uno latere maxime elongato, altero vero brebifimo, utroque autem in fua extremitate inclufili feu aperto Es biante.

D. I. Concha margaritifera $f_{8}$ Mater Unionum dieta, a cortice libe= rata. Bonan. Cl,II, num.I, pag.93.

D. 2. Concha margaritifera cum cortice.

D. 3. Pinna marina, Bonan, Clafr. II, num, 23, it, Job. Fonftonus de Exangvib. squatic, Tab.XVI. pag.67.

D. 4. Balanus Narbonenfis, Bonann. ClaflII, num.49, Lifferus Hift. Animal. Angl. Tab. V. Titul.38. pag, I9z.

D. 5. Mytulus lavis violaceus, colore albo ftriatus, Bonsn, Clafr, II, num.30. Anatomen Mytuli inttituit \& publicavit Anton. de Heyde.

D. 6. Concha Rhomboides valvis leviter denticulatis, Bonann. $\mathrm{Cl}$. If. num.32. Rumphius Tab,XLIV. Lit.P.

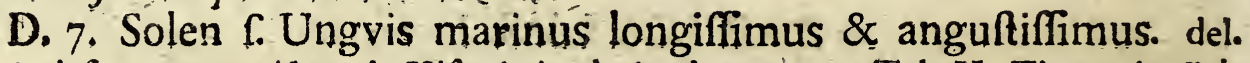
\& defcr, Mart, Liflerus in Hitt. Animal. Angl. pag. 192. Tab.V. Tit.s7, it. Foh. Hinr. Locbnerus in Mur, Besl. Tab.XXII. pag.76.

D. 8. Concha fquamofa e littore Drepanitano Incolis Sartaniello dieta. Bonann. Clafr.II. num.58. C. Avicula Rumphii Tab, XLVI, Lit. G. fol.152. D. 9. Oftrea multis oftreis minoribus turgida, valvis diffimilibus, Bonann, Claff.II, num. 70.

D. Io. Concha leviter imbricata alba e rubro mari $f_{\text {. Tragum al- }}$ buim Ramphii. vid. Amb. Rar. Kam. Tab.XLIV. pag.142. Lit. H.

D. I1. Concha imbricata rubra fruetus ejusdem maris $f$. Tridachnes fonfloni de Exangvib. aqv. Tab.XIII,

D. 12. Chama literata alba friis in circulum ductis. Rumpbius Amb. R. K. Tab.XLIII, Libr.II, Lit. B. pag.139.

D. 13. Concha coloris tophacei, Cor Veneris dika, in ambitu ferrata, f. Cartiffre Hartjes Rumphii Tab.XLiII. Lit. E. fol.132. 
D. 14. Concha rariffima alba, valvis ferratis \& leviter imbricatis aureis. Bonann. Claffilli. num.374.

D. 15. Concha in ambitu ferrata valvis leviter imbricatis purpureis, (tefte Bonann. L. C. ClaffiIIr. num.žr. raro invénitur.)

D. 16. Concha pellucida, lactea, longiffima, inftar marmoris ex: polita.

D. 17. Concha Striata cum Zona flavo, albo \& nigricante colore fegmentata.

D. 18. Concha Veneris armata I. echinata, ftriis purpureis. del. \& defcr. Adam. Olearius Gottorpifch Kunft Kam. Tab. XXIX. num.4.pag. 56. it, Rumpbius Amb. R. Kam. Tab. XLViII. num. 4. pag. I58. Secundum .7. H. Locbnerums in Muf. Besler. Tab. XXI. fig. XI. pag. 75. Vulloa marina aculeís inflar pubis borri$d a$ it. Fec. Frid. Ernef. Bräckmannum de Vulva marina \& Concha venerea. Sive Concha echinata $R u y$ /cbii, quam elegantiff. effigiavit \& defcripf. in Theatro univerfali omnium animalium Libro de Exanguibus aquaticis Tab. XIII. Artic. V. punEo 1. pag. 42.

D. 19. Concha Veneris non armata tota tuberculofa.

D. 20. Concha Veneris non armata lævis alba.

D. 21. Concha Veneris alba non armata, ftriis punctatis nigris.

D.22. Concha Veneris læviffima, coloris aurei faturatioris.

D. 23 . Concha Veneris non armata, ftriis purpureis in circulum ductis.

D. 24. Concha longiffima cœrulea radiis albis fpectabilis $f$. Tellina violacea Purpere Sonneftraal Rumphii Tab.XLV. Lit, E. pag. 147.

D. 25. Concha alba, Zonis fubfufcis cineta.

D. 26. Concha leviffime ftriata coloris cinerei punctis nigris adsperfa.

D. 27. Concha Rhombrides ftriata valvis leviter denticulatis annexis tubulis vermicularibus oblongis. salem delin. \& defar. Carol. Clufus Exotic. Libr. VI. Cap. XV. pag. 129.

D. 28. Concha alba ftriis in circulum ductis, radris purpureis.

D. 29. Concha Umbone acutiffino, ftriis eminentibus.

D.30. Concha margaritis immaturis confpicua. talem delin.'Ferran. dus Imperatas Hiftor. Natur. Libr. XXIIX. Cap. I. pag. 9o5. it.Mufeum Calceolarianum Sect. I. pag. 31. it, Roche. Multa huc fpectantia collegit Micb. Bernb. Valentini in Muf, Mufeor. Part, I. Libr.III. Cap.XXXVI. pag. 479. ubi finul Pifca- 
torem delineavit de Pifcatione ipfa vid. Job. Bapt. Taverniers Reife. Befchr. Part. 11. Cap. XX. \& XXI. pag.132.-136. Ol. Wormii Mur. Libr. I. Cap. XIX. pag.1́og. Hiftorifibe Remarqu. an. 170\% pag. 18\%, de Generatione ex pluvia guttulit vid. Ind. Oriental. Part. VII. Cap. XV. pag. 69. Ex rore vid. preter Dlinium, Rochefort Befchr, der Antillen Infuln Cap. XIX, num. 9. pag. 328. Ex morbo-vid. Pbil. Po. nanni Recreatio mentis \& oculi Parc. IIt. Trublem 1 . quod five Ovela Concharum margaritiferarum vid. F. F. Mylius in Memorabil. Saxon. Subter. Part.'It. Rel. I. pag. 18. feqq. plur. vid. Artic. de Gemmis, ubi de Margarita agitur.

D.31. Concha fluviatilis maxima interne fubltantiz argentex.

D. 32. Concha margaritifera minima intus tuberculofa.

D. 32. Concha Cor Veneris dicum album non ferratum. Bonannii Clafi. II. num. 49.

D.34. Concha ponderofa fubftantiæ marmoreæ, notis puniceis \& purpureis fine ordine flexuo fe excurrentibus, in qua a centro ad oram ftriæ admodum craffx, profundæ \& fquamof diriguntur, major \& minor. B̈onann. Cl,II, num.81. \& 82. it, Rumpbius Tab.XLII. Lit.C. fol. 138.

D. 35. Mytulus marinus levis colorís corulei, maculis albis infignitus.

D. 36. Concha imbricata elegantiffima, colore albo \& citrino difincta.

D. 37 . Concha ejusdem ftructura crocea, fquamis albis erectis con. decorata.

D.38. Concha imbricata talis purpurea ita fquamofa.

D.39. Concha punicea, cum fquamis albis ita difpofitis, f. Cha. mæ fquamatæ Nagellchulpen. Rumpbii Tab. XLIII. Lit. A. fol, 126.

D. 40. Concha fluviatilis Maslenfis Silefiaca maxima interne tuberculofa, quæ margaritus referunt. Huc fpectantia evol. in Ephem. Natur. Curiofor. Dec. I.An. III. Obr.XXXVI. pag. 58 .

D. 41. Mytulus ex coruleo niger firmiter annexus oftreo. del. \& defcr. Mart. Lifterus in Hiftor. Animal. Angl. Tab. IV. Titul. XIIX. pag. 182. is. Carolus Nic. Langitus de Teftaceis marinis pag. 82. examen per Anatomen inftituit. Anton de Heide in Anatome Mytuli.

D. 42. Oltreum eleetrinum. Rumphis vid. Amb. Rarit. Kam. Tab.XLVII. Lit، L، pag, 158 .

D. 43. Concha fluviatilis morgaricifera a cortice externo liberata. 


\section{ARTICVLVS II. \\ Pectines.}

Sive Concbs aurite valvis diffmilibbus una plana altera concava, mediocriter vel leviter umbonate, magis vel minus rugofa Ariis canaliculatis latioribus ac comprefjis feu quafi undulatis confpicue. Germ. Sacobo פMild $\operatorname{seln}$.

+1. Pecten totus echinatus \& ftriatus. Bonannus Clafr. II, num. 96. 72. Peeten auritus elegans ftriis valde minutis, interne fecundum longitudinem difcurrentibus, valva una rofea, alcera alba ftriata, Id. Claff. III. num. 354 .

+3. Peetunculus fulphurei coloris.

4. Pecten fabflavus ftriis latiffimis.

+5. Peeten fupra album colorem levisfime ftriatus.

+6. Peetem albus quatuor farciis aureis fignatus,

77. Peeten auritus ftriis rubentibus.

78. Pe:ten auritus albus, ftriis multum eminentibus.

+9. Pecten totus ftriatus ruber.

tro. Peeten niger ftriatus.

tir. Pecten albus ftriis ordinatisfimis a bafi ad mucronem difcurrentibus.

+12. Pecten ftriatus coloris fufci.

+13. Peeten fubalbus fafeiis nigricantibus,

+ I4 Peeten cinerei coloris.

t 15 . Peeten ftriatus albus elegans, colore ex atro rubefcente maculatus.

+ 16. Peeten lacteus elegantisfime canaliculatus, fquamis totusafper. Bonannus Cláff. Il. num. 71.

+17. Fecten albus ftriis levisfime imbricatis.

t I8. Peeten niger ftriis valde minutis fignatus in utraque teftagib. bofus. Bonann, Claff. II, num. 5 .

† 19. Pecten auritus colore albo \& fanguineo variegatus, ftriis eminentibus. 
†20. Pecten ruber totus echinatus \& ftriatus.

†21. Peeten albus ftriis minutisfimis infignitus.

+22. Pectunculus rutili coloris ita ftris condecoratus.

\section{ARTICVLVS III. \\ Telline.}

Sive Conchs, tenuioris tefte, minus concava figura abuna cardinis partelon. giore, ab altera breviore, fgura fere rbomboide, leves alie, alia firiata. Germ. Tell = Miulcheln.

llarum diverfimode variegaturum fpecies num. XXXI. eX quibus maxime confpicuæ:

E. 8. Tellina flavefcens maculis nigris denticulata. Bonann. Claf. III. num. $37 G$.

E.9. Tellina maculis triangularibus nigris, fupra album colorem diffeminatis .. Chama optica. Rumpbii Tab.XLII. Lit.K. fol.139. E. 25. Tellina colore fpadiceo minutisfimis ftrrigis rugofa. E. 26. Tellina elegans fecundum longitudinem ftriata. E. 3 I. Tellina maxima fufea radiis faturatioribus infignita.

\section{Claftis IV.}

Teftaceorum univalvium Turbinatorum.

$$
\begin{aligned}
& \text { ARTICVLVS I. } \\
& \text { Cochlex: }
\end{aligned}
$$

sive Teftacea marina unibaloia turbinata, figura fua cocblearum in modum intorta, ita ut intima corum Spira aliquo faltem modo promineat $\tilde{\sigma}^{5}$ producatur. Germ. Siet" Sthneten.

F.I. Cochlea colore fulphureo, fafciata linea fubnigra per medias fpiras.

F.2. Cochlea lactea rotunda leviter turbinata. Rumpbizs Tab.XXII. Lic, $\overline{7}$.

F.3. Cochlea depreffa rofei coloris, fafcia alba quam notulæ aureæ exornant in turbing circumduetá. 
F.4. Cochlea piriformis mire reticulata colore vineo. Bonann. Clafr. III. num. 15. f. Ficus een Vyg Rumpbii Tab. XXVII. Lit.IK. pag. 9 r.

F. 5. Cochlea Echinophora colore tophaceo, coftis ubique gibbo. fis firmata. Bonenr. Claff. III. num.19.

F. 6. Cochlea funiculis fpiffis cincta, colore terreo. Bonann. Cl. III. nnm. 26.

F.7. Cochlea maxima formam habens galex five galeiformis flavefcens. Bonanni Claft. Ill. tium. 183.

F. 8. Cochlea cortice loricato afpero tuberofo, colorem margarita rum fub purpurafcente vefte celans, diverfæe magnitudinis. Bonann. Cl. III. nutm. 3r. Rumpbius Tab.XX. Lit. H. fol.72..

F.9. Cochlea loricata argentei fplendoris, tuberculis albis fecundum firarum duelum pofitis.

F.10. Cochlea Indica major variegata coftis latioribus in longitudinem, \& lineis tranfverfim duetis. Eonann. Claff.IIt. num. is8:

F.II. Cochlea talis minor, faturatioris coloris, coftis tenuoribus inAructa.

F. 12. Cochlea lutea eleganter ftriata.

F.13. Cochlea fla vefcens cum punctulis nivei albedinis,

F. I4. Cochlea mole parva mire punctata.

F. I5. Cochlea flavá notulis faturatioribus fignata.

F.16. Cochlea tuberofa e colore viridi, fufeo \& albo variegata. Bonannus Cl. III. num. XVII.

F. 17. Cochlea Tulipa dieta, maculis quæ album colorem difcriminant fufcis, Bonannus Claff. III, mum, 318.

F. 18. Cochlea geographica alba, maculis quæ provincias indicant aureis Bonann. Cl. HII. num.319.

F. 19. Cochlea badii coloris, incifuris in longitudinem ductis,

F.20. Cochlea alba tenuiffima, labro inflexo teftam ovi referens $\boldsymbol{r}_{\text {. }}$ Bulla Blasjes Rumpbii Tab. XXVII. Lit. H. pag. 9r.

F.21. Cochlea fub alba canaliculata, coltis aureo colore notatis, ore labrofo. 1d. Rumpbia Tab. 27. Lit. A. fol. 91 -

F.22. Cochlea maxima nitidisfima argentei fplendoris. Bonanniws $\mathrm{Cl}$. III. num. $1 \%$.

F. 23. Cochlea galericulata coloris ftraminei, coltis aureo colore punetatis: $\mathrm{R}_{3}$ 


\section{PROMTVARIVM RERVM NATVRALIVM}

E.24. Cochiea alba notulis aureis oblongis fine ordine difpofitis,

F.25. Cochlea argentei folendoris, inferius maculis nigris oblongis decorata.

F.26. Cochlea fubviridis elegantisfima, colore atbo yariegata, lineis aureis tranfverfim infcriptis.

F, 27. Cochlea duplicata five depreffa, fafciis verficoloribus alternatim teffellulatis pluries cincta. Bonann, $\mathrm{Cl}$, III, num, 27. \& 28, r, Um. blicasa Rumphii Tab. XXVII. Lit, L. fol, 91 .

F.28. Cochlea tenuisfima coloris argentei.

F.2. Cochlea tenuis albida maculis fubrubris depieta.

F. 30. Cochlea labro inflexo, punetis albis \& maculis nigris fupra vinofum colorem pofitis. Bonannus Claff. HII, uum, 4 . $f$, Kievits - eyeren Rumph. Tab. XXVVII. Lit. G. \& H, fol, gr,

F. 3T. Cochlea alba coltis fecundum longitudinem duetis, quas notulæ \& linex aurex exornant, ore extenfo f. Harpa minor, Rumpbii Tab. XXXII. Lit. M. fol, I04.

F. 32. Cochlea maxima coloris aurei, tuberculis eminentibus, labro craffo inferius eleganter maculato. $f$, Casfis rubra rarisfima. Rumphii Amb. Rarit. Kam. Tab. XXIII. Lit. B. pag. 80.

F. 33. Cochlea depreffa flavefcens, linea oftrina fubnigra per medias fpiras fafciata.

F.34. Cochlea Echinophora argentei fplendoris.

F. 35. Cochlea levis verficolor, notis aureis, turbine fesfili.

F.36. Cochlea flavefcens, fafciis faturatioribus, turbine depreffo.

F.37. Cochlea alba colore aureo maçulata, coltis depresfis, ore elẹganter crenato.

F.38. Cochlea qux Velum nauticum vocatur, fpiris qua labrum infleetitur abfconditis.

F. 39. Cochlea aurei coloris ftriata, maculis femilunaribus albis

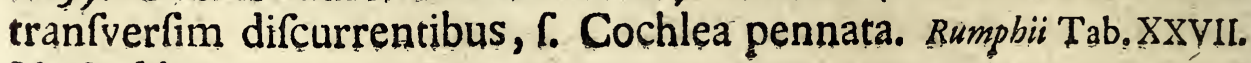
Lit. C. fol. 90 ,

F. 40. Cochlea labro inflexo turbine abfcondito punctis obfcure albis fupra rufum colorem pofitis.

F. 4I. Cochlea ejusd. ftrueturæa alba, punctis rutilis \& fufcisita condecorata. Rumpbii pag. 9I. T. XXVII. 
ET ARTIFICIALIVM KVNDMANN. VRATISLAV. 135

F.42. Cochlea cum Cancello inclufo. id. Rumph. Tab. XXIIX, num. Is it。 Lib.11. fol. 165 .

F.43. Cochlea Indica major multicolor ftriata, coltis anguftisf. mis f. Harpa major. Rumpbii Tab. XXXII. Lic. K. fol, 104.

F.44. Cochlea Indica minor coftata, lineis finuofe inflexis, ore extenfo.

F.45. Cochlea tota ftriata alba, maculis aureis quadrangularibus infignita.

F.46. Cochlea f. Cymbium, fpiris qua labrum inflectitur circumplicatis, gekroonde Bax of Kroonhorn. Rumpbii Tab. XXXI. Lit. A. Fol. 102, Banann. Cl..1I. num.t.

F:47. Cochlea elegantisfima argentei fplendoris, cujus orbes ftrix fupereminentes, turbinem vero papillæexornant, Bonann. Cl. III. num. II.

F.48. Cochlea alba coftis fupereminentibus quas maculæ fufcæ quadratæe exornant, ore extenfo, $f$. Cochfea olearia. Rumpbii Amb. Rarit, Kan. Lib.II. Tab.XXVII, Lit. A. pag. 90.

F. 4\%. Cochlea f. Cymbium minimum lave, fpiris in turbine cir. cumplicatis. vid, Rumphius L.C.

F. so. Cochlea fufci coloris ftriata maxima maculis femilunaribus albis tranf́rerfim difcurrentibus, f. Cochiea pennata major. Rumpbii Ámb. R. K̇. Lib.II. Tàb.XXVII. Lit.O. pug. 90.

F. 51. Cochlea terrei coloris mucronibus ferundum fpirarum du. etum poritis f. Calcar. Rumpbii Amb. Rar. Kam. Tab. XX. Lit. 1. pag. 73. F. 52. Cochlea talis a cortice liberata argenteifplendoris.

\section{A RTICVLVS II. \\ Turbines.}

Sive Cocbles marine, ore admodum parbo, fuperius soucrone, ommitm lons gifimo. Germ. Schtallb:Şörnet.

G. 1. Turbo tuberculofus lapideis coftis munitus.

G. 2. Turbo in Spongiarum cavitatibus vivens, in quo fpiræ funiculis conjunguntur. Bonann. ClaffIII. num.3. . Buccinum fealare het Wendeltrapje Rumpbii Tab.XXIX. Lit. W. fol.98. 


\section{PROMTVARIVM RERVM NATVRALIVM}

G. 3. Turbo cui nomen eft Cornu cervinum, notuli ex purpureo colore nigricantibus, juxta fpirarum commifluras in gyrum pofitis. G. 4. Turbo maximus qui dicitur Pontificia Tiara, triplici corona condecoratus, quem fpirx tuberculis eminentibus in eono formant, notulis quadratis arantiatis, (ob raritatem xftimatur tefte Bonanno L. C. Clan.III. num.II9. vid. Rumpbius Tab.XIX. Lit. J. fol.g6.

G. 5. Turbo auritus colore flavo.

G. 6. Turbo auritus filis aureis finuore inflexis, labro expanfo. Bon.sinus ClaffiII. num.146.

G. 7. Turbo nitidus albus, quem duæ fafciole aurex, in fpiram contortæ, pluries cingunt.

G. 8. Turbo elegantiffimus, duplicatis orbium fpiris cochleatus, ubi teffellulis croceis pulchre difcriminatur color albus. Bonann.Claffo III. num.II8.

G. 9. Turbo ventricofus, ore dentibus munito, variegatus colore badio \& albo. Id. Clafr.III, num.44.

G. IO. Turbo coloris fubfufci, coftis fecundum longitudinem \& li. neis transverfim ductis.

G. II. Turbo mole parvus eleganter punetatus.

G. 12. Turbo aibus leviffime ftriatus.

G. 13. Turbo terrei coloris coftis nodofis.

G. I 4. Turbo albus ubique punctulis fufcis adfperfus, tuberculis uberum inftar ex orbibus fpirarum pendentibus. Bonannus. Claf. III. num. 69.

G. I5. Turbo auritus lacteus, labro expanfo. Id. Bonann. Cl.III, num.14\%. G. 16. Turbo colore ligneo, tuberculis fecundum fpirarum ductum pofitis. Id. Claft.III. num.327.

G. 17. Turbo tuberculis a fummo vertice mucronem usque circumvolutus, coloris terrei, $\mathrm{f}$. Strombus angulofus, Ruige TrommelSchroeven Rumphii Tab.XXX. Lit. O. fol.rot.

G. I8. Turbo albus tuberculofus maculis fufcis infignitus.

G. 19. Turbo albus ore longiffimo, fpiris eleganter punctatis, $f$. Turris Babylonica Rumpbii Tab.XXIX. Lit.L. fol.97.

G. 20. Turbo colore pallido, cujus orbes crenæ a bafi ad mucronem usque profequuntur. 
ET ARTIFICIALIVM KVNDMANN. VRATISLAV. 137

G. 2I. Turbo ejusdem ftructuræ colore ligneo . Strombus Tympanorum, Trommel-Schroeven Rumpbii Tab.XXX. Lit. M. fol.100.

G. 22. Turbo aureus commiffuris leviffimis obvolutus. Bonann. Clan. III. num.107.

G. 23. Turbo ore longiffimo, notulis quadratis arantiatis fupra laEteum colorem diffeminatis C. Mitra Epifcopalis Rumpbii Tab.XIX. Lit. K. fol.97.

G. 24. Turbo rugofus cinereus tuberculis in orbium commiffuris difpofitis, f. Caffls cinerea lævis Rumpbii Tab.XXV. Lit. A. fol. 83 .

G. 25. Turbo Atriatus, maculis croceis, turbine tuberofo, ore denticulato.

G. 26. Turbo tuberculofus albus pentadactylus. Bonann. Claff III. num. 85 .

G. 27. Turbo auritus albus filis craceis mire inflexis.

G. 28. Turbo coloris cinerei maculis quadratis nigris infignitus.

G. 29. Turbo fafcia alba \& rutila alternatim cinetus.

G. 30. Turbo tenuis albus non ftriatus, maculis aureis, ore longisfimo, Avena marina Bonanni Clafr.III. num. 57 . \& Terebellum, een Kuipers boor Rumpbii Tab.XXX. Lit.S. fol.10r.

G. 3I. Turbo albus punctulis ubique binis croceis fecundum fpirarum duetum pofitis.

G. 32. Turbo albus labro expanfo lineis aureis in turbine circumduetis. Bonann. Clafillit. num.33.

G. 33. Turbo depreffus colore croceo, linea oftrina fubnigra per medias fpiras circumvoluta. Bonann. Claffilli. num.5.

G. 34. Turbo albus, coftis fecundum longitudinem munitus.

G. 35. Turbo, . Cochlea ventricofa Indica leviter turbinata alba, maculis aureis femilunaribus ftriisque fecundum longitudinem \& transverfim lignatus, ore dentato. Bonann. Cl.III. num.323.

G. 36. Turbo limofus orbibus planis \& rotundis.

G. 37. Turbo colore zizyphino, foffulis æquali intervallo inter fe diftantibus. Bonannus Clarf. III, num.84. f. Strombus caudatus Rumpbri 'Tab.XXX. Lit. K. fol.100.

G. 38: Turbo echinatus colore ligneo, binis tuberculorum lineis circumvolutus. 
G. 39. Turbo albus, quem dux farciolx aurea \& nigra alternatim cingunt. Bonann. Claff.III. num.379.

G. 40. Turbo coftis fecundum longitudinem, \& fafcis rubentibus, notulis aureis quadratis transverfim difcurrentibus, Rumpbius Tab.XXIX. Lit. V. fol. 98 .

G. 41. Turbo albus maculis lunaribus nigricantibus condecoratus. G. 42. Turbo albidus notulis quadratis in firirali linea circunduetis. G. 43. Turbo colore cinereo orbibus crenatis. Bonansus C!IIII. num.23. G. 44. Turbo nivex albedinis, fafciis nigris fignatus. id. Bonan. Cl.III: num.reg.

G. 45. Turbo albus apicibus pendentibus, punctulis aureis in fpirali linea diftributis. Bonann. Claff:III. num. 83 .

G. 46. Turbo albus tuberculis \& notulis fufcis cinclus.

G. 47. Turbo albus tuberofus magnus, uberibus ex orbibus fpirarum pendentibus, maculis furvis. Boonann. Claffilit. num.69. . Strom. bus angulofus Rumpbii Tab.XXX. Lit. O. fol.ror.

G. 48. Tuba f. Turbo longiffimus variegatus, funiculis duobus a bafi ad mucronem circumductis.

G. 49. Turbo fubalbus cottis tuberculofis fecundum longitudinem difcurrentibus.

G. 50. Turbo minutiffimis fulcis afper in omnibus fpiris, excepta maxima, colore carneo.

G. 51. Turbo totus tuberculofus, colore badio.

G. 52. Turbo cinereus lineis faturatioribus inflexis.

G. 53. Turbo coloris vinei, frigis reticularibus, appendice ereeta. Bonamn. Claff.III. num.lor.

G. 54. Turbo ventricofus albus, ore dentibus munito, puneulis aureis.

G. 55. Turbo coloris carnei,fafciis fine ordine difcurrentibus, frigis canaliculatis inftruetus, cujus labrum inverfum teffellule nigra exornant. Rumpbius Tab.XXV. num.7.

G. 56. Turbo ejusdem coloris levis, lineis in turbine flexuofis, la. bro craffo ita maculato.

G. 57. Turbo albus tredecim fpiris convolutus, cingulo diffecto, lineolis punctisque aurei coloris a bafi ad mucronem fignatus. 
G.58. Turbo albus, papillis fupra orbes eminentibus, quos puneta colore aureo in duplici linea difpofita, exornant, f. Strombus dentatus Rumpbii Tab.XXX. Lit. E. fol.ıoo,

G. 59. Turbo albus colore aurep variegatus, labro inverfo maculato, ftriis a bafi ad mucronem repentibus.

G. 6o. Turbo albidus, ventre eminenter ftriato, labro inverfo,turbine ordinatiffime ftriato \& tuberculofo.

G. 6I. Turbo nitidus, quem fafcia alba \& atrorubefcens, alternatim cingit.

G. 62. Turbo aurei coloris, fafcia alba decorata, fulcis fecundurk longitudinem \& transverfim difpofitis.

G. 63. Turbo alatus teffellulis arantiatis, turbine tuberofo.

G. 64. Turbo albus gibbofus, maculis aureis, ore fabnigro mire Itriato.

G. 65. Turbo albus maculis in turbine aureis.

G. 66. Turbo auritus albus labro expanfo, incifuris flavefcentibus in turbine ordinatiffímis I. Epidromis Rumpbii Tab. XXXVI. Lit. M. fol. 100 .

G. 67. Turbo albus colore aureo variegatus.

G. 68. Turbo ejusdem coloris turbine coftis munito.

G. 69. Turbo colore aureo \& cinereo variegatus pentadactylus; tuberculis a vertice mucronem usque convolutis.

G. 70. Turbo albus ex nigro variegatus tuberculis fecundum fpirarum ordinem difcurrentibus. Rumpbius Tab.XXX. Lit.N. fol.100.

G. 7I. Turbo fafciis albis \& flavis alternatim obvolutus.

G. 72. Turbo carnei coloris, labro inverfo albo teffellulis nigris ornato, fafciis in ventre flexuofis, f. Fimbriata lavis Rumphii Tab.XXV. Lit. E. fol.84.

G. 73. Turbo albus maculis aureis fpiraliter cin $q u s$.

G. 74. Turbo albus colore nigro notatus, friis eminentibus.

G. 75. Turbo ejusdem coloris reticulatus, notulis quadratis aureis ordinatiflime difpofitis, T. Areola Rumpbii Tab.XXV. Lit. B, fol.84. G. 76. Turbo lacteus, labro inverfo, filis eminentioribus fecundum longitudinem, \& ftriis tranfverfim difcurrentibus.

$$
S 2
$$


G. 77. Turbo talis ftructuræ, maculis quadratis flavefcentibus fupra colorem vineum ordinatiffime dispofitis.

G. 78. Turbo friatus colore albo \& fufco variegatus, ore longisfimo.

G. 79. Turbo fubrufus notulis albis decoratus.

G. 80. Turbo coloris vinofi totus reticularus, labro inverfo.

G. 81. Turbo mole parvus, in quo fpiræ filis conjunguntur.

G. 82. Turbo parvus nftidus, quem linea punctata, a bafi ad mucronem cingit.

G. 83. Turbo totus cinereus valde exiguus.

G. 84. Turbo albus, lineis granulatis fecundum longitudinem duetis.

G. 85. Turbo granulatus firmiter annexus oftrex:

G. 86. Turbo albus maximus, maculis oblongis nigris quadratis majoribus, \& fuperius minimis fecundum fpirarum du\&tum obvolutus. Rumpbius Tab.XXX. Lit. A. fol.roo.

G. 87. Mitra Epifcopalis f. Turbo ore longiffimo teffellulis quinis arantiatis juxta fpirarum ordinem difcurrentibus num. VIII. Bonann. Claff.III. num.120. Rumpbius Tab.XXIX. Lit. J. fol.96.

G. 88. Turbolabro craffo, coloris carnei, punetulis albis adrperfus. G. 89. Turbo lacteus, ore longiffimo aureo, cujus orbes crenæ \& papillæ depreff $x$ a bafi ad mucronem usque profequuntur, . Fufus een Spil Rumpbii Tab.XXIX. Lit. F. fol.96. Bonarn. Clafi.III. num.160.

G. 90. Turbo flavefcens, ventre ftriato, turbine toto tuberculofo. G. 91. Turbo coloris carnei lævis, labro inverfo, teffellulis nigris, \& turbine notulis quadratis aureis condecorato.

G. 92. Turbo albus fecundum longitudinem totus friatus.

G. 93. Turbo albus, ore longiffimo, notulis nigris, a fummo vertice mucronem usque circumvolutus.

G. 94. Turbo aureus, commiffuris binis leviflimis fpiraliter cinEus, maculis albis fine ordine flexuofis excurrentibus.

G. 95. Turbo fubalbis lineis denticulatis \& linea alba a bafi ad mucronem difcurrente.

G. 96. Turbo albus lineis aureis fecundum longitudinem mire circumductis, C. Strombus lanceatus Rumpbii Tab.XXX. Lit, G. fol.100. 
G. 97. Turbo elegantiffimus albus téfellulis nigris juxta fpirarum commiffuram extimam poititis.

G. 98. Turbo maximus albus, teffellulis aureis ita exornatus.

G. 99. Turbo Pontificia Tiara minima dicta, teffellulis arantiatis fupra lacteum colorem pofitis, num.VI.

G. 100. Turbo albus, cujus orbes crenæ fine papillis a bafi ad mucro: nem usque profequuntur, ore longiffimo, maculis oblongis aureis condecoratus.

G. IOI. Turbo ejusdem coloris reticulatus, notulis quadratisflavefeentibus ordinatiffime difpofitis, incifuris in turbine ordinatiffimis inftruetis.

\section{ARTICVLVS III. \\ Strombi,}

side Cocblea marine ore $\forall$ mucrone frmul infigniter Ilongatis, $\sigma$ prime pira notabiliter angufiore quam in buccinis, Germ. Schtaub:Schnecten.

H. I. Strombus maximus lavis argenteus a cortice albo colore purpureo maculato liberatus. Bonännins Clafr.III, num. 102. five Trochus pyra. midalis fonfoni de Exangvib. aquat. Tab.XI. pag.47. Rumpbims Tab.XXI. Lit.A. fol.74.

H. 2. Strombus maximus albus cum cortice externo, colore viridi, rubro \& albo variegato, $\mathrm{C}$. Trochus primus maculofus Rumpbii Amb. Rar. Kam. Libr.II. Tab.XXI. Lit. A. fol.74. Bonann. ClaffIIII. num.JO2.

H. 3. Strombus longiffimus argenteus, tuberculis fecundum fpirarum duetum inftructus diverfa magnitudinis num.VIII.

H. 4. Strombus decorticatus, fulcis ubique minutiflimis rugofus, chalybem politum coeruleum referens.

H. 5. Strombus ejusdem figuræ cinereus punctulis fanguineis adfperfus.

H. 6. Strombus violaceus, granulis allois fpiraliter cinctus.

H. 7. Strombus argentei fplendoris in circulum ftriatus.

H. 8. Strombus argenteus Itriis granulatis circumduetus (majores \& minores.) 


\section{PROMTVARIVM RERVM NATVRALIVM}

H. 9. Strombus tuberculis in linea f pirali diftributis, fubftantix argentex, quem cutis colore viridi \& purpureo variegata, circumdat. H. 1o. Strombus longiffimus ftriis mucronatis albis elegantiffimis fupra colorem margaritarum pofitis.

H. Ir. Strombus albus inferius punctulis rubris fecundum fpirarum ductum notatus.

H. 12. Strombus fuperius argentei fplendoris, inferius colore albo, nigro \& fubviridi variegatus.

H. 13. Strombus cinereus punctulis oblongis purpureis a bafeos modiolo verticem usque tendentibus.

H. I 4. Strombus parvus albus fafciis ita repentibus fufcis.

H. I 5. Strombus fubviridis, colore purpureo maculatus.

H. I6. Strombus albus maculis quadratis oblongis fanguineis adfperfus, inferius punctulis dilutioribus in linea fpirali diftributis.

H. 17. Strombus fuperius argenteus $f_{\text {. a }}$ cortice liberatus; inferius colore albo \& viridi variegatus, vid. Rumph, Tab.XXI, pag.74. fub nomine Trochorum.

H. 18. Strombus ubique tuberofus argentei fplendoris, Bomann. Clan: III. numm, 20 .

\section{ARTICVLVS IV. \\ Cylindrî,}

sibe Cocblee pyramidales, bafi volutarum ad infar fonicarum vel Carine thiacarum in fpiras convolute, ore longifimo, Germ. Cylindev: Sthnetten.

I. I. Cylindrus albus, notulis piceis quadratis minimis condecoratus. Bonann. Cl. III. num. 122. Rumapbius Tab. XXXI. Lit.D.

I. 2. Cylindrus albus maculis croceis quadratis \& oblongis alternatim cinetus.

I.3. Cylindrus albus colore aureo notatus.

I. 4. Cylindrus albus maculis nigris incurvis circumductus . . $\mathrm{Mu}$ fica rufticorum Rumpbii Amb. R.K. Tab. XXXIII. Lit. BB. pág, 106.

1.5. Cylindrus albus mire variegatus.

I. 6. Cylindrus coloris vinei, zona alba cinctus, quam notulæ nigra diftinguunt. Bonann. Clar, ill, num. 139. 


\section{ET ARTIFIĈLLLIVM KVNDMANN. VRATISLAV. 143}

1.7. Cylindrus lacteus.

1.8. Cylindrus tigrinus niger notulis rotundis albis infignitus. Olear. Gostorp. K, K. Tab. XXXI. n. 2. p. 60.

I. 9. Cylindrus lacteus punetis fufcis minimis ornatus.

1. 10. Cylindrus albus maculis piceis curvis in fpiram contortis.

I. II. Cylindrus fufcus, quem zona \& maculæ albæ circumdant.

I. 12. Cylindrus notulis quadratis nigris, fupra flavum colorem diffeminatis.

I. 13. Cylindrus maximus albus notulis quadratis nigris circumduEtus, f. Voluta muficalis Rumpbii Amb. Rar. Kam. Tab. XXXI. Lit. C. fol. 102 .

1. 14. Cylindrus maximus niger, colore albo maculatus.

I. 15. Cylindrus lacteus, maculis fufcis \& punctulis ejusd. coloris in fpirali linea difpofitis, f. Voluta maculofa Rumpbii Tab. XXXIr. Lit.Q. fol. 105.

I.16. Cylindrus albus colore ceruleo \& nigro variegatus.

1. 17. Cylindrus maximus maculis albis, per colorem nigrum fparfis. Rumph. Tab. XXXII. num. I.

1.18. Cylindrus candidus, fafciolis piceis fegmentatus.

I.19. Cylindrus albus, colore aureo variegatus, lineis faturatioribus fecundum longitudinem repentibus, ff. Voluta filofa Rumpbii $\mathrm{Tab}$. XXXIII. Lit. W. pag. 106.

1. 20. Cylindrus notulis albis \& fufcis, fupra colorem carneum dif feminatis.

I.21. Cylindrus albus fafeiis flavefcentibus obvulutus.

J. 22. Cylindrus aureus colore albo denticulatus. num.IV.

1.23. Cylindrus maculis oblongis \& triangularibus albis per nigrum colorem fjarfis f. Voluta marmorata Rumpbii Tab.XXXII. Lit. N. fol. 104. Numer. $X$.

1.24. Cylindrus lacteus colore aureo totus maculatus.

1.25. Cylindrus ejusdem coloris, incifuris in apice ordinatisfimis. 1. 26. Cylindrus albidus, lineis fufcis a bafi ad mucronem circum. duetis, $\Upsilon$. Voluta filis cinifta rarisfima. Rumph. Tab. XXXI. Lit. V.fol.1os. 1.27. Cylindrus fpadicei coloris, fuper quem fafcia alba mire varie. gata in medio difcurrit. 


\section{PROMTVARIVM RERVM NATVRALIVM}

I. 28. Cylindrus albus maculis oblongis aureis obvolutus.

1,29. Cylindrus albús colore fufco \& cœruleo variegatus.

I.30. Cylindrus albus maculis viridefcentibus \& punetis-nigris, in fpirali linea diftributis. Convenit cum delineatione pretiofiflimi Cylindri 500. fluren. xftimati, fub nomine Admiralis, quam dedit Rumphitus Tab. XXXIV. Lit. A. fol. IO8.

1. 31. Cylindrus albus punctis fufcis minimis ornatus, $\mathrm{r}$. Voluta arenata, Zandhoorntjes of. Vliegefcheetjes Rumphii Tab. XXXIII. Lit. AA. fol. 106.

\section{ARTICVLVS V. \\ Turbines Cylindroides,}

Sive Cocblea aquali craffitie in longum products ore longiffimo, in bafi vere mucronem turbinatum referentes, Germ. Cylinorifdbe Sctitaub:

f̧órner.

K. I. Turbo Cylindroides coloris nigricantis. Bonannus L.C. Claff. III. num. 326 .

K. 2. Turbo cylindroides lævisfimus atrorubefcens $\mathbf{f}$. Cylindrus niger Rumpbii Tab.XXXIX. num.2. pag. I19.

K. 3. Turbo cylindroides rufus, maculis albis triangularibus totus adiperfus.

K. 4. Turbo cylindroides niger ita maculatus.

K. 5. Turbo cylindr. colore albo, fubviridi \& aureo mire variegatus. Bonann. Cl. III. num. I42.

K. 6. Turbo cylindr, notis albis \& fufcis triangularibus diftinetus.

K.7. Turbo cylindr. albus colore fulphureo maculatus.

K. 8. Turbo cylindr. albus notulis fufcis infignitus.

K. 9. Turbo cylindr. albus, maculis cœruleo triangularibus notatus.

K. 10. Turbo cylindroid. totus cinereus.

K. II. Turbo cylindroid. variegatus inter album \& viridefcentem colorem.

K. 12. Turbo cylindr.colorealbo \& aureo variegatus, lineis nigricantibus 
ET ARTIFICIALIVM KVNDMANN. VRATISLAV. 145

tibus in triangulum elegantiffime duetis. Olear, Gottorp. Kunft- $\mathrm{K}$. Tab. XXXI, num, I.

K. 13. Turbo cylindr.albus lineis purpureis ita ferpentibus, ut usquequaque parvos triangulos efforment. Id. Olearius L. C.Tab, XXXI. num. 4. pag. 60.

K. 14. Turbo cylindr. coloris fufci $\&$ albi, minutisfimis fulcis leviter rugofus.

K. 15. Turbo cylindr. albus maculis \& pungtisaureis ornatus.

K:16. Turbo cylindr. colore pallido.

K. 17. Turbo cylindr. albus lineis fufcis finuofe inflexis.

K. 18. Turbo cylindr, coftatus lacteus maculis fanguineis.

K. rg. Turbo cylindr. coloris vinei, maculis triangularibus nigris.

K. 20. Turbo cylindr. fufcus fafcia albida fupra dorfum dueta.

K. 2I. Turbo cylindr. albus, maculis \& punctis nigricantibus notatus.

K. 22. Turbo cylindr. colore albo \& aureo variegatus, lineis nigricantibus fine regula difcurrentibus.

K, 23. Turbo cylindr. maandris nigricantibus \& maculis fufcis fupra colorem flavum \& album diffeminatis. Bonam. Glaff, III. num. i4 $\mathrm{r}$. it. Rumph. Tab. XXXIX. num.9.

K. 24. Turbo cylindroid. aureus colore albo denticulatus, fafciis albis tranfverfim cinctus, $f$. Luhnana Rumpbii Amb, R. K. Tab. XXXVII. Lis, S, fol, irI.

K. 25. Turbo cylindroides colore albo \& fufco variegatus, lineis fub. nigris in triangulum ductis.

K. 26. Turbo cylindroides fubalbus, fafcia lactea obvolutus.

K. 27. Turbo cylindr. albus, colore rutilo dentatus.

K.28. Turbo cylindr. maculis triangularibus albis totus adfperfus.

K.29. Turbo cylindr. coloris nigricantis, maculisalbis \& lineis ejusd. coloris tranfverfim cinftus.

K. 30. Turbo cylindr. cinereus ejusdem fruquræ, minutiffimis fulcis leviter rugofus, $\mathrm{f}$. Voluta tigerina Rumpbii Tab.XXXI. Lit. F. fol.,103. K. 3I. Turbo cylindr. albus, fafcia \& notulis nigris infignitus. K. 32. Turbo cylindr, coloris fpadicei, maculis triangularibus albis condecoratus. 


\section{PROMTVARIVM RERVM NATVRALIVM}

K. 33. Turbo cylindr, rofei coloris, ore carneo, fafcia nigra notato.

K. 34. Turbo cylindr. albus, fufco colore maculatus, fuper quern line: aure in triangulum ductæ difcurrunt.

K. 35. Turbo cyl. albus, colore aureo variegatus, lineis furcis ita ferperitibus, ut meros triangulos efforment.

K. 36. Turbo cyl. maculis triangularibus albis \& caftanei coloris diftinctus.

K. 37. Turbo cyl. albus, lineis punctatis aureis circumduetus.

K. 38. Turbo cyl. albus, notulis nigris \& cœruleis, quæ in aureum abeunt, condecoratus ore violaceo.

K. 39. Turbo cyl. albus, maculis nigricantibus ita infignitus.

K.40. Turbo cyl. colore albo \& aureo variegatus, lineis nigris inordinatim repentibus, quem farciæ dua colore nigro maculatæ cingunt. vid. Rumpbii Amb. Rar. Kam. Lib. I. Tab. XXXLX. fol. 120. num.3.

K. 4I. Turbo cyl. albus, lineis fufcis ita infcriptis, ut meros parvos triangulos efforment. id. Rumpb. L. C. num. 5 .

K. 42. Turbo cyl. flavus totus notulis nigris infperfus. id. Rumph. L. C. num. 6 .

K 43. Turbo cyl. aurei coloris, maculis triangularibus albis, quas lineæ fufcæ circumdant, refertus.

K. 44. Turbo cyl. albus maculis nigris triangularibus prope turbinem obvolutus.

\section{ARTICVL V̈S VI. \\ Buccinx,}

Sive Cocblea marine ore Es mucrone fimul elongat is, prima pira notabititer bentricofa, Germ. Kinch = SDơner, Soln= Sdbueden,

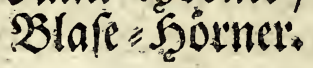

L. 1. Buccina Tritonis maxima antonomaftice dicta, quam maculæ femicirculares rufæ, albæ \& fpadiceæ invicem alternatæ, con . decorant. del. \& defcr. Bonennus Claft. III. num. 188. Fob. Henr. Locbneras Muf. Beslerian. Tab. XXI. pag. 73 . de ufu in cibis \& Medicina fufe $12 l$. Aldropandus de Teftaceis Libr.Ill. Cap. VI. fegq.

L. 2. Buccina minor elegans, maculis femilunaribus albis \& aureis diftincta. Rumpb. Tab. XXIIX, Lit. B. fol.94. 
ET ARTIFICIALIVM KVNDMANN. VRATISLAV. 147

L.3. Buccina inter quinas firiras mucronata, maculis atrorubefcentibus oblongis fupra albam teftam difperfis, interne velo rofeo velata. Bonann. Clafr.III. num. rgz.

L. 4. Buccina flavida, fafciola badii coloris a bafi ad mucronem vittata, C.Buccinum lineatum Rumpbii. Tab. XXIX. Lit.P. pag.97.

L. 5. Buccinula alba tenuiffimæ ftrueturæ.

L.6. Buccina ftriata \& undata colore aureo \& cinereo variegata. Mart. Lifferu Hiftor. Animal. Angl. Cap. II. Titul, II. pag. I\$6.Tabul. III.

L.7. Buccina undiquaque alba ftriata.

L. 8. Buccina crufta tuberculofa inftrueta.

L. 9. Buccina monftrof nigra, adnatis variis crifpaturis $\&$ tubulis vermicularibus.

L. Io. Buccina limofa, minutiffinis fulcis afpera in omnibus fpiris. L. ir. Buccina limofa minor acuminata, fafciis eleganter crifpatis. L. 12. Buccina colore aureo per totum roticulata. Bonainus Claff.III. num. 190.

L. I3. Buccina ftriata, orbibus duobus albis, cæteris aureis, ore circumplicato.

L. I4. Buccinula alba, fafcia \& linea fufca alternatim cineta.

L. 15. Buccina tota ftriata, carnei coloris, labro inverfo.

L. 16. Buccina fubflava, ftriis fecundum longitudinem \& latitudinem difcurrentibus, coltis eminentioribus.

L. 17. Buccinula alba, colore purpureo \& flavo variegata.

L. I8. Buccina aculeata Rumpbii Tab. XXIX, Lit.N. fol.97.

L.19. Buccina lineis albis \& fufcis alternantibus a bafi ad mucronem circumductis. Bonannus Claff. III. num. 47 .

L. 20. Buccina omniex parte alba \& maxima.

8

$$
\begin{gathered}
\text { ARTICVLVS VII. } \\
\text { Murices, }
\end{gathered}
$$

Sibe Cocblea canaliculate extrorfum incurbata, mucronate vel tubero/s, prope fummitatem e latere dextro fulcate E aurite, Germ. Stadficl= Sctinicten.

M. I. Murex fubflavus, duplici fafciola badii coloris in Ipiram conT 2

torta, 


\section{PROMTVARIVM RERVM NATVRALIVM}

torta, a vertice mucronem usque circumvolutus, fructus eft maris Perfici \& tefte Bonanno magni pretii, (vid. Claff. III. num. 287.) S. de Gebande Knobbel-Hoorn Rumpbii Tab.XLIX. Lit. K. fol.16t。

M.2. Ejusdem fpecimen minimum dilutioris coloris.

M. 3 . Murex muficus pallidus $\mathcal{C}_{\text {. a }}$ natura lineis VI, aureis, \& notis muficis nigris infignitus.

M. 4. Murex talis muficus, totus elegantiffime variegatus. Bonannus Claff. III. unum. 297. Lifferus in Hiftor. Conchil. Libr. IV. Sect. XI. Cap. II.num.805. Locbnerus Muf. Besler. Tab. XXI. pag. 75, Rocbefort Befchr، der Anrillen-Infuln Cap.XंXX. nuni.XI. pag. 332 .

M. 5. Murex muficus, lineis tribus aureis \& notulis nigrismire jux. ta fe pofitis.

M. 6. Murex multis apicibus inftructus, ore rugofo variegato, coloris fublutei, $\mathrm{f}$. Cornuta millepéda, Duizentbeen Rumpbii Tab.XXXVI. Lit. I. fol. t12.

M. 7. Murex talis colore cinereo \& aureo variegatus, ore rugolo. Bonann. Claff. IIt, num. 3 t2.

M. 8. Murex pentadaAylus, ore carneolavi. Bonam. Cl.ilt. num. 3it. Rumph. Tab. XXXV. Lit. F. fol. Ito.

M. 9. Murex feptem appendicibus decorus, 1 . Heptadactylus, coloris albidi, ore interne coccineo.

M. 10. Murex maximus variegatus, ore rofeo corrugato, fenis apicibus canaliculatis inftructus, $f$. Harpago Duivelsklauw Rumpbii Tab. XXXV. Lit, A. fol. 109. vid. Gob. Henr. Locbnerus in Muf, Besler. Tab. XXI. pag. 74. it. Liferus in Hiftor, Conchilo num, 870. Gottwaldus Muf. Conchylior. Tab. IV. Cupr. VII. num. i4t.

M. If. Murex alatus externe albus, interne carnei coloris maximus. Bonann. Cl.III. num. $40 \%$.

M. 12. Murexalbus fafciis fulcisque nigris circumvolutus.

M.13. Murex crufta terrea veftitus, ad oris aperturam mire inflexus.

M. 14. Murex fufcus, maculis albis triangularibus decorus. M. 15. Murex colore albo \& nigro variegatus, aculeis fupra fpirarum orbes difpofitis, $f$. getackte Switzers - broek Rumpbii Tab. XLIX. Lit. L. fol. Iót. Bonann. Claff. 111. num.286.

Mi 16. Murexauritus validifimus tuberofus, ex albo \& fufco verficolor, labro inverio. 
ET ARTIFICIALIVM KVNDMANN. VRATISLAV. 349

M. 17. Murex aureus, fafcia alba ramofa infignitus.

M. 18. Murex ex flavo \& fufco denticulatus. Bonannus Claff. IIt. num. 30 s. M. 19. Murex elegantiffimus variegatus, cottis in lóngitudinem \& lineis tranfverfim ductis, C. Harpa Rumphii Tab. XXXlit. Lit. L. fol. to 40 numero VI. diverfe magnitudinis.

M.20. Murex albus tuberculis nigris, ore monftrofo ceerulea

M. 2I. Murex validiffimus tuberofus, coloris carnei.

M. 22. Murex albus, fafcia aurea cinctus.

M. 23. Murex rofei coloris, turbine tuberofo.

M.24. Murex Americanus maximus, coloris terrei, cui interne fub. eft rofeus.

M. 25. Murex auritus tuberofus validiffimus, maculis aureis fupra album colorem diffeminatis. Bonannus Claff. III. num. 301.

M. 26. Murex lacteus coltatus, incifuris in turbine ordinatiffimis. M. 27. Murex laeteus coftis tuberculofis, labro extenfo, fub quo precipua pars coni occultatur. Bonannus Claff. IIr. num. 175.

M. 28. Murex albus ftriis aureis obvoluttis ore longiffimo. $2 d$. Claff. III. num. 306 .

M. 29. Murex limofus coftatus elegans, minutiffimis mucronibus afper in omnibus fpiris.

M. 30. Murex coloris rubicundi, mucronibus canaliculatis inftru. Eus. Bonann. Claffi III. num.299.

M. 3t. Murex auritus tuberofus albus, eleganter lineolis fufcis in. friptus.

M.32. Murex alatus nivex albedinis colore aureo variegatus aculeis longióribus. Bonannus Claft. IIt. num. 321.

M.33. Murex auritus albus, tuberculis in turbine ordinatiffimis.

M. 34. Murex auritus albus, colore flavo maculatus, ore interno coccineo. Bonann. Cl. Ill, num. 302.

M. 35. Murex lasteus elegans totus tuberofus, maculis aureis. M. 36. Murex albus, coftis eminentibus ad oris aperturam inflexus, maculis aureis fecundum longitudinem repentibus. Rumph. Tab. XXXV. Lit. C. fol. 109 .

M. 37. Murex totus ftriatus albus, mucronibus fecundum ordinem inftructis. 1d. Tab. Xsill, Lit. D. fol.80.

$$
\text { T } 3 \text { M. } 38
$$


M. 38. Murex ftriatus cinereus, fafciis binis albis cinctus. Bonannus Claff. III. num. 357.

M.39. Murex oleaginei coloris maculis albis triangularibus infignitus, mucronibus in turbine ordinatiffimis \& robuftiffimis.

M.40. Murex colore vineo, turbine mire crenato.

M. 4I. Murex albus, colore nigro variegatus, mucronibus validis totus armatus. Rumpbius Tab. XX. Lit. I. fol. 72.

M. 42. Murex alatus albus, incifuris in turbine ordinatiffimis.

M. 43. Murex colore albo \& aureo variegatus, coltis tuberofis in appendices definentibus. Bonann. Cl. III. num. 315. Rumpb. Tab. XXXV. fol. ro9.

M. 44. Murex rofeus ftriatus \& alatus fuperne appendicibus deco. rus, ore purpureo, ventre albo, colore aureo maculato, ${ }_{2}$. Alata lata Breed-lipp Rumpbii Tab.XXXVI. Lit. L. fol. Iro.

M. 45. Murex auritus totus tuberofus, quem color carneus, in album abiens, hinc inde terminat, f. Cornuta decumana Rumph.Tab. XXXV. Lit. H. fol.no.

M. 46. Murex tuberofus, maculis aureis faturatioribus fupra album colorem diffeminatis.

M. 47. Murex fubflavus, coltis ad cris aperturam eleganter inflexis. M. 48. Murex albus mucronibus nigris ubique inftructus. Rumpl. Tab.XXIV. Lit. E. fol.82.

M. 49. Murex coloris albi, turbine crenulis ordinatiffime inftructis, labro extenfo.

M. 50. Murex badii coloris, duplici fafciola alba in firam contorta, a vertice mucronem usque circumvolutus. Bonan. Claff.llI. num.357. M. 5I. Murex coloris rutili, mucronibus tine ordine difpofitis, fafciis lineisque albis circumductis. Id. num.295.

M. 52. Murex albus apicibus VII. nodofis inftructus, ore rugofo, Podagrica vulgo, f. Cornuta nodofa Rumpbii Tab.XXXVI. Lit. K. fol.100. Bonan. Claff.III. num, 3 I2.

M. 53. Murex candidiffimus, colore aureo maculatus \& quinque appendicibus inftructus, fœmina; de Podagræ Kreeft Rumpbii Tab. XXXVII. num.i. fol.ri2. Bunan. Claff.III. num. 14 . \& 315 .

M. 54. Murexalbus inturbine leviter tuberculofus. 


\section{ARTICVLVS VIII. \\ Purpuræ,}

sibe Cocblea canaliculate crafsiores, ore ex latere finiftro labiofo e pluribus laminis fob invicem impofitis, cocbleate, friate $\mathcal{E}$ rugofe,

\section{Puipul: Sctinecten.}

N. I. Purpura echinataf: Hyftrix marina coloris terrei. Bonann. Clafr. III. num.269. Ferrand. Imperatus Hift. Nat. Libr.XXVIII. pag.912. Olearius Got: torp. Kunft-Kam. Tab. XXIX. num.i. pag. 5 .

N. 2. Purpura leviter ftriata flavefcens, fafcia alba cineta.

N. 3. Purpura tota tuberculofa.

N. 4. Purpura alba ventricofa validis mucronibus armata. Bonann. ClaffiII. num.28.

N. 5. Purpura alba ventricofa, aculeis clavorum inftar acuminatis, Id. Claff.HI. num. 283.

N. 6. Purpura echinata, quam crufta terrea circumdat. Id. Claff. III.' num. 282 .

N. 7. Purpura alba canaliculo oblongo inftrueta, tuberculis, lineis, notulisque flavis \& furvis depieta. Id. Bonannus Clafr.III. num,268.

N. 8. Purpura echinophora ore circumplicato afpero.

N. 9. Purpura pallida undiquaque tuberofa \& tonfillis plena. Bonann. Claff.III. num.280.

N. 10. Purpura triangularis undiquaque rugofa. Idem. C1.IIr. num.290. N. II. Purpura triangularis crifpata canaliculis circumplicatis, ore coccineo, $I d$. Claft.III. num.27б.

N. 12. Purpura fafciata fupra teftam prævalidam aculeatam. $I d . \mathrm{Cl}$. III. num.186.

N. 13. Purpura tribus fpiris convoluta, aculeis canaliculatis inftrueta, f. Cáffis tuberofa Rumpbii Tab.XXIII. Lit. A. fol.79.

N. 14. Purpura rariffima triangularis ftriata, triplici ferie ut crifpatæ lactucæ ciftus circumplicatus. Bonasm. Clafto III. num. 276. $\Upsilon$. Murex ramofus Rumpbii Tab.XXVI. Lit. A. fol.85.

N. 15. Purpura alba tuberofa zonis arantiatis, ore denticulato monftrofo, f. Haairige Ooren Rumpbii Tab.XXIV. Lit. F. fol.\$2.

N. 16. Purpura alba ráriffima, appendicibus nigris crifpatis condecorata.Rumph. Tab,XXVI, Lit, C. fol, $8 \sigma_{\text {. }}$

N. 57. 


\section{PROMTVARIVM RERVM NATVRALIVM}

N. 17. Purpura alba trànsverfim coftata \& rugofa mire informis, crenulis imbricatis, oris apertura angufta. Bonann. Claff.III. num. 35 . N. 18. Purpura colore aureo coftis tuberculofis, fecundum fpirarum duetum inftrueta.

N. 19. Purpura cinerea yentricofa br evibus mucronibus armata. Bonann. Claff.lli, num.28r.

N. 20. Purpura fubalbida elegans, fafciis rufis cincta, cujus orbes coftæe eminentiores muniunt. Bonann. Claff HI. num.278.

N. 2 I. Purpura fafciis albis \& fufcis tuberculisque fecundunt ordinem circumvoluta.

N. 22. Purpura mucronibus duplicatis \& tuberculis elegantiffime fupra album \& aureum coloren alternatim pofitis.

N.23. Purpura alba, coftis fubnigris eminentibus denticulatis cineta, N. 24. Purpura alba, appendicibus nigricantibus, a turbine usque ad apicem difcurrentibus.

N. 25. Purpura alba, mucronibus \& tuberculis obvoluta.

N. 26. Purpura coloris rufi, fafciis albis transverfim, \& coftis eminentibus fecundum longitudinem inftrueta.

N. 27. Purpura tota aculeata elegantiffima, f. Tribulus Spinne-Kop Rumpbii Tab.XXVI. num, 3. fol,86.

N. 28. Purpura echinata maxima,coloris carnei, Id. Rumph. L.C. Lit.G. N. 29. Purpura alba coltata, fafciis albis \& fufcis alternatim cincta. N. 30. Purpura fubcoerulea tuberculofa, canaliculo oblongo inftrueta, lineis maculisque flavis \& nigricantibus picta.

N. 3r. Purpura fufca ventricofa validis mucronibus armata. N. 32. Purpura talis coloris nigri.

\section{ARTICVLVS IX. \\ Porcellanx, five Venerex,}

Sibe Teftacea marina univalbia non turbinata, fed ita in fe fecundum longitudinem contorta, ut eorum circumbolutiones nulla ex parte promineant, apertura rims inflar angufta, dentata vel friata, quandoque etiams levi, ac per bafmextenfa, Germ. Porcellain: Sdinc:

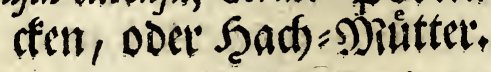

O. I. Venerea lactea, $\mathrm{C}$, Ovum marinum intus flavum Rumphii $T$ ab. XXxvill. 
ET ARTIFICIALIVM KVNDMANN. VRATISLAV. 153

XXXVIII. Lit. Q. fol,IIs. Bonann, Claff,ill, num.252, Conf, Epbem. Nat, Curiof. Dec.II. An.V. Obferv. CXII. pag.26.

O. 2. Venerea lactea tribus fafciolis nigris fegmentata, num.XXV. 0.3 . Venerea alba filis aureis finuofe inflexis, quam labra melle flavelcentia \& puneta rufa fpeetabilem reddunt. Bonan. Claff.II. num.242. 0.4 . Venerea rufa, ftellulis albis condecorata, (qua loco pecunix habetur in Philippinis infulis.) Bonan. Claff.III, num,247. f. kleine Slangekoppen Rumpbii Tab.XXXVIII, Lit.F. fol,II4.

0. 5. Venerea teftudinis inftar gibbofa, colore fpadicea, in dorfoftelIulisalbis infignita. Bonan. Claff,iII. num,258.

0. 6. Venerea fubrufa, notulis rotundis albidis pieta, quarum centra punetis nigris indicantur.

0.7. Venerea pallida parva, ventre albo.

0.8 . Venerea granulata, labris mirifice crenatis.

O. 9. Venerea alba, circulo in dorfo croceo. Rumpbius Tab.XXXIX. Lit. D. fol.117.

O. 1o. Venerea alba Africana, , Moneta Nigritarum. vid. Joh.Bapt.Ta . verniers Reife-Befch. P.II. pag.219. \& 223.

O. I1. Venerea colore vineo punctulis albis adfperfa.

O. 12. Venerea colore aureo.

O. 13. Venerea diverficolor, fafcia aurea fupra dorfum duefa.

O. 14. Venerea alba, notulis aureisinfignita.

0.15 . Venerea cinerei coloris, punctulis nigris fupra dorfum fecundum longitudinem pofitis, $\mathcal{f}$. Ifabella Rumpbii Tab.XXXIX. Lit. G. fol.II8. 0. 16. Venerea mole parva alba ftriata.

O. 17. Venerea alba, filis aureis ita ferpentibus, ut angulos acutos frpiffime efforment, num.XX.

O. 18. Venerea coloris badii, notulis fubnigris, quarum centra punCtis albis indicantur, ventre purpureo.

O. 19. Venerea literata Chinentis.

0. 20. Venerea literata Arabica, C. Dorfo velut characteribus nigris picto, Letter-hoorntjes Rumpbii Tab.XXXVIII. Lit. M. fol..IIs. Conf. Epbem. Nat. Curiof. Dec. II. An. V. Obf. CXII. pag. 222. it. Mufeum Gothwaldias. num Tab.III. Capf.V. \& Tab.II. Capf.XXVI. \& F. H. Locbneri Muf, Besler. Tab. XXI. fig.8. pag.75. 
O. 2I. Venerea coloris cinerei, punctis albis.

O. 22. Venerea ex albo flavefcens.

0.23 . Venerea alba, notis rutilis.

O. 24. Venerea carnea, labro punctato.

0. 25. Venerea albida, fafciis rufis.

O. 26. Venerea maxima Tigris antonomaftice dieta, C. Porcellana guttata Rumpbii Tab.XXXVili. Lit. A. fol..ll.

O. 27. Venerea minor alba maculis piceis.

0.28 . Venerea obfcure albicans notis quæ nigrum difcriminant fufcis.

0. 29. Venerea læviffima, maculis nigricantibus.

O. 30. Venerea alba noris \& fafciis aureis cincta.

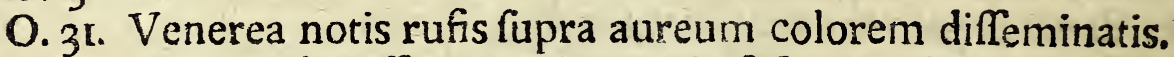

O. 32. Venerea læviffima variegata \& fafciata colore fubviridi, Bonann. Claffilil. num.207.

O. 33. Venerea fubflava notis albis adfperfa. Bonann. Claf.III. num.2 $\{4$.

O. 34 Cochlearia num.XII. ex cochleis venereis diverfimode maculatis, \& conchis margaritiferis parata Brafilienfium. vid. Georg. Marcgravii de Braflitix Regione \& Indigenis Cap.VI. pag.IG.

0.35 . Venerex interna mira facies.

O. 36. Venerea tefta prævalida elegans, colore rutilo variegata, dentibus fufcis armata \& inftar marmoris expolita. Bonann. Claf, iII. num. $26 \mathrm{r}$.

0.37 . Venerea alba notis paucis nigris iniignita.

O. 38. Venerea Americana ftriata dorfo finuato, $f$. Pediculus Rum. pbii Tab.XXIX. Lit, P. fol.I18.

O. 39. Venerea dorfo coeruleo, ventre albo.

O. 40. Venerea crocea eleganter maculata \& oculata. Bonan. Clarf. III. num. 359 .

O. 4I. Venerea alba maculis in ventre aureis.

0.42 . Venerea dorfo cinereo cingulo variegato.

0.43 . Venerea coloris fubflavi, Ifabella difta.

O. 44. Venerea læviffima, colore amethyftino, labro albo, notulis adfperfis nigris, in apice leviter turbinata.

O. 45. Venerea alba medio annulato, labris expofitis. Benann. ClariIII. num.249.

0. 46 . 
O. 46 . Venerea coerulea notulis albis \& fufcis pieta.

0. 47. Venerea fuperius aureis, inferius nigris \& carneis notulis pradita.

O. 48. Venerea fubflava, fafciis duabus faturatioribus fupra dorfum ductis, ventre fufco, $f$. Talpa een Mol Rumpbii Tab. XXXVIII. Lit. I. fol.tr5.

O. 49. Venerea dorfo violaceo, ventre albo.

O. 50. Venerea alba in dorfo maculis flexuofis ornata, labro pun. Etato.

0. 5I. Venerea tota tuberculofa alba ventre mire crenato, $f_{0}$ Nuffatella granulata Rumpbii Tab.XXXIX. Lit. I. fol.ı18.

O. 52. Venerea alba maculis oblongis aureis condecorata num. XVIII.

O. 53. Venerea alba oblonga minima Entalia $\mathrm{r}$. Antalia dicta.

O. 54. Venerea maxima alba maculis nigris infignita,dorfoque inftar marmoris expolito.

0. 55. Venerea alba colore fubflavo \& cinereo variegata, in apice leviter turbinata.

0. 56. Venerea dorfo coeruleo, colore fufco maculata, ventre albo. 0. 57. Venerea crocea dorfo, literis nigris arabicis fimilibus infcripto.

O. 58. Venerea alba, in dorfo tuberofa, . Witte Jamboezen f.Hoog- $^{-}$ ruggen Rumpbii Tab.XXXVIII. Lit. H. fol.,Il6.

0. 59. Venerea maxima nigricans, dorfo maculis rubentibus ro. tundis \& fufcis infignito, ventre depreffo: Groote Slangekoppen Rumpbii Tab.XXXVIII. Lit. E. fol..I4,

0. 6o. Venerea rariffima albida, annulis aureis undiquaque eleganter condecorata, five Argus Rumpbii Amb. Rar. Kam. L.II. Tab.XXXVIII. Lit. D. pag.II4. pro omnium pretiofiffima habetur a Bonamno Claff.III. num. 263. pag. 146.

O. 6I. Venerea carnei coloris, fafciis tribus albis fupra dorfum du:etis, f. Carneola Rumpbii L. C. Lit. K. pag.Irs.

0. 62. Venerea coerulea colore fpadiceo maculata', in apice leviter turbinata. 


\section{I56 PROMTVARIVM RERVM NATVRALIVM}

O. 63. Venerea alba in dorfo notulis minimis fufcis \& aureis, infe. rius majoribus \& rarioribus infignita.

0.64 . Venerea diverficolor notulis nigricantibus undiquaque obfita.

0.65 . Venerea cinerei coloris maculis badiis notata.

0. 66. Venerea fubnigra notulis albis adfperfa.

\section{ARTICVLVS $\mathrm{X}$. \\ Neritæ,}

Sive Cocblea marine brebiores perpendiculariter anomale paucis jpiris $E^{\circ}$ mucrone vel umbone param aut nibil eminentibus, ore falcato, Germ.

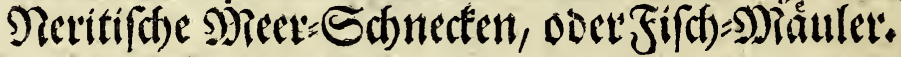

Conf. Carol. Nicol. Langii Methodum Teftacea marina in fuas debitas claffes, genera \& fpecies diftribuendi.

P. I. Nerita fingularis ftructuræ, quafi coralliorum rubrorum lineis circumvoluta, quas linea globulis albis \& nigris alternatim variatæ, interfecant, Pharaonia dieta Bonann. Claff.1II. num.22.

P. 2. Nerita tota cinerea.

P. 3. Nerita colore fubviridi.

P. 4. Nerita nigra.

P. 5. Nerita punctulis albis fupra nigrum colorem diffeminatis.

P. 6. Nerita cinerea colore nigro variegata.

P. 7. Nerita colore aureo maculis albis.

p 8. Nerita elegans rutila, farciolis circumductis nigris, albo colore variegatis, num.VI. Rumpbius Tab.XIX. num.7. fol.zo.

P. 9. Nerita alba maculis nigris infignita.

P. 10. Nerita ftriata albicans ore falcato.

P. II. Nerita coloris terrei, canaliculis nigris in fpiram circumvolutis.

P. 12. Nerita maxima prævalida, corice terreo, maculis nigris.

P. 13. Nerita crufta tuberculofa veftita.

P. 14. Nerita coloris pallidi.

P. 15. Nerita alba maculis femicircularibus nigris, ftriis eminentibus. 
P. 16 Nerita fubrubra, fafciolis nigris \& albis in fpiram contortis. P. 17. Nerita alba tuberculofa, maculis croceis \& appendicibus canaliculatis inftructa, f. Cochlea lunaris afpera Rumpbii Tab.XIX. Lit.E. fol. 7 3.

P. I8. Nerita ftriata alba punctulis coeruleis notata.

P. 19. Nerita parva coloris fulphurei.

P. 20. Nerita alba maculis quadratis aureis pluries cineta. Rumpbjus Tab.XXII. Lit. C.

P. 21. Nerita læviffima coloris flavefcentis.

P. 22. Nerita colore badio inferius fafcia alba circumdueta.

P. 23. Nerita fubviridis, globulis nigris $\&$ albidis, fecundum fpirarum dustum inftrueta.

P. 24. Nerita alba purpureis meatibus \& lineis fubnigris exornata. Bonann. Claffill. num.355.

P. 25. Nerita perlata alba, lineis finuofis purpureis.

P. 26. Nerira alba lævis, ventre oblongo.

P. 27. Nerita viridis ftriata, fafciis albis fanguineo colore maculatis, pluries cincta.

P. 28. Nerita tuberculis in linea fpirali diftributis, fubftantiæargentex, quam cutis viridis circumdat.

P.29. Nerita alba colore rutilo variegata, cujus maximum orbem mucrones ornant, ore aurei nitoris.

P. 30. Nerita alba fafciis luteis pluries obvoluta.

P. 31. Nerita alba colore aureo denticulata.

P. 32. Nerita ftriata nigra, fafcia firali alba condecorata.

P. 33. Nerita ftriata viridis, eleganter colore nigricante maculata.

P. 34. Nerita nigra punctulis albis adfperfa.

P. 35. Nerita cinerea, lineis nigris, denticulata.

P. 36. Nerita ejusdem coloris \& ftrueturæ lineis nigris fine ordine difcurrentibus.

P. 37. Nerita alba nitidiffima, colore purpureo variegata, quem linex nigræ circuindant.

P. 38. Nerita alba elegans, colore rutilo ftriata, faliata \& macu. lata. 


\section{PROMTVARIVM RERVM NATVRALIVM}

P. 39. Nerita alba fafciis nigris ita ferpentibus, ut undiquaque angulos acutos efforment. Rumpbius Tab. XXII. Lit. N. fol. 78 .

P. 40. Nerita cinerea, fafciis quatuor albis, colore nigro punfatis, cinta.

P. 41. Nerita colore albo \& fufco variegata, fafciis nigris \& albis diverfimode maculatis, \& in fpiram contortis.

P. 42. Nerita coloris aurei.

P.43. Nerita aurea, colore rutilo denticulata.

P. 44. Nerita alba, notulis oblongis nigris in fpirali linea circumductis.

P.45. Nerita tranfverfim ftriata, finulque colore albo \& nigro variegata.

P. 46. Nerita maxima prævalida alba, colore nigro maculata.

P. 47. Nerita argentei fplendoris, mole parva.

P. 48. Nerita tota coftata alba, maculis nigris infignita.

P.49. Nerita flavefcens lineis IV. nigris circumdueta.

P.50. Nerita parva lactea laviffima.

P.5I. Nerita colore nigro denticulata, quam fafcia alba interfecat. Rumpbius Tab.XXII. num.7. fol.78.

P.52. Nerita cinerea maculis quadrangularibus albis in fpirali linea circumduclis.

P. 53. Nerita cornea fafcia alba turbinata.

P. 54. Nerita depreffa alba lævis, $f$. Vitellus depreffus Rumpbii Amb. Rar. Kam. Lib. Il. Tab. XXII. Lit. B. pag. 76. Batav. Witte Kalfs Oogen.

P. 55. Nerita colore albo \& aureo variegata fafciis faturatioribus a fummo turbine ad os tendentibus, ore extenfo, Rumpb.ibid.Tab.XIX, num. 7. pag. 70.

P.56. Nerita elegantiffima maculis fufcis \& albis diftincta, quam faf́ciæ virides colore albo variegatæ fpectabilem reddunt. Id. Rumpb. L. C. num. 5 .

P. 57. Nerita tota nigra ftriata ore albo crenato.

P. 58. Nerita Arachnoides elegantisfima alba, notulis purpureis \& flexuris nigris ubique adfperfa, quæ araneas parvas accuratisfime referunt. 


\section{Sectio II. \\ Regnum Vegetabile.}

QI. Herbarium vivum, aliquot Voluminibus comprehenfum, continens arbores \& frutices optime confervatas, præcipue exoticas, \& officinales fupra 2000. Methodum conficiendi Herbaria viva de. monftr. Guil. Laurenbergitus in Hiftorica Defcriptione Ætetitx. Modum vero colligendi, exficcandi \& confervandi plantas, ita ut pro herbario vivo infervire queant, docuit Eman. Koenig. in Regnó Vegetabili Cap. XXII.

Q.2. Collectio Graminum, Juncorum, Cyperorum, Cyperoidum iisque affinium fupra 120. ex donat. Dni. Petiverii Angli. defcr. \& del. Job. Ant. Bumaldus in Bibliotheca Bocanica in fine, prc. Fob. Scheucbzerus in Agroftographia, it. Fob. Rajus in Methodo Graminum, Juncorum \& Cyperorum fpeciali, adjecta ejusdem Methodo Plantarum pag. 167. it. Fof. Monti in Catalogo Stirpium agri Bononienfis it. Graminuun ac ejusmodi affinium.

Q.3. Florilegium vivum fingulare, in tabula alba vitro tecta, expreffum, flores pietos referens.

Q.4. Flores artificiales ex laminis orichalceis, ferico, linteo, papyro, pennis, cera, phærulis vitreis, quorum elegans ftructura per compresfionem herbarum \& florum vivorum perit.

Q.5.6. Imago viri \& fominæ, tota ex feminibus artificiofe exftru$\mathrm{eta}$, conven. cum delineat. que reper. in $\mathrm{Ad}$. Olearii Gottorpifch.Kunf -Kam. Tab. V. num. 5-8. pag. 6 .

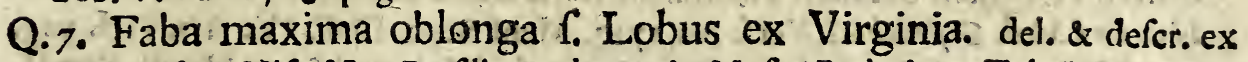
Guil. Pifonis Hift. Nat. Brafilix Locbnerus in Mufeo Besleriano Tab. VI. pag.23. Conf. Carol. Clufii Exoticor. Libr. III. pag. 6I.

Q. 8. Lobus Brafilianus maximus in filiqua. del. \& defcr. id. Cliffus L. C. Lib. III. Cap.I. pag. 60. it. Fob. de Laet in Novo Orbef. Defcripc. Ind. Oc. cidental. Libr. XV. Cap. XI. pag. 569.

Q. 9. Item talis longe major extra filiquam.

Q.10. Semen Anifi ftellati f. Badianæ cum caule. vid. Bartb.Belli Defcr. Anifi ftellati, it. Car. Clufus Hiftor. Pfantar. rariot. Libr. VI. Cap. XXV. Conf. Epbem. Nat.Curiof. Cent. I. Au. VI. \& VII. Obf. LXXIX: pag. Mi.

Q. I I. Fiftula Casfiæ Kgyptiacx. del. \& defcr. in Hort. Malabaric. Parr. I. Tab. XXII. in Profp. Alpini de Plantis \&ggyptiacis pag, 2.Mufeo Calccolar. Vero- 
nenf. Sect, V. pag. 540. Ol. Wormii Muí. Libr. II. Cap. XXIV. pag. 194. Petr. Bellonii Qbf. Libr, II. Cap. XXXVI. pag. 108. Guil. Pifonis Hift. Nat. \& Medic. Ind. Occidentalis Libr.IV. Cap. XXII. pag.158. Jac. Bontii H.ft. Nat, \& Madic. Ind. Oriental. Libr. VI. Cap.X. pag. IOI. Franc. Hernanaez Rer. Medic. Nov. Hilpanix Lib. III. Cap. XLIV. pag. 87. Ol. Dapperi Befchr, von Africa pag. II2, Erafm. Francifci OIt-und Weft-Ind. Luft. Garten Part. I. Tab. XV. p.g. 697. Petr. Pometii Mater. und Spez. Händl. Tab. XXXIX. fig. 220. pag. 383. prc. eleg. del. in Micb. Bernb. Valentini Mufeo Mufeor, Part. L, Libr. HI. pag. $34 \mathrm{r}$.

Q.12. Canna Bambuina. del. \& defcr. Neubofus in Befchr, des Reichs Sina pag. 33r. Erafm. Francifei im Oft . und Weft. Ind, Luft. Gart. Part. I. Tab. IX. fig. I. pag. 253. it. Dionyf. Kao in Befchr. des Kayferth. China Cap. XXIII. pag. 413. qua reperitur poft $r_{s b r}$. Ides Befchr, Chinx pag. 257. feqq. \& Geurg. Mei. fers Oriental. Ind. Kunft - und Luft - Gärtner Cap. VIII, num. XXVII. pag.Ioo.

Q. 13. Semen Abri coloris coccinei, 1 . Phafeolus coccineus IEgyptiacus maximus. vid. Muf. Calcealar. Veronenf. Sect. V. pag. 585. it. Job. Henr. Locbneri Muf: Besler. Tab. VI. pag. 24 .

Q. 14. Canna Saccharifera, del, \& defcr. Ant. Deufingius in Libr, de Manna, Saccharo \& Monocerote, in Muf. Calcealar. Veron. Sect. III. pag. 531. Fob. Rajus Hift. Plancar. Tom.II. Libr. XXII. pag. 1278. Guil. Pifo in Hift. Nat, \& Medic. Ind. Occid. Libr. IV. Cap. I. Rocbefort in Befchr. der Antillen Inful. Cap. X. num. VII. pag. 174. Job. Neubofus in Befchr, des Reichs Sina pag.329. Gearg. Meifter in Oriental, Indian. Kunft - und Luft-Gärtner Cap. IX. num. 33. pag. 128. prc. Frid. Slare in Experimentis \& Oblervationibus circa Lapidem Be. zoardicum, una cum vindiciis Sacchari, Parte tota altera, Frid. Hoffmannus in Differt. Hiftoriam Sacchari Naturalem \& Medicam exhib, it. Unfere Samml. von Nat. und Med. Gefcbicht. I. Verf. An. 1717. Menf. Sept. Claff. IV. Art. VIII. pag. 79. Modum conficiendi defcr. Petr, Ponet in Mat, und Spez, Händl, Part,II. pag I10. feqq. \& ex eo Mich. Bernh. Valentimi in Muf. Mufeor. Part. I. Cap. XVII. pag. 24t. feqq. it. Guil. Pifo in Hift. Nat. \& Med. Lib.IV. pag. 108. feqq. Erafm. Francifci im Oft - und Weft.Ind. Luft.Garten Part. I. Tab. IX. pag. 269. prc. Fob. Bapt. Labat in Relatione Itineris \& moræ in Infulis Americx Antillanis facte Tom. III. it. Fob. Sloane Hift. Itiner, in Infulas Maderam, Barbacam, Nivium, Sti Chriftophori \& Jamaicam pag. 108. ubi plures Auchores præter fupra allegatos, qui Hiftor. Sacchari dederunt, nominavit.

Q. 15. Nux Mofchata I. Myriftica Bantamenfis cum cortice duro interno.

Q.16. Nux Morchata Bantamenfis cum floribus \& corticibus. del. 
ET ARTIFICIALIVM KVNDMANN.VRATISLAV. 16r

del. \& defrer. Carol. Clufius Exotic. Libr.I. Cap. XV. \& XVI. pag. I3. feqq. Muf. Calceolar. Veronenf. Sect. V. pag. 590. Petr. Pomet im Material-und Spezer. Händl. Tab. XXXVII. fig. 190. 191. pag. 259. Job. Hugo Lintfcboctanus Ind. Oriental. Part. IV. Cap. XXII. pag. 52. Ad. Olcarius im Anhang und Befchreib. etlicher Orientalifch. Infuln Libr. III. pag. I58. Georg. Meifter im Oriental. Ind. Kunft - und Luft. Gärtner Cap. VIII. num. 2. pag. 72. Arnold. Montanus in der Gefandfch. an unterfchiedl. Kayler von Japan pag.356. feqq. Guil. Pifo in Mantiffa Aromarica Cap. III. pag.173. adjecta ejusdem Hift. Nat. \& Med. Ind. Occidental. Erafm. Francifci im Oft - und Weft.Ind. Luft-Gart. Part. I.pag. 396. Tab. XII. num. 5. Chr. Vielbeuer in Befchr. frembd: Materialien pag. 129. Fob. Henr. Lacbrierus in MuI. Besler. Tab. III. pag.12. prc. evolvend. Mich. Bernb.Valentini in Oft-Indianifchen Rapporten Num. XIII. pag. 81.-90. \& in Mufeo Mufeor.

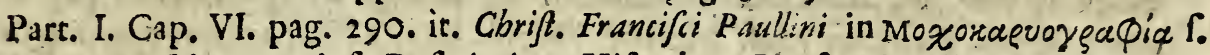
Nucis Mofchate curiofa Defcriptione Hiftorico - Plyfico-Medica \& Job. Henr. Dietzius in Difl. de Nuce Molchata.

Q. 17: NucesMofchatæ Malabaricæ inodoræ. del. \& defcr. Fob. Jonflonus in Hift. Natural. Arborum \& Frutic. Lib. III. Tab. LIII. pag. 160. Ephem. Nat. Curiofor. Dec. II. An. IV. Obf. XXXI. pag. 83. prc. in Ejusd. Valendini OftIndianifchen Rapporten Tab. IV.pag. 83.

Q.18. Nux Mofchata, quæ ultra anni fpatium in Capone delituit. vid. Catalogus Mulei Speneriani num. 25. pag. 198.

Q. I9. Cardamomum maximum in capfula. del. Fob. Fonftonus Hif. Nat. de Arboribus Tab. LVIII. pag. 187. Job. Henr. Locbnerus in Mufeo Beslerian. Tab.IV. pag. 14. it. Mich. Bernb. Valentini in Muf. Mufeor. Part. I. Lib.II. Cap. XIII. fig. II. pag. 124 .

Q.20. Ramus arboris Caryophillorum aromaticorum. del, \& defc Fob. Neubof in Befch. des Reichs Sina pag 434. Guil. Pifo in Mantiff. Aromatic Cap. V. pag. 177. adjecta ejusd. Hiftoriz Natural. \& Med. Ind. Occid. George Meifter im Oriental. Indianifch. Kunft - und Luft - Gärtner Cap. VIII. num. III. pag. 74. del. pag. 83. Mich. Bernb. Valentini Muf. Mufeor. Part. I. Lib. II. Cap. VII. pag. 294. prc. in Ejusd. Oft - Indianifchen Rapporten Tab. II. pag.75.

Q.21. Cerafa botryformia. del. \& defer. in Valentini Muf. Mufeor. Part. II. Tab. XIV. fig. 8. it. in Ephem. Nat. Curiof. Dec. III. An. V. \& VI. Obf. C. pag. 199. fig. 46. Conf. Obferv. meam in Bresl. Samml.XXIV. Verf. An. 1723. Menf. Jul. Claff. IV. Art. VI. pag.92.

Q.22. Fructus Opuntiæ maximæ five Ficus Ind. Oriental. del. \& defcr. in Bresl. Samml. von Nat. und Medic. Gefcbicbt. VII. Verf. An. 1719. Menf Mart. Claff. IV. Art. X. pag. 328. Conf. Ol. IVormii Muf. Libr. Il. Cap. VII. pag 
148. Fob. Fonfloni Hift. Nat. de Arboribus Tab. XXV. pag. \$3. Guil. Pifonis Hift. Nat. \& Medic. Ind. Occidental. Lib. IV. Cap.XXXV.pag. 188. it. Hans Jac. Breunings Oriental. Reifen, I. Meerf. Cap. VIII. pag. 3I.

Q.23. Ramus Palma DaAtyliferæ montanæ Hifpanorum. del. \& defcr. Ol. Wormius Muf. Libr.II. Cap. XXVIII. pag. 205. Rocbefort in Befchr. der Antil. Infuln in America Cap. V1. pag. 119. Fr. Leguat Reif. nach 2. OftIndifch. Infuln Part. I. pag. 90. feqq. Guil. Pifo Hift. Nat. \& Med. Ind. Occidental. prc. accurat. delineav. Foh. Chrif. Volckamer in Appendicef. Befchreib. etlicher fremder Gewächfe Cap. II. pag.222,- 227.

Q.24.25. Ejusdem fructus cum cortice fubflavo minor, it. alius major coloris fufci ex Perfia. vid. f̧ab́. de Lact Nov. Orb. f. Defcr. Ind. Oc. cidental. Fob. Fac. Saars Of - Indianitche XV iährige Kriegs - Dienfte pag. 132. Micb. Bernb. Valentini Muf. Mufeor. Part. I. Cap. XIII. pag. 312. prc. Engoibr. Kämpferus Amœnit. Exotic. Falcic. IV. Rel. V. pag. 703. fegq.

Q.26. Ramus Palmæ Indicæ cocciferæ. defcr. \& del. Ol. Wormius Muf. Libr. II. Cap. XIV. pag. 164. Fob. Fonftonus Hift. N.t. Arbor. \& Frutic. Libr. II. 'Tab. XLIV. pag. 137. Guil. Pifo Hift. Nat. \& Med. Ind. Occidental. Libr. IV. Cap.XII. pag. 130. Erafm. Francifci im Oft - und Weft -Indifch, Luft - Garen Part. I. Tab. IX. fig. VIII. pag. 299. feqq. citante fob. Hugon. Lentfcbotto in Navigutione in Orientem. De Germinatione Amftelodami fagta vid. Ephem. Nat.CÄriof. Dec.ll. An. VII. Obr. CCL. fig. 45. pag. 467 .

Q. 27. Nux Palmæ Indica, $f$. Coccos in cortice externó villofo. del. \& defcr. Rocbefort in Befchr, der Antillen-Infuln in America Cap. VI. pag. 124. in IV altber Scbultzens Oft-Indianilch. Reifen Libr.II. Cap.VII. pag. 172. Thevenot Oft.Indifch. Reif, Part.Ill. Lib. I. Cap. VIII. pag. 33. Fob. Neubofs Befchr. des Reichs Sina pag.341. Pomet im Materialift. und Spez. Händl. pag. 278. fig. 211.-215. Defcript. Phyficam, vid. in Car. Clufii Cur. Pofterior. pag.69. Ol.WVormii Mufeo pag.209. Garc, ab Horto Aromatum Hiftor. Libr.I. Cap.XVI. pag. 10r. feqq. Willb. Dampiers Reife um die Welt Part. I. Cap.. X. pag. 53 G. Mich. Bernb. Valentini Muf. Mufeor Part.I. Cap.XVI. pag.324. in Micell. Nat. Curiof. Dec.II. An.VII. pag.476. Nierembergii Hift. Natural.Libr.XIV. C p.VIII. pag. 296. Ufum varium fpectantia multa collegit Plukenet in Almageft. Botanico pag. 135. Chrif. Vi elbeuer in Befchreib. fremder Materialien pag.98. Georg. Meiffer iu Orientalifch. Indian. Kuntt und Luf.Gärtn Foh. Henr. Losbnerus in Muf. Beslerian. Tab.V. pag.19. Tsbrand. Ides in der Reife nach China Cap. XXIII. p. 402. Tentzelii Monati. Unterred. An.1694. pag. 12. Nehem. Grew in Mufeo Regal. Socierat. pag.197. Erafm. Francifci im Oft-und Weft-Ind. Luft-Garten pag.300. prc. Nucem in \& extra corticem del. \& defcr. F. C. Volcksmer in Befchreib. frein- 
der Gewächfe Cap.III. p.rg.228---23r. De textura funium ex cortice villofo vid, Fob. Pecr. Maffejus Hiftoriar. Indicar. Libr. VII. pag. 310. De confectione vini, aceti \& facchari ex nuce vid. 9o.. Isdus in Navigatione, qux reperitur inter Defcriptiones novarum Novi Orbis Infularum Cap. CXXXVIII. pag.T49. De expreflione Olei vid. Ca/p. Barlai Brafilianifche Gefchichte unter Regierung Furftens Joh. Moritz vun Naflau.

Q. 28. Nuculæ Indicæ. vid. Valentini Muf. Mufeor. Part. I. Cap. XVI. pag. 325. pre. Engelb. Kämpferus Amoenit. Exor. toto Fafcicul.IV. Obr.1.--X. pag. 659.--764. ubi Palmarum omnia genera fimul defcr. \& Tab.I. pag.673. delin.

Q.29. Nux Palmæe eleganter polita.

Q.30. Poculum ex Nuce Palmæ Maldivenfis cum figuris argento munita. tale poculum del. \& defcr. Garcias ab Horto ap. Carol. Clufum Aromat. Hift. Libr. I. Cap. XXVI. pag.193. it. Erafm. Frincifci im Oft und WeftIndifch. Luft.Garten Part.I. Tab.XVI. num.9. pag.\{26.

Q.3I. Nuces Ahoay venenatiffima Indix Occidentalis. del, \& defcr. Guil. Pijo in Hift. Natural. \& Medic. Ind. Occidental. Lib. V. Cap.XVIIl. Car. Clufaus in Hiftor. rarior. Plantar. Lib.II. Cap.XI. Job. Fonflonus Hift. Nat. de Arboribus Tab.XL. pag.u19. Erafm. Francifci im Oft-und Weft. Ind. Luf. Garten Parr.I. Tab.XX. num.1.2.3. pag. 379. feqq. Joh. de Laet in Americx utriusque Defcr. Libr.XV. Cap.IX, pag.562. J. H. Locbnerus in Muf. Beslerian. Tab.VII. pag.25. num.I. Ad. Olearius Gottorp. Kunft-Kam. Tab.XVIII. num.2. pag.27. Q. 32. Pepira Indicae fruetus $C a \int p$. Baubini in Pinace Theatr. Botanic. Lib: XI. Sect.VI. pag.442. Pepita del Peru f. Acini Peruani Clufai Exoticor. Libr.II. Almendras del Peru Plukenetii in Almageft. Botanic. pag.28. conf. del. \& defcr. Job. Henr. Locbneri MuI. Besl. Tab.IV. pag.18.

Q. 33. Golfypium in nucibus apertis \& claufis cum folis ex Turcia. vid. Ol. IV ormius in Muf. Lib.II. Cap.XXIII. pag. 189. Schurtzius Material. Kammer pag.5. Mich. Berrib. Valentini Muf, Mufeor. Part. I. Cap. XXIX. pag. 353. Peir. Pomet im Material. und Spez. Häudl. Tab. XLII. fig. 252. \& 253. pag. 307. prc, eleg. delineavit f. C. Volckamer in Befchreib. etlicher fremiden Gewächle Cap.V. pág.23r.feqq. frucicem ap. Sinenfes del. \& defcr. Job. Neuboff in Befohreib. des Reichs Sina pag.326.

Q.34. Goffypii Silefiaci variz fpecies, vid. Unfere Sammi. von Nat. und Med. Gefibichi. I. Verf. An.1717. Menf. Jul. Clafr.IV. Arr.VI. pag.76.

Q. 35. Frubtus arboris laniferæe ex Infula Java foliis digitatis, per marginem leviter crenatis, fructu quinquecapfulari. vici. del. \& defcr. in unferen Samml. von Nat. und Mled. Gefch. II. Verf. An.17i7. Menl. Dec. 
Clafr.V. Art II. pag.451. conf. Hort. Malabar. Tom.III. Tab.LII. Jac. Bontii Hift. Nat. \& Med. Ind. Oriental. Libr. VI. Cap.XIV. pag. 105. Ol. WVormii Muf. pag. 205. prc. conv. cum del. Car. Clufii Exotic. Libr.I. Cap.XIV.pag. 12. it. Fob. Fonftoni Hift, Natural. Arb. \& Frutic. Libr.Il. Tab. XLIV. pag.132. cum aliis arboribus laniferis defcr. Erafm. Francifci im Oft und Weft-Ind. LuftGarten Part.I. Tab.XVII. num.9. pag. $5\{3$.

Q. 36. ConusPinus fativa Indicus apertus fructu majori. del. \& defer. fob. Henr. Locbnerus in Mu؟. Besler. Tab.II. num.3. pag.5.

Q. 37. Conus Pinaftri maritimi conclufus minor dilutioris coloris, vid. id. Locbnerus L. C.

Q. 38. Conus Abietis marinæ. del. \& defcr. prxter Baubinum \& Bellonium Nebem. Grew in Muf. Soc. Regal, in Angl. Part.II. Cap.V. pag.212, it, Locbnerius ibid. pag.5.

Q. 39. Fructus peregrinus abiegnæ nuci fimilis. conv, cum delin. \& defcr. Caral. Cluffi Exotic. Lib.II. Cap.IIt. ad Palmampinum a Lobelio de, fcript. accedens, vel ex mente Neh. Grew in Muf. Soc. Reg. pag.200. ad Palmam coniferam. del. \& defcr. Gob. Henr. Locbnerus in Muf. Besler. Tab. I. pag. 4.

Q. 40. Fructus Cupreffi arboris peregrinæ. defer. Georg. Nic. Scburtzius in der Material-Kam. pag.62. it. Job. Jonftonis Hift. Nat, de Arboribus Tab. XCI. pag. 330.

Q. 41. Conus Laricis arboris in Alpibus R hæticis Tyrolenfibus frefrequens. defc. \& del, id. Locbnerus in Mur. Besl. Tab.lII. pag.7.

Q. 42. Tedæ arboris conus. vid. id. Locbnerus L. C. pag.5:

Q 43. Amygdali Regni Granatenfis putamine duro \& craffo, tuberculis per univerfum corpus fparfis, interne continens nucle, um fluctuantem. del. \& defcr. Carol. Clufues Exoticor. Lib.II. Cap.VI.pag. 27. Ot. Wormius Muf. Libr.II. Cap. XXI. pag. 180. Joh. Jonfonus Hift. Nat. de Arbor. Tab. XLII. pag.125. Fol. de Laet Defer. Ind. Occidental. Lib.XI. Cap.XIV. pag. 581. Ad. Olearius Gottorp. Kunft-Kam. Tab.XIX. num.I. pag.28.

Q.44. Semen Acajou vel Anacardium Orientale, $\mathrm{C}$ ex Brafilia,renis ovilli figuram referens. del. \& defcr. Rocbefort in Befchreib. der Antill. Inf. Cap. VI. pag. In. Guil. Pifo Hift. Nat. \& Med. Ind. Occident. Libr.IV. Cap. VI. pag.121. it. in Ejusdem Mancifa Ảromatica Cap.XIV. pag.i93. Fob. de Laet in Nov. Orbe I. Defcript. Ind. Oscident. Lib XV. Cap.VII. pag. 598 . Gob. Jonflonus de Arbor. Tab.XLIX. pag.Iss. Muf. Calceolar. Veronenfe Sect.IV. p.686. Cl. du Molinet dañs le Cabinet de la Bibliotheque de St. Genevieve Part. II. Tab. 


\section{ET ARTIFICIALIVM KVNDMANN. VRATISLAV. 165}

IV. Erafin. Francifci im Oft-und Weft-Ind. Luft-Garten Part.I. Tab.XV. num.5. pag.440. prc. Ol. Wormius in Muf. Libr.II. Cap.XIV. pag.192. plures Autho. res, \& multa huc fpectantia congeflic Job. Henr. Locbrierus in Muf. Beslerian. Tab.IV. pag.17.

Q. 45. Anacardium Orientale cordi exficcato fimile, C. Faba Malaccana Bonanni in Mureo Kircheriano Claff.VII. de Fructibus num.15. f. Oepata Horti Malabarici Tom.IV. fig. XLVIII. Conf. Mich. Bernb. Valentini Muf. Mu• feor. Part.I. Libr.II. Cap.IX. pag.3OI. J.H. Lochneri Mur. Besler. Tab.IV. pag. 16. Mofcardi Mufeum Lib.III. Cap.XCV. pag.25ร. aliosque.

Q. 46. Corallina arborea retiformis lutea Mexicana. conv. cum. del. Ad. Olearii in Gottorp. Kunft-Kam. Tab. XXXV. num. 2. pag. 69. Locbneri in Muf. Besler. Tab.XXIV. pag.78. it. Erafm, Francijci im Oft-und Weft-Ind. LuftGarten Part.I. Tab.XVIII. num.5. pag. 564 .

C. 47. Corallina arborea nigra reticularis, r. Calbahar. vid. Rumpbii OA. Ińdif̧̧he Rapporten in Valentini Muf. Mufeor pag.jog. \& no. it. Claud.du Molinet dans le Cabinet de la Bibliotheque de St. Genevieve Part. II. Tab.IV.

Q. 48. Corallina marina arborea fetis oblongis- del. Ad. Olcarius Gottorp. Kunft.Kam. Tab.XXXV. num, I. pag.69. Job. Henr. Locbinerus in Muf. Besl. Tab.XXIV. pag.78. Meerheyde, Erafm. Francifici im Oft-und WentInd. Luft-Garten Part.I. Tab.XVIII. num.9. pag. $56 \xi$.

Q.49. Antipathes coralloides planum, fortioribus ramis expanfis. Q.50. Corallina ramis tenuioribus Ericæ facie Clufii Exocicor. Libr. VI. Cap.V. pag.I22.

Q.51. Corallina nigra arborea faxo duriffimo, in quo non veftigium terræ, vel rimulæ apparet, infidens. convo cum delo in Ephem.Nat. Curiof. Dec.II. An.III. Tab.V.

Q.52. Corallina arborea alba, colore fufco pundtata, faxo plano inharens.

Q.53. Corallina arborea nigra, quam crufta alba, colore purpureo punctata, circumdat, cum radice.

Q. 54. Corallina arborea baccifera crufta alba obvoluta.

Q.55. Quercus marina coralloides Theophrafti, terrei coloris, apicibus violaceis. del. \& defcr. Erafm. Francifci im Oft und Weft-Ind. LuftGarten L. C. num.7. citante Clufio.

Q. 56. Quercus Coralloides talis, coloris rutili, ramis tenuioribus. Q.57.58.59. Quercus Cäralloides nitidiffimx, fuperius crufta au$\mathrm{X}_{3}$ 
rea, in latere violacea elegantiflime veftitæ, curn radicibus quoad ramorum tenuitatem diverfe, num.Iil. Conv. cum del. Car. Clufai Exoticor. Lib.VI. Cap.IV. pag.12r. it, Cur. Pofterior. Libr.VI. pag.47. it, fob. Henr. Locbneri Muf. Besler, Tab,XXIV. pag.78.

Q.60. Pinna marina fructicofa, ex mari Siculo, fuper faxum rotundum lævem adnata. De nutritione ab ambiente fluido vid. Nehem. Grew in Mur. Reg. Societar. pag.244. feqq. Circa radices Æenx innatas lapidibus arbores vírides invenit Bartbolinus Cent. I. Epift. Medic.XII. pag.22I. it. Ranunculum táfciatum, Linum marinum \& Quercum marinam filici innatam del. \& defcr. id, Bartbolinus in Aat. Med. \& Phil.Haf, An.1671. \& 1672. Obf.LIX. pag.118. \& 123. Et prope Vefuvium faxa fungifera viḍ. in Mifcel. Nat. Cur. An. II. Obl.XLV. pag.109.

Q.6I. Porus cervinus Regni Bantamenfis Imperati ex filice duriflimo prominens. vid. Hift. Natur. Libr.XVII. Cap.IV. pag.820. C. Cornu Alcis Pifonis Hift: Nat, \& Med, Ind. Occidental. Libr.VI. Cap.XXIII. pag.I2I.

Q. 62. Alga intybacea ex Concha echinata protuberans. Conchx inherentes frutices del. \& defcr. Carol. Clufus Exotic. Libr.VI. Cap.XV. pag. 129. it. in Hiftor. rarior. Plantarum Lib.I. pag.35. \& ex eo Erafm. Erancifci im Oft-und Weft-Ind. Luft-Garten Part.I. Tab.XIX. num.4. pag.567.

Q.63. Flores Auriculis muris fimiles, prope fontem urbis Samariæ in Judæa (uti ferunt) collecti.

Q.64. Frutus f. Conus Cedri de monte Libano. del. \& defer. Petr. Bellonius Obfervationum Libr.II. Cap.CX. pag.162. Ul. Aldropandus Mur. Metall. pag.829. Ol. Wormius Muf. Libr.II. Cap.XXV. pag.195. Ad. Olearius Gottorp. Kunft-Kam. Tab. XIX. num.2. pag. 29. Foh. Henr. Locbnexus Muf. Besl. Tab.II. pag.6. petrefactus ap. Locbnerum L.C. Tab.XXXI. pag.9r.

Q. 64. Cacao in nuce. del. \& defcr. Rocbefort in Befchr. der Antill. Inf. Cap. VI. pag. 126. Francifc. Hernandez Rer. Medicar. Nov. Hifpanix Lib. III. Cap. XLVI. pag.79. Mui. Calceolar. Veronenf. Sect.IV. pag.686. prc. Ol.W ormius Muf. Libr.II. Cap.XXIV. pag.19ı. Carol. Clufius Exoticor. Lib.II. Cap.XXXVIII. pag. Is.leqq. Fob. Jonftonus Hift. Nat. de Arboribus \& Fruet. Libr.II. Tab.XLII. Erafm. Francifci im Oft und IVeft. Ind. Luft G.rten Part. I. Tab. XVI. num.3: pag.488. Tbom. Gage in der Reife-Befchr, nach Neu.Spanien Part.II. Cap.XIX.' pag. 22I.feqq. Guil. Pifo in Mantifa Aromatica Cap. XVIII. pag. 197. adjecta ejusd. Hif. Nat. \& Med. Ind. Oicidental. Petr. Pomet im Materialift. und Spezer. Händt. Part.I. Libr.VII. Cap.XIV. Tab.XXXVII. fig.196. pag.256. it. foh. de Laet in Nov, Orbe f. Defcripr. Ind. Occidental. Libr. VI. Cap. XI, pag. 318. NYeb. Griw in Mufeo Regalis Soc. pag.204. De Chocolata ex Cacao Nuce \& aliis 
aromatibus compofita, vid. Bartb. Marradoni Dialog. de Chocolata, it. Pbil. Syloefl. du Four Traitez nouveaux \& curienx du Café, du The \& du Chocolate Part.III. ubi fimul Authores nominat, qui in Hifpania, Gallia \& Ánglia, prolixe eam defcripferunt; quibus jungendus du Blegny le bon ufage du The, du Café \& du Chocolat pour la præfervation, \& pour la guerifon des Maladies Libr.III.

Q. 65. Rofæx proliferæ. del. \& defer. Sigismundus Graffus in Epbem. Nat. Cu:riof. Dec.I. An.IV. \& V. Obf.XCIV. pag. 94. 7ob. Henr. Hottingerus Dec. III. An.IX. \& X. Obf.CXXXII. fig.22. pag.249. Conf. Mich. Bernb.Valentini von Kunft-und Natural. Kam. pag.22. f. Mul. Mufeor. Part.I, in fine, it. Bresl.Samml. von Nat. und Med. Gefcb. XVII. Verf. An. 1721. Menf. Aug. Claft.IV. Art. VII. pag.169. XX. Verf. An.I722. Menf. Aug. Claff.IrI. Art.I. pag.\$73. XXI.Verf. An. 1722 . Menf. Jul. 'Cl.IV. Art. II. num.2. pag. 50. it. Obfervationem meam ibid. XXV. Verf. An.I723. Menf. Jul. Claf.IV. Art.VI. pag.86.

Q 66.Rofxe falicumSilefiacæ, prc. Maslenfes. has defcr. \& delin. Leonh. Dav. Hermann Maslugraph. Part. II. Cap. XII. pag. 232. Conf. Bresl. Samml. von Nat. wnd Med. Gefcbibt. VIII. Verf. An. 1719. Menf. Jun. Claff.IV. Art. III. pag. 713. feqq. it. Claft. VI. pag. 752. feqq. \& XVI. Verf. An. I721. Menf. Maj. Claff.IV. Arc. V. pag. 518 .

Q67. Excrefcentia tales querna, rofis conclufis fimiles.

Q.68. Rofa de Jericho 1. Hierichuntina ex Arabia deferta, defcr. Hier. Drexelius in Aurifodin. Part. II. Cap. VI. pag. 167. delin. Beslerius in Horto Eyftedterffi Clasfis Autumnalis Ordin. IV. fol. I. Job. Fonflonus Hift. Nat. de Arbor. Tab. CXI. pag. 390. feqq. Petr. Pomet im Materialift. und Spez. Händl. Part. I. Cap. XXVII. Tab.VI fig. 32. pag. 46. Fob. Eufebius Nierembergius de miraculofis nacuris Terrx promifle Cap. XI. Erafm. Francifei im Oft - and WeftInd. Laft Garten Parr. I. pag. 357. Claud. du Molinet dans le Cabinet de la BiBliotis. de St. Geneviev. Part.II. Tab.IV. Marcus Mappus in DifT, de Rofa de jericho. De Ufu fuperftitiolo vici. Ol. Wormitus in Muf. pag. 152 . Fob. Sturmius in pecul. Traciar. Chir. Fr. Patsllini in Philofoph. Luft-Stunden Para. I. nam. Vir. pag. 53. feqq. it. ex Paall Ammanni Ireniso Num. Pompil, cum Hippocrat. Quxf. V111. WUilk. Erneft. Tenzelinu in Monatl. Unterred. An.1689. Menso Aug. pag. 873. ptc. Pbil. Paucus f. de Peu in Praxi fubverviendi garturiensibus Lib.1. Cap. $Z$. alizinue.

Q69. Cariophillus fuper fjicam frumenti. del. \& ceferr. in Ephiem. Nat. Curiof. Cent.fli. \& IV. pag. 368. in Bresl. Samml pon Natur und litedic. Geficb.

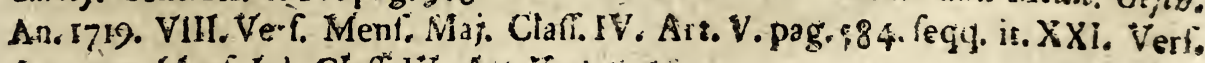
Anci722. Menf. Jul. Claff, IV. Aru, ii. ping. 49.

Q.70. Gitrus in Citro. defcr, in Fob. Hornungi Cifta Medica Epift. CXLV. Job. 
Lafelii Cetrio pregnante, Ol. WFormii Muf. Lib. Il. Cap, XXVIII. pag. 206. Pbil.

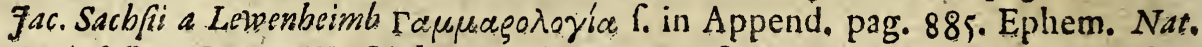
Curiof. Dec. I. An, III, Obl. CCXLI. pig, 432. feqq. Fob. Bapt. Ferrarii Hefperid. Lib. III. Cå. XIX.pag. 263. F. C. Volckameri Nürnbergifch. Hefperid. Part. III. Cap. XXXVIII. pag, 173. it, pag. 175. Mala Aurantia foetifera defcr. Mich. Bernb. Valentini in Muf, Mufeor, Part. I. Libr.II. Cap. XI. pag. 309. Ferrarius L. fupr. c. Lib, IV. Cap.VIII. pag. 403. Poma Aromatica pragnantia vid, in Sacbfii Ganımarol, Lib. I. Cap. VIII. pag. 144. De Caufa impregnationis vid, Ferrar. L. C. Libr.III, Cap. XIX, pag, 263. Valentini von Kunft-und NaturalKammern pag. 23. Conf. Obfervationem meam in Bresl. Samml, pon Nat, und Med. Gefch. XXV. Verf. An. 1733. Menf. Jul, Claff, IV, Art, Vl. pag. 86. feqq.

Q.71. Malum Citrium monftrofum, Conv, cum, del, \& defcr. Limo-

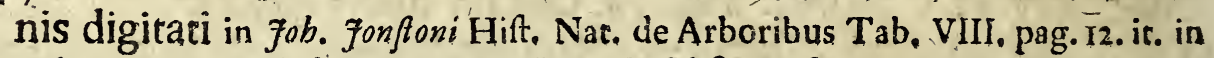
Ephem. Nat. Curiof. Dec. I. An. IX. \& X. Obf, III. fig. I. pag. 3I. It. Dec. II. An. II. Obr. XI. pag. 33. feqq. prc. evolv. Job, Bapt. Ferrarius Hefperid. f, de Malorum aureorum cultura \& ufu Lib, III, pag. 215. it. Foh. Chrifloph. Volckamer. in Continuat, der Nürnbergifch, Hefperidum Part. III, Cap. XXXIV. pag. 14,6 .

Q. 72. Aurantium Hermaphroditum $\Upsilon$. mire corniculatum, vid, id. Ferrarius L. C. Libr.IV. Cap.IX, pag, 407, \& 409, it, Volckamer in Nürnb. Hefp. Part.IV. Cap.XI. pag.19I.

Q.73. Excrefcentia Salicis monftrofa. conven, cum delin, in Ephem. Nat. Curiof. Dec.I. An.III. Obr.CXLIII. pag.264.

Q.74.75. Secale \& Triticum Sicilianum Maslæ in Silefia plantatum. defcr. Leanb. Dav. Hermann in Bresl. Samml. won Nat, und Med. Gefch. XIII.Ver., An.1720. Menf. Aug. Claff.IV. Art.VI, pag.2Ir.eqq.

Q.76. Spicæ Triticeæ num.IX. in uno culmo.

Q.77. In uno culmo fpica VI. Secalina, itemque in aliis num.II. \& plures. Multa huc fpectantia colleg. frmulque fpicas miraculofas delin. id. Leonb. Dav. Hermann Maslograph. Part.II. Cap.XIII. pag. 245.reqq. Spicam fecalinam mirabilem evolvo in Ephem. Nat. Guriof. Dec. I. An. VI. \& VII. Obr. CXV. pag.Iri. Dec.III. An.III. Obr.LXXVI. fig.V. pag.Iro. it. in Bresl.Samml. von Nat. und Medic, Gefch. XIII. Verf. An. 1720. Menf. jul. Claff.IV. Art. VII. pag.87. fegq. Conf. Job. Math. Fabri fpicas miraculofas in Epbem. Nat. Curiof. Dec.III. An.II. in Append. pag.23. \& del. pag.22. Gafp. Scbotti Phyfic. curiof. in Append. ad Libr.V. Cap. I. pag. 639. Chrift. Franc. Paullini Zeit-kürtzend. erbaul. Luft Part.III. Them.XII. Tentzelii Monatl. Unterred. An.1695. Menf. Sepr. pag.8@3.feqq. An.1697. Menf.Sept.774. Avenaceam vid. ibid. it. An. 1698. pag.774. feqq. \& Hermanni Maslogr. fupr. citat. pag.246. . Q.78. 


\section{ET ARTIFICIALIVM KVNDMANN. VRATISLAV. 169}

Q. 78. Caffave $\mathrm{f}$, Panis Americanus Cubæe Infulæx, ex radice Mandihoca vulgo lucca $\mathrm{f}$. Hiucca venerofa candidiffimus, Vid. Neuerôffretes Rariteten. Cabinet num. LIII. pag. 45. prc. Ol. Wormius in Mur. Cap. VIII. pag. 365. Conficiendi modum, it. de mira proprietate venenola Europxis innoxia egit Atb. Kircberus Mund. Subter, Tom. II.Libr, IX. SeQ.II. pag. 138. it. Guil. Pifo Hiftor. Nat, \& Med. Libr. IV. Cap. III, pag. II4. feqq, ubi fin mul frutex delin. \& Libr, V. Cap. XVII, pag. 305. Ol. Dapper in Befchr. von Africa pag. 580. Erafm. Francifici im Oft und Weft - Ind.Luft G. Part.I. Tab. XVI. num, 4. \& 5. pag. 516. feqq, it. Part. II, pag. 998. Caßp. Barlaus in den Brafilianifch. Gefchicht. pag. 382. Panem ejusmodi in Mufeo affervayit Ath. Kircberus, vid. Mund, Subt. Tom. II. Lib, IX, pag.139,

Q.79. Panis Mexicanus ex radice Quanheamotli. vid. Ol. Dapper in Befchr, von America pag. 76. Arborem Farinaceam aliam defcr. \& delin. id. Kircherus Chin. illuftrat. Part. IV, Cap. VI. pag. 77. \& Fob. Fonfonus Hift. Nar. de Arborib. Tab. XLV.

Q.80. Panis ex Weftphalia vulgo Pompernickel, defrr. Frid.Hoffmannus in Propemptieo Inaugural. de Pane groffiori Wettphalorum, vulgo bon pour nickel, annexum ejusd. Differt, de prudenti Medicamentorum applicatione in tempore. Naturam ejusd, examinavit $I d$, in Obfervationibus Phyfico-Chymicis Selectioribus Libr. II. Obf. XXII. pag. 2ir. feqq.

Q. 8I. Panis ex glandibus tempore annonæ in Silefia prc. in Duca. tu Glogovienfi An. 1720. confectus, vid, Neu eröffnetes Rariteten-Cabinet pag. 134.

Q.82. Panis, quem ex marga candida f. farina minerali Klikcenfi f. Coswicenfi Anhaltina An, I713. coxerunt. defcr. in Bresl. Samml. von Nat. und Med. Gefch. An. 1720. Menf. Febr. Claft. IV. Art. VII. pag. 196. it. Menf. Mart. ejusd. Claff, IV. Art. IV. pág. 322. De Marga ejusmodi vid. Ephem. Nat. Curiof. Dec. III, An, VII. \& VIII. Obf. CCIX. Steph, Blavcard. in Collect. Med. Phyfic. Cent, II, pag. 230. Aufgefang. Briefe III, Paquet $\uparrow 0$. Correfpônd. fol, 275. Job. Cbriftopb. Becmanni Hift. des Fürftenthums Anhalt Part. II, Cap.III. pag. 69. Fob. Jac: Grofers Bafeler Chrcnica pag. 25I. it. Dav. Sig. Büttneri Ruder, Dil. teft. pag. 14r.

Q.82. Mufcus Alpinus Africanus, C. Orchille.

Q.83. Mufcus albus corallino fimilis ab erucis corruptus.

Q. 84. Mufcus petrofus Neulandenfis prope Lembergam.

Q. 85. Ramus veræ arboris Theiferæ, del. \& defcr. Eph. Nat. Curiof.Dec. II. An. VII. fig. \{O. pag. 486. Fob. Neulbofius in Befchr. des Reichs Sina pag.324. fas. Bontius Hift. Nat, \& Medic. Ind. Oriental. Libr. VI. Cap. I. pag. 87. feqq. 


\section{0 PROMTVARIVM RERVM NATVRALIVM}

7oh. Nic. Pecblinis in Theophilo bibaculo f. de Poru Thex Dialogo, Pbil. Sylo. dis Four Trait. du Café, du The, \& du Chocolate Part. Il. de Blegny in ejusd. Argumenti Tradt. Lib. I. ubi multa de Ufu medico, it. Andr. Cleyeri Epift. in Act. Med. \& Phil. Hafnienf. Vol. IV. Obi.1. pag. I. Joh. Thiele in Theelogia Medica f. Ulu \& Abufu potus calidi cum herba Theé. prc. Engılb. Kämpferuss Amcenitar. Exotic. Fafcic. III. Obf. XIII. pig. sos. feqq. it. Unfere Samml. don Nat. und Medic. Gefchicbt. II. Verf. An. 1717. Clafr. V. Art.I. pag. 343. feqq. it. IV. Verl. an. 1718. Menf. Maj. Claft. V. Art. II. pag. Ino9. ubi pl, rep. Authores.

Q. 86. Flores Herbæ Thex.

Q 87. Semen Sabatili.

Q 88. Medulla Cinamomi.

Q. 89. Cortex Maffoy f. Oninius. defc. Mich. Bernh. Valentini in Oft-Indianifch Rupporten pag. I18. it. in Ephem. Nat. Curiofor. Dec. II. An. I. \& II. ObF, XXII. pag. 5 -

Q.90. Cortex aromaticus Indicus. del. \& defer. Nit. Monardes Simpi.Med. Hift, ex Nov. Orbe delator. Cap. XVI. pag. 32 ş. qui eft Libr, X. Cluffi Ex. oticor.

Q. 9I. Gummi Kikekunemalo.

Q. 92. Gumi Galdx.

Q.93. Gummi de Lock.

Q 94. Nuces juglandes num. XII. it. num. XIV. fibi invicen connexæ, de An. 1723.

Q. 95. 96. Flores Aloes Lipfienfes \& Prauffenfes Silefix cum Iconibus \& Defcript. Multa huc fpectantia fimulque Catalogum, ubique locorum florentium publ. Joh. Dan. Major in der Americanifchen zu Gottorff blühenden Aloë pag. 10. feqq. prc. Pbil. Jac. Sacbs a Lezvenbeimb in Ephem. Nat, CKriof. Dec.I. An:I. Obf.XG. pag.207. it. Bresl. Samml. von Nat. und Med. Gefib. X. Verf. An.1719. Menf. Octobr. Claff.IV. Art.V. pag.478.feqq. ubi fimul Prauffenfis defcrib. \&2 delineat. de altera vice florente vid. XVIII. Verf. An.3721. Meni. Octobr. Claff.IV. Art.lV. pag.376. Conf. XVI.Verf. An.1721. Claff.IV. Art.VI. pag.407. De Aloë cum triplici caulé in horto Mauritii Guilielmi Ducis Saxonix fiorente vid. Guil. Zapfi Epiftel. qux reperitur in Adis Eruditor. Lipfien566. An,668. Merr. Marto pag.121. ubi elegantiffime quoque delineavit Viennen. fem An. 1720. florentera, defcr. in Bresl. Samml. von Nat. und Med. Gefbicbr. XIII. Verf. An. 1720. Menf. Jul. Claff. IV. Art.VIII. pag.89. Anno 1721. Lim. bachi prope Dresdam quogue Aloë floruit, gux defers, id, in Bresh, Sammol. XVI. 
Veri. An.172t. Menf. April. Clafi.IV. Arr.VI. pag.407.legq. \& fecusda vice An. 1722. vid. L.C. XIX. Verf. An. 1722. Menf. Mart. Claff. IV. Art.IV. pag. 284. Viennenfis alia An. 1723. florens vid. id. in Bresl. Samml. An.1723. Mepfo Aug. Claff.IV. Art.III, pag.173.

Q.97. 98. Aloë variolofa \& alia colore albo maculata. Varias fpe cies, it. Ulum Medicum Dixteticum \& Mechanicum prxter fupra nominatos vid. in abr. Mustingii $\mathrm{Tr}$. de vera antiquórum herba Britannica, ubi in fine Aloëdarium annexum.

Q. 99. Cortex Jubaba.

Q.100. Lignum Carabaccinum.

Q. Ior. Lignum Draconis arboris.

Q.102. Sanguis Draconis ex arboribus ftillatitius in foliis Palma datyliferæ. defcr. Ol. Wormius Muf. Libr.II. Cap. XXXIV. pag.229. Nic. Monardes Simpl. Medic. Hiftor. Cap.XXXVIII. pag.330. qui eft Libr.X. Clufii Exot. Cbr. Vielleeuer in Befchreib. fremder Material. pag. 149. Petr. Perset im Material, und Spez. Händl. Tab.XLVI. fig. 289. pag. 390. prc. evolv. Engelb. Kämpfferus Amoenit. Exaric. Fafc. III. Obl. VI. pag. \{\{2. leqq. 7ob. Cbriftopb. Volckamer in Befchr. fremd. Gewächfe Cap.IV. pag.232,--235. Micb.Bernb.VAlentini in Muf. Mufeor, Oft-Indianifch. Rapporten pag.99. it. Job. Erider, Ochs in Diff. de Sanguine Drącouis,

Q. 103. Fungus Querni fingularis fructurx. conven. cum defcript. in Epbem. Nat. Curiof. Dec. II. An. VII. Obf. LV. pag. 100. Fungum alium monftrofum vid. in unferen Samml. pon Nat. und Med. Gefib. VI. Verf. An.1718. Menf. Octobr. Claff, IV. Artic.V. pag.173\%.

Q. I04. Tubera terræ edibilia. del. \& defcr. Franc. Ern. Bruckmannu in Specimine Botanico, exhibens fungos fubterraneos vulgo Tubera terra diktos.

Q.105. Colocyn?his Egyptiaca maxima cum cortice, f. Cucurbita amara. del. \& defcr. Cbrif. Vielbeser in Befchr. fremder Material. pag.96. Petr. Pomet im Material. und Spez. Händl. Part. I. Libr. VII. Cap.XXXVIII. Tab.X. fig. 229. pag. 290. it. Mich. Bernh. Valentini in Muf, Mufeor. Part, I. Libr.II. Cap.XXIV. pag.343.

Q. 106. Mala Punica ex hortis Vratislavienfibus matura. Contra Ca/po: Sebrwenckfeldii Catalogum ftirpium \& foflil. Silef. pag.304. Cbrift. Vielbesers Befchr. fremd. Material. pag.123. it. Paul. Jac. Marpergers Neueröffn. KauffmannsMagazin pag.549. prc, vid. Obfervatio mea in Bresl. Samml. von Nat. und Med. Gefch. XXII. Verf. Menf. Nov. An.1722. Clafi.IV. Art.VI. pag.547.fegq. Q. 107. Vanigliæ filiquæ fingularis longitudinis, defcr, \& del, Petr.Po. $\mathbf{Y}$ 
met in Mater. und Spez, Händl. Part.I. Libr.VII. Cap.XVI. Tab.XXXVIII. fig. 197. pag. 269.

Q. 108. Arum paluftre polyphyllum Zeylanicum maximum. defcr. \& delin. Aug. Quirin. Rivinus in IntroduQ. generali in Rem Herbariam inter Icones Plantar. qux lunt flore irregulari monopetalo' $T a b$. ultim. pag.22. it. Paulus Hermannus in Paradifo Batavo pag.73.

Q. 109. Kamus arboris peregrinx afterculum referens cum fron. dibus.

Q. ¿o. Galla cornutæ \& tuberofæ Turcicæ glandibus annexæ. deicr. \& del. Fob. Fonfonus Hift. Nat. Arbor. \& Frutic. Libr.IlI. Tab.LXI. p.197.

Q. III. Collare ex femine Althex Egyptiacæ C. Abelmofcho. del.\& defcr. in Ol. Dapperi Befchreib. von Africa pag, 81。 it, in Mich. Bernb. Valentini Muf. Mufeor Part.I. Libr.It. Cap.I. pag.ic8.

Q. II2. Lazaroli Italorum.

Q. I13. Lignum quernæ arboris quod lapidem magni molis inclu. dit。

Q. II Radix peregrina interne cordata.

Q. 115. Radix Serpentariæ Virginianæ, odoris fragrantiflimi,cum foliis. del. \& defcr. Petr. Pomet im Mater. und Spezer. Händl. Part. I. Cap. III. fig.39. pag 59. Paul. Boccone in Mur. Phyf. \& Experimental. Obr.XLII. Micb. Berwb. Valentini in Mur. Mufeor. Part.I. Libr.II. Cap.X. pag.15G. prc. Georg. IVolffg. We delius in Diff. de Serpentaria Virginiana.

Q. 116. Fructus arboris Terebinthinæ Cypriz. del. \& defcr. id. Valen. tini in MuC. Mufeor Part. I. Libr.II. Cap. XXI. pag. 407. aliique. Conf. Frid. Hoffmanni Difr. de Terebinchina.

Q. I17. Pifa eleganter coccinea Indiæ Orientalis cum hilo nigro,vulgo Dapes Efavi ex lentibus rubris. vid, Caralogus Muf. Speneriani num. I. pag.198.

Q. II8. Semen Melocardui echinati maximum Indiæ Occid. defcr. Car, Clufun Exoticor. Libr.IV. Cáp.XXIV. fruclum del. \& defcr. Erafm. Francifii im Oft.und Weft.Ind. Luft. Garten Part.I. Tab.XXIII. num. 6. pag.648. alii-

Q. II9. Dotter 1. Datura Indorum. De mirabili effectu vid. Clufuis Libr. VIII. qui eft Garc. ab Horio Libr. II. Cap.XXIV. pag. 238. Erofm. Francifci im Ott-und Weft.Ind. Luft.Garten Part.I. pag. 471. Fob. Albrecht won Mandelslo. Morgenl. Reife-Befchr. Libr. II. Cap. VII. Georg. Meifer im Oriental, India-, nifch. Kunft und Luft.Garten Cap.IX, num.XXXI. Pag. 126. Fob. Dán. Geierus 
in Epbem. Nat. Curiof. Dec.Il. An.VIII. Obferv.CXL. pog.299. Georg. Anderfen Oriental. Reiren Libr. 1. Cap. IX. pag.II. Job. Hug. Lintfibottanus Ind. Ori. ental. Part.II. Cap.XXXIII. pag.84ifeqq. it. Part.IV. Cap. XVII. pag. 44.feqq. Ol. Dapper in Befchr. voo Africa p.1t1. Cafp. Schottus in Phyfica curiof, in Ap. pend. Libr. XII. Cap.III. pag.1335. De Carniolenfi vid. Fob. Weich. Valpaffor in der Ehre des Herzogth. Crains Tom.11l. pag.19. num.152.

Q. 120. Frufus p̂neregrinus abiegnæ nuci fimilis Clufii Exotic. Libr.II. Cap.III. pag.24. C. Palma conifera Grewii in Muf. Soc. Reg. pag.22. conf. del. \& defcr. Locbneri in Muf.Beslerian. Tab.I. pag.4.

Q. 12r. Cucurbita Japonenfis cum figuris.

Q. 122. Semen Ganitri Ambonenfe Corallium nigrum in globulis referens. defcr. Micb. Bernb. Valentini in Oft -Indianifch. Rapport. num. XXVIII. pag.95. feqq.

Q. 123. Semen Ricini maximæ Americanum variegatum, del. \& defcr. Nic. Monardes Hift. Simpl. Medicamentor. Cap. IV. pag.290. Guil. Pifo Hiftor. Natural. \& Med.Ind.Occidental. Lib.IV. Cap. XXXI. pag. 180. Petr. Po. met im Material, und Spez, Händl. Párt.lo Libr. VII. Cap.XXXIX. Tab.XL. fig.230. pag.292. gob. fonfonus Hift. Nat. de Áruoribus Tab.LXIV: pag.2Is.

Q.124. Boleti five Tubera cervina, non vulgaris magnitudinis. del. \& defcr. Ul. Aldrovandas de Quadrup. Libr.I. pag.346. Ol. Wormius in Muf. Libr.II. Cap.II. pag.I38. it, Mich. Bernh. Valentini in Muf. Mufeor Part.I. Libr. III. Cap.IV. pag. 43 I.

Q. 125. Myrobalanorum V. Species, ut Chebuli, Bellirici, Emblici, Citrini, Indi f. nigri. del. \& defcr. Gracias ab Horto Aromat. Hift. Libr. I. Cap.XXVII. pag.194. qui eft Cár. Clufii Exoticor. Libr.VII. Job. Fonfonus Hift. Nat. de Arb. \& Fruet. Tab.XXXI. Lib.I. pag.82, G. H. Velfibius de Vena Medinenfi Cap.X. Foh. Henr. Lochnerus Muf. Besl. Tab.IV. pag.I12. Cum arboribus del. \& defcr. Petr. Pomet im Material. und Spez. Händl. Tab.XXIX. fig.224... 227. p.285. seqq. Fob. Hug. Lintfchottanus Ind. Oriental. Part.IV. Cap.XXXVIII. pag.74. it. Fac. Bontius Hift. Nat. \& Medic. Ind, Oriental, Lihr.VI. Cap.XXIV. pag.ili.

Q.126. Lignum Cephaloides, f. Excrefcentia mira alni arboris, caput infantis recens nati exacle repræfentans.

Q.127. Hyfteroxylon mirabilis Atructura, r. Excrefcentia arboris betula, ex meris parvis vorticibus concreta pudendum muliebre referens. Ligna monftrofa defcr. Ol. Wormius Muf. Libr.II. Cap.XIX. p.I74. Q. 128. Piper Brafilienfe coloris rubri elegantiffimi del. \& defcr. Guil. 
Pifa Hift. Nat, \& Medic, Ind: Occid. Libr.IV. Cap.LI. pag.225. f. Piper Chilenfe Bontii, vid. Ejusd, Hift. Nat. \& Medic. Ind Oriental, Libr.VI. Cap.XL. pag.130, it, Joh. Fonfloni Hift, Nat, de Artioribus Tab.LVI. pag.176. C. Piper filiquofum Mexicąnum Hernandez Rer. Medicar. Nov, Hifpan. Libr. V. Cap.III. pag.134. feqq.

Q. 129. Piper F, thiopicum nigrum. prxter Wormixm evolv, Mofcardus Mur. Libr.III. Cap. LXXXIX. pig. 252. Z̃ob. Jonfanus Hift. Nat. Arb, \& Frue. Libr. III. Tab. LVII. pag. 179. Mufẹum Calccalar. Veronenf. SeQ. V. pag. 589. Mich. Berab.Valeatini Muf. Mufeor Part,I. Seç.V. Cap.VIII. S.13. p. 299. 疋ob. Henr. Lachnerus Muf. Besler. Tab.lII. pag.8. Petr. Pomet im Material. und Spez. Händl, Tab. XXXV. fig. 184. pag. 252, Erafm. Francifci im ORsund Weft-Ind. Luft-Garten Part.1, Tab.XIII. num q.

Q. 130. Roucou f. Indigo cum foliis herbæ Anil. Arborem del. \& deTẹr. mọdụmque Inåigo confiçiendi doeuit, Authoresque collegit, Herb. Jeger in Ephem. Nat. Curiof: Dec.ll. An.II. Obr.IV. pag.j. Conf. Mich. Bermb. Lralen. zini Muf, Mufeor. Part.I. Cap,III. p.IQ.leqg, it. Oft-Indianilch, Rápport. uum. XXVI. P.92, Pętr, Pomet Material. und Spezer. Händl. Part.I. Libr.V. Cap.IX. pag.186. fig.138.feqq. Georg. Nic. Scburtzii Material. Kam. pag.4\%. Pbit. Baldei Beich. der Küften Malabar und Coromandel Cap.XXIV. pag.163. Dampiers Reife um die Wele Part.1. Cap.VIII. pag.24I. Tavernsas in der Indianifch. Reife-Be, fch. Lib.Il. pag.109. 7ob. de Laet de Imperio Magn. Mogolis f. India vera pag. 99. feqq. it, in Nov. Orbe f. Defcript. Ind. Occidental. Libr.VII. Cap.IX. pag. 330. feqq. prc. fuffinime \& accuratifine defcribitur, it. qua ratione paretur colos in gean. Bapt. Labai Nouveaux Voyages aux Isles de l' Amerique Tom. III.

Q. 131. 32 , Cucurbitarum lagenas referentes item piriformium diverfa fpecies. vid. ol. Worroius Muf. Libr.ll. Cap.XXV. pag.i97.

Q. 133. 134. Faufel f. Areca major \& minor in cortice lanuginolo \& extra corticem. del, \& defer. Garzias ab Horto Aromat. Hitor. Lib. I, Cap.XXV. pag.189. qui ef Carol. Clufii Exoticor, Libr. VI. O1. Wrormins Nín. Libr.II. Cap.XIVI. page 199. Ad, Olearius Gottorp. Kunft-ían. Tab. XVIII, num.9. pag.28. Fob. Henr. Locbnerus in Muf. Besl. Tab.V. pag.22. Petr. Pames Im Material. und Spez. Hă̈ndl, Part.I, Libr.VII, Cą.XXXVI, Tab,XXXV. fig. 176. pag.290.

Q. 135. Lignum Arecæ arboris mire ftriatum. defor. fob, Hugo Lim\% fibottanus Ind. Oriental. Part.IV. Cap.XVI. pag.40. it. Goorg. Meifler im Orientalifch. Indian. Kunft-und Luft-Gärti. Cap.VIfI, num.I, pag.7I.

Q. 136. Mehenbethene capillata \& fine capillis. del. \& defer. Neb. Grete 


\section{ET ARTIFICIALIVM KVNDMANN. VRATISLAV. 175}

in Muf. Soc. Reg. pag.206. Car. Cluffus Not, in Garc, ab Horso Aromatum Hit. Libr.I. Cap.XXVI. Domin, Clbabreus in Stirpium Iconib. \& Sciagraphia pag.20. 3ob. Henr. Locbnerus in Muf. Besler. Tab.V. pag.23.

Q. 137. Pannus ex A pocyno Cynocrambe f. Huatte. del. \& defcr, Petr. Pomet im Mat. und Spez. Händl. Part.I. Libr.VII. Cap.L. Tab.XLII. fig.255. pag. зro. f. Golfypium Javenfe foliis falicis Baubini. conf. Mich. Bernb.Valentini Mur, Mufeor. Part.I. Cap.XXIX. pag.354.

Q. 138. Quercus marina veficularis. vid. Ol.Wormius Muf. Libr.II. Cap. XXXV. pag.23r.

Q. 139. Cortex odoratus Indicus. conv. cum defcr. Wormii L. C. Lib.It. Cap.XX. pag. 177.

Q 140. Fruetus Suberis arboris interne glandem fluctuantem oculatuin continens. defer. \& del, prater Matbiolum \& Clufum Petr. Pomet im Mat.und Spez. Hxndl. Part.I. Lib.IV. Cap.IX. Fob. Henr.Locbnerus in Mur. Besler. Tab.II. pag. 6. Arborem del. \& defcr. Valentini in-Muf. Mufeor. Tom. I. Libr.IV. Cap.IX. pag.136.

C. 14I. Excrefcentia orbicularis maxima in radice picex reperta. Q.142. Folia Ananafæ Brafilienfis. del. \& defcr. Job. Lerius Hift. Navigat. in Brafil. Cap.XIII. pag.162. Nardus Ant. Reccbus Rer. Med. Nov. Hifpan. Libr. VIII. Cap.LXXVIII. pag.3Ir. Rocbefort in Beichr. der Antil. Int. Tom.I. Cap.X. p.170. Fr. Hernandez in Hift. rer. Medic. Nova Hilp. Libr.VIII. Cap.LXXVIIr. Gob. de Laet in Nov. Orbe f. Defer. Ind. Occidental. Libr. XV. Cap.X. pag. $\left\{69_{0}\right.$ Gril. Pifo in Hift. Nat. \& Medic. Ind. Occidental. Libr.IV. Cap.XXXVII. p.195. 01. Wormims in Muf. pag.185. Muafeum Calccolar. Veron. Sec.V. pag.612. Erafm. Francijsi im Oft und Weft-Ind. Luft. Garten Part.I. Tab.XIV. num.J. \&2 2. p.4I9. Georg. Meiffer im Oriental. Indianifch. Luft - Gärtn. Cap. IX. num. 21. pag.r16. Mick. Bernb. Valentini Mur. Múfeor. Part.I. Libr. II. Sec. V. Cup.I. pag.280. unfere Samml. von Nat. und Med Gefib. V. Verf. An.I718. Menf. Sept. Claff.IV. Art VII, pag.1616.feuqq. XIII. Verf. An.r720. Menf, Sepr. Clafr.IV. Art.V. pog. 302. prc. Micb. Frid. Lecbscres in Commentat. de Ananafa f. Nuce pinea Indica valgo Pinhas. De ufu vario \& Medico vid. Fob. Henr. Tbiemrotbs Difiert. de Plarita \& Fructu Ananas hujusque ufu Medico.

Q. 143. Flores fedi maximi elegantiffimi.

Q. 144. Cortex flexilis arboris peregrinæ, ex qua veftimenta in Regno Golcondx parant.

IN certas Claffes redegerunt Plantas: Robertus Morinfon Scorus, in Libr, cui Titul. Plantasum umbelliferarum diftributio nova ex Libro Nasurx obfervata; it. Paulus 
Hermannus in Paradifo Bacavo f, Defcriptione rariofum Plantarum. Lug, Quirinus Rivinus vero in IntroduAione generali in rem Herbariam novam firpium methodum, fecundum florum differentias, tum petalorum numeri refpecu, cum figuræ regularis aut irregularis, publicavit, idemque $f 0 / e p$ bus Pitcon Tournefort, Parifienfis Elementa Botanica I. Methodum cognófcendi plantas Gallico fermone fcriplit, in quibus generum notas characterifticas a florum forma f Aructura defumfit; quibus addendus fob. Rajus in nova Methodo Plantarum.

Phyfiologiam Plantarum confignavit Marcellus Malpigbisus Italus Operum Tom. I. f. in Anatome Plantarum, \& Nebemias Grew Anglus in Anatom. Vegetabilium primordiis, it. Fob. Dan. Major de Planta monftrofa Gottorpienfi, ubi quadam de Circulatione fucci nutritii primus protulit. (vid. Morbofi Polyhift. Phyfic. Cap. XL. pag. 458) Quibus jungendi Perrault de Circulat. fucci nutritii in Plantis, Kenclmus Dygbeus in Differt. de Vegetatione Plantarum Dedu in Tencamine Phyfico de Anima Plantarum (Gallice fcript.) 70h. Woodwardus in Meditationibus \& Experimentis circa Vegetationem Plantarum,(qux reper, in Tranfact.Phil, Anglic, Menf. Jun. An.1699. pag.193.feqq.) de Vallemont in Curiofitatibus Naturæ \& artis, f. de Vegecacione, Agriculcura \& Horticultura perfecta, fob. Mich. Ssbirimmer in Deliciis Phyfico-Hortenfibus, 7 $h$. Bapt. Triumfettus in Obfervationibus de Ortu ac Vegetacione Plantarum, it. Em. Konig in Regno Vegetabili,aliique. Tenta. men Multiplicationis univerfalis omnium arborum, fruticum \& florum publicavic Francifc. Drope in brevi \& certa methodo plantandi \& in ordinem difponendi ar. bores fructiferas, prc. Georg. Andr, Agricola im Verfuch der Univerfal-Vermehrung, cujus examen inflituitur in Bresl. Samml. von Nat, und Med. Gefcbicbt. II. Veri. An.I721. ClafrV, Art.I. pag.233. feqq. XXI. Verf. An.1722. Claff.V. Art. I. pag.rog feqq. XXVI. Verf. An.1733, Claff.V. Art.I. it. Friderici Küffneri Prodromus Agricolx, Non Agricolx.

Sylveftrium folummodo fob. Caroli de Carlowitz in der Anvveifung zur yvilden Baum Zucht oder Wälder anzulegen; qua ratione vero cicurari queant, docuit Petr. Bellonius in Libello, de neglecta ftirpium cultura, qui reperitur in Car. Clufii Exoricor. Libr.

De vera caufa mulciplicationis frumenti vid. Cbriffiani Wolffii Entdeckung der vvahren Urfache von der vvunderbahren Vermehrung des Getraydes.

Vlum Medicum Plantarum ex Diofcoride \& Plinio, Georg. a Turre in Hiftoria Plantarum, \& ante eum Petr. Andr. Matbiolus im Comment. fupra Diofcoridem; ex plerisque vero recentioribus Herbariis collegit Sim. Pauli in Quadripartito Botanico.

De dignof cendis. Medicis plantarum \& corporum quoramcunque virtutibus, ex folo fapore \& odore, demonitr. Fob. Bapt. Montanus in Medicina univerfa Part. III. pag.731. Seqq. it, Dav.Abercrombius in Opufculis Medicis Libr.IV. prc. Job.Casp. 
Mangoldus in Materiæ Medicx Idea nova Part.I. Ex fignaturis, figuris, coloribus aliisque materix conditionibus \& fimilitudine cum hominis partibus, adionibus \& morbis; vid. Foh. Bapt. Parte Phytognomonica \& de humana Phyfiognomia,item ejusmodi argumenti Libri, quos publicavit Leonh. Thurzeiffer, Fofeph. Quercetanus, Oswaldus Crollius, Carricbter, fob. Andr. Scblegelius \& multialii, quos refucavit Helmantius it. Eman. Koenig in Regno Minerali Cap.XXXIV. prc. Sim.Pau. li in Quadripartito Botanico Claff.III. pag.445. \& Job. Forgetus in artis fignatre defignata fallacia.

Catalogüm auctorum qui rariores Plantas diverfarum Regionum defcr. collegit Dn. Dr. Jab. Kanoldus in Bresl. Samml. pon Nat. und Med. Gefcb. III. Verf. An.1718. Menf. Febr, Claff.V. Art.IV. pag.724. it. Jul. Bernb. 'von Robr in der Phyficalifchen Bibliathec Cap.VII. \$.32.-143. pag.H8. Teqq. Quibus addendi Profperus Alpinus, de Plantis Exoticis, Caralus Plumerius in Defcript. Plantar. America, item qui fingularum Regionum vel Infularum Plantas defcr.ur. Franc. Hernandez, qui Hift. Plantar. Mexicanorum, Jacobus Cornutus, qui Hift. Plantar. Canadenfium \&c. Leonh. Plukenet, qui in Phytographia Indix Orientalis Plantas rariores defcr. \& del.Henr, van Rbeede, qui Malabaricas in Horto Malabarico, Cafp. Cumamelinus, qui itidem in Flora Malabarica, Micbael Boyms, qui Sinicas in Flora Sinenfi, Georg. Everh. Rumpbius qui Plantas Moluccarum Infular. (in Epbem. Nat. Curiof. Dec.II: An.I.) prc. 70 . Pitton Fournefort, qui exteras regiones Orientales invafit, \& plantas ibi rariflimas 1326 . ac inter has 25 . genera prorfus nova invenit, quas in Co. rollario Infticutionum rei Herbarix accuratiflime defcripf. \& delineavit. Conf.

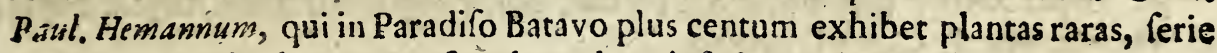
alph 3 betica difpofatas, atque figuris aneis \& defcriptionibus illuftratas.

Plántas quoque rariores num. 1703. defcr. \& delin. Jac. Barreliekus de Plantis per Galliam, Hifpaniam \& Italiam obfervatis; Infulæ Luzonis, Georg. Fofeph. Camellus in Hiftoria Stirpium hajus Infulx; Sicilix, Melitæ, Corficx, Paul. Boccone inMufeo; Hollandix, Jac. Breynig in Prodromo Fafcicul. rariorum Plantarum Hollanuiix, indigenas $70 h$. Commelinus in Catalogo Plantarum indigenarum Hollandix, Horti

Medici Amftelodamenfis id. Commelinus in Platarum Horti Medici-Amfte. lodamenfis Defcriptione, Horti Academici Lugd. Bat. Hermannus Boerbaave in Indice Plantarum quze in Horto Academico Lugduno Batavo reperiuntur. \&c. 


\section{SECTIO III. \\ Regnum Minerale. \\ Claffis I.}

Gemma $\mathfrak{E}$ Lapides pretiofi, diverfimode figurati, iisque affines.

\section{ARTICVLVS I.}

\section{Rudes.}

R. I. Rupes Adamantum fplendidiffimorum Orientalium, adnati cryftallis albis. conv. cum del. quam ded. Petr. Wolfart Hiftor. Natural.Hasfix Inferior. Part.I. Tab.I. fig,2. it. Mart. Zcillerus in Opere fuo Epiftolico Part.II. Epift. 533. \& in Manuali Part.I, pag. 541. prc. defcr. Neb. Grew in Mur. Regalis Societ. Lond. pag.275.

R. 2. Adamantes $f$. Pfeudoadamantes duriffimi \& elegantifimi in matrice flavefcente Regni Bohemiæ. vid. Bobusl. Balbinus Mifc. Regn. Bohem. Lib.I. Cap.XXX. p.75. Conf. Ans. Boetium in Hift. Gemmar. \& Lapid. Lib. II. Cap. LXXIII. pag. 219. \& ex eo Car. Nic. Langius in Hiftor. Lapid. Figurat. Helvet. Parr.I. Cap.VI. pag.13.

R. 3. 4. Adamantes f. Pfeudoadamantes Hungarici \& Silefiaci.

R. 5. Adamantes cum pluvia (uti ferunt) in Bohemia delapfi. vid. id. Balbinus Libr.I. Cap.L. pag.II7.

R. 6. Androdamas Helveticus pyramidalis, qui intenfius calefactus in tenebris ad tempus notabile lucet. Obfervationes de Adamante in tenebris lucente reper. in Rob. Boyle Experimentis de coloribus; noftrum vero defcr. Fob. Fac. Schewcbzer in le Clerc Bibliotheque choifie Tom.XVII. pag.192. it. in Meteorolog. \& Oryctographia Helvetica fig.6.-10. pag.139.feqq. Conf. Bresl. Samml. XVI. Verf. An.r723. Claff.IV: Art.V. pag. 537.

R. 7. 8. Amethyftusin, \& alius fine matrice Wolckenfteinenfis, it. alia Hohenfteinenfis Mifniæ. vid. Haubımanns Befchr. des Wolckenfteinifchen vvarmen Bades pag.80.

R. 9. Amethyftus f. Pfeudo-Amethyftus in fuperficie matura, inferius cryftallina, ex Regno Bohemiæ Steinfeiffenfis, item aliæ ex Silefia Georgenbachenfes \& Ehrenfriderfteinenfes. $\quad$ R. 10. 
R. 10. Chalcedonius cinerei coloris, fafciis lineisque albis \& cinereis alternantibus ita circumductis, ut propugnaculum exacte referunt.

R. II. Chalcedonius totus albus ex Mifnia.

R. 12. Chalcedonii diverforum colorum ex diftrietu Gradlicenfi Bohemix.

R. 13. Chryfitis pyramidalis.

R. 14. Chryfolithus Bohemicus.

R. 15. Granati Helvetici montis St. Gothardi maximi Argyrite obvoluti. del. \& defcr. Car. Nic. Langiw in Hift. Lapid. figurat. Helvetix, Part, II. Cap.I. Tab.III. Lit. A. Pag.24.

R. 16. Granati Bohemici elegantiffimi ex argento felium prominentes. vid. Epbem. Nat. Curiof. Dec.I. An.II. Obr.LXXXVIII. pag.546.

R. 17. Granatis turgida minera ex Silefia prope Schmidebergam.' Integras venas, imo univerfos montes granatos in fe continentes defcr. Fob. Georg. Greijelius in Ephem. Nat. Curiof. Dec.I. An.II. Obf.LXXVIII. pag. 646. it. Pecr. Albinus Meifnifcher Berg-Chronica pag.II 6.feqq.

R. 18. GranatiHungarici Preifenfes.

R. 19. Jafpis rubra ex monte Pörfchulano Silefiæ prope Landshuttum.

R. 20.21. Jafpis rubra, \& alia viridis Neofolienfis.

R. 22. Jafpidum diverforum colorum ex diftrietu Gradlicenfi Boz hemix.

R. 23. Lapis Lazuli Orientalis punctis aureis adfperfus, it. ex Saxonia colore viridi variegatus.

R. 24. Malachites botryoides cum marrice, cui particula lapidis Lazuli adhæret.

R. 25. Onyx reticularis, fuperius albo, inferius ungvis colore.

R. 26. 27. Opalus cum, 8 alius fine matrice ex Hungaria.

R. 28. Opalus alius in matrice fplendentis coloris.

R. 29. Rubini Orientales.

R. 30. Sapphirus CPfeudo-Sapphirus ex confiniis Bohemix.

R. 3I. Sarda, I. Carneola adnata Cryftallo albæe.

R. 32. Sardonyx urbem munitam triangularem repræfentans.

R. 33. Sardonyx cujus dimidia pars alba, altera rubra. 


\section{PROMTVARIVM RERVM NATVRALIVM}

R. 34. Sardonyx Cremnicenfis colore albo \& rubró variegata.

R. 35. Smaragdus Orientalis præftantiffimus in inatrice alba pyrite infperfo,

R. 36. Smaragdoprafius fubviridis coloris.

R. 37. Topazius Eibenftokenfis f. ex montibus Mifnixe.

R. 38. Topazii fubnigri ftria hexagona maxima, fimili fluori fub nigro Scbeucbzeri, vid Nat. Gefch. Part III. pag. 57 .

R. 39. 40. Topazius citrini coloris Bohemicus \& alius Hungaricus. R. 4. Turcois Kupferbergenfis Silefiæ.

R. 42. Varix Gemmx \& Lapides, diverforum colorum, ex Silefia, Bohemia, prc. ex Diftrifu Gradlicenfi, it. ex Hungaria.

R. 43. Gemmæ, prout a Ceylanenfibus, Europæis parvo pretio offeruntur, \& ex urna per fortem educuntur. Modum defcr. Georg.Anderfen in der Orientalifch. Reife-Befchreib. Lib.II. Cap.XI. pag.66. it. Erafm. Franciffi im ausländifchen Luitt-und Staats. Garten Libr.II. Sec.XXXIII. p.759.

\section{ARTICVLVS II. \\ Gemmx fcalptæ \& politx.}

r. 1. Ex Achate carnea vafculum, in qua lineæ albæ ita difcurrunt, ut propugnaculum exacte repræfentent.

r. 2. Ex Achate aliud vafculum in cavitate malleo quafi procufum,

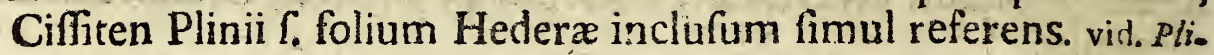
mii Hift. Natural, Libr.XXXVII. Cap.X. Conf. Jot. Jac. Sibeucbzeri Meteorolog. \& Orgetogr. Helveric. pag. 236.

r. 3. Achates alba cum arbufcula nigra, Belgis Boomfteen f. Dendrachates Surattenfis, ex montibus Indoftanenfibus India Orien. talis. velel. \& defcr. Georg. Everb. Rumpbiess Amboinf. Rarit. Kam. Tab.LV. \& LVI. pag.287. Conf. Job. far. Scbeucbzeri Herbar. Diluvian. Pag. 18.

r. 4. Achates diarhana cum Erica tenuifolia.

r. 5. Achates rariffima, a natura ordinatiffime collocatâs arbores, opere miniato, $f$. en miniature referens.

r. 6. Achates alba, cum mufco rubro corallino accuratifimo inclu. fo. conven. cum delineat. ap. Ill. Aldrovandwm in Muf. Metallic. Lib.IV. Tab. 1. num.2. pag.908. Onychem talem defcr. Georg. Baglidius Operum Differt. v. 5. VIII. pag. Yor. Erytallum Job. Jac, Scbeucbzerns in Herbario Diluv. Tab. $1 \mathrm{X}$. 
r. 7. Achates mellei coloris, magni pretii, $f$ Cerachates, in qua natura carduum floribus croceis accuratiffime expreffit, vid. Obfervatio mea in Bresl. Samml. XXV. Verf. An.1723. Claf.IV. Art.V. pag.185.

r. 8. Achates diaphana, in qua arbores quafi ex palude protrinentes nigra confpiciuntur.

r. 9. Achates anthropomorpha alba, cum \&thiope a natura forma. to, qui dorfo nefcio quid geftat, a parte vero antica fafciculum tabaci convoluti tenet. defcripfi in Bresl. Samml. XXV.Verf. An. 17.23. ClafT.IV. Art.V. pag.18.5. alios tales lapides anthropomorphos.defcr. \& del. 0\% Dapper in Befchreib. Africe pag.27, it, G, Ev. Rumpbius Amb. Rarit. Kam. Tab. XLVI. num.t.

r. 10. Achates alba in cujus medio natura caput laureatum aureo colore effigiavit. Notas Achatis charafterifticas \& varias f́pecies explicavis fob. Far. Scheucbzer in SpecimineLexici Mineralogici,quod reperitur in Aa. Erudit. Lipfrenf. Supplem, Tom.VI. Sed.IV. pag.178.leqq.

r. II. 12. Ex Achate integra alba \& fubflava annuli Romañi, tales delin. \& defcriph. Lamrent. Begerus in Thefauro Brandenburgico leleço pag. IsO. feqq.

r. 13. Amethy ftus ex Bohemia, cujus dimidia pars immatura f. cry. ftallina, altera violacea.

r. 14. Amethyftus Orientalis puriffima.

r. 15. Ex Amethy to Orbis maximus cum radice alba.

r. 16. Aftroites $\mathrm{f}$. Rofoites \& Rhodites albus, rofis minimis nigris infignitus. Ex Gefneri de Fig. Lapid. Cap.1. fol.35. del. \& defcr. Añs, Boetius de Boot in Hiftor. Gemmar. \& Lapid. Libr.II. Cap.CXLVI. pr 298.

r. 17. Aftroites f. Rofoites cardioides elegantiffimus, rotis majoribus nigris in albo lapide pofitis. del. \& defcr. Job. de Laet de Gemm. \& Lapid. Libr.II. Cap.I. pag.97.

r. 18. 19.20. Aftroitarum rariffimorum cardioidum num.3. Atellulis quoad magnitudinem diftinctis formæ maximæ. del. \& deicr. ul. Aldrovandus Muf. Metall. Libr. IV. pag. 878. Ol. Wormius in Mufeo Lib. I. Cap.X. pag.67. Mufeum Calceolar. Veronenfe Sea.III. pag.370, Erafm. Francifci im Oft-und Weft-Indifch. Luft-Gart. Part.II. Tab.XLII. fig.2. p.1218. pre. Fob. Henr. Locbnerus in Mul. Besler. Tab.XXXV. pag.100. it. Georg. Hier. Vel. fibius Obfervat. Phyfic. Medic. Hecatof.I. Obf.XLIV. pag.6o. Conf. Boetizm de Boot in Hift. Gem. \& Lapid. Libr.Il. Cap.CXLVI. pag.298. Plures Auchoreś $\mathrm{Z}_{3}$

magno 
magno congeflic ftudio Hans Sloane in Hift Nat. Jamaice Vol.I. pag. 54. quos fimul recemfuic præter fúpra nominatos fob. Jac. Scbeucbzerus in Querelis \& Vindiciis pifcium pag.32. item collegi in Bresl. Samml. won Nat. und Medic. Gefcbich. XXIV. Verf, An.5723. MenC. Maj, Clan.IV. Art.III. pag.\$24.

r. 2I. Belloculus in Onyche. del. Jub. de Laet de Gemm, \& Lapid. Libr. I. Cap.XVIII. num.V. pag.68.

r. 22. Belloculus duplex in Sardo. id. L. C. num.r. pag.68.

r. 23. Cardites ruber in Jafpide alba. defcripfi in Bresl. Samml. XXV. Verf. An.1723. Claffir. Art.V. pag.185.

r. 24. Cati Oculus f. Leucophthalmus coloris viridefcentis.

Carnivla vid. Sarda num. r. 173 .

r. 25.26.27. Cati oculi in aureum colorem ambientes.

r. 28. Cati Qculus ad colorem rubicundum accedens.

r. 22. Cati Oculus albiffimus.

r. 30. Chalcedonius coloris cinerei maximus, cui caput album Alexandri Magni in convexo elaboratum, fingularis elegantia. conv. cum delinear. quam dectit fob. Jac. Bayerus in Thefauro Gemmarum aftabre fculptarurn quiem coliegit fob. Fac. ab Ebermäyer Tab.X. num.26f.

r. 31. Chalcedonius cinereus a natura bufto aurei coloris ornatus.

r. 32. Chalcedonius cinereus albo colore denticulatus.

r. 33. Chalcedonius cryftallinus lineis ląteis in quadractum duftis.

r. 34. Chalcedonius cinerei coloris, lineis fubtiliffimis albis ita circumductis ut propugnaculum exacte efforment,

r. 35. Chalcedonii ejusdem fpecimen minus.

r. 36. Chalcedonius in matrice fuperius politus urbem munitam fafciis lineisque fufcis \& albus alternantibus referens.

r. 37. Chalcedonius in quo fafcix carnex, circa areolam albi coloris.

r. 38. Chalcedonius colore carneo $8 r$ albo variegatus, cum capite Honorii Imperatoris infculpto.

r. 39. Chalcedonius cornei coloris, lineis albis in mucronem definentibus.

r. 4. Chalcedonius ejusdem formæ cúm capite Hoftiliani Imperat. incifo.

5. 4i. Chalcedonius albus fafcia cinerea cinctus.

r. 4I. Chalcedonius diaphanus, in utraque parte pentagonum lineis fubtiliffimis albis referens. 
ET ARTIFICIALIVM KVNDMANN. VRATISLAV. 183

r. 42. 43. Chrylites major \& minor.

r. 44. Chryfolithus Orientalis.

r. 45. Corfoides $\mathrm{f}$. Jafpis canitiem hominis referens.

r. 46. Crucifer Lapis, $\int$. Jafpis alba cruce nigra infignita. defcripfi in Bresl. Samml. XXV. Verf. An.1723. Claff.IV. Art. V. pag. 185. defcripr. \& delineav. Ol. Wormin in Muf. Lib.I. Cap.X. pag.69. it. Job. de Laet de Gemm. \& Lapid. Libr.I. Cap.XXII. pag.8I. Conf. Ephern. Nat. Curiof. Dec. I. Obferv. CXVI. An.I. pag.270.

r. 47. Crucifer lapis coloris flavi femiglobularis.

Dendrachates vid. Achates r. 3 .

r. 48. 49. Granati Bohemici \& Orientales maximi. Bohemicos Orientalibus effe preftantiores ex multis Authoribus demoniftravit Bobusl. Balbinus Mifcell. Hitt. Regn. Bohem. Lib.I. Cap. XXXI. pag.77. Conf. de pretio Ans, Boetii Hift. Gemsm. \& Lapid. Libr.II. Cap.XXVI. pag. Is .feqq.

r. 50. Galaxia f. Galactites Plinii r. Jafpis laqei coloris, vid. Hift, Nat. Libr. XXXVII. Cap.X.

Hæmachates vid. Jafpis r. nüm.62.

Heliotropius vid. Jaspis $\mathrm{r}$. num. 75 .

r. 51. Hyacinthus Orientalis.

r. 52. Jafpis nigra f. Sigillum literis Rufficis infcriptum.

r. 53. Jafpis coloris ex albo \& viridi variegata.

r. 54. Jafpis ex atro rufefcens femiopaca.

r. 55.56 .57 . Jafpis viridis $\mathrm{f}$. Lapis Nephriticus coloris vinei num.3. quoad magnitudinem diverfi, vid. Augerii Cluti Calsvee f. Differt, de Lapide Nephritico, qui annex. Gril. Laurenbergii Hift. Defcript. Extitis Cafp. Barzbolinus in pec. Trą. de Unicornu \& Lapide Nephritico, it. Georg. Hier. VelScbius in Epbem. Nat. Curiof. Dec.l. An.III. Obr. XXX. pag.46. De factitio vid. 1bid. Dec.I. An. VI. pag. I29. Ufum in Medicina defcr. Nit. Monardes de Lap. Bezaar Cap.XIIr. it. Epbem. Nat. Curiof. Dec.II. An.VII. pag.4.

r. 58. Jafpidis talis tabula maxima quadrangularis.

r. 59. Jafpis talis faturatioris coloris, punctulis aureis adfperfa.

r. 60. Jafpidis talis tabula, quæ lapidis Lydii loco effe poteft.

r. 6r. Jafpis viridis fafciis fanguineis infcripta.

r. 62. Jafpis tota rubra f. Lapis fanguinalis Boetii Hiff. Gemm, \& Lapid. Libr. II. pag. 257. \& Hæemachates Imperati Hift. Natural. Libr. XXII. Cap. XXXIX pag.697. 
f. 63. Jafpis rubra colore aureo, coccineo \& nigro maculata.

r. 64. Jafpis alba, . Lapis Geographicus lineis provincias indicantibus purpureis. \&

r. 65. Jafpis alia rufefcens in qua provincix maculis albis delineantur.

r. 66. Jafpis multicolor in qua fafcia repens lutea, tam fupra quam infra habens fimbriam, fitum venarum metallicarum in terra demonftrat.

r. 67. Jafpis diverfis coloribus confpicua, capite humano a natura efformato.

r. 68. Jafpis colore carneo, partem propugnaculi lineis albis reprafentans.

r. 69. Jafpis elegans fafciis punctatis diverficoloribus, \& lineis nigris cincta.

r. 70. Jafpis rubra Qrientalis cum pentagono parvo albo infcripto. r. 71. Jafpis maxima colore aureo.

r. 72. Jafpis lineis diverficoloribus undas fluviorum æmulantibus.

r. 73. Jafpis cryftallina, ftriis viridibus, qua gramen referunt, im: merlis.

1.74. Jafpis cujus dimidia pars alba, altera fubflava, quam traftus quafi montanus interfecat.

r. 75. Jafpis viridis colore rubro variegata $f_{\text {. Heliotropius orienta- }}$ lis cum fcorpione incifo. De viribus faberftitiofi vid. Cafp. Schbenckffeldus in Catalogo ftirpium \& foffil, Silef. Libr.III. pag.382.

r. 76.77.78. Jafpides talis form $\&$ colorum diver $x$ magnitudi. nis num. 3 .

r.79. Jafpis pellucida, maculis viridibus, quas color fufcus circumdat. r. 80 . Jafipis alba, ubi cor fanguinei coloris ab utroque latere cernitur.

r. 8I,--II2. Jafpidum diverfis coloribus eleganter notatarum \& maculatarum Bohemicarum \& Siletiacarum num. 3 I.

r. II3. Kay Ceylanenfis coloris flavefcentis.

r. II4. Lapis Lazuli Orientalis punctis aureis donatus.

r. 15. I 16 . Lapis Lazuli colore albo variegatus, totus punctis aureis adfperfus num.2. 


\section{ET ARTIFICIALIVM KVNDMANN. VRATISLAV. 185}

r. 117. Lapidis Lazuli Orientalis tabula maxima.

r. I 8 II9. Lapidis talis tabulix num.2. marmore albo variegati. r. 120. Lapis Lazuli maximus, in quo caput Cleopatrz eminenter optime incifum. conven. cum delineat. quam dedir Leonb. Auguffinus de Gemmis \& Sculpeuris antiquis Part. II. Tab.XLII. pag.68.

r. 121. Lapis Lazuli cum Icuncula Palladis infculpta. Ejusmodi del. \& defcr. Epbem. Nat. Curiof. Dec.II. An.V. Obf.XXXXVI, it. Decur.I. An.VI. \& VII. Obf.CCXVIII, meretur quoque lectionem Diff, quam Melcb. Sebizim de Lapide Lazuli Argentor. public.

Lapis Geographicus vid. Jafpis num, r. 64.

Lapis Nephriticus vid. Jafpis num. r. 55,--60.

Leucophthalmus vid. Onyx num. r. 139.

r. 122. Lyncurus linea per medium divifus, Succini ad inftar pellucidus, Luchfenftein.

r. 123. Malachites ad colorem Turcoidis accedens.

r. 124. Malachites Malvæ inftar viridis.

r. 125. Malachites colore faturatiore variegata.

r. 126. Malachites, in qua cœruleus color intermixtus eft, Tyro. lenfis prope Schwatz. vid. Fob. Henr. Locbneri Muf. Besler. Tab.XIX. p.89. r. 127.128.129. Margàritæ oculatæ Scoticæ, \& non oculatæ Regni Bohemiæ, item ex Quiffo fluvio. has defer, Sam. Ledelius in Ephem. Nat. Curiofor. Dec.II. An. VIII. Obf.CL. pag. 327. Bohemicas vero it. Pifcationem Bobusl. Balbinus in Mifcell. Hiftor. Regn. Bohemix Libr.I. Cap.XXIX. pag.73. fegq. Scoticas Rob. Sibbaldus in Scotia illuftrata f. Prodromo Hift. Naturalis Sect.IV. Cap.XII.

r. 130. Margaritæ Orientales maturæ \& immaturæ. De generatione, ex pluvix guttulis, vid. India Orientalis Part.VII. Cap.XV. pag.69. Ex rore,prater Plinium Rocbefort in Befchr. der Ancill. Inf. Cap.XIX. num.9. pag.328. Ex morbo Pbil. Bonannus in Recreation, mentis \& oculi Part.III. Problem.I. pag. 176. Quod fint ovula Concharum margaritiferarum, vid. G. F. Mylius Memorabilium Saxonix fubter. Part.II. Relat.I. pag.18. de Pifcatione vid. Foh. Bapt. Taverniers Reife-Befchreib. Part. II. Cap. XX. \& XXI. pag.132,--136. Thom. Gage Reif-Befchreib. nach Neu-Spanien Part.II. Cap.V. pag.158. Georg. Nic.Scburtzii Material. Kam. pag.57. it. Mich. Bernb.Valentini in Muf. Mufeor. Part.I. Cap.XXXVI. pag.495. ubi fimul Urinatorem pifcatione unionum deffinatum delineavit. Multa huc SpeEtantia collegit Carol, Clufus Aromatum Hiftor. Libr.I. Cap.LVII. pag. 223. Joh. Hug. Lintschottanus Ind. Orient, Part. IV. Cap. XL. pag. 80. Ol. Wor. 
mius in Muf. L.br. I. Cap. XIX. pag. 109 Guil. Rondeletius de Pifcibus marinis Part.II. Libr.I. Cap.LII. pag. sr.feqq. Wilb. Dampier in der Reife um die Wele Part.I. Cap.VII. pag.323. Tbevenot in Reilen Part.I. Libr.III. Cap.X. pag. 2j5. it. Libr.IV. Cap. I. pag. 247. olffg Franizius Hift. Animal. Parc. III. Cap. VIII. Erafm. Francifci im Oft und Weft Ind. Luft-Gart. Part.I. pag.1245.leyg. Hiflorifebe Remarquen An.1707. pag.182, pre. Epbem. Nat. Curiof. Dec.I. An.II. Obf. CCXXVIII. pag. 329. it. Scbol. Dec.I. An. Ill. Obf. XXXVI. pag. 58. Dec.II. An.III. Obr.XXXVI. pag.99.feqq. it. pag 417. Dec.II. An.VIII. Obl.CL. pag. 327. Conf. Petr. Pometis Material. und Spez. Händl. Parc. II. Cap. XLVI. \& XLVII. pag. 6rs.feqq. it. Cbr. Vielbeuers Befchr. fremd. Mater. pag. 176. feqq. Examen Chymicum inftituit Guerner. Rolfin kius in Differt. de Margaritis, Fob. Sopbron. Kozack. de Sale medicamentofo in margaritis.

r. 131. Melites Boetii. vid. ejusd. Hiftor. Gemmar. \& Lapidum Libr. II. Cap. CCXXXI. pag. 416.

Nephriticus lapis vid. Jafpis num. r. \$\$, 60.

r. 132. Obfidianus Lapis Agricole niger Gagatem referens. vid. de Nát: Foffil. Libr.IV. Cap. V. pag. 474 .

x. 133. Onyx cujus dimidia pars alba, altera lineis purpureis \& albis diftindta.

r. 134. Onyx unguis colore maximus, cui caput album Hadriani Imperatoris in convexo elaboratum auro cinctum cum margaritis appenfis; magnæxftimationis.

r. 135. Onyx Fauftinæ caput ita incifum repræentans, minoris formæ. conv. cum del, Leonb. Auguftinz̈ de Gemm. \& Sculpturis antiguis Part. I. Tab. LXXXV1l. pag.30.

r.136. Onyx talis parvus cum capite Philofophi, id. L.C. Part. I. Tab. XXI. pag. 9. Gemnas rales defcr. \& delin. Laurent. Begerus in Thefauro Bran. denburgico felecto, f. Gemmarum \& Numifnatum in Cimeliarchio Electorali Brandenburg. ferie, Idem, in Thefauro Palatino Gemmarum \& Numifmatum. Conf. Erb. Reufsbii Capita Deorum \& illuftrum hominum in Gemmis, qua collegit Joh. Mart. Ebermayer, Fob. Fac. Bayeri Thefaurum Gummarum affabre fculptarum, quem collegit idem fob. Mart. ab Ebermayer, Jacobi Sponii Mifcellz. nea eruditze antiquitatis, in qquibus marmora, ftatux, mufiva, torevmata, Gemmx Qc. illuftrantur, Micb. Angeli Caufei Romanum Mufeum f. Thefaur. eruditx antiquitatis, it. Ejusd. delineationem Gemmarum antiquarum, jac. de Wilde Gemmas Veteres, Anonymi Catalogum lapidum pretioforum, Achatum, Ony. chum \&c, ac omnis generis antiqux fuppelledilis, Cárol. Heidani Thefaurum Grecorum \& Romanorum Numifmatum, item Curalliorum, Gemmarum * Celaturarum plurimatumque rerum pretiofarum it. Obfervationem meam in 
ET ARTIFICINLIVM KVNDMANN. VRATISLAV. 187

Bresl. Sasomb. pan Natumesed MLedic, Gefib. XX, Verf. An. 1722. Menf, Maj. Clafr. IV. Art. X. pag. 499 .

r. 137. Onyx cujus dimidia pars diaphana, inferior tractum montolum efformat.

r. 138. Onyx in medio trapezium referens.

r. 139. Onyx oculum exprimens $C$ cum conea oculi nigra, quam linea alba cingit, $\int$. Leucophthalmus.

r. 140. Onyx in qua fafcia rubra colorem album interfecat, inferi. us unguis colore elegantiff.

r. I41. Onyx cinerea lineis nigcis circumferipta, in cujus medio ánnulus albus maculam flavefcentem cingit.

r. 142. Onyx unguis colore, lineolis albis transverfim difcurrentibus, macula alba exacte rotunda fimul notata.

r. 143. Onyx ex cinereo \& nigro variegata, quam fuperius oculus cœruleus cum pupilla flava exornat.

r. I44. Onyx talis cum pupilla oculi flava ex nigro punctata, quam fafcia alba circumdat.

r. 145. Onyx nigra, maculis faturatioribus fecum invicem connexis, quas lineæ albæ diftinguunt.

x. 146. Onyx flava annulo albo infignita.

r. 147. Onyx cornea, quam macula duæ lineolis albis cinct $x$ fpeelabilem reddunt.

r. 148. Onyx cryftallina cum oculoalbo.

r. 149. Onyx talis cum oculis duobus cornei coloris, in cujus me. dio pupilla alba cernuntur.

r. 150. Onyx albicans in qua maculæ binæ peralbæ.

r. 151. Onyx cornei coloris cum maculis tribusita immerfis.

r. 152. Onyx cinerea maculis multis albis depicta.

r. 153. Onyx albicans fafclis lineisque albis \& nigris ita infcriptis,ut propugnaculum referant.

r. 154. Onyx cornei coloris elegantiffima Cepiti Rumpbi: fimilis, (Tab. LVI. Lit. F.) nifi quod mole major fit, \& fafcis lineisque albis, fufcis \& aureis ita circumdufta, ut urbem munitam efforment.

r. 155. Onyx tribus circulis albis juxta fe continuis pofitis.

r. 156. Onyx, quam inferius linex diverficolores cingunt, fuperius 
vero cornea cinerea \& pupilla oculi flavefcens fpeftabilem reddunt.

r.157. Onyx colore nigro maculatus, cujus medium annulus albus circumdat.

r.158. Onyx elegans maculis multis exacte rotundis albis picta. Conven. cum delin, ap. Ul. Aldrovandum in Muf. Metall. Libr. IV. Tab. I. \& II. pag. 918. it. Job. de Laët de Gemm. \& Lapid. Libr. I. Cap. XVIII. pag. 68. \& 69.

r.159. Opalus in Hungaria Sup. repertus.

r. 160. Opalus cujus dimidia pars aurea, altera diverfis coloribus confpicua Indræ Orientalis.

r.16I. Opalus máximus pellucidus, quem variæ flexuræ albæ fpe: ctabilem reddunt.

r. 162. 163. Opalus Orientalis preftantiffimus major \& minor.

r. 164. Opalus diaphanus vulgo Eine Weehfe.

r. 165. Opalus talis ad colorem viridefcentem accedens.

Rofoires vid. Aftroites num. r. 16.17.

r. 166. Rubini Orientales.

r.167. Rubinus in quo imago Salvatoris cum Matre Virgine, artificiofe in convexo elaboratum.

r. 168. Sanguinalis lapis Boctii Lib.II. Hift. Gem. \& Lap. Cap.CLXXXIV. pag. 375. Conf. Nicol. Monardi Hiftor. Simpl. Medicamentor, ex Nov. Orb. delatorum pag. 5r. it. Mufeum Calceolar. Veronenfe Sect.111. pag. 403.

r,169. Sapphirus Orientalis.

r.170. Sarda C. Carneola cum capite humano galeato a natura mire efformato. Achates Rudolpbi II. Imp, vultus humani funilitudinem referens defer, Bobusl. Balbinus Mifcell. Hiftor. Bohem. Libr. I. Cap. XXXII. pag. 80. Onychinus lapis Colonienfis in quo picta funt duo capita juvenum peralba defcr. Albertus M. de rebus Metallicis Lib. II. Cap. II. pag.II8.

r. 171. Sarda, quam lineæ albæ \& rubræ transverfim diffecant.

r. 171. 172.173:174. Aliæ num. IV. diverfimode lineis albis \& nigris infcriptx.

r. 175. Sarda alba punctis fanguineis fpectabilis, f. Stigmites.

r. 176. Sarda C. Carneola ex Perfia rubicunda.

r. 777. Sarda alia faturatioris coloris. 


\section{ET ARTIFICIALIVM KVNDMANN. VRATISLAV. 189}

r. 178. Sarda f. Carneola maxima, in qua duæ pupillæ exactx rotundæ, quafi circino defcriptæ effent, cernuntur. vid. Georg. Agricola de Nat. Foffilium Libr. VI. Cap. XXVI. pag. 612.

r.179. - 188. Sarda diverforum colorum, ubi una ex atro rubefcens, alia dilutioris coloris, alia rubicundi, alia carnei coloris, alia aurei, alia flavefcentis, alia candidi, alia candidiffimi.

r. 189. Sarda alba linea rubra per medium divifa.

r. 190. Sarda talis punetulis rubris adfperfa.

r. 191. Sarda alba punctulis \& maculis fanguineis infignita.

r. 192. Sarda alba lineis laeteis per medium duetis.

r. 193. Sarda alba guttulis quafi fanguineis notata, f. Gemma D. Stephani, vid. Obfervatio mea in Bresl. Samml. pon Nat, und Med. Gefcbibt. XXV. Verf. An, 1723. Claff. IV. Art, V. pag. 185.

r. 194. Sarda f. Sigillum literis Turcicis infcriptum.

r. 195. In Sarda tigillum tale aliud.

r. 196. Ex Sarda integra elegantiffima annulus.

r. 197. Sardonyx mirabilis fructurx, urbem munitam exacte referens, lineis fubrilisfimis albis, circum \& contra vallum ductis. ?

r. 198. Sardonyx talis major, lineis vallum referentibus latioribus, magnææattimationis.

x. 199. Sardonyx zonis cryftallinis \& flavis in mucronem definentibus, quafi bicolor tenturium egregie repræfentans, cujus pertica rubra cœruleo globo eft ornata.

r. 200. Sardonyx lineis albis \& rubris alternantibus.

r. 20I. Sardonyx cujus dimidia pars rubra, altera flava, lineis tribus albis transverfim infcriptis, cum viro incifo.

r. 202. Sardony $x$ in una parte hexagonum, in altera pentagonum lineis fubtiliffimis albis referens.

r. 203. Sardonyx in utraque parte cum hexagono albo ita inferipto.

r. 204. Sardonyx lineis fubtiliffimis albis in quadratum ductis, cir$\mathrm{Ca}$ areslam rubri coloris.

r. 205. Sardony $x$ talis alia cum areola oblonga rubra, quam linea alba cingit.

r. 206. Sardony $x$ in qua areola cryftallina, quam fafciaalba \& rubra circumdat. 
r. 207. Sardony x/pudendum muliebre reprafentans.

x. 208. Sardonyx coloris carnei, lineis fubriliffimis albis ita infcriptis, ut pentag onum efforment. Ita figuratas gemmas del. \& defcr, ulyjf. Aldro, Dandus in Mul. Metallic. Libr. IV. pag.?20. Erafm. Francifci in Oft. und Weft - Indianifchh. Luft - Gart. Part I. pig. 162. feqq. it, Georg. Everh. Rumphius Amboinfch, Rarit, Kam, Tab. LV. Liter. A. B. C. D. E.F. pag. 288.

r. 209. Scolopendrites lapis diaphanus pediculis viridibus ubique transparentibus. conven. cụm delin, \& defcript. ap. Job. de Laee de Gemm. \& Lapid, Libr, II. Cap. XXIIX. pag. 176.

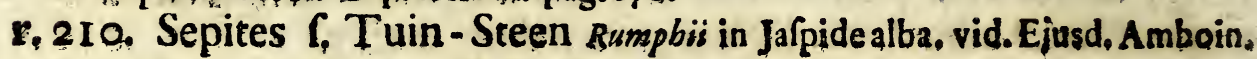
Rarit, Kam. Lib. III, Cap. XLIV. Tab.LV.

r. 21 I. Smaragdoprafius Orientalis puriffima.

r. 212. Smaragdus vulgo Orientalis. vid. Francife, Leguas Reilen nach zweyen unbevvohnt. Infuln Part. II. pag. 349.

r. 213. Thracius lapis Boctii Hift, Gemmar, \&Lapid, Libr, II. Cap. CLXIV. pag. 336 ,

F. 214. Topafius $\mathrm{f}$. Topazius Orientalis.

r. $215^{-223}$. Topalii pellucidi elegantiffimi, quoad colorem \& fi. guram diftincti num. IX. diverfa magnitudinis.

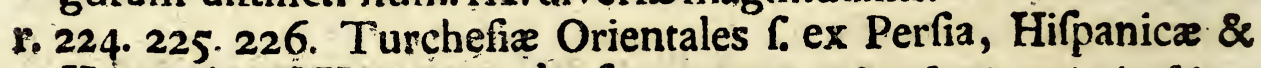
Hungarica f. Herrngrundenfes. Perficas defcripfit Tapernier in feiner Reife-Befçhr. Part.II, pag. $13 \mathrm{I}$,

GEmmas Lapidesque pretiofos erudite defcripfit frepe allegatus Anfelmaus Beetim de Bnet in Hittoria Gemmarum \& Lapidum Libr,II. it. Job. de Laet de Gemmis Libr.II. Et ante hos Camilles Leonardus in Speculo lapidum, fob. Kentmannus in Nomenclatura foffilium Tit. IX. fol. 46.--53, Georg. Agricola de Natur. fosifil. Libr. VI pag. $59 \%$ 622. Garcias ab Horco in Aromatum Hiftoria Libr.I. Cap. XLVII...LVII. pag. 218. feqq. Job. Hug. Lintfchottanus Ind. Oriental. Part, IV. Cap.XLI.- XLVII. pag. 82. feqq. Mufeum Calccolar. Veronenf. Seç. III. pag. 207.- 257 . ulyff. Aldrovandus in Muf. Metallic. Libr.IV. pag.884. Ferrand. Imsperatus Hift. Natural. Libr.XXII. \& XXIII. pag.662,- 716 , Quibus jungendi Ola. Wormies Muf. Libr. I. Cap. XIV..-XIX. pag.92,.-112. Erafm, Francifci im QRund Weft-Indianifch. Luft.G Irt. Part. II. pag 1213, -1240. Fob. Kunckelius in Arce Virraris experimentali Part,II. pag.97. Eman. Königi in Regno Minerali, Sed. III. Georg. Everk. Rumpbius Aimb. Rar. Kam. Libr.IIL, Cap.39. pag.282. Reqg. it. Gaff. Gotcbold Jentfas in Difl de Gemm. Lipf, hab. prc. de Generatione Gem- 
marum egit Georg. Baglivins Operum Differt. V. pag. so3.feqq. it. 'Georg. Hier. Velfcbius Obterv. Phyfic. Medic. Hecarof.I, Obfer. XXXVIII. pag.jI.

Gemmas figuratąs delin. dx defcr. ul. Aldrobandus in Mut. Metall. Lib.IV. Tab.I.II. s III. p3g.9es.feqq. Job. de Laes de Gemm. Lib.l. Cap.XVIL. pag.68. \& 69. Erafm. Francifci im Oft.und Weft Indian. Luft.Gart. Part.I. pag.16z.leqq. Giorg. Hier. Velfbim Obferv. Phyfic. Medic. Hecaroft. I. Obf.XXII. pag.34. delin. pag. 27. it. Obf XLII. pag. 57. Fob. Dan. Geierm de montilus conchiferis Tril. \$. I4. pag.15. Frid. Lasbmundus in Orgetograph. Hildesheimenfi in Prxfatione, Job. Everb. Rumpbius Amb. Rarit. Kam. pag.289. \&c. Conf. Georg. Wendium, qui occafione Examinis Suecici cujusdam lapidis mire figurati, plures Authores nomina. vit. Methodum per artem pingendi marmora \& getrimas proponit Atbanaf. Kir. cberm in Mundo Subrér. Libr. VIIl. SeA.I. pag.42. it. Heñr. Oldinburgiv in AR. Soc. Reg. in Ang!. An.1665. Menf. Dec. pag.94. De XII. Gemmis in vefte Aaronis vid. Epipbansus Epifcopus, it. Kircberu Mund. Subr. Tom. II. Libr. VIII. Sec. III. pag. 83. prc. Ca/p. Neumannue in biga difficultatum Phyfico.Sacrarum de Gemmis Urım \& Thummim dickis. De Gemmis, quarum Apocalypfis memis nit, vid. Franc. Rueus.

De Gemmis Bohemicis vid. Bob. Balbinas Mifc. Hift. Regn. Bohem. Libr. I. Cap. XXX. XXXI \& XXXII. pag.75. Carniolx, Valvaffor in der Ehre des Herzogrh. Crams Parr.t. Lib.III. Cap.XXX. pag.428.feqq. de Silefiacis Georg. Ant. Volck: mann in Silei: Subterr. Cap.1. 5.3. 22. pag.13.-34. de Saxonicis Pror. Albinu in der Meilinilch. Berg. Chronica Tit. XVIII. pag.143. it. G. F. Mylius in Memorab. Suxon. Subterran. Part.II. Relat.I. pag.I.feqq. de Helveticis Catol. Nicol. Langius in Hiftor. Lipid. figurat. Helvet. Part.II, Cap.I. p.23.leqq. de Borusfiacis Georg. Andr. Heltwing in Lithugraph. Angerburgic. Part.l. C.ip.IV. pag.21.

De pretio \& aftimatione Ans. Bostus in Hift. Gem. \& Lapid. \& Thom. Nicols in Be. fchreib. der Edelgeftzine famt denen Eigenfchafften, Preis und Warrh, prc. Taver. mier in feiner XL-jährigen Reife. Beichreıb. Part.II. Cap.XV...XX. P 120. 138. d Thevenot in Reifen Parr.III. Lib.II. Cap.V. pag..195.

De Ulu in Medicina, evolvendi prater Diofcoridem \& Plinizm aliosque antiquos Scri. ptores, it. Conr. Gefiserum, Gbrifiopb. Encelium. Ans. Boetium de Bsot, Job. de Late Ec. Marbodetis in Oprre de Genmarum \& Lapidum pretioforum fornis, natura \& viribus, Andr. Bacctis de Gem. \& Laps pretiofis eorumque viribus \& ufu, Atbu. Kircberus Mund. Subter. Tom.II. Libr. VIIl. Sect.III. Pag 78. Petr. Pomet im

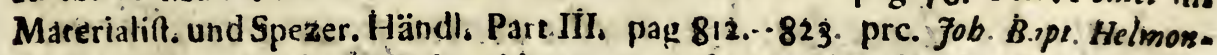

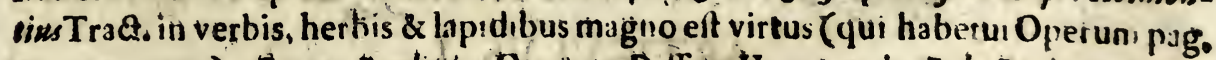
m. 544.-sr2.). Georg Baglivius Operum Dilfert. V. P.519. it. Rob. Boyte in Trac. de Origıne \& Virtutibus Gemmarum S-a II. pag.30ileqq. Quibus le oppolue. re Antonius Mufa Braffavolus un Examiue omnium Simplicium, Petr. Poterise in 
Pharmacopoea Spagirica, prc. fob. f.sc. Spenerus in Differt, fua Inaugurali de Ufi. bus Gemmarum fuperftitiofis.

De Affectibus Gemmarum fupernaturalibus ac ex fuperftitione natis multa congesfit Albertus Magnis, de virtutibus herbarum, lapidum \& qu rundam animalium Thom. Nicols in Befchreib, der Edelfteine famt denen Eigenfchafficen, Preis, and Werth pag. 35.feqq. it. Chriftian. Johann. Langius de Materia Medica Cap.IV. pag.325. quæ habetur Operum Medicorum pag.277.feqq.

\section{ARTICVLVS III. \\ Fluores \& Cryftalli fcalpte, referentes}

S. I. Amethyftum.

S. 2. Granatum.

S.3. Hyacinthum.

S. 4. Opalum.

S. 5. Rubinum.

S.6. Sapphirum,

S.7. Smaragdum,

S. 8. Topafium, \& alios. de his legendus ul.Aldropandus in Muf. Metal. Libr. IV. pag. 927. feqq. Ol. Wormius in Muf. Libr, I. Cap XVI. pag. IOI. Atban. Kircberus in Mund, fubt. Tom.II. Libr. XII. pag. 458. feqq. Rob. Boyle in Tr. de Origine Gem. prc. Joh. Fac, Scheuchzerus Natur - Gelchichte des SchvveirzerLandes Part, III. pag. 59. feqq.

S. 9. Cryftalli puriffim $æ$ diverfæ magnitudinis \& forma num. XX. de artificiofa fcalptura Mediolani vid, id. Scheucbzerus L. C. pag. 55 .

S. 1o, Cryftallus maxima colore viridi imbuta vulgo doublette \& alize diverforum colorum.

S. I I. 12. Cryftallus adamantem maximum Magni Mogoris, \& alia Florentinum repræfentans.

S. 13. Vitrum interne variis flexuris aureis \& rubris pietum.

\section{Claffis II.}

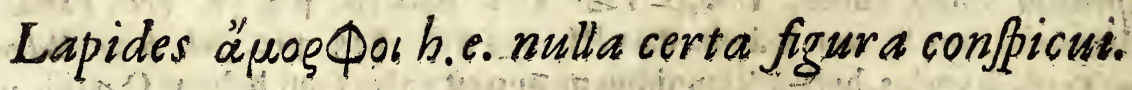
ARTICVLVS I.

Lapides Cryftallini, Fluores iisque affines.

1. Cryftallus cum gramine immerfo. 
ET ARTIFICIALIVM KVNDMANN. VRATISLAV. 193

2. Cryftallina concretio omnium rariffima ex parvis quafi catenulis fplendentibus contexta.

3. Cryftalli Freibergenfes minimæ nitentes, ab omni metallo liberæ.

4. Minera Hercyniæ fylvæ, ftriis albis fine ordine difpofitis.

5. Quartzum flavum, ex fodina Hohenbricknerenfi Freibergenfium.

6. Cryftalli rubræ, pauxillo fabulo fplendenti infperfæe, ejusd, loci.

7. Striæ cryftallinæ albæ Freibergenfes.

8. Minera ex marmore metallico, miculis fplendentibus \& vitriolo compofita, ejusdem loci.

9. Cryftalli r. Pfeudoadamantes Schœenbrunnenfes, vulgo Pribor: nenfes Silefix, inter fe connexi.

10. Cryftalli ejusdem loci feparatæ longiffimæ. del, \& defcr, Georg. Ant. Volckmann. Silef. fubter. Part. I. Cap. I. pag. I6.

I1. Minera Schneebergenfis tuberofa cryftallina, Marcafita infperfa, plumbo adhærens.

12. Minera ejusdem loci cry ftallulis æqualibus fplendentibus infitis, coloris rubicundi \& albi.

13. Cryftalli pellucidæ Clausthalenfes cum pauxillo pyrite:

14. Cryftalli lactei coloris, ejusdem loci \& ftructure.

15. Striæ cryftallinæ longiffimæ Pyrite intermixtæ.

16. Cryftalli rubræ æqualiter inter fe diftantes ex Hungaria.

17. Morion Agricole $\mathcal{C}$ fluor nigricans Stolbergenfis, vid, ejusd, de Natur. Foffil. Libr. VI. pag. 606.

18. Minera fquamis ereetis maximis ex marmore metallico formatis, infitis miculis paucis fplendentibus.

19. Minera fquamis ita difpoffitis minoribus, infperfo pulvere aurifero, viridi \& flavo nitente.

20. Minera ejusdem ftrueturæ, $f$. ex fquamis ereetis minimis compofita, qux particulis cubicis ex marcafita aurea exornatur.

21. Cryftalli femiopacæ multo pyrite imbutæ.

22. Minera rariffima, fabulo viridi, coeruleo, rubicundo \& aureo confpicua, infperfis ftellulis albis.

23. Quarzum flavum, globulis nitentibus in fuperficie inftruetum. 24. Minera mammillaris, cryftallis minimis emergentibus. 


\section{4

25. Cry ftalli alba ex fuore amethyftino prominentes.

26. Cryftalli pellucidæ, intermixtis ftriis fplendentibus granulorum inftar minimorum.

27. Cryftalli, materia tophacea obduftæ.

28. Cryftalli Bohemicæ inter fe cohærentes nebulore.

29. Minera Atriis radiantibus longioribus, globulis aurei nitoris \& cufpidibus albis, item fquamulis flavis diftineta.

30. Minera fquamofa egregia, miculis cœruleis colore flavo variegatis, prominentibus papillis albis.

3I. Cry falli albæ elegantiffimæ femiopacæ, adnatis globulis auriferis \& fquamis luteis.

32. Cryftalli particulis viridefcentibus undique confperfæ.

33. Minera ex cryftallis absque cufpidibus \& Marcafita aurea compofita.

34. Cryftalli obtufius mucronatæ plumbo adhærentes.

35. Minera cryftallina alba cufpidibus translucidis \& miculis Marcafita infperis, $f$. Cryftalli, veluti intus nivem habentes.

36. Cryftalli particulis fplendentibus diverficoloribus ornatæ.

37. Minera ex meris globulis aureis \& marmore metallico albo concreta.

38. Minera elegantiffima una parte ex cryftallis marmoreis five grandinis inftar femiopacis, pyrite fimul infperfo, altera ex pyrite ut meras guttulasefformet, compofita.

39. Cry ftalli inter fe connexæ majores, inhærente pauxillo pyrite nitente.

40. Minera ex cryftallulis albis mire efformata.

41. Minera æris, prominentiis diverficoloribus cryftallinis elegan-

ter notata.

42. Minera uno latere ex Quarzo, altera ex Cryftalli conftans.

43. Quarzum rubrum Hungaricum corallia æmulans.

44. Striæ cryftallinæ ereetæ longiffimæ, inferius pyrite infperfæ.

45. Ex Marcafita aurea, plumbo, cupro \& quarzo concreta minera.

46. Minera plumbi ex meris cubis formata, cryftallis ubique pro-

minentibus.

47. Cry ftalli minimæ argento nativo adhærentes. 
ET ARTIFICIALIVM KVNDMANN. VRATISLAV. 195

48. Cryftalli depreffx marmore metallico infitæ, adjacentibus mammillis pyrite infperfis.

49. Striæ cryftallinæ fecundum longitudinem eleganter difpofitæ. del. \& defcr. Fob. Fac. Stbcucbzerus Natur.Gefchichte des Schvveitzerl. Part.III. Tab.I. num. 3. pag. 6९:

50. Cryftalli ereetæ \& depreffx fibi invicem mixtæ ftiriæformes. 5I. Minera fferri rubicunda, cryftallis fplendentibus in fuperficie adnatis.

52. Cryftalli minime Freibergenfes fine ordine difpofitæ.

53. Cryftalli albæ ex montibus fylvæ Hercyniæ.

54. Cryftalli f. Pfeudoadamantes Bohemici Kamelenfes.

55. Cryftalli nigræ Schneebergenfes, f. minera ftanni folida rariffima.

56. Cryftalli albæ nigris intermixtæ Freibergenfium ex fluore amethyftino \& quarzo cinereo prominentes.

57. Cryftalli nigræ in marmore metallico albo Eibenftockenfi. 58. Quarzina minera alba, zona plumbea transverfim difcurrente, Clausthalenfis.

59. Minera turrita Antimonialis Cremnicenfis, in fundamento cryftallino.

6o. Flores flavi cryftallini Antimonio Cremnicenfi, ignem nondúm experto, adhærentes.

6I. Cryftalli maximæ orientales cum radicibus.

62. Cryftalli puriffimæ tales minores.

63. Cryftalli maximæ albæ \& rubræaus der Mummel-Grube beym krummen Hübel am Riefen-Berge.

64. Cryftalli longiffimæ inter fe connexæ ex Hungaria.

65: Cryftalli ex monte PörfulanoLandshuttenfi Silefia infperfis pifis lapideis.

66. Cryftalli minimæ Svidnicenfes Silefix.

67. Cryftalli nigra ex Valle Joachimica.

68. Minera plumbi cubica Gottesbergenfis c. cryftallo: 69. Minera plumbi ex meris cubis compofita llcufienfis Polonix, cryftallo adhærens.

70. Cryftalli rubræ fplendentes, fupra mineram argentiferam pofita. $\mathrm{Bb} 2$ 


\section{PROMTVARIVM RERVM NATVRALIVM}

71. Cryftalli maximæ Amethyftinæ Hirfchbergenfes Silefiæ.

72. Flores æris Oenipontani f. Cryftalli pellucidx ereftæ coloris viridefcentis, ex matrice faturatiori prominentes, elegantiffimæ.

73. Cryftalli Islandica cubus puriffimus.

74. Cryftalli ejusdem Regni ftria maxima hexagona $2 \frac{2}{2}$. libram ponderans.

75. Minera cryftallina viridis Walthersdorffenfis prope Kupferbergam, cui multum æris ineft.

76. Cryftallus f. Kay Ceylanenfis, vid. Defcr. in Monconys curiöfer ReifeBefchreibung.

77. Cryftalli minimæ, intermixtis quibusdam majoribus.

78. Minera fquamofa flavefcens infperfis paucis miculisaureis.

99. Minera ex meris cubis aureis formata, Quarzo adhærens.

80. Striæ fubalbæ fine ordine ex marmore metallico pyrite infperfo, prominentes.

81. Cryftalli inter fe connexæe longiores cum brevioribus.

82. Cryftallus obtufe mucronata.

83. Cryftalli minus erectæ elegantisfimæ.

84. Cryftalli nigricantis coloris Eibenftockenfes Topafium ærnulantes.

85. Cryftalli marmore metallico albo infperfx.

86. Cryftalli longisfimæ crifpis intermixtæ, initis paucis miculis aureis.

87. Cryftalli rubræ minimæ miculis cubicis flavefcentibus infignitze.

88. Cryftalli minimæ minus ereetæ.

89. Cryftalli Temidiaphanæ albæ Stolbergenfes.

90. Cryftalli longiffimæ æqualis magnitudinis.

91. Cryftalli minimæe miculis auriferis infperfæ.

92. Striæ maximæ ex Quarzo flavo.

93. Minera plumbi ex meris cubis concreta cryftallis albis ubique infperfis.

94. Cryftalli tartarifatæ Freibergenfes fupra marcafitam \& plumbum pofita.

95. Cryftallus opaca nigricans $\mathbb{f}$. Fluoris fubnigri ftria maxima. del, Wormitu in Mur. pag. $10 \%$

96.Cry- 
ET ARTIFICIALIVM KVNDMANN. VRATISLAV.

96. Cryltalli minimæ fubnigræ, adhærentes marmori metallico albo.

97. Cryftalli opacx nirentes in marmore matallicoalbo.

98. Cryftalli uno latere amethyftinæ, altero faturatiores rubræ, ob. tufius mucronatæ.

99. Minera verrucofa ex pyrite compofita.

100. Cryftalli minimx ex mammillis ordinatim difpofitis prominentes.

101. Cryftalli fplendentes fquamulis \& pulvere auriferoubique infperfa.

102. Cryftallus puriffima elegans ex Helvetia.

103. Cryftallusalba cum purpurea, A methyiftumgemmam referens, f. Amethyftus cryftallina.

104. Cryftallus pellucida plumbo inhærens, quam miculæ fplendentes ex marcafita aurea, item mammillæ \& ftellulæ albæexornant.

105. Cryftalli opacæ Freibergenfes miculis fplendentibus ex Pyrite inferius adnatis.

106. Cryftallus montana pellucida \& mucronata hexagona elegans. talem delin. Aldrovandus Muf. Metall. Libr. IV. Tab. V. pag. 940, it. G. F. Milius Memor. Saxon. Subter. Part. II. Rel. I. pag. 8.

107. Cry ftallus adnatis fquamis erectis maximis ex Marcafita aurea formatis.

108. Cryftallus fquamis ita difpofitis minimis, quæ meras papillas efforment.

109. Super Cryftallum albam opacam exfructx prominentix ex Marcafita formatx \& topho iterum incruftatæ.

110. Cryftallus ex Norwegia.

111. Cryftalli femiopacæ infperfo pulvere aurifero.

112. Cryftalli aurei coloris mineris Martis infiftentes ex Ducatu Glogovienfi Silefix.

113. Cryftalli prominentes ex minera argenti folida, infperfis paucis miculis aureis.

114. Cryftalli cum multo Pyrite. 


\section{PROMTVARIVM RERVM NATVRALIVM}

DE Generatione Cryfalli vid. Cbriff. Hugesii Traité de la Lumiere f. Tr. de Lu. mine Cupit. V. Fob. Facabi Scbeucbzeri Natur. Garchichte des Schvveitzerl. Part. III.pag.53.63.\& 75. Meteorologian \& Oryckographiam Helveticam pag.139. feqq. it. Herbarium diluvian. Tab.9. fig. 2. pag. 31. Ex nive vel glacie vid. Plinius Hiftor. Natural. Libr.XXXVII. Cap. II. \& plerique antiqui Naturalium rerum Scriptores, quos ull. Aldrobandus in Mufeo Metall. Lib.IV. pag. 940. it. Foh. Fonfanus Thavmarogr. Natural. Claff. IV: Cap. XIX. recenfuit, itemque collegit Fob. Henr. Hottingerus fimulque falfitatem demonftravit in Defeript. montium. glacialium Helveticor Cap. VII. qux reperitur in Ephem, Nat. Curiof. Dec. III. Ann. IX. \& X. in Append. Phoen. V. pag. 6r. feqq. Conf. Conrad. Gefneri de Fi. gur. Lapid. Cap. I. pag. 17. Ol. Wormii Mufeum pag. 100. Mufeum Calceolarianum Sect. III. pag. 193. Erafm. Bartbolini Experimenta Cryftalli Island. Ul. Al. दrboandus Muf. Metal. Libr.IV. pag. 934. Atban. Kircberi Mund. Subrer. Tom. II. Libr. VIII. pag. 24. Ans, Boetii de Boot Hift. Gem. \& Lapid. Lib. Il. Cap. LXXIII. pag. 217. feqq. G. H. Velfcbii Objervat, Phyf. Medic. Hecat. I. Obferv. XC. Ferrand. Imperati Hiftor. Natur. Libr. 24. pag. 716.-726.70ban. IV oodivardi Geograph. Phyfic. pag. 147. Chrift. Vateri Phyfiolog. Experimental. Sect. V. Cap. VI. Qvatt. I. pag. 418. \& 419. ir. Mauritii Ant. Cappeler Prodromum Cryftallographix. De ufa mediçamentofo vid. fob. Muys in Podalirio redivivo pag.

\section{ARTICVLVS II.}

Marmora, Stalactitæ, Lapides fpeculares, calcarii, tophacei, Arenx \&c.

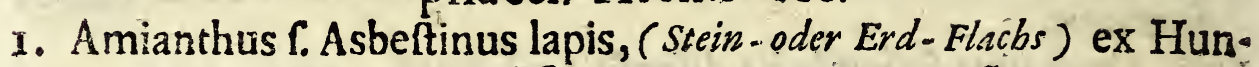
garia prope Cibinium ad filamenta proparatus (S.144.)

2. Amianthus ejusdem Regni in tabulis ( S.256.)

3. Amianthus viridis ex Rhetia (S. 514 .)

4. Amianthus Turcicus albus, ex filis longiffimis conftans.(S.26r.) hunc delin. \& deicr. ulysf: Aldrovandus in Mufeo Metallico Libr. IV. pag.657; feqq. it. Fob. Fac, Scbeucbzerus in Meteorologia \& Orytograph. Helvetica pag. 132. Conf, Georg. Agricole de Nat. Foffill. Libr. V. Cap. IX. pag. \{20. Conr. Gef. neri de Figur. Lapid. fol. ケ. Anf. Boetii Hiiftor. Gemmar. \& Lapid. Libr. II. Cap. CCIV. pag. 382. Andr. Libavii Singul. Part. III. in fine, prc. Foh. de Lä̈t de Gemm. \& Lapid. Libr.II. Cap. VHiI. pag. II8. feqq. Ol. Wormii Mufeum Libr. I. Cap. VI. pag. 5 . Atbanaf. Kircberi Mundum Subter. Tom: II. Libr. VIII. Sect. III. pag, 166. feqq. it. Ej. Chinam illuftrat. Part, IV. Cap. XI. pag.20\%. Claud. du Molinet dans le Cabinet de la Bibliotheque de St. Genevieve Part. II. Tab. VI.\&c. 
Multa huc fpectantia,prc.' de linteo incombuftibili colleg. Tilingius in Epbem. Nat* Curiof. Dec. Il. An. II. Obr LXI. pag.109. Wormius L.C. fupr.citat: Kircber. L.C.p. 67. ir. Petr. della Valle Reife-Befchr. Part.IV. Send-Schreib. XI. pag. 205. Linteum incombuftibile defer. \& delin. Ferr. Imperatu Hift. Natural. Libr. XXV. Cap. V. pag. 767. \& ex eo Boetius in Hiftor. Gemmar. \& Lap. Libr. II. Cap. CCIV. pag. 383. it. Nich. Bernb. Valentini Mur. Mufeor. Part. I. Cap. XVIII.pag. 49. (plur.vid. in bujus Promisuarii Part. Il. Sect. IV. Clafr. IV. Artic. I. num. 9.) 5. Alabaftrit $x$ candidi tabula inferius flavedine quadam tin 9 a. (S.325.) defcr. Anf. Boctius in Hiftor. Gemmar. \& Lapid.Libr.II. Cap. CLXIIX. pag. 490. Job. de Laet de Geinm. \& Lapid. Libr. II. Cap. XXV.pag. I66.

6. Ammochryfos fingularis, C.Lapis flammulis cubicis aureis in fuperficie confperfus ex Rhetia, (S. 194.)

7. Ammochryfos, f. Sciffilis lapis aurei fplendoris, Goldglimmer, Katzengold, (S. 246.) defcr. Conr. Gefnerus de Figur. Lapid. pag. 76. Boetius Hift. Gem. \& Lap. Libr. Il. Cap. CXL. pag. 424. Fob. de Laët de Gení \& Lap. Libr. II. Cap. XXI. pag. 147.

8. Argyrites, f. Mica argentei fplendoris ex monte Sabotho prope pagum Gurcke Ducat. Suidnicenf. Silef. Silber-Glimmer, KatzenSilber (S. 245.)

9. Argyrites fubruber ex fundo fontis Johannei (S.4IO.)

10. Argyrites ibidem erutus argenteifplendoris (S. 4 II.)

II. Argyrites, $\mathrm{C}$. Mica alia ftriata in Bohemiæ montibus frequens, (S. 412.) defcr. Ol. Wormius Muf. Libr. I. Sect. II. Cap. X.I. pag. 13O. prc. Georg. Fabritius Obferv. de rebus Métallic. Obr. X. pag. 28. it. Car. Nic. Langius in Hiftor. Lapidum Figurator. Helvetix Part. II. Cap. V. pag. 42.

12. Arena multicolor in littoribus Boruffiæ marinis collefta, cui ineft nigra Martialis (T.396.)

13. Arena talis elegantior, in littoribus prope urbem Barth in Pomerania frequens ( $T$.418.)

14. Arena alba cum Mica, ex lacu viridi montium Carpatbicorum. ( $\mathrm{S.555.)}$

14. Arena nigra qux in lacu Slawenfi Ducat. Glogovienf. Silefiae re. peritur. (T.419.) Arenam talem nigram Ambonenfem defcr. Georg. Everb. Rumpbius Amboinf. Rarit. Kam. Libr.lli. Cap.XVI. pag.223. De Qualitate ufuque arenxe evolvend. Atban. Kircberus Mund. Subter. Tom.II. Libr.VIt. pag.326. feqq. prc. Ferrand. Imperatus Hift, Nat. Libr.II. Cap.XVI, pag.49.leqq.

15. $\mathrm{Ba}=$ 
15. Bafaltes uci in Mifnia, prope Dresdam copiofe eruitur, ferrei coloris (S.305.) defer. Ans. Boetius in Hiftor. Gem. \& Lapid, Libr.Il. Csp. CCLXXIII. pag. 496.

16. Bononienfis lapis, 1. Litheofphorus \& Phofphorus nativus it. Lapis lucifer. (S.206.) defcr. Ol. IV ormius in Mufeo Libr.I. Cap.V. pag. 46. ir. Car, Nic. Langius in Hiftor. Lap. Figurat. Helver, Parr.I. Cap.VI. pag.I5. Tab. II. Lit, A. In peculiari Tractat, vero Fortunius Licetus in Litheofphoro I. de Lapide Bononienfi, Chriffianus Mentzelius in Tract. cui Titul. Lapis Bononienfis in obfcuro lucens, collatus cum Phofphoro Hermetico Cbrif,. Adol. Balduini, it. Ludo.

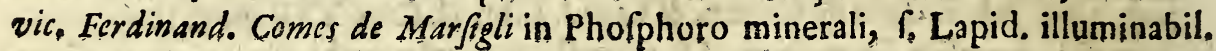
Bononienf. Prxparationem hujus lapidis \& vires exhibent id. Langins L. Cit. it. Paulis Boccone in Obfervat. Natural. Obferv. XV.

17. Calcarius lapis cinerei coloris, fylvæ Hercyniæ prope Wolfferode ( $\$ .250$.

18. Calcarius lapis Islebienfis cinereus $(S, 251$.)

19. Calcarius lapis albus ex montibus Hercyniæ (S.252.)

20. Calcarius lapis albus Silefiæ Superioris fpiculis fplendentibus (S.253.)

2I. Calcarius lapis nigricantis coloris maculis quadratis infitis, Rofenauenfis Silefiæ (S.253.) Calcarios lapides defcr. Gearg. Agricola de Nar. Foffil. Libr. VII, Cap, XVIII, \& XIX. pag. 651. Ull. Aldrovandus Mur, Metall. Libr.IV, pag.745. Ol. Wormius in Muf. Cap.LV, pag.45. Ans, Boetius in Hift. Gem. \& Lapid. Libr.II. Cap.CCXCIII, pag.522. aliique.

22. Calcis Flos, vid, Befchreib, des Fichtelberges pag.240. f. Cremor Thermis Carolinis fupernatans, (S.226.) dẹfcr, Ol, Wormius in Mur. Libr, I, Cap.VI. pag.si. Cbriftian Lange de Thermis Carolinis, Fabianus Sommerus de inventione, defcriptione, temperie, viribus \& ufu Thermarum Caroli $I V_{\text {: Impe- }}$ rat. Frider. Hoffmannus in Differt. de Carolinis Thermis Cap.II. \$.10. pag.22. it. Georg. Hier. Velfchius Obferv, Phyf. Medic. Hecatoft.I. Obferv.LXV. pag.88. 23. Chryfites notulis quadratis aureis adfperfus. (S.230.) 24.25. 26. Cos coloris nigri \& viridis, olearia, item alia arenaria, $f$. aquaria (S.288.) del. \& defcr. Conrad. Gefnerus de Figur. Lapid, Cap.VI. p. 10I. Georg. Agricola de Natur, Foffil. Lib.V. Cap.XX. pag. 545 . Boetius Hift. Gemmar. \& Lapid. Lib.Il. Cap.CCICV. pag. 542 , Ul. Aldrovandus in Muf, Metall. Libr.IV. pag.719.

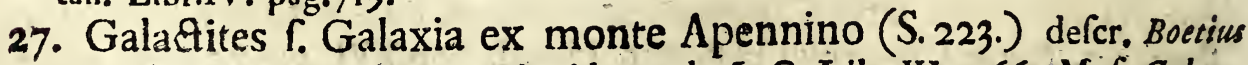
L. C. Cap.CCXXIX, p.412. Ul. Aldrobandus L. C. Libr.IV. p.66. Muf, Galceolar. 
lar. Sec.111. pag.399. De magna xefimatione apud Turcas vid. Eduard. Browne Reife-Befchreib. pag.I I.

28 29. Galaftites arbufculis aureis \& alius nigris refertus (S.435. \& 436.)

30. Gypfum Lauchenfe ftriatum album (, 420.$)$

3I. Lydius lapis coloris nigri (S.262.)

32. Magnes IV. Libras Ferri habens. (S. 452.) Multa Magnetem fpeetantia collegit Athanaf. Kircherus de Arce Magnetica, it. Fr. Tertius de Lanis in Magifterio Naturx \& Artis Tom.III. Libr.XXIII. pag.213.feqq. Math. Haly in Magnetifmo magno i. Contemplationibus Metaphyficis \& Divinis a confideratione Magnetis fubnat. Guil. Gilbertus de Magnete Magneticisque corporibus Phyfiologia nova, fob. Valent. Scbeid. Difiert. de Magnete, Micb. Bernb. Valentini in Muf. Mufeor. Part.I. Cap.XVII. pag.47.feqq. prc. Part.III. pag.78.--10z. De armatura vid. Nic. Bions Mathematifche Werck. Schule; Plures Auctores alleg. Foh. Henr. Losbnerus in Mur. Besler. Tab. XXIX. pag. 88. Errores detexit Foh. Fac. Spenerus in Differt, de Magnete Lipf. 1688. habit. Conf. llnfere Samml. pon Nat. und Medic. Gifch. IV. Verf. An,1718. Menf. Jun. Claff.V. Art.X, pag.1267. it, XV. Verf. Añ.I72 I. Menf. Januar. Claff.V. Art.II. pag.I00. it, pecul. Tract. de $l^{2}$ Aiman f. de Magnete. Magnetem ponderis LX. librarum defcr. Nebem. Gretw in Muf. Regal. Societat. pag.310. \& alium XX. libras ferri attrahens Va. lentini L. fupr. citat, pag. 47 .

33. Marmor duriffimum album, in quo lineæ rubræ transverfim discurrunt, ex Thermis Carolinis, vulgo dem Prudel, exemtum

(S.228.) defcr. Erid. Hoffmannus in Differt. de Carolinis Thermis Cap.II. \$.6. pag.21.

34. Marmor tale cortice croceo obvoluntum (S.552.)

35. Marmor arenofum Franconia fubrubrum in fuperficie a $\mathrm{Na}$ tura vitrificatum (S.413.)

36. - 46. Marmora \& lapides varii politi diverfas figuras referentes (S. 166.184.185. 186. 187.188.189.190.191.192.)

47. Marmor nigrum duriffimum politum, cui variæ flguræ cryftallinæ, circulares, lunares, denticulatæ \& aliæ immerfæ. (S.183.) 48. Marmor nigrum duriffimum ex monte Sabotho,Ducatus Suidnicenf. Silefiæ, auro dives (S. 428.)

49. Marmor colore viridi \& fufco variegatum, cui aurum ineft, ex eodem monte (S.424.) 
50. Marmoris nigri duriffimi tabula lineolis albis hinc inde difcurrentibus ex Duc. Altenburgico (S.528.)

51. Marmoris cinerei tabula cum figura occuratiffime expreffa
ejusdem Ducat (S.529.) 52. Marmoris albi tabula punctulis infperfis nitentibus ibidem frequens (S. 530.)

53.54.55. Marmora Silefiaca, ut Pribornenfia, Montis Sabothi, Wederizzenfia aliorumque locorum (\$.531.532.533.)

56. Marmor fubviride, Italis Verdello digtum, quo utuntur ibidem lapidis Lydii loco(S 2r4) vid. Wormius in Muf, Libr.I. Sect.II. Cap.IV.p.43. 57. Ex Marmore Florentino, colore albo, rubro, cinereo \& viridi variegato, globus maximus exacte fpharicus ( $\mathrm{S.472.)}$ 58. Ex Marmore Salisburienfi albo \& rubro globus minor (S.283.) 59. Ex marmore cinereo Bohemico punctulis nigris infperfo globus ejusdem magnitudinis ( . 284.) hunc defcr. Bob. Balbinus Hiftor. Bohem. Libr.I. Cap.XXXIII. p.22. \& 82. Marmora alias defcripfic Georg. Agricola de Nat. Follil. Libr.VII. pag.622..640. Ans. Boetius in Hift. Gemm. \& La. pid. Lib.II. Cap.CCLXVI. pag.487.fegq. Ferrand. Imperatus Hift. Natural, Libr. XXV. pag.770 feqq. prc. Lul. Aldropandus Mur. Metall. Libr.IV. pag.746.fegq. $\checkmark$ arias fpecies vid. in Joh. Weichart Valpafors Ehre des Herzogth. Crains Tom. I. Libr.IIl. Cap.XXX. pag. 430.feqq. De Artificio tingendi Marmora, vid. Franc, Tertias de Laniss in Magitter. Natur. \& Artis Tom.II. Libr.I. pag.35.

60. 6r, 62. Marmor metallicum album,Spath,Gottesbergenfe in apice cryftallinum, Clausthalenfe, \& Goslarienfe (247.248.249.) 63. Marmor abum metallicum in nigro repens (S.198.)

64. Marmor album, quod venas metallicas per transverfum fecat (\$.199.)

65. Medulla Saxorum terricorii Pragenfis, in qua lapides varii immerfi confpiciuntur (S.20I.)

66. Morocheus lapis coloris mellei (S.295) defcr. Ans. Boetius Hit. Gemm. \& Lapid. Libr.11. Cap.CCXXIX. pag. 4 Iz.

67. Pyrites externe albus, intèrne nigricans, ex montibus cretaceis RegniDanix (S.387.)

68 -82. Saxa num.XV. ex montibus Mifnix, diverforum colorum, quæ rcalpturam \& polituram admittunt, \& varias gemmas referunt $(5.535 .-549$. 
ET AR TIFICIALIVM KVNDMANN. VRATISLAV. 203

83. Saxum fiffile in tabulis Mansfeldeufe, cui æs ineft (T.3I.) defcr. G. F. Mylius Memorab. Sax. Subr. Part.I. Rel.I. pag.r.feqq.

84. Saxum fuillum fo foetidum nigrum ex Infula Hovitzholmenfi Norwegix (S. 406.) hoc eleganter defcr. Ol. Wormius in Mur, pag. 38. it. Afubb. Bernh. Valentini in Muf. Mufeor. Part.II. Cap.lI. pag.2O.

Spathum vid. Marmor metallicunı fupra num.60.

85. Specularis lapis pellucidus \& alius coloris argentei ex Mofcovia, Erauen.Eifs (T.463.)

86. Specularis lapis Reichfteinenfis Silefia niger,f. Áphrofelinus ob.

fcurus Schwenckfeldii. vid. ejusdem Catal. Follil. Silef. Libr.III. p.363.(T.452.)

87. Specularis lapis niger in thatrice, r. Marmore metallico ex mon-

te Sabotho Ducatus Suidnicenfis Silelix (T.460.)

88. Specularis lapis ejusdem loci, a matrice feparatus (T.46I.)

89. Specularis lapis Hungaricus (T. 464.)

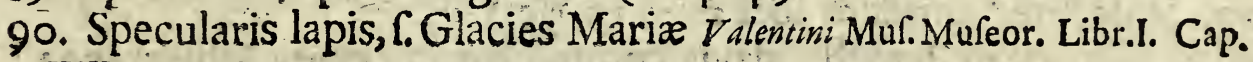

XVI. pag. 46.

9r. Specularis lapis Steinkirchenfis prope urbem Strehlen in matrice $(T .456$.

92. Specularis lapis a matrice feparatus in particulis ( $T$. 457.)

93. Specularis lapis cinereus opacus, ex Ducatu Troppavienfi Sile: fix (T.465.)

94. Specularis lapis albus diaphanus ibidem erutus $(\mathbf{T} .466$.$) Lapi-$ dem hunc alias defer. Gearg. Agricola de Nat. Foffilium. Libr. V. Cap. VHI. pag. 517. Ans. Boetius in Hiftor. Gemmar. \& Lapid. Libr.II. Cap.CCXV. pag.396. Georg. Hier. Velfsbius Obfervar. Phyfic. Medic. Hecatoft.I. pag.9r. Guido Pancirolhus de rebus deperditis Tit.VI. pag.21.feqq. Car. Nicol. Langius in Hift.Lapid. Fie gurat. Helvet. Part.II. Cap.I. Gener.III. pag.27. it. Valentini in Muf. Mufeor. Part.I. Cap.XVI, pag.46. Ferr, Imperatus Hiftor. Natur, Libr.XXVI. Cap.X. pag. 803. aliique.

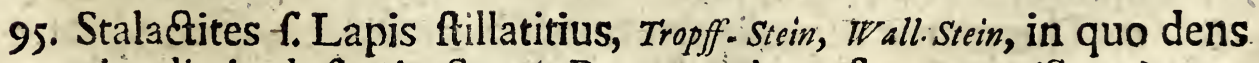
animalis inclufus in Specu Baumanniano frequens (S.I2I.) Specum defcr. \& delin. Tentzelius in Colloquiis Menftr. An, 1697. Menf. Auguft. pag.666. Hermannus von der Hardt in ACt. Erudit. Lipfienf. An. 1702. Menf. Jul. pag.305.feqq. prc. Georg. Henr. Bebrens in Hercynia curiofa Cap.I. pag... feqq. de Stalactite evolv. Anton. Deufingius de Foetu Muflipontanu pag. I5 7. S.I24. fegq. Mart.Zeillerus in Topographia Ducatus Brunfvicenfis fol. 39 . \& 3r. Sylv. 
Boccone in curiöfen Anmerckungen über natürliche Dinge; Car: Nic. Langius in Hiftor. Lap. Figurat. Helvetiz Part.II. Cap.II. pag.29. prc. Bebrens L. C. 96. Stalactitæ ftiria-formes majores oblongi, $f$. pyramidales ejusdem loci. tales del. \& defcr. Ill. Aídropandus Muf. Metall. Libr.IV. pag.103. (S.257.)

97. Stala tites maximus VI. libras ponderans ibidem erutus (S.525.) 98. Stalactitæ tubuli minores in Crypta Schartzfeldica frequentes, imitantes ftirias,quæ de teetis brumali tempore dependent.'(S.12.2.) conven. cum delin. \& defcr. ap. Job. Fac. Scbsucbzerum in Meteorol. \& Orycto. graph. Helvetic. pag.I54. Tentzelium Colloq. Menftr. An.s698. pag.698. feqq. Boesium Hift. Gem. \& Lapid. Libr.II. Cap.CCXXXVII. pag. 421. Job. de Lact de Gemm. \& Lapid. Libr.II. Cap.XX. pag.144. Ol. Wormium in Mui. pag.52.

99. Stalactitæ tubuli oblongi albi in fuperficie rubri Kauffungenfes, ex monte, vulgo dem Mühlberge (S. 96.) defcr. Georg. Ant. Volckmánn inSilefia fubterran. Cap.III. \$.17. pag.73.

100. Stalactites ejusdem loci alius (S.95.)

101. Stalaetites ex lamellis flavis compofitus in crypta fubterranea alia ibidem frequens (S.289.)

102. Stalatires cum rudimentis ramorum per longitudinem ftriatus ex Regno Borufliæ (S. 93.) del. \& defcr. Georg. Andr. Helwingius in Lithograph. Angerburgic. Part.I. Cap.VI. Clafi.I. Sea.II. Tab.II. num.7 p.42. 103. Stalaktites peralbus ex Carinthiæ cryptis (S. 526.)

104. Tartarus in tabulis prope Lignitium, $\Gamma_{\text {. ex Thermis Gruntha- }}$ lenfibus (S.154.) detcr. in Georg. Ant. Volckmanni Silefia Subterran. Cap. XIV: 5.19. pag 299.

105. Tartaro albo involuta terra \& fruftula ligni ex cellis fubterraneis (S.255.)

106. Terra argillacea cinerea prope Mifniam effolfa, ex qua Dresdx vala Porcellana conficiunt ( $\mathrm{S} .453$ )

107. Tophus f. Porus, Toff-Stein oder Topff-Stein luteus, in fuperficie undulatus Thermarum Carolinarum duetibus adhærens ( $\mathrm{S.224}$ ) vid. Frid. Hoffmanni Differt. de Carolinis Thermis Cap.II. \$.6. pag.21.

108 Tophus ibidem una nocte in argillam recens coctam præcipitatus, five in ftatuam Johannis Evangeliftæ, \& in leonem ex ea formatum (S.225.) id. Hoffmannus L.C.

109. Tophus friabilis luteus ex iisdem Thermis (S.227.) 


\section{ET ARTIFICIALIVM KVNDMANN. VRATISLAV. 205}

I 10. Topho Ovun cotum ibidem incruftarum (S.513) Tophun huns defer: Gotbofred.Bergerius de Thermis Carolinis pag. I4 $\ldots 20$. Alios vero defcr. Georg. Agricola de Nat. Foffil. Libr.VII. Cap.XII. pag.040. Ans. Boctius in Hift. Gem. \& Lápid. Lib.II. Cap.CCXIX. pag.402. Fob. de Laet de Gemm. \& Lapid. Libr.II. Cap.XII. pig.I32. pre. Ul. Aldrovandies in Muf. Metallic. Lib. IV. pag. 70j. Ol. Wormius in Muleo Libr.I, Cap.V1. pag. \{1. Bob. Balbines Mifcell. Hiftor. Regn. Buhem: Libr. I. Cap. XXIV. pag.63. it. Rob. Ploot Nat. Hiftor, of. Oxfordshire pag. 34. \& ex eo Job. Jac. Scbeucbzerus Hydrographiz Helvetice (qux eft Hiftor. Natur. Helvetic Part.II. pag.320.) conf. Carol. Nic. Langii Hift. Lap. Fig. Helveriz Part.II. Libr.III. Cap.II. pag.is.

III. Tophus ex Thermis Stubnenfous ( S.200.)

112. Tophus albus ex Fonte Kukus Difrictus Gradlicer fis in Bo-

hemia (S.3'7.) vid. Carol. Valentin. Kircbmeyeri Deferiptio Fóntis pag. 20. Conf, Chrif. Gottl, Langii Kukus Brunn.

Verdello vid. fupra Marmor num. 56.

I13. Trichites Diofcoridis in Egypto frequens, $f_{0}$ Alumen Schifton, feu foiffile album ( S. 485) optime defer. Ferr. Imperatus in Hift. Natkral. Libr. XIII. Cap.XX.\&XXI.pag:440. feqq.

114. Violaceus lapis, r. Jolithus, cum mufco flavo fortiter adlixrenti, odorem violx Martiæ fpirans, diverforum colorum ex montibus Giganteis Silefiæ, Veilcken-Stein (S. 124.) defcr. Cafp. Schwenckfeld in Befchreib. des Hirfchberger Bades pag. 181. Ol. Wormins in Mu. feo Libr. I. Sect.II. Cap. II. pag. 37. prc. Mifcell. Nat. Curiof. Dec. II. An VIII. Obferv.XXIIX. pag 81. it. Georg. Ant. Volckmann Silef. Subter. Part. I. Cap.II. pag. 47. De Caufa odoris hujus lapidis, vid. Siblvenckfeld L. fupr. cit. Georg. Agricola de Nat. Foffil. Lib. 1. Cap. V. pag. 346. prc. Carol. Nicol. Langias in Hiftor. Lapid. Figurat. Helvet. Part. I. Cap. VI. pag. 12.

115. Violaceus lapis $\mathrm{C}$. Jolithos ex Fonte Johannea (S.405.)

116. Violaceus lapis fubalbus Aldebergenfis Mifnix fine mufco

(S.312.) defcr. Fob. Kentmannus in Nomenclatura rerum folfilum Tab.vi. fol. 36. Georg. Agricola de Natura Foffil. Lib.1. Cap. V. pag. 346. Ul. Aldro. vandus in Mufeo Metallico Libr. IV. pag. 709. it. Petr. Albinus in der Meifnifchen Berg-Chronica Tit. 10. pag. 154 .

117. Zeblicius lapis C. Marmor Boetii ex Mifnia (S.242.) vid. Ejusdem Hitt. Gem. \& Lapid. Lib. II. Cap. CCLXXVIII. pag. 502. fẹq. Ot. Wormius Muí. Lib. I. Sect, Il. Cap. IV. pag. 43. prc. G. F. Mylius Sax. Subter, Memorabil, Part, I. pag. 72. leqq.

$$
\text { Cc } 3 \text { 118.Ze- }
$$




\section{6, PROMTVARIVM RERVM NATVRALIVM}

118. Zeblicius lapis alius viridis, colore nigro oculatus raro occurrens. (S. 484.)

II9. Zeblicius lapis atrorubefcens, ubi vafa tantum pro Rege con. ficiuntur. (S. 44I.)

120. Zeblicius lapis mire flexuofus. (S.442.)

\section{Claffis III.}

\section{ARTICVLVS I.}

Lapides $\varepsilon^{\prime} \mu \mu \rho \rho \Phi$ oi, 1 . figura certa gaudentes ex lufu $\mathrm{Na}$ ture vel Phantalix.

I. Ttites peregrinus albus lævis lineis undiquaque obvolutus rariffimus Adler - Stein, Klapper-Stein. (S. 477.) convenit cum Meftica-Kiappa Rumpbii inAmboinfch. Rarit. Kam. Lib.II. Cap.LX. pag.309.

2. Ttites lævis five politus Arabicus ovi anferini magnitudine, coloris aurei. (S.I.) maxinus capite humano \& alius ovo ftruthionis major, defcr. in Petr. Albini Meifnifcher Berg. Chronica Titul. XIX. pag. 154. it. in Valpafors Ehre des Herizogch. Crains Part. I. Libr. III. Cap. XXX. pag. 430. alium Baribolinus Neapoli in Muf. Ferr. Imperati, vidit caput humanum magnitudine fuperantem, ut teftatur Cent. I. Epiffol. Medicinal. XLIX. pag. 202.

3. Etites in Arabia frequens minimus levis rotundus, coloris fu. fci $($ S.316.) Accedit ad delin. Anf. Boetii Hitt. Gemm. \& Lapid. Libr. II. Cap.CXCVII. pag. 376. it. Zoh. Henr. Locbveri in.Muf. Beslerian. Tab. XXX.

4. Atites talis rotundus Ochram nativam referens ( $\mathrm{S} .48 \%$ )

5. Etites Hildefienfis colore ex pullo nigricante (S.220.) vid. Fridexic. Lacbmund Orjelograph. Hildesheimenfis Cap.XII. Fig. VII. pag. 30.

6. Ftita interior facies adripam Moldavia prope Motfchen in Bohemia repertus. (S. 219.)

7. Ftites coloris cinerei exacte fphæricus ex Mona Infula (S.299.) convenit cum delin. \& defcr. in Mifccll. Nat Curiofor. Dec. II. An. VI, Obferv. I. pag ${ }_{*}$. talem fphxricum quoque delineav. Locbnerus in Muf. Beslerian. Tab. XXX. pag.90.

8. Etites Aldebergenfis Mifniæ interna mire facies (S.300.)

9. Etites agri Romani niger raro occurrens, qui ob duritiem \& polituram lapidis Lydii loco effe poteft. (S.317.)

10. 画 
ET ARTIFICIALIVM KVNDMANN, VRATISLAV. 207

10. Ferites duriffimus externe ruber, interne cryftallinus ex Diftrictu Gradlicenfi Bohemix ( $\mathrm{S} .467$ ) conven. cum delineat. ap. Ans. Boctium Hiltor. Gemm. \& Lapid. Libr. II. Cap. CXCVII. pag. 377.

11. Atrites cufpidatus oblongus coloris aurei (S.478.)

12. Arites furcus levis duriflimus ex meris lamellis compofitus.

(S 488.$)$

13. Ftito-Ammonites, r. Cornu Ammonis elegantis fructuræ, Atitem fimul referens, coloris fufci $\left(S_{.2}\right.$. $_{\text {. }}$ ) conven. cum delineat. qux reperitur in Frid.Lacbmundi Oryetographia Hildesheimenfi Cap. XIl. Fig. VII. pag. 30.

14. Ftito-Bucardites ejusdem coloris, five Concha bivalvis, interne continens Callimum fuduantem (S.434) tal. defcr. apud Georg. Hieron. Velfibium Obferv. Phyfic. Medicar. Hecatof. I. pag. \{3. it. ii E. pbemerid. Nat. Curiofor. Dec.II. An. VI. Oblerv. III.pag.5.

15. Etito-Campoides Aldebergenfis Mifniæ ( $S .300$.)

16. Atito-Geodes maximus, i. Lapis, arenam \& callimum fluEtuantem in fe continens ex Ducatu Jaurovienfi Silefiæ (S.44.) Etitem prater fupra nominatos defcripf. Guiliclm. Laurenbergius in Hiforica Defriptione teticx f. Lapidis Aquilx; it. in peculiari Schediafmate Fob. Laurent. Baufcbius \& ferme omnes Lithologi recentiores, qui pro fruau petrificato, \& Callimum pro feminibus habent. vid. Nicol. Venette in Tra. Cat. de Lapidibus Cap.1V. Art. It. Obferv. IV. pag.28. Quibus jungendi, qua probant eum in nido Aquilarum reperiri, fob. Agricola de Nat. Fosfil. Lib. V. Cap. XVII. pag. 538. Reqq. Conrad. Gefnerus de Figuris Lapid. Cap.I. pag. 10. Lev. Lemnius de Occult. Nature miraculis Lib. IV. Cap. XII. pag. $4 \mathrm{C} 7$. Mu. feum Calceolar. Sect. III. pag. 320. Ferrand. Imperatus Hiftor. Natural. Libr. XXIV. \& XXVI. pag. 736. prc. pag. 408. Gecrg. Everb. Rumpbius Amboinfch. Rarit. Kam. Libr. III. Cap. LX. pag. 309. aliique. Deviribus Etita mirificie, quod brachio alligatus abortum precaveat, inferioribus contra partibus admotus foctum \& fecundinas pellat, venena infuper ac fures prodat, amorem concilier, aliisque vid. Løin. Lemnius L. fupr. cit. Franc. Rueus de Gemmis Cap. XIII. pag. 238. Mich. Doringins de Medicina \& Medisis adverfus Jarromaftigas \& Pfeudiatros Part. I. Sect. IIt. Cap.VII. pag. 108. Anf. Bortirs in Hiftor. Gemmar. \& Lapid. Libr. II. Cap. CXCVHI pag. 378. kll. Aldrovanásis in Mur. Metall. Libr.IV، pag. 580. Ol. Wormins in Mufeo Libr. I. Seet. II, Cap, XIII.pag. 77. Petr. Bellonius Obfervat. Lib. II. Cap. XXIII. Vires has fuperfitionibus adicribit Paulus Ammannus in Manuduat ad Mater. Medic. p9g.18. Cbrift. VA.

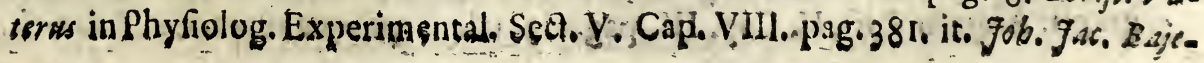


rus in Orycograph.-Norica Cap. V. pag. 33. Quas \& alias reftituere nititur Georg. Baglivius Operum Differt. V. \$.II. pag. 502. Vitus Riedlinus Linear. Medicar, An, IV. Mart, Linea XXIIX. it. Foh. Peir. Albreclat in Ephem. Nat. Curiof. Dec. II. An, IX. Obferv. LXX. pag. 136. aliique.

17. Alveolus maximus ab aliis fejunctus Maslenfis (S.336.)

18. Alveoliplures fimul juncti \& concreti in matrice lapidea (S. 199.) delin. Leonb. Daw. Hermann Maslograph. Tab.XII, num.32. pag. 227. five Cauda Cancri petrefaeta Helwingii in Lithograph. Angerburgic. Part. I. Tab. VII. num.23. pag. 64. it. Georg. Ant. Volkkmanni Silef. Subter. Part. III. Tab. VI. num. 3. \& Gamarolithes Langii Hift. Lapid. Figurat. Helver. Parc.II. Libr. III. Cap.II. pag. 67. Ichthyofpondyli five Vertebræ pifcium fecurd. Eduard. Luidium in Lithophil. Britannic, Ichnograph. Claff. XII. Capf. XXII. pag. 82. \& Spondylolithi f. Dolicolithi Velfchii in Ephemerid. Nat. Curiof. Dec. I, An. I. Obf, CLVII. pag. 337. Conf. Ul. Aldropandi Muf. Metall. Lib.IV. pag, 49 I.

19. Afteria media columnaris pentagona Tubingenfis, radiolis eminentibus Entrocho fimilis, zugefpitzter Stern-Stein , (S.417.) delin. \& defcr. Fab. Baubinus de lapidibus a Natura in terra figuratis pag.31. Joh. Jac. Scheuclszerus in Meteorologia \& Oryctograph. Helvetica pag. 323 . fig. I 2 2. G. H-Velfcbius Obf, Phỵfic. Medic. Hecatoft, I. pag. 52, prc. Carol. Nicol. Langizs in Hift. Lap. Figurat. Helvecia Part. II. Libr. III. Cap, Il. Tab, XX. pag. 64.

20. Afteria minima fibi invicem feparata Echterdingenfis elegans (S. 418.) accedit ad delineationem quam habet ulyff. Aldrovandus Muf. Metall. Libr. IV. pag. 880. Pro Vertebris cujusdam Stellæ marinæ tardigradx habet Eduard. Luidius Lithophil. Britannici Ichnograph, Epift.IV. pag. 115 .

21. Afteria columnaris Entrocho fimilis radiis minutiffimis (S.II7.) del. \& defcr, Fob. Fac. Scbeucbzerus in Meteorol. \& Oryctograph. Helvetic, fig. 158. it, Carol. Nic, Langius in Hift. Lap. Fig. Helvet. pag. 64.

22. Aftroites tubularis, . . P feudocorallina alba Indiæ Orientalis ftriata, ftellulis maximis elegantiffimis totam fubftantiam permeantibus, Stern-Stein. (S. 90.) fimilem delin. \& defcripf, ulyff: Aldrovandus in Mufeo Metallico Libr. IV. pag, 878. Dav. Sigifm. Büttnerus in Coralliographia fubterran, Cap.III, pag. 19. Tab. I. fig. 7. prc. G. A. Heliving. in Lithograph. Angerb. Part. II. Cap. III. pag. 123. talem quoque reprefent. Eduard, Luidius 
ET ARTIFICIALIVM KVNDMANN. VRATISLAV. 209

dizs in Lithophil. Britann. Ichnugraph. Tab, penultima. Conf. Car. Nic. Langit

Hift. Lap, Figurat. Helvet. Part, II. Libr, III. Cap, II, Tab. X VII. pag. 57.

23. Afroites ejusdem ftructura, Atellulis minimisinfignitus (S.gr.) 24. Aftroites reticularis, in quo fparia oblonga ftellulis elegantifimis adimpleta ( 5.368 .)

25. Aftroites reticularis a!ius ftellulis fexangularibus ubique refer-

tus (S.369.) convenit cum delineat, quam dedit ulyf. Aldropandus in Muf:

Metall. Libr. IV. pag. 878 .

26. Aftroites favaginofus Cameracenfis, fec, delineat, Leonb. Dav. Her.

manni Maslograph. Tab. XI. num, 29. pag. 221. (S. 17.)

27. Aftroites. . Columellus flavus Maslenfis ftriis minutiffimis (S.5I.)

id. L. C. Tab. XI.num, I5. pag. 220 .

28. Aftroites ejusdem loci fllicex fubftantia, ftellulis minimis impreffis $(5.52$ )

29. Aftroites Maslenfis major (S.76.)

30. Aftroites ejusdem loci minimus (S.77.)

3r. Aftroitæ alii ejusdem magnitudinis $(0.342$.)

32. Aftroites peregrinus ftriis evidentibus, \& rotulis albis cylindraceis fimul adimpletus (S.338.)

Aftroirz five ftellares lapides rarioris nota vid, in hujus Promtuarii Sect.III, Claff. I. Artic, II,

Batrachites minor vid. Lapis Bufonis.

33. Belemnites, Pfeil - Stein, Schofs-Stein, Alpenfchofs, Strahl-Stein, Maslenfis Silefia albus per medium divifus f. Cryltallinus(S.47.) delin. L.D. Hermann Maslograph. Tab. XI. num, 63, pag. 222,

34. Belemnites ejusdem loci electrinus in longitudinem diffiffus \& canaliculatus, cum ftriis transverfis, five interna facies (S.258.) Internam faciem delineavit fob. Muraltus in Ephemerid. Natur, Curiof. Dec. III. An.V. \& VI, Obr. XV. pag, 45. fig. 37. Car. Nic, Langius in Hift. Lapid. Figurat, Helvet. Part. II, Libr. VI. Cap. II. Tab. XXXVII. num. 2. pag. 131. it. Gearg. Ant. Volckmain Silef. fubter. Part. I. S. 26. pag. I55. \& I56. Tabul.XXIIX. fig. 5. prc. canaliculatum vid, in job, Jac. Bajeri Orychograph. Norica Tab. I. num. 6.

35. Belemnites erofus, \& quafi vermibus exefus ( $\mathrm{S} .203$.)

36. Belemnites coloris nigricantis $f_{\text {. }}$ Coracinus, Rabenftein, ex ampla radice in tenuem aciem definens, agri Altorfini. (S.296.) Dd del. 
del. \& defcr. Job. Jac. Bajerus Oryctograph. Noricx Cap. V. pag. 37. Conf. Frid. Lachmundi Oryctograph.Hildesheim. pag.25.\& pag.226. it. G.A. Volckmanni Sil. Suterr. Cap. V. S.16.pag. Is5.

37. Belemnites ele Arinus cylindroidæus Helveticus (S.472.) deicr. \& delin, Car. Nic. Langius in Hiftor. Lapid. Figurat. Helvet.Part.II. Libr. VI. Cap.II. Tabul. XXXVII. num. 2. pag. 13I.

38. Belemnites ex Helvetia prope Schaffhufiam femiconcavus (S, 109$)$ defcr. Job. Jac. Scbeuchzerus in Meteorol. \& Oivetograph. Helvetica pag. 1;8. delin. Fob. Fac. Bajerus. Oryct. Noricx Tab. I. num.6.

39. Belemnites Hildefienfis Succini ad inftar pellucidus (S. 108.) vid. Frid. Lacbmundus in Oryagograph. Hildesheimenfi Sea. III. Cap. X. pag. 24. feqq. delin. in Ephemerid. Natur. Curiofor. Dec. III. An. V. \& VI.pag.45. fig. 32. \& 33 .

Sunt autem Belemnites fecundum Andream Libavium Singular. Part. III. f. de Bitu. minibus Libr.VIII. Cap.XIIX. pag.200I. Succinum in lapidem mutatum; fecundum Dav. Sigifm. Büttnerum, in Coralliograph. fubterran. Cap. I. \$.3. pag. 2. Particule animalium quorundam marinorum ; quod experimentis probavit Baltbaf. Erbart in Differt. de Belemnitis Suevicis; fecundum Eduard. Luidium Epift.IV.pag.117. Cornu pifcis Narval petrefactum vel ignoti cujusdam Mo. nocerotis; fecund. Car. Nic. Langium in Hift. Lapid. Figurat. Helvet. Libr.VI. Cap.II. p3g.132. Fluor concretus ex Tubulis aut Penicillis marinis, vel Stalactites ftirixformis; fecund, fob. Fac. Scbeusbzermm in Meteorol. \& Oryctograph. Helvetica pag. 158. incerti originis : Plures Auctores preter fupra nominatos qui Belemniten defcr. congeffit fob. Henr. Locbnerss in Muf. Beslerian. pag. 99. it. Georg. Andr. Heliving in Lithograph. Angerburg. Part. 1. Cap. V.pag. 27. feqq. Examen per ignem inftituit fob. Lscas Rbiem in Differt. de Ebore follil. S. 16 .

40. Callimus Maslenfis colore ex pullo nigricante. (S. 107.) convenit cum delin. ap. Anf. Bottiam Hift. Gem. \& Lapid. Libr.II. Cap.CXCVII. pag. 376.

41. Cafeus lapideus albus depreflus (S. 449.)

42. Ceraunia f. Lapis Fulminaris cuneiformis niger egregius cum foramine, Donnerkeil (S. I 50.) delineavi \& defcripfi in Bresl. Samml. pon Nat. und Med. Gefcbibt. XXIII. Verf. An. 1723. Meirf. Febr. Clatr. IV. Arr.VI. pag. 182. talem quoque exhibet Gearg. Andr. Helwing in Lithograph. Angerburg. Part.I. Tab. X. pag. 79.

43. Cerauniæ $\mathrm{C}$ Lapidis fulminaris particula (S.259.) Authores de La. pide Fulminari collegic Georg. Andr, Helwing in Lithograph. Angerburg. Part.I. Cap. 
Cap.VII. Sect.I. \$.7. pag.89. Godofred. Wagnerus in Differt. de Lapid. Fulminari, it. collegi in Bresl. Samml. L. C. pag.182. quibus jungendi qui pro vero lapide fulminari eum habent, ut Petr. Albinus in ler Meifnilchen Berg - Chronica Tit. XIX. pag.153. Job. Kentmannus in Nomenclatura rerum Foffil. fol.30. recenfetque de Figuris lapidum fol.64, \&66. unum 300. librarum e colo delapfum,quod confirmat Conr. Gefnerus Rerum Fosfil. fol.66. Anfelm. Boetius in Hiftor. Gemm. \& Lapid. Libr. II. Cap CCLXI. pag 481. Ol. Wormius in Muf. pag.74. Alium tres \& dimidium peden longum defcrib. Everb. Wilbelm. Happelius in Relat. Curiof. Tom. III. pag. \{9.60. Gasp. Scbottus in Phyfica curiofa Lib. XI. Cap. XIX. pag.1238. it. Car. Nicol. Langius in Hift. Lapid. Figurat. Helvet. Part. II. Libr. I. Cap.III. Gen.III. pag.32. quos Recentiores refutant, \& pro malleis five cuneis \& inftrumentis bellicis Veterum habent, prc. id. agit Höcbftetterus in Differt, de Lapid. Fulminari Altorfi 170r. habit. Fob. Gotefr. Lave in Dift. de Telo fumineo, fob. Henr. Scbutteus in Oryctographis Jenenfi Cap.VI, 5.8. pag.67.feqq. Gualtb. Cbarletonus in Inquificione Anatomico-Phyfica I. Conf. Trogil. Arnkiel de re Funebr. Populor. Septentrional. Libr.II. pag.166. Fob.Dan.Majoris Neubevölckertes Cymbrien pag.44. \& 45. Cbriftian. Sticffi Epift. de Urnis in Silefia Lignicenfibus \& Pilgramsdorfienfibus pag.32. ic. Epiftol. ibid. D. D. Cbrifiani ab Helwig. Lconb. Dav. Hermanni Maslograph. Libr.III. Cap.XV. p.160. Dav. Sigism. Büttneri Ruder. Diluv. teft. 5.69. pag.92.feq\%. Georg. Ant. Volckmanni Silef. fubter. Cap.III. 5.19. pag.77. Jac. a Melle in Nov.Liter. Maris Baltici An.1699. IVilb. Erneft. Tentzelii Monatl. Unterred. An.1690. Menf. Novembr. pag.894. \& 899. it. An. 1695. Ménf. OAtobr. pag.945. \& An.1696. Menf. Jul. pag. 655. Ephem. Nat. Curiof. Dec.II. An.IV. Obf.LIII. in Scholio, prc. Gcorg. Andr. Helwingii Lithograph. Angerburg. Parc.I. Cap.VII. Sect.I. Tab.X. pag.79.feqq.

44. 45. Columelli varii punetati, Atriati, turbinati, reticulatiMaslenfes, \& alii (S. 20. 51.) del. \& defcr. Leonb. Dav. Hermann Maslograph. Tab. XI. pag. 222. prc. G. Andr. Heliving in Lithograph. Angerburg. Part. II. Cap.III. pag.103.feqq. AdVegetabilium Claffem refert id. Helwingius L. C. pag.Irt. 46. Confetti de Tibuli, L.Bellaria Tiburtina (S.123.) defcr. \& delin. ol. Wormius in Muf. Libr.II. Sect.II. Cap.VI. pag.\{2. UlyJJ. Aldrovandus in Muf. Metall. Libr.III. Cap.I. pag,278. Sim. Majolus Dier. Canicular. Tom.I. Col.XVIII. pag.235. Car. Nic. Langius Hift Lap. Fig. Helv. Part.II. Cap.III. pag.3I. pre. Job. Henr. Locbnerus in Mur. Besler. pag.IO2.

Coracinus vid. Belemnites fupra num.36.

47. Crucifer Lapis f. Stavrolithos lapidi Lydio fimilis, in quo Crux alba, non procul'a Fano Div. Jacobi Compoftella erutus (S.401.) conven, cum delineat, ap. Fob.Henr.Locbnerum in Muf. Besleriàn, Tab.XXXVIII. 
it. Georg. Ant. Volckmannum in Silel. Subterr. Tab.VI. Fig.27. Cap.IIl. I 21 . pag. 78. Conf. Defcriptionem Ambrofini in Ul. Aldrovandi Muf. Metallic. Lib.IV. num.2.' pag.735. it. pag.88r. MuI. Calceolarian.Sect.III. pag.392. Claud du Mo. linet dans le Cabinet de la Bibliotheque de St. Genevieve Part.II. Tab.VI. it. Ob. fervationem meam in Bresl. Samml. von Nat, und Medic. Gefcbicht. XXV. Verf. An. 1723. Claft.lV. Art.V. p.185. Alios cruciferos lapides vid. incer Gemmas, I. Sect. 1iI. Clarf.I. Art.II.

48. Cupri Neofolienfis cæmentati variæ figuræ (S. 160.) vid. Mifcell. Acad. Natur. Curiofor. Dec.I. An.VI. Obf. CXX. pag. 155. Lacum talem ferrum in cuprum vertentem apud Chinenfes defcr. Atb. Kircherus in China illuftrata Part. III. Cap.V. p.174, it. Erafm. Francijciin Oft-und Weft-Indif́ch. Luft.Gart. Part.II. pag. 1307.

Cyfteolithos vid. Spongix lapis.

49. Dadtylus Idæus Cretenfis femiconcavus (S. IO9.) defcr. \& delin. Petr. Bellonius Obferv. Lib.I. Cap.XV. pag.21. Muf. Calceolar. Veronenf.Sect.III. pag.302. ic. Fob. Henr. Locbnerus Muf. Besler. Tab.XXXV. pag.99.

50. Fiftularia f. Minera ferri fiftulofa Malmicenfis, Ducatus Glogovienfis Siletia (S.130.) defcr, in unfern Samml.von Nat. und Med. Gefcbicbt. 1. Verf. An.1717. Menf. Sepr. ClafT.IV. Art.III. pag.61. Conf. 7:G. Liebknecbis Difcurs. de Diluvio maximo occafione inventi in mineram ferri mutati ligni.

51. Fiftularia five Ofteocollus Maslenfis ferruginei l. cinerei coloris, ex aqua ibidem defumtus (S.158.) del. \& defer. Leonb. Dav. Hermannus Maslogr. Part.II. Libr.II. Cap.III. pag.19I. Tab.VIII. mum.5.

52. Geodes Mícrocofmicus $\mathrm{f}$. Calculus veficæ humanæx, ex lamellis verficoloribus compofitus, interne arenam fonantem continens (S 145.) vid. Obfervatio mea in Bresl. Samml. von Nat, und Med. Gejab. XXVII. Verf. An.1724. Menf.Jan. Claft.IV. Tales Lapides prxgnantes defcr. Erafm.Frañ. sifci im Gefchicht-Kunft-und Sitten-Spiegel ausländif́cher Völcker Libr.I. Cap. XXVIII. p.258. it. Tbom. Bartbolinus in Epbem. Nat. Curiofor. Dec.I. An.I. ObC. XXXVI. pig.12r.

53. Geodes Maslenfis Hyfterolithum referens, ex quo Bolus ibidem albus præparatur (S.3I.) vid. Hermannus Maslograph. Part. II. Cap. III. pag.191.

54. Geodes ex foffis argillaceisLignicenfibus (S. 98.) vid. Georg. Anto Volckmann. Siler. Subt. Part.I. Cap.III. pag.69.

55. Geodes agri Romani niger raro occurrens, qui ob duritiem \& polituram lapidis Lydii loco effe poteft (S.317.) conven. cum delin.

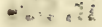


ET ARTIFICIALIVM KVNDMANN. VRA TISLAV. 213

\& deficripe. UlyfJ. Aldrovand in Muf. Metallic. Libr.IV. pag.590. Authores de Geode vid. fupra ubi de Ætite.

56. Globulus Viadrinus Bregenfis Silefiæ, f. Globularis Pyrites fluviatilis Kopenfis Silefiæ duriffimus (S.155.) defer. ap. Nic. Henelium Silefiograph, renovat. Part.l. Libr.1II. pag.385.

57. Globulus Viadrinus Kopenfis alius niger, totus Vitriolo imbu. tus ( 5.409.$)$

58. Globularis minera Martis Solaris Kleinfchweinerenfis Silefiæ, co. loris crocei ( $\mathbf{3 . 8 8 . )}$

59. Globularis minera Solaris Haffiaca, vulgo Ovum Philofophicum (T.495) defcr. \& examinav. Fob. Rudolpb. Glauberus in Furno nov. Philo. foph. it. Wolffus in Epbem. Nat. Curiofor: Dec.II. An.VII. pag.395. Conf. Mich. Bernb. Valentini Muleum Mufeor. Part I. Cap.I. S.12. pag.4.

6o. Globularis minera Martis cinerea egregia ex MarchionatuByruthino (S. 439.)

61. Globularis Pyrites fplendefcens ex Scania (S.16I.) vid. Ol. Wormius in Muf. Libr.I. Cap. V. pag.40.

62. Globuli lapidei duriffimi albi ex Comitatu Liptovienfi (S.326.)

63. Globuli lapidei tales in matrice, $f$. fibi invicem cohærentes (S.451.) 64. Globulus exacte fphiæricus plumbei coloris prope Czenftochoviam in Polonia effoffus (S. 317.) ralium meminit in Borusfia Georg. Andr. Hehving in Lithograph. Angerburg. Part. 1. Cap. V. pag.25. De Generatione Globulorum talium, evolvend. Ol.Magnus Hiftor. Septentrional. Lib.1I. Cap. XXVIII. Ferrand. Imperatus Hiftor. Natural. Libr.XXIV. Cap.XXVII. pag.760. 65. Globuli vel potius Granula nigra pulverem pyrium amulàn. tia montis Wartenbergici, Diftrictus Kannebergenfis Thuringia (S. 379.)

66. Lapis circularis numifmaticus, a Sto Ladislao Reg. Hungariæ (uti vulgus credit) ex nummo aureo per preces in lapidem durisfimum mutatus, in Campo Aradienfi Tranfylvaniæ frequens; totam Hiftoriam recenfuit Carol. Cluffus in Hiftoria rariorum Stirpium, per Pannoniam, Auftriam \& vicinas provincias, \& ex eo fob. Pbilipp. Breynius in Epiftoia de Melonibus petrefactis montis Carmel pag.21.

67. Lapis Div. Srephani, f. Lapis terreus maculis fanguineis adfperfus prope Francofurtum ad Viadrum (S.414.)

68. Lapis talis rotundus punqulis fanguineis notatus Maslenfis - (S. 3.46.$)$

$\mathrm{Dd} 3$

69. La. 


\section{4

69. Lapis ejusmodi politus cinereus $\mathrm{C}_{0}$ colore fanguineo maculatus \& lineis nigris ftriatus (S.464.)

70.71. Lapis ftrata nigra \& alba; etalius ftrata cinerea $\&$ alba alternatim referens : S. 437. \& 483 .)

72. Lapis ferri dives nativus ita exefus, ut meras parvas columnas efformet (S. 23I.)

73. Lithoftrotion C. Bafaltes ftriatus \& ftellatus (S. 50.) vid. Leonb. Davo Hermann Maslograph. Part,II. Cap.X. Tab.XII. pag.226.

74. Milleporis Imperati, (S.293.) vid. Ejusdem Hift. Natural. Libr.XXVII. Cap.IV. pag 81\%.

75.-83. Marmora Florentina elegantiffima, f. Tabulx politæ Florentinæ majores \& minores, rudera, montes, tempia turrita, tractus cum aềre $\&$ nubibus, aliaque memorabilia a Natura expreffa repræfentans (S175,--182. it. 465.) vid. Ol.Wormii Muf, Libr. I. Cap. IV. Sect.II. pag. 44. ir. Micb. Bernb. Valentini Muf. Mufeor. Part. I. Cap. XXI.

pag. 55. Marmor tale Sinenfe defcr. in Valvafors Ehre des Herzogth. Crains Tom. I. Libr.III. Cap.XXX. pag.433.

84. Ombrias flavus notulis minus confpicuis (S.167.) vid. gob. de Laet de Gem. \& Lapidib. Libr,II. Cap.XXV. pag. 160.

85. Ombrias faturatioris coloris, notulis fecundum longitudinem a vertice difcurrentibus (S. 168.)

86. 87. Ophthalmici lapilli majores \& minores Grunthalenfes prope Lignitium \& Hirfchbergæ colleeti, Augen-Steinlein (S.309.) de Lignicenfibus vid. Georg. Ant.Votckmanni Siles. Subterr. Cap.XIV. \$.20. pag.299. Thermas defcr. \& delin. in unferen Samml. von Nat, und Med. Gefcb. VI. Verf. Avo. 1718. Menf. Dec. Claff. IV. Art. XIII, pag. 2005.feqq. Hirfchbergenfes defcr.

Cafp. Scbivenckfeld in Catalogo Stirpium \& Folfil. Silef. pag.386.

88. Ovalis lapis ex Jafpide rubra (S.460.)

89. Ovalis alius niger (S.45 I.) convenit cum delin.ap. Georg.Ant.Volckman-

num in Silef. Subter. Tab.IV. num.7.

90. Ovalis depreffus albicans (S. 452.)

91. Punetularia f. Stigmites fubalbus punctulis nigrisadfperfus Mas-

lenfis (S. 16.) vid. Leonb. Dav. Hermanni Maslograph. Tab.XI. num.36. p.22r.

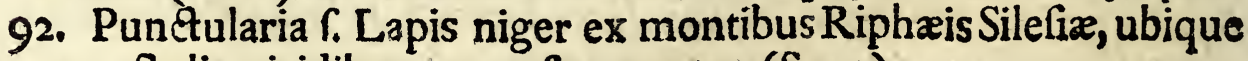

punctulis viridibus ex mufco notatus ( $(5.75$. 93. Punetularia ftriata alba (S. 58.) 
ET ARTIFICIALIVM KVNDMANN. VRATISLAV. 2is

94. Punetularia minima Maslenfis (S.34L)

95. Retepora elegans cellulis quinqueangularibus, agri Oxonienfis (S.86.)

96. Retepora corallina alba mire circumplicata (S.287.) defcr. ot. Wormius Mni. Libr.II. Cap.XXXV. pag.235.

97. Retepora alba Maslenfis Silefix (S. 7 1.)

98. 99. Rotularia ejusdem loci, five Lapis cum Rotula fingulari magna (S. 78.) del. Leonb. Dav. Hermamn Maslograph. Tab.XII. fig.33. pag. 227. it, alia parva ibidem reperta ( $\$ .350$.

100. Rotularia ftellata, $\int$ Lapis Rotulis \& Trochitis diverfæ magnitudinis in medio perforatis \& Atellatis infignitus (S. 80.) convenie cum Afterifco ap. Volckmannum in Silef. Subterr. Tab.XXVII. num. I3. pag. I62, 10I. Rotularia egregia, $\Gamma$ Lapis cinereus rotulis cylindraceis albis \& pectunculis parvis plenus, Maslenfis (S.83.)

102. Rutularia in lapide fufco duriffimo (S. 349.)

103. Rotularia Islebienfis imperfeeta, C. alii calculo infixa (S.84.) 104. Rotularia-r.Lapis cinereus in fuperficie rotulis albis (pectabilis (S.348.)

105. Selenites $\mathrm{C}$. Lapis politus terrei coloris flexuris albis (S.166.) 106. Selenites cinereus, in quo flexura alba (S. 347.) Lapis talis $L_{10}$ naris deicrib. a Job. Kuntkelio in Ephem. Nat. Curiof. Dec.III. An.V. \& VI. Obi. LXXII. pag.14I. Et alii in Atbanaf. Kircberi de Arte Magnetic. Part.V. Libr. III. Cap.IV. pag. str. feqq. it, in Erafm. Erancifci OAt-und Weft.Indifch. Luft-Gart. Part.I. pag.62.

107. Smegmatiformis lapis cubicus (S. I56.)

108. Stalagmites albus duriffimus ex Comitatu Liptovienfi Hungarix (S.327) vid. Ol.Wormius Mur. Libr.I. SeQ.II. Cap.V1. pag.82. 109. Stellæ Judaica Imperati Beuthenæ Silefiacæ (S. 313.) vid. Ejusdem Hift. Natur. Libr.XXIV. Cap.XXII. it. Ol. Wormii Muf. Lib.I. Cap.X. pag 110. Silex perforatus niger ex agro prope Grabichen Duc. Vratisl. Siles. delineavi \& defripfi in Bresl. Samml. Don Nat, und Med. Gefeb. XXIIt. Verfo An.1723. Claff.IV. Art.VI. p. 182. convenit cum Silice perforato Sibeutb. zeri in Meteorol. \& Oryeograph. Helvet, pag.128. \& delinent. sp. Petr. Wolfart Hift, Natural, Huft. infer. Tab. XXIII. num. 2, p. j1. . Lapis Vaccinus Kub. Stein Scbeucbseri L. C. \& Car. Nic. Langii in Hiftor. Lap. Figurat. Helvet. Part.1. Cap.VI. pag.13. De Ufu \& Gaufa foraminis vid, Langius ibidem. 
III. Teffera luforia Badenfes (S.I25.) del. \& defcr. Mich. Bernb. Valentini in Muf. Mufeor. Part.1. Cap.IV. pag.28. Bresl. Samml, pon Nat, und Med, Gefch. VII. Verf. An.1719. Menf. Jan. Claff.IV. Art. V. pag. 57 feqq. \& Menf. Febr. Claff. IV. Arr, VI. pag. 178 feqq, it, XVIr. Verf An. 1721. Menf, Dec. ClaniIV. Art.VII. pag.610. prc. Fob. Jac. Scbeusbzeress Hift Nat. Helvetic. Part. II. pag.153. ubi pro arte factis eas habet, it. Wagnerus in Hitt. Nat. Helvet. fol, 329. \& Carol. Nic. Langius in Hittor. Lapid, Figurar, Helvet. Part.II. Libr,III. Cap.II. Tab.LI. pag.68.

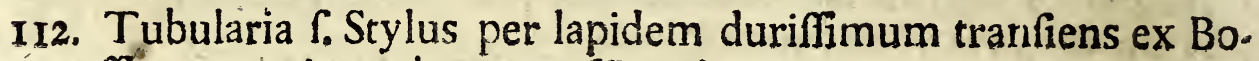
ruffía prope Angerburgum ( $\mathrm{S.94}$.)

113. Tubularia in Topho ex fonte Kukus, Diftriftus Gradlicenfis in Bohemia (S.320.) vid. Carol.Valentin. Kircbmeyeri Befchr, des Kukus.Brun. nes pag,20, it. Cbrif. Gottl. Langii Delcr. ejusdem Fontis.

I14. Tubularia rubra cum papillis fupereminentibus ex Thermis Carolinis ( S, 229.) talem exhibet Georg. Andr. Helwing in Lithograph, An. gerburg. Tab, IV. fig. 8.

Vaccinus lapis, vid, Silex perforatus.

115. Undulago f. Lapis eleganterundulatus Cameracenfis, (S. 46.) del. \& defcr. Leonh. Dav. Hermann in Maslogr. Tab. XIII, num.102, pag 223. 116. Undulago f. Aqua petrefacta ex Hungaria Kirchdorffenfis prope Epperies ( $\mathrm{S}$ 202.) defcr. Phil. Jac. Sachs a Lewenbeimb Gamma. rol. in Appendic, pag. 889. it. Georg. Ant. Volckmann in Silef. Subter. Part, II. Cap. VIII. pag. 45. f. Coagulum aqueum lapideum Langii in Hiftor. La. pid. Fig. Helvet. Part. II. Lib. III. Cap. Il. pag. 73. conf. Ol. Wormium in Muf, fol. 52. Fontem talem India Occidental, defcr. Erafm, Francifci im Oft - und Weft - Indifch. Luft: Gart. Part. II. pag. 1262. De Aquis aliis perrificantibus vid. Ploot Nat. Hift. of Oxfordshire pag. 34. \& ex eo foh. Fac. Scbeucbzerus $\mathrm{Hy}$ drographix Helveticx, qux eft Hiftorix Naturalis ejusdem Helveticx Pars II, pag.320. it. Fob, Hug. Lintfchottus in Navigac. in Orient, Part. III. Cap. VI.

117. Undulago $\mathrm{r}$. Tophus undulatus ex Thermis Carolinis (S.224.) Lapides qui ibi reperiuntur, defcr. Fob. Kentmannus in Nomenclat. Rer. Foffil; Tit. VI. fol. 38. variaque in iftis Experimenta inftituit $\tilde{f}^{\circ} b$. Gotbofr. Berger. in Diff. de Thermis Carolinis Cap. III. pag. 18. 19.20. it. Frid. Hoffimannus in Diff. de Carolinis Thermis. 
ET ARTIFICIALIVM KVNDMANN. VRATISLAV. 217

\section{ARTICVLVS II.}

Lapides qui referunt corpora Vegetabilium,eorundemque parres, ut Arborum, Fructuum, Nucleorum, Fungorum \& $c$.

1 Amaranthus Caxeus elegaritiffinus ( $S .287$.) delin. ap. Valentinum in Oft - Indifch. Berichten und Rapporten Tab. VIII. Fig. 6. pag.108. it. in C.N. Langii Hift. Lap. Fig. Helvet. Part. II. Libr. III.Cap. II. Tab. XII. pag. \{2.

2. Amygdaloides Hensdorffenfis prope Cygneam, continens intus filiculum flavum amygdali formem, crufta autem gypfea eft, qux A mygdalain faccaro incruftatam refert, Mandelftein (S.419.) defcr. ex Conr. Gefnero de Fig. Lapid. pag. 126. Fob. He Laët de Gemm. \& Lapid. Libr. II. Cap. XXVIII. pag. 175 . it. G. Andr. Helwing L ithogr. Angerb.Part. I. Cap. VI, Cl.I. Seet. I. pag. 38. delin. G. F. Mylius Memor. Sax. Subt. Part.I. Rel: V. Atb. Kircberus Mund. Subr. Lib. VIII. pag. 82. Aldrovandus Mur. Metall. Lib. IV. Cap. I. Locbneres in Muf, Beslerian. Tab, XXXVI. pag. 103. Fob. Jac. Bajerus Orydogr. Noric. Tab. I. num.23. pag. 45. Car. Nic. Langius in Hift. Lap. Fig. Helvet. Parr. II. Lib.III. Cap. II. Tab. XIX. pag. s6. it. Valentini in Mur. Mufeor. Part. II. Cap.II. pag. 19.

3. Amygdaloides Landshuttenfis Silefix ex monte Pörfchulano. (S. 127.) del. \& defrr. Georg. Antb. Volckmann Sil. Subter, Part. I. Cap.III. pag. 62. \& I3I.

4. Carpolithus Landshuttenfis Silefix, Frucht-Stein f, Hammites major Gefneri (Libr, de Fig. Lapid. pag.73.) (S, 126.) Id. Volckmannus Lib. C. Conf. 尹. G. Bajeri Oryetograph. Noricam pag. 146, it, D. S. Bïttneri Rud. Diluv.Teft. G.122. pag.200.

5. Carpolithus ex Hungaria, in quo femina viridis funt coloris (S. 524:)

6. Cenchrites Hirfenfein coloris nigri Querfurtenfis ( S. 258.) del, \& defcr. Car. Nic. Langius in Hift, Lapid. Figurat. Helvet. Part. Il. Libr. III. Cap. II. Tab. XVIII. pag. 69.

7. Corallium verum arborefcens mas, coloris coccinei elegantis (S. 353.)

8. Corallium verum arborefcens feemina coloris ex rubro pallefcentis, cum radice (S.8.) del. \& defcr. Georg. Agricola de Nat. Foflil. Libr. IV. Cap. XIX. pag. 499. Reqq, Conr, Gefnerus de Figur. Lapid. Cap.X. pag. 131. ex eo del. Anf. Boetius Hift. Gemm. \& Lapid. Libr. Ee 
II. Cap. CLVI. pag. 318. Ul. Aldropandus Muf. Metall. Lib. III. pag. 284. 29\%. 7ob. Ludovic, Ganfius in Hiftor. Coralliorum. Petrus Pomet im Materialift. und Spezerey - Händl. Tab.XXXI. fig. 146. - I52, ex eo Misb. Bernh. Valentini Muf. Mufeor. Part. I. Cap.XXXIIX. pag. 104. De mollitie in fundo maris fabulofa vid. contra Boetium Hiftor. Gemmar. \& Lapid. Lib. Il. Cap. CLill, pag. 305. Baglivium Operum Diff. V. S.XI. pag. 502. \& Erafm. Francifci im Oft.und Welt Indifchen Luft - Gart. Part. I. pag. 199. Pelzbofersus in Tyrocinio Chymico Libr. II. Cap.X. pag. 153. Ol. Wormius in Muf. Libr. II. Cap. XXXV. pag. 230. Ul. Aldrovandus in Muleo Metall. Libr. III. pag. 286. Antban. Kircherus Mund. Subterran. Tom. Il. Libr. IX. Sec. III. pag. 158. Hifforifche Remarquen An. 1707. pag. 148. Ferrand. Imperatus Hiftor. Natural. Libr.XXVII. pag. 808. G. F. Mylius Memorab. Saxon. Subter. Part. II. Rel. VII. pag. 6i. Po. mtt L. fupra cit. De pifcatione vid. Foh. Bapt. Taverniers Reife. Befchreibung Part.II. Cap.XXIII. pag. 138 .

9. 10. Corallium mas f. Taleolus coloris rubri faturati (S.212.) it. Corallium fœmina f. Taleolus alius coloris ex rubro pallefcentis (S. 213. (Lagenx inclufus.)

11. Corallium f. Pfeudocorallium rubrum tubulofum majus (S.6.) del. \& defcr. Georg. Hier. Velfsbius Obferv. Phyf. Medic. Hecatoft.I. Obr.XXX. p3g. 44. delin. pag. 53. . Tubularia purpurea Ferrand. Imperati Hiftor. Natural. Libr. XXVII. pag. 822. f. Calamites Aldrovandi vid. Muf. Metal. Libr.111. pag. 291. . Alcyonium maris rubrum foh. Henr. Locbreri Muf. Besler. Tab. XXIII. pag. 77. C. Tubularia Coralloides fob. Matb. Fabri de Pilx marinx Anatome pag. 202. qua reperitur in fine Ephemerid. Natur.Cariof. Decur. III. An. X. pag.20I.

12. Corallium Cardioides minus ejusdem ftructuræ, coloris dilutioris (S.354.) conv. cum delin. ap. Erafm. Francific im Oft - und Weft - Indi, fchen Luft -Garten Part. I. Tab. XIX. num. 2. pag. $\$ 66$.

13. Corallina tabula rubra in qua Cornu Ammonis (S. 7 )

14. 15. Corallium album \& aliud fubfufci coloris Cochleis adnatum (S. 195. \& 196.) Modum incruftandi defcr. Georg.Ant. Volckmann Silef. Subterran. Part. 1. Cap.IV. pag. 14. it. Mylius Memor. Sax. Subter. Part.II. Rel. VII. pag. 60.

16. Corallium f. Pfeudocorallium nigrum, alias Ebenum marinum, f. Ramus ligneus incruftatus maffa lapidea picei coloris (S. 5.) del. \& defcr. Aldropandus in Muf. Metall. Libr. III. pag. 289. Petr. Po. met im Materialift. und Spezerey - Haindl.;Tab. XXXI. fig. 149. pag.203. ex hoc Mich. 
ET ARTIFICIALIVM KVNDMANN. VRATISLAV. 219

Mich. Bernb. Valentini Muf. Mufeor. Part. I. Cap. XXXIIX. pag. 104. Conf. Bocconis Obferv. circa plantas marinas Ephem. Nat. Curiofor. Dec. IIL Ann.IV. pag. 148. in Appendic.

17. Corallium album ramofum, \& depreffum f. Equifetum, marinum ( $S$ 9.) Conven. c. delinear. in Ephem. Natur. Curiof. Decur.Il. An. I. \& II. Obf. CLXXIII. pig. 408.

18. Corallium cinereum madreporæ fimile, fquamis furfum fpeetantibus, five Saxum $A$ brotonoides Clufii (S. ni.) vid. Ejusd. Exoticor. Libr. VI. Cap. VII. pag. 123. convenit c. delin. ap. Ul. Aldropandum Muf. Metall. Libr. III. pag. 278. ir. Car. Nic. Langium in Hift.Lap. figurat. Helver. Part. II. Lib. III. Cap.II. Tab. 17. num. 1. psg. \{i.

19. Corallium fubfufci coloris ejusdem ftrueturæ (S. 12.) Simil.del. - 7. H. Locbnerus Muf. Beslerian. Tab.XXVI. fig. 4.it. Erafm. Franciffi im Oft - und Weft-Indifchen Luft - Garren Part. I. Tab.XIIX. num. 12. pag. $\$ 6 \varsigma$.

20. Corallium ex tubulis minimis compofitum lineis albis totam fubftantiam permeantibus (S.355.) Vid. Mich. Bernb. Valentini Indianilche-Berichte und Rapporten Cap. V. pag. Ir4. Tab. VII. fig. 7.

21. Corallium album ramofum \& fpongiofum elegantiffimum magnæ molis ( $\mathrm{S} .375$ )

22. Corallium $\mathrm{C}$. Porus cervinus petrefactus Imperati (S. 434.) vid. Ejusdem Hift. Natur.Libr. XXVII. Cap. IV. pag. 820.

23. Corallium littoreum cinereum C. Hippuris faxea Carol. Clafii (Exoticor. Libr. VI. Cap. IIX. pag. I24.) articulata, f. ex meris nodulis faxeis conftans, quos lignum nigrum duriflimum conjungit; \& per cavum ejus tranfit (S.356.) defcr. Georg. Andr. Hehving Lithograph. Angerb. Part. II. Cap. II. Sect. II. pag. 95. delineav. \& defcr. Caßß. Baubinus Hiftor. Plantar. Tom. III. Libr. XXXIX. Cap. XLVII. Ad. Olearius Gottorpifch. KunftKamm. Tab. XXXV. num.4. pag. 69. prc. Fob. Henr. Locbnerus Mur. Besl. Tab. XXIII. pag. 78. conven. c. del. in Ephem. Nat. Curiof. Dec. II. An. I. \& II. Tab. III. conf. Micb. Bernb.Valentini Indianifche-Berichte und Rapporten Num. LIL. Cap.II. Fig. III. pag. 109.

24. Corallium ita fiftulofum \& nodofum minimum nitide albicans, geniculis nigris, $\mathfrak{f}$. Equifetum minimum Orientale petrefactum fec. Job. Cbrifoph. Gottwaldum in Ephen. Nat. Curiof. Dec III. An. IX. \& X. Obf. CLX. Tab. XXVII. pag. 289. conven. c. delin. in Epbem. Dec. II. An. I. \& II. Obf. CLXXIII. P. 408. (S.358.)

25. Corallium terreum ramofum \& porofum (S.357.) Ee 2 


\section{0

26. Corallium minimum ramofum album, $\mathrm{f}$. Erica marina Valentini

in Indianifch. Bericht. and Rapport. Loc. paulo fupra citato, item del. Petri Po. met Marerialift, und Spez. Tab.XXXI. fig. I\{2.p.g. 205.(S.360.)

27. Corallium lenticulare album $\mathrm{f}$. Lenticulæ marinæe fibi invicem connexæ 1. Fuci fungulares Imperati (S.362.) vid. Ejusd. Hiftor. Nacural. Libr. XXVII. Cap. XII. pag. 859.

28. Corallium album monodonum. vid. delin. in Micb.Bernb.Valentiki In. dian. Bericht. und Rapport. Tab. VIII. fig. I. Lit.C. ex Ephem. Nat. Curiof.Dec, II. an. I. \& II. Tab. III. (S.363.)

29. Corallii albi congeries vermicularis ( $\$ .364)$

30. Corallium fiftulofum album f. Tubularia Coralloides ( $\mathrm{S} .13^{*}$ ) Vid. Valentini Indian. Rapport. Part. I. pag. 107. . Madrepora maxima arborea Tournefortii. vid, Locbnerus in Muf. Besler. Tab.XXV. pag. 82.

31. Corallinus mufcus albus (S. I4.)

32. Corallinus mufcus fungiformis (S.15.)

33. Corallinus mufcus officinarum articulatus cum radice (S. 359.) convenit cum delineat. Coralline fiftulof $x$ fragilis ap. Locbnerum Muf. Beslerian. Tab. XXVII.

34. Corallium album remofum totum foraminulis præditum (S.36r.)

35. Corallium album verrucofum (S.267.) del. \& defcr. Valentini Mur. Mufeor. Part. I. Libr. I. Cap. XXXIIX. pag. 104. it. F. H. Locbnerus Muf. Beșl. Tab. XXV.pag. 82.

36. Corallium flavum verrucofum $\mathrm{f}$. fiftulofum foraminulis crenatis inftructum (S.27I.) del. Ferr. Imperates Hifor. Natural. Libr.XXVII. pag. 815 .

37. Corallium album tubulofum ramis fortioribus expanfis (S.291.) 38. Corallium ramulis maffæ lapidex immerfis. (S. 18.) del. \& defcr. G. Andr. Helwing Lithograph. Angerb. Part. II. Cap. IIl. pag. 126. Táb. VI. fig. !.

39. Corallina reticularis alba rariffima $\mathrm{C}$ Reticulum marinum mire circumplicátum (S.287.)

40. Corallina maffa eminenciis fiftulofis turgida (S.53.) del. id. Helwing

Lithogr. Angerb. pag. 41. Tab. V. fig. 2.

41. Caralloides arbor tubulofa alba cum radice (S.10.) 42. Malfa Coralloides albicans parofa, marisfuctuationem egregie 
repræfentans (S.368) conv. cum del. quam dedit $M$. B. Valentini in OnIndianifch. Rapportei Tat. IX. fig. I. pag. IIG. it. Erafm. Francifci im Oft - und Weft -Ind. Luft Gart, Part. I. Tab. XIX. num. T. pag. 566.

43.44.45.46.47.48. Dendroidæ Florentini, reetius Veronenfes cinerei, albi \& flavi politi, f. Marmor dendrites Aldrobandi, $E$, Saxa nemorofa, $\mathrm{r}$. Pietra imbolcata Imperati, in quibus arbores majores \& minores elegantiffimi a natura effigiati ( S. 1IO. I I I.II2. 113. 272.273.)

49. Dendroides Wonfidelenfis Byruthinus egregius in Lithomarga alba lævi, cum arbufculisaureis ( $\mathrm{S}$. 435.)

50. Dendroides ejusdem loci, árbufculis nigris infignitus. $\left(S_{436 .)}\right.$ 51. Dendroides Maslenfis Siletia rotundus (S. 64.) del. Leonb. DaD. Hermann Maslograph. Part. II. Cap. XI. pag. 227. feqq.

52. Dendroides Glacenfis Bohemiæ ruber, cum Erica tenuifolia (S.65.)

53. 54. Dendroites Kuntzendorffenfis Silefia rotundus flavus \& cinereus mufco coralloidi latifolio fimilis (S.66.2II.) conv. c. del. gob. Jac. Scbencbzeri in Herbario Diluvian. Tab.IIX. fig. VI. pag. 42.

55. Dendroides Mancbachenfis Ducatus Saxo-Gothani cinereus (S.68.) Defer. G. F. Myliws Memorabil. Saxon. Subterran. Rel. III. Part. I. pag. 20. feqq. \& ex eo Mich. Bermb. Valentini in Muf, Muf. Part. II. Libr.I. Cap. V. pag. 32.

56. Dendroides elegans flavus f. Arbufculi exmontibus prominentes, Kuntzendorffenfis. (S210.)

57. Dendroides Silefiæ fuperioris, $\mathrm{r}$. Lapis calaminaris albus cum Erica tenuifolia nigra.(S.292.) vid. G. F. Mylii Memorabil, Sax. Sub. terran. Part. I. Relat. VIl. pag. 51.

58. Dendroides Sulenfis f. Marmor album arbufculisflavefcentibus. aureis \& nigris in utraque fuperficie eleganter depifum opero ut vocant miniato fimilis. (S. 439.)

59. Dendroides ejusdem loci, arbufculis denfe fuper trastum montofum pofitis. (S.440.)

60. Dendroides ibidem effoftus, ubi quafi in ripa fluminis arbores majores \& minores, itemque frutices diverforum colorum locati. $($ S. 44 I. $)$ 
61. Dendroides talis arbufculis fparfis ex terra nigra prominentibus ( $S$ 442.)

26. Dendroides, in quo frutices humiliores \& depreffi confpiciun. tur. (S. 443.) Accedunt ad delineationem \& defcr. quam dedit G. F. Mylitus in Memorab. Saxon. Subterran. Parc.I.Relat.VII. pag. \{2. \& ex eo fo. Jac. Scheuchzerus in Herbario Diluvian. Tab. VI. pag. 23. it. Mich. Bernb. Valentini in Mur. Mueor. Part. II. Tab. VI. Cap. V. pag. 36 .

63. Dendroides elegantiffimus in lapide fiffili marmoreo flavefcen. te, denfum lucum feu fylvulam ex arboribus aureis, qux fuperius in nigras definunt, conftituens, ex Lapicidina pagi Solnhoff Comitatus Pappenheimenfis ( $S .447$ )

64. Dendroides in lapide fiffili tali candido, ubi una fuperficies fylvulam arboribus nigris erectis \& altioribus collatos, altera frutices flavefcentes aureos \& nigros, arboresque depreflas, demonftrat (S.444.) talem del. \& defcr. Job. Fac. Scbeusbzerus in Herb. Diluv. Tab. VII. fig.8. pig. 40.

65. Dendroides flavefcens in quo arbor aurei coloris maxime dilatatus \& paulatim in minutas frondes diffufus apparet, prope Cüftrinum ex Marchia Nova (S.445.)

66. Dendroides albus ejusdem loci, cum Mufco corallino montano colore aureo \& cinereo variegato (S.446.)

67. Dendroides Saaifeldenfis f. Lapis fiffilis marmoreus albus, totus nemorofus ex arboribus erectis fufcis (S.448.)

68. Dendroides Eyftädtenfis rariffimus in lapide fiffili marmoreo albo, arbore nigra confpicua fuperius cum figura funduli pifcis exacte impreffa (S. 449.)

69. Dendroides ejusdem loci in tali marmore cum ramo oblongo frondofo \& fibtiliter intorto nigro, quem arborum apices aurei coloris floribus fimiles fecundum longitudinem profequuntur (S: 450. )

70. Dendroides in lapide albo Eyftadienfi, cum Erica tenuifolia nigra in uno latere, \& arbufculis aureis in altero, delineatis (S.428.) 71 .Dendroides ejusdem loci flava alia mufco corallino fimilis (S.333.) del. \& defer. Erafm. Francifci im Oft-und Weft-Iñdifch, Luft-Gart. Part.Il. pag; 1188. citante Bafil. Besloro in Faf́ciculo rariorum, 
72. Dendroides f. Marmor de monte Sinai album arbore nigra fubtiliter depiktum (S.I1O.) convenit c. Defcript. ap;0l. Wormium Muf.Libr,i. Cap.IV. pàg.45.

De Dendroide vid. Ferravdus Imperatus, qui modum fiendi ab exhalatione bituminofe materia demonfravit Hiftor. Natural. Libr.XXIV. Cap, XXIV. pag. 746 . Confer qux in hunc fcopum experinentatus eft Scbultzius Medicus Vratislavienfis Clariff. vid. Epiftol. Fob. Jac. Scheucbzeri ad Locbnerum, qux reperitur in Mifcell. Nat. Curiof. Dec.III. An.V. \& VI. pag.57.feqq. in Appendic. ir. Scbercbzerus in Herbario Diluvian. pag. 25 . de modo fiendi alio vid. Alb. Kirchérus in Mundo Subter. Libr. VIll. pag. 37. Confer. DaD. Sig. Büttneri Rud. Diluv. teft. 5.84. pag.124. it. Georg. Ant. Volckmanni Sifel. Subter. Libr.I. Cap.III. \$.6. \& 7. pag. 57.-60. Tab.II. \& III. Pro lufu Naturx habet pre. Eyftädtenfes Pbil. Jat. Sacbs a Lewenbeimb in Gammarolog. Cap.VIll. pag. Is3.feqq.

73. Flores Martis in fodinis ex albicante matrice repullulantes Besleri (S. 207.)

74. Florum Martis alia concretio candidiffina (S.461.)

75. Flores Martis Halcyonio Milefio Imperati fimilis (S.462.) vid. Ejusa'em H.ffor. Natural. Libr.XXVIII. Cap.I. pag.83i.

76. Flores Martis alius fruequræ nivex albedinis tabula maxima, f. Itriis fuperius ereetis, inferius depreflis mire juxta fe poficis, (S.294.) del. \& defcr. Beslerus in Gazophylacio fol.8. prc. Carol. Ohmb in Mifcell. Nat. Curiof. Dec. II. An. VI. pag. 297. Conf. Ul. Alarovandi Min! Metall. Libr.I. pag.135. item Hoeff ri Hercul. Medic. Libr.III. Cap.V. pag.i69. G. Hier. Velfcbii Obferv. Phyl. Medic. Hecatof.I. Obf.XXXVII. pag. 50. Milib. Bernh. Valentini Muf. Mufeor. Part.I. Lib.L. C.p.XXXI. pag.86.

77. Fungiformis lapis ftriatus magna molis, f. Placer ta coralloides albicans finuofa, $\int$. Aftroites undulatus (S. 163.) vid. Yob. Henr. Locb. neri Muf. Besler. Tab.XXVI, pag 83. ir. M. B. Valentini Muf. Mufeor. Part.II. Cap.III. pag.25. fig.6.

78. Judaicus lapis f. Glandarius fecundum longitudinem tuberculofus major, Juden.Stein (S. igI.) conv. cum del. \& defcr. Grorg. Andr. Helwin. gii Lithograph. Angerburg. Tab.I. fig. 15. pag.38. Similis Pinex nurcleo ap. J. H. Locbnerum Mur. Besleriain. Tab.XXVII. pag.104.

79. Judaicus lapis tuberculofus minor (S.152.) del. \& defcr. in Epberm. Nat. Curiof. Dec.III. An.V. \& VI. pag.45. fig.34, it, ap. Georg. Ant, Volkmannum Sile. Subterr. Part.l. paǵg.is4.

80. Judaicus lapis lavis (S.153.) talem del. \& defer. Job.de Latt de Gemm. \& Lapid. Libr.ll. Cap.XVI. pag 137\%

81. Ju= 
81. Judaici lapilli minimi ftriati cum \& fine pediculo, Hirfchbergenfes Silel. ex fluvio Bober ( $\mathrm{S}$.335.)

82. Judaici lapides fubbinerei rotundi \& oblongi, partim tenuiffime ftriati, partim punctati, cum \& fine pediculo (S.297.) Accedit ad Piper longutia lapideum Locbneri in Muf. Besler. Tab.XXVII. pag.104. delineav. quoque Ol. Wormius in Mufeo Lib.I. Cap X. pag 69. it. Langins in Hitt. Lap. Fig. Helvetix Part.II. Libr.VI, Cap.I. Tab.XXXVI. pag.126.

83. Judaicus lapis per fuperficiem lineis \& fulcis copiofis infignitus (S.204:)

84. Judaicus lapis maximus Florentinus totus tuberculofus $(S .455$. Hos pro particulis animalium marinorum habet Dav. Sigifm, Büttnerus in Coralliographia Subterranea Cap. I. 5.3. pag.2. Pro Radiis Echini marini fob. Jac. Scbeucbzerus in Meteor, \& Oryctograph. Helvetica pag.319. G. F. Mylius in Memorabil. Saxonix Subter, Part.II. Relat. VII. pag. 67. Eduard. Luidius in Litho. phil, Britannic. Ichnograph. Epift.II. pag. IO3. it, Petr. Cbriftian. Wagnerus in Differt, de Lapidihus Judaicis Cap.III. \$.6. pag. 30. Dubia cuntra hanc affertionem moverunt Car. Nicol. Langius in Hift. Lapid. Figurar. Helvetix Lib.VI. Cap. II. pag.128. it. Fob. Fac. Bajerus in Oryctograph, Norica Cap.V, pag.45. De viribus medicamentofis vid, id, Wagnerus L. C. Cap. IV. pag. 42. De magna copia effofforum ad Wohnfiedel vid. Ausführliche Befchreibung des Fichtelberges pag.II2. Authores, qui hunc lapidem preter fupra nominatos defcripf, recenfet 7oh. Henr.Locbnerus in Muf. Beslerian. pag.101. \& 102.

85. Malum Aurantium immaturum, cujus dimidia pars nigra \& quafi femicorrupta apparet prope Malifchau ex Bohemia (S.329.) Accedit ad de.ineat. ap. Georg.Ant.Volckmannum Silef. Subterran, Part.I. Cap.IV. S.58. Tab,XXIII. fig.r.

86. Nux Mofchata f. Myriftica tota filiceæ fubftantiæ, referens ex affe Nucem Molchatam fruAtu oblongo (S.173.) talem delineav. Gob. Baubinus de Lapidibus a Natura in terra figuratis pag.35. prc. cum interiore facie 7ob. Fac. Scbeuchzer in Herbario Diluvian. Tab.XIII. num.I. \& 2. pag. I07. it, ex Ejusdem Specimine Lithographix Helveticx pag.42. G. F. Mylius in Memorabil. Saxon.Subterr. Part.II. Relat.VIII. pag.74. Conf, Ol. Wormii Mufeum Libr. I. Cap XIII. pag.87. Georg.Ant.Volckmanni Silef, Subter. Cap.IV. Tab.XXII. fig.

phuribuig of Walch 6. pag.129. Gcorg. Andr. Heliwingii Lithograph. Angerb, Part.I. Cap.VI. Claff.I. in hat

87. Óftebcolla ramofa in monte arenario Maslenfi frequens, ex qua foffile ibidem arborefcens præparatur, Beinbrucb.Stein (S.30.) del. \& defcr. Leonb. Dad. Hermann Maslograph. Part.II. Cap.II, pag.182.

88. 
ET ARTIFICIALIVM KVNDMANN.'VRATISLAV. 22

88. Ofteocolla coloris ferruginei fiftulofa Maslenfis (S.758.) del. \& defcr. id. Hermannus L.C. Parr.II. Cap.III. pag.rgr.

89. Ofteocolla cortice albo obdueta cum medulla fufca fpongiofa (S.264.) del. \& defcr, ulyjf. Aldrovandus Mur. Metall, Libr.IV. pag.626. 90. Ofteccolla ramofa Dammerenfis prope Namslaviam Silef. effolfa (S. 426.) vid, Leonb. Dav. Hermann Maslogr. Part.II. Cap.II. pag.187. 91. Ofteocolla fubrubra ex montibus Mifnia (S.265.)

De Ofeocolla, five ut Thom. Erafus vocat, Lapide fabulofo, multa collegit id. Eraffus Operum Tom.II. in five, it. Ol. Wormius in Mufeo Libr.I. Cap.VII. pag. 53. lll. Aldrovandus in Mur. Metallic. Libr.IV. pag. 626. Defcribit fub nomine Cartilaginis terræ Eduard. Luidius in Lithophil. Britannic. Ichnogr. Clar?. XI. num, I519. C. Xyloftei vel ligni'petrefacti idem; C. Offium in lapidem mutatorum Ans. Boctius de Boot Hift. Gemmar. \& Lapid. Lib.II. Cap. CCXXXIV. pag.417. De Mutatione Radicum in Ofteocollam vid. Ferrand. Imperatus Hiftor. Natur. Lib.XXIV. Cap.XXVI. De generatione per adhæfionem circa radices arborum picearum vid. gob. Cbriffopb. Beco mannus in Ad. Philor. Soc. Reg. in Angl. An.1668. Menf. Sept. pag. 645. it. Gce org. Andr. Helwing in Lithograph. Angerburg. Part.I. Clafi.I. Sec.lII. pag.47. Situm precipue in terra, del. \& defcr, id. Hellwing L. C. Part, I. Claft. I. Cap.VI. Sea.III, pag.43.feqq. Tabul..III, it. Leonb. Dav, Hermann Maslograph. Part,II, Cap.II. pag.182. Tab.VIII. De Ufu in Medicina vid. Ant. Boetius in Hift.Gemm. \& Lapid. Lib. II. Cap.CCXXXIII. CCXXXIV. \& CCXXXV. fuperftitiofum ex Matbiolo \& 2uercetano refutavit Fabritius Hildanus Obferv. Chirurg. Cent.III. Libr.I. Obr.XC.

92. Conus lapideus pineum fructum æmulans (S. 447.) conv. cums delin, \& defcr. Ul. Aldropandi in Muf. Metall. pag. 829. Fob. Henr. Locbneri in Muf. Beslerian. Tab.XXXI. pag.91. Georg. Ant. Volckmanni in Silef. Subterran. Tab.XI. it. Tab.XXII, num.4.

93. Pifa Bethlehemitica alba durisfima in matrice (S.268.) defcr. Petr. Bellonius Obfervat. Lib.II. Cap.LXXXVII. Rauwolvius Reife-Befchr. pag. 449. Monconyfurs der Reifen Tom. I. pag. 313. Thepenot in Reifen Lib. II. Cap. XLIV. pag.271, prc. del. \& defrr. Fob. Pbil. Breynius in Epittol, de Melonibus petrefaQis montis Carmel pag.IG,feqq.

94. Pifa Carolina C.Pifolithus ex Thermis Carolinis albus, Erbfen-Stein

(S.I43.) Simil. del. \& defcr. Conr. Gefnerus de Figur. Lap. Cap.IV. pag.71. \& 72 e

Q exeo ans, Boetius in Hift, Gem. \& Lapid, Lib.ll. Cap.CCXCII. pag.423. ulo F $\mathbf{f}$ 
Aldrovandus in Muf, Metall. Libr.IV. pag.635. Ol. Wormius Muf, Lib.I. Sect.II. Cap.VI. pag. $5 \%$ prc. vid. Bergerum de Therm._Carolinis pag.15.

95. Pifolithus viridis ex monte Bononienfi (S.515.)

96. Pifolithus Cothenii, dum muros exftruerent, effoffus, (S.516.)

97. Pifolithus f. Minera Martis nigra botryoides elegans von der Mardla am Fichtelberge (S.209.)

98. Prunum lapideum coloris cærulei ( $\mathrm{S}_{459}$ ) defcr. \& delin. fob. fac. Bajerus Oryctograph. Norice Tab.I. num.22. Cap.v. pag.45.

99. Pyrenes f. Olivaris lapis coloris ex nigroviridefcentis, Oliven.Stein (S.277.) defcr. Georg. Ant. Volckmannus in Sil. Subter. Cap.III. \$.XI. pag.62. 100. Pyrenes f. Olivaris lapis, globulis in fuperficie adnatis lapidi duriffimo inclufus ( .323 .) del. \& defcr. Fob. Fac. Bajerus in Oryctograph. Norica Tab. I. num.20. \& 21. Cap. II. pag. 45. Nucleum Da\&tyli ira inclufum defcr. \& delin. D. S. Büttnerus in Rud. Diluv. teft. 6.74. pag.10z.'Tab.XVI. num.8. Caftaneam, Idem Tab.XIX. pag.20I, alios fructus G. A. Volckman. nus L. C. paulo fupra ciraio.

IOI I02. Rhodites f. Rofoites major \& minor in lapide albo, Rojen. Steim. del. \& defcr. Fob. de Láet de Gemm. \& Lapidib. Lib.II. Cap.I. pag.97. it. G. F. Mylius in Memurab. Saxon. Subterran. Part. II. pag. 3\%. it. Georg. Hier. Velfcbius in Obf. Phyfo Medic. Hecaroft.I. Obferv.XL. pag.60.

103. Spongites $\mathrm{f}$. Spongia lapis cum tubulo vermiculari ferpentiformi purpureo, Scbwamm-Stein. (S.463.) tales del. \& defcr. Georg.Hicr.Vilfchirus de Vena Mediuenfi Cap.III. pag.93.

104. Spongia lapis $\mathrm{f}$. Cyfteolithus fiftulofus cum ramo arboris $\mathrm{cu}$ jusdam marini per cavum ejus tranfeunte (S.164.) fimil. del. \& defcr. Cosr. Gefnerus de Figuris Lapid. Cap.XI. pag.135. \& ex eo Fob. de Lact de Gem. \& Lapid. Libr.II. Cap.II. p.Ioz. Conf. Llyff. Aldrovasdi Muf. Metallic. Lib. IV. p.67i. it. Job. Henr. Lockneri Muf. Besler. Tab.XXVIII. Naturx (ut vocat) Lufus varios in Spongite del. \& defer, Foh. Matb. Fabri.jn Ephem Nat. Curiofor. Dec.III. An.I. Obl.CXXI. pag. ig6. feqq. prc. Georg. Hier. Velfcbius Ouf. Phyf. Medic. Hecatoft.l. Obf.XIX. pag.30. \& 3 I.

ฐo5. Stelechites f. Ofteocolla fiftulofa Tirolenfis alba, ex meris globulis compofita ( $\mathrm{S} .263$ )

106. Stelechites f. Minera Ferri fiftulofa Malmicenfis Ducatus Glogovienfis Silefiæ (S.130.) defcr. in unferen Sammlungen von Nat. und Med. Gefcb. J.Verf. An.1717. Menf. Sepsembr. Claff. IV. Arc. Iil. pag.6r. feqq. fimil. delin. Ul. Aldrovandus in Muf. Metall. Lib.I. pag. 143. Conf, Petr. Albini Meilnifche 


\section{ET ARTIFICIALIVM KVNDMANN. VRA TISLAV. 227}

nifche Berg. Chronica Titul.VII. pag.7I, prc. Fob. Georg. Licbknecbts Difcurs. de Diluvio maximo, occafione inventi nuper in Comiratu Laubacenfi \& ex mira metamorphofi in toineram ferri mutari ligni.

\section{ARTICVLVS III.}

Lapides qui referunt corpora Animalium \& eorundem partes.

Achatas, Belloculos, Onyches,Sardos etc. parteshominum \& animalium referentes vide fupra SeC.III. Clafi.I. Artic.II. ubi de Gemmis fcalptis \& politis.

1. Arachneolithus, Arachnites, $f$. Arachnoides lapis fietitius durisfimus, Spinnen-Stein (S.157.)

2. Arachnites verus, $\Upsilon$. Aranea exficcata maxima lapillum referens (S.466.) vid. Rofin. Lentilii Paralelifm. ad Obfervat. Ephemerid. Dec.I. An.IV. \& V. p.96. prc. Obferpatio mea in Bresl. Samml. von Nat, und Med. Gefcb. XXIV. Verf. An.1723. Menf. Majo Claf.IV. Artic.III, pag.422.

Dari Aracbnitem confirmat \& ufum commendat 70 ob. Francius in Ephem. Nat. Curiof. Dec.II. An.V. ObI.CCXL. pag.462. it. fupra Dec. II. An. III. pag.97. \& Juf. Frid. Dillenius ibid. Cent.III. \& IV. Obr,XLIV. pag.97. ir. Paul. Fac. Marperger im Kauffmanns-Magaziu pag. 1217. Cum aliis eum delin. \& defcr. Fob. Henr. Lochnerus in Mứ, Beslerian. Tab,XXXV. pag.ıoc. Fabulofiflimx originis effe demon. Atravit Sim. Pauli in Quadripartito Botanico Clañ.II. p. m.179. Wolffius in Scrutineo Amuletorum Cap.II. SeC.I. pag.192. prc. Frid. Errief. Briückmannus de Fabulofiffimæ originis Lapide Arachneolitho Epiftola. De modo acquirendi vid. id. Marperger L.C. \& Cbrift. Frider, Garmannus de Miraculis mortuorum Libr.III. Titul.III. \$.85. pag.II6. prc. Cbriftoph. Helhoig im Neu-angelegten curiöfen und zur edlen Medicin kurtz verfaften Thier-Garten pag.286. Cbr. Frid. Paullini in Philofophifchen Luft-Stunden Part.I. num.LXII. pag.424. Conf. Micb. Bernb. Valentini Muf, Mufeor. Part, I. Libr.III. Cap. XLIII. pag. \{16. it. Mifcell. Nat. Curiofor. Dec.III. An.III. א. Rofini Lentilii Paralelifm. ad Obfervat. Decur.I. An. IV. \& V. Obferv.XC. pag.96.

Batrachites vid, Bufonites,

3. Bucardites lævis, margine in aciem demiffa, interne continens lapidem vel Callimum fluctuantem, Hertzmufcbel. Stein oder Ocb̆jenbertz-Stein (S.324.) Pectinites talis defcr, ap. Eduard. Luidium in Lithophil. Britannico Ichnograph. Capf.IX. num.646, pag.33. Bucardiam talem del. \& defcr.

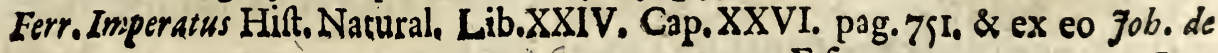


Laët de Gem. \& Lapid. Libr.Il. Cap.XXXII. pag.209. \& 210. it. Ul. Aldrovandus Mur. Metall. Libr.IV. p. 479. Car. Nic. Langius Hift. Lap. Fig. Helvet. Lib. VII. Cap.II. Tab.XL. P.I4I. it. Job. Henr. Locbnerus Mur. Besler. Tab.LXXIII. pag. 104. Lapides exacte cordiformes, qui ingenti copia reperiuntur prope Arcem Aursberg in Carniola, deícr. Job. Weich.Valvafor in der Ehre des Herzogth. Crains Tom.III. pag.19.

4. Bucardites coftatus Plotii (S.315.) vid. Ejusdem Hift:Natural.Oxon. (Angl. fcript) Tom.VII. fig.3. it. Ol. Wormii Muf. Libr.I. Sect.II. Cap.XII. pug.80. 5. Buceros f. Ceratites Maslenfis, Hörnel - Stein (S.81.) del. \& defcr. Georg. Ant.Volckmannus Sil. Subt. Tab.V. Fig.2. pag.64.

6. Bufonites $\mathrm{f}$. Ichthyodontes fcutellatus Luidii Orientalis maculis fufcis infignitus, oculi inftar convexus, Kröten-Stein (S.275.) vid. Ejus. dem Lithophil. Britann. Claft.X. Capf.XX. pag.69.

7. Bufonites fufcus femiglobularis in altera parte planus (S.276.)

8. Bufonites coloris cinerei concavus, five inftar capfulæ glandis quercinæ, C. Batrachites Orientalis Gefneri (S.274.) hunc ex Lib. XIII. Ejusdem de Fig. Lapid. pag.161. del. \& defcr. Ul. Aldrovandus in Muf. Metallic. Libr.IV. Cap.LX. pag.814. it. Ans. Boetius Hift. Gémm. \& Lapid. Lib. II. Cap. CXLIX. pag.30r. pre. Ol. Wrormius Múf. Lib.II. Cap.XVIII. pag.107.

Dufoniten fabulofifimæ originis effe fribit Sim. Pauli in Quadripartito Botanico ClaffiII. pag.180, maximum Librarum V. \& alium trium unciarum del. \& defcr. Andr. Libavius Singularium Part.IV. Cap.XXIII. pag.424. ubi fimul multa de ufu Medico fuperftitiofo. De modo obtinendi vid. Conr. Gefnerus Hift. Animal. Libr.IV. Capite de Ranis \& Rubetis, it. Pbil. Baldeus in Befchreibung der Küften Malabar, Coromandel und Zeylon pag.162。

9. Campoides Aldebergenfis Mifnia, Raupen_Stein (S.300.)

10. II. Chelidonii lapilli oculati, cufpidati \& depreffi, Scbwalben-Steinlein (S.436. \& 437.) defer, \& delin. Conr. Gefnernes de Fig. L3pid, pag 107. it. Mich. Bernh. Valentini in Bedencken von Kunft-und Natural, Kammern Cap.IX. pag. 58. Conf. Ans. Boetium Hift. Gemm. \& Lapid. Libr.II. Cap.CLXX. pag.343. pre. Carol. Nic. Langii Hift. Lap. Fig. Helv. Part.II. Libr.V. Cap.V. pag.Ins. Tab.L. Georg. Hier.Velfcbii Obf. Phyf. Medic. Hecatôt.I. pag.74. Pbil. Gac. Sacbs a Leewenbeimb Gammarol. pag.306.' Thévenots Reifen Lib.I. Cap.V. pag.8. De ufu Medico \& acquirendi modo e pullorum hirundinis ventre (fec, vulgus) vid. Irancifc. Rueus de Gemmis Cap.XXII. pag.236. qui reperitur poft Levin. Lemnii Herb. Biblic, Explicat. pag.7 r.feqq. Tbom, Bartbolinus Epift. Medicinal. Cent.Il. Epift. XI. pag.438. it. Cent.I. Epift.LIII. pag.224. Fob. Reiskius de Gloffopertis Lune. burgenf. pag. 55. prc. Langius L. fupr. cit. \& Fob. Fac. Scbsusbzerus in den NaturGefchichten des Schweitzerlandes Part, Ill. pag.143. 12. Co. 
ET ARTIFICIALIVM KVNDMANN. VRATISLAV. 229

12. Colites corrigatus fine tefticulis ex Topho undulato Thermarum Carolinarum (S. 404.) accedit ad delineationem, quam dedit Car.Nic.Lan. gius in Hift. Lap. Fig. Helvet. Part. II. Libr. III. Tab. X. Cap. Io pag. 48. \& Georg. Andr.Helwing Lithograph.Angerburg.Part. I.Tab.VII. fig. 6. pag. \{7. it. ₹fF. Bajerus Oryçogr. Noric. Tab.I. num. 38. pag. 47.

13. I4. Echinites, Meer-Igel - Stein, vulgo Brontias major \& minor elegantis ftrueturæ quinis lineis geminatis, quæ parvis forami. nibus diffecantur, æqualiter a puncto fuperiori ad bafin procedentibus, perforatus, \& non perforatus, (S.169.170.) Simil. delin. \& defcr. ill. Aldrovandus in Muf. Metall. Lib.IV. pag. 454. \& fegq. Ad. Olearius Gottorpifch. Kunft - Kam. Tab.XXII. pag. 33, it, Ol. Wormius Muf. Libr. I. Sect. II. Cap.:XII. pag. 76.

15. Echinites talis figuræ obfcurioris coloris (S.490.)

16. Echinites zonis eminentibus a bafeos modiolo, ad verticem ten. dentibus (S.17I.)

17. Echinites in faftigium mucronatum definens ex Wagria-in lit. tore maris Baltici. (S. 527.) del. \& defcr. Fac, a Melle in Epiftol, de E. chinitis Wagricis.

18. Echinites fibularis inferius annulo notatus regularis convexæ rotunditatis, lineis \& foraminulis carens (S. 172.) tal. del. \& defcr。 Georg. Andr. Helwing Lithograph. Angerburg. Part. I. Cap. VI. Claff. II. See.III. pag. 72. Tab. VIII. fig. 16. 1\%.

19. Echinites depreffus coloris rubicundi lavis (S.330.)

20. Echinites maximus oblongus fquamofus, $f$. Chelonites, Operimentum $\mathrm{f}$. Teftam Teftudinis aquaticæ variis quadrangulis diftin ?tam referens (S. 324.) convenit cum del. \& defcr. quam dedis fob. de Lä̈t de Gem. \& Lapid. Lib.II. Cap.XXV. pag. 160.

2I. Echinites aurei coloris fafciis quinque albicantibus inftruetus (S. 269.)

22. Echinites talis faturatioris coloris foraminibus fecundum duetum linearum impofitis (S. 489.)

23. Echinites lavis fafciis \& lineis carens(S.486.)

24. Echinites obfcure viridis coloris, oblongus, quinis lineisduplicatis \& punctatis circumferiptus(S.270.) Simil.del. Jaco\& Melle de Echin nitis Wagricis pag. 12. fig. 4 .

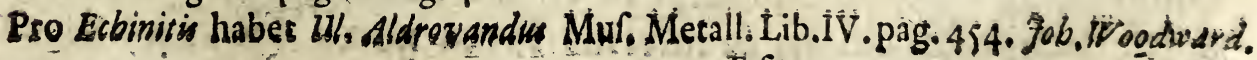
If 3 Hif́tor. 
Hiftur. Tellur. Narural. illufr. pag. 182. \& 233. Mart. Lifterus Hiftor. Animal. Angliz Tab. VII. pag. 219. Georg. Andr. Helwing Lichogr. Angerburg. Part. I. Claff.Il. Sect. III, pag.68. G. F. Mylius Memorabil. Saxon. Subterran. Part. II. Relat.IV. pag. 44. feqq. Carol. Nsc. Langius de Origine Lapid. Figurator. Lib. 1. Cap. X. pag. 35. Job. Jac. Scbeuchzerus Hift. Natural. Heivet. Parr. I. pag.III. Job. Jac. Bajerus Oryctograph. Norice Cap.VI, pag. 70. it. Auguft. 2uirin. Ri. virus Differ tation. Medicar, Difput. V. Cap. IV. S.4. pag.97.prc. Jac.a Melle de Echinitis Wagricis.

Nonnulla circa Echinitas oppofuit, ratione multarum fpecierum Eduard. Luidius Lithophil. Britan. Ichnograph. Epift. V. pag. 125. it. quod femper aculei defint' Idem Claf, VI. Capf. V. pag. 44. \& Epift. II. pag. I02. Pro Echinorum apo. graphis haber Id. Capf. VI, Claf, V. pag. 44. Pro Bufonitis, Jauus Ant. Sarscersus de Pefte Cap. VII. pag. 219. Chrifloph. Encelius de Re Metallica Lib. III. Cap. XXXVII. pag. 221. Lapides fui generis appellat Rob. Ploot in Hift. Natural, Oxon, pag. 93. \& 115. it. Langius L. C. Líbr. VI. Cap. I. pag. 125. An Brontia f. Cerauniæ i. e. cum roniţru, an Ombriæe, quod cum imbribus cadant, refutavit Georg. Agricola de Nat. Foflil. Lib, V. Cap. XIll. pag.528. \& ex eo Anf. Boerius Hift. Gemm. \& Lap. Lib: II. Cap. CCLXIV. pag. 486. it, Bresl, Samml von Nat. und Med. Gefeb. IX. Verf. An. 17 19. Menf. Aug. Claff. IV. Artic. XX. pag. 2 s. item XViII. Verf. An. 1721. Menf. Dec. Clafi. IV. Art. VII. num. 2, pag. GIr. aliique: Quos tamen Georg. Everh. Rumpbius pro veris Brontiis 1. Donderfteenen in Amb. Rar. Kam, Lib. III. Cap. VIII. pag. 207. \& feqq. num.6.7.8.9, venditat, \& figuris æneis repræfentat. An ab Angvibus, unde Ova Anguina, ut vult Plinius Hift. Nat, Lib. XXIX. Cap.III. confulendus Ol. Wormius Muf, Lib. I. Sect. II. Cap, XII, pag. 76. it. Langius L. C. Part. II. Libr, VI, Cap. I. An operimenta Teftudinis aquatica in lapidem conyerfa, vid.Anf. Boetims Hift, Gemm, \& Lapid, Lib.II, Cap.CCLXIV. pag. 486.

25. Echini capitula petrificata radiolorum (S. 444.) del. \& defcr. Car. Nic. Langius in Hiftor, Lap. Figurat. Helverix Part, II. Libr, III, Cap. II. Tab.XX. pag. I23.

26. Echinitarum Radioli tenuiffime friati \& alii minimis punetis donati (S. 445.) del. \& defcr. idem Langius L. C. Lib. VI. Cap. I. Tab.VI. num. 1. 2.3.4. pag. 127 .

26. 27. Echinometræ Pelagii aculei Ariftotelis, f. Aculei digitati Echinometrx Rumpbii purpurei \& cinerei coloris petrefacti, in apice fafciis albis cineti, \& inferius fovea notati (S.1I4.) Echi- 


\section{ET ARTIFICIALIVM KVNDMANN. VRATISLAV. 231}

nus del. \& defcr. ap. Pbil. Bonannum in Recreatione Mentis \& Oculi Claff.II. num. 19. pag. 92. Pedes vel aculei delin. in Ephem. Nat. Curiof. Dec.11. An, \& II. Tab. III. pag. 56. it. An. IIX.pag. Irg. it. ap. Georg.Everh.Rumpkium im An. boinfch, Raric. Kam. Tab. XIII. Lie. D. fol. 30.

28:29. Echini marini pedes . Aculei petrefaeti nigri \& alii rutili longiffimi \& acutiffimi, fafciis albis circumducti \& inferius fovea notati, ubi papillis adhæferunt ( $\mathrm{S}$. 1 I 5 :) conven. cum delin. quam dedit Pbil. Bonannus in Recreat. Ment. \& Oculi Claff. Ir. num. 17. Lit.B. it. Georg. Everb. Rumphius Amb. Rar. Kam. Tab.XIII. Lit. E. fol. 30. Echinum cum aculeis in lappidem mutatum del, Ferrand. Imperatus Hift. Nat. Libr. XXVI. pag. 759.

30. Enorchis fubrubri coloris ex Regno Bohemix (S. 197.) del. \& defcr. Conr. Gefnerus de Figur. Lapid. Cap.I. pag. 13. it. Anf. Boctius Hif. Gemm. \& Lapid. Libr.II. Cap. CIII. pag.38r.

31. Entrochus, Spangenftein, radiis eminentibus in matrice territorii Spangenbergenfis Hafliæ (S. I 16.) fimil delineav. Petr. Wolfayt in Hift. Natur. Hasfix inferior. Tab.IV. num. 12. pag.3! defer. Anf, Boetius Lib. II. Cap. CCXXVIl pag. 4 Ir.

32. Entrochus radiis minutiffimis ferratis adhuc invicem conjun\&ीus (S. 117.)

33. Entrochus Hirfchbergenfis Silefia ex fluvio Bober tuberculis albis externe inftructus (S. 436.)

34. Entrochi columnares copiofiffimi majores \& minores faxo du. riffimo immerfi radiis eminentibus, articulis eleganter diftin fis in agro Nordhampton enfi Anglicano effosfi (S. 208.) conven. cum delin, Georg. Andr. Helwingii in Lithograph. Angerb. Part. II. Tab. IV. pag.IIT. f. Matrix Afteriarum Petri Wrolfarti in Hift. Natural. Hasfia Infer. Tab.II. pag. 28. it. G. F. Aiylit in Memorabil. Saxon. Subterran, Part. II. Relac. III. pag. 33.

35. 36. Entrochus cylindraceus major \& minor geniculatus \& arcuatus luteus ex XIV. Trochitis conftans, ita ut Radii unius alterius itriisinferantur (S. $118 . \& 299_{*}$ )

Prater fupra allegatos, Entrocbos defcripf. \& delineav. Mur. Calceolariani. Veronense Sect. III. pag.312. Car. Nic. Langizs in Hift. Lap. Figurar. Helvet. Parr. II. Lib. III. Cap. II. Tab. XX. pag. 63. Gearg. Ant. Volckmannus Silef. Subter. Part, I. Cap. V. 5. 22, pag. 162. fob. Henr. Locbnerus Mur. Besler. Tab. XXXV. piag. IOI. Micb. Bernb, Valentini Muf. Mufeor. Part.II. Cap. II. Tab.III. fig. 20. pag-17. 
9ob. Fac. Sibeucbzerus in Specim, Lithograph. Helvetic, pag. 2. it. in Ejusd, BeCchreibung der Natur - Gefchichte des Schweizzerlandes Part. I. num, 23. pag. 91. Dav. Sigm. Büttnerus in Rud. Diluv. Teft.pag. 27\%. ir. Fob. de Laët de Gemm, \& Lapid. Lib. II. Cap.XVII. pag. 138. Conr. Gefnerus de Figur. Lapid. Cap.V, fol. 89. Georg. Agricola de Nat. Foffil. Lib. V. Cap. XIV. pag. \{29. Secund. E. duard, Luidium in Lithophil. Britann. Ichnograph, pag. 114. habentur Entrochi pro Vertebris Spinx dorfi connexis animalis cujusdam marini fub nomine Ichthyofpondylorum, \& ap, eundem Epif. VI. pag. 135. pro fractis Stel. larum marinarum radiis. Conf. Georg. Everb. Rumpbii Amb. Rar. Kam. Tab. XVI, pag. 42. it. G. F. Mylii Memorabl. Sax. Subter, Part.II.pag.33.

Gammarolithes vid. Alveoli.

37. Gloffopetra Melitenfis longiffima \& læviffima coloris viridefcentis cum radice aurea, Natter-Zünglein ( $S_{132}$.) del, \& defcr. Ll. Aldrevandus Mur. Metall. Lib. IV. pag. 600.

38. Gloflopetra maxima Melitenfis cum radice nigra, 1 . Dens pifcis triangularis in acumen definens scbeucbzeri, (S.3II.) vid, Ejusdem. de Querel. \& Vindic. Pifcium pag. 20. accedit. ad delin. quam dedic Anf. Boetius Hift. Gemm, \& Lapid. Lib.II. Cap. CLXIIX, pag. 341,

39. Gloffopetra Melitenfis in matrice terrea alba (S.48I.)

40. Gloffopetra Daventrienfis albida fine radice (S.312.) hane delin.

fob. de Laëc de Gem. \& Lap. Lib. II. Cap.III. Fig. 3.pag. 104.

41. Gloff petræ Biberacenfes cinereæ parvæ (S.407.)

42. Gloffopetra Melitenfis coloris carnei minima, fine radice (S. 303.)

43. Gloffopetra recurviroftra lævis minima, fimillima dentibus Carchariæ vel Lamiæ pifcis, f. Ornithogloffum recurviroftrum minus coloris cinerei, cum radice nigra ( $\mathrm{S} .304$.$) talem delin.$ Job. Fac. Scbeucbzerus de Querel. \& Vindic. Pifcium pag. 21, feqq.

Glofopetras profapix mineralis \& lapides fui generis effe demonftravir Conr. Gefnerus; Anf. Boetius, Rob. Hoockius, Gob. Dan. Geyerus, Georg. Hier.Velfcbius, Joh. Reiskius aliique, qui Reiskius in Commentat. de Gloflopetris Lüneburgen-

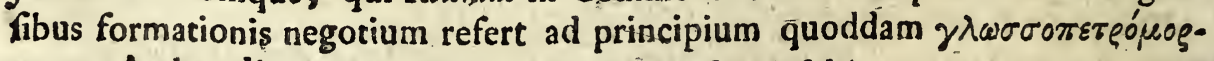
Qov, Animalis profapix effecontendit Andr. Cafalpinus, Petr. Poterius, Fabius Columna, Cajp. Bartbolinus, Paul. Boccone, $\mathcal{G}_{c}$. Incerti originis probant Ephem. Nat. Curiof. Dec. I. An. IX, \& X. Obferv. CXIX. pag. 28. feqq. G.F. asylius Memorab. Saxon. Subter. Part. II. Relat. IIX. pag. 73. Conf, Georg.

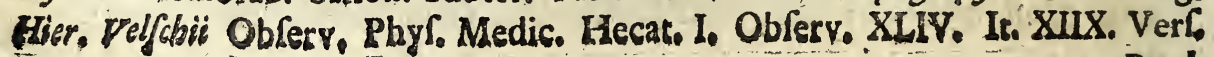
Bresle 


\section{ET ARTIFICIALIVM KVNDMANN. VRATISLAV.}

Breslo Nat, und iMedic. Gefcb. Aan. 1721. Menl. Novembr. Clafr. IV..Arr. V. pag. 487. fqq. XXV. Veri. Ann 1723. Meni. Auguft Claft. IV. Art. V. pag. 186. \& Obfervationem meam ibidem XX. Verf. An. 1722. Menf. Jun. Claff. IV. Art. V. pag. 597. Pro Lamiæ five Carcharix pifis dentibus habent foh. de Laët de Gemm. \& Lapid. Libr.II.Cap.III.pag. 103. Ol. Wormius Mur, Lib. I. Cap.X. pag. 67. it. Lib. III Cap.IX. pag. 272. Nic. Steno in Defcriptione Anatomica Canis Carcharix pag. 110. $\int$. in fine, qua habetur in Myologix

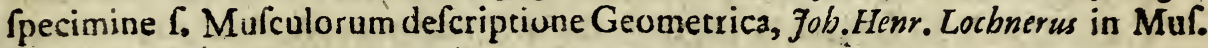
Beslerian. Tab. XXXIII. pag. Ioร. Car. Nic. Langius in Hift. Lap. Fig. Helvet. Tab. X. Lib. III. Cap. I. pag. 49. Dav. Sigifm. Büttnerus Rud. Diluv. Teft. §. 145. pag. 242. Petr. Wolfart Hift. Natural. Haflix inferior. Tab. XXI. pag. $45^{\circ}$ fob. Pbil. Breynius in Epiftol. de Melonibus petrefaet. montis Carmel. pag. 20. Pro inciforiis dentibus fub nomine Ichthyodontium culpidatorum, Eduard. Luidius Lithophil. Britann. Ichnogr. Capf.IX. pag.63. Unde

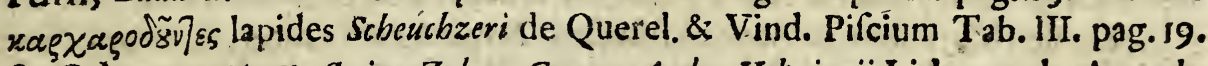
\& Odontopetræ Stein-Zabne Georg. Andr. Helwingii Lithograph. Angerb. Part.I. Cap. VI. Clafi. II. pag. \{9. Gloffopetras Meliteńfes alias defcripfit Mich. Bernb. Valentini in Mufeo Mufeor. Part. I. Cap.XXIV. pag.65. it. im Bedencken von Kuntt - und Naturalien-Kammern Cap.IX.pag. 18. Alszeienfes \& Flensheimenfes, Job. Dan. Geierus de montibus conchiferis Trai.II. pag.18. Mansfeldicas, V'alent. Alberti in Difr. Lipfix habita de Figuris variarum rerum in lapidibus \& Ppeciatim foffilibus Comitatus Mansfeldici : Lüneburgenfes, Anf. Boetius in Hift. Gemm. \& Lapid. Lib. II. Cap. CLXIIX. pag. 34r. prc. Fob. Reiskius in Comment. Phyfic. \& Hiftor. de Gloffopetris Luneburgenfibus pag. 27. Helveticas, Car. Nic. Langius in Hift. Lapid. Figurat. Helvet. it. Mifc. Nat. Curiof. Dec. II. An.IIX. Obferv. CXLIII. pag. 303. Holfaticas, Fob. Dan. Major in feiner Vorftellung etlicher Kunt - und Naturalien - Kammern: Boruffiacas, Georg. And. Heliving in Lithograph. Angerburg. Part. I. Claff. II. Sect. II. pag. \{9. feqq. 'Carniolas, Job. Weichert Valvafor in der Ehre des Hertzogth. Crains Tom.I. Cap. XXX. pag. 3'4. prc. Lib. IV. Cap. I. pag. 469. Silefiacas, Georg. Ant. Voirkmann in Silef. fubter. Cap. V. \$. 19.pag. 159. Je Ufu in Medicina fingulari vid. Mifc. Natur.Curiof. Dec. I. An. IX. \& X. pag. 289. it. Decur.III. An. IV. Obferv. LXXI. pag. 157. Foh. Reiskins de Gloffopetris Luneburgenf. pag. 42. Valvafor L.C. Tom.I. Lib.IV.Cap.I. pag.474. it.Mick.Bernh. Valentini in Mur. Mufeor. Part. I. Lib.I. Cap. XXIV. pag. 66.

44. Glottis Cardani flavi coloris, $\int$. Lingua animalis cujusdam ex quadrupeduin genere (S. I74.) conven. cum delin. \& defcript. Georg. Andr.Heliwingii in Lithogr.Angerb.Part. I. Cap.VI.Clafr.II. Tab. VII. Fig.8.p. 59. 
45. Hammites f.Oolithus ex monte Pörfulano Silef, prope Lands. huttum, fluore cryftallino infperfus, Rogen. Stein (S. 100.) defir. \& del. Georg. Ant. Volckmann Silef. Subter. Part. I. 5. 17. pag. is6. \& 168 .

46 Hammites f. Oolithus Querfurthenfis cinereus, in quo ovulorum quafi nembranx cum vitello confpiciuntur ( $(2.25$ ) conven. cum dei. \& defrr. Car. Nic, Langii in Hift. Lap. Figurat. Helver. Part. II. Lib. III. Cap.II. Tab. XIX. num, 2. pag. 67. it. D. S. Bïttneri in Ruder. Diluvianis 5.46. \& 47. pag. 244. Per microfcopium examinavit, \& cortices, albumen \& virellurn confpexit \& delin. Eranc. Erneft. Brückmanmus in Hitt. Naturali, Oolithi Fig. IX. pâg. 28.

47. Hammites albus in fuperficie ovulis adfperfus $\left(\mathrm{S}_{4}\right.$ 08.) Icon de. dit Georg Andr. Helwing in Lithograph. Angerburg. Tab. VII. fig. 2i. Oolitbum peculiari Schediafmate deicripfit Eranciff. Erneff. Brïckmannus, cui Titul, Specimen Phyficum exhibens Hiftoriam Naturalem Oolichi, f. Ovariorum Pifcium \& Concharum in Saxa mutatarum; Ubi fub finem Authores collegit, qui Oolithos diverforum locorum defcripferunt. Totos montes alias ex Hammire in Helveris allegat Joh. fac. Scbeucbzerus Natur -Gefchichte Part. I. pag. 106. it. in Suxunia G. F. Mylius Memorabil. Sax. Subt. Part. II. pag. 69. prope Weferlingam in Ducatu Halberftadienfi ad infinita millia centumpondiorum reperiri vid. Büut:kmannus L.C. S. II, pag. 23.

48. Hyfterolithus albus Geodem fimul referens, ex folfis argillaceis Lignicenfíbus Silefix, Mutter-Stein (S.260.) Silefiacos del. \& deicr. G. A.Volikmann Silef. Subrer. Part. I. Cap. IIL pug. 69. conveni, cum delin. ap. Perr. Wolfart Hitt. Nat. Huff. infer. Tab. XXIV. num. 5. pag. 30. it. in Ephem. Natur. Curiofor. Cent. III. \& IV. Obferv. LXXXVIII. Fig. IV, pag. 221.

49. Hyfterolithus in Sardoniche ( $\$ .248$ )

50. Hyfterolithus nigricantis coloris hemifpharicus mirabilis Arueturæ prope Caftrum Braubach in Comitatu Catimelibocenfiin. feriori erutus ( $\$ .240$.) hune defcr. Georg. Ernef. Tentzelius Colloquior. Menftruor An. 1694. Menf. Anguft. pag. 6i6. accuratifime fimul delineav. - Ol. Wormius Mur. Lib. I. Cap.XIII. pag. 83. Petr. Wolfart in Hiftor. Naturil. HarT. inferior. Tab. III. num. 4. \& ५. pig. 29. Car. Nic, Langius in Hiftor. Lap. Figurar. Helvet. Part. II. Libr. III. Cap. I. Tab. X. nam. I. pag. 48. pre. in \& extra matricem Fob. Melchior. Verdrics in Ephem. Natur. Curiofor. Cént, III. \& IV. Oblerv. LX. XXVIII. Fig. I. pag. 221. ubi pro Concharum apugraphis habet. 


\section{ET ARTIFICIALIVM KVNDMANN.-VRATISLAV. 235}

51. Ichthyites $f$. Lapis fifflis albus cum figura funduli pifcis aurea Eyftädtentis (S.550)

52. Ichthyiies talis in Dendroide ejusdem lóci elegantisfimus (S. 449.)

53. Ichthyites ex Bolga Valle Agri Veronenfis $\mathrm{r}$. Marmor album cum figura pirciculi tota exacte imr:efla $(\mathrm{S} 334$.) conven. cum delin. \& delcri fob. Henr. Lochneri in Mur. Beferian. Tab. XXXII. pag.93.

54. Ichthyites ilmenavientis in Saxo reniformi nigro ( $\mathrm{S}$ 482.) 55. Ichthyires $f$. Lapis fiffilis pifce inflexo nigro lævi confpicuus Bottendorffenfis (S. 129.) defcr. G. F. Mylius in Memorabil. Saxon. Subterr. Part. I. pag. 8.

56. Ichthyites $f$. Lapis Islebienfis fiffilis niger pifce metallifato fquamofo e Truttarum genere, f. fquamis aureo colore micantibus, refertus (S. 128.) defcr. Petr. Albinus in der Meifnifchen Berg. Chronica Tir XIII. pag. 105. it. Valentin. Alberit in Differt. de Figuris variarum rerum in Lapidibus \& fpeciatim in Foffilibus Comicarus Mansfeldici.

Icbthyite alias jam meminit Livius Lib. XLII. Cap. II. Fupenalis Satyr. XIV. Verf. 63. Seneca Notura!. Quxtt. III. Cap. XVII. aliique, quos Gasp. Schottus in Phyfic. curiof. Lib. X. Cap. XVI. pag. IIIG, recenfuit. Scriptores recentiores, qui lapidem defcripferunt, collegic Pbil. Fac.Sachs a Levenbeimb Gammarol. Cap. VII. pag. 122. feqq. it. Schottus L C. pag. I12O. quibus addendi qui pro Lufibus Nature eos haberit, ut VlyJ. A'drovandus Muf. Metall. Libr. I. pag. IOI. Ol. Wormius Mur. Lib. I. Seê. Il. Cap. II. pag. 38. Eduard. Luidius Lithophil. Britann. Ichnogr. Epitt. VI. pag. 135. Fob. Jac. Lungersbaufen de Imitamentis Naturx pag. 5. Mifcellan. Berolinenf. pag. Ic3. feqq. Pro Ichthyomorphis agnofcie atbanaf. Kircberus Mund. Subterran. Tom. I. Libr. VIII. Se.d.I. Cap. IX. Tab. III. pag. 34. Regq. Joh. Foacb. Becberus Specim. Subterran. Mixt. pag. 186. Pro Teftibus Diluvii fob. Gial. Bajerus Foffil. Diluv. univerfal. Monument. S. 16. pag.26. Dav. Sigifm.Bïttnerus Rud. Diluvianor. 5.138.-145. pag. 227・2 242.70b. WVodwardus Specim. Geograph. Phyficx pag. 13. feqq. in Prolegomen. it. Part. I. pag. 32. 56. 61. \& 155. Petr.Wolfart Hiff. Natural. Haff. infer. Tab.XII. - XX. fob. Henr. Locbnerus Muf. Besler. Tab. XXXII. pag. 93. Nonnulla colleg. Fob. fonfonus de Pifcibus Cap. VII. pag. 153. Inftar omnium vero effe poteft Gob. Gac. Sibeushzerus in Querelis \& Vindiciis Pifcium. Conf. Chrifian. Maxim. Spenerume in Mifcellan. Societat. Reg. Berolinenf. Tom. I, Fig.XXVI. XXXI. pag. IOץ. Muf. Calceolarian. Veronenf. Sea. III. pag. 428 . ubi multa genera defcr \& delin. it. obfervationem meam in Bresl. Sanimil. von Nat. und Med. Gefcbibt. XXV. Verf. An. I723. Claff. IV. Art, V. p. 186. 
57. Ocuii Serpentum Melitenfes (S. 470.) defor. Mich. Heberer pon Bretten in Asgyptiaca Servitute Libr. III. Cap. XVI. Hier. Megiferus in Delic. Ordi. num Equeftrium Cap. III. pag. 268. . Dentes molares pifcium fecund. 7ob. Pbil. Breynium de Melonibus petrefactis montis Curmel p.21. Oolithus vid. Hammithes.

58. Pes lapideus Capræ albæ fimilis in agris Maslenfibus Silefiæ repertus (S.341.)

59. Pediculus humanus ex Jafpide viridi ( $\mathrm{S} .45^{\circ}$ ) convénit cum de. - lineat. quam habet Georg. Ant. Volckmann in Siter. Subrerr. Tab. V. num. . it. Leonb. Dav. Hermann Maslograph. Tab. XI. continuar. nam. 82. prc. Job. Jac. Stheucbzerus Meteorolog. \& Ory Qlogr. Helvericx Fig. I 59.

60. Politus lapis pyramidalis, in quo facies barbata a natura efformara (S.19i.)

61. Alius faciem fœmineam exprimens (S.192.)

62. Alius fpinam dorfi animalculi referens. (S. I87.) convenit cum delin. quam dedic Carol. Nico Langius in Hift, Lapid. Figurat, Helvet. Part. II. Lib.MII. Cap. I. Tab.XI. pag. \{I.

Tales lapides are incifos repreientant ul:Aldropandus Mur. Metall. Lib. IV. pag. 541. feqq it. pag. 726. Atbanaf. Kircbsrus Mund. Subterran. Tom. Il. Libr. V. Sea. UII. Job. Jonftonus Thavnatograph. Cl.IV. Cap. XVIl. Jac. Gaffarellus in Curiofitatib. inauditis Cl. V. Cap.XI. Leonb.Dav. Hermann iil Maslograph.'Tab. XIII. pag. 227. Georg. Andr. Hething in Lithograph. Angerb. Tab. VII. \& XII. Part. I. G. F. Mylius in Memorabil. Saxon. Suberran. Part. I. p. 73. feqq. Conf. Th. Bartbolini Epiftol. Medicinal. Cent. IIT. Epift. VIII. pag. 3r. it. Obferpationem meám in Bresl. Samml. XXV. Verf, Ann. 1723. Claf. IV. Art. V. pag. 183. feqq.

63. Perca pifcis lapis (S.343i) del. \& defcr. Car. Nic Langius in Hifl. Lap. fig. Helver. Part, II. Lib. III. Tab. XX. pag. 5 T.

64. Pröafites f. Lapis corneus niger ex montibus cretaceis Norwegiæ, mufculum lumbarem infantis exacte reterens ( $S_{\text {. 339.) }}$ Ejusmodi lapides partes hominum \& animalium referentes del. \& defcr. $\mathrm{ll}$. Aldrovandus in Muf. Metall. Lib. IV. p. 481. feqq. aliique.

65. Serpentinus lapis diverfarum flexurarum \& colorum Zeblicenfis, Serpentin - Stein (S.31 8.) defr, G. F. Mylizis in Memorabil. Saxon. Subeerran. Part. I. Rel. IV. p. 3I.

66. Serpentinus lapis Plinii ad Lacædemonium accedens (S. 49i.) vid. Valuafors Ehre des Hertzogth, Crains Tom. I. Lib. III. Cap.XXX. p. 43 I. 


\section{ET ARTIFICIALIVM KVNDMANN. VRATISLAV. 237}

67. Serpentinus lapis alius Rochlicenfis, f. Ophites (S.241.) id. My/ius L. C. Part.I. pag.72.78. it. Sam. Fabritius in Cofmotheor. facra Cap. XXXIll. pag. 43 I.

68. Trochitæ Beuthenæ Silefiæ fuperioris elegantes perforati, \& a foramine ad peripheriam diverfimode ftriati, Rädervoder Mübl.Steine (\$. 23.) del, \& defcr. Giorg. Ant. Volckmannus Sil. Subterran. Tab.XXVII. Part.I. Cap.V. pag.16r. \$.22. num.g.io.11. conven, cum deliu. quam dedit Erid. Lacb.

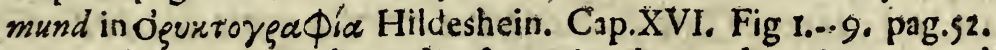

69. Trochitis \& rotulis cylindraceis plenus lapis totus politus (S.184.) Simil. delin. \& defcr. Conrad. Gefnerus de Figur. Lápidum Cap.V. pag.89. \& ex eo Ant. Boetius in Hiftor. Gemmar. \& Lapid. Lib.Il. Cap.CCXVII. pag.410. Fob. de Laët de Gemn. Libr.II. Cap. XVII. pag. 138. OL.WVormius Muf, Libr. I. Cap. X. pag.70. Ul. Aldrovandus Muf. Metall. Libr.IV. pag.624. Petr. Wolfart Hift. Natural. Hafro infer. Tab.IV. num,1.-1 12. pag.31,

Sunt autem Trocbite fecund. Eduard. Luidium in Ichinograph. Lithophil.Britann. pag. 31. \& Ir4. Vertebræ fpinæ dorfi animalis cujusdam marini; lecundum Volckmannum Sil. Subcerr. Part. I. Cap.V. pag.I61. partes fpina dorfi pifcium cartilagineorum ; fecund. Luidium Epift.VI. pag. I35. it. Langium Hift Lapid. Figurat. Helvet. Part.II. Libr.111. Cap.11. pag.65. Articuli capitis Medufæ, $f$. Stellæ marinæ quintæ fcolopendroides, quarn Georg. Everb. Rumpbirs in Amb. Rarit. Kam. pag.4I. delin. Conf. Mufeum Calceolar Sect.III. pag.3ir. Georg. Andr. Heliwingii Lithograph. Angerburg. Part.11. Cap.IV. pag. IIG. it. G. F. Mylii Memorabil. Saxon. Subterran. Rel.JII. pag.136. An LufuS Naturæ vid. id. Mylius L. C. pag.32. it. Dav.Sig. Büttner in Ruder. Diluvian. it. in Coralliograph. Subterr. pag.275.feqq. An incertæ originis vid. id. Büttnerus in Rud. Dil. pag. 186. it. Job. Fac. Bajerus in Oryct. Noricx pag.31. \& 48. de Viribus inedicamentofis vid. Lacbroundi Oryctogr. Hildesheimenf. p. ¡t. 70. Variolites viridis maculis rotundis albis depictus Lucernenfis, Mafern-oder Pocken. Stein (S.483.) del. \& defcr. Carol. Nic. Langius in Hift. Lap. Figurat. Helvet. Part.II. Cap.V. Tab.X. pag.40.

7I. Variolites rariffimus ex atro viridis tuberculis albis confpicuus (S.310.) fimil. del. \& defer. ul. Aldrounndus in Mur. Metallic. Lib.IV: Cap. LXVII. p.883. \& ex eo Mich. Bernb. Valentini in Mur. Mufeor. Part.I. Cap.XIS. pag. $\{$ r. Borufliacos defcripf. Georg. Andr. Heliwing in Lithograph. Angerh. Part. I. Claff.II. Sect. I. \$8. Tab.VII. fig. 7.- Scoticos, Rob. Sibbaldus Scor. illuftrat. Part.II. Libr.IV. p.I49. de Pretio vid, Petr. Pometii in Anmerckungen des Ma. serialiften pag. 898 . 


\section{PROMTVARIVM RERVM NATVRALIVM}

72. Vermicularis lapis politus coloris terrei flexuris albis ( $S_{1}$ 166.) 73. Vermicularis lapis niger marinus ubique tuberculofus (S.25.) 74. Vermiculares tubuli, .. Tubulites Vermicularius (\$ 57.) vid.Eduard. Luidius Lithoph. Brit. Ichn, num.12iz. feqq.

$$
\begin{aligned}
& \text { Claffis IV. } \\
& \text { Lapides } \mathrm{E}^{\prime \prime} \mu \mu \rho_{\rho} \Phi_{06} \text {. Figura certägaudentes } \\
& \text { ex Tranjmutatione. } \\
& \text { ARTICVLVS I. }
\end{aligned}
$$

Vegetabilia quædam eorumque partes, partim petrefactæ, partim tartarifatæ.

1. Anthracodendron Sangershufanum (S. I38.) vid. Dav.Sigifm. Büttne$v i$ Rud. Diluv. Teft. p.303. prc. Fob. Jac. Scbeucbzeri Meteorol.\& Oryctograph. Helvet. pag. 240.

2. Dendrita cum Equifeto paluftri fetis longioribus Landshuttenfis (S. 60.) del. \& defcr. Georg. Ant.Volckmann Silef. Snbterr. in Appen. Tab.IV. Fig. VII. psg.333. fimilem quoque delin. \& defcr. G. F. Mylius in Memorabil, Saxon. Subterr. Part.I. Fig.I2. p.30. Fob. Jac. Scbeucbzerus in Herbar. Diluv. Tab. I. Fig.III. \& V. pag.II. it. Mifcell. Berolinenfia pag.99. Fig.XXIII.

3. Dendrita cum Filicula petrefaeta fontana, folio vario Tournefortii ex Ducatu Svidnicenfi Silefix prope Altwaffer (S.6I.)

4. Dendrita cum Filicula petrefacta foemina I. Tabernæmontani ejusdem loci (S.62.)

5. Dendrita cum Filicula petrefaeta \& foliis impreffis femen ferentibus Planitzenfis prope Cygneam (S.55I.)

6. Dendrita cinereus Rothenbachenfis, cum Filicula fontana majori, C. Adiantho albo Filicis folio (S.63.) accedit ad del. \& defcr. Job. Jac. Scbeucbzeri in Herbar. Diluvian. Tab.I. Fig.VII. pag.i6.

7. Dendrita f. Folium Betulæ in Lithomarga fubrubra (S.335.) fimil. del. \& defcr. lll. Aldrovandus in Muf. Metallic. Lib.IV. Tab.I..-VI. pag.848.-854. it. Carol. Nic. Langius in Hift. Lapid. Figurat. Helvet. Part.II. Tab.vI. Cap. IV. pag. 40 .

8. Dendrita f. Folium Alni petrefactum topho inclufum ex Fonte Principis prope Jenam (S.422.) Tales del, \& defcr. G. F, Mylius Memo- 
rab. Suxon. Subter. Part I. pag.69. it. Georg. Andr. Helwing in Lithugraph. Allgorb. Part.I. Cap..VI. ClanI. Sect.II. Tab.11. Fig. 4. \& 5. prc. Job. Far. Scbcucb. zerus in Herbar. Diluv, pag. 98. nuni. 408. Tophus talis candidus Mifenus, in quo folin zuercus \& alni ita funt imprefla, defcr. \& del. gob. Kentmannus in Catalogo Rer. Fulli. num.38. prc. Car. Nic. Langius in Hift. Lap. Fig. Helvet. Part.II. Libr.III. Cap.II. Tab.XVI. pag.54. Modum fiendi defcripf. Scbeucbzerus in Epiftol. ad Lochnerum, qux reperitur in Epbem. Nat.Curiof. Dec.III. An.V. \& VI. in Append. pag.79.

9. Dendrita in lapide fiffili albo Anglicanus, cum Rubia anguftifolia fylveftri ( $\mathrm{S}_{424}$ ) conven. cum delineat. quam dedit Georgius Ant. Volck. mann Silef.-Subterr. Part.I. Cap.IV. Tab.XV. num.3. pag.II2, R. cum Gallio albo vulgari \& facie arundinea ftriata ap. fob. fac. Sbeucbzerum Herbar. Diluv. Tab.IV. numi.r. pig.19.

10. Dendrita f. Afphodeli folium ftriatum \& petrefactum (S.384.) II. Dendrita-f. Lapis fisfilis Manebachenfis, Ducatus Saxo-Grathani in Thuringia niger, cum Filice ramofa \& punetis impresfis, feminum rudimenta indicantibus (S. 332.) defcr. ex G. F. Mylli Memorabil. Sixon. Subterr: Part.I. Rel.IV. pag.17. Micb. Bernb.Valentini in Mufeo Mufeor. Part.II. Libr.I. Cap.V. pag.32.

12. Dendrita $\int$. Filix mas folio dentato, ex fodinis carbonariis Wettinenfibus prope Halam Magd. (S.421.) Similes del, \& defcr. fob. fac. Scheucbzerus in Herb. Diluv. Tab.II. Fig.lII. pag.1\%.

13. Dendrita cinereus ex fodinis Lithanthracum ad pagum Altwaffer, duobus a Svidnicio milliaribus, cum Fumaria officinarum Bauhini,cui multum fimul ftraminis nigri compreffi ineft (S.216.) Accedere videtur adIconem ratione ftraminis geniculatiap. Fob. Fac. Sc beucbzerum in Herbar. Diluvian. Tab.III. Fig.IV. pag.I9. Fumariam vero hanc hoftram del. Georg. Ant. Volckmann in Silef. Subt. Tab.XIV. Fig.2. pag.IIt Conf. Leonb.Dap. Hermanni Mas!. pag.203.

14. Dendrita talis cum arundine, fecundum Volkmannum faccharina anticulata (S.423.) del. \& defrr. in Siler. Subterr. Tab.XIII. fig. 7. pag. nro. 15. Dendrita ibidem erutus cum Pinu fylveftri Tabernæmontani (S.425.) del. \& deffr. frepius allegatus Volckmannus L.C. Tab.XIV. num.4. pag. III.

16. Dendritæ tabula maxima colore albo \& rubro variegata elegántiffima, in quo Filix ramofa mas, pinnulis obtufus mucronatis \& folia Afphodeli exacte ita impreffa, ut in lapidis parte akera præ. 
mineant, in altera vero inftar moduli excaventur, Conradswaldauentis Silefiæ prope Landlihuttum ( $S_{215 *}$ ) del. \& defcr, id. Volckmannus L.C. Cap.IV. pag.I06. \$.28. Tab.XI. num.2. \& 3.

17. Dendrita cinereus $f$. Apium ruontanum ampliori folio Anglicanum (S.67.) de Anglicanorum in carbonariis maxima copia vid. Guiliel.Camdenus in Britannia pag.692.

18. Dendrita C.Excrefcentia Cynosbatos eleganstota, cum foliis multis, topho fubrubro duriffimo incruftata (S.534.)

DeDentrizis ex Diluvio univerfali remanentibus vid, 7ob. fac. Scbeucbzerus in Herbario Diluv. Tab.I. num.3.4.7. Tab.II, num.8. Tab.Ill, num.3.8. Tab.IV. num. 5.I0. Táb.XXII. it. Ejusdem Meteorol, \& Oryctugraph. Helvet. pag.203. Conf. Scbeus bzeriEpiftol. ad Losbnerum, que repericur in Epbem. Nat. Curiof. Dec.III. An.V. \& VI. in Append. pag.78. vi.J. quoque G. F. Mylius in Memorab. Saxon. Subt. Part.I. Rel.III. pag.24. D. S. Bü̈tnerus in Ruder. Diluv. Teft. S.121. pag. 192. pre. Géorg. Ant.Volckmannus Sil, Subt. Libr,I. Cap.IV. S.29. pag.106.--114. Tab.XI.XII.XIII.XIV.XV.

19. Elatites $f$ : Fruftum Ligni abiegni petrefactum, in quo color \& fibra exacte adhuc difcerni poffunt prope Caffelium (S.IO4.) del. \& defer. Conrad. Gefnerus de rerum foffilium, lapidum \& gemmarum figuris fol.125. Ol. Wormius in MuS. Lib.I. Cap.XIII. pag.89. Ferrand. Imperatus Hift. Natural, Lib.XXIV. pag.752.feqq. Georg. Andr. Helwing in Lithograph. Angerb. Part.I, Cap.VI. Claff.I. SeE. II. pag.4I. Tab.II. num.6. nominatur ap. Scheuch. zerum in Appendice Herbarii Diluvian. num. 575 . pag.109. Modum petrificandi demonftravit fob. jac. Liebknecbt in Difcurfü de Diluvio maximo occafione inventi in mineram ferri mutati ligni,

20 2i. Fungitæ Maslenfes majores \& minores tophacei, pileati, favaginofi \& alii (S.29.) del. \& defcr. Leonb. Dav. Hermann in Maslograph. Part.II. Cap.IX. pag.219. Tab.XI. num. 1.--6. Georg. Ant. Volckmann Silef. Sub. terr. Cap.IV. \$.70, pag. I37. Tab.XXIV. \& XXV. Conf. Ul, Aldropandi Muf. Metallic. Libr.IV. pag-495.feqq.

22. Fungitæ petrofi Angerburgenfes naturalibus fungis colore fimiles (S.400.) del. \& defer. Georg. Andr. Helwing in Lithograph. Angerburg. Part.I. Cap.IV. Claf.I. SeEt II. pag.40. Tab.II. num.2. Alios delin. \& defcripf. ull. Aldrovandus in Muf. Metallic. Libr.IV. pag.495. Mufeum Calceolarian. Sect. III. pag.4.17. Car. Nic. Langius in Hiftor. Lap. Figurar. Helvet. Part.II. Libr.III, Cap.II. Tab.XII. pag. \{2. prc. Job. Henr. Lochmerus in Mufeo Besleriano Tab.XL. pag.IIo.fegq. 
ET ARTIFICIALIVM KVNDMANN. VRATISLAV. $24 \mathrm{~T}$

23. Gramen Tartaro rubro totum incruftatum ex Thermis Carolinis (S.290.)

24. Clethrites f. Lignum Alni poft 200. \& fupra annos incorruptibile, ex metallifodinis Sylvæ Hercynix erutum. (S.352) De ligno tali in lapidem indurato vid. Georg. Andr. Helwing in Lithograph. Angerburg. Part.II. Sect. II. Cap.II. \$. 6. pag IOI. it. Erafm. Erancifci in Olt-und Weft-Indifch. Luft-Garten Part.I. pag. I33.

25. Lignum fosfile nigrum Diebenfe ad Muldam Alumine prægnans, 3. leucis a Lipfia (ubi fitus toci \& alix circumftantiæ oftendunt, non a particulari inundatione hoc lignum deduci poffe) (S.432.) vid. Job. Fac. Scbeucbzerus in Mufeo Diluviano pag.9. num.125.

26. Lignum fosfile birumin ofum, feu Matrix Succini Hartmanni fine,

\& cum Vitriolo, ex littore maris Baltici (T.96.) defcr. Georg. Andr. Helwing in Lithograph. Angerburg. Part.11. Cap.V. S.7. p.74. it. unfere Samml. von Nazur. und Medic. Gefchicbt. V. Verf. An.1718. Menf. Jul. Claft.IV. Art.XII. pag.1397.

27. Lithoxylon argentei (plendoris f. Argyroplites Aldrovandi in Svecia prope Portum Caroli frequens (S.137.) vid. Ejasdem Muf.Metall. Libr.I. pag.86.

28. Lithoxylon C. Lignum petrefactum Landishuttenfe ex m.onte Pörfulano vulgo Trinck-Tobis ditto (S.1 4l.)

29. Lithoxylon late ftriatum, ibidem ex monte Kirchberg erutum (S. 139.)

30. Lithoxylon lineis rectis \& transverfis cancellatum (S.438.)

31. Lithoxylon denfe ftriatum \& nodofum ejusdem loci (S.328.)

32. Lithoxylon ita ftriatum non nodofum (S.I40.)

33. Lithoxylon ftriatum per matricem lapideam tranfiens (S.39r.)

34. Lithoxylon ftriis minutisfimis infignitum (S. 386.)

35. Lithoxylon matrici lapidex firmiter connexum (S.392.)

36. Lithoxylon Landishuttenfe cortice fuo adhuc veftitum (S.393.)

37. Lithoxylon aliud ftriatum \& articulatum prope Lubecam ad pagum Behlendorff, 3. mill. a Lubeca (S.142.)

38. Lithoxylon fiftulofum cum radicibus (S. I34.) conven. cum delineat. ap. Ferrand. Imperatum Hiftor, Natural. Lib.XXIV. pag.758. \& Virgultis petrificatis ap. Car. Nic. Langium in Hift. Lapid, Figurat. Helvet. Parrt.II. Libr. III. Cap.II. Tab.XIV, pag. 53 . 
39. Lithoxylon f. Arundinites ftriatus \& nodofus aldrovandi (S. 135.) vid. Muf. Metall. Lib.IV. num.2. pag. $8 \$ 4$.

40. Lithoxylon in quo cortices evidentiffimi ex montibus arenariis Querfurtenfibus (S.523)

41. 42. 43. Lithoxylon nodofum, it. aliud cum rudimentis ramorum (S.135.136. 137.) Ligna hec perrefaca Landishurtenfia del. \& deferr. Georg. Ant. Volckmann in Silef, Subterr. Cap.IV. Tab VII. VIII. IX. \& X. pag.92. feqq.

Cxterum de Lignis allis in lapidem mutatis jam dudum peculiaris Liber Italico fer. mone prodiit, cui Titulus Francif. Stelluti Trattato del Legno fofile minerale nouvanente fcoperto nel quale brevemente fi accenna la varia \& mucabil natura di detro legno, qui in Latinam lingvam translatus \& Ephemerid. Nat. Curiofor. Dec. 1. An.llI. pag.606. Appendicis loci annexus; Cui jungendi Fob. Fac. Beckman. nus in Hiftor. Orbis Terrarum Geograph. \& Civil. Car. Nic. Langius in Hiftor. Lapid. Figur. Helvet. Part.II. Libr.III. Cap.II. Tab.XV. pag.54. D. S. Büttnerus in Rud.Diluv. Teft. pag.187.feqq. Fob. Guil. Bajerus in Foffil, Diluv, univerfal. Monument. \$.3. pag.5.Seqq. prc. Fob. Jac. Scbeucbzerus in Herbar. Diluv. pag. 40.feqq. Originem lignorum in lapidem mutatorum demontr. Atban. Kircberus in Mund.Subterr. Tom.II. Libr.VIII. Sect.III. pag.65. Joach. Billinger de Bitumine \& ligno Foffil. Henr. Oldenburgius in Aat. Soc. Reg. in Angl. An.1665. it. Fob. 7ac. Bajerus in Oryctograph. Norica Cap.VI. pag. 53. Bresl. Samml. von Nat. und Metic. Gefch. IX. Verf. An. I719. Menf. Seps. Claff. IV. Art. X. pag.359.feqq. De fitu fingulari vid. Mart. Scbookius de Turfis pag 90. 7ob. Fac. Scbeucbzerus in Herbar. Diluv. pag.4r. Conf. Micb. Bernb.'Valentini Múf. Mufeor. Parr.ll. Cap. IV. pag.25. Multorum delineat. dedit Ll. Aldrovandiss in Muf. Metall. Libr.IV. pag.848. feqq. qux tamen omnia pro Lufibus Naturæ agnofcit, cui confentit $\mathrm{Val}$ vafor in der Ehre des Herzogth. Crains Tom.l. Libr.IV. Cap.II. pag.477.

44. Müfcus ex Fonte Principis Jenenfi cum Topho (S.243.)

45. Mufcus ibidem totus in lapidem mutatus (S.376.) vid. phil. gas. Sacbs in Differr. Refponf, de mirand. Lapid. natura, ad Gob. Dan. Majorem fo in Epitol. de Cancris \& Serpent. petrefact. pag.70.feqq. Conf. Job. Dan. Geyerum in Ephem. Nat.Curiof. Dec.II. An.V. Cap.III. S.7.

46. Niufcus Topho totus incruftatus ex Fonte prope Francofurtum ad Viadrum (S.244.) vid. Job. Cbrifoph. Becmanni Notitia Univerfitatis Francofurtanx Cap.III. pag.3\%.

Modum petrificandi \& incruftandi explicavit 疋ob. fac. Bajerus in Ory gographia fua Norica pag.49.50.51. it. Fob. Henr. Scbütteus in Ory gograph. Jenenfi Cap.lit. 6.20. pag.31. Ejusmodi Aqux omnia injeat in lapidem mutantes paffim reperiuntur in Islandia, quas defcr. Dietbmarus Blefkenius in Defcriptione Islandia Cap.VI. 
ET ARTIFICIALIVM KVNDMANN. VRATISLAV. 243

Cap.VI. pag.50. Peruvia fontem habet, qui ferverri aqua fcater lapidefcente te. te $P$. Laurenbergio in Acerra Philologica Cent.IV. Hift.LIII. pag.645. Et Narva in Rufis ejusmodi aquam invenic Adam Olearius vid. Perfianifche Reife-Befchr. Libr.II. Cap.X. pag.II6. plures ciustnodi Aquas defer. Pbil. Fac. Sacbs a Lewen. beimb in Differt. Fpifol. fupra citat. pag.7c.ferq. \& in Gammarol. Lib. I. Cap. VIII. p3g. 170. feqq. Conf, Boetium in Hif. Gemm. \& Lapidum Libr.II. Cap, CCC. pag. s31.feqq.

47. Porus cervinus petrefactus Imperati totus fpongiofus (S.363.) vid.Hilt: Natural. Libr XXVII. Cap.IV. pag.820.

\section{ARTICVLVS II.}

Animalia Teltacea univalvia \& bivalvia, corumque partes petrefacta, item aliis lapidibus infixa.

1. Chama lævis, margine in acien demifra, interne continens lapidem fluctuantem (S.324.)

2. Chamites elegans valvis claufis ex lapicidina Querfurtenfi (S 402.) conven. cum delin. ap. Job. Jac. Sibeucbzerum in Meteorol. \& Oryctogr. Helverica fig. 85. pag. 294 .

3. Concha coftis eminentibus inftructa bivalvis (S.315)

4. Concha Anomia lævis in matrice roftro prominulo incurvo ex lapide calcario prope Querfurtum (S.33.) conv. cum del. \& defrr. Carol. Nic. Langii in Hift. Lapid. Fig. Helvet. Libr.VII. Cap.VII. Tab.XLIX. num. 2. \& 3. pag. I58.

5. Concha Anomia roftro prominulo ex agris Noricis major \& minor $\left(S_{3}\right.$ 6.) del. Job. fac. Bajerius in Oryctograph, Norica Cap.VIII. Tab.V. fig.26. pag.79.

6. Concha Anomia . Terebratrula Luidii ftriata, valva fuperiore ventricofa, inferiore lacuna donata Helvetica (S.446.)

7. Concha Anomia Jenenfis in Jafpide rubro ( $S .37$.)

8. Concha Anomia roftro quafi pertufo prope Kuntzendorff in Silefia (S.38.)

9. Concha Anomia maxima \& Peefunculis confpicuum Marmor incarnatum ex Archiepifcopatu Salisburienfi (S.55.) Simil. delin. Job. 7ac. Scbeuchzerus in Meteorol. \& Oryctograph. Helvetic. pag. 121.

10. Concha Anomia duriffima ex Comiratu Neocaltrenfi Anglix (S.97.) 
11. Concha ftriis latioribus ex agris Noricis (S.I65.) del. Job. Jac. Bajerus in Oryctograph. Nor:c. Cap.VIII. Tab.V. Fig.9. pag.78.

12. Concha maxima circinata in matrice ejusdem lapidis (S.518.) 13. Conchifera arena Heidenheimentis (S.553.) vid. Ephem. Nat. Curiof. Cent.I. \& II. pag.276.

14. Conchifera arena ex lacu Comitatus Mansfeldici falfo (S 554.) vid. Petr. Chriftiani Wagneri Differt. de Lapidibus Judaicis Can. III. S.14: p.40. 15. Conchinula ftriata impreffa lapidi lævi duriffimo prope Coburgum (S.89.)

16. Conchites cum pe?tunculis ftriis altioribus colore fubnigro exaratis (S.28.) conven. cum delin. qux habetur in L, D. Hermanni Maslograph. Tab.XI. num. I. pag.2Ir.

17. Conchites talis elegantisfimus coloris flavefcentis, externe po. litus agri Bafileenfis (S.92.) vid. Wagneri Hift. Natural. Helver. pag.22I. reqq.

18. Conchites magnus nón ftriatus planus in lapide Calcario (S.34) talem exhibet Petr. Wolfart in Hiftor. Natural. Hasfix infer. Tab.IV. num. 15. pag.32. it. Georg. Ant.Volckmann in Siles. Subter. Part.I. Cap.V. Tabul.XXXIV. num.7. pag.185.

19. Conchites politus, punctulis albis, rubris \& cinereis ubique adfperfus (S I88.)

20. Conchites cinerei coloris in lapide polito annulo \& turbine fimul notatus (S.I89)

21. Conchires egregius in lapide calcario durisfimo Legerii Montis. (S.517.)

22. Conchites fubviridis politus, notulis cylindraceis \& quadratis confpicuus (S.196.)

23. Conchites pyramidalis totus politus (S.19r.)

24. Conchites cum aculeis entrochiformibus articulatis $(5.383$. conven. cum delin. \& defcr. Georg. Andr. Helwingii in Lithograph. Angerb. Part. I. Cap.V. Tab.I. num.12. pag.32.

25. Conchites pefunculis \& entrochis cylindraceis articulatis plenus (S.40.) del. Georg. Andr. Helwing in Lithugraph. Angerb. Tab.I. Fig.XII. pag.33.

26. Conchites cum pectunculis argentei fplendoris, ftriis capillaribus, prope Schoenbrunn Duc.SvidnicenC. Siles. $\left(S_{.42 .}\right.$ ) tales argen- 
ET ARTIFICIALIVM KVNDMANN. VRATISLAV. 249

rei fiplendoris conchas del. \& defcr. lll. Aldrovandus in Muf. Metall. Libr.I. pag. 88. feyq.

27. Conchites cum pectunculis f́plendentibus aliis, ejusdem loci

(S.44.)

28. Conchites pectunculis ftriatis plenus, prope Camerau ad Svidnicium (S.43.)

29. Conchites durisfimus, qui fruftulum ligni cum cortice inclu$\operatorname{dit}($ S.59.)

30. Conchites territorii Würtenbergenfis, inter lapides calcarios frequens (5.70.)

31. Conchites Anglicanus, $\mathrm{C}$. Maffa egregia, ex durisfimarum concharum teftaceis fosfilibus compacta (S.193.)

32. Conchites, Ferri minera adnatus, $\mathrm{f}$. Mineræ Martis conchis fimul referta, ex monte Odenberg, haud procul ab urbe Gudens. berga Hasfia (S.131.) Mineras Martis has conchis refertas del. \& defcr. Petr. Wolfart in Hiftor. Natural. Haft, inferior. Tab.XI. num.1. \& 2. pag.4 $\mathrm{r}$.

33. Conchites pectunculis diverfe magnitudinis refertus Islebienfis (S. 54.)

Echinitæ f. Lapides Echinos marinos referentes vid. fupra Claf. III. Art. 1.

34. Mufculites fafciatus \& ftriatus Maslenfis (S. 56.) del. \& defcr. Leonb. Dav. Hermann in Masleograph. pag.213. Tab. IX. num. 39.

35. Mufculites in matrice ex utroque cardinislatere æque diffufus, ex agris circa Lürgeren Comitatus Badenfis ( S. 519. )

36. Mufculites rariffimus ex Comitatu Neocaftrenfi A nglix, C.Ta.

bula maxima lapidea ex Mufculis marinis \& alis Conchyliis item-Vertebra dorfi humana accuratiffime compacta. (S. 120.) Accedit ad delin. ap. Petr. Wolfart in Hiftor. Natural. HarT. infer. Tab. IX. pag. 37. it. D. S. Bürtnerum in Rud. Dil. Teff. Tab. XXIIX. pag.264.

37. Mufculites Kleinfteinenfis ex Ducatu Oppavienfi Silefix (S. 433.)

38. Mufculites rugofus in lapide arenofo ex littoribus Albis prope

Pirnam. (S. 415) conven cum delin. Chamit. ap. Langiuse in H.ff. Lap. Fig. Helvet.Lib. Vul. Cap.I. Tab.XXXIIX. num. 5. p. 138.

39. Mynlus lavis in calculo grifeo ex fluvio Silef. Katzbach dito (S. 4I.) 
40 Mýtilus totus petrefactus valvis clautis Querfurrenfis (S.402.) conven. cum del. \& defer. quam dedit Petr. Wolfart in Hiftor. Natural. Haflize infer. Tab.XI, sum. 3. pag. $4 \mathrm{r}$.

41. Mylitus ex lapide arenario compałus, fimilis Mytiloide Humberiano Liidii ( S. 493.) vid. Lithophil. Britann. Ichnograph. Tab. VI. Clati. V. num. 896 . pag. 43 .

42. Nautilites, vulgo Cornu Ammonis difcoides elegans coloris badii, interne continens lapidem fluctuantem (S.2.)

43. Nautilites filiceæ fubftantiæ totus árticulatusagri Altorfini, ditionis Norimbergenfis (S.3) del. \& defcr. Job. Jac. Bajerus in Oryctograph. Norica Tob.III.Fig. V. pag. 6 ;

44. Nautilites in matrice ex Marchionatu Byruthino (S. 4.) conven, cum delin. in Ephem. Natur Curiofor. Dec. I. An. III. Obf. LX. Lit.A. 45. Nautilites in matrice rubra corallina. (S.7.)

46. Nautilites in matrice non articulatus montis Legerii (S.87.) vid. Foh. Fac. Stbeucbzerus in Meteorol. \& Oryctogr. Helvetic. p. 254.

4\%. Nautilites hæmifphæricus valde articulatus prope Querfurtum $(\mathrm{S}, 22 \mathrm{I}$.

48. Nautilites in particulis ibidem effoffus ( S.342.)

49. Nautilitæ mire articulati \& Atriati particula f. Cornu Ammonis friis valde denfis \& eminentibus undatim incurvatis, \& in fpinam fulcaram abeuntibus frufum, ejusdem loci ( $S .222$.$) con-$ ven. cum delin، ap. Carol. Nicol. Langium in Huttor, Lapid. Fig. Helvet. Part. II. Lib. IV. Cap. IX. Tab. XXIV. num. 3. pag.95.

50. Nautilitæ Querfurtenfes in matrice lapidea duriffima (S.394.) del. Dav. Sigifm. Büttmerzs in Rud. Diluv. Teftib. Tab. XIII. Similes del. \& defcr. G. F. Mylius in Memorabil. Saxon. Subterran. Part. I. Relar. 9. pag. 67. Georg. Andr. Helwing in Lithograph. Angerb. Part. I. Cap. VI. Claft. II. SeQ.III. pag. 67. Tab.VIII. Fig. I. it. Car. Nic. Langies in Hift. Lap. Fig. Helv. Part.II. Lib. IV. Cap. XI. Tab. XXIIX. pag. 100.

5I. Nautites politus friis eleganter undulatis ejusdem loci, concamerationibus fluore cryftalino infaretis' (S. 395.) tales delin. \& defcr. Dav. Sig. Biutuneres in Rud. Diluv. Teftib. Tab. XIV. num. 2. \$. 163. pag. 273. elegantius delin. Petr. Wolfart in Hift. Natural. Haff. infer. Part. I. Tab. VII. num, 2. \& Tab. VIII. num. 6. pag. 36. \& 37. it. fob. Reiskius Tr. de Cornu Ammonis, qui reperitur in Ephem. Nat. Curiaf. Dec. II. An. VII. in fine, Job. Jac. Scbeuchzerus in Meteorol, \& Oryctograph. Helvetic, pag. 248. it. Fob. Mural: 
ET ARTIFICIALIVM KVNDMANN. VRATISLAV. 247

Muralius in Mifcell. Natur. Curiofor. Dec. III. An. V. \& VI. pag. 44. fig. XI. \& X́II.

52. Nautilites ftriatus elegantiffimus, Nautilum marinum exacte referens (S.378.) conven, cum delin. ap. Carol. Nir. Langium in Hiftor. L ppid. Figurat. Helvet. Part. II. Lib. IV. Cap. X. Tab. XXVII. num. 7. pag. 97.

53. Nautilites plarium circumvolutionum denfeque ftriatus ex Helvetia, fubftantiæ arenofo-lapidex. (S.396.) vid. Id.L.C.Tab. XXVII. num. 9 .

54. 55. Nautilitæ minores Echterdingenfes Ducatus Würtembergici læves, articulati \& non articulati. (S.397.\& 398.) conven. cun delin. \& defcript. quam dedit fob. Baubinus de lapidibus a natura in terra figurats pag. 21. it. Georg. Andr. Helwoing in Lithogr. Angerb. Part. I. Cap. VI. Claft. II. Sea. III. p3g.87. Tsb. VIII. Fig. 3. it. Car. Nic. Langius in Hift.Lapid. Fig. Helvec.Part. II. Lib.IV. Cap. I. Tab. XXIII. pag. 92. feqq.

56. Nautilites cujus cavitas lapillis \& conchinulis adimpletus ore amplo, f. Gryphites rugofus roftro fubtereti \& adunco Luidii Lithoph. Britann. Claff. V. Capf. VIII. num. 473. pag. 26. (S.399.) talem delin. Georg. Everb. Rumpbius Amboinf. Rarit. Kam. Tab. LIX. num. B. foh. de Laë̈ de Genım. \& Lapid. Lib. II. Cap. XXIX. pag. 192. it. Fob. Müraltus in Ephen. Nat Curiof. Dec. III. An. V. \& VI, pag. 44. f. Cornu Ammonis, củjus interna fubftantia e mevis conchinulis Anomiis friaris coagmentatus. vid. Carol. Nic. Langius in Hiftor. Lapid. Figurat. Helvet. Part. Il. Lib. IV. Cap. III. Tab.XXII. num. 1. pag. 82.

57. Naurilites coloris aurei fplendentis minor denfe friatus, $\mathrm{f}_{\mathrm{r}}$ ex Pyrie Stutgardienfis, vulgo Chryfammonites \& Dracoritia Reiskii, vid. ejusd. Tract. pag. 185. qui reperitur in Ephem. Nat. Curiefor. Dec. III. Ann. VII. (S. 234.) prextér hune de Chryfammonite evoiv. lll. Aldrovan. dus in Muf. Metall. Lib. I. pag. 54. feqq. Fob. Henricus Locbner:s in Muf. Besler. Tab.XXXIV. pag. 96. G. F. Mylius in Memorab. Sax. Subr. Part. II. Relat. V. pag 54 .

58. Nautilites f. Chryfammonites ejusdem fubftantix \& loci articu. lis lationibus (S. 235.)

59. Nautilites métallifatus totus tuberofus \& crenatus ex Regno Anglia prope Bathoniam (S. 236.) Merallicos pre. ferreos deficr. \& del. Gob. Reiskius in Tr. fupr, cit, in fine it, in Ephem.Nat, Guriof. Dec. II. An.

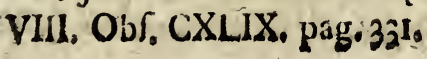


60. Nautilites maximus $f$. VIII. pollices latus ftriis undulatis, usque ad tertiam partem refertus ex montibus calcariis Neo. fultzenfibus (S.456.) conven, cum delin. \& defript. Naurilite r. Cornu $^{2}$ Ammonis Spangenbergenfis ap. Petr. Wolfart in Hiftor. Nät. Haff. infer. Part.I. Tab. VIII. num, 6. pag. 37. it, Ifenacenfis ap. G. F. Mylium in Memor. Sax, Subter, Part. II. Rel. V. pag. $\{3$.

De Nautititis, vulgo Cornibus Ammonis, \& eorum xftimatione ap. Veteres, vid. Plinius Hift, Natur. Lib. XXXVIr. Cap. X. Nautilitas ea effe nominanda demonfrav. G. F. Mylius in Memorabil. Saxon. Subterran. Parr. II. Rel. V. pag. 42. Edvard. Luidius in Ichnograph. Lithop. Britann. Clafr.IV. pag. 15. feqq. it. Epift. II. pag. 102. Joh. Woodwardus in Specim. Geograph. Phyf. pag. 28. Dav. Sigifm. Büttnerus in Rud. Diluv. teftibus pag. 268. \$. 160. 70h. Fac. Bajeras in Oryctograph. Norica Cap.IV. pag. Go. \& ferme omnes Lithologi recentiores. Pro Serpentibus petrefactis habent Bobusl. Balbinus in Mifcell, Hiftoricis Regni Bohem. Cap. LI. num. 13. Ol. Wormius in Mufeo, it. Muf. Calceolar. Veronenf. Seat. Ill. pag.423. Conf. Fob. Dañ. Majoris Differt. Epiftol, de Cancris \& fer. pentibus petrefactis. Pro Spinis Serpentum petrefactis, majores; pro Vemibus \& infectis marinis contortis minores habet Car. Nic. Langius in Hif. Lap. Fig. Helv. Part. II. Lib. IV. Cap. V. pag. 86.

61. Pectinites magnus Lifteri elegans ftriis latiffimis \& altiffimis in matrice (S.I62.) vid. Mart. Lifteri Hift. Animal. Angl. pag. 233. Simil. quoque del. \& defcr. Fob. fac. Bajerus in Oryetogr. Noric. pag. 73. it. Car. Nic. Langius in Hift. Lap. Fig. Helvet. Lib, VII. Cap, IV. Tab. XLIII. num. S. pag. 143.

62. Pectinites Gedanenfis coloris nigricantis ftris minutiffmis (S. I 05 . ?

63. Pectinites Maslenfis Silefiæ, duriffimæ fubftantiæ, annulo albo notatus (S. 277.)

64. Pectinites egregius friis altioribus prope Angerburgum ma. trici iminerfis, cujus fuperficies polita, faciem humanam repræ. fencat (S. 45.)

65. Pectinites ftriis minutiffimis ex Regno Bohemiæ (S.331.)

66. Peetinites fubftantiæ filiceæ convexus elegans, margine latiori \&incurvo, una valvula ab altera fejuncta ( $\mathrm{S} .302$.

67. Pectunculitæ Helvetici varii fubnigricantes elegantiffimi \& argentei fplendoris a matrice feparati friis denfioribus, \& extra imam oram productis. (S.24,) accuratif. del, \& defcr. Car. Nic. Lan. 
ET ARTIFICIALIVM KVNDMANN. VRATISLAV. 249

gius in Hift. Lap. Fig. Helvet, Lib. VII. Cap. VII. Tab, XLV. num, I, \& 2. pag. 147.

68. Peetunculita femicirculares plani flabelliformes Atriis capilla. ribus prope Kuntzendorff Silef. (S.39) Simil, delin. Leonb. Dav. Hermann Maslogr. Tab. IX. num. 18.

69. Peetunculites f. Lapis ftriatus oblongus peetunculo in apice impreffo (S. 69.)

70. Peetunculis \& tubulis vermicularibus refertus lapis, ex agro

Cumbrienfi (S. 57.)

71. Peetunculites Maslenfis ftriis minutisfimis notatus (S.73.)

72. Peetunculites flabelliformis planus ejusdem loci, ftriis capilla-

ribus denfe exaratus (S. 74.) del, \& defcr. G. A. Volckmann Sil. Subt. Parto

I. Cap. V. pag. 183. Tab. XXXI. num. 6.

73. Peetunculis albis elegantisfimis adimpletus lapis Maslenfis (S. 337.)

74. Peetunculites ex diverfimode figuratis \& Ariatis Pequnculis conftans ejusd. loci ( $S .35$ I.)

75. Peetunculites $f$. Concha Anomia Lifteri réinoßos Atriis latioribus ex monte Legerio (S. 165.) del. \& defcr. Job. Jac. Scheucbzerus in Meteorol. \& Oryct. Helvetica Fig. 102. pag. 299. గ. Terebratula ftriata minor ftriis tenuioribus valva fuperiore lacuna lata donata Langii in Hitt. Lap. Fig. Helvet. Lib. VII. Cap.XII. Tab.XLIX. num. 1. \&2. pag. 158 .

76. Pectunculites talis Gedanenfis in matrice (S. 106.)

77. Peetunculites f. Concha Anomia roftro prominulo Lifteri, f. Terebratula Luidii minor ftriata pellucida ex monte Tabor (S.32) del. \& defar, Car, Nic, Langius in Hift. Lap, Fig. Helver. Libr. VII, Cap. XI. Tab. XLVIII. num.3. pag. I54.

78. Peetunculites rotulis cylindraceis refertus Freibergenfis prope Suidnicium Silef. (S.430.)

79.80. Purpuræ totæ lapideæ num. 2. undique exefæ, annexis tubu-

lis vermicularibus (S. 281.)

81. Tellina Jenenfis petrefaeta (S. I02.)

82. Tellinites f. Maffa durisfima albicans, in qua Tellinæ innumeræ æqualis magnitudinis, quæ interne terram ferrugineam aurei faturatioris coloris continent, immerfæ, ex montibus Calcariis Neofultzenfibus (S.457.) 


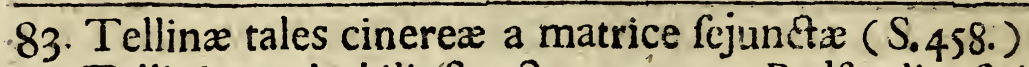

84. Tellinites mirabilis ftructuræ ex agro Bedfordienfi Angliæ f.Marfa faxea durisfima Tellinis referta (S.119.)

85. Tellinites Kleinfteinenfis ex Ducat. Oppavienfi Silefia, cum Nautilo compreffo. (S. 429.)

86. Turbines albi ex montis cacumine vulgo die Zinne prope Coroniam Tranfilvaniæ (S.388.)

87. Turbinites in matrice friabili \& congerie Tellinarum facile feperabilium, Schrappelauenfis Comitatus Mansfeldici (S.340.) 88. Turbinites in lapide polito conchis fimul referto (S.185.)

89. Turbinites $\mathrm{f}$. Lapis duriffimus fubalbidus Borusfiacus, in quo multi parvi Turbines immerfi (S.389.)

90. Turbinites Maslenfis in lapide polito, five Buccinites Bajeri (S. 187.$)$

9r. Turbinites Querfurtenfis rarioris notæ clavicula longiori ex materia arenofa duriúfcula (S.35.) del. D. S. Büttnerus in Ruder. Diluvianis Tab. XXVII. uum. 9. \& IO.

92. Turbinites elegantislimus ejusdem fubftantix \& locimaximus

(S. 380. ) del. id. Bütnerus L. C. Tab. XVI. num. r. Ad. Olearius Gottorpifcher Kunt-Kammer Tab. XII. p. 34. num. 4. Minor, in Carol. Nir. Langii Hift. "Lap. Figur. Helvet. Tab. XXXII. num. 8. pag. no.

93. Turbo ejusdem ftructuræe elegantisfimus in matricelapidea durisfima ( $\left.S_{390 .}\right)$ vid. id. Büttmerus L. C. Tab. XXIX. it. Ephemer. Nat. Curiof. Dec. I. An. III. Obf. LXX. p. I19.

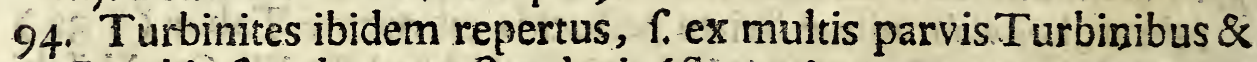
- Conchis fimul compactus lapis $(\mathrm{S} .403$.

95. Turbines \& Conchylia varia faxo durisfimo immerfa (S.49.) Similes delineav, Georg. Andr. Helwing in Lithograph, Angerb. Part. I. Tab.VIII. num. 10.

96. Turbinites cinereus, rlapis durisfimus ex Cochleis \& Pectunculis fimul compofitus juxta Francofurtum (S. 72.)

97. Turbo magnus faxo curiofe immerfus, ita ut interior facies fimul compareat (S. 520.)

98. Turbo longisfimus in congerie Tellinarum \& Pectinum diverfimode Atriatorum \& fafciculatorum (S.280.) talis del. \& defcr. in Aibanaf. 
Acbanaf. Kircberi Mundo fubcerraneo Tom. II, Libr. VuI. Cap. II. See. II. pag. 48.

99. Umbilicus marinus lapidi durisfimo immerfus, ( 5.79.$)$ del. Helwing in Lithograph. Angerburg. Part. I. Tab. IIX. Fig. 6. Job. Jac. Scbeucbzerus Natur - Gefchicht. des Schweitzerlandes Part I. Tab. VII. num. 3I. pag.99. \& in Lithograph. Helvetic. pag. 24. Tab.' III. Fig. 3I. it. Car. Nic. Langius in Hiftor. Lapid. Figurat. Helvet. Part. II.Lib.V. Cap. V. Tab.L. p. II6.

A Uthores, qui Conchas has petrefactas pro Diluvii univerfalis teftibus, \& alii, qui pro Lufu Naturx eas agnoicant, collegit Pbil. Jac. Sacbs a Levenbeimb in Gam: marologia Lib. IIX. pag. I5g. feqq.

Quibus addendi priora ftatumina defendentes, fob. Jac. Bajerus in óguxroyga థíá Norica Cap. IV. pag. 67. Fob. Fac. Scbeucbzerus in den Schweitzerifchen Natur - Gefchichten Part. I. pag. 89. Job. Rajus de Diffolut. \& mutat. mundi pag. 141. feqq. Fob. Woodivardus Tentam. circa Hiftoriam Natural. Telluris, fob. Guil.Bajerus de Foflil. Diluv, univerfal. monumentis, Dav. Sig.Büttnerus in Rud. Diluv. Teftib. pag. 129. 256. 288. feqq. Petr. Wolfart in Hiftor. Natur. Haflixe infer. Part. I. pag. I4. feqq. Conf. Epiftolam Scheuchzeri ad 7oh. Cbrifopb. Sturmium, qux reperit. in Ephem. Nat. Curiof. Dec. III. An. IV. in Append. pag.57\%. Varia cum illis experimenta inftituit Car. Nic. Langius de Origine Lapidum Figuratorum Lib. Cap.X. p. 34. feqq.

His non fubferibunt Gob. Kentmannus in Catalog. Rerum Foffil. Tit. I. pag. I. it.' Tit. XI. pag. 55. ul. Aldropandus in Mur. Metall. Libr. IV. pag. 462.-474. \& pag. 822. feqq. it. de Teftaceis Lib. III. Cap. I. Ol. Wormius in Mufeo Lib. I. Seâ. II. Cap. XII. pag. 80. Acbanaf. Kircberus in Murdd. Subterr. Libr. XII. Sea. II. Cap. VIII. fol. 373. Fob. Fonfonus in Thavmarograph. Naturali Claft. IV. pag. 32. Jacob. Gaffarellus in Curiofitat. inauditis Libr. II. Cap. V. S. 4. pag. 84. Bobusl. Balbinus Mifcell. Hiftor. Regni Bohemix Lib. I. Cap. LI. pag. 128. Valvafor in der Ehre des Hertzogth. Crains Tom. I. Lib. IV. Cap.II. pag. $4 ; 6$. Job. Dan, Gejerus de montibus conchiferis pag. 8. Georg. Baglivins Operum Differt. V. pag.\{22. Cbrift. Frid. Paullini in der Zeit - kürrzenden erbaul. Luft Part. II. Them. XLIV. Car. Nicol. Langius in Hiff. Lap. Fig. Helvetix Part. II. Lib.VII.

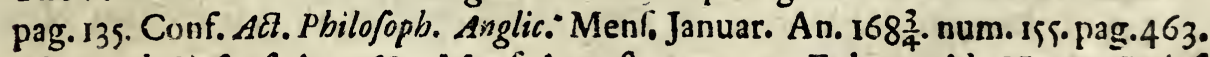
AQ. Erud. Lipfenf. An. I685. Menf. Auguft, pag. 371. Ephemerid. Natur. Curiof. Dec. II. An. VIII. Obferv.CXLIX, it. Obfervationem meam in Bresl. Samml. XXV. Verf. An. 1723. Claff. IV. Art. V. pag. 187.

Animalia \& Vegerabilia foffilia a Diluvio in terrx vifcera neutiquam effe depofita, fed eorum femina mediante pluvia \& vaporibuse mari, terra \& fuminibus clevari, hinc inde per fifturas terrx diffundi, \& a calore fubterraneo foecundari af- 


\section{2

ferit Eduard. Luidius ; pro peculiari femine habet Car. Nic. Langius in Hift. Lapid. Fig. Helvet. Part. II. Lib. V. Cap. I. pag. 104.

\section{ARTICVLVS III.}

\section{Aliorum Animalium partes petrefactx.}

I. Erucæ petrefaetæ diverforum colorum accuratiffinæ (S.372.) Erucam lapidi impreffam defcr. Georg. Andr. Heliving in Lithograph. Angerb. Part. II. Sect. III. pag. 129. ad quam accedere videtur erucxformis lapis \$p. Scbeucbzerum Meteorol, \& Oryctograph. Helveticx Fig. 169. p. 331.

2. Manuibulæx fragmentum cum dente inhærente \& alveolis dentium ex Comitatu Ifenburgenfi ( $S .38 \mathrm{I}$.) convenit cum delineac. ap. Ul. Aldrovandum Muf. Metallic. Lib. IV. pag. 829.

3. Odontopetra f. Dens lupino fimilis fubftantiæ filiceæ, vulgo Dens Draconis ex montibus Carpathicis (S.454)

4. Odontopetra alba f. Dens molaris calcinatus marga fimul friabili obvolutus prope Vratislaviam in urna fepulchrali repertus (S.279.) delin. \& defcr. Lonh. Dav. Hermann in Maslograph. Lib. II. Cap. XI. S.2. pag. 134. feqq. Sive Dens molaris major Atriatus longiffimus Hip. popotami fecund. Car. Nic, Langium in Hiftor. Lapid. Fig. Helvetix Part. II. Lib. III. Cap. I. Tab.XI. num. I. pag. ؟O. conf. delin. Georg. Ant. Volckmanni in Silef. fubterr. Tab.XXVI. num, 2. qui Buchvvaldi prope Schmiedebergam in Silefia repertus fuit.

5. Odontopetra five Dens molaris petrefactus major ftriatus animalis incogniti, Cantadii An. 1710. in terra repertus, coloris fufci (S. 237:)

6. Odontopetra $\mathrm{f}$ Dens inciforius talis ibidem effuffus (S.380.) Hos defcripf. DAD. Spleisfus in Oedipo Ofteologico f. in Diflert. Schiaffhule publi. cat. de Cornibus \& oflibus foffil. Canftadienfibus ; conveniunt cum dentibus equi petrefactis ap. Ul. Aldropandum in Muf. Metallic. Lib. IV. Tab.IIX. pag. 830. .' Dentibus Giganteis ap. Conr. Gefnerum Lib. IV. de PIfcium Natura pag. 497.

7. Odontoperra giganten molari mimilis alba, ftalactitx inclufa,e fpecu Baumanniano fylvæ Hercyniæ (S. 233.) Specum defcr. Ten. izelius in Monatl. Unterredung. Ann. 1697. Menf. Auguft. p3g. 657. feqq. prc. Grorg. Henning Behrens in Hercynia curiofa Cap. I. pag. I. feqq. aliique. De Offbus \& Sceletis giganteis multa collegit Atbanaf. Kircberus in Mund. fubt. Tom. 
II. Lib. VIII. SeA. II. Cip. IV. pog. \{3. Jeqq. Erafm. Francifos im GefchichtKunf - und Sitten Spiegel Lib. 1. num. 17. pag. 122. fegq. Robert. Sibbaldus in Scotia illuftrata feu Prodromo Hift. Natural. Part. II. Tom. 11. Sec. I. Cap. II. num. 4. Godofr. Voigtius im Phyficalifch.Zeit - Vertreiber Cent. III. Quxft. LIV. pag. 662. it. Thom. Barrbolinus in Aat. Hafnienfib. Obferv. XLVI. pag. 83. prc. Hoffmannis in Differr. de Gigantum offibus Cap. II. Sect. II. Mifcell. Nat. Curiof. Dec. II. An. VI. pag. 176. Valvafor in der Ehre des Herzogth. Crains Lib. XII. Cap.XI. Guil. Camdenus in Britannia pag. $35^{1}$. Tentzelius Monatl. Unterredung. An. 1695. pag. 948. Theatrum Europxum Meriani Part. V. fol. 574. Quxe omnia pro Elephantum offibus habentur in Ephem. Natur. Curiofor. Dec. II. An. VII. Obferv. CCXXXIv.pag.446. De Gigantibus antediluvianis vid. Gafp. Scbotti Phyficam curiofam Lib. III. Cap.IIX. p 384. Reqq. Sceletus totus giganteus defcr. in Erafm. Francifci Oft-und Weft-Indifchen Luft Garten Part. I. Tab. V. num. 9. pag. 187. Noftro fimilem del, \& defcr, Llyff. Aldropandus in Mufeo Metallic. Lib. IV. pag. 828. Fob. Henr. Locbnerus in Muf. Beslerian. Tab. XXXI. pag.9r. G. F. Mylius in Memorabil. Saxon. Subterran. Tabul. fub fign. Dum.2. pag.81.

8. Odontopetra talis fufci coloris ex montibus Carpathicis. (S. 475.)

9. Odontopetra $f$. Dens leonino fimilis, ex iisdem montibus (S. 476.)

10. Odontopetra $f$. Dens fuillum referens ibidem effolfuslongiffimus (S. 239.) hunc delin. id. Mylius L. C. num. 4. pag. 8r.

11. Odontopetra f. alius cinereus molaris ibid. repertus (S. 383.) 12. Odontopetra five dens oblongus coloris lignei prope Vratisla. viam ad Pagum Dirgenilch ex fonte effolfus (S. IOZ.) conv.cum delin. ap. fob. Henr. Locbnerums in MuC. Besleriano Tab. XXXI.

Oolithus vid. Hammites fupra Claft. III. Art. III.

13. Os Femoris cum procesfibus inferioribus \& medulla fpongiofa Canftadienfe totum petrefactum (S.382.)

14. Os Femoris ex montibus Carpathicis maximum, vulgo Draconis, cortice lapideo obductum (S. 473.) totus Sceletus talis del. \& defcr. Erafm. Fraxcifi im Oft - und Weft - Indianifch. Luft-Garten Part. I. Tab. V. num. 9. pag 187.

15. Os Coxendicis tale maximum totum petrefactum ibidem efforfuin ( $\mathrm{S.474.)}$

16. Os Fibula cum cofta dimidia in urna fepulchrali repertum. (S. 416.) 
17. Osficula petrefaeta avicularum alba accuratisfima ex monte Hasfix vulgo dem Vogels-Berge eruta (S.3I4.)

18. Osficula talia petrefaeta lævia Maslenfia coloris nigricantis (S. 322.) vid. Leonb. Dav. Hermann Maslograph. Part. II. Cap. IX. pag. 224. Varias opiniones collegit Dav. Sigm. Büttnerus in Rud. Diluvian. pag. 304 .

19. Osfium petrefactorum fragmenta $f$. Unicornu fosfile ex lapide calcario Querfurtenfi (S.22.) defcr. Foh. Henr. Scbütteus in Orygaogr. Jenenfi Cap.VH. §.8i. p. 8I.

20. Osfium talium fragmenta in Specu Schartzfeldico Sylvæ Hercyniæ frequentia $(S .21$.) vid. Georg. Henning. Bebrens in Hercýnia curiofa Cap. I. pag. 19. pag. 39. 44. 53. . 61. feqq. Specus defcrib. in Tenzelii Monatl. Unterredungen Ann. 1697. Menf. Aug. pag. 666. feqq. it. Bebrens L. C. Cap. I. pag. I.

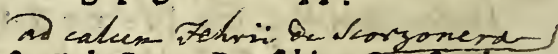
Unicornu fosfile alias peculiari Traatatu defcripfit Fob. Laur. Baufsbius. Conf. Thom. Bartbolini de Unicornu Obfervat. nov. \& Parentem Cafp. Bartbolinum de Unicornu, Tentzelii Monatl. Unterred. An,1696. Menf. April. it. Epiftol. de Sceleto Elephantino Tonnx nuper effoffo, Car. Nic. Langii Hiff. Lap.Fig.Helvet. Part.II. Lib.III. Cэp.II. pag.57. aliosque. Contra Unicornu verum pugnat copia, de qua vid. Befchreib. der Naturl. Dinge Rufslandes Henr. Wilb. Ludolffs, annexa der Befchreibung der Chinefifchen Reife zu Lande aus Mofcau Adami Brands pag. 197. it. Fob. Lucas Riem in Difr. de Ebore fosfili §.XI. Pro Bitumine coagulato habet Andr. Libavins Singular. Part.III. Libr.VIII. Cap.XVII. p. rog6.feqq. Pro Marga Ans. Boetius in Hift. Gem. \& Lapid. Lib.II. Cap. CCXLII. fol.209; it. Car. Nic. Langius in Hift. Lapid. Fig. Helvet. Part.II. Libr.III. Cap.II. pag. 58. ProLufu Naturæ, Conr. Gefnerus Rerum Fosfil. Cap.XI. fol.iso. Athan. Kircheres Mund. Subterr. Lib.VIII. Sea.II, pag.60. ful. Caf. Scaliger de Subtilitate Exercitat. DCCXXXVII. pag. 46r. Pbil. Facob. Sacbs a Leivenheimb Gumma. rolog. Lib.ViII. pag.I59.feqq. Adalbert Tylkowsky in Philofophia curiofa Part. II. pag. 3r. Thom, Bartbolinus in Act. Medic. \& Philofoph. Hifnienfibus Obf. XLVI. pag. 83. Bobuslaus Balbinus in Mifcell. Hiftoric. Regn. Bohemix Lib.I. Cap.XLIX. pag. II 4. feqq. Ol. Wormius in Mufeo pag. 54. Baufchius L. C. Dan. Sennertus in Epitume Natural. Scientiar. Lib.V. Cap.IV. p. 422. Bebrens L. fupr. cir. Cap.I. pag. 5 4. aliique. Examen per ignem docimafticum confideratu dignum inftituit Job. Samuel Carl in Lapide Lydio Philofophico. Pyrotechnico ad Osfium fosfilium Docimafiam analycice demonfrandam adhibito; Conf. Guil. Erncfto Tentzelii Munatl. Unterredung. An.1697. Menf. Januar. pag.4 Ifeqq. Job. Fac. Scbeucbzeri Natur.Gefchichte des Schweitzerlandes Part.II, p.186. Georg.WVolff. 
ET ARTIFICIALIVM KVNDMANN. VRATISLAV. 255

W. Medic. Gefcbicbt. VI. Verf. An.1718. Menf. Dec. Claff IV. Artic. V. pag. I981. item Obfervarionem meam ibidem L. C. XXV. Verf. An.1723. Claff.IV. Art.V. pag. 187.

2I 22. Paguri f. Squillæ marinæ petrefalta Sinenfes, ubi una fuperiorem teftam, altera caudam cum chelis accuratiffime demonftrat (S 370. \& S.371.) del. \& defcr. Conr. Gefncrus Rer. Fosfil. Cap.XIV. fol.167. Ul. Aldrobandus in Muf. Metallic. Lib.IV. pag.460. Muf. Calceolarian. Veronenfe Sect III. pag.429. Wagnerus in Hift. Natural. Helver, pag.331. Carol. Nic. Langius in Hift. Lapid. Figurat. Helvet. Part.Il. Lib.III. Cap.I. pag.47. Job. Fac. Scbeucbzerus in Querel. \& Vindiciis Pifcium pag.29. Fob. Hcnr. Locbnerus in Muf.Besler. Tab.XXXIIl. pag.95. Georg. Everb. Rumpbius in der Amboinfch.Ra. rit. Kamm. Tab. LIX. num.I. \& 2. pag.335. prc. evolvend. Fob. Dan. Major in Differr. Epiftolic. de Cancris \& Serpentibus petrefactis pag.6I. \& Pbil. Facob. Sacbs a Lewenbeimb Gammarol. Cap.VII, pag. I 41. ubi fimul Authores recenfuit, qui pro Lufibus Naturx eos agnoverunt, \& Cap.VIII. pag.176.feqq. qui pro Teftibus Diluvii univerfalis habuerunt. Conf. Atbanaf. Kircberi. Chin. illuftrat. Part.IV. Cap.IX. pag.202. De Aqua apud Chinenfes, per quam fquills omnes in lapidem mutantur, vid. Joh. Neuhofii Befchr. des Reichs Sina pog.358. it Erafin. Francifci im Oft-und Weft Indifchen Luft.Garten Part.I. Cap. CLXXXVII. ci. tante $P$. Martino Martinio in Aclante Sinico \& quidem in Defcriptione provincix Quantung fol.is9.

23. Vermicularis lapis, f. Vermium petrêfactorum concretio rarisfima maxima coloris flavi, $f$. Halcyoneum Milefium Imperati (vid. Hiftor. Natural. Libr.XVIII. Cap.I. pag.835.) Batavis Verfteend WormeNeft, ex Mur. Wilb. d' Orville, vid. Ejusdem Catalogus van een Uytmuntend $C_{3}$ binet pag.52. talem quoque nominavit Cbrift. Maxim. Spenerus in Catalogo Mufei fui (S.365.)

24. Vermium talium concretio cinerea minor (S.366.)

25. Vermicularia aurea minima (S.367.)

26. Vertebra humana, ubi cavitates ftalactite repletæ $\left(S_{.52 \mathrm{r}}\right.$ )

27. Vertebra humana accuratiffirna, lapidi durifimo conchis fimul referto, immerfa (S. 120) Vertebras binas dorfuales petrefaetas delin. \& defcr. Job. Jac. Scbeäcbzeres in Querel. \& Vindic, Pifcium Tab.III. pag.22. Alias fub nomine Ichthyofpondylorum del. 7ob. Fac. Bajertes in Ory tograph Nu= rica Tab XVII. Fig.XXXII. \& Carol.Nic. Langius in Hift. Lap. Fig. Helver. Pars. II. Lib. IV. Cap. I. pag. 75.feqq. Conf. Dav. Sigifm. Büttmeri Rudera Dilaviana Tab.XXIll. S.130. pag.221. Ostrald. Grollii Trątati de Signaturisrefum internis 
p.5. qui habecur Bafilice Chymicx in fine Tentzelii Monatl. Unterred. An.1690. Menf. Febr, pag,184. Av.1696. pig. 364. \& 366. An.1697. Menf. Januar. prc. torum Sceleton humanum petrefactum lapidi durisfimo inclufum defcr.id. Tentzelius L. C. An,1690. Menf. Febr. pag.127. citante Happelio in der Schatz-Kammer übernatürl, und wunderbarer Gefchichte.

28. Vertebrella Luidii in medin perforata minima (S.344.) vid. Lithophil. Britannici Ichnograph, Clafr.XI. Capf.XXI. num.I569. pag.80. del. \& deicr. quoque fob. Henr. Lochnerus in MuI. Beslerian. Tab.XXXI. pag.91.

\section{Claffis $V$.}

Minera metallifere iisque affines; ut: Auro nitentes; Argentifere crippata, capillares, aspera, rudes fui coloris, rubra, nigra, cinerea, alba; Cupricrippata, genuine EE variegata; Stanni cryfallina absque recrementis E alie; Plumbi nitore confpicue; Ferrivariorum colorum E: fgurarum; Mercurii, virgineo tumentes है Cinnabarins; Metallaque puria \& Minera. lia media, item varia Recremen. ta five Scoria.

\section{AR TICVLVS I. \\ Mineræ Auri.}

x. Monticulus artificiofus, ex mineris rariffimis cry ftallinis \& metal. liferis, item ramis Corolliorum \& Ferri florum exftructus, in quo fimul Operationes a Metallifofforibus ex argento formatis confpiciuntur. Talem defcr. Ol. Wormius in Muf. Lib.IV. Cap.V. pag.359.

2. Arena aurifera ex Sala fluvio prope Jenam (T.490.)

3. Flammulæ auri puriffimi ex arena Salæ fluvii prope Calam Altenburgicam per loturam feparatx (T.49I.) vid. H. J.H. Nachricht von dem Gold, Kupfer und Eifenfteinen it. von Edelgefteinen, welche bey und um Jena gefunden vverden, Cap.I. S.3.--7. pag.5. Alia Flumina \& Regiones auriferas defcr. Georg. Adam. Struvius in Differt. de Auro fluviatili f. vom WafchGold; De generatione auri talis in ipfa arena vid. Hier. Cardanus de Subtilitate 


\section{ET ARTIFICIALIVM KVNDMANN. VRATISLAV. 257}

Libr.VI. pag.147. Georg. Agricola de Ortu \& caulis Subterr. Lib. V. p. 77. Ge. org. Engelb. Löbneys im Bericht von Berck. Wercken Part. VII. pag. 129. Tilemann Friefe in Müntz.Spiegel Libr. IV. Cap. XXXV. aliique. Modum aurum ex arenis in $Æ$ thiopia eruendi docuit Alvaretz in Delcr. Æthiopix Cap.XXXIX. pag. 162. Modum feparandiaurum, quo Rhenenfes utuntur, defcripf. Mich. Heberer in Egyptiaca Servitute Libr.I. C.1p.VI. Qualem vero in Comitatu Schvvartzburgico adhibeant, vid. Tourneyfer zum Thurn in Pifone Lib.V. Cap.V. Singularia Luc fpectantia collegit Cbr.Frid. Paullini in Philofophifchen Luft-Stunden Part. I. pag.jos.fequ.

4. Minera auri Hungarica, cui in fuperficie quarzum rubrum adnatum (T. 72.)

5. Minera auri Shemnicenfis Hungarica argento mixta (T.73.)

6. Minera aüri tufa Zuckmantelenfis Silefiæ, cui multum Vitrioli ineft (T. 93.) has defcr. Cafp. Schbvenckfold in Catalog. Stipium \& Fosfil, Silefix pag.376. Nic. Henclius ab Hennefeld in Silef. renovat. Cap.III. S.38. pag.306. \& \$.39. pag. 314. Georg. Ant.Volckmann Siles. Subterran. Part. Il. Cap, II. S.7. pag.205. it. Ilnfere Samml. von Natur-und Medicin. Gefcbicht. II. Verf. An. I717. Menf. Nov. Clafr.V. Art.II. pag.345. it. VI. Verf. An.1718. Menf. Novembr. Clafi.IV. Art.V. pag.I973.

7. Minera auri R.egni Hungariæ cum multa Cinnabari (T. I40.)

8. Minera auri Sofauerenfis ad Eibenftock in lapide metallico molliore (T. I 4 I.)

9. Minera auri cum argento \& pyrite mixta, ex monte Giganteo Silefiæ (T.183.)

10. Minera auri ære \& ferro punctulisque flavis infperfa Goldbergenfis Silefix (T.198.)

11. Minera auri, cui cuprum ineft in quarzo albo, ad Zuckmantelam (T.214.)

12. Aurum in marmore nigro, inte:mixtis Zonis albis prope W.ohnfiedel (T.265.)

13. Minera auri tufa Schemnicenfis Hungarica ( $T$. 295.)

14. Minera auro dives Schemnicenfis, cui multum fimul argenti ineft, aus dem Wind-Schacbt (T.299.)

15. Minera auri f. Aurum marmori metallico albo infperfum ex Hungaria (T.312.)

16. Aurum Peruanum in granulis copiofe faxo albo inhærens ( $T$.313.) $\mathrm{K} \mathbf{k}$ 
17. Auri particula marmore albo metallico infira ex Bohemia (T.338.) 18. Minera auri Reichiteinenfis Silef in terra fufea molliore (T.339) defcr. Nic. Henelius Silefiograph, renovat. Cap.III. p.3=9. it. Georg. Ant. Volckmann Silefiograph. Subter. Part.II. Cap.II. \$.6. pag.205.

19. Minera auri cui argentum ineft Schemnicenfis in faxo albo (T.348.)

20. Minera auri Goldbergenís Sil. ignem nondum experta (T.373.) 21. Minera talis tofta miculis aureis infperfa (T.374.)

22. Arena aurifera Goldbergenfis, aurei fplendoris (T.375.)

23. Minera Schemnicenfis, ubi faxo albo \& nigro miculæ aureæ infperfe ( $T$ 382.)

24. Minera auri Cranachenfis ex Marchionatu Byruthino(T.54I.) 25. Minera auri, f. aurum folidum, faxo cinereo infperfum ex Tranfilvania.

26. Minera auri cui multum argenti genuini fimul inelt, vonWendifch-Leuten Hung. fuper. (T.365.)

27. Minera auri genuina rariflima ex bracteis aureis in marga alba molliore Triftienfis Ducatus Tranfylvaniæ (T.383.)

28. Minera niridiffima ejusdem loci, in qua aurum crifpatum \& capillare purum f. nativum faxo cinero adhæret (T.384.)

29. Marga coerulea \& flava Schemnicenfis, ex qua aurum lavatur (T.385.)

30. Aurum in Pyrite e fodinisEulauenfibus Regni Bohemiæ (T.399.) 31. Saxum nigrum duriffimum montis Sabothi Silefiæ, ex quo Itali olim aurum coxerunt (T.4Or.) vid. G. Ant. Volckmann in Sil. Subtr. Part. II. Cap. 1I. 6.9. pag. 208. ic. Linfere Samml. von Nat. und Medic. Gefcb. IV. Verf. An.1718. Menf. April. Clafill. Artic.II. pag 939. it, XXIII. Verf. An.I723. Menf. Fetr. Clafliı. Art.V. pag.IGg.

32. Aurum in minera ferri Goldbergenfi Siles. (T.406.)

33. Minera auri Zuckmantelenfis in faxo albo (T.434.)

34. Minera auri rubra raro occurrens (T.436.)

35 Minera auri globularis, cui antimonium ineft (T.443.)

36. Minera auri talis argyrite obvoluta globofa major ( T.444)

37. Aurum in marmore viridi colore fufco variegato, ex monte Sabotho, Ducatus Svidnicenf. Siles. (T.427.) 
ET ARTIFICIALIVM KVNDMANN. VRATISLAV. 259

39. Minera Schemnicenfis flammulis aureis infperfa ( $T .563$.

39. Minera auri nigra friabilis cum multo Vitriolo ex Regno Bohe$\operatorname{mix}(T 615:)$

40. Minera auro \& argento dives in Lithomarga molliore exHungaria (T.629.)

41. - Granati, argyrite obvoluti, quibus multum auri ineft Zehlicenfis Sax. (T.635.)

42. Granatis turgida minera aurifera ex Bohemia (T.636.)

\section{ARTIGVLVS II. \\ Mineræ Argenti.}

I. Minera nigra Reichfteinenfis Silefiæ argento turgida, aus der Himmelfartb (T.46:)

2. Minera argenti Reichfteinenfis fpiculis infitis fplendentibus oblongis, ex metalifodina vulgo dem Reichen-Troft effoffa (T.57.)

3. Minera ejusdem loci nigra, quafi foliolis argenti infperfa, aus dem Falckenberger (T.48.)

4. Minera argenti ibidem eruta corulea, colore viridi five cupro mixta, pyrite fimul impleta (T.49.)

5. Minera argenti nigra, punctulis fplendentibus confpicua ( $T$.50.)

6. Minera argenti Reichfteinenfis in pulverem contufa (T.58.)

7. Minera argenti ibidem frequens alba, vom goldenen Efel (T.6I.)

8. Minera argenti Neofolienfis Hungarica, miculis fplendentibus quadratis inftructa (T.135.)

9. Minera argenti Saalfeldenfis, lapidi metallico nigro adhærens.

10. Minera argentum fovens Freibergenfis (T.I46.)

II. Minera argenti Johann Georgenftadrenfis, in marmore metallico fubrubro fpongiofo, punetulis flavis infperfo (T.I 74)

12. Minera argenti Schneebergenfis lapidi metallico friabili mixta (T.149.)

13. Minera arg. in terra molliore fufca \& flava ejusdem loci(T.159.)

14. Minera arg. tufa, aus St. Peters. Grube bon der Schneekuppe (T.188)

15. Minera argenti folida cœrulea, cui plumbum ineft, montis Gigantei aus dem Teufels. Grunde (T.I9I.) 
16. Minera nigra ftris argentiferis in marmore metallico albo difcurrentibus, prope pagum Kolbnitz, ex Ducat. Jaurovienfi Silefixe (T. 197.)

17. Minera cryftallis confpicua, cui argentum capillare adnatum (T.203)

18. Minera arg. Radebergenfis prima, in faxo albo, rubro \& viridi (T.205)

19. Minera fubfequens ejusdem loci, in faxo flavo, prominentibus bracteis argentiferis, pyite infperfis (T.206.)

20. Minera arg. ibidem frequens, in marga friabili metallica flava ( $\Gamma .207$.

21. Minera arg. genuina alba Hungarica, prope Iglavam (T.219.)

22. Argentum nativum afperum, $\tilde{f}$. variis protuberantiis præditum, in marmore metallico albo ejusdem loci (T.220.)

23. Minera argenti genuina rubra elegantiffima, C. Argentum rude rubineum Freibergenfe (T.223.)

24. Minera argento dives Schemnicenfis Hungarica (T.233.)

25. Argentum nativum cum cryftallis infitis, in marmore metallico albo Gottesbergenfe Sil. (T.244.)

26. Minera arg. Bohemica ex meris granatis conftans (T.257.)

27. Minera arg. nigra Freibergenfis, foliolis argentei fplendoris infperfa (T.259.)

28. Minera argenti cinerea prope Neofol. fpiculis fplendentibus ( $\mathrm{T}$ 277.)

29. Argenti malla genuina absque recrementis, e fodina dem Römifoben Adier eruta Joh. Goorgenfadtenfis (T.285.)

30. Minera argenti ejusdern loci in tabulis, ex marmore metallico compolitis (T.287.)

3I. Minera arg. Neololientis, cui cuprum ineft, colore rubro variegata (T.304.)

32. Minera ejusdem loci cinerea prominentibus friis paucis cry. fallinis (T.305.)

33. Argentum capillare quarzo albo copiofe inharens Schneebergenfe (T.3II.) convenit c. del. quam dedic Ferrand. Imperatus H.t. Natur. Libr.XVI. p.5I6. Mineras has item alias argento dives defcr. Petr. Albinus Meifo mifcher Berg. Chronica Titul,IV. pag.40.feqq. 
ET ARTIFICIALIVM KVNDMANN. VRA TISLAV. 261

34. Minera argento dives Schemnicenfis (T.329.)

35. Minera infperfa argento nativo rubro (T.331.)

36. Minera Schemnicenfis nitidiffima, cui multum argenti ineft (T.332.)

37. Argentum capillare adnatum braeteis albis marmoreis Schnee: bergenfe (T.333.).

38. Argentum nativum absque recrementis Norwegicum, inhæ: rente ftria cryftallina alba (T.335.)

39. Minera argenti afpera Andreasbergenfis cum quarzo albo mix.

ta (T.336.)

40. Argentum rude atrorubefcens e fodinis metallicis Johann-Ge.

orgenftadtenfibus (T.337.)

4I. Minera argentifera fubrubra ejusdem loci, cum multo pyrite

(T.340.)

42. Argentum nativum album Gottesbergenfe (T.34I.)

43. Minera argenti Leifersdorffenfis alba (T.342.)

44. Minera argenti parumper glebofa,de montibusHercynix (T.343.) 45. Argentum per fufionem in aquam mire figuratum, $\&$ in particulas redątum (T.350.)

46. Argentum purum Leutfchovienfe absque recrementis (T.352.) 47. Minera in faxo albo Marienbergenfis (T.3Gi.)

48. Argentum capillare crifpatum, plumbo \& cryftallis albis infitum, ex Lotharingia (T.364)

49. Argentum genuinum ita dietum rubrum Ranicenfe egregium, prope Freibergam ( $\mathbf{T} .365$.)

50. Argentum nativum Hungaricum in quarzo albo ( $T .367$.)

51. Argenti minera genuina, marmore albo metallico mixta ( $T$.372.) 52. Minera argenti ex meris granatis compofita prope Hirfchber. gam Siles. (T.64.)

53. Argentum nativum Schneebergenfe, in quarzo albo (T.117.)

54. Minera argenti genuina in faxo albo Gablauenfis (T.irs.)

55. Argentum nativum crifpatum Joh. Georgenftadienfe (I.131.)

56. Minera argenti genuina rubra \& alba Schemnicenfis Hurgarica elegantiffima, cui aurum fimul inelt, $X$. lothones ponderans (1.209.) 
57. Minera argenti genuina rubra \& alba, ex qua marcafica aurea fimul emicat (T.221.)

58. Minera Schemnicenfis alba, prominentibus lamellis argentiferis inter ftrias cryftallinas ( $(T .376$.)

59. Argentum nativum afperum, $f$, variis protuberantiis preditum ejusdem loci, cum cryftallis infitis (T.377.)

6o. Minera argenti genuina rubra $\Lambda$ ndreasbergenfis, in marmore metallico albo ( $T$.378.)

61. Minera argenti fquamofa ibid. frequens, cum multo pyrite mixta (T.379.)

62. Minera argenti immatura alba Schemnicenfis aus dem WindSchacbi (T.386.)

63. Marga mollis alba ex Comitatu Cepufienfi Hungarix,cui argentum ineft ( $T_{387}$.)

64. Minera argenti rubra Chemnicenfis Saxon., cum raro pyrite (T.388.)

65. Minera argenti cinerea Dittmannsdorffenfis Silefix, aus der Ga. bel.GOttes.Zeche (T.404.)

66. Minera argenti alba genuina in marmore metallico ejusdem coloris, Gotresbergenfis Silefix (T.407.)

67. Minera argenti genuina alba elegantiffima in quarzo albo ære infperfa Freibergenfis (T.523.)

68. Argentum capillare fubriliffimum f. crifpatum in faxo nigro Schneebergenfe (T.540.)

69. Minera argenti cornea folida (T.545.)

70. Minera argenti genuina ex meris filis argenteis compofita Johann-Georgenftadtenfis ( $T .550$.)

7r. Minera argenti genuina Neofolienfis quarzo albo inhærens (T.552.)

72. Minera argenti genuina nigra Freibergenfis (T. 553 .)

73. Minera argenti genuina cornea Johann-Georgenftadtenfis (T. 554 )

74. Minera argenti genuina cui aurum ineft ex Tranfilvania (T.556.)

75. Minera argentı genuina rubra Marienkirchenfis alfatix ( $T$.557.)

76. Minera argenti genuina Norwegica, in faxo albo(T.558.)

77. Minera argenti genuina Mofcovitica (T.559.) 78. Py- 


\section{ET ARTIFICIALIVM KVNDMANN. VRATISLAV. 263}

78. Pyrites tabulatus, cui multum argenti inelt (T.560.)

79. Minera argenti genuina Finlandica Hyalæ effoffa (T.562.)

80. Pyrites tabulatus in matrice Freibergenfis, cui multum argen-

ti, \& parum xrisineft. (T.56\%.)

81. Minera argenti Haffiaca cinerea( T.569.)

82. Minera egregia Hungarica argento dives ( $T .570$. )

83. Minera argenti genuina Schemnicenfis, per exhalationes ardentes corrupta (fo die Witterung in denen Bergen berbrannt) (T.584.)

84. Marga alba Schemnicenfis, cui argentum ineft (T.585.)

85. Minera argenti Schmuckfeiffenfis Silefix (T. 587.)

86. Minera argenti de auro \& fulphure participans, prope Schrniedebergam, von krummen Hïbel (T.58\%.)

87. Minera argenti cinerea, cui cuprum ineft ex Bohemia, von St. Pe$\operatorname{ter}(\mathrm{T} .616$ )

88. Minera argenti in faxo cinereo Molchenfis, prope Marienber. gam (T.623.)

89. Min:ra argenti genuina alba Braunsdorffenfis (T.624)

90. Minera Bohemica von Hoben Elb, Chalybem politum referens, cui multum argenti \& parum æris ineft. (T.4IO.)

91. Minera argenti Zuckmanrelenfis alba fplendefcens. ( T.44I.)

92. Argentum genuinum album, cum vena æris viridi \& cœrulea, in marmore merallico albo transcurrens, Tyrolenfis ( $T$. 458.)

93. Minera argento dives cum Cryftallo montana Schneebergenfis ( $T$.489.)

94. Minera noviter inventa Reichfteinenfis nigra quafi foliơlis argenti infperfa ( $T .498$.)

95. Minera argeni Peruana ex meris filisfubtiliffimis conftans, $\mathrm{Hi}$ fpanis Aranna dieta.

96. Minera argentigenuina alba Chemnicenfis auro dives, aus dem Pacber. Stollen (T.627.)

97. Minera argenti genuina alba cum foliolis auri infperfis ex Tranfylvania (T.6;1.)

98. Minera argenti genuini flammulæ marmori metallico nigro \& albo infperfe $(T, 6,7$. 


\section{ARTICVLVS III. \\ Mineræ Aris.}

1. Minera æris Goslarienfis genuina, f, ex monte Rammelsberg (T. 5.) Montem \& mineras delcripl. Fetr. Albinus in der Meisnilchen Berg. Chronica Tit. XIII. pag. Iir. feqq. G. E. Löbneys im Bericbt pon Berg. Wercken fol. 77.-84. it, Cbriftianus Berwardus in Interprete Phrafeolcgix metallurgicx pag. 29. leqq. de truftatione prc. ninerarum illarum vici. Dav. Kelneri Praxis metallica curiota pag. 2 Ir. it. pag. 292. feqq.

De Erre alias Dn. Cbrifianus ab Helwich Schediafma publicavit, quod reperitur in appendice Ephem. Natur. Curiofor. Dec. III. Ain. VII. \& VIII. pag.143.

2. Minera æris alba ejusdem loci (T. 7.)

3. Minera æris folida, colore flavo, ibidem eruta (T.8.)

4. Minera æris ex monte Rammels - Berg femel tofta rubicunda. $(T, 10$.

5. Minera æris bis tofta friabilis, in qua fulphur emicat, vulgo GabrErtz, (T. II.) Toftionem hane defcr. fupra allegatus Löbneys L. C. fol. 80. \& $8 \mathrm{r}$.

6. Panes primarii ex ære rudi Goslarienfi conflati vulgo RoberStein (T.14)

7. Panes fecundarii ejasdem loci, in quibus argentum adhuc ineft ejusdem loci, vulgo Scbiwartz Kupffer (T.27I.)

8. Panis æris (pongiofus, ex quoibidem cum plumbo, quod additur, argentum eft extractum, vulgo Kien-Stock ( $T .467$.)

9. Cadmia metallica, qua utuntur ibidem pro ære tingendo. (T.15.) defcr. Lazerus Erker in Aula fubterranea pag. I 3 .

I0. Æs coetum cadmia metallica tinetum Goslarienfe (T. I6.) De modo \& Enchyrifi vid. Löbneys L. C. pag. IIz, it. Berwardus L.C. pag. 32. Dav. Kelnerus L. C. pag. 243. feqq. Erckerus L. paulo fupra cit. pag. Iร3. feqq.conf, ul. Aldrobandi Muf. Metall. Lib. I. pag. 126.

10. Es in faxo fiffili nigro ex Comitatu Mansfeldenfi (T. 3 I.) Aris fodinarum Islebienfium ortum, progreffum \& ftatum prefentem, nec non quadraginta novem ftratorum geners ibidem reperiunda preter Petr. Albinum in der Meisnifchen Berg - Chronica Tit. XIII. pag. 104. defcr. G. F. Mylius in Memorabil. Saxon. Subter. Rel. I. Part.I. pag. I. feqq.

11. Saxum tale fisfile femel toltum cinereum $(T, 32$. 
ET ARTIFICIALIVM KVNDMANN. VRATISLAV. 265

12. Saxum dupliciter crematum flavum ejusd. loci (T.33.)

13. Panes æris primarii ex faxo fisfili Islebienfi Rober-Stein (T.468.)

14. Panes aris fecundarii Islebienfes, $\mathcal{C}_{\text {. qui ultima vice detrahuntur, }}$ Scbwartz-Kupffer (T.30.)

15. Panis ærisibidem toftus, Spur-oder Spor-Stcin (T. 30.)

16. Panis æris fatifcens, ex quo cum plumbo argentum eft extraEtum, Kien. Stock (T.36.)

17. Es cœruleum cui argentum ineft Tyrolenfe, in marmore metallico albo. (T.34.)

18. Minera æris Kupferbergenfis Silef, flava in faxo albo \& rubro (T. 63.) defcr. Georg. Ani.Volckmann in Sil. fubter. Part. II. Cap. VI. pag. 227.

19. Panes primarii ex are rudi Kupferbergenfi conflati (T.469.)

20. Minera ex ære, argento, plumbo, marmore metallico albo \& nigro compofita Zellerfeldentis fylv. Hercynix (T.88.)

21. Minera æris folida flava ejusdem loci (T.9o.)

22. Min. æris flava cum multo marmore metallico, ibidem effolfa (T.92.)

23. Cuprum per aquam cæmentatum Neofolienfe r. Herrgrundenfe Hungaricum cordiforme (T.95.) vid. Mifcell. Acad. Natur. Curiofor. Dec.I. Ar. VI. Obf. CXX. pag. 155. Lacum talem ferrum in cuprum vertentem ap. Chinenfes defcr. Aiban. Kircberus in China illuftr. Part. III. Cap. V. pag. 174. it. Erafm. Francifsi im Oft - und Weft - Indifchen Luft. Gart, Parh, II. pag. 1307.

24. Cuprum tale Schmelnicenfe ejusdem Regni (T. 402.)

25. Minera Mansfeldenfis cum ære nativo (T.128)

26. Minera æris concreta in marmore metallico albo ( $\mathbf{T}$. 130.)

27. Min. xris Hungarica flava, raro faxo albo \& nigro infperfa (T.136.)

28. Minera æris fingularis Hungarica, in quo color viridis inter fquamas emicat (T. 137.)

29. Minera æris flava Kupferbergenfis Sil. (T. I38.)

30. Min: æris Saalfeldenfis, colore rubro, flavo, cœruleo \& viridi variegata, adhærens marmori metallico albo, miculis aureis infperfo. (T. 150.) 


\section{6

3r. Min. æris fquámofa coloris flavi, ex Diftrictu Eibenftockenfi vom Glückauff- Stollen. (T. 15I.)

32. Minera æris ex Regno Sueciæ, coloris aurei faturatioris (T. 152.)

33. Minera æris Saalfeldenfis in marga metallica, flore purpureo, viridi, cœruleo \& aureo eleganter adfperfa (T. I53.)

34. Min. æris Bohemica Georgenftollenfis, colore aureo \& albo variegata (T.154.)

35. Min.æris cum Vitriolo, ex monte GiganteoSilefiæ (T.I84.) 36. Min. æris flava in marmore metallico Neuendorffenfis Hungarica . ex Comitatu Cepufienfi. (T. 192.)

37. Min. æris prope Schœnau ad Polnifch-Hundorff in Lithomarga molliore. (T. 193.)

38. Min. æris Schneebergenfis egregia flava intermixto colore viridi. (T. 200.)

39. Min. æris genuina flava, colore purpureo variegata, ex Hungaria, prope Iglavam (T.217.)

40. Min. æris ejusd. loci infperfa raro faxo albo \& flavo (T.218.) 4I. Minera æris flava Hungarica, colore purpureo variegata

(T.224.)

42. Min. xris Tyrolenfis egregia, multicolor prope Sterzingen eruta. ( T.225.)

43. Min. æris optima, coloris flavi Schmœlnicenfis (T. 227.)

44. Min. æris ejusd. loci, colore viridi \& purpureo mixta, cum multo faxo nigro ( $\mathrm{T} .229$.

45. Min. æris ex Hungaria fuper. cum multo pyrite (T.230.)

46. Min. æris Regni Hungariæ purpurea, colore aureo variegata (T. 23I.)

47. Minera æris ejusdem regni fpongiofa, cui pyrites fimul inelt

(T. 234.)

48. Min. xris optima Kupferbergenfis Sil. ex purpureo cœrulea ( $\mathrm{T} .238$.

49. Min. æris flava, cortice nigro veftita \& per exhalationes ardentes corrupta, vulgo fo die Witterung in denen Bergen verbrannt. (T. 245.) 
50. Min. æris viridis in Lithomarga fufca ( T:248.)

5r. Panes æris fpongiofi Kupferbergenfes (T.250.)

52. Minera æris cœruleallmenavienfis ( $T$.25I.)

53. Min. æris ad Zuckmantelam, cui pyrites \& vitriolum ineft

(T. 252.)

54. Minera æris Kupferbergenfis colore viridi \& aureo notata (T.260.)

55. Min. ære turgida alia, ejusd. loci (T.26I.)

56. Min, ibidem eruta ex flavo cœrulea, in faxo albo, cum pauxillo ære. (T. 262.)

57. Es fui coloris granulatum nativum, gekörnt Kupfer. (T.263.)

tale defrripf. Nebem. Grelv in Mufeo Regalis Societat. pag. 326.

58. Min. æris Bottendorffenfis alba aus dem Glatzer Ländlein (T.267.)

59. Ts lapidi fiffili copiofe mixtum prope Querfurtum (T.268.)

60. Min. $x$ ris viridis genuina Islebienfis $(T: 276$ :

6I. Min. æris Suecica, colore viridi \& aureo egregie diftineta, in faxo nigro. ( T. 29r.)

62. Ts viride Kupferbergen(e nativum (T.293.)

63. Min. æris cœrulea miculis viridibus emicantibus, Regni Sueciæ (T.292.) defr.' Petr. Allinus in der Meisnifch. Berg-Chronica Tit. XV. pag. 12I.

64. TS viride aureo nitore confpicuum von Polnifch-Hundorff (T. 297.)

65. Min. xris Hungarica flava, floribus purpureis \& violaceis variegata ( $\mathrm{T}$. 300.)

66. Min. æris argentifera Hungarica paululum glebofa ( $T$. $30 \mathrm{I}$ )

67. Fss e fodinis metallicis Hungaricum nativum dendroides rariffimum (T.307.) conv. cum del. \& defer. in Mifcell. Acad.Nat. Curiofor. Dec.II. An.III. Obr. XXXIX. pag. IIo.

68. Ats viride Neofolienfe Hungaricum ( $T .315$.

69. Min. xris flava genuina prope Thermas Embfenfes eruta (T. 314.)

70. Min. ALris Kupferbergeniis coloris cœrulei faturationis aureo intermixto $(\mathrm{T} \cdot 317$. 
7I. Min. xris in marmore albo $\&$ rubro metallico, plumbum \& pyritem fimul fovens $(T \cdot 318$.)

72. Min. æris in faxo nigro, miculis aureis \& purpureis infperfa (T.319.)

73. Ess in lapide fiffili Reichenwaldenfi Sil. ( T.325.)

74. Es caldarium Hungaricum, funditur tantum malleis fragile Lebeter-Kupffer. ( T. 327.)

75. Iss fui coloris capillare Regni Norwegiæ rariffimum, ex lapide viridi prominens (T.328.) defcr. Ol. Wormius in Muf. pag. 12t. it. Nebem. Grev in Muf. Regalis Societ. pag. 326.

76. Min. æris flava colore purpureo variegata Herrngrundenfis prope Neofolium (T.330.)

77. Minera æris Leut fchovienfis multicolor, immixto marmore metallico albo. (T.35I.)

78. Min. æris Dittmannsdorffenfis Silefix, plumbum fimul fovens $(\mathrm{T} .363$.

79. Min. æris in quarzo albo argentifera (T.236.)

80. Min. æris purpurea, colore aureo \& albo variegata Vallis Joachimicæ (T.357.)

81. Min. æris Schneebergenfis aurea, cui color viridis \& cœruleus intermixtus ( $T$. 115 .)

82. Min. xris egregia Rudelftadienfis (T, 120.)

83. Minera ære dives prope Könitz, colore viridi intermixto ( $T$. 122.)

84. AEs in faxo fiffili albo Sylvæ Hercynix (T. 2.)

85. Min.æris Neofolienfis Hungarica cœrulea, cui viridemontanum ineft ( T. 389.)

86. Minera æris egregia, cœruleo \& viridi montano variegata. (T. 108.)

87. Min. æris rariffima fubcœrulea Olonicenfis Regni Mofcoviæ (T.409)

88. Min. ære dives ejusdem coloris Kupferbergenfis aus dem Piafusstollen. (T.412.)

89. Minera ibidem frequens colore aureo, purpureo \& cœruleo va. riegata elegans. (T.413.) 


\section{ET ARTIFICIALIVM KVNDMANN: VRATTSLAV. 269}

90. Min. æris cœrulea Wagendrüffelenfis Hungarica. (T.416.)

91. Es Japonenfe coloris purpurei $(\mathrm{I}: 417$.)

92. As malleabile nondum ignem expertum Rippoldenfe $f$. ex montibus Abnobiis $T$. 432.)

93. Es rude plumbei coloris, cui ferrum ineft ( $T$.433.)

94. Minera æris egregia, quæ quarzo iniermixta $(T .522$.

95. Mínera æris Auerbachenfis prope Reichenbachium in Voigtlandia (T.524.)

96. Etris liquamen cum cupro rubro filofo ( $T$. 525.)

97. Minera æris diverficolor Schneebergenfis (T. 526.)

98. Minera zris elegantiffima \& rariffima Japonica (T.527.)

99. Minera æris Freibergenfis aus dem Kub-Scbacbt (T.528.)

100. Minera æris Kolbergenfis prope Plaviam (T.529)

IOI. Minera æris Langenbergenfis prope Neu-Saltze (T.530.)

102. Minera æris Schneebergenfis, am Flasff. Graben eruta (T.531.)

103. Minera æris Bottendorffenfis (T.532.)

104. Minera æris Nickelsbergenfis (T. 533.)

105. Minera are dives ex Mofcovia ( $\mathrm{T}$. 534 )

106. IEs in lapide fciffili Bottendorffenfes (T. 571.)

107. Minera æris viridis ex meris lamellis filofis compofita, Tyrolenfis ( $\mathrm{T} .572$.

108. Minera æris genuina egregia rubra Schneebergenfis (T. 574.) 109. Minera æris rubra, fingularis elegantiæ Taloccenfis Suecica

( T. 57 6.)

110. Minera æris folida Tyrolenfis viridis, fuperne cœrulea ex meris protuberantiis compofita rariffima ( $T$. 577.)

III. Minera æris genuina coloris viridis Könitzenfis ( T. 578 .)

I1 2. Minera æris Hungarica cum multo Vitriolo emicante (T.579.) 113. Cuprum Könitzenfe elegantis rubri coloris (T.582.)

114. Cupri arbufcula Epperienfis Hungarica (T.583.)

115. Minera æris optima Kupferbergenfis Silefiæ colore aureo, virfdi \& nigro variegata, intermixto quarzo albo, ubi centenarius Libr. XL.cupri \& lothonem j. argenti continet. (T.589.)

116. Minera æris viridis cum cæruleo pauco montano, continens 23. libr. cupri (T.590.) 
I17. Minera æris Kupferbergenfis tota ccrulea (T.59I.)

II8. Minera æris Kupferbergenfis cœrulea, colore aureo notata (T. 592.)

119. Minera æris multicolor Kupferbergenfis, colore purpureo, aureo \& nigro eleganter variegata (T. 593.)

120. Minera æris talis multicolor cum quarzo albo intermixto - (T.594.)

12I. Minera æris Kupferbergenfis colore ex aureo rubefcente. ( T. 595.)

122. Minera æris argentifera Tyrolenfis egregia prope Schwatz, Chryfocollam \& lapidem Lazuli æmulans (T.452.) Metallifodinas Tyrolenfes defcr. Petr. Albinus in der Meisnifchen Berg - Chronica Titul. XI. pag. 94 . feqq.

123. Minera æris crocei coloris miculis fplendentibus ex Alfatia (T.598.)

124. Minera æris ex Suecia (T. 605.)

125. Minera æris Rudelsdorffenfis Silefix in faxo nigro (T. 606.)

126. Minera æris diverficolor,f.Flores æris Gröslicenfes ex Bohemia

prope Johann-Georgenftadt (T.622.)

127. Minera æris Schaumannsthalenfis prope Ilefeldam (T.626.)

128. Minera æris folida Kintzenfis prope Saalfeldam (T.632.)

129. Minera æris Kuttelsbergenfis Bavarica (T.633.)

I30. Panes primarii ex ære rudi Neofolienfi conflati, Rober - Stein (T.64I.)

I31. Panes fecundarii ejusdem loci pulvere quafi cupreo infperfi; Scbwartz-Kupffer (T.642.)

132. Lapis fcifflis ære dives colore purpureo \& viridi variegatus Riegelsdorffenfis Haffiacus ( T.634.)

\section{ARTICVLVS IV. \\ Mineræ Stanni.}

I. Minera Stanni genuina Ehrenfridrichdorffenfis ex particulis minoribus. (T.166.) Min. has defcr. Petr. Albinus Meifn. Berg-Chronic. Titul.XVI. pag. 130 . 
2. Min. ftanni Eibenftockenfis quarzo albo mixta. (T. IбI.)

3. Min. ftanni in terra alba molliore metallica, Schneebergenfis. (T.162.)

4. Min. ftanni in particulis majoribus cum pauco marmore albo mixta Seifferfwergenfis, pon der Sau. Scbwemme (T. 163.)

5. Concrementum arfenicale fterile, in fodinis ftanniferis Saxonicis frequens, vulgo Wolffram (T. 164.)

6. Concrementum fplendens ftanni minerisadhærens, Zinn-Glimmer. (T. 165.)

7. Stanni Marcafita f. Bifmuthum Schneebergenfe. (T. 170.)

8. Stanni matrix Freibergenfis, intermixtis ftriis fplendentibus cryftallinis. (T. 179.)

9. Stannum purum, adnatum marmore metallico albo cryftallis mixto, Eibenftockenfe (T.185.)

10. Stannum in lapide fiffili viridi Gierenfe ad Greiffen - Stein, Silefiacum. (xftimatur quia ibid. amplius non reperitur) (T. 194.) defcr, G. A. Volckmann in Sil. Subt. Part. II. Cap.V. pag. 224.

II. Stannum nativum in particulis fubrubris (plendentibus, Schneebergenfe (T. 195.)

12. Stanni minera hexagona ex Valle Joachimica (T.235.)

13. Stanni genuina maffa alba absque recrementis, e fodinis metal. licis Cornubienfibús Anglix eruta (T.521.)

14.Stannum nativum ex Saxonia Waldauenfe, ftriis maximis (T.I16.) 15. Stanni minera cryftallina, marmori metallico albo inhærens, Freibergenfis ( $T$.403.)

16. Stannum Malaccenfe optimum, Indix Orientalis (T.415.)

17. Stanni excrefcentia fingularis genuina, pediculo ex ftanni mineris nativi infiftens (T.487.)

18. Stanni genuina maffa nigra absque recrementis fingularis pulchritudinis ( $\Gamma .262$.

19. Minera ftanni cui pyrites ineft Zienwaldenfis (T.S13.)

20. Minera ftanno dives Stolbergenfis (T.5 I 4.)

2I. Minera ftanni cryftallina Altenbergenfis (T.515.)

22. Stannum nativum in particulis Pobrifchauenfis (T.5I6.)

23. Minera ftanni Eibenftockenfis, aus St. Georgen Fund-Grube (T.5I7.) 24. Mi- 
24. Minera ftanni Greiffenbergentis Siletix (T.600.)

25. Minera ftanni cui plumbum ineft ex Rhetia (T.639.)

\section{A R T I C VLVS V. \\ Miner e Plumbi.}

I. Minera plumbi folida Goslarienfis fplendefcens (T.3.) Traetationem harum minerar. defcr. Dav. Kelnerus in Praxi metallica curiofa pag.241.

2. Minera plumbi Goslarienfis cum ære mixta ( $(\mathrm{T} .4$.

3. Minera plumbi cœerulea ejusdem loci (T.6.)

4. Minium ex plumbo Goslarienfi (T.9.)

5. Lithargyrium de plumbo Goslarienfi (T.13.)

6. Minera plumbi Reichenbachenfis Sil. alba in particulis (T.62.) defcr. G. A.Volckmann in Sil. Subr. Par..II. Cap.IV. pag.22z.feqq.

7. Minera plumbi Schemnicenfis Hungarica, cum fpiculis fplendentibus majoribus (T.74.)

8. Minera plumbi Hungarica ( $\mathrm{T} .75$.

9. Minera Clausthalenfis, ex plumbo, cupro, quarzo, marmore metallico, albo, rubro \& cinereo compofita (T.76.)

10. Zona plumbea, per quarzum album tranfcurrens, Clausthalenfis (T.79.)

11. Vena tota plumbea, in faxo albo ejusdem loci (T.80.)

12. Vena fuperius plumbea, inferius cuprea, per marmor metallicum album tranfiens, Clausthalenfis (T.8I.)

13. Plumbum in glebis Zellerfeldenfe, quarzo albo adnatum (T.82.)

14. Plumbi particula ejusdem loci, in quarzo albo (T.83.)

15. Minera plumbiZellerfeldenfis globofa, $f$. modico argento intermixta, grobfpeifger Bley. Glantz (T.84.)

16. Minera plumbi ex fimplici in globofam tranfiens, aus dem Klein. Speifgen ins Grobfpeifge abfetzende Ertz (T.86.)

17. Minera plumbiZellerfeldenfis fimplex, cui multum argenti ineft, kieinfpeifger Bley-Glantz (T.85.)

18. Minera plumbi folida ibidem frequens, cupro \& argento dives (T 87.)

19. Minera plumbi Zellerfeldenfis cœrulea (T.89.)

20. Minera plumbi ejusdem loci in marmore metallico albo.(T.gr.) 


\section{ET ARTIFICIALIVM KVNDMANN. VRATISLAV, 273}

21. Minera plumbi in aqua ibidem contufa (T.129.) Traçationem minerarum Zelierfeldenfium \& Clausthalenfium defrr. G. E. Löbneys im Beriche von Berg-Wercken fol.84, b.

22. Minera plumbi folida ad urbem Ilkufch Regni Polonix (T.r34.) defcr. Georg. Agricola de veteribus \& novis metallis Libr.II. it, Petr. Albinus in der Meifnifchen Berg-Chronica Titul.IX. pag 84.

23. Minera plumbi Gottesbergenfis Sil. ex fodina Wags mit Gott (T.139.) defcr. Volckmannus L. C.

24. Minera plúmbi Freibergenfis parumper glebofa argentifera (T.143.)

25. Minera plumbi ejusdem loci, fpiculis nitentibus majoribus,cum pauxillo argento (T.I 44)

26. Minera plumbi Johann-Georgenftadtenfis in pyrite cinereo inhærens (T.145.)

27. Minera plumbi rarifimaZfopauenfis Silefix, ex cryftallis flavis compofita (T.155.) id. Volckmann.

28. Minera plumbi Schneebergenfis (T.156.)

29. Minera plumbi Schmiedebergenfis Sil. nigra, miculis fplendentibus, modico ære intermix to $(T, 181$ )

30. Minera plumbi, cui argentum nigrum ineft, in marmore metallico, Kupferbergenfis' Silef. (T.I 96.) id. Volckmannus L.C. 31. Minera plumbi Tarnowitzenfis Silef, argentum fovens in Marga flava. (T.237.) id, Volckmann,

32. Minera plumbi cubica Gottesbergenfis Sil. aus der neuen FundGrube (T.243.)

33. Minera plumbi Silberbergenfis Silef. cum pauco argento ( $T$.255.) 34. Minera plumbi ejusdem loci in tabulis (T.284:)

35. Minera plumbi Hungarica in faxo nigro, cui æs ineft (T.288.) 36. Minera plumbi paululum glebofa in marmore metallico albo Andreasbergenfis fylv. Hercyn. (T.289.)

37. Minera plumbi montis gigantei, aus dem Teufels-Grunde (T.290.) 38. Minera plumbi nitidiffima Neofolienfis, ex meris lamellis fplendéntibus conftans (T.309.)

39. Minera plumbi æs fimul fovens in marmore metallico colore albo \& nigro variegato ( $T .320$. 
40. Minera plumbo \& argento dives Hungarica (T.345.)

41. Minera plumbi llkulienfis Polonica ex meris cubis majoribus formata (T.349.)

42. Minera plumbi Dittmannsdorffenfis Silel. cui pauxillum argenti inelt, aus der Gabe GOttes (T.362.)

43. Minera plumbi Gottesbergenfis Sil. in faxo nigro (T.366.)

44. Minera plumbi Schneebergenfis, infitis fpiculis majoribus fplendentibus (T.368.)

45. Minera plumbi elegantiffima, ex meris cubis compofita, cryftallis albis ubique prominentibus, cui aurum \& argentum ineft ex Regno Hifpanix (T.371.)

46. Minera plumbi ejusdem ftructuræ, cryftallis longioribus,infperfis miculis aureis Freibergenfis (T.359.)

47. Minera plumbi Freibergenfis, f piculis nitentibus infitis majoribus (T.123.)

48. Minera plumbi cui argentum ineft, adnatis floribus æris diverficoloribus (T.69.)

49. Minera plumbo dives ex Ducatu Bregenfi Silefiæ (T.23.)

50. Minera plumbi Anglicana prope urbem Novum Caftrum eruta (T.239.)

51. Minera plumbi folida Tarnowitzenfis Silefia (T.240.)

52. Minera plumbi elegantiffima, ex meris cubis compofita, ubi pyrites aureus interftitia adimplet (T.380.)

53.- Terra flavefcens plumbi fera ex Regno Hibernix (T.439.) defcr. Job. Cbriftian von Neidfcbütz in 7. jähriger Reife-Befchreibung pag. 528 .

54. Minera plumbi pellucida alba ex Palatinatu fuper. (T.440.)

55. Plumbum genuinum in granis, ex arena Gros-Zauchenfi prope Maffel collectum, faccharoSaturni incruftatum. (T.445.) vid. Leonb. Dav. Hermanni Maslograph. Cap.IV. pag.195. \& 196.

56. Minera plumbi fimplex Strasbergenfis prope Stollbergam ex fodina dem getreuen Berg.Mann (T.492.)

57. Minera plumbi genuina Hartzgerodenfis Anhaltina ex meris cubis compofita fodinæ ab Alberto nomen habentis (T.493.) 58. Minera plumbi fecundum longitudinem itriata, ibidem eruta ex fodina dem Drufen-Zuge $(\mathbf{T} ; 494$.$) Defcriptionem Metallifodinarum$ \& Mi- 
\&Minerarum Hartzergedenfium dedit Job.Ernef. Müller in Breslauifch.Samml.von Natur.und Medic, Gefcbicbien XIX.Verf. An.1722. Menf. Febr. Claff.IV. Art.IV. pag.I68.feqq. XX. Verf. Menf. April. Claf.IV. Art. III. pag.374.feqq. Menf. Maj. Clafr.IV. Art.XH. pag.504.feqq. Menf.Jun. Claff.IV. Art. VII. pag.605. feqq. XXI. Verf. Menf. Jul. Clafr.IV. Art.VI. pag.75.feqq. Menf.Auguft. Claft. IV. Art.XI. pag.192.feqq. Menf. Sept. Clalf.IV. Art.XI. pag.320.feqq. XXII. Verf. Menf. Octobr. Claff.IV. Art.XI. pag.445.feqq. Menf. Novembr. Clafr.IV. Art.IX. pag.56r.feqq. Menf. Decembr. Claff.IV. Art.VI. pag.672. feqq.

59. Minera plumbi fimplex ex Palatinatu fuperiori.

60. Minera plumbi in faxo albo Freibergenfis (T.5io.

61. Minera plumbi genuina cryftallina flava ex Mifnia (T. 5 I I.)

62. Minera plumbi genuina talis viridis Freibergenfis, aus der Tzerper Fund-Grube (T.512.)

63. Minera plumbi peralba Tzfopauenfis rariff. (T.52r.)

64. Minera plumbi Freibergenfis turrita cum argento (T.544.)

65. Minera plumbi ejusdem loci, aus dem Kub-Scbacbt, cui multum argenti ineft (T.549.)

66. Minera plumbi Gottesbergenfis Silefix ex fodina Wags mit GOtt (T.597.)

67. Minera plumbi in calcis lapide albo prope Goldbergam, zu Hafel (T.6or:)

68. Minera plumbi Schlaizana Voigtlandiæ globofa (T.602.) 69. Minera plumbi Kolbnicenfis Silef. ex Ducat.Jaurovienfi (T.603.) 70. Minera plumbi ex fimplici in globofam tranfiens Schwartzbergenfis Mifnica (T.604.)

7I. Minera plumbi Königsgrudenfis Hungarica (T.617.)

72. Minera plumbi fpecularis ex Rhetia (T.6I8.)

73. Minera plumbi Weiftericenfis ex Ducatu Jaurovienfi Silefix (T.619.)

74. Minera plumbi folida cui æx fimul ineft Rhenofeldenfis (T.62i.) 75. Minera plumbi Neofolienfis in faxo albo (T.625.)

76. Minera plumbi fpecularis egregia Andreasbergenfis (T.635.)

77. Minera plumbi Steinachenfis Dillenburgica (T.638.)

78. Minera plumbi ftriata, cui multum argenti ineft, Strasbergenfis Stollbergica, aus der Eleonora.

79. Minera plumbi rariffima alba tubularis Bleyftadtenfis Bohemica (T.529.) M m 2 


\section{ARTICVLVS VI. \\ Mineræ Ferri.}

1. Minera ferri Quedlinburgenfis rubicundá (T.25.) de variis ferri Mineris, vid. Mart. Liffer de fontibus medicatis Anglix; de Ferro quoque Nic. Mhonardes Dialogum publicavit, qui habetur poft Cluffi Exoric. Libr.f. inter Monardi Magno. Medicin. Secreta pag.19..-33. Conf. Guern. Rolfnncii Differtationes Chimicas in fine.

2. Minera ferri alia ejusdem diftrictus (T.26.)

3. Minera ferri Hüttenrodenfis fylv. Hercynix ex atrorubefcens, cum faxo albo mixta (T.27.)

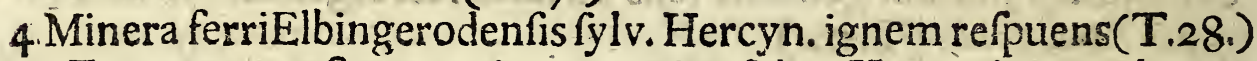
5. Ferram excoctum optimum totius fylva Hercynix, aus dem Ritben-Lande (T.29.)

6. Minera ferri coerulea ex Diftritu Schosnizowicenfi ('Г.66.)

7. Minera ferri folida Kupferbergenfis, colore in fuperficie rubro, interne cœruleo (T.67.)

8. Minera prope Hirfchbergam de ferro, fulphure \& Vitriolo participans (T.68.)

9. Minera ferri fubflava friabilis Tarnovvizenfis Siles. fuper. (T.94.J 10. Ferri flores ex Stiria fuper. in fodinis ex albicante matrice repullulantes Besleri (T.107.) vid. Ejus Gazophylacium fol.8. pre. del. \& defcr. Carol. Oebmbius in Mifcell. Acad. Nat. Curiof. Dec,II. An.VI. pag.297. it. Ul. Aldrovandus in Muf. Metall. Libr.I. pag.135.

11. Ferri flores albi mire inflexi cum matrice (T.213.)

12. Minera ferri Schmidebergenfis Silef, nigra marmori metallico albo inhærens (T.132.) vid. Volckmannus Sil. Subt. Part.1I, Cap.VII. p.232, 13. Ferri Schiftus ruber ex Mifnia Glafs-Kopff (T.I66.)

14. Ferri minera rubra ex Mifnia, adnatis cryftallis fplendentibus (T.167.)

15. Minera ferri tolta, coloris aurei faturatioris (T.182.)

16. Minera ferri rubra, f.Hæmatites Eibenitockenfis, bom Eifen-Hammer. (T.202.) Hxmatiten \& Schiftum defcr. \& del. Georg. Agricola de Nar. Fofil. Libr.V. Cap.V. p. 509. Ans, Boetius in Hift. Gem. \& Lapid. Lib.11. Cap. CCV. pag.386. \& Cap.CCXI, pag.392, Ml. Aldropandus in Mui. Metall. Libr. 


\section{ET ARTIFICIALIVM KVNDMANN. VRA TISLAV. 277}

IV. pag.646. Calceolarii Mufeum Sect.III. pag.269. Ol. Wormins in Muf. Libr.

I. Cap.IX. pag.64. pre. Job. Laur. Baufcbius in Schediafm. Lipf, 1669. public. 17. Minera ferri Hungarica flavefcens ex tabulis minimis compolita, Herrngrundenfis (T.215.)

18. Minera ferri Hungarica nigra in fuperficie miniatà (T.216.)

19. Minera ferri tofta ejusdem Regni (T.226.)

20. Minera ferri alba Vacorienfis (T.302.)

2I. Minera ferri magnetica Schmiedebergenfis (T.3 IO.) defcr. Volckmannus in Sil. Subt. Part.II. Cap.VII. pag.235.

22. Minera ferri fiftulofa ex Ducatu Glogovienfi Silefix (T.354.) defcr. in unferer Sammlung von Natur-und Medicin-Gefchicbten, An.1717. Menf.Sept. Clafr.IV. Art. III. pag.6r. feqq. Conf. Petr. Albini Meifnifche Berg - Chronica Titul.VII. pag.7r. convenit cum delin. \& defcr. quam dedit 7. G. Liebknecbt in Difcurfu de Diluvio maximo, occafione inventi nuper in Comitatu Laubacenfi \& mira metamorphofi in mineram ferri mutati ligni \&c.

23. Minera ferri Malmicenfis Silefiæ nigra friabilis colore cœruleo emicante (T.353.)

24. Minera ferri nigra ignem refpuens duriffima ejusdem loci (T.355.)

25. Minera ferri flava mollis ibidem frequens (T.356.) vid. unfere Sammlungen von Natur-und Medicin. Gefcbicbten L.C. it. G. A. Volckmanni Sil. Subter. Parr.II. Cap.VII. pag.233.

26. Schiltus ex rubro niger, ffriis longiffimis Neuhammerenfis, prope Eibenftock (T.III.) conven. cum del. \& defcr. ap. F. H. Lochnerum in Muf. Besler. Tab.XXIX. pag. 88. it. Fer. Imperatum Hift. Natur. Libr. XXVI. pag.792.

27. Minera ferri f. Hæmatites Schmœlnicenfis (T.I12.)

28. Schiftus ftriatus coloris nigricantis prope Neukrantz ad Eibenftock (T.178.)

29. Minera Martis globularis Kleinfchweinerenfis Silefiæ (T.178.) 30. Minera ferri ramofa ibidem effoffa (T.395.).

31. Arena Martialis multiculor, in littoribus Boruffiæ marinis colleeta (T.396.)

32. Arena nigra perMagnetem ex arena antecedenti extracta, fufionem refpuens ( $T$.397.)

33. Minera Martis globofa durifima Malifchauenfis Bohemica(S.329.) Mm 3 
34. Minera ferri mulcicolor Goldbergenfis Siles. ( $T$.405)

35. Minera ferri fubcærulea Kupferbergenfis Silefiæ (T.4II.)

36. Minera cui ferrum ineft Seitendorffenfis prope Altwaffer ex Ducat.Schwidnic. Siles. (T.4I 4.)

37. Minera ferri candidiffima ex Stiria fuperiori (T.488.) -

38. Minera Martis folaris Haffiaca Meg-Almerodenfis (S. 495) exa-

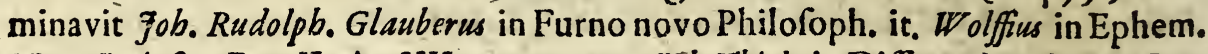
Nat. Curiofor. Dec.II. An.VII. p.359. pre. Fob. Tbiele in Differt. de Minera Martis folari feu acidularum artificialium materia. Conf. Valentini Mufeum Mufeor. Part.I. Cap.I. S.I2. pag.4.

39. Minera Martis cinerea ex meris granulis compofita raro occurrens prope Redwitz Marchionat. Byruthini ex fodina der neuex Glïcks-Grube (T.507.)

40. Minera Martis folaris egregia nigra botryoides, von der Mardla, am Ficbtelberge (T.505.)

41. Minera Martis rariffima aurifera coloris obfcure viridis fplendentis, aus dem Eulen-Locbe am Ficbtelberge (T.506.)

42. Minera Ferri Wiefenthalenfis (T.520.)

43. FerriSchiftus ruber Auersbachenfis ( $($.539.)

44. Ferri minera Hungarica in tabulis, externe viridis, interne cro. cei coloris (T.564.)

45. Ferri minera fingularis elegantix Leynauenfis prope Bernam Helvet. in fuperficie Pifolithum referens (T.637.)

\section{ARTICVLVS VII. Mineralia, five metallis affinia.}

1. Minera Antimonii folaris ex Hungaria adnatis cryftallis flavis (T. 39.) talem del. \& defcr. $12 l$. Aldropandus in Mur.Metall. pag. 188. De Antimonio alias evolvendus Bapt. Codroncbius in Tr. de Antimonio, qui reperitur poft Librum de Chriftiana \& tuta medendi ratione, Angelus Sala Tr. de Antimonio five Operum Chimicorum Tr.1X. de ufu medico vid. Lucas Stenglius in Apologia adverfus Stibii Spongiam, Lamy Differt. de Antimonio gallice frripta, it. Fuff. Vefti Differt. Erfurt. An. 17II. habit. Analyfin Chimicaminttituit Lemery Tr. de l'Antimoine aliique.

2. Cadmia metallica ex Silef. fuper. Tarnowicenfis (T. $7 \mathrm{I}_{\text {. }}$ ) 
ET ARTIFICIALIVM KVNDMANN. VRATISLAV. 279

3. Minera Reichfteinenfis Silefiæ nigra, lapidem fpecularem æmulans cum Nihilo metallico, aus dem Fürfen - Stollen (T.5I.)

4. Minera talis tofta Ammochryfon referens (T. 52.)

5. Minera Beichfteinenfis nullo igne domabilis( $T .53^{\circ}$ )

6. Min. talis nigra miculis argentei fplendoris $(T \cdot$. 54.)

7. Min. ignem refpuens tota nigra ibidem frequens. ( $T .55$.)

8. Min. Reichfteinenfis obfcure rubra, punctis emicantibus aureis (T.56.)

9. Min, duriffima nigra ex meris ftratis compofita (T.57.)

10. Minera Reichfteinenfis, ex qua Arfenicum fublimatur (T. 497.) defcr. Georg. Ant. Volckmann in Silef. Subter. Part.1I. Cap, X. pag. 249.

II. Min. Bifmuthi punctis aureis infperfa Bogantzenfis Hungariæ (T. 133.)

12. Marcafita aurea polygona rariff. ex meris cubis formata, GoldKieß. (T.I48.) talem del. \& defcr. Ol. Wormins in Muf. Libr. I. Cap. III. pag. 40 . Georg. Fabritius in Obf. de reb. metallic. Obf. XI. pag. 29. Anf. Boetiuss Hift. Gem. \& Lap. Lib. II. Cap. CCXC. pag. 517 . prc. Ferr. Imperatus Hiftor.Natural. Libr.XVI. pag. 514. feqq.

13. Minera Cobalti f. Cadmia metallica cum floribus Scheibenbergenfis, ex qua Smalta, Bifmuthum \& Arfenicum coquitur. (T.157.) Modum preparandi docuit Fob. Kunckelius in Annotation. in An.

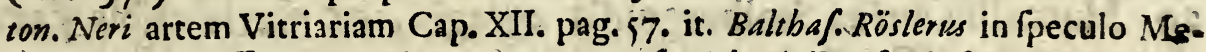
tallurgix politiffim. Cap. XX. pag. 162. conf.Valentini Mur. Mufeor. Part. I. Lib. I. Cap.XIV. pag. 39. feqq.

14. Vitrum cœruleum ex quo Smalta prxparatur (T. 158.)

15. Vitrum tale in pulvere \& granis $\left(T: 294^{\circ}\right)$

16. Minera antimonii nativa nondum ignem experta Eibenftockenfis (T. 168.)

17. Marcafita ex Hungaria (T.169)

18. Concrementum, argenti fpumæ fimile ex Mifnia vulgo Mißs puickel. (T.172.)

19. Chryfocolla nativa $f$ Minera, ex qua Viride montanum conficitur Berg-Grïn, Stein - Grün, Schiffer - Grïn, Schwartzenbergenfis (T. 174.) vid. ul. Aldrovandus in Mur. Metall. Libr. II. pag. 348 . prc. Fob. Laur. Baufsbius in Schediafmate pofthumo de Coeruleo \& Chryfocolla. 
20. Alumen plumofum aurum in terra indicans (T. 175.)

21.' Minera Cinnabarina rubra Alsheimenfis (T. I80.) Cinnabarim Phyfice, Medice \& Chymice examinavit. Mattb. Tilingins in Defcr. Cinnabaris, it. Gerard. Goris in Mercurio Triumphatore.

22. Minera antimonii cum multo pyrite ex montibus Sudetis Silef. beym Pecb-Ofen (T.199:)

23. Minera rariffima Hydrienfis, f. Idrienfis cui argentum, cinnabaris \& multum Mercurii virginei in globulis ineft. ( $T .208$.) defcr. in Valvafors Ehre des Hertzogth. Crain Part. I. Lib. LII.Cap. XXVI. pag. 396. feqq. it. in Henr. Oldenburgii Adt. Philof. Soc. Reg. in Angl. An. 1669. Menf. April. pag. 16.

24. Pyrites metallaris aureus ex Helvetia teffellatus ( $S, 125$. convenit cum del. Car. Nic. Langii in Hift. Lap. figurator. Helves. Part. I. Cap. VI. Tab. II. num. 4. pag. I4.

25. Minera cinnabarina ex Tranfylvania cinerea punctulis aureis infperfa, aurum fovens. (T.222.)

26. Pyrites aureus ex Regno Hungarix (T. 223.)

27. Vena tota cinnabarina per margam metallicam albam tranfiens Regni Japonix (T. 253.)

29. Minera antimonii genuina ex Regno Hungarixignem nondum experta (T.254.)

29. Marcafita aurea Stolbergenfis egregia, ex meris cubis parvis compofita (T.258.)

30. Minera antimonii optima Hungarica ftriis fplendentibus oblongis (T. 286.)

31. Minera antimonii Cremnicenfis egregie ftriata (T. 298.)

32. Minera ex qua in Mifnia Arfenicum præparatur. ( $T \cdot 306$. vid. Fob. Kunckelii Annot, in Ant. Neri Art, vitrariam experimental. Libr.I. Cap. I. pag. 59.

33. Regulus antimonii arfenicalis ftanno fplendorem \& duritiem argenti concilians. (T. 322 .)

34. Antimonium Hungaricum optimum ( $T$. 323.)

35. Minera cinnabarina miniata ex Ducat. Tranfylvaniæ,cui aurum \& argentum fimul ineft. $(\mathrm{T}, 326$.

36. Min. cinnabaris Hungarica rubra miculis fplendentibus in $\mathrm{Li}=$ thomarga alba ( $T .334$. 
ET ARTIFICIALIVM KVNDMANN. VRATISLAV. $28 \mathrm{I}$ 37. Minera antimonii Freibergenfis vom Ober-Haufe Sarbfen-Zecbe (T.344.)

38. Chryfocolla nativa five viride montanum in marga metallica rubra ( $T$. 347.)

39. Cadmia botryites metallica, $f$. Cobaltum torrefactum cinereum egregium, in quo vi ignis granula argenti puriffimi fimilia extracta, eminent, Vallis Joachimicæ. ( T.369.) vid. Ol. Wormius Muf. Libr. I. Sea.II. Cap.X. pag. 128.

40. Minera Seitendorffenfis f. Dittmannsdorffenfis Silef, prope AltWaffer, ex qua Magnefia rubra præparatur. (T.414) vid. lnfere Samml. von Nat. und Med. Gefcbicht.IV.Verf. An.1718. Menf. April. Cl.V. Arr.III. pag. 1006. feqq.

4I. Magnefia rubra ex minera antecedenti, Braunfein (T. 372.)

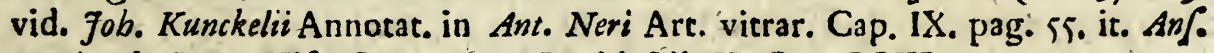
Boetius de Boor Hift. Gemmar. \& Lapid, Lib.II. Cap.CCIX. pag. 390.

42. Talcum nigrum Reichfteinenfe (T.59.;)

43. Talcum $\mathrm{f}$. Alumen Scisfile petrxum album \& rubrum Jenenfe alternatim pofitum Ketze.. Stein ( T.I I3.) vid. Georg.Ant.Volckmann Sil. Subrer. Part. I. Cap. II. pag. 44.

44. Talcum rubrum ejusdem loci colore cinereo variegatum

(T. II 4)

45. Talcum totum rubrum ibid. frequens (T.III.)

46. Talcum petræum tale candidisfimum (T.112.)

47. Talcum carnei coloris ibid. erutum (T.455.)

48. Minera Arfenicalis flava Auftriaca (T.177.)

49. Talcum Venetum coloris laetei ftriis fplendentibus (T.I06.)

50. Sterile nitidum aurei fplendoris ftriatum ex Mifnia Gold - Glimmer (T. 127.) defcr. Georg. Fabritius Obf, de rebus metallicis Obf. X. pag. 28. lit. b.

51. Mercurius in granis Hydrix in Iftria effoffus ( T.70.)

52. Cœruleum, Berg. Blau \& viride montanum Saalfeldenfe nativum (T.108.) hoc defcr. Fob. Laur. Baufcbius in Schediafm. pofthunio fub titul. de Coruleo \& Chryiocolla, quod Jenx I668. prod.

53. Arfenicum nativum citrinum (T.190.)

54. Cadmia rudis nativa cum arbufculis nondum ignem exper$\mathrm{Nn}$ 
ta, coloris nigricantis, Krapitzenfis ex Sil, fuper. Galimey.

(T. 400.)

55. Cadmia talis calcinata metalli expers ( $\mathrm{T}$.38I.)

56. Minera cinnabarina in marmore metallico albo \& nigro,cui pý-

rites infperfus, ex Comitatu Cepufienfi Hungariæ. (392.)

57. Minera cinnabarina in faxo nigro ibidem effoffa, ignem refpuens

( $\mathrm{T} .393$ )

58. Minera turrita antimonialis magna Cremnicenfis ( $T$. 394.) defcr. Ol. IVormius in Mui. Libr. I. Sect. II. Cap. VIII. pag. 126.

59. Chryfocolla cui æs fimul ineft Neofolienfis Hungarica ( $\mathbf{T} . \hat{\mathrm{B}} 89$.) 60. Pyrites ex parvis cubis formatus argentei coloris Regni. Bohemix, weiffer Waffer-Kieß. (T. 398.)

61. Pyrites albicans faxo duriffimo albo adhærens, ejusd. Regni prope Eulau (T.399.)

62. Magnefia folaris cinnabarina Schemnicenfis Hungarica (T.39I.) 63. Magnefia aurei fplendoris (T.12.)

64. Lapis fpecularis pellucidus, \& alius coloris argentei ex Regno Mofcovix (T. 463.)

65. Lapis fpecularis Reichfteinenfis Silefiæ niger, Aphrofelinus obfcurus Scbwenck feldii (T.462. vid. Fjusd. Caralogus fofil. Silef, Libr. III. pag. 363 .

66. Lapis fpecularis niger in matrice f. marmore metallico albo, ex monte Sabothu Ducat. Suidnicenf. Siler. (T.460.)

67. Lapis fpecularis ejusd. loci a matrice feparatus (T.4.

68. Lapis fpecularis Hungaricus (T.464.)

69. Glacies Mariæ ex Regno Mofcoviæ (T.482.)

70. Minera Mercurii Carinthiaca colorisatrorubefcentis. (T.435.)

71. Minera Mercurio dives Reichfteinenfis Silef. argentei fplendo-

ris ( $T .438$.

72. Minera cinnabarina obfcure rubra Regni Hungarix (utuntur

pro Ethiope minerali) (T.446)

73. Marcafita argentea Schœenbrunnenfis Siled. (T.453)

74. Minera arfenicalis rarioris notæ fplendens Vallis Joachimia

(T.454.)

75. Arfenicum genuinum rubrum,aurum in terra indicans (T.176.) s... 76. La- 
76. Lapis fpecularis Steinkirchenfis prope urbem Strehlen in ma: trice (T. 456.)

77. Lapis fpecularis a matrice feparatus in particulis (T.457.)

78. Lapis fpecularis cipereus opacus ex -Duc. Troppavienfi Silef. ( $\mathrm{T} .465$ )

79. Lapis fpecularis albus diaphanus ibid. erutus (T.466.)

80. Pyrites cubicus ex fodinis carbonariis Rothenbachenfis ( $T .470$.

81. Min. cinnabarina fplendens genuina ex Comitatu Cepufienf Hungarix (T.47r.)

82. Min. cinnabari dives Schemnicenfis, miculis parvis fplendentibus (T.472.)

83. Min. cinnabarina in marmore metallicoalbo Clausthalenfis Sylv: Hercyn. ( $T .473$.)

84. Minera cinnabarina Rudibanienfis Tranfylvaniæ genuina ( $T \cdot 474$ )

85. Minera in qua cinnabaris rubro colore, \& faxum album in ftriis elegantiffime fe diftinguit, Indiz Orientalis. ( $T .475$.

86. Minera cinnabarina Hungarica $\int$. Vena tota cinnabarina per faxum nigrum miculis aureis \& argenteis infperfum, tranfiens (T. 476.$)$

87. Minera cinnabarina Rofenauenfis Hungarica ( $T$. 457.)

88. Minera cinnabarina Chemnicenfis folaris ( $T$. 478.)

89. Minera cinnabarina ejusdem loci alia in particulis $(T .479$.

90. Min. cinnabarina ibid. eruta, cui aurum ineft ( $T .480$.

91. Talcum \&. Alumen fciffile album ftriis fplendentibus ex Duc:

Tranfylvaniz (T.48I.)

92. Minera antimonii egregia turrita Cremnicenfis (T.109.)

93. Minera antimonii genuina Hungarica $(T$.498.)

94. Minera antimonii in faxo albo Braunsdorffenfis prope Freiber: gam. (T.499.)

95. Minera antimonii Stolbergenfis ignem nondum experta (T.500)

96. Minera antimonii Hungarica cum ftriis nitentibus(T.501.) 
97. Minera antimonii Hungarica tota ftriata (T.502.)

98. Pyrites fingularis flammulis cubicis aureis in fuperficie confperfus, ex Rhetia (S. 194.)

97. Gobaltum venenatiffimum ex lamellis compofitum, scherbenCobalt, aus der Kayfer- Fofephs-Zecbe am foichimstbal (T-508:)

100. Concrementum Freibergenfe fplendens, vulgo Mifpichel, aus dem Kub-Schacht. ( T. 5 18.)

101. Bifmuthum Lotharingicum (T.519.)

102. Pyrites Vitriolo dives ( $T, 536$.

103. Minera ex monticulis albis femidiaphanis compofita (vulgo Sinter) (T.537.)

104. Talcum lunare Mofcoviticum (T.538.)

105. Minera cinnabarina Regni Japonix ( T.542.)

106. Minera cinnabarina ejusdem Regni fingularis elegantix tabulam politam albam colore coccineo variegatam referens. ( $T$. 543 .) 107. Cœruleum montanum cum Chryfocolla in faxo cinereo (T.546.)

108. Minera Cobalti Wolckenfteinenfis(T.547.)

109. Cœruleum montanum nativum Saxonicum, cui argentum ineft. (T. 548.)

110. Pyrites tabulatus in matrice Freibergenfis argento dives (T.567.)

II I. Bifmuthum Schneebergenfe (T.568)

112. Talcum album ex Stiria (T. 575.)

I13. Cobaltum Kupferbergenfe ex miculis (plendentibus ( $T$.596.)

114. Cobaltum Schwartzbergenfe ex Mifnia (T.599.)

115. Minera nigra antimonii ex Voigtlandia (T. 607. )

116. Minera antimonii Regni Bohemix, cui parum argenti ineft

(T. 608.)

117. Minera antimonii folida ex Marchionatu Byruthino (T.609.)

118. Minera antimonii mire ftriata ex Tranfylvania (T. 610.)

I19. Minera antimonii ibidem eruta ftriis robuftioribus (T. 6 II.)

120. Minera antimonii turrita maxima Cremnicenfis (T.612.)

121. Minera talis minor ejusdem loci (T.613.) 


\section{ET ARTIFIGIALIVM KVNDMANN. VRATISLAV. 285}

122. Minera ex ftriis antimonialibus \& cubris cryftallinis albis com:

pofita $($ T.6r4.)

123. Minera antinonii ex montibus Riphæis beym groffem Teiche

(T.620.)

124. Minera antimonii Hungarica, cui argentum fimul ineft

( $\mathrm{T}, 628$.

125. Cadmia rudis Chemnicenfis (T.630.)

126. Marcafita aurea, ubique prominentibus papillis, \& cufpitibus (T.640.) talem defcr. Fob. Baubinus in Hift. Fontis \& Balnei Bolhenfis pog. 37 .

127. Marcafita aurea ex meris tabulis conftans (T. 643.)

SCriptores rerum. Metallicarum collegit in eleganti de Are Schediafmate $D^{\circ}$ Cbrifianus ab Helwich, quod annexum Mifcellan. Acad. Nat. Cariofor. Dé. III. An. VII. \& IIX. pag. 143. Quibus jungendi : Hieron. Cardanus de Subtilitate Lib. V. \& VI. pag. 116. I60. ubi de mixtione Metallorum \& Metallis ipris agit. 7oh. Matthefius in Sarepta, quam in compendium redegic D.av. Kelner im Bergund Salz-Wercks - Buch; Andr. Libavius in Commentationibus Metallicis, qua annex. ejusdem Alchemix. Job. Fonflonus in Thavmatographia Naturali, it. in Ejusdem Nottia Regni Mineralis Cap. V.pag. 86. Atban. Kircbérus in Muído fubter. Lib. X. pag. 162. - 230. Bernh. Cafius in Mineralogia. Ul. Aldrovandus in Mur. Metallic. toto Libr. I. pag. 1. - 205. Lud. de Comitibus in Elucid. Metallor. \& Metallicarum Naturx opum. Ol. Wormius Muf. Libr. I. Sect. IIl. pag. I13. Feqq. Ferrand. Imperatus Hiftor. Natural. Lib. XVI. \& XVII. Eman. Köng in Regn. Mineral. Sect. I. \& II. \&c. De Generatione \& Mixtione Metallorum \& Mineralium fubterranea, inftar omnium effe poteft 7ob. Foacb. Becberus in Phyfica fubterran. precip. editio, quam cum fpecimine Becberiano Georg. Erneft. Stablius publicavit; Cxteros Authores huc pertinentes it. varias opinicnes collegit Joh. Zach. Blattner in Differt, de Generatione Metallorum Lipf. habita.

De Metallifodinis Silefiacis evolvend. Georg. Ant. Volckmannus in Silefia Subterr. Part.II. p 193:1eqq. de Metallifodinis montis Gigantei vid. Th. Cretzmar in Mineralogia montis Gigantei; de Bohemicis Bobusl, Balbinus in Mifcell. Hitt. Regn. Bohem. Libr.I. Cэp.XIII. pag.37.feqq. ir. 7ob. Georg. Greifelius in Ephem. Nat. Curiof. Dec.I. An II. Obferv.LXXVIII. pag.I40.feqq. de Johánn.Georgenftadtenfibus in Saxonia fob. Chriflian Engetfchall in Befchreibung der Exulanten-und Berg . Stadt Johann Georgenftadt Part. III. de Annxbergicis Paulus Jenifus in Hift. Annxhergx; de Mifnicis Petr. Albinús in der. Meilinilchen Berg.Chronica Partall. p.17. Cbriff. Melizer von denen Ertzgebürgifchen Silber. Bergvvercken, 
it. Ad. Rechenberg in Difl. de Hermuncturorum arigentaria oder von Ertzgebürgifchen Silber-Bergvverck; de Hungaricis Matb. Belius in Hungarix antiquo \& novo Prodromo Lib.III Cap.IX. pag.I5z. de Carniolenfibus Valpafor in der Eure des Herzogch. Crains Libr.IlI. Cap.XVI..-XXIX. pag.318.feqq. SylvæHercynia Fob.Henr. Meibomius in Differtation. deMetallifodinarum Hartzicarum prima Ori. gine \& Progreffu Helmftad. habit. de Harzgerodenfibus Cbriflopb. Mafkius in pecul. Difl, de Goslarienfibus id. Meibomins L. C. it. Läbneys im Bericht von Berg. Wercken fol. 7\%. de Brunfvigenfibus \& Lineburgenfibus Tbom. Scbreiber im Hiftorifchen Bericht von Ankunffe und Anfang der Braunfchv veig-und Lüneburgifchen Berg. Werclke auf dem Hartz; de Helveticis fob. Fac. Scheucbzerus in Narur. Gefchichten des Schvveitzerlandes Part.II. pag.I7.feqq. de Svecicis Job. Frid Leopold inRelatione Epiftolica de Itinere fuo Svecico An. 1707. facto; deLap. ponicis \& aliorum Regnorum Septentrionaliutn fob. Scbefferus in Lapponia, it. Olaus Rudbeckius in Lapponia illuftrata; de Americanis Alvarus Alonfus Barba im Berg. Büchl. ubi prxcipue tractationem auri \& argenti in Potofianis \& confinibus fodinis defcripfit, quam cum aliis delin. \& defcr. Erafm. Francifciim OAt.und Weft. Indif hen Luft-Garten Part.II. Tab.XL. num.2. pag.II20.feqq. de Habeflinis 7ob. Ludolfus in Commentar, ad Hiftoriam, Ethiopicam Cap.VII.

De Metallurgia Pyrotechnica \& Docimafia metallica confulend. Andr. Libavius in $\mathrm{Tr}$. de arte probandi mineralia, qui reperitur in fine Alchemix five pag.163. Mo. definus Facbs im Probier - Büchl. it. fupra allegatus Imperatus L. C. Libro toto XVIII. XIX. \& XX. Georg. Engelbard Lëbneys im Bericht von Berg. Wercken, Lazarus Ercker in Aula Subterranea, Baltbaf.Röeslerus in Speculo Metallurgiæ politis. fino, oder Hellpolirten Berg.Spigel, Job. Rudolpb. Glauberus in Furno Philofophico Part, IV. Scbindlerus im geheimen Müntz-Guardein und Berg - Probirer, nebft beygefügter metallifchen Probier-Kunft, Dav.Kelnerus inPraxi metallica curiofa, oder curiöfen und experimentirten Schmeltz-Proben, it. im Berg und SaltzWercks-Buch, Casp. Cramerus in Collegio Chymico Differt.V. Cap.I. it. Abrab. a Scbenberg in der ausführlichen Berg. Information, Valent. Kräutermann im accuraten Scheider und künftlichen Probirer, prc. Georg. Erneft. Stablius in Differt. de Metallurgiæ Pyrotechnicx \& Docimaf. Metallic fundanientis.

Enchyrifes varias docuit Sincerus Renatus in der goldenen Quelle der Natur und Kunft pag.189. usque ad finem, it. Foh.Conr.Barchufen in Pyrofophia prc. Part. II. \& III. Methodum Hydroftaticam prætentandi minerarum æftimationem propofuit Rob. Boyle in Hydroftatic ad Materiam Medicam applicatæ Appendice. Terminos Metallurgicos explicavit Chriftian. Berwardus in Phrafeologia metallurgica, qua annexa Erckeri Aul. Subterran. it. multos inferioris Saxoniæ metallifodinis receptos explicuit Mod. Facbfius im Probier-Buichl. it. G. Fungbanfius in Vocabulario Metallico; pluribus id egic Apdr. Bayerus im Chriftlichen Bergmann, und 
Bergmannifchen Chriften; Perfectum vero Dictionarium Scbenbergio debemus, quod reperitur in fine der ausführlichen Berg-Information.

Naturam Metallorum \& Medicamenta ex Regno Mineralipetita collegit Cbrifloph. Encelius de re Metallica, hoc eft, de Origine, Veritate \& Natura Corporum Metallicorum, Lapidum, Gemmarum etc.adMedicin $x$ ufum infervientium, Eman.Kö.nig in Regno Minërali, Valent. Kräutermann im Hịtorifch. Medicinifch. Regno Minerali, prc. Fob. Agricola in feinen Anmerckungen tiber die Chymifche Artzneyen Job. Poppii, qua cum annotationibus' Fob. Henr. Funckens prodiere.

Salia Metallorum examinavit in Differt. Med. Chymica fob.Wolff. Künftel von Saltz der Metallen, infonderheit des Goldes und Queckfilbers : De Sulphure vero Metallorum vid. fob. Frid. Hoffmannum de Sulphuribus Metallorum, prc. Siablii Differtat. fupra allegat. ubi prior pag.6. Catalogum Authorum huc pertinentium propofinit.

\section{A R T IC V-L V S VIII. \\ Recrementa Metallica I. Scorix.}

1. Recrementum nigrum metallicum f: Scoria Scblacke punctis albis infperfa Zellerfeldenfis, quæ mineris Goslarienfibus additur (T.I.) Caufam fcorias has addendi defcr. G. E. Löbneys im Bericht von Berg. Wercken pag.82. it. Dav. Kelner in Praxi metallurgica curiofa 1.24r. De Scoriis multa alias collegit Ol. Wormizu in Mufeo Libr.I. SeC.II. Cap.XIV. pag.I32. ul. Aldrovandus in MuI. Metall. Libr.I. pag.14. Ferrandus Imperatus Hiftor. Na. turalis Libr.XXVI. pag.788. aliique.

2. Recrementa varia Goslarienfia (T.I5.)

3. Recrementa ex affervatoriis vetuftioribus Islebienfibus, quibus æs adbuc ineft, quare de novo mineris adduntur (T.35)

4. Recrementa æris diverforum colorum Islebienfia (T.37.)

5. Recrementa cœrulea qux ferro Rübenlandenfi Hercynia detrahuntur (T.38.)

6. Diphryges $f$ Recrementum ultimum quod in fundo fornacis fuforio remanet, Unter-Ofen-Brucb (T.43.) defer. ull. Aldropandus in Mu: Metallic. Libr.I. Cap XIV.

7. Recrementa Zellerfeldenfia æri fupernatantia (' $\Gamma \cdot 45$ )

8. Saxum nigrum ad fluorem mineris conciliandum (T.77.)

9. Recrementa nigra quæ de are Goslarienfi detrabuntur ( $T .270$. 10, Recrementa ex affervatoriis vetuftioribus Malmicenfia Silefi. ex 
Ducatu Glogovienfi, quibus ferrum adhuc inelt, quare ad coltionem iterum præparantur (T.272)

II. Recrementa fterilia Malmicenfia (T.358)

12. Recrementa ejusd loci ultima, cui ferrum adhuc ineft (T. 356. ) 13. Recrementum quod de lapide arario Kupferbergenfi in ultima coftione ex Catino detrahitur, \& de novo mineris additur (T.274.) 14. Recrementa cum $\$$ te prope Schœnau ad novam fufionem deftinata.

15. Galena factitia in fornacibus depuratoriis auri \& argenti remanens, Teft oder Herd-Kleyen (T.316)

16. Scoria Martis corulea Reifingenfis ( $T .451$.)

\section{ARTICVLVS IX. \\ Salia, Bitumina \& Sulphura.' \\ I. Salia.}

1. Flores Salis ex Hungaria (T.60.) del. \& defcr. in Bresl. Samml. vok Nat. und Medic. Gefib. VII. Verf. An.I719. Menf.Febr. Claff.IV. Artic.VII. p.I29.

2. Sale petrofo virgulæ incruftatæ, ex opere ftillatitio Luzenfi, prope Lipfiam (T.447.)

3. Crufta falino terrea, ( Scböp dicta) cortinis aqux falfe Halenfibus depofita (T.II) ) vid. Frid. Hoffmannus in der Befchreib. des Saltz. Wercks in Halle Cap.IX. pag.3\%。

4. Sal foffile cryftallinum Cracovienfe $f$. Wilicenfe Polonicum ex meris cubis concretum cum variis ex eodum figuris ( $T .483$.)

5. Sal foffile lanuginofum cœruleum ex RegnoHurgariæ (T.424.) De Sale peculiarem Traet. publicav. Job. Tholdius cui Titulus Haliographia; it. Sopbronius Kozack, quibus jungend. Dav. Kellnerus im Saltz-und Bergvverck-Buch, Ant. a Maffa Salis anatomia, in qua origo, facultates, differentix \& felectus falis defcr. Matb. Unzeri Phyfiologia Salis, it. de vario ufu Ant. Scbneebergerus de multiplici Salis ufu, Georg. Cafp. Kircbmayer in Eph. Nat. Curiof. Dec.II. An.VIII. in fin. Conf. Franc. Baconis de Verulamio Hiftoriam Sulphuris, Mercurii \& Salis in operibus fuis, Matb.Willens $\mathrm{Tr}$. de Salis origine ejusque incremento, accremento \& decremento, it. Hermanni Conringii Difputationem de Sale, Nitro \& Alumine, in quá vero tantum de Sale agitur. Varios coquendi modos docuit Georg. sgriıola de re Metall. Libr.XIL pag.439.feqq. it. Eman. König in Regno. Mineral. SeQ.IV. Part.I. 
6. Nitrum Mofcoviticum tubulofum album (T.23.)

De Preparatione varia \& ufu vid. Ul. Aldrovandi Muf. Metall. Libr.III. pag.32r. feqq. it. G. E. Löbneys im Bericht von Berg-Wercken pag.333. prc. Laz. Ercker in Atrl. Subt. oderProbier. Buch Libro V. int gro; De differentibus nartibus \& redintegratione Nitri vid, Rob. Boyle. Tentamiua Phy fiolog. De Figura varia cryAtallor. vid. defer. \& delin. Mart. Lifferi de Fontibus medicatis Anglix, Dominici Guilielmini in Meditationibus Philofophicis circa figuras Salium Italice fcr. Ant. Leerrenbeckii in Anatomia ope Microfcopiorum Epift.IX. pag.Irg. detect. prc. Carol. Nicol. Langii Hitt, Lap. Fig. Helvet. Part.I. C.p.II. pag.2. De uft Medico polychrefto vid. Differt. Frid. Hoffmanni de Nitro ejusdemque Natura \& ufu in Medicina, it. Georg. Ern. Stablii Obferv. Chym. Phyfic. Medic. An,1698. Menf. Mart. Conf. Francifci Baconis de Verulamio Hift. Vit. \& Mort, pag.105. it. Baltbaffar Timai von Güldenklee Operum I. Cafuum Medicinalium Lib.III. CaS. LII. pag.176. Guneb. Cbriftoph. Scbelbameri Commentation. de Nirro cum Veterum tum Noftrorum, præc. de Nitro Veterum vid. Joacb. Jungii Doxofcop. Phyfic. Part.Il. Sec.II. Cap.VII. it. Mart. Lifieri Conchyliorum bivalvium Exerc.iIl. p. I4I.fegq.

7. Nitrum murale calcarium f. Aphronitrum in tubulis (S. 278.) defer. Mart. Lifterus de Fontibus medicatis Angl. Cap. I. num. 9. pag. 6. it. Job. Jac. Stbeuchzerus in Meteorol.' \& Oryctograph. Helvetica pag.177.

8. 9. Vitriolum album \& viride Goslarienfe nativum (T.20.)

10. Vitriolum album fpongiofum Gcslarienfe nativum, Kupfferrauch (T.17.)

11. Vitriolum ftillatitium album ejusdem loci r. ex monte Rámmelsberg, weiffe fockeln, oder fockel-Gut (T.I8.)

12. Vitriolum (tillatitium viride in tubilus, ejusdem loci, grüne fockeln (T.19.) defcr. in Georg.Henning. Bchrens Hercynia curiofa Cap.VI. p.147. De Mineris hic prac. evolvend, G. E, Löbncys im Bericht von Berg. Wercken fol.79. b. Modum coquendi docuit Baltb. Rösler in Speculo Metallurgix politiflimo Cap. XVII. pag.I5G. it. Cbriftian. Berwardus in Interprete Phrofeolog. Metall. pag.33. \& Dap. Kellner in Praxi metallic. curior. pag. 247. prc. pag.294 Anatumiam Vitrioli inftituit Angelus Sala Operum Medico.Chemicor. Tract.X. De Natura \& Proprietate Vitrioli vero egit Operum Tract.XI. Raymundus Mindererus, Difquifit. de Chalcantho, it. Pomet im Materialift. und Spezer. Händler Part.III. Libr.I. Cap.LVII. pag. 36 .

13. Minera Vitrioli f. folaris Haffiaca (T.65.)

14. Minera Vitrioli tufa folaris adZuckmantelam (T.93.)

15. Minera Vitrioli ex montibus Mifnia (TV17I.) 
16. Minera Vitrioli Montis Gigantei, cui mul um xris ineft (T.I 84)

17. Minera Vitrioli folaris ftriata in Pyrite ex Hungaria (T.269.)

18. Vitriolum nativum plumólum Cremnicenfe Hungaricum (T.279.)

19. Vifriolum nativum Hungaricum elegantiffimum ex meris filis fubalbis longiffimis conftans (T.644)

20. Minera Vitrioli coloris aurei, antimonii ad inftar ftriata, prope Kaizenelnbogen $(\mathrm{T}, 296$ )

21. Chalcitis dura, $f$. Vitriolum in lapide rubro Goslarienfi, rotber Atrament-Stein (T.23)

22. Melanteria, $\{$. Vitriolum in lapide cinereo ejısdem loci, grauer Atrament-Stein (T.22.) defcr. cun Chalcitide in Muf. Calceolar. Veronenf. Sect.IV. p. 427. \& 476. Ferrand. Imperatus Hift. Natural. Lib.XIII. Cap.XIV.-. XVIII. pag.432. feqq. Löbneys in Bericht von Berg. Wercken fol.79. G. H. Beb. rens Hercyniz curiolx Cap.lV. p.147. it. Mich.Bernb. Valentini in Muf. Mufeor. Part.I. Libr.I. Cap.VIII. pag.25.

23. Vitriolum cryftallis adnatum (T.Ii7.)

24. Vitriolum vitriformi Hartmanni (T.g6.)

25. Terra Vitrioli flava Cremnicenfis Hungarica (T.391.)

26. Vitrioli flores, $[$. Vitriolum nativum lanuginofum $(T .421)$.

27. Vitriolum nativum ramofum coloris cærulei Hungaricum (T.423.)

28. Vitriolum Romanum ex monte Trinitatis,Lapidem Lazuli æmulans (T.425.)

29. Minera Vitrioli nativi Pyrite inharens (T.55I.)

30. Lignum foffile, ex quo Alumen coquitur prope Diben in Saxonia (T.426.) vid. Petr. Albini Meifnifche Berg-Chronica Tit.XXiV. pag. 183. Job. Casp. Kirsbmeyeri de Sylva Dübenfi. Conf. de AlumineiJoscb. Jungii Doxofcopiam Phyficam Part.lI. Sect.CCVI. it. Job. Franc. Kbuon Diff. de Alumine, ubi S.XVIII.-.XXX. pag.19.-28. prc. virtutes medicamentofas expofuit.

31. Minera aluminofa ejusdem loci nigra (T.472.)

32. Minera aluminofa Reichenbachenfis Voigtland. (T.428.)

33. Minera cui alumen ineft Lähnenfis Bohemica (T 408)

34. Alumen Tolfenfe Romanum fluorem Amethyftinum referens (T.104.) defcr. Atban. Kircberus in Mund. Subterran. Tom.I. Cap de Alunine pag.314. Erafm. Francisci im Oit-und Weft-Ind. Lut Garten Part.II. p.I16\%. Modüm 
ET ARTIFICIALIVM KVNDMANN. VRATISLAV. 291

Modun urendi lapiden \& coquendi vid. Kbuon in fupr. cit. Diff. $\int .156$ pag.16.

35. Alumen nativum Anglicum coloris albi (T. IO5.) Artificium parandi Alumen finculare in Anglia ufitatum accurate expofuit Fob. Rajus in Append. ad Collect. Vocab. Angl. fingul. pag.20r. Io Germania vero folennes modos declararunt præ cxteris Georg. Agricola de re Metallica Lib, Xll. ic Lazar, Ercker in Aul. Subterran. Lib.V. pag.190.

\section{Bitumina.}

1. Lignum foffile bituminorum Ruffinovicenfe Ducatus Oppavien: fis Silefix, Vitriolo imbutum \& quafi exuftum $(T, 420$.)

2. Lignum bituminofum foffile Halenfe ( $T$.459.)

3. Lignum bituminofum Prufficum friabile, Vitriolo imbutum, five Succini mater Hartmanni (T.96) defcr, inunferen Samml. von Nat,und Med.Gefch. V. Verf. An.1718. Menf. Jul. Clarf. IV. Art. XII. pag.1397. it. ap. Georg. Andr. Helwwing in Lithograph. Angerburg. Part.II. Cap.V. 5.7. pag.74. it. Matb.Zachar. Pilling in Traet. de Bitumine \& Ligno Bituminofo; Conf. Tb.Barthotini Act. Med. \& Philofoph. Hafnienf. An.167I. \& 1672. Obf.LVII. pag.IIO. 4.Succinum foffilePrufficum crufta farinacea alba obductum (T.97.) defcr. Tbeopbil. Bonetus in Medicin. Septentrional. Collatitia Part.II. pag. 509, Succinum ejusmodi terreftre Sinenfe $P$. Martinus Martini in Atlante Sinico T. Defcript, Provincix Suchuen pag.65. b. it. Georg. Everb. Rumpbius in Amboinfch. Rarit. Kam. Lib.III. Cap.LXXXVII. pag.340. de Differentia vid. Idem, it. Natban. Sendelius de Succino Indico, qui reperitur poft Breynii Epift. de Melonibus petrefactis pag.35.feqq. De Succino foffili in Bohemia vid. Bobusl. Balbinus Miicell.Hiftor.Regn. Bohem,Dec.I. Libr.I. Cap.L. pag.II5. In Moravia fob. Ferd. Hertodt in Tarcaro-Maft, Part.I. Cap.V. pag.30. In Marchia \&Saxonia, prc. prope Vitembergam, Mifc. Natur. Curiof. Dec.I. An.IX. \& X. pag.223. \& pag. 102. Aliorum locorum Pbil. Fac. Hartmann de Succino Cap.I. \&c. In Silefia vid. UnSere Samml, von Nat, and Med. Gefch. IV.Verf. An:.1718 Menf. Jun. Claff. IV. Art.1X.pag.1234 it. V.Verf. An.1718. Claff.IV. Artic.XII. pag.1397.feqq. In Hotfatia prope Rendsburgum vid. Nebem. Grew in Muf. Regal. Societat. pag.343. in Italia Paulius Boccone in Obfervat. Nat. Obferv. IX. \& c. De catero Succinum defcripf. Andr. Libavius Singular. Part.I. \& III. pag. 4or. feqq. Seperinus Gabelius (qui habetur in Conrad. Gefneri de rerum foffil. Libr.) Pbil. Fac. Hartmannus in Succini Prufliaci Hiftoria Phyfica \& Civil. Job. Wigandus, in vera Hiftoria de Succino Boruffico, Georg. Andr. Helwing in Lithograph. Angerburg. Part.II. Cap. UI. \$.7. pag.74. fegqo, aliique. 
Succinun pro Bitumine terre haber Georg. Agricola de Natur. Folhi. Libr.IV. Cap. IX. pag.48I. Hartmannus fupr. allegat. L. C. Ans. Boetius in Hift. Gemm. \& Lapid. Lib.1I. Cap.CLIX. pag.326. lll. Aldrovandus Muf. Metall Lib.III pag.406. Atban. Kircberis in Mund. Subterran. Tom.I. Lib.VIII. Sect.III. Cap.III. pag.75. Erafm. Francifci im Oft. und Weit Indifch. Luft-Garten Part.I. pag.184. prc. 7 oh. 7ac. Scbeucbzerus Nasur-Gefch. des Schweizzerland. Part.III. pag 68. Frid.Hoffmannus in Obfervationibus Phy fico-Chymicis Selectioribus Lib.ll. Obferv.XXIII. pag.217.feqq. ubi fimul generation $m$ in terra demonitravic.

Pro Petroleo concreto Paul. Boccose in Mufeo f'hyfico \& experimentali Obferv.V. Pro Arboris Gummi veteres ferme omnes Naturalium rerum Scriptcres, quos - collegir Gobann. Rudbeckius Atlantic. Part.I. Cap.XIV. it. Part.II. Cap.VI. quibus jungendi Petrus Belonius Oblerv. Libr.II. Cap.XXVII. p.13.4. Ferrand.Im: peratus Hiftor. Natural. Libr.XIV. pag.449.feqq. Petr. Tumet im Material. und Speżerey-Händl. pag. 85 . prc. Thom. Bartbolinus in AQ.. Medic. \& Philufoph. 1. Hafnienf. An.1673, Obferv.CXXII. pag.30g leqq.

De factitio apud Sinenfes vid. Erafm. Frarcifci in Oft-und Weft.Indifch. Luft-Gart. s) citant. P. Mart. Martinioin Atlante Sinico f. Defcript. Provinc. Suchuen p.65. b. 5. Succini particula in qua mufca inclufa ( $\mathbf{\Gamma} .98$.

6. Item alia cum culice (T.99.)

7. Succini fruftulum cum Scarabao parvo (T.100.)

8. Stylus ex fuccino, in quo mufca corpore exili confpicitur, lagenæ inclufus ('T.208.)

9. Aranea parva pedibus longiffimis, quam fuccinum rubrum circumdat (T.281.)

10. Succinum cardioides, in quo aranea maxima elegantifima (T:484.)

11. Succinum in quo culices \& muliææ fepultæ (T.282.)

12. Succini fruftum cum tribus formicis reconditis ( $\left.T: 485^{\circ}\right)$

13. Succini fruftulum cum Scarabæo (T.186.)

r. Succini particula cum Mufca parva inclufa (T.210)

Fruftum Succini flavi cum Cicada inclufa ut $\&$ alia cum culice, mufcis, \& fimilibus - infectis reconditis delir. Andr. Libavius Singular. Part. III. five de Bituminibus Lib. V. Cap. XXXV.pag. 693. feqq. Thom Bartbolinus in A A. Hafnieuf. An.1673. Oblerv. CXXII. pag. 3Ir. Nebem. Grew in Muf. Regalis Societat. nag. 334. La. certam fuccino inclufam reprafentant Athanaf. Kirtbnerats in Mund. Subterr. Tom.II. Libr. VIII. Cap. IV. Sect, III. pag. 76. it. Dan. Hermannus Difcurf, de

- Rana \& Lacerta fuccibo Pruflico infitis, Ranam nominatus Hermannus L. C. it. Erafm. Francifoi in Oft-und Weft -Indifchen Luft. Garten Part, I. pag. 183. a 
Gryllum expanfum Tbom. Bartbolinus in Act. Hafnienf. An. 1671. \& 1672. Ob. ferv. LVII. pag. I12. Conum abietis Id. L. C. An.1673. Obf. CXXII. pag.309. Pifces \& Ova pifcium Andr. Aurifaber Cap. I. quem edidit Scboltzius in Operibus Cratonia nis.

Qux omnia pro ludibrio habentur ab Adalbert. Tylkowsky in Philofopia curiofa num. IX. Infecta admittic, perfectiora vero animalia, ut ranas, lacertas, pifciculos Src: pro artis fallaciis haber Pbil. Fac. Hartmannus in fuccincta Succini Pruffici Hiftoria \& Demonftratione; quod exemplo probat Tbom. Bartbolinus in AR. Hafn. An. 1671. \& 1672. Obf. LVII. pag. IIs. Quomodo vero in Succinum veniant vid. Kircberus L. C. Cap. V. \& ex eo Erafm. Francifci L. fupr. C. pag. 184.

15. Succini albi tabula cum fœmina nuda eminenter incifa (T.21r.) 16. Succinum aureum cardioides lagenæ incluf.(T.212.)

17. Cor maximum ex Succino (T.496.)

18. Ex Succino colore albo \& flavo variegato capfella (T.486.)

19. Succinum dendroides album, $f$. Nemus umbrofum in alba bafi ( T. 422.) conv. cum defcr. Tb. Bartbolini in Aa. Hafniese. An. 1673. Obr. CXXII. pag. 309.

20. Succinum nigrum ex monte Apennino (T.430.)

21. Ampelitis Anglicana (T.102.) defcr. Georg. Agricola de Nat. Foffiv. Lib. IV. Cap. V. pag. 472. Anf, Boetiuu in Hift. Gemm. \& Lapid. Lib. II. Cap. CLXVII. pag. 339. Mart. Zeilerus in Itinerar. Magne Britaunix pag. 224. prc. Frid. Hoffmannus in Obferv. Phyfico. Chymic. Lib. II. Obr. XXIV. pag. 224. ir. Bresl. Samml. von Nat. und Med. Gefcbicbto XIX. Verf. An. I722. Menf. Jan. Clatf. IV. Art. III. pag. $5 z$.

22. Lithanthrax $\mathrm{f}$ Carbo foffilis in tabulis ex Ducatu Svidnicenfi Silefix (T. 246.) defcr. G. Anit.Volckmann in Silefia Subterr. Fart. II. Cap XII. pag. 374 .

23. Carbo foffjlis Regni Siciliæ valde fulphurens (T.429.)

24. Afphaltum Terræ Sanetx f. Bitumen Judaicum de Mari mortuo (T. s04.) defcr. Andr. Libavius Singular. Part. III. Lib. VII. pag. \$19.873. Conf. Mattb. Zack. Pillingii Trakt. de Bitumine \& Ligno bituminofa foffilt it. Ferrand. Imperati Hift. Natural. Lib. XIV. Cap.11. pag. 446. feqg.

25. Afphattum Neocomenfe Helveticum (T. 503.) defcr. 7oh. Fa $a$ : Scbeucbzerus in Meteorol. \& Oryclograph. Helvetic, pag. 184. conf. ul. Aldropandi. Muf. Metall. pag.369.

26. Cesbites bituminofi varii Torff (T:101.) defor. Carol, Patinus \& Mare 003 
ting. Schaokius in Tr. de Turfis, Andr, Labavius Singuisrium Parc. III, Lib. VII!. Cap.lV. pag. 1008 . feqq. it. Georg. Cafp. Kircbmajerus in Difert. de ignium miraculis locisque femper ardentibus, fingulatira de carbone fosfili Cap. toto :I. Pro reliquiis ligni, foliorum, radicum, feminum antediluvianis habet fob. $\mathrm{Jac}$. Scheuchzerus in Herbario Diluviano pag. 42.

27. Pholphorus liquidus \& folidus (T.I03.) defer. in Ephem. Natur. Curiofor. Dec, I. Ann. ViII. Obferv. XIX. pag. 37. feqq. ir. Dec. II. Ann. VIII. in Append. S. 17. \&.18. it. Dec. III. Ann. IV. Obferv. XXV. pag. 68. feqq. Hiftoria inventionis Phofphori vid. in Mifcellan. Berolinenf. Part. 1I. num. to pag.91. leqq. Modus Boyleanus conficieridi Phofphorum defcr. in Tranfact. Philuf. Angl. An. 1693. num. 196. \& 197. pag. 583. feqq. Comierii Tract. de Phofphoris cum fecreta ipforum compofitione; ex Scarabxis lucentihus, vid. Valpafor in der Ehre des Hertzogth. Crains Tom. I. Lib. III. Cap. XXXVI. pag. 458. Conf, 7ob. Sigifm. Elsbolzii Obfervationes de Phofphoris, it, Mich. Bernh. Valentini Muleum Mufeor. Part. 1I. Cap. IX. pag. 57. feqq. Bernb. Albini Diflert. de Phofphoro liquido \& folido, Frid. Slare Relat. diverforum Experimentorum factorum cum Phofphoro quam liquido tam folido, five $A A_{1}, E$ rud. Lipf. An. 1682. pag. 282. \& 285. ir. An. 1684. Menl. Oaubr. pag. 457. Frid. Hraffmanni Obfervat. Phy fico - Chymicx Selea. Lib. III. Obf XIV. pag.335. feqq. De Cauf lucis in Phofphoris vid. Job. Henr. Cobaufen Tract. fub Tit. Lumen novum Phofphoris accenfum t. Exercitatio Phyfico-Chymica de caufa lucis in Phofphoris tam naturalibus quan artificialibus, it. Dortous de Mayran Diff. fur la caufe de la Lumiere des Phofphores \& des Noctiluques, De Phofplioro. Mercuriali, qui in Barornetris lucet, \& ejus rationibus vid. Fob. Frid. Weidlerus de novo Phofphoro athereo, it. Diff, hujus argumenti Job. Frid. Myri.

\section{Sulpbura.}

x. Terra foliata Sicula fulphurea feu mineralis, qua accenfa, ibidem, pro fedanda Paffione Hyfterica commendatur ( T.43I.)

2. Cinis arenofus ex monte Gibelino f. FEnna fupra XX. milliaria Italica trajectus ( $\mathrm{T}$ 448. ) vid. Fob. Henr. Mullerus de montibus ignivomis f. Vulcanis pag. 7. Henr. Oldenburgii Act. Philof. Soc. Reg. in Angl. Anr. 1669. Menf. Octobr. pag. 866. it, Bresl. Samml. von Natur - und MedicinGefcbicbten IV: Verf. An. 1718. Menf. April. Claff.IV. Art. IV. pig. 971. feqq. 3. Lapis Gibelinus f. fluentis Etnæ coagulum grave metallicum de An. 1669. (S.302.) Typum montis Atux elegantif. vid.in Atban. Kir. cheri Mund. Subterr. Tom. I. Lib. IV. Sect. I. pag. 187. it. in Erafm. Francifici - Oft-und Weft - Indifchen - Luft-Gart, Part. I. Tab. VII. pag. 209. Inundatio- 


\section{ET ARTIFICIALIVM KVNDMANN. VRATISLAV. 295}

nem igneam urbium \& pagorum adjacentium del. \& defcr. Fob. Henr. Seyfried in Medulla memorabilium naturæ Lib. Il. Cap.1. pag.374. prc. Baylius Inftit. Phyfic. Tom. II. Parr. I. Lib.III. Set. I. num. 74. it. T. Burnet in Teluris Theoria Sacra Cap. VII. Conf. Pauli Bocconis Anmerckungen über einund andere Natüliche Dinge Obferv. 1X. \& ex his Tentzelii Monatl. Umerred. An. 1697. Menf. Aug. pag. 641. it, An. 1690. Menf. Dec. pag. 1097. Conf. Ol. IVormii Muf. Lib. I. Cap. V. pag. 47. Tbom. Bartbolini Epiftolar. Medicinal. Cent. I. Epif. LII. pag. 118. feqq. it. Job. Alphonfi Borelli Hiftoriam \& Meteorologiam incendii Asnei. Defcriptionem aliorum Montium ignivomorum vide in Mas. joli Diebus Canicularibus Colloqu. XVI. preprimis in Tbom. Ittigii lucubrationibus Academicis de Montiun incendiss, it. in Erafm. Francifci Oft - und WeftInd. Luft - Garten Part. I. pag. 205. feqq. conf. Bernb. Varchii Geograph. general. Lib. I. Cap. X. Prop. V. Fob. Bapt. Ptolomai Philofoph. Ment. \& Suuluum Phyfic. particul. Diff. IV. Sed, III. Zabnii Specul. Phyfico-Mathematic. Tom.I!. pag. 18. it. Tranfact. Anglic. An.1669. pag: 826 .

4. Sulphur Islandicum citrinum ( $\mathrm{T} .450$.

5. Minera Sulphuris folaris Regni Syberiæ ( $T$.449.)

6. Minera Sulphuris ex Hungaria çoloris cinerei punctis rubris inperfa (T.303)

7. Sulphur rubrum ex minera antecedenti (T.308.)

8. Sulphur Mercuriale robrum Hungaricum (T.273.)

9. Sulphur ftillatitium. Goșlarienfe puriffimum (T.12.) Modum colligendi defcr. \& delin. G. E. Löbneys im Bericht von Bergvvercken fol. 80. b. it. Dav. Kelneres in Praxi Metallic. curiof. pag. 248 . it. 328. b.

10. Sulphủn vivum duriffimum coloris nigricantis ex RegnoSiciliæ (T. 78.)

I1. Minera Barnsdorffenfis tofta, de Sulphure, Vitriolo \& Ferro participans, prope Hirfchbergam Silef: qua uruntur in fic dicio Neu -angelegtem Schwitz-Bade. (T.68.) vid. Unjere Samml. von Narur-und Med. Gefabich. 1. Verf. Ann, 1717. Meni. Jul. Claff. IV. Art. IV. p.73.

12. Minera Barnsdorffenfis ignem nondum experta (T.189.)

13. Minera Sulphuris cum Pyrite (T.169.)

14. Minera Surphuris cai Plumbum inett Freibergenfis ( $T$. 324.)

15. Minera fulphurea tofta jusdem loci coloris flavi \& rubri fplen: dentis (T.535.)

66. Minera Sulphuris aurea colore purpureo variegata, miculisminimis fplendentibus ( $T .346$. 
17. Minera Sulphuris multicolor Freibergenfis cum pauco ære mixta (T.124.)

18. Minera Sulphuris f. Pyrites Sulphure dives, ex parvis cubis con. cretus Annæbergenfis (T.125.)

19. Minera Sulphuris ejusdem ftructuræ, cryftallis albisobfita (T. 126.) vid. Baltbaf. Röster. in Specul. Metallurg. politifr. Cap. XVI. pag. I5ร.

De Sulphure \& viribus ejusdem vid. Georg. Agricola de Nat. Foffil. Lib. III. Cap. XXIV. pag. 456 . feqq. Atban. Kircberus in Mund. Subterr. Tom. II. Lib. IX. Sect. III. pag. I4r. Ulyf. Aldrovandus in Mur, Metall. Lib. III. pag.362. Mattb. Inzerus in Tract. Medic. Chym. de Sulphure, Ferr. Imperatus in Hif. Natural, Lib.XV. pag. 470. Conf, Rer. Metallicar. Scriptor. fupra allegatos, prec. Experimenta, naturam, mixtionem \& generationem Sulphuris concérnentes, inftituir Frid. Hoffmannus in Obferv. Phyfico-Chymicis felectioribus Lib. III. ObC IX. pag. 304. feqq, it. Dominicus Guilielmus in Diff. de Principio falphureo, ubi prc. Sulphur Philofophorum examinatur.

\section{ARTICVLVS $\mathrm{X}$.}

Terre figillatx, medicinales \& quarum fingularis ufus eft apud Mechanicos.

1. Terra figillata Lemnia rubicunda (V. I.)

2. Terra figillata Lemnia alba (V.2.)

3. Terra figillata aliz ex albo rubra Lemnia (V.99.)

4. Terra figillata Lemnia coloris rubri faturatioris (V.4.) Hane defcripf. Foacb. Camerarius in Obferv. de Bolo Armenia \& Terra Lemnia, Ferran. Imperatus Hiftor. Natural, Lib. V. Cap. XXXII. \& XXXIII. pag. 16I. feqq. ol. Wormius in Muf, Lib. I. Cap.'IV. pag. 9. Petr. Bellonius Obfervat. Lib. I. Cap. XXII. pag. 28. 34. cum aliis Eman. König in Regno Minera!. Set. IV. Part. III. Conf. Hans gäob Breunings Orientalifcher Reife 1. Meerf. Cap. X. pag 40. it. Erafm. Francifci Oft - und Weft - Indichen Luft - Garten Parr. II.Tab.XLI. pag. II57.

5. Terra figillata Florentina coloris carnei (V.3.)

6. Terra figillata Florentina alba (V.5.)

7. Terra figillata Florentina flavefcens alia (V.I22.)

8. Terra figillata Melitenfis cum effigie Sti Pauli Apoftoli (V.6.)

3.Terra figillataMelitenfis alba cumIconeSt.AntoniiEremita ( V 82.) 
ET ARTIFICIALIVM KVNDMANN. VRATISLAV. 297

10. Terra figillata Melitenfis alba cum effigie Sti Pauli $\&$ ferpente (V.85.)

11. Terre figillatæ Melitenfis alia fpecies alba minima, cúm Imagine ejusdem Apoftoli (V.7.) vid. Ol. Wormii Muf. Libr. I. Cap. IV. pag. 's.

12. Terra figillata melirenfis alba maxima, cum nomine I I $\pm_{1} S_{\text {; }}$ VI. unciarum pondere (V.129)

13. Terra figillata talis, in qua imago Salvatoris, cum St.Maria \& Jofepho, ejusdem ponderis \& molis (V.r3o.)

14. Terra figillata minor, cum vultu Chrifti, linteo, ut dicunt, impreffo, \& verbis infcriptis: Vultum meum deprecabuntur; Latus averfum repræfentat Infigne Magni MagiftriMelitenfium,cum verbis: Initium Sapientix timor Domini (V.I $3 \mathrm{I}_{\text {. }}$ )

15. Terra figillata alia octangularis cum capite Matris Deiparæ (V. $13^{2}$.)

16. Terra figillata cum capite Johannis Baptifx \& cruce Melitenfum Infcr. P.P. optime Veritatem \& Juftitiam; In parte averfa vifitur Infigne Mi. Magiftri Melitenf, cum verbis: Initium Sapientiæ timor Domini ( V.I33.)

17. Terra figillata Melitenfis cum Capite Johannis Baptiftæ \& gladio, item animalibus noxiis, quorum venenis, uti volunt, terra medeter; qualia funt : vipera, lacerta, aranea, fcorpio, ferpens (V.134.)

18. Terra figillata, in qua caput St. Pauli \& Vipera, cum Infcr.Vera pietra della grotta di Paolo; Latus averfum repræfentat Infignia Melitenfia, cum Infcriptione paulo fupra indicata (V.I35.)

19. Terra figillata alia major cum Icone St. Petri (V. 136.)

20. Terra figillata ejusdem loci octangularis cum Sto Jacobo Apoftolo (V.137.)

Plurimas has, ufumque fuperfitiofum, defer. Ol. Wormins Muf. Cap.IV. pag.7. de raritate vid. Idem Cap.IV. pag. 9. del. Micb, Bernb.Valentini Muf. Mufeor. Part, II. Tab. I. Locum natalem defcr. Micb. Heberer von Bretter in Kegptiaca fervitute Lib. III. Cap. XVI. pag. 436. Hier. Megiferis in deliciis Ordinum Equeftr. Cap. III. pag. 268, Tbevenot feinen Reifen Part. I. Lib. I. Cap. V. pag. 


\section{PROMTVARIVM RERVM NATVRALIVM}

8. Th. Bartbolinus Epiftol. Medicina'. Cent.I. Epift. LIII. pag. 223. prc. vid. Ob. fervatio mea in Bresl. Samml. von Natur-und Medicin. Gefcbicbt. XX. Verf. An. 1722. Menf. Jun. Claff. IV. Art. V. pag. 597.

21. Terra figillata Hierofolymitana alba (V.8.)

22. Terra figillata Hierofolymitana alia alba (V.IO0.)

23. Terra figillata Hierofolymitata flava (V.9.)

24. Terra figillata cœrulea cum forpione (V.112.)

25. Terra figillata flava Arabica (V.II.)

26. Terra figillata fufca Arabica (V.I2.)

27. Terra figillata pretiola rubra Sinenlis ibidem Tenfchee dieta (V.110.)

28. Terra Sinenfis fternutatoria alba (V.I 47.)

29. Terra rubra Infulæ Sumatræ (V.124.)

30. Terra figillata Indica alba (V.83.)

3I. Terra figillata Indica rubra (V.84.)

32. Terra cruda Goldbergenfis Silefiæ alba (V.1!7.)

33. 34. Terra figillata Goldbergenfis rubra major (V.94.) \& minor (V. I5.) De Terris figillatis \& Medicinalibus Silefix vid. G. Ant Volckmannus Silef, Subterr. Part. II. Cap. toto XIII. pag. 279.-298. it. pecul. Diflertat. Ludop. Fridr. Jacobi de Terris Medicatis Silefiacis.

35. Terra figillata Goldbergenfis cinerea (V.16.)

36. Terra figillata Goldberg. alba antiqua.(V.I7.)

37. Tera figillata Goldbergenfis alba novisfima, $f$ de An. I720. (V.1OI.)

38. Terra figillata Goldbergenfis talis aurei coloris (V.IO2.)

39. Terra figillata Goldbergenfis antiqua fufca cum Icone Confulis, f. Inventoris Johannis Montani Med. Doc. \& Archiatri S. Cef. Mai. Rudolpbi 11, vid. Tract, ejusdem de Terra figillata prc. Strigonienfi. 40. Terra figillata Goldbergenfis fufca alia (V.Io3.)

41. Terra figillata Goldbergenfis alba antiqua cum Icone jam nominati Joh. Montani (V.19.)

42. Terra figillata Goldbergenfis alius fignaturæ (V.104.)

43. Terra figillata Strigonienfis Silefiæ tufca (V.15.)

44. Terra Strigonienfis flava in matrice, f. in Minera nigra lapidea (V. II8.) 


\section{ET ARTIFICIALIVM KVNDMANN. VRATISLAV. $29 \overline{9}$}

45. Terra figillata Strigonienfis flava (V.24.)

46. Terra figillata Strigonienfis flava alia. (V.ros.)

47. Terra figillata Strigonienfisalbida (V.25.)

48. Terra figillata Strigonienfis cinerea (V.127.)

49. Terra figillata Strigonienfis lutea (V.57.)

50. Terra figillata Montis acuti lutea ( $V .13$.$) vid. Obfervatio mea in$ Bresl. Samml. xon Nat. und Med, Gefbicht. XX. Verf, An. 1722. Menf, Jun. Clarf.

IV. Art. VI. pag. 604.

51. Terra figillata fufca cum aquila Imperiali, proStrigonienfi ven: ditata (V.126.) vid. Georg. Ant. Volckmanni Silef. Subterr. Part. II. Cap. XIII. S. 6. pag. 278. delin. Tab, I. fig. 12. it. Obfervatio mea paulo fupra citat.5, is Bresl. Sammi. L. C.

53. Terra ligillata Jaurovienfis Silefiæ cinerea $(V .20$.

54. Terra figillata Jaurovienfis cinerea alia (V.99.)

55. Terra figillata Jaurovienfis fufca $\left(V, 2 r_{0}\right)$

56. Terra figillata Lignicenfis Silefiæ alba ( $V .22$.

57. Terra figillata Lignicenfis cinerea $(V .23$.

58. Terra Lignicenfis crudá cinerea (V.26.)

59. Terra figillata Nobarfovienfis Silefix flavefcens. (V.27.) defrr. \& delin. Fob. Sinapius Olsnograph. Part. II. pag. 283. 60. Terra figillata Nobarfovienfis alba (V.28.) 6I. Terra figillata Olsnenfis Silefix alba (V.29.)

62. Foffile arborefcens Maslenfe \& Kleinfchweinerenfe album Silefiacum (V.30.) del. \& defcr. Leonb, Dav. Hermann Maslograph. Part.II. Cap. II. pag. 182. Tab.IIX, num, 3.

63. Ofteocolla in monte arenario Maslenfi frequens, ex qua ibidem Foffile arborefcens præparatur (V.128.) del. \& defcr. Idem Hermannus L. C.

64. Terra exalbo \& rubro variegata Maslenfis (V.II6.)

65. Terra figillata alba Maslenfis (V.3I.) Id.Hermannus Maslograph.p.189;

S.2. Continuatad Tabul. IIX.

66. Terra figillata rubra Maslenfis (V.32.) Id. pag.189. S.2.

67. Terra figillata cinerea Maslenfis(V.33.) Idem L. C.

68. Bolus aureus Maslenfis in minera (V. I2I.) defcr. Id. L. C. S. 3. pag. 190. 
69. Bolus figillacus Maslenfis aureus (V.34) Idcm L. C.

70. Terra ligillata Gehnwitzenfis Silefix fubrubra, cum Infign. Illuftr, Dn. Comit, de Noffitz (V.35.)

71. Terra Ggillata Gehnwitzenfis flavercenstalis (V.36.)

72. Terra Gehnwitzenfis ejusd. figil. fufca (V.38.)

73. Terra tigillata Grofs-Gehnwirzentis lutea alia (V.55.) vid. 06 . ferbatio mea in Bresl. Samml. von Natur-und Medicin - Gefcbich. Lib. fupr. cit pag. 603.

74. Terra figillata Brechelwitzenfis Silefix fufca cum figillo Conventus Leubufienfis ( V. 40.)

75. Terra figillata Brechelwitzenfis aurea (V.54.)

76. Terra figillata Seichauerenfis Silefiæ rubra, cum Infign. $D n$. de Falckenbayn (V.37.)

77. Terra figillata alba Petersdorffenfis Silefiæ $\int_{0}$ Dn. de Reicbenbacb $(\mathrm{V}:$ 96.)

78. Terra figillata Magni Plufnicenfis Silefix rubra cum Infign. Dn. de Webmer (V.39.) defcripfi \& delin. in Bresl. Samml. L. C. pag.602. 79. Terra alba medicinalis Tarnowitzenfis Silefix (V.IIg.)

80. Terra eleganter rubra Zuckmantelenfis Silefix (V.123.)

81. Terra ligillata cinerea Dceblicenfis Bohemica (V.42.)

82. Terra figillata alba Dceblicenfis (V.43)

83. Terra figillata rubra Dœblicenfis (V. 44.)

84. Terra figillata corulea Doblicenfis (V.56.)

85. Terra figillata Dceblicenfis colore rofeo $(\mathrm{V} .58$.

86. Terra figillata Bohemica fufca (V.47.)

87. Terra figillata Bohemica Jablonenfis .f. Gabelenfis rubra

( V.86.)

88. Terra figillata Gabelenfis coloris faruratioris (V.87.)

89. Terra figillata aurantia ejusd. loci (V. 88.)

90. Terrafigillata coloris perfici Gabelenfis ( V.89.)

91. Terra figillata cinerea ibidem formata (V.90.)

92. Terra figillata alba Gabelenfis (V.91.) defcr. Eobusl. Balbinus Mifcell. Bohem. Lib. I. Cap. XLIX. pag. II4.

93. Terra figillata Zwickavienfis Saxon. lutea (V.45.)

94. Terra medicinalis Laubacenfis coloris fufci (V.107.) 
95. Terra figillata Laubacenfis rubra (V.108)

96. Terra figillata ejusd. loci alba (V.109.) defer. Bernb. Wilhelm Geilfufuus de Terra figillata Laubacenfi in fine f. pag. 353. Keqq. conf. Fob. Georg. Fir. knerbt Metamorphof. in mineram ferri mucati ligni del. Tab. I. fig. I.

97. Terra medicinalis carnea Rudelftadienfis (V.120.)

98. Terra figillata Norimbergentis f. ex crypta Veldenfi (V.139.) def́cr. \& del. Job. Jac, Bajcrus in Oryctographia Norica Cap. III. Tab. I, pag. 14.

99. 100. 101. Terra medicinalis alba, carnea \& flava Naumburgenfis (V.143. I44.145:)

102. Terra figillata Neofolienfis Hungarica flavefcens rotunda ( V. 4r.)

103. Terra figillata alia quadrangularis ejusdem loci, coloris faturatioris (V.II4.)

104. Terra figillata Neofolienfis aurea (V:I15.)

105. Terra medicinalis cruda Neofolienfis (V.148.)

106. Terra medicinalis Hungarica flava $(\mathrm{V} .5 \mathrm{~F}$ )

107. Terra medicinalis flava ex Comitatu Cepufienfi Hungaria,

prope Wagendrüffel. ( $\mathrm{V} .110$.)

108. Terra medicinalisrubra ex Hungaria fuper. (V.63.)

109. Terra medicinalis Haffiaca fufca in tabulis ( V. I06.)

110. Terra figillata alba Regni Irlandix (V.I40.)

Iii. Terra figillata alia coloris carnei ejusd. Regni (V. I 4I.)

112. Terra figillata cœrulea ibidem parata (V.I42.)

113. Bolus Armenix rubra (V.48.)

114. Bolus Armenix atro rubefcens (V.71.) hunc defer. Joacibim. Camerarius, Pater, in Obferv. de Bolo Armena.

115. Terra medicinalis Turcica colore carneo $(V .50$.

116. Terra medicinalis rubra variegata Turcica $(\mathrm{V} .52$.

117. Terra medic. Turcica variegata cinerea (V.53.)

118. Bolus Orientalis ex albo rubra (V.68.)

119. Bolus rubra-Toc'cavienfis (V.r13.) defcr, in ACa. Pbilofoph. Sor, Angl. An. 166 \%. Menf. Mart. pag. 8.

120. Terra f. Fæcula Orellana rubicunda odoris violacei (V.59.) vid, Loonb. Plukenet Phytograph. Tab. CCXIX. Fig.IV. 
121. I22. I23. Paftilli aurei, lutei \& fufci Florentini (V.75.76.77.)

I24. Terra Umbrix f. exDucatu Spoletano (V.78.)

125. Terra eleganter rubra Anglicana (V.73.)

126. Lac Lunæ e crypta Kauerheimenfi Norica (V.64.) defc. job.

gac. Bajerus in Oryctograph. Noric. Cap.III. pag.I7. f. Agaricus mineralis Ferr.

Imperati Hift. Nar. Lib.V. Cap.XLL p.I76. \& Litmas Anglorum, vid. Tranfact. Angl. num.179. pag.26. \& 38. De maximo proventu in Helvetia vid. Wagnerus in Hift. Nat. Hc!vet. pag. m. 34.0. prc. Carol. Nicol. Langius in Hiftor. Lapid. Figur. Helver. Part.1. Cap.III. pag.6. De ufu in Medicina vid. foh. Dan. Majoris Diff, de Lache Lunæ Cap.VII. 5.9. it. Langius L. C. pag.8.

127. Rubrica Norimbergenfis nativa ex monte Weiffenbrunnenfi

(V.72.) defcr. id. Bajerus L. C. pag.15.

128. Bolus rubra Goldbergenfis Silefiæ (V.69)

129. Bolus f. Ochra nativa lutea ejusd. loci (V.70.)

130. Bolus Silefia rubra Provenfis (V.49.)

13T. Terra viridis Veronenfis (V.65.)

132. Ochra nativa Goslarientis (V.93.)

333. Creta Rochlicenfis Mifnia, coloris perfici ( $V^{\top}$.92.) defer. Cafp. Henr.

Graunius in der Hiftorifchen Befchreibung der alten Stadt und Graffich. Rochlitz

Cap.VIII. it. Cbriff. Perfor in Tr. vom Rochlitzer Steinmarck.

134. Terra Veldenfis ex luteo punicea prope Norimbergam, aus dem

Geifs-Loch (V.8I.) vid. it, Bajerus L. C. it. Ca/p. Hoffmanni Paralipom. Officinal. Cap.XLV. pag.665.

135. Pnigitis $f$. Creta nigra Badenfis Helvetica (V.74.) vid. Ferrand. Imperatus Hiftor. Natura!. Lib.V. Cap.XIX. \& XX. pag. I54. it. Herm. Conrin. gius in Differt. de Terris $\$ .75$.

136. Marga faxatilis coloris viridefcentis (V.80.) vid. fob. Dan, Majoris pecul. Tractat. de Marga.

137. Bolus lutea f. Ochra nativa Zwickavienfis (V.97.)

130. Marga f. Farina mineralis alba prope Halam Magd. An.1709.

effofla (V.123.)

139. Marga fubflava friabilis Kofwicenfis $\mathrm{f}$. Klickcenfis Anhaltina, $\mathrm{f}$.

Farina mineralis, ex qua An.1713. it. An.1649. 1684. it. 1697. panem coxerunt (V.95) vid. Bresl. Samml. von Nat. und Medic. Gefch. An. 1720. Menf. Febr. Art.VIII. Claffiv. pag.196. it. Menf. Mart. Clafr.IV. Art. IV. pag. 322. XIII. Veri. An, I720. Menf. Sept. Claf.IV. Art. VII. pag. 31.7. De ejusmod. Marga vid, Ephem. Nat. Gur. Dec.III. An,VII. \& VIII. Obf. CCXIX. Steph. 


\section{ET ARTIFICIALIVM KVNDMANN. VRATISLAV. 303}

Stepb. Blancardus in Collea. Med. Phyfic. Cent.II. pag 230. Aufgefangene Briefe III. Paqùet 30. Correfpond. fol.275. Beckmann Hift. des Füritent. Anhalt. Part. II. Cap.III. p3g.69. Dav. Sigm. Büınerus Rud. Diluv, pag.141.

I40. Panis ex farina minerali f. Minera antecedenti (V.98.)

141. Terra Tripolitana cinerea (V.66.)

142. Terra Tripolitana flava (V.67.) de Terris Medicatis Mechanicis \& vulgaribus vid. Atb. Kircberus in Mund. Subter. Tom.I. Lib.VII. pag.330,feqq. prc. Ul. Aldrovandus in Muf. Metallic. Libr. toto II. pag, 206,-272, ubi fimul Margas, Cretás \& varia ex iisdem vafa defcr. Ferr. Imperatus Hift. Nat. Libr.I...V. pag.I.--74. Eman. König in Regno Miner. Sect.IV. Part.III. it. Hermannus Conringius Differt. de Terris. De ufa vero Medico prc. Terrarum figillacarum vid. Andr. Bertboldus de Terræ figillatæ nuper in Germania repertæ viribus atque virtutibus admirandis, it. Gok. Auguft. Rivinus in Differt. de Terris Medicinalib. Cap. II. pag $16 . .27 \%$

243. Trochifci Cypheorum figillati aurei coloris, maximi (V.60.) 244. Trochifci Cypheorum figillati parvi, fufci coloris (V.6I.) 245. Trochifci ex Vipera (V.62.) de Modo conficiendi vid, Fob. Zwelfferi Animadverfiones in Pharmacop. Auguftan. pag.295. Qux viperæ eligendæ vid. Job. Maria Zonca de Viperis pro Trochifeis eligendis, prc. Marc. Aurcl. Severinus in eleganti Opere de Viperx Nacura \& de mirificis ejusd. facultatibus, $P$ ctr. Andr. Matbiolus in Comment. fupr. Diofcoridem Lib.II. Cap.XVI. pag.169.feqq. Conr. Gefnerus Hiftor. Animal. Lib.V. qui eft de Serpentium Natura fol.76.feqq. Trochifcos del. \& defer. ex Petr. Pomet Materialift. und Spez. Händl. Part. Ir. Cap. XXVII. Tab.LIX. Fig.36r.-364. pag.360.feqq. Mich. Bernt. Valentini in Mur. Mufeor. Part.I. Lib.IIl. Cap.XXXIX. pag.504. De vano ufu in Medicina vid. Obfervatio mea in Bresl. Samml. von Nat. und Med. Gefch. XXI.Verf. An.1722. Menf.Jul. Clafr.IV. Artic.V. pag.74.

\section{Sectio IV. Arte Facta. Claffis I. A R T I G V L S I.}

W. I. Infigne opus Nature \& Artis in Chrifto cruci affixo, ex Mus rice maximo Americano elaboratum; Ubi totum corpus albidum, 


\section{PROMTVARIVM RERVM NATVRALIVM}

dum, peitus verce lineolis in circulum duetis, rubrum, \& quafi flagellis \& virgis cafum apparet, brachia \& crura itidem paululum fuperius rubent, qux umbram indicant, clavisque adamantibus ornatis, ligno firmantur. Pluribus defrr. in Bresl. Samml, von Nat,

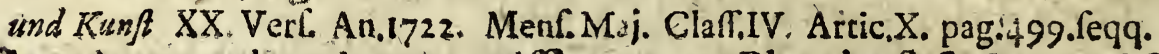
W. 2. Aurum chymicum puriffimum ex Plumbo fufo \& cum Mer. curio fubacto, tranfinutatum ab artifice apud Batavos; tefte oculari infpestione, \& examine docimaftico Facultatis Medicx Halenfis Unciæ ii. (vid. a Ciarifl Stablio, tunctemporis Decano, Propempticon inaugurale, Differtationi mex de Regimine annexuni \& An.1708. Halæ Magdeburgicx publicatum; it. Commentatio mea de Intellectu hominis ante \& poff lapfum Libr.II. Cap.III. S.14, feqq. pag. edic, novisfime qux An.1720. in 8 vo prod.) 253. Quatuor millia circiter Authorum de Tranfmutatione Metallorum collegit Petrus Borellus in Bibliotheca Chemica f. Catalogo librorum Philofophicorum Hermeticorsum; quibus addendi, qui de veritate artis Tranfmutatorix fcriplerunt, ut fob. Jeach. Beckerus in Experimento Chynico novo, Dan. Georg. Morbofus in Epiftola de Metallorum Tranfmutatione ad Langelottum, Gabriel Clauderus in Differt. de Tinctura univerfali, ubi varia \& rara hujus Metamorphofeos in medium produxit exempla, Job. Frid. Helvetius in Vitulo aureo, Erafm. Francifci im auserlefenen Kunft-und Sitter-Spiegel Libr.IV. Sect.I. p. I203.reqq. des getreuen Erkards entlarfften Marckr-Schreyer und endiaffenen Chymico, Pbil. Fac. Sachs a Levenbeimb in Tract, cui Titul. Aurum Chymicum it. in Ephemerid. Nat. Curiof. Dec. 1. An.I. Obferv.XVII, pag.65. feqq. ir. An.IV. \& V. pag.297. Petr. Job. Faber Ibid, Dec,II, An.VIII. pag.73. Dec.III, An.V. \& VI. Obf.LXXVII. pag.t II. Job. Iudop, Hannemannus in Jafone, Olaus Borricbius in Confped. Chemic. illoftrat. Feg-Feuer der Scheide-Kunf, Wilb. Freýberrn von Schröders Fürftl. Schatz-und Rent-Kammer pag.400.feqq. Conf. Job: Jac. Mangcti Bibliothecam Chemicam curiofam, ubi prreter fupra nominatos plures Aurhores in unum congesfit Volumen. W. 3. Cauda Pavonis fecundum vulgus Alchymicon in vitro. W. 4. Scurella five Patinæ Iridis coelcttis argentex; vel potius Nummi bracteati argentei, vid. Goh, Dan. Majoris defcript. Num. Bracteatorum Mifcell. Acad. Nat. Curiof. An.IIl. Dec.II. pag.33. it. Mich. Bernh.Valentini in Muf. Mufeor. Part.II. Cap.XI. pag.6z. prc. fob. Chriflopb. Oleariu in Iligoge ad Nummophylacium Bracteatorum, fob. Georg. Liebknecht in Differt. Epiftolic. de nonnullis Bracteatis nummis Hasfiacis, Otio Sperlingias in Epiftol, ad Jac. a Mellen data, fub Tirul: DeHiftotia Nummorum Bracteatorum \& cavorum, 7ob.Georg. Leuckfeld in Hiftorilchér Befchreibung vieler alten Blech Müntzen, it. Job. Pctr. Ludwig in der Énleitung zu dem Teutichen Müitz-Wefen mittlerer Zeiten.Mul- 


\section{ET ARTIFICIALIVM KVNDMANN. VRA TISLAV. 305}

ta huc fpectantia collegit Wilb. Ern. Tenzelius in Monatl. Unterredung, An.1689. Menf.Sept. pag.896.feqq. it. An.1695. Menf. Octob. \& Novembr.

W.'5. Poculum argenteum fingularis artificii \& plus 500, granatis

fcalptis diftineta a fob. Georgio II. Eleet. Sax. Proavo meo D. Sylbefro Kundmanno tunc Archiatro muneri datus.

W. 6. Lagenæ vitreæ magñ artificium, in qua per os non admodum amplum exftructum eft ex duabus contignationibus opus, quod condecoratum gemmis fcalptis \& politis diverfarum fpecierum, ftatuis \& figuris argenteis, eburneis, vitreis, cereis \& ex Succino factis, conchis \& cochleis fimul rariffimis, lapidibus certa figura gaudentibus, mineris cryftallinis \& metalliferis, ramis coralliorum rubrorum \& alborum, item floribus Martis, infeetis, floribusque artificialibus variis: Præcipue epiftomium ligneum os arcte claudit, cui interius tranfverfum lignum ad amplitudinem vafis fatis magnum trajectum, quod appendiculis fimul inftruetum. convenit cum Defcript. Ol. Wormii in Mufeo Libr. II. Cap.XII. pag.389.

W. 7. Lagenula puriffima ex cryftalloMediolani fcalpta. Ratio Cry: ftalli fecandx atque poliendx optima communicatur in Cbrift. Hugenii Traet. de Lumine, conf. Fob. Fac.Scheucbzeri Natur-Gefch. des Schweitzerl. Part.III. pag.55. W. 8. Lagenulæ eleganter fealptæe, epiftomiis argenteis claufæe, qua catenulis firmantur, in ciftula.

W. 9. Lagenula fubcærulea, efformata, e cincre humano materiæ

vitrefcenti mixta. vid. Obfervatio mea in Bresl. Samml. von Nat. und Medic.

Gefcb. XXIII. Verf. An.1723. Menf. Febr. Clan.IV. Artic.VI. pag.179.

W. 10. Cyathus vitreus viridis, e cinere tabaciconfeetus, variis em-

blematibus \& inferiptionibus condecoratus.

W. II. Capfella ejusmodi viridis eleganter fcalpta.

W. 12 Capfella vitrea coloris aurei, e tali cinere.

W. 13. Cyathus rubineus a Kunckelio confeetus, cum aliis, vario co:

lore tinctis. Artem Vitra hrec conficiendi docuit Gob, Kunckslius in Arte vitraria experimentali. Conf. Fob. Matbeffi Sareptam XV.Predigt, pag. 178.feqq.

W. 14. Papyrus incombultibilis ex Asbefto, Vratislaviæ confecta.

W. 15. Papyrús incombuftibilis ex Asbefto Cremnicenfis Hungariæ. defcr. Georg. Ant. Volckmann in Silef, Subter. Part.I. Cap.II. pagr\{3. Modum conficiendi docuit Atbanafus Kircberus in Mund, Subterran. Tom. II. Lib. 


\section{PROMTVARIVM RERVM NATVRALIVM}

VIII. Seet.III, pag.74. De Papyro incombuRtibili Veneto \& Libro ex eo, literis aureis infcriptis, vid. Job. Henr. Seyfrid in Medulla Memorabil. Natur. Lib.1I. Cap.V. 5.39. pag.441.

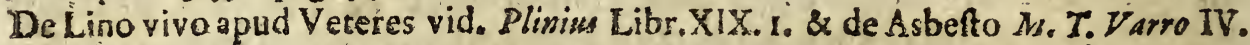
de L. L. Ex quo lintea \& veftimenta, qua ignis non abfumeret, fed mundarer, Tur nebi opinione, vid. XXIII. Adverfar. Cap.!. ex quo Jofepb. Scaliger in Comm. Mappas sañtum concedit. Telas ex tali lino confectas rebus in totum deperditis accenfuit Guido Pancirollus in eleganti de rebus deperditis libro Tit.IV. pag. I6. sotius reifidem in dubium vocantes negarun, linteum ejusmodi unquom extitis. fe, Dakersmpius in Plinium \& Scbildius in Commensar. ad. Sveconium: Conf. de Modo graparandi lapidem Aniantum Ol. DYormii Mul. Lib.I. Ca.VI. pag.i4. Kirchersm L fupr. cit. pag.67. Thingizm in Ephem. Nat. Curiof.Dec.Il. An.ll. Obi.LXI. p. Ijg. Petr.della Valle Reife-Befchr. Part.IV. Sendichr.XI. pag.zos, prc. Pssl. Ammannum in Manuduca. ad Mater. Medicam Part.I. Cap. III. \$.3. pag. 18. it. G.H. Delfckitm Obferv. Phylic Medicar.Hecarof.I. Obferv.X. P.I1. Segmentum panni incombuttibilis, opera Chinenfis cujusdam in llius Regni Proviača Lanquirs a Mandarino comparazum, ac Societat. Anglican. sransmifitu examinifubjecit Rabert. Ploo in Obfervatione de Panno quodam incon, butib.l., una cum Annotationibus fuper eo fachis, qua reperitur in Tranfaco onibus Pbilofipb. Anglic An.1689. Meni. Jun. pag.1049. feqq. Quomodo in Tartariz Provisis Chinchintalas lanuginofum hoc minerale eruatur, \& conficiendis telis feu pannis apturin reddatur, delcr. Rark. Paslws Veneius de Regionibus Orientaibus Libr. prc. Modum flandi docuir 7ob. Ciampinus de incombuftibili Lino f. Lapide Amianio ejusdemq; flandimodo. Panmum del. \& defor, Ferr. Imperatus Hift. Nat。 Libr.XXV. Cap.V. pag.757. \& ex eo Ans. Boctius in Hiftor. Gemmar. \& Lapid. Libr.M. Cap.CCIV. pag.383. Simom. Majolss Dierum canicularium Colloqv.XX. fol.633. feqq. \& Rich. Bernb. Jaleweini in Muf. Mufeor. Part.d. Cap.XVIII. pag. 49. it. Erafin. Franeifcs in Of-und Weft.Indich. Luft. Garten Part. 1. Tab.XVIIL. warn.2. \& 3 . pag. 58 .

ه. 16. Rapyrus Sinenfis ex férico albo, $\&$ alius.

WV. 17. Rapyrus ex interiore cortice Bambuino, vid. le Comte im heut:gen Sina VII. Sendichr, pag.271.feqq. prc. Engelbert, Kämpfer Am cénicz. Exotic.

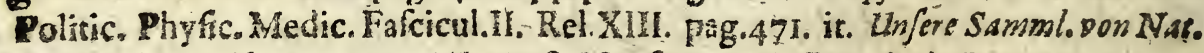
und Medic, Gefco. An.1718, IV", Verf. Menf.Jun. Claff.V. Artic.Lo pag.1240, W. 18. Capfella ex nucibus Indicis elaborata.

W. 19. Currus fubtiliffimus ex ebore. Subtilifime zornatura exenpla alia vid. in 3ac. Frid. Reimanni Hiftor. Literar, Part.IIl. Cap. II. Quxft.202. p.495. feqq. ie in Erafm. Francijsi Ofeund Weft. Ind. Luft-Gart. Part.1I. pol349. citan-

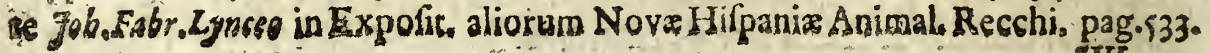




\section{ET ARTIFICIALIVM KVNDMANN. VRATISLAV. 307}

W. 20. Currus pondera maxima facile auferens. defcr. \& delin, in un-

feren Samml. von Naturound Medic, Gefabicbs. IL. Verf. An I717. MenfdNov. Clat. IV. Art.II. pag. 360.

W. 2t. Pocula lignea num. 50. ita comparata, ut unum alterum excipiat ordine, donec ad minimum fuerit deventum, tantæ tenut. tatis, ut contactum vix ferant, theca lignea firmiore claufa, defer. ab 0l. Wormio Mur. Lib.IV. Cap.IX. pag.37I.

W. 22. Vitrum Sinenfe interne rubro, externe cceruleo \& albo colore variegacum \& friatum.

W. 23. Orbis vitreus obfcure viridis, ex feneltris ante VI. ferme fecula exftruétus.

W. 24. Excutia ventriculi. Multa huc fpectantia cum Authoribus collegi in

Consmentatione mea de Intelledtu boninis ante ES pof lapfum Lib.II. Cap.III. \$.29. pag.284.fequ. defcr. \& dSlin. in AE. Erud. Supplem. Tom.V. Sect.IV. Tab.l. num.7. pag.183. Conf, Bresl. Samml, van Nat.und Medic, Gefab, VII. Verf. An. 179. Menf. Febr. Clafr. Artic.III. pag.229.feqq.

W. 25. Cauda equina alba, fignum militare Turcicum fuperius argento obdueta, cum involucro ferico. defcr. Petr. de Valle Reife.Befchr. Part.1. Sendrchr.VI. pag.64. Tbevenot feiner Reifen Lib.I. Cap. LIV. pag.IIr: De origine vid. Cbrifl. Franc.PaulliniZeit-kiurtzender erbaul. Luft Part.II. Them. CXXXIV.

W. 26. Pileus balnearis Turcicus, egregie ex filis aureis acu pictus. W. 27. Calendarium Turcicum orbiculare.

W. 28. Fiftula Tabaci Turcica, e pluribus tubulis fibi mutuo inferendis, exterius variis coloribus depicta \& filis aneis catenulis: que exornata. vid. Ol. Wormius Muf. Libr.IV. Cap.IX. pag.37r.

W. 29. 30. Sagittæ Turcicæ alatæ lineis aureis cinctæ, cuppidatæ \&

obtufre. Sagitcas varias defcripf. Erafm. Francifci im Auslïndifch. Kunft-und

Sitten-Spiegel Lib.II. Sect.XXIV. pag.6cg.feqq. Turcicas vero pag.618.

W. 31. Culter Turcicus literis aureis infcriptus.

W. 32. Pugio Turcicus fclopetis inferendus.

W. 33. Funis pyrius $f_{0}$ incendiarius Turcicus, ex ftramine Oryza confectus.

W. 31. Urceus Turcicus ex cupro, ad coquendam potionem Coffee, cum operculo inaurato. 


\section{PROMTVARIVM RERVM NATVRALIVM}

W. 35. Collare Turcicum oblongum ex pilis humanis contextuin, quo monachi ibidem utuntur pro caftigatione.

W. 36.37 . Sigilla Turcica \& Mofcovitica.

W. 38. Ludus cum Conchis pietis Japonenfium, Batavis Japanfe

Speel doubletten. vid, Wil. d' Orville Catalogus van fyn Cabinet num. 50 . pag. 25.

W. 39. Suffimentum Japonicum tubulare.

w. 40 . Pecten Sinenfis e bacillis ligneis.

W. 4I. Fiftula TabaciSinenfis lævigata, auro \& nigro colore pi@a,

W. 42. Fiftula Tabaci Tartarica, ex corio flexili.

W. 43. Libella r. Statera Sinica, ponderandis monetis deftinata, defrr. Ol. Wormius Muf. Lib. I. Cap.V. pag. 35s. it. Nebem. Grew in Muf. Regal. Societat. pag.369.

W. 44 . Baculus arundineus Sinenfis, variis figuris \& literis Sinicis inferiptus.

W. 45,46. Ciftulæ \& Tabulæ Sinicæ veræ ex ligno elaboratæ, \& lac-

ca lavi \& durabili obductx, quas variæ imagines ex lineis aureis ornant.

W. 47. Excutia Sinenfis ex Canna Bambuina Lacca rubra depieta. w. 48. Orbis Sinicus fortilegus ex terra rubra Sinenfibus Tenfcheé dieta formatus, multis charaeteribus \& literis infcriptus, quo utuntur pro felici fepulchri loco inquirendo. Similem ferme del. \& defcr. Ol. Wormius in Mufep, Lib.IV. Car.IX. pag. 372 .

w. 49. Capfella longa Indiæ Orientalis ex Canna Bambuina. Capfellam hanc defc. Georg. Meiffer im Orientalifch. Indianiích. Kunft und Luft.Gärtner Cap.VIII. num.27. pag. 1OI، it. im Neu-eröffinetem Raritaten Cabinet num. 73. pag.65. Cannam del. \& defcr. Fob. Neubofus in Befchreib. des Reichs Sina pag.33I. \& ex eo Erafm. Francific im Oft-und Weft-Indifch. Lunt-Gart. Part. I. Tab.IX. pag.263.

W. 5o. Flabellum Sinenfe ligneum cum feellulis rotantibus, lacca nigra obduetum, \& lineis aureis depietum vid, id, Neubofius L.C. pag.262. \& Erafm. Eranciffi L. C. Part.1I. pag.1049.

w. St. Flabellum Sinenfe aliud duplicatum, cum variis concumbendi fchematibus expreffis, defer. id. Neuboff L. C. pag.24r.

W. 52. Catenæ plumbex, quibus apud Romanos Ufurarii pravi cædebantur.

it

W.53. 
ET ARTIFICIALIVM KVNDMANN. VRATISLAV. 309

W. 53. Urnæ \& Ollæ fepulchrales \& facrificales majores \& minores, cum \& fine operculis, diverforum colorum \& figurarum, ut Regni Poloniæ, item Silefiacæ̃ Lignicenfes, Maslenfes, Wildfchützenfes \& Grabifchenenfes prope Vratislaviam, Beuthenenfes, Dammerehfes \& aliæe. Pólonicas defc. fac. a Melle in Hift. Urn. Sepulchral. Sarmaticx, it. Bresl. Samml. von Nat. und Med. Gefib. XV!. Verf. An.1721. Menf. Maj. Claffiv. Art. VII. pag. 528.feqq. Lignicenfes Cbrift. Stieff in Epiftol. de Urnis in Silefia Lignicenfibus \& Pilgramsdorfienfibus, Maslenfes Leonb. Dav. Hermann Maslographi Part.1. Cap.VII. pag.78.feqq. Georg.Ant. Volckmannus in Silef. Subterran. Part.1I. Cap.XV. \$.20. pag.317. Beuthenenfes \& alias id. Volck. mannus L. C. pag.313. Wildfchützenfes Carol. Obmbius in Epift. qux excerpta legitur in Wilb. Erneft. Tentzelii Monatl. Unterred. An.1696. Ment. Jul. pag.648. Grabifchenetrles delcripfi \& delin. in Bresl. Samml. von Nat. und Med. Gefbicbt. XXIII. Verf. An, I723. Menf. Febr. ClaffIV. Art.VI. pag.I7I.feqq. Sive Ollx na. tive fec. defcr. \& del. Fob. Henr. Seyfridii in Medulla Memorabil. Natur. Lib.II. Cap.XVII. pag. 463. Job. Matbefit in Sarepta XV.Predige pag.178. it. Bobusl. Balbini in Mifcell, Hiftoric. Regni Bohemix Libr.I. Cáp.XEIX. pag.IIs.

Auchores de Veterum comburendi \& fepeliendi ritu ex Gottbilff Treueri Bêfchreib. der Heidnifchen Todren-Töpfe, \& quidem ex Prxfat, collegit Georg.Ant.Volıkmann in Siler. Subterr. Part.II. Cap.XV. S.37. pag. 327.

w. 54. Taleolus argillaceus foraminulis inftruetus, in Urna fepulchrali prope Grabilchen repertus. vid. obfervatio mea in Bresl. Samml. L. C. pag. 180.

W. 55 . Tubulus inflexus orichalceus vitro viridi incruftatus, ibidem repertus vid obfervatio mea ibid.

w. s6. Stylus elegantiffimus fcriptoritus ibidem erutus. conven. cum del. \& defer. Leonh. Dav. Hermanni in Maslograph. Tab.VI. Cap.XII. pag.i4O. feqq. Georg. Ant.Volckmanni in Silef. Subterran. Tab.VII. VIII. IX. \& X. Cap. XV. pig.308. Cbrift. Sticfjit in Epift. de Urnis in Siler. Liguic. \& Pilgramsdorff. Tabul. uit. Jac. a Mellen in Hift. Urn. Sepulch. Sarmatic. Tab.IV.

w. 57. Nummi cuprei Romani Carolobergi in Ducatu Tranfylva. nix, dum ante paucos annos munimenta \& xdificia exftruerent, in urnis fepulchralibus ibidem eruti: It. Hadrianus Imperator in nummo, cum aliis Leubufii in Ducatu Wolano Silefix, ubitem. plum Martis olim fuiffe dicitur, \& Grabifchenæ reperti. vid. 06 . fervatio mea in Bresl. Samml. XXIV. Verf. An. I723. Claffi. V. Artic.VI. pag. 435. feqg. 
W. 98. Amuletum Romanum in Hungaria effoffum, cum Diana, dextra lunam \& finiftra haftam tenente. vid. Obfervatio mes ibidem 1., C. pag. 439 .

W. 59. Amuletum aliud cum curru triumphali \& hoftibus currum trahentibus; aut fponfo \& Sponfa, cum Cupidine \& mulieribus bacchantibus id delin \& defcr. ibidem.

W.60: Pugio Romanus latiffimus fingularis artificii. convenit eum delin. quam dedir Guil. de Cboul de la Religion des Anciens Romains p. 289. W. 6 r.Sclopetum Turcicum Damafcenum aliquot libris argenti munitum, lineis eminentibus argentei fplendoris in tubo difcurrentibus.

W.62. Sagitta vetus Tartarica f. de Ann. 1242. tota ex ligno quercino, excepta armatura ferrea, qua trium unciarum pondus habet.

W. 63. Sagittula Indix Orientalis f. Infula Bornenfis veneno inftar nigribituminis indueto, infectæ, qua ab Incolis per tubulum excavatum mittuntur. defcr. in Francif6. Leguat Reifen nach zvveyen unbevvohnten Infuln Part. II. pag. 34I. conf. Nebem. Grew Mufo Regal. Societ. pag. 368.

W 64 Culter Molcowiticus maximus.

W.65. Culter Sinenfis in Capfella cum bacillis ligneis, forcipe \& inftrumentis aures $\&$ dentes mundificantibus, vid, Catálog. Muf. Spe. neriani pag. 13.

W. 66. Culter talis cum bacillis ex ebore faetis in capfella cærulea fquamofa, forfan exuviis ferpentis peregrinæ. rales defrr. Job. Neubofius in Befchreib. des Reichs Sina pag. 249. it. Bionyf. Kay in Befchreib. des Kayferthums China Cap. XXIIV. pag.418. qux reperitur in Ysbr. Ides Reife mach Chima pag. $25 \%$.

W.67. Culter corio piloro veltitus, ad jocum factus.

W. 68.69 Catena \& laqueus patibuli.

W. 70. Ab Hisbenio ex lapide Pario en relief, ut Galli vocant, ave in convexum elaboratæ imagines fidami \& Evæ.

W. .7r. Icon Sopbia Cbarlotte Reginæ Boruffiæ ita incifum Muricis Americani parti rofeæ. Exemplar tale elegantifimum défcripfi in Bresl. Sament. von Nat, und Med. Gefibicbt. XX. Verf, Ano 1722. Menf. Maj. Clafr. IV. Art, X. pag, 499. Seqq. 
W. 72. A Blongio Londinenfi-preftantiffimx figuræx æencx pieturarum coloribus oleo mixtis expreffarum fpeciem exacte referentes.

W. 73. Tabula Anamorphotica, f. Caput fœmin $x$ in tabula $x e^{2}$ quod varii habitus Statuum \& Nationum in glacie Mariæ expreffi, permutant \& fpectabile r eddunt.

W. 74. Accipiter infignis magnitudinis ad vivum delineatus.

W.75. Ab Alberto, Dürero piaum Capur Fobannis Baptifs, cum filia Herodiadis.

W. 76. D. Martinsus Lutberus of Pbilippus Melancbtbon a, Luca Cranacbio pictus.

W.77 Theopbraflus Parace?

W. 78 . Effigies Melcbioris Hedlow homicidæ in Silefia famigeratiffimi.

W. 79. Scriptura ab homine qui digitis carebat, calamo exarata.

W. 80. Alphabetum germanicum magno artificio a Mattb. Bucbino gero fine pedibus \& manibus nato, fcriptum, cum Icone ejusdem. delin. \& defer. in Micb. Bernb. Valentini Mur. Múfeor. Part. III. Cap. XXII. pag. 76. Conf, Breslo Samml. von Natur-zund Medicin-Gefbbicbeen X. Verf. An. I779. Mení. QQiobr. Claff. IV. Art. XII. pag. 504. Alios homines mancos a nativitate, \& artificiofa queque perperrantes defcr. ful. Cafar Scaliger de Sub. tilitar. Exerc.CCCXXXIV. pä.1063. Martin. IV eindricbius Commentar.de MonAtris Cap. XXXVII. Pbil. Cameratries Hor. fubcifiv. Cent,I. Cap.XXXVII. Mart. Zeilerss Epift, Cepro. VI. Epift. 100. Paul. Zasbius in Quxft. Med. Legal, Lib. VII. T. I. Quxef. IX. S. 6. Godofr. Voigtims im Phy ficalifh. Zeit-Vertreib. Cent. II. Quzif, X. pag:246. Pbil. Facob. Sacbs a Lewenbeimb Gammarolog. Cap.XXI.

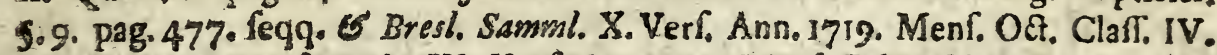

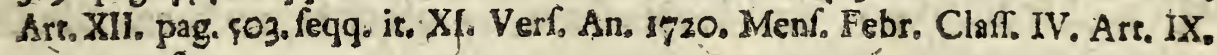
pag. 200. feqg.

W. 81. Mícrographize fpecimen f. Catechifmus parvus D. Lutberi in chartula pergamena, volam manus vix fuperante, confignatus. vid, Ol. TVormius Mur. Lib. IV. Cap.VIo pag. 387. Mich, Bernb. Valentini im Bedencken yon Kunff - und Natural. Kamın. Cap. VI. pag. sz. five in Eitusd. Mur.

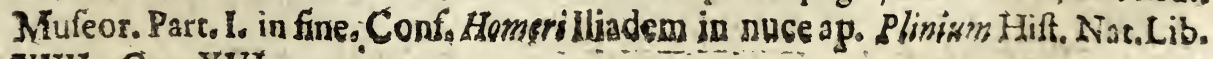
XVId, Capo XVt, 


\section{PROMTVARIVM RERVM NATVRALIVM}

W.82. Micrographiæ Turcica volumen elegantisfimum f. Alcoranus totus Arabicus XIIX. ulnarum; crumenæ fericæ inclufus. De caritate Alcorani vulgaris vid. Ad. Olearii Perfianif́che Reife - Befchreib. Lib. V. Cap. XX. pag. 316 . it. Hans Jacab" Breunings Oriental. Reife I. Meer - Farth, Cap.XIIX. pag. 73. alicujus 10000. aureos nummos xftimati meminit Erafm. Francisci im ausländifch. Kunt - und Sitten Spiegel Sect. XVII. pag. \{28. noftro fimilem defcr. Chrift. Polycarp. Leporin im Leben der Gelehrten in Teutfch Land Part. IIX. pag. 840.

W. 83. Contractus matrimonialis Malaicus ita in longum porrectus.

W. 84. Commeatus militaris Turcicus.

W.85. Epiftola Perfico idiomate exarata.

W. 86. Libellus ex charta ferica cum figuris \& literis variis Sinicis a fummo paginæ ad imum impresfis. De modo imprimendi \& fcribendi ibidem, vid. Fob. Neubofii Sinifche Reife - Befchreib. Cap.Il.pag. 223. it. Cap. III. pag. 236. fegq. Ol. Wormii Muif, Lib.IV. Cap.XII. pag. 381. it. Erafmo Francifci Kunft-und Sitten - Spieg. Lib. IV. Sect. IV. pag. 1243.

W.87. Panno ferico intertextæ literæ Sinicæ ex chordis argentatis \& inauratis.

W: 88. Libellus parvus, fimul charta luforia.

W.89. Manufcriptum genealogicum curiofisfimum Canum ab Illultr. Dn. Com. de s. fuftentatorum.

W. 90. Concumbendi XXXV. diverfa fchemata in ære eleganter incifa cum explicatione, f. L'Ecole de fille it. Aloifia Sigea five Job, Meurfii elegantiis Latini Sermonis.

W. 91. Generatio Papilionum \& Erucarum coloribus eleganter ad vivum exprefla a Maria Sibjlla Greffina nata Meriana Pars Ima \& IIda.

W.92. Medicorum Vratislavienfium, quotquot prodiere, tabulis æneis expreffæ, effigies.

W.93. Globus Ambræ perforatus f. Mofchimagni pretii apud Turcas, vid. Petr. della Valle Reife - Befchreib. Part. IV. Send - Schreib. XI. pag. 189.

W.94. Capfella Tabaci, qua in Scotia utuntur molendini fimul loco.

W.95. Capfella Tabaci elegantisfima ex Cochlea C.Harpa Rumphï. W. 96. 
W. 96 . Hippocampus ex ligneo buxeo adfumigandum Tabacum aptatus.

W.97. Capfella Tabaci ex Lobo Brafiliano maximo, argento ob. ducta. 'Lobun del. \& defcr. Car. Clufus Exotic. Lib. III. Cap. 1. pag. 60.

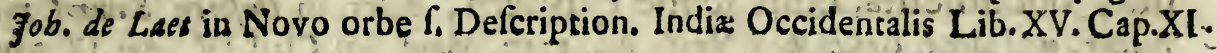
pag. 569.

W.98. Capfellæ ex Nucibus Mofchatæ oblongis Malabaricis inodoris. Arbor. c. Nucibus del. \& defcr. ap. Fob. Jonfonum in Hiftor. Natural. Arbor. \& Frutic. Lib. III. Tab. LIII. pag. 160. in Ephem. Nat. Curriofor. Dec.II. An.IV. Obf, XXXI. pag. 8j.prc. in Mibb. Bernb. Valcnini Oft-Indianifchen Rapporten Tab. IV. pag. 83 .

W.99. Atramenti Sinenfis Tabula oftangularis maxima, mire figurata, quo utuntur ad Sacra fcribenda, vid. Ol. Worminis Mur. Lib. IV. Cap. X. pag. 376. Erafm. Francifci Oft - und Weft - Indif. Luft-Gart. Part.I. pag. 282. prc. Fob. Neubofii Sinifche-Reife pag.241. \& Mich. Bernb. Valentini Mul. Mufeor. Part. I. Cap.VII. pag. 21.

W. Ioo. Japonenfis Atramenti Tabula longisfima. accedit ad delin. ap. Arnold. Montanum in der Gefandfchafft an den Kayfer zu Japan p.323. W. IOI. Atramentum tale Indix Occidentalis.

W. 102. Imago Veneris in convexum elaborata ex Succino. W. IO . Culter cum forcipe per catenam, ita ut fingula anfulx integra fint, contiguus, ex ligneo buxeo, ab homine coeco confectus. Miracula talia Coecorum ex Scrvio \& Digbiao confignavit Pbil. Fac. Sachs a Lewenbeimb Gämmarol. Cap, XXI. S.10. pag.480. multa quoque huc fpectantia collegit Gafp. Scbottus in Phyfica curiofa Lib. III. Cap. XXXIII. pag. 487. feqq. Sculptorem coecum defcripfit Antonius Fureterius in Diationario univerfali Gallice fcripto, guod excerpt, leg. in Aat. Erud. Lipf. Ann. 1690. Menf. Jul, pag.326. Coecum feribendi fcientis preditum defer. Gob. Muyss in Podalirio redivivo pag. 37. feqq. it. Fob. Conrad. Peyerus in Parergis Anatomicis \& Medicis Parerg. IV. Virginem coecam talem defer. Gilbert Burnet in Itinere per Helvetiam in Italiam \& quasdam Germanix \& Galliæ provincias Epift. II. in fine. Sculptorem Iralum, qui cocus ftatuas atque perfonas accurate delin. item ex cera imagines protocypo fimillimas effigiavit, vid. de Piles Cours de Peinture par principes, if. Lud, Phil, Tbïmmigs merckwürdige Begebenheicen in der Natur Part. I, num. 7. pag. $\{0$. feqq. Viros coecos eruditione preclaros vid. in Cbrifian Francifci Paullini Zeit-kürrzender erbaul, Luft Part. III. Them. XLIX. 


\section{PROMTVARIVM RERVM NATVRALIVM}

W. 104. Corbis ex femine Melonum major \& minor.

W. 105. Sacculus ex argento artificiofe paratus cum gemmis infitis.

W. 1 06. Funis a Preudo-Simfone difruptus \& alia roboris, ut voluit, documenta, cum Icone ejusdern, defcr. in Unferen samml. von Natur-zud Med. Gefbbicb. I. Verf. An. 1717. Menf. Jul.Clanf. IV. Art.IX. pag. 82. Feqq. prc. III. Verf. An. 1718. Menf. Mart. Art. VIII.Claff.IV. pag. 822. V. Verf. An. 1718. Menf. Auguft. Clafr. IV. Art. VIII. pag. I YII. feqq. XXV. Verf. An. 1723. Clafr. IV. Artic. XV. pag. 33r. Conf. Curiöfe Nachricht von ftarcken Leuren, fonderlich dem ftarcken Mann Eckenberg it. VIII. Verf. Bresl. Samml. An. 1799. Cl.IV. Art. XV. pag. 470 . leqq. Alia de corporis infolito \& vero robore collect, leg. ap. Plinium Hift. Nat. Lib.VII. Cap. XX. ap. Gellium Noct. Atric. Lib. XV. Cap. XVI. pag. m. 40 s. it. Ephemerid. Natur. Curiofor. Dec. I. An.IV. \& V. Obf, CXLIV. pag. IIt. Decur. II. An. X. in Appendic. pag. 58. it. ap. Zeilerum Theatr. Tragic. in Notis ad Hiftor.VI. pag. 192, feqq. \& Gafp.Stbottum in Phyfica curiof. Lib.llI. Cap. XXXVI. pag. 499 .

W. 107. 108. Urceus major \& minor ex Terra Sigillata alba Gabelenfi Bohemica cum figillo. vid. Besleri Gozophylac. Rer. Natural.pag. 14. prc. Bobusl. Balbini Mifcell. Hiftor. Regn. Bohem. Lib. I. Cap. XLIX. pag. 114. Vafa alia ex Terra figillata alba Melitenfi vid, in Erafm.Francific Oft-und Weit-Ind. Luft Gart. Part.11.'Tab.XLI. num. 5. pag.II 7 .

W. 109. Urnæ \& Statux ex Terra figillata rubra ejusdem loci.

W. ro. Monticulus, cui vir, fœminaque nuda infidet, ex Terra Sigillata alba Goldbergenfi Silefix.

W.III. Vafa majora \& minora murrhina, rarioris notæ, Porcellana vulgo dieta, diverforum colorum \& pieturæ Sinenfia \& Japonica. Conficiendi modum vid. in Ivan Goncalez de Mendoza Hiftoir. du Grand Rojaume de la Chine Lib. I. Cap. ult, in Gob. Hugon. Lintscbosti Navigation. in Orient, Part. I. Cap. XXIII. in ACZ. Philos. Soc, Reg. in Angl. An.1666. in Erafm. Franciffi Oft - und Weft - Indifchen wie auch Sinefifch. Luft - Garten Part. II. pag. II I. feqq. in Atbanaf. Kircberi China illuftrata Part. IV. Cap. XI. pag. 208. in Arnold. Montani Gefandfch. an den Kayfer zu Japan, pag. 393. feqq. in Gob. Neubofii Sinifcher Reife. Befchreib. pag. 95. feqq. in Dionyf. Kay Befelireib. Chinx Cap.X. pag. 305. adjecta Ysbr. Ides Reife nach China, in Georg. Eperb. Rumpbii Amboinfch. Rariter. Kamer Lib. III. Cap. XXIII. pag. 234. feqq. prc. Journal des Scavans Menf. Octob. 1717. pag. 399. 4 13 . it. Memoires de Trevoux Ann. 1717. Menf. Jan. pag. 39. feqq. unfere Samml. von Nat.und Meo dis, Gefobicbto. II. Verf. Ans, 1717. Mienf, Octobr, Clafr, V, Art. III, pag. 242. it. 
ET ARTIFICIALIVM KVNDMANN. VRATISLAV. $3 T 5$

Obfervatio mea Ibidem XXVI. VerI. An. 1723. Claff.IV. Art.VII. pag. 428. feq9. Multa fabulofa de preparatione fcripf. Jul. Cafar Scaliger de Subrilitate Exercir. XCII. pag. 328. it. Guido Pancirollus de rebus deperditis Part. II. Tit, II. pjg. 69. feqq.

W.II2. Lychnuchus penfilis ex Vafculis murrhinis Orientalibus. W. i13. Vafa Sinenfia \& Delphenfia rubra alia, argento obdueta. W. II4. Lagenula murrhea tota cœrulea operculo argenteo claufa. W.II5. Vafa majora \& minora Porcellanis fimilia, Clodoaldenfia, Delphenfia, Viennenfia, Dresdenfia, Berolinenfia, Moravica \& Vratislavienfia. vid. Obfcrvatio mea in Bresl. Samml. L. fupr. c. W. II6. Vafcula Porcellanica a Preuslero \& Pottengrubero cum variis picturis per artem miniculatoriam eleganter expreffis. vid. Obfervatio mea ibid. it. Leonb. Cbrifl. Sturmii Bau-Meifter-Academie pag-72. feqq. I. Tom. I. des Ritter-Platzes,

W. 117. Vafcula \& capfella cinerei coloris Coloniæ Agrippina confecti.

W. I18. Poculum ex Nuce Coccus de Maldiva argento inclufa. tale poculum del. \& defcr. Garzias ab Horto in Aromatum Hiftoria Lib. I. Cap. XXVI. pág. 193. editionis qux inter Carol. Clufii Opera prod.

W. I I 9. Vafcula \& lagenæ ex alabaftroalbo, defcr. in Muf. Calceolarian. Sect. Ill. pag. 391.

W.120. Caprella perf́picua ex tegumento Teftudinis, argento munita \& ornata.

W.121. Ciftula Medica ex ligno Nucis Regiæ.

W.122. Ciftula mirabilis fructuræ tota ex vitro diverforum colorum \& figurarum artificiofe exftrueta.

W. 123. 124. Vafcula ex A chate num.ij. mire variegata \& Atriata. W. 125. 126. 127. Annuli ex Achate integro albo \& fubflavo confe: Eti, item alius ex Sardo.

W. 128. Annulus totus aureus in Anglia confectus, in qua variæ fle: xuræ, qua literas indicant.

W. I29. Vafa majora \& minora ex lapide ferpentino. vid. G. F. Mylic Memorabil. Saxon. fubterran, Part. I. Relar. IV. pag. 3t. \& 32.

W. 130. 131. 132. Statuæ Herculis, Veneris \& Saturni metallifata fecun. dum exemplar antiquorum. 
W. I33. Statux ex Terra argillacea rubra Delphenfi Batavorum: W:134. Pyramides ex terra colore albo \& rubro variegata Maslenfi Silefix.

W.135. Statua metallifofforis eburnea-monticulo ex mineris inf1ftens, lagenæ inclufa.

W. 136. Varixeminenter excif tabella ex ebore, item yaria fubtiliffime tornata.

W.137. Chriftus cruci affixus ebori artificiofe incifus.

W.138. Pennæ feriptoriæ ex vitro cœruleo \& albo.

W.139. Sera cum clave, lentis magnitudinem vix æquans,

W. 40 . Corbis ex cerafi nucleo elaborata. defcr. Ol. Wormius Muf. Lib. IV. Cap.X. pag. 376 .

W. I4I. Corollæ I. Sphærulæ precatoriæ cum appenfa Deipara, fecundum Pontificios miraculofa, cum catalogo miraculorum.

W. 142. Corollæ precatoriæ Turcicæ ibidem Thefsbich dietæ, ex fuccino. dsfor. Hans Jaiob Breuning Oriental, Reife II. Meer-F. Cap. IV. pag. 108. Ol. Dapper in Befchreib. von Africa pag. I35. prc. Thevenot in Reifen Part.I. Lib. I. Cap. XXXVII. pag. 68.

W.143. Collare Hifpanicum ex fphærulis nigris, gradiffimum odorem fpargens.

W.144. Collare fcalptum ex Ampelite Anglicana, provincix Staffordshire. defcr. in Bresl. Samml. XIX. Verf. Ann. 1722. Menf. Jan. Claff.IV. Art. III. pag. $\{3$.

W. 145. Cochlearia num. XII. ex cochleis porcellanicis diverfimode maculatis \& conchis rnargaritiferis parata Brafilienfium, cum manubriis argenteis inauratis. defer. Georgius Marceravius de Brafil.Region. \& Indigenis Cap. VI. pag. 16.

W.146. Baculus ex ligno Brafilienfi, qui fimul fiftula.

W. 147. Gladius magnete imbutus, qui unciam ferri tenet.

W. 148. Gladius percufforius ferratus infignis magnitudinis \& artificii.

W. 149. Gladius Hifpanicus longiffimus ictorius.

W. rso. Collare ex conchinulis albis, pro ornatu Brafilienfibus. vid, Rocbefort. Befchr, der Antill. Infuln Cap. XIX. num.X. pag.331。 
ET ARTIFICIALIVM KVNDMANN. VRATISLAV. 317

W.151. Linteuin ex filis toliorum Aloês aculeate. vid. Bresl. Samiml. von Nasur - und Médicin - Gefbbicbt. XII. Verf. An.1720. Menf. April. Clarr. IV. Art. XI. pag. 456. it. XVI. Verl. Amn, 1721. Menf. April, Clan. IV. Art. VII. pag. 409.

W.152. Pannus uno latere ruber, altero cœruleus.

W. 153. Capfella pro culicibus captandis. de!. \& defer. in Micb. Bernb. V.alentini Mul. Mufeor. Parr.III. Cap. XXI. pag. 76.

W.154.155.156. Tres Tabulæ cuprex elegantiffime in convexum elaboratæ, repræfentantes Herculem cum Cerbero, Juftitian \& Parem fe fe invicem exofculantes, item Virtutis formæque pravia.

W. 157.158. Afferculi ex fecamentis ligneis diverficoloribus, item ex particulis per limam comminutis, \& iterum agglutinatis, qui varias flexuras referunt.

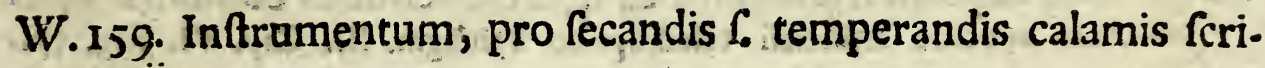
ptoriis.

W.I 60 . Chriftus cruci affixus ex Sale cryftallino formatus. vid. Micb. Bernb. Valentini Mur. Mufeor. Part. I. Lib. I. Cap. IV. S. I. pag, 13.

\section{ARTICVLVS II. Inftrumenta optica \& alia.}

X. .. Microfcopium Anglicanum maximum ad modum illius, quod Cbrift. Gottl. Hertelius defcripf, fub Titul. Microfcopium noviter inventum. A. liud invenit 7ofeph. Campanus in Defcr. Novi Mic ofcopii, aliud defcr. Fob. France Griendelius in Micrographia nova Obferv. I. Microfcopiorum variorum conftruCaiones vid. in Fob. Zabnii Oculo artificiali Teledioptrico Syntagm. III. Cap. I. II. III. \& IV. pag. 524. - 559. it. in Appendice pag. 780. Authores alios, qui Micrographicis inclaruerunt fcriptis vel Microfcopia perita manu aut confece. runt aut defcripferunt, collegit Pbilippus Bonannus in Obfervationibus circa Viventia, qux in rebus non viventibus reperiuntur, cuin Micrographia curiofa; cui addendus Cbrift. Gottl. Hertelii vollfändige Anvveifung zum Glafs-Schleiffen. Corpufcula, quxe exilitate fua aciem vifus noftri fubterfugiunt, armatis perluftravit oculis Henr. Powerus in Obfervationibus Microfcopicis \&: Robert Hoockius in Micrographia, it. Ant. Leetvenbokius in Anatomia f. Inter. rerum animatarum ope Microfcopiorum detect. quibus addend. iupra allegatus Grindelius L.C. Obferv. II, - IIX. Bonannus L. C. it. Foh. Cbrifophorus Sturmius in Co!• $\operatorname{Rr}_{3}$ 


\section{PROMTVARIVM RERVM NATVRALIVM}

leg. Experimental. curiof. Parc. I. Tent. XV. pag. I46. Paradoxa de Microfcopiis annotavit $\mathcal{F}$. F. Becherus in der närrilchen Weifsheit und v veifen Narrheit Part. II. num. XXXVII. pag. I;8.

X.2. Microfcopium ex II. lentibus conftans.

X.3. Microfcopium ejusdem ftructuræ minimum:

X. 4. Microfcopium ex III. lentibus fingularis ftruetura.

X. 5. Microfcopium cum fchematibus variis, ad ea amplificanda.

X. 6. Microfcopium globulare per aquam.

X.7. Microfcopium ex unica lenticula vitrea.

X. 8. Tubus opticus XII. pedes longus, per quem annulus Saturni \& fatellites ejus, itemque Jovis confpici polfunt, cum variis vi. treis orbibus imponendis. vid. Cbriff. Hugenii Aftrofcopia compendiaria Tubi optici molimine liberata.

X. 9. Telefcopium maximum ex quatuor lentibus conftans. defcr. foh. Zabn in oculo artificiali teledioptico Syntagm. III. Cap. VI. pag. 57 i. feqq.

X. IQ. Laterna Catoptro-Dioptrica, per quam figuræ, vivas fuperantes, repræfentantur. Mcdum conficiendi docuit id. $Z_{a} b n$ L.C. Synt. V. Cap. V. pag. 726. feqq. Fob.Cbrifloph. Sturmius in Colleg. Experimental. Tentam, XVI. Phon.Il. fig. 80. p.163. it. Fob. Cunr. Creilingius in Difr. de Phœnomenis Laterne Magicx, \& Bonifacitus. Henric. Ebrenbergerus in Dif. de Laternx Magicx augmento.

X. II. Camera obfcura portatilis, non vulgaris ftructuræ, ad transferendas in chartam picturas quascunque, etiam a rei pictoria ignaris. conven. cum delineat. \& defeript. quam dedit Sturmius L. C. Tent. XVI. Phœm. I. fig. LXXIX, pag, 161. Alius inventionis defer, a Marco Anton. Cella in Act. Erud. Lipfienf. An. 1687. Menf. Dec. pag. 701. delin. Tab.XI. De ufu Camerx obfcurx in delineandis objectis quibuscunque vid, G.J.Gravefandii Eflais de Perfpeque in fine.

X. 12. Camera obfcura alia cum lente objectiva, \& oculo ligneo, cujus ope in omnes partes converti poteft, inclufa.

X. 13. Tabulæ variæ catoptricæ, juxta leges opticas elabo. ratæ.

X. I 4. Speculum concavum caufticum ex vitro. defcr. Micb. Bernb. Valentini in Muf. Mufeor. Part.III. Cap.X. pag.39. Aliud ex Papyro vid. in un. Seren Samml, von Nat, und Med. Gefob. IV. Verf. An,1718. Menf. Maj. Claff.V. 
Art.VI. pag.112I. ex Ligno, Ibidem XVIII. Verf. An.1721. Menf. Nov. Clafr. V. Art.1. pag. 544. Ex Glacie \& Stramine in Job. Joacb.Becheri Närrifch. Weish. und Weif. Narrh. Sect.I. num. 49. pag. 92. Conf. Hambergeri DifTert. de Frigore Phoen. 85. it. de mirabili effeclu Henr. Oldenburgii AAt. Soc. Reg. in Angl. An. 1665. Menf.Nov. pag.73.feqq.

X. 15. Vitrum convexam caufticum, vid. Unfere Samml. von Natur.und Med. Gefcb. IV. Verf. An.1718. Menf. Maj. Claff.V. Art.VI. pag.II21.feqq. pre. XVIII. Verf. An.I721. Menf. Nor. Claft.V. Art.II. p. 545.feqq. Ex Glacie vid. id. Becberi L. C. Part.I. num.49. pag.91. Effecta vitri cauftici fingularia leg. in 1E. Erud. Lipf. An.1691. Menl. Nov. pag. §18. it'. An.1697. Menf.Sept. p.414. ubi fimul de magnis lentibus caufticis: Hiftoriam \& Ufum Lentium \& Speculo. rum caufticorum vid. in Bresl. Samml. von Nat. und Med. Gefib. XVIII. Verf. An. 1721. Menf. Nov. Clarr.V. Art.If. pag. 545 .feqq.

X. 16. Globus caufticus per aquam.

X. 17. Speculum Anamorphoticum concavum ad deformanda objecta. Machinam talem delin. \& defcripf. Jac. Leupoldus in Att. Erud. Lipf. An. 1712. Menf. Aug. pag.367.

X. 18. Polyedrum $\mathrm{f}$. vitrum polygonium. defer. in Leonh. Cbrif. Sturmit Mathefi compendiaria Part.IV. Multa huc fpectantia f. de mixcione reflexionis \& refraQionis vid. Ephem. Nat. Curiof. Dec.I. An.VI. \& VII. fub finem.

X. 19. Prifma triangulare cryftallinum. vid. defer. in 01 . Wormii Mur. Libr.IV. Cap.VII. pag.326. Modum conficiendi inftrementa optiea docuit fob. Chrifopb. Koblbans in Tract. Optico: alia vero ad Opticen fpectantia vid. in Atban. Kircberi Arte mogna Lucis \& Umbra aliique.

X. 20. Vitra tonantia S. Globuli vitrei fulminantes. vid. in Mich. Bernb. Valcntini Muf. Mufeor. Part.III. Cap.XVII. pag.67.

X. 21. Lacryma vitrea ferpentiformes.

X. 22. Lacrymæ vitrex aliæ. pecul. Tract, defict. Italus in Speculazione Fi. fiche fopra gli effetti que Vetri temperati, it. Zoh. Jac. Bajerus in Differt. de Lacry. mis vitreis. Conf. Cbriflopb. Merstti Obfervat. fo foh. Kunskelii $\Lambda$ rt. Vitrariam Experimental. pag. 320. Fob. Cbriftoph. Sturmii Colleg. Curior. Experimental. Part.II. Tentam.VI. pag.92. Marci Marci Philof. Veter. reftitutsm Part.V. Sect. I. Subfea.VIII. pag. $\{27$. Ephem. Nai. Curiof. Dec.II. An.VII. Obr.LXVI. pag. II s. Mich. Bernb. Valentini Muf. Mufeor. Part.III. Cap.XXVI. pag.67.

De mirabili effectu vid. id. Ephem. Nat. Cur. Cent.I. \& Il. Obf.XI. p.go. ic. Frasc. Redi in Experiment. circs res diverfas Naturales, in fine.

X. 23. Crater diabeticus Scbotti totus ex vitro. vid. Papini Inventa nova Hydragogica ex Trangacr. Pbilof. Anglic. Menf. Dec. An.1685. pag.1254. Franc. 
Tertii de Lanis Magift. Nat. \& Artis Tom.II. Mariotte Grundlehren der Hydroftacic und Hydraulic. Georg Alb. Hambergeri Hydraulicam.

X. 24. Cyathus vitreus, per quem aër folummodo hauritur.

X. 25. Campana urinatoria. Talem delin. \& defcr. Job. Cbrif. Sturmius in Colleg. Experiment. Curiof. Part.II. Tentam.I. pag.I.feqq. De Urinatoribus \& Urinandi arte vid. Melch. Sebizii Diff. Argentorat. publ. it. Job. Foacb. Becheri Narrifch. Weish. und Weife Narrh. Part.I. num.25. pag.38. Aliam delin. \& defer. Tbom. Bartbolinus in Ac. Med. \& Phil, Hafnienf. Vol.IV. Obferv. XXII. pag.62.

X. 26. Oculi artificiales vitrei, naturalibus fimiles.

X. 27. Barometron bicrurale minimum. del. \& defer. in Bresl, Samml. von Nat. und Med. Gefcb. XXI. Verf. An.1722, Menf. Sept. Clafr,V. Art.I. pag. 343. feqq. aliud vid. XII. Verf. An.1720. Menf. Apr. Clan.V. Art.IV. pag.47I.

X. 28. Barometra varia. Ulum Geometrico Phyficum elegantif. demonftr. 7ob. Fac. Scbestcbzerus in der Natur.Gefchicht. des Schweitzerl. Part.III. pag.16i. De Caufa afcenfus \& defcenfus in Bsronetro vid. Bernbardin. Ramazinus in Ephemerid. Barometricis Mutinenfibus An.1694. it. Laurent. Gobart in Trae. PhiloSophico de Burometro, Facob. Placentinus in Diff.'de Barometr. Barometron fingulare marinum a Martino Hoockio inventum defcr. Edimund. Halley in Aat. Pbilo. fopb. Angl. An.r701. pag.789. Aliud orbiculare ibid. An.1666. Menf. Jun. pag. 164. Aliud ftaticum L. C. Menf. Jul. pag.175. Obfervationes varias propofuic Henr. Oldenburgius in ACT. Soc. Reg. in Angl. An.1666. Menf. Mart. pag.12O. ic. Menf. April. pag.137. Conf, Franc. Tertii de Lanis in Migifter, Nat. \&Artis T.II, Lib.VI. pag.282. ieqg.

X. 29. Thermometra Florentina, Belgica, portatilia ferpentina \& alia. defcr. \& del, id. Er. Teriii de Lanis L. C. 'T.II. Libr.VIII, pag.380. feqq. Sturmius L, fupr. c. Part.II. Tent,IX. pag.164. Fob. Andr. Scbmidius Differt, de Thermometris.

X. 30. Hygrometra varia. pertinet huc Comiers d' Ambrum I' Homme artificiel Anemofcope, ou Prophete phy̧fique du changement des temps, Gothofr. Teuberi novum génus Hygrometri minutiflimas äeris mutstiones duplici modo oftencicns, quod defcr. \& delin. in ACr. Erud. Lipf. An.1687. Menf. Febr. Tab. II. pag. 76 . it. An.1688. Menf. April, pag. 179. it. Frideric. Helfric, Lichtscbeidii no-va acceftio ad Hygrometrum ex Chorda confici folitum ibid, pag.18r. D.Amontows Hygrometron noviter inventum defcr. \& delin. ibid. pag. 374. Tab. VII. Fob. Cbriflapb. Sturmiuu in Coll, Experim. fo curiofo Part.I. Tent.XIV. pag.Izo. ieqq. ubi plures fimul citantur authores.

X. 31. Quatuor Elementorum artificiofa repræfentatio in vitro. defere 


\section{ET ARTIFICIALIVM KVNDMANN. VRATISLAV. $32 t$}

fcr. Hier. Ambrofius Langenmantelius in Ephem. Nat, Curiof. Dec.II. An. VIL. Ob fer.CCXXXII, pag.440.

X. 32. Sipho perpetuus ad jocum factus.

X. 33. Inftrumenta varia Hydroftatica. vid. Mariotte in Grundlehren der Hydroftatic, unid Hydraulic. it. Sturmius in Coll.Exp. Curiof. Part II. Tentam. IV. pag.58.leqq. Conf. Rob. Boyle Paradoxa Hydroftatica novis experimentis maximam partem Phyficis \& facilibus evicta.

$\mathrm{X}$. 34. Libra accuratiffima docimaftica cum variis ponderibus.

X. 35. Inftrumentum acufticum argenteum, pro aêre ex aure fugendo. De cura per futionem vid. Gatrophilus Sincerus in Unterweifung die Kranckheiten zu curiren pag.59. prc. Cbriftian. Tbeoph. Reufneria in Ephem. Nat. Curiof. Cent.V. \& VI. Conf. Unfere Samiml. von Natur-und Med. Gefib. I. Verf. An.1717. Menf. Sept. Clıf.v. Art.X. num.11. pag.119. Multa huc fpectantia, item alia inftrumenta \& tuhas acufticas vid. in Mifcell. Nat. Curiof. Dec.I. An.I. Obr.XXXV. prc. inScholio pag.112. in Anton. Nutkii Experimentis \& OF erationibus Chirurgicis Exper. XV. Conf. Fob. Cbrifoph. Scurmii Coll. Exp. Curior. Part.II. Tent.VIII. pag.152. Nebem. Grew in Mui. Soc. Reg. pag 359. De Tympanò acuftico P. Seb.lf. Trusbel vid. Bresl Samml, von Nat. und Med. Gefab. IV. Verf. An 1718. Menf April. Claf.V. Art.I. pag.loci.feqq.

X. 36. Machina Mufculorum aetiones ftupendas in corpore animali illuftrans. defcr. \& del. Sturmius in Coll. Exp. Curiof. Part.II. Tent XI pag. 187. feqq.

X. 37. Tubus ftentoreus, defrr. \& del. itemq; Aucores collegit id. Sturmius L. C. Part.II. Tent.VIII. pag 142,feqq. quibus addendi fob. Math. Hafius in Dif. fert. Phyf. Math. de Tubis ftentoreis. Varia experimenta inftituit Franc. Tert. de Lanis in Magift. Nat. \& Art. Tom.II. Lib.X. Cap.I. pag.42r.feqq. Aibar.Kircherus Phonurgix Lib.I. Sect. III. Cap. II. Morlandi Stenterophonicon Anglica. num fingulare defcr, 7. 7. Becherus in Närrifch. Weifsh. und Weif. Narrh. Part.I. num, 18. pag.27.

$\mathrm{X}$. 38. Agrimenfor ex aurichalco, fingularis inventionis.

X. 39. Laterna cum Lampade verfatili.

X. 40. Tormenta bellica minora ex ære fingularis inventionis, ad citiffimam explofionem inventa. De rei Tormentarix variis tracationibus \& ipfis tormentis vid. Job. Furtenbachs Büchfenmeifter Schule, Memoires d' Artillerie par le Sr. Surery de S. Remy Tom. II..-Cafamir Simienowicz vollkommene Gefchütz-Feuer-Werck-und Büchfenmeyfterey-Kuntt, Fob. Brangii künftHiche Feuer-Wercke und Kriegs-Inftrumenta : plures Authores collegit Leonb. Cbrif. Sturmius in der'geöffneten Feftang, $f$ im Ritter-Platz Fom.I. pag.136.leqq. 
X. 41. Inftrumenta Anatomica \& Chirurgica del. \& defcr. Job. Andir. a Cruce in Chirurgia univertali, Fabritius ab Aquapendente in der Wund-Arezney Part.Il. in fine, prc. Job. Scultetus in Armamentario Chirurgio bipartito Part. I. Tab.I..-XXV. pag.4.--34.

X. 42. Inftrumenta Mufica, Pyrobolica \& Mechanica.

\section{Claffis II. \\ A R TIC VLVS I.}

Y. I. Series Imperatorum Romanorum a fulio $C a$ are usque ad Au. guftifimum Imperatorem CAROLVM VI. a Wermutbio CCXIX. nummis expreffa. vid. Catalogus ab eodem editus, prc. Hubert. Goltzii Thefaurus rei Antiquarix, it. Continuatio Cafparis Gevartii a Julio Cafare usque ad Ferdinandum III. Levini Hulgii feries Imperatorum Romanor. a C. Jul. Caf. ad Rudolpbum II. ex prilcis recentibusque Numifmatibus. Conf. Th. Treteri Imperatorum Romanorum effigies a C. Jul. Cafare usque ad Rudolpbum Imperat. Authores plures huc pertinentes colleg. Leonb. Cbrift. Sturmius im geöffneten MüntzCabinet pag.184.feqq. C. im Ritter-Platz Tom.I. Sec.II.

Y. 2. Res geftx Leopoldi I. Jofepbi I. \& CAROLI VI. Auguftiffimorum Imperatorum ex nummis CCLX. vid. Hiftorifche GedächenisMünzen, prc. Hiftoriam Numímaticam CAROLI VI. Rom. Imper. publicatam a fob. Fac. Mofer de Filsberg \& Weyhlerberg.

Y. 3. Series Pontifum Romanorum a tempore Concilii Conftantienfis f. a Martino V. usque ad Benedictum XIII. num. LXXXXVII. defcr. in Dominisi Tempefte, Romani, Vitis Summor. Pontificum, a C. J. ad Clementem VII. Latino Italicoque fermone breviter confcripta, cum effigiebus corum ex nummis, \& piaturis excerpris, Fob. Bapt de Cavalieriis omnium Pontificum Ro. manorum Icon a Sto Petro ad Clementem VIII. additis fingulorum infignibus, prc. evolvend. Claud. du Molinet in Hiftor. Summor. Pontificum a Martino V. usque ad Annum 1699. qui vel auctoritate publica vel privato genio in lucem prodiere. Conf. Job. Palatii Gefta Pontificum Romanorum.

Y. 4. Nummi Regni Hungaris, prc. in Coronationem \& triftem interitum Ludovici Reg. Hungar. vid. Job. Jac. Luckii Sylloge Numifmatum elegantior.pag.62. it. Teckelii \& Ragntzkii nummi.

Y. 5. Collectio Nummorum Gallicanorum a Ludobico XII, usque ad Ludovicum XV. num.LXXVIII, vid Medailles du Regne de Louis le Grand par l' Academie Royale des Medailles \& des Infript, it, Menetrierii Hiftoire de $\therefore$ ald

Roy 


\section{ET ARTIFICIALIVM KVNDMANN. VRA TISLAV. 323}

Roy Louis le Grand, par les Medailles, Emblemes, Devifes, Jcttons, Infcriprions, prc. Opus pretiofisfimum, cui Tit. Medailles fur les principaux evenemens du Regne de Louis le Grand avec les explicarionsHiftoriques, it. Le Blanc Traité Hiftorique des Monnoies de France depuis le commencement de la Monarchie jus. ques a prafent.

Y. 6. Anglicanorum ab Eduardo VI. usque ad Georgium Ludovicum num. CXL VIII. vid. Bizot Hiftoire Metallique de la Republique de Hollande, it. ejusdem Supplement a l' Hiftoire Metallique etc. prc. evolv. Nicol. Cbevallier Hiftoire de Guillaume III. Roy de Angleterre par Medailles.

Y.7. Danicorum num.X LVIIl, vid. Job. Muleni E Tbome Bircberodii Numifmata Danorum, it. Oligeri Jacobxi Mufeum Regium Hafnienfe.

Y. 8. Svecicorum a Cbriftinno II. I. Cbriftierno usque ad ulricam Eleonoram \& Regium Maritum Fridericum in continua ferie num. CV. vid. Elias Brenner in Thsfaura nummorum Sveo. Gothorum XXX. annorum Spatio collectorum I. a Gufavo I. ad Carolum XII. Conf. Wilb.Erneft.Tenzelii Mo. natl. Unterred. An.I694. Menf. Januar. it. Auguit. pag.646.feqq.

Y. 9. Polonicorum cum iis qui in coronationem \& res gettas Stanislai Lefczynsky inventi num. XIVII.

Y. 10. Boruffacorum, num.XXXVI. defcr. Dicteric. Kemmericbius Dilf. de Corona Boruflis Friderico a Deo data.

Y. II. Electoralium.

Y. 12. Mofcoviticorum.

Y. 13. Reipublicæ Veneta. vid. Job. Palatii Fafti Ducales Veneti.

Y. 14. - - - Hollandie cum ferie Gubernatorum, f. a Duce de Alba \& Guilielmo Araufionenfium Principe, usque ad Guilielmum II. poftmodum Regem Angliæ num LXVIII. vid. Bizot Hiftoire Metallique de la Republique de Hollande, it. Cornel. Alksmade gaude en zilvere Penningen der Graven en Gravinnen van Hollarsd.

Y. 15. Ducatus Silefie num.LVIII. vid. Gotbofr. Deverdeck in Silefia Nu:nifmatica.

Y. 16. Metropolis Vratislabie num. XLVIII. vid. id. Devverdeck L. C. Libr.V. Cap.XII. XIII. XIV. pag.78r.feqq.

Y. 17. Sacrorum \& Profanorum num.LXXIV.

Y. 18. In Jubilea \& Inaugurationes Academiarum \& Societătum num.

LIV. vid. Fob. Petr. Ludwigs Programma vom Jubel-Jahr, (unter den kleinen teutfchen Schrifteen.)

Y. 19. In D. Latberi Reformationem \& Jubillaum Lutheranum An, 617 . $\mathrm{S} s 2$ 
celebratum num. XXXVIII. it. fecunda vice An.1717. num. LI. vid. Cbriftian. Funckers Ehren-Gedächenifs Lutheri, fob. Jac. Luckii SyllogeNumifmatum recentiorum, it. Ern. Sal. Cypriani Theologifch Hiftorifch. Bericht vom andern Evangelichen Jubel-Jahr, Part.lII.

Y. 20. Viros eruditos \& artifices fiftens fupra C.

\section{ARTICVLVS II.}

Collectio Thalerorum cum Inlcriptionibus notabilióribus \& aliorum, ur:

Pbilippi Magnanimi Landgr. Haffix cum Infer. Beffer Land u. Lud verlorn, als en falfchen aid gefchworen, de anno 1552 Ejusd. cum Infcr. Was GOtt befchert, bleibe unerwehrt. Ludovici Landgr. Haffiæ cum Infcr. Ich getraue GOtt in aller Noth, de An:1588.

Mauritii Landgr. Haff. cum Infcr. Confilio \& Virtute, de An.1626. Wilbelmi Landgr. Hafr, cum Infcr. Uno volente humilis levabor, de An.1627.

Ejusdem c. Infer. Deo volente humilis levabor, cum arundinibus a ventis depreffis, de An.I63o.

Ejusdem cum Infcr. Fata Confiliis potiora, de An.1633.

Guftavi 1. Regis Sveciæ, cum Infcr. Salvator mundi adjuva nos, de An.1543.

Fjusdem cum Infeript. Omnis poteltas a Deo eft, de An.I 534 . Jobannis III. Regis Svecor. cum Infcr. Deus Protector nolter \& Salvator Mundi falva nos, de An.1576.

Caroli IX. Reg.Svec. c. Infer. Jehovah folatium meum, \& Salvator mundi falva nos, de An.I6Io.

Guftabi Adolpbi Reg. Svec. c. Infer. Ein guter Hirt läflet fein Leben für die Schaffe, de Ân.1633.

Ejusdem cum fymbolo militari f. Infer. GOtt mit uns.

Ejusdem c.Infer. Dexteră tuaDomine percuffit inimicum, de An.1632. Cbriftine Regin. Svecor. c. Infer. Salvator mundi falva nos, de An. 1645 .

Caroli XIr. Reg.Svec. c. Infcr. Collapfam fortiter reftituit, $f_{\text {, in me- }}$ moriam Tract. Altranttadienf, de An.170g. 
Friderici II. Regis Danie cum Infcr. Deus refugium \& fiducia mea, de An.1572.

Cbriftiani IV. Reg. Dan. c.llnfer. Regna firmat pietas, it. Benedietio

Domini divites facir, de An.1624.

Comitum de Mansfeld cum verbis tegumento equi infcriptis: St.Georgius Patronus ora pro me, de An,1523.

Gebb. Alberti \& Pbil. Com. de Mansfeld de An.1538.

Davidis Com de Mansf. c. Infer. Bei GOtt ift Rat, und Thăt, de Añ. 1613. (xettimstur, quia in his literis nummericis fimul latet verbum judicii $\int$. JVDICIVM.)

Henrici Com. de Mansf. c. Infer. Commifi Domino \& ipfe faciet. Frider. Cbrifophori Com, de Mansf. Geduldt in Unfchuldt, Trew ift Wildpret.

fobannis Georgii Com. de Mansf. c. Infcr. Fortiter \& Conftanter, de An.1658.

Henrici Ducis Brunfvi-\& Lüneburgenfis c. Infcr. Juftus non derelinquitur, de An.1537.

Ejusdem cum Infer. In GOttes Gewalt, hab ichs geftalt, der hats ge-

fïigt, das mirs genïgt.

Ejusdem c. Infcr. Non vidi jufturn derelietum.

Fulii Duc. Brunfv. c. Infer. Aliis inferviendo confumor,de An. 1586. Ejusdem c. Infer. Washilfft den Augen Licht und Brill,der fich felbft nicht helffen und kennen will, de An.1589.

Item in Ejusd. Obitum cum viro fylveftri, dextra candelam, finiftra arborem tenens, e dextra pendet cranium humanum, fub quo horologium \& oculare, c. Infcr. Luctu publico, de An.1589. Henrici fulii cum Interitu Coræ \& Infer. Non recedet malum a Domo injufti \& fuperbi, it. Dormiens confcientia ficut canis, it. No. li me tangere, de An.1595.

Ejusdem cum Victoria leonem anterioribus pedibus capram tenentem coronans; c. Infer. Huete dich für de Tadt, der Luegen wird wol Rad, de An.1596. item: Tandem bona caufa triumphac. Fjusdem $c$. Infer. Recte faciendo neminem timeas. Veritas ftans ereeta, ad pedes Calumnia \& Mendacium, c. Infcr. Veritas vincit omnia, Calumniam Mendacium, de An.is97. 
Ejusdem, cum fafcibus, quos leo \& urfus cuftodiunt, c. Infer. Unita durant, de An.1599.

Ejusdem, Pelicanus pullis peetus aperiens, c. Infcr. Pro aris \& focis, de An.1599.

Ejusd. Bienen-oder Muicken-Thl. fuper Leonem aquila,circum apes, de An.1599.

Ejusd. cum viro fylveltri, dextra arborem avulfam tenens, c. Infcr.

Honeftum pro patria, de An.I6II.

Chriftiani Duc Brunfv. c. Infcr. Tout avec Dieu, it. GOttes Freund

der $\mathrm{Pf}$. Feind, de An.I622. it. alius cum enfe, quadrato facerdo-

tali infixo, cum eadem infcriptione.

Pbilippi Duc. Brunfvi. c. Infer. GOtt giebt, GOtt nimet.

Friderici Ulrici Duc. Brunfv. Peregrinator ad St. Jacob. Compoftell.

conchis collo \& peetore circumd. dextra fcipionem, finiftra li-

brum tenens, \& fub pedibus conchas habens, c. Infcr. Ui conchas

auge noftra metalla Deus, de an.1633.

Georgii Duc. Brunfv. cum Infer. AufGOtt trawe ich, de an:1638. Augufti Duc. Brunfv. Thalerorum feries cum campanis, de an.1643.

c. Infript. Alles mit Bedacht.

Imo Campanæ deficit piftillus additis verbis: SIC. NISI. \& litteris

T.S. C.E. B. C. Tandem Sortientur Confilia Exitum Bonum.

In IIdo reperitur eadem fignatura, cum verbis: UTI. SIC. NISI.

In IIItio folus adeft piftillus cum Infcript. ex A pocalypf. Cap.XIII. verf. I0. Hic eft patientia \& fides Sanctorum, \& verbo: SED.

In IVto \& Vto adeft campana cum piftillo, \& Infcr. Tandem, ir. literis: E. W.A.I.D.I.R. five:Tandem ergo Wolfferbytum ab injuftis detentoribus invite reftituetur. M. VII. B. 13. $\phi$, hoc eft: Menfe Septembre decimo tertio die, qui erat Mercurii; In altero M. VII. B. I4. 24. hoc eft. Menfe Seprembri decimo quarto die, qui erat Jovis, f. evacuationis.

In VI. tres manus campanam trahunt, cum Infer. NVntius PACis EX SOno EJus. it. Tandem Patientia vißtrix. Ad hanc feriem $a b$ aliquibus VIImus etiam numeratur cum Nave \& Infcr. Jaeta eft alea, \&: Alles mit Bedacht. Ejusdem alius cum viro fylveftri \& Infer. Alles mit Bedacht, de an. 1655. 
Friderici Duc. Brunf. de an. 1637.8 1639. c. Infcr. Fried ernehrt, Unfried verzehrt.

Chrifiani Ludobici cum Infer. Sincere \& conftanter, de an.1668. Electorum Saxonix in continua ferie, ut: FridericiSapientis, Jobannis. Conftantis, Fob. Friderici Magnanimi cum Infer. Soli Deo Victoria, it. Parcere fubjeetis \& debellare fuperbos, r. in Fœdus Smal. caldicum. Ejusdem fobannis Friderici captivi cum Infc. Natus Elector Saxonix, de an.1552. Mauritii de an.1549. Augufi \& quidem in Obitum de an.1586. In Cbriftiani 1. obitum cum Infer. Haud timet mortem, qui vitam fperat, de an.159 1. Chriftianill. de an. 1602. Fobannis Georgii I. c. Infcr. Pro Lege \& Grege, de an.I619. Ejusdem alius cum Infer. Nomen Domini Turris fortiffima, de an.1613. In ejusdem Obitum alius f. de an.1656. In Obitum Mag. dalene Sibjlle uxor. foh. Georg I. cum Infcr. Wie GOtt will mir gefchehe, de an.1659.

Jobannis Georgii II. cum Infcr. Deo \&s Patria, (Deo ad caudam, \& caput equi pofitum)de An.1657. In Obitum Magdalense Sibylle Uxor. Fob. Georg. II. c. Infcr. Sola fpes mea, de Ann. 1687. In fobannis Georgii III. Obitum, de Ann. 169I. In Obitum Anne Sopbia Uxor. Fob. Georg, IIIt c. Infcr, Deo duce portum invenit, de ann. 1717 . Fob. Georg. $I T$. c. Infer. Qui male fentit, erit difmale cerpendus, de an.1693. In Ejusdem obitum de an. 1694. Friderici Auguficum poft exceffum fofepbi I. Imperatoris Vicarius Imperii conftitueretur de an. 1710 .

Fob. Cafmiri \& foh. Ernefli Duc.Saxon. cinfer. Fried ernehrt, Unfried

verzêhrt, dean. 1624 .

Ejusd.c. Infer. GOtt beffre die Zeit undLeur, de an, 1638. Augufi Duc. Saxon. c. Infcr. In GOttes Segen, ift alles gelegen. Bernbardi Duc. Saxon. c. Infer. Deo duce, comite fortuna, de an.

1633.

Ejusdem cum Infer. Salvator mundi adjuva nos, de an, $16_{33}$.

Henneb \& Imenavienf. c. Infer. Tuetur \& auget, de an.1698.

Friderici Elector. Palat. sum Infr. Herr nach deinen Willen, de an. $156 \%$. 
Georgii Johannis 1. Comitis Palatini c. Infer, Invia virtuti nulla via. Ejusd. c. Infcr. Deoaufpice, de an, 1588 .

Friderici Elector Palat. c. Infer. Herr nach deinen Willen, de an. 1567. Friderici IV. El. Pal, c. Infcr, Regier mich Herr nach deinem Worth, de an. 16ro.

Wolffangi Wrilbelmi cum Infer. In Deo mea confolatio, dean.1624. Caroli El. Pal. c. Infcr. Suftentante Deo, de an. I681.

Rudolphi II, Comit. de Hohenlohe c, Infcr, Quis Deo refiftat, de an. 1609 .

Ludovici Guftavi Cóm, de Hohenl. c. Phonice \& Infcr. Ex flammis orior, de an. 1696.

Alberti El. Brand, c. Infcr. Si Deus pro nobis quis contra nos, de An. 1542.

Gohannis Marchion, Brandenb, c. Infer. In filentio \& fpe fortitudo, de An, 1545 .

Georgii Wilhelmi El, Brand, c. Infcr. Im Anfang bedencke das Ende, de An.1628.

Aquila curn duobus fcutis, Brandenburg. \& Wurtemb. cum Infcr. In memoriam domiduAtionis Brandenburg. Wurtemberg. In parte averfa Pars Zodiaci, in qua Sol in Leone, Venus in virgine, Infcr. Nunc fequitur, poft hac femper comitatur euntem, de Ann. 167I.

Gebbardi Electoris Colonienf. c. Infcr. Tandem bona caufa triumphat, de An. 1583.

Anfelmi Francific Archiepifcop. Moguntini, c. Infer. Pax prævalet armis.

Comitum de Plauven c. Infcr. Vivit poft funera virtus, de An.16r9. In Memoriam Maximiliane Ricbt. Com. \& Dom. de Plavia nat. Com, de Hardegg, cum corde, in cujus centro nomen JESU feriptum, quod a duabus manibus de cœlo coronatur, c. Infer. Cuiefcit ad Gloriam furrectura, de An. 1678.

Pbilippi Julii Ducis Pomeraniæ, c. Infcr.Fata feren. fe pari patientia palmam, de An. 16rig.

Ejusd. c. Infcr. Sapientia non violentia.

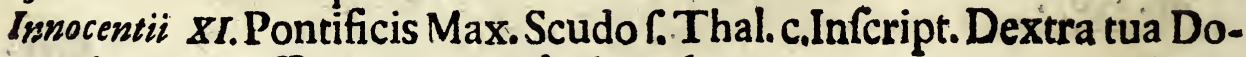
mine percuffit inimicum, de An. 1684. Alexars. 
ET ARTIFICIALIVM KVNDMANN. VRATISLAV. 329

Alexandri IIX. c. Infcr. Legione ad bellum facrum inftrueta, $169 \mathrm{r}$ Innocentii XIr. c. Infcr. Cogito cogitationes pacis, I694.

Clementis XI. Fontis' \& Fori ornamentum.

Elifabetbe Regin. Anglix c. Infcr. Pofui Deum adjutorem meum.

facobi Reg. Scotize c. Enfe \& Infcr. Pro me, fi mereor, in me.

oliv. Cromevellii, c. Infcr. Pax quaritur bello, de An. 1658.

Parlaments - Thl. c. Infcr. God with us, $\mathrm{C}$. Deus nobifcum, de An.

1653.

Caroli Emanuelis Duc. Sabaudix c. Infer. Omnia dat, qui jufta negat.

Caroli I. Ducis Mantux c. Infcr. Nec retrogradior, nec devio.

Caroli II. Duc. Mant. c. ead. Infcriptione.

Ferdinandi Duc. Mant. ,c. Infcr. Nihil ifto trifte recepto; de An. 1614.

Ulrici Duc. Megapol. c. Infcr. Omnes in manu Dei fumus, ipfe bene faciet nobis.

foh. Alberti Duc. Megap. c. Infcr. Domine ne da inimicis verbi tui, de

An. 1549. it.

Alberti Wallenffeinii, de An, 1632.

Wladislai Regis Hungariæ Thaler. cum equite, Matrem virginem

hafta percutiente.

fobannis II. Reg. Hung. de An. 1565.

Gabrielis Princ. Tranfylvaniæ Achatii Barcfai c. Infcr. Deus provide-

bit, . in Obfidionem Cibinienfem, de An.16rI.

Guilielmi Ducis Jul. Cliv. \& Berg. c. Infcr. In Deo fpes mea.

Arma Dominorum Slicenfium Stepbani \& Franciffi Comitum de Bafan

Thl. varii.

Friderici 1. Ducis Silęf. $c$, Infcr. Verbum Domini manet in æternum;

de An.154r.

Cbrifiani Duc. Siler, Lignic, Breg. \& Wolav. Confilium Jehovæ ftabir, dé An.166r.

fob. Huffii Thalerus, cum ipfius Vaticinio: Centum revolutis annis refpondebitis Deo \& mihi.

D. Mart. Lutberi c. Infer. GOttes Worth und Luthers Lehr, vergehẹt nun, und nimmermehr, de An. 166r. 
Ejusdem cum Infcr. Verbum Domini manet in aternum, de An. 1617. It. Packe di Sathan du Interim; \&: Dit is min leve Son, den f. gi horen.

Thoms Munfleri Thl. c.Infer. Ein Godt, ein Gelove, eine Dœre, it. Dat

Wort is Fleifch geworden, un waner in uns; Er we nichr gebore is uit de Wdier u. Geift mag nic \&c. de An. 1534 .

job van Leyden Thal.

Bernbardi Cbriflopbori van Galen, Epilc. \& Prin. Monafter. Thal. c.

Infer. Porrector meus, \& in ipfo fperavi, qui fubdit populum meum fub me. Pfalm. CXLill, de An. 166\%

Ludovici Guntheri \& Alberti Guntheri Comitum in Schwartzburg Thal.

cum S. Martino.

Ludovici $X I V$. Regis Galliarum, non vulgaris fignaturæ c. Infcr. Benedietio Domini divites facit.

In Fœdus Helvetiorum, ubi tres ruftici armati deliberantes.

Ducatus Breme \& Verde, c. Infcr. In Jehovah fors mea ipfe, faciet, de An. 1660 .

Maris Comit. de Jevr. cum Infcr. Dorc God hebbe ick dit erholden, de An. $156 r$.

Ejusd. Vertrowe God, fo werd he di uthelpen, de An.150\%.

Theodoli Epircopi Sedunenfis de An. 1501. Epircopus genu flexus cum Infula, Pedo in dextra \& gladio in tiniftra ante Aliare, in quo omnia inverfa, fed ab Angeloreftaurata, poft diabolus cum campana, \& Infcr. Exaudita eft.

Erici Epifc. Ofnabrug. \& Paderborn. c. Infcr. Verbum Domini manet in xternun, de An. 1542.

Gobannis Abbatis Fuldenfis c. Infcr. Fiat voluntas Domini perpetuo, de An. 1539.

Jobannis Godefridi Epifcop. Herbipol. c. Infcr. Nulla falus bello, pa. cem te pofcimus omnes.

Antonii Comit. de Oldenburg c. Infcr. Dóminus protector vitæ meæ, a quo trepidabo.

Alberti Comitis a Naffau, Weilb. \& Saarbr.c. Infcr. Alles nach GOttes Willen, de An.1592. 
ET ARTIFICIALIVM KVNDMANN. VRATISLAV. 33K

Civitatis Confantienfis c. Infcr. GOtt ift unfer aller Heil und Hoff: nung, de An, I54I.

Civit. Bafleenfis c. Infer. Domine conferva nos in pace,

Domus Dei Curienfis c. Infcr. Conferva nos in pace.

Civit. Genepenfis c. Infer. Poft tenebras Lux, de An. I562.

Civit. Vratislabienfis cum Leone Bohemico \& Infcr. Vicit Leo de tri. bu Juda, de An. 1543 .

Civit. Luneburgenfis c. Infcr. Vifitavit nos Oriens ex alto, de An. 1547. Civ. Hamburgenfis cum Matre Dei, fub qua urtica Stormar. \& Infcr, Fiat mihi fecundum verbum tuum.

Civ. Gedanenfis c. Infer. Defende nos Chrifte Salvator.

Civ. Tboruinien/is c. Infer. Fides \& conftantia per ignem probata, de An. 1629.

\section{ARTICVLVS III,}

Nummi quibusdam Regionibus proprii, vulgo: Landund Scheide-Müntzen ex Auro, Argento, \& $\mathrm{Cu}$ pro a minimo ad maximum.

Z. I. IMPERATORIS Auguftisfimi, ubi ex auro minimi, qui alias ex argento.

Z. 2. Pontificis Romani,

Z.3. Electoris Moguntini,

Z.4. - - Trebirenfis.

Z.5. . Colonienfis,

Z.6. - - Palatini,

Z.7. - Bavarici.

Z.8. - - Saxonici.

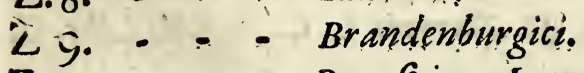

Z.10. - - Brunfwigo-Luneburgici; Clausthalii, Zellerfeldæe \& Andreasbergæ cufi.

Z. Ir. Ducatus Silefie.

Z. 12. Metropolis Vratislapies. 
Z: 13. Ducis Stolbergenfis, aliorumque Principum, Statuum ac Civitatum Imperii.

Z. I4. Regni Hungarie, prc. Ragozianorum ex auro, argento \& cupro.

Z.15. - - Bobemia.

Z.16. - - Portugallie.

Z.17. - Hippanie, Regni Neapolitani \& Ducatus Brabanti\&.

Z.18. - Gallia.

Z.19. - - Anglie.

Z.20. - - Danie.

Z. 21. - - - Svecis, cum maximis cupreis quadratis, item minimis ejusdem valoris Ann. 1715.-1719. f. tempore belli cufis. Delineationem horum Thalerorum cum Icone Regis Svecix Caroli XII. publicavit Hafnix 3ob. Georg. Hopfnerus Academ. Typographus.

Z. 22. Regni Polonie, \& Magni Ducatus Litbuanis, cum is in quibus $\mathrm{A}$.

Z.23. - Boruffia.

Z.24. - Sardinis.

Z.25. Reipublicæ Venete.

Z 26. - - Raguse.

Z.27. - - - Hollandia.

Z. 28. Regni Mofrovie cum iis qui An. 1724. cuff.

Z. 29. Regni Turcia. defcr. Hans Jac. Breuning Oriental. Reife r. Meer - F. Cap. XXXI. pag. 97. it. Thevenot feiner Reifen Part. I. Lib. I. Cap. LXVIII. pag. 92.

Z.30. - - Egypti Maidin dieti ex argento, \& Furles ᄃ. Bulbis ex cupro. defer. idem Thepenot L. C. Part. I. Lib. II. Cap. LXXXII. pag. 377.

Z $3 \mathbf{I}$. - Perfis, del. \& defcr. Ad. Olearius in Mofcovvitifch. und Perfianifch. Reife-Befchr. Lib.v. Cap. VI. pag.294. it. Petr. de Vale Reife-Befchreib. Part. II. Send - Schreib.IV. pag. 85. Thevenot L. C. Part. Il. Libr. II. Cap. VII. pag. 128.

Z.32. - - - Magni Mogoris. del. \& defcr. Volquart Iverfen in Oft-Indianifch. Reife - Befchr, Lib.IV. Cap. XII. pag. 161. Fob. de Laët de Imperio M3.

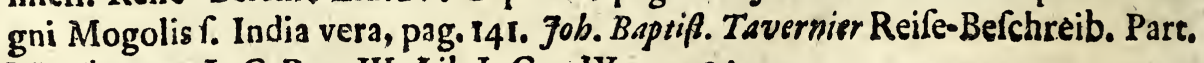
III. Thepenot. L. C. Part. III. Lib.I. Cap.1X, pag.34. 
Z.33. - - Sinenfis perforati ex cupro Petties $\mathrm{f}$. Pithis, item alii ex argento globofi Tikal dieti. de quibus vid. Ol. Wormius Muf. Lib. IV. Cap. VI. pag. 360. Confo Job. Neubofii Befchreib, des Reichs Sina pag. 105.

Z. 34- Regnil Acbinenfis perforati ex plumbo ibidem Cashs dieti. vid. Wilbelm Dampiers Reile um die Welt Part. II. Cap. VII. pag. 246.conf. A. nonymi de Mirandis Sinx \& Europx.

Z.35. Infularum Pbilippinarum, Ambonenfis \& Nigritarum. defcr. fob. Bapt. Tavernier Reife - Befchr. Part. II. pag. $219 . \& 223$. del. \& defcr. Rocbefort in Befchreib. der Artillen Inf. Cap. XIX. pag. 332. Ol. Dapper in Befchreib. von Africa pag. 586. Petr. Pomet in Materialift. und Specerey-Händl.Part.II. Cap.XLIX. Tab.LXVI. Fig. 393. pag. 630.

De Valore vid. Durchlauchtige Welt, it. C.W. Staats. Geographie \& Europxifche Reifen, prc. de Orientalium evolvend. Fob. Bapt. Tavernier Reife - Befchreib. Part. I. Cap.XII. pag. 50. Part. II. pag. 217. it. Part. III. pag. 145. Arnold. Montanus Geländfch. an den Kayfer zu Japan pag. 432. feqq. Georg. Meiffer im Orientalifeh. Indianifch, Kunft - und Luft- Gärtn. Cap.XX. pag. 280. feqq. Erafm. Franciffi im ausländifchen Kuntt - und Sitten . Spiegel Lib. II. Sect. XXXI. pag. 706. feqg. Conf. Ad. Olearii \& aliorum Hodocporica fupra allegata.

\section{ARTICVEVS IV. \\ Nummi Singulares.}

*I. Numınus papyraceus obfidionis Leidenfis XIV. affes tunc tem. poris æftimatus, cum Leone, gladium clypeumque ferens, cum Infcr. Pugno pro Patria. delin. \& defcr. Job. Meurfius Athenarum Batavicarum Lib. I. Cap. XXII, it. Bizot Hiftoire Metallique de la Republique de Hollande, conf. Ol. Wormii Mufeum Lib. IV. Cap. VI. pag. 36t.

*2. Nummus, tempore obfidionis Infularum cufus, c. Infcr. Prodefenfione Urbis \& Patrix, de an. 1708.

*.3. Nummus quadratus talis UImenfis c. Infcr.Da Pacem nobis Do. mine, de an. 1704.

* 4. Nummus talis f. tempore obfidionis Gedani cum ChriftoSal. vatore \& Infcr. Defende nos Chrifte Salvator, de an.1577.

* 5. Item talis Wifmarienfss.

*6. Regni Gallix Libra cuprea S. Libre de France ex neceffitate an. 1719. cufa.

$$
\text { Tt } 3 \quad 7, \text { Re. }
$$


* 7. Regni Svecia cuprei num. X. cum Planetis \& variis Infcriptionibus f. I. T haler Silffer - Münt.

*8. Nummus aureus Guftaphi Adalpbi Regis Sveciæ, cum figno 全 \& фo ex auro Chymico, uti creditur, paratus. vid, Samuel. Reyberus in Defcriptione aureorum \& argenteorum quorundam nummorum ex metalli Chymicisper transmutationem factorum, $\&$ ex eo Wilbelm.Erneft. Tentzelius Dia. log. de re Literaria Sermone Germanico fingulis menfibus hactenus publ. An. 1692. Menf. Maj. pag. 423. feqq. Joh. Francifi. Buddeus in Differt, an Alchemiftx fint in Republica tolerandi, num. I. pag. 48. Mich. Bernb. Valentini in Muf; Mufeorum Part. II. Cap, XI, pag, 65. it, Mifcell, Natur. Curiof. An. I. Dec.I. Ob. ferv, XVII. pag. 6\%. feqq. Rofini Lentilii Paralelism, in Ephem. Nat. Curiofor. Dec.III. An.Ill, pag. III. Hiftorifche Remarquen An.1702. pag 382. feqq. Conf. Valerii Bonvicini Lancis Peripat. Cap. XIII. Joh. Zwelferi Manciflam Spagiricam Part. I. Cap. I. pag. 463. Erafm. Francifci ausläod. Kunft - und Sitten - Sp egel Lib, IV. Sea. I. pag. I201. feqq. it, Joh. Foacbim, Becberi Oedip. Chymic, pag. 185,

* 9. Nummmus aureus talis alius Guftapi Adolpbi.

* 10. Groffus Erfurtenfis c. jisdem fignis. vid. Ephem, Natur. Curiofor, Dec. I. An. IV. \& V, pag. 298. ir. Buddei Diff, fupra allegat, pag, so. \& sI. num. 5 .

*II. Nummus maximus argenteus cum fignis iisdem, Erfurti, in Victoriam Guflavi Adolphi Lipfienfem cufus.

* 12. Nummus vulgaris XVII. crucigerorum (Kayferl. 17. Creutzer) cui Fridericus Auguftus Rex Poloniarum Indicis veftigia fortiffime impreffit, De modo Regis ejusdem frangendi foleas ferreas clavos. que vid, Ephem, Natur, Curiofor. Dec, III. An, IX. \& X. Obferv, XXCV. pag, 158. cunven, qux defcrib, Ibidem Dec. I. An.I. Obferv, XCVIII. pag. 228. it. Dec. II. An. X, in A ppend. pag. 58. Conf. fob. Wierum de Prxttigiis Dxmonam Lib I. Cap. XVIII, pag. 90. \& 92. it, Martin. Zeilerum in Theatr. Tragico \& quidem in notis ad Hiftor, VI. pag. 192, feqq. prc. Calp. Schotsum Phyfic, suriof, Lib. III. Cap.XXXVI. pag. 499. feqq.

* 13. Nummus facer dictus, uti a Pontifice Romano peregrinantibus diftribuitur.

* 14. Grofficulus eleemofynarius Lignicenfis, vid, Luce Chronicon Part. II. pag. I199. Henelii Silefiograph. renovac. in Schol. Cap. VII. pag. 287. \& 288. prc, Godofr. Dewerdeck Silefia Numifmatica Scen. II. Cap. II. pag. 342. * 15. Nummulus ex vafe cupreo, a ruftico confectus. Simile exem. plum 
plum recenjet Fob. Petr. Ludwig in der Einleitung zu dem Teutfchen MüntzIVefen mittler Zeiten pag. $\{8$.

* 16. Nummi per negligentiam metalli cuforum notabiles.

* 17. Monetæ maximi nunc minimi valoris \& pretii An. 1621. \& 1622. in Bohemia, Silefia \& Saxonia tempore ærufcatorum, vulgo, zur Kipper-und Wipper-Zeit, cufx. vid. Andr. Lampii Fefte Bruth und Fruclic der Kipper und Wipper, Fob.Opfelbacbii Wipper-Gevvint, Crefcentii Steigers Wachtel - Gefang von Wippern, Anonymi jedermanns Jammer-Klage, über die falfehe Wipper-Waage, Hiftorifcbe Remarquen An.1;05. pag. 42. Godofred. Dewerdeck Silefia Numifmatica pag. 43. it. pag. 822. leqq. it. Georg. Capp. Kircbmajerus Differtat. de Denar. veter. Mutatione \& adulterati num. pon3, pag. 9. feqq.

* 18. Nummus magicis figuris infignitus, ex VIl. metallorum mixtura. De iis evolvend. Theopbraftus Paracelfus Libr. VII. Archidox.

*19. Talifinan ex ære literis Hebraicis totus infcriptus. del. \& defcr. Leonb. Cbrift. Sturmius im geöffneten Ritter-Platz Part. I. Sect. II. pag. $89 .-88$.

* 20. Talifman cum Leone \& Planetarum characterumque va. riorum confignatione, \& Infcript, Sigillum Salomonis. vid. id. Rit. ter - Platz L.C.

*21. Talifman alius Hebraicus, cum nomine Jehovah, Elohim, \&c. vid. id. L.C. Multa de Talifmanis ex fac. Gafferello, Petr. Petico, Cbifle. tio ac aliis Scriptoribus affert Carol. Cafar. Baudelot de Dairval in Tract. de utilitate peregrinandi gallice fcripto, Tom. I.

* 22. Nummus cum capite galeato ex meris priapis formato.

- 23.24. Nummus vulgo Rhodius f. Siclus Hebræorum pofteriorum temporum ex argento, item alius ex vitro in utroque latere fignatus, vid. Ol. Wormius Muf. Libr. IV. Cap. VI. pag.36r. Schema. tifmos Siclorum omnis generis vid. in Atbanaf. Kircberi Turri Babel Lib. III. Cap. VI. pag. 16i.

*25. Florenus Ernefti Augufi Elestoris Brunfvigo-Luneburgici, ubi fiffura inftrumenti cuforii equo cornu impofuit.

* 26. Ejusd. alius cum fangvine e naribus fillatitio. *27. Thalerus talis Ludovici XIV. Galliarum Regis. *28. Florenus ejusdem Regis, cum Lilio ad nares. 
*29. Georgii Ludobici Filii Ernefti Augufi, cum equo, cui pes alter deficit.

*30. Friderici Augufi Regis Poloniarum, cum infigniis mire juxta fe pofitis.

*31. Friderici Wilbelmi Regis Boruffix, cum crinibus caudam anterius formantibus, ex auro \& argento, a minimo ad maximum.

*32. Thalerus in quo CXX. Capita.

*33. Nummi maximi moduli rotundi \& quadrati in uno latere fignati, qui in Hungaria, Tranfylvania, Saxonia \& Silefia lucem adfpexerunt.

*34. Nummi varii Germanici in Mofcovia aut cruce, autSt. Georgio Equite fignati.

*35. Nummus quadratus Norimbergx, poft Pacem Weftphalicam cufus, vulgo der Stecken-Reiter-Pfennig. defcr. \& delin. in Job. Cbriftoph. Wagenfeilii de S. R. I. libera civitate Norimbergenfi Commen: tario Cap. XXXI. it. in Hifforifchen Remarquen Part. IV. pag. 65. 


\section{A T A L O GUS \\ AUCTORUM ET LIBRORUM ALLEGATORUM,}

cum

\section{Editionibus quarum ufus fum.}

A.

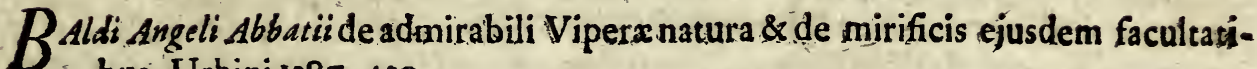
bus. Urbini 1587.4 to.

Dapid. Abercrombii Opufcula Medica.L ondin, 1687.12 mo.

Adami Differtatio de.Offe ex corde cervi. Giefix 4 to.

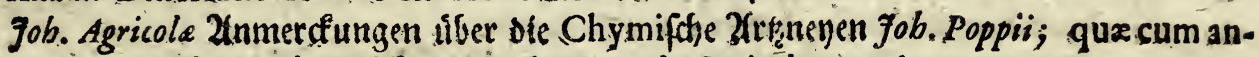

notationibus fob. Helfrici funckens prod. Norimberg. 1686. $4^{\text {to. }}$

Georg. Agricole de natura Foffilium. Witteberg. 1612.8vo.

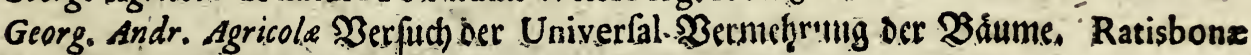

1716. fol.

Valentini Alberti Differt. de figuris variarum rerum in Lapidibus \& fpeciatim Foffilibus Comitatus Mansfeldici-Lipf. $167 \%$. 4to.

Alberti Magni de virtutibus herbarum, lapidum \& quorundam animalium Libellas,

uns cum aliis, Argentorat. $1637.12 \mathrm{mo}$.

Bernb. Albini Differt. de Phof phoroliquido \& folido.Francof.1688. 4 to.

Petr. Albini \$leißnifche Berg . Chronica-Drefd. 199c. fol.

Lly. $\int$. Aldrovandi Ornithologix h, e. de Avibus Hiftor. Libr.XII. S. de Avibus rapa. cibus. Bonon.1599. fol.

- - Ornithologix Tom. II. f. de Avibus terreftribus menfx infervientibus. Ibid. 1600 . fol.

- - Ornithologix Tom.1II. f. de Avibus aquaticis. Ibid. 1603. fol.

- - de Animalibus exangvibus Libr. IV. nempe de mollibus, cruftaceis, teftaceis \& zoophitis. Ibid. 1606. fol.

- - de Pícibus Libr. V. Ibid. 16rz. fol.

... de Animalitus infectis Libr. VII. Ibid, 1620. fol,

- - de Quadrupedibus folidipedibus. Ibid. 1616. fol.

- - Quadrupedumomnium Bifulcorum Hiftoria.Ibid.16r3.

- Hiftoria Serpentium \&Draconum Libr.II, lbid. 1640. fol, 
- - Monftrorum Hiftoria cum Paralipomenis omnium animalium. Ibid. 1642. fol.

- - Mufeum Metallicum, Ibid.1648. fol.

Cornel. Alkemade gaude en zilvere Penuingen der Graven en Gravinuen van Hol.

land. Delftr. 1700. fol.

Proßeri Alpini de Plantis exoticis. Venet.1625. 4to.

Pauli Ammanni Manuductio ad Materiam Medicam, prod.una cum Enumeratione

Plantar. Horti Medici Lipfienfis, Lipfix 1675. 8vo.

Georg. Anderfen Orientalifhe Nelfen, prod, una cum Adami Olearii Mofconitts

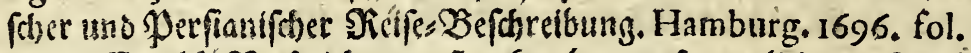

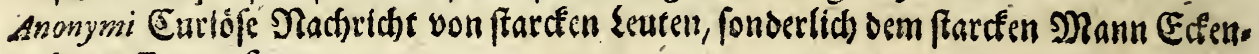

berg. Francof. 1720.4 to.

Anonymi de Miranclus Sinz \& Europx. Francof. 1615.

Anonymi Traittés des Barometres, Thermometres, \& Hygrometres.Amftel.1688.fol. Anomymi Traittés del' Aiman. Amftel. 16 $\$ 7.8 \mathrm{vo.}$

Anonymi Catalogus Lapidum pretioforum, Achatum, Onychum \&c. ac omnis gene. ris antiqux fuppellectilis. Amftel. 1677.12ma.

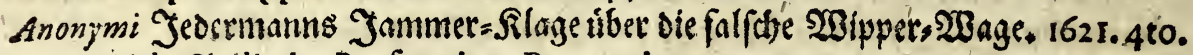

Anonymi la Sicilia in Profpettiva. Panormi 1708.4 to.

Arifotelis Opera Lugdun. I $\$ 90$. fol.

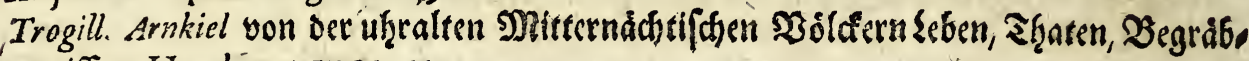
nifen. Hamburg. 1703.4 to.

Leon bardi Augufini de Gemmis \& Sculpturis antiquis, a fac.Gronovio in Latin. translat. Franequer. 1694 . 4tc.

B.

Andres Baccii de Gemmis acLapidibus pretiofis eorumque viribus \& ufu. Francof. 1643. 8vo.

- - . de Magna beftia ab Antiquis Alce germ. Elend vocato ejusque Vngula pro Epilepfia \& confimilibus morbis abigendis, viribus \&ufu, ex Italico idiomate in Latin, converf. Stutgard. 1598. 8 vo.

Georg. Baglivii Opera Medico. Practica \& Anatomica. Lugdun. 1710. 4to, Job. Fac. Bajeri Oryctographia Norica Norimb. 1708. 4 to.

- - Differt. de Lacrymis vitrejs. Altorf. 1708. 4to.

- - Thefaurus Gemmarum affabre fculptarum defcript. quem collegir Joh.

Marnin. ab'Ebermayer. Norimb.1720. fol.

Fob. Guil. Bajeri Foffil. Diluv, univerfal. Monument.

Bobusl. Balbini Mifcellan.Hiftoric. Regai Bohemix. Pragx 1679. fol. Pbilip. Baldei Befdreibung Der Dft, Indiffen Sîften Malabar, Coromandel uno Zeylon. Amitel.1672. fol. 
Baltici maris Nova Literaria. incep. an.1698. \& prod. in 4 to.

Job. Conrad. Barcbufen Pyrofophia. Lugd. Bat.1698. 4 to.

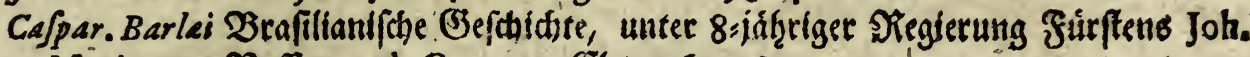
Moritz von Mafau. ed. German. Sleve 1659.8vo.

Jacob. Barrelieri Plantæ per Galliam, Hifpaniam \& Italiam obfervatæ, \& Iconibus xneis exhibitx \& editz ab Ancon. de Juffieu, Parif. 17 14 . fol.

Cafp. Bartbolini de Unicornu, f. Opufcuia IV. fingularia. Hafnix 1628. 8vo.

- - de Lapide Nephritico. Hafn.1627. 8vo.

CaJp. Bartbolini Th. fil. Exercitationes Mifcellanex varii argumenti, imprimis anatomici. Lugd. Bat. 1675. 8 vo.

Erafmi Bartbolini Experimenta Cryftalli Islandici. Hafnix 1670. 4to.

Tbom. Bartbolini Anatome. Lugd. Bar.1673. 8vo.

- Epiftolx Medicinales. Hafn. 1663. 8vo.

- - Qbfervationes novx de Unicornu. Amftel.1677. $12 \mathrm{mo}$.

-.. - Acta Medica \& Philolophica Hafnienfia. Hafn. 1673.-1680. 4 to.

Carol. Cafar Baudelot de Dairval del' utilité des Voyages, f. de utilitate peregrinandi. Parif, 1686. 12 mo.

CaSp. Baubinus de Lapidis Bezaar Orientalis \& Occidentalis ortu, natura, differentiis veröque ufu, Bafil. I625. 8vo.

- niva乡 Theatri Botanici Bafil. 1671. 4 to.

fob. Baubini Hiftoria Plantarum, Ebrodaui 1690. fol.

Ejasdem Hiftoria Fontis \& Balnei Bolnenfis, five de Lapidibus metallicisque miro

Naturz artificio in ipfis terræ vifceribus figuratis. Montisbelgard. 1598. 4 to.

fob. Laurent. Baufcbius de Coeruleo \& Chryfocolla. Jena 1668. 8v.0.

- - - de Hxmatitide \& Ætite. Lipf. 1665. 8 vo.

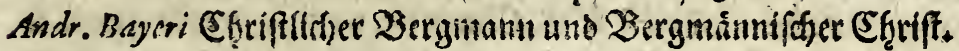

fob. Joachim. Becberi Experimentum Chymicum novum, quo artificialis \& inftanta.

nea Metallorum Generario \& Tranfmutatio ad oculum demonftratur. Francof.

1671. 8vo.

- - Phyfica Subterranea cum Specimine Becheriano Georg. Erneft. Stahlii. Lipfix 1703. 8vo.

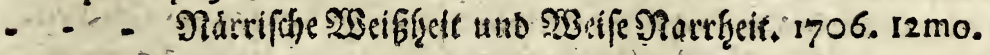

Fob. Chriftopb. Becmanni Hiftoria Orbis Terrarum Geographic. \& Civil. 1673.

- . - Siftorie Des Jurftentfums Kuhalt. Serveft. i7ro fol.

- - Notitia Univerfitacis Francofurtanx. Francof. ad Viard. 1707.

Georg. Henr. Bebrens Hercynia curiofa. Nordhuf 1703. 4 to.

Laureniii Begeri Thefaurus Brandenburgicus feleaus, $f$. Gemmarum \& Numifmatum in Cimeliarchio Eleftorali Brandenbügico feries. Colon. March. 1696. fol.

- - Thefaurus Palatinus Gemmarum \& Numînarum. Heidelberg. 6 65. fol. 
Matb, Belii Hungarix antiqux \& novæ Prodromus. Norimberg. 1623. fol. Petr. Bellonii Obfervationes, una cum Clufi Exocicorum Libr.1609. fol. Bartbol. Belli Defcr. Anifi fellati.

Gothofr. Bergeri Diff. de Thermis Carolinis. Guelferbyti, an.1709. 4 to. Berolinenfis Regix Societatis Mifcellanea. Berol. 1710. 4to.

Andr. Bertboldi Terra figillatx nuper in Germania reperte vires atque virtutes admirandx, ejusque adminiftrandx ac ufurpande ratio. Mifnix 1583. 4tc.

Cbriffiani Beriwardi Interpres Phrafeologix metallurgice, annex. Erckeri Aul. Sub. ter. 1703 . fol.

Bafil. Besleri Fafciculus rariorum. 1616.

- - Hortus Eyftedienfis. 1613. in fol, major.

Blano Truité Hiftorique des Monnojes deFrance depuis le commencement de la Mo.

narchie, jusques a prefent. Parif in 12 mo.

Godefr. Bidloo Anatomia Humani corpuris. Amftelod. 1685 . in fol. major.

foach. Billingerus de Bitumine $\bar{\alpha}$ Ligno foffil. Altenburg. $1673.8 \mathrm{vo.}$

Ludovic. de Bils f. Bilfii Specimina Anatomica. Roterodam. 1663 . 4 to.

Fob. Binbards Thtiuringif fde Chronica.

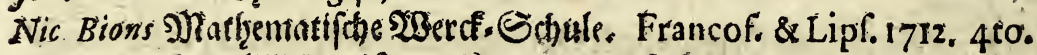

Thom. Bircberodii Numifmata Danorum. Hafn, 1701. 4to.

Bizot Hiftoire Metallicque de la Republique de Hollande. Amftel. 1690. 8vo, addito

tertio Volum, f.Supplement, a l' Hịfoire Metallique \&c.

Stephar. Blancirdi Collect. Medic. Phyfic. Amftel, 8 vo.

- - Schouburg der Rupfen, Wormen, Maden en vliegendeDierkens, . Thea-

trum Erucarum, Vermium, Termitum, qua ex his oriuntur beftiolarum volatili-

um. Amftelod. 1688. 8vo.

Nic. de Blegny le bon ufage du Thé, du Caffé \& du Chocolat, pour la prafervation \& pour la guerifon des Maladies. Parif. $168 \%$. 12mo.

- - Zodiacus Medico-Gallicus f.Mifcellaneorum Medico-Phy ficorum Gallicorum. Genev. 1682. 4 to.

Paul. Bocconis Mufeum Phyficam Experimentale. $169 \%$.

- - Icones Plantarum rariorum Sicilix,Maltr, Corficx \&c. Amftel.1697.4to,

- - Obfervationes naturales, in quibús variaMedico-Phyfica \& Botanica,Pro: ductiones item Naturales, diverfi Phofphori, ignes fubterranei Italiz aliaque cu. riofa continentur prod. Italico Idiomate Bononix 1684. $12 \mathrm{mo}$. Germanic. fab Titu! Z(rmercfungen uifer natúrlid) Dinge Vratislav. $12 \mathrm{mo}^{\circ}$

Hermanni Bocrbaave Index Plantarum que in Hortu Academico Lugduno. Batavo reperiuntur. Lugd. Batav. 17 10. 8 vo.

Anfelm. Boetii de Boot Hiftoria Gemmarum \& Lapidum. Lugd. Batav. 1636. 8vo. Pbilipp. Bonanni Numifmatum Pontificum Romanorum, qux a tempore Martini V. 
vel authoritate publica, vel privato genio in lucem prodiere, Romæ 1699. fol.

- . - Recreatio mentis \& oculi in Obfervatione animalium teftaceorum Latin. edit. pr. Romx 1684. 410 .

- Muleum Kircherianum. Romæi709.

- Obfervationes circa viventis qux in rebus non viventibus reperiuntur cum Micrographia curiofa. Rom* I69r. 4 to.

Tbeopbil. Bonetti Medicina Septentionalis collatitia. Genev. 1684. fol.

fob. Bontii Hiftoria Naturalis \& Medica Indix Örientalis, prod, una cum Guil, Pifo.

nis Hiftor. Nat. \& Med. Indix Oriental. Amftel. 1658 . fol.

fob. Alpbionfi Borelli Hiftoria \& Meteorologia incendii Aitnæi 1669.

Petr. Borelli Hiftorix \& Obfervationes Medico-Phyficx. Francof. 1676. 8vo.

- - Bibliotheca Chymica foralogus Librorum Philofophicorum Hermetrcor. Parif. 1654. 12mo'.

Olai Borricbii Confped: Chymic. illuftrat. Hafnix 1697. 4 to. Wilb. 20finanns Sieife nad Guinea ed.Germ. Hamb, 1708. 8vo. Bourdelot Recherchies \& Obfervations h.e. Judicium \& Obfervationes circa Vipe. ras. Parif. 167\%. $12 \mathrm{mo}$

Robert. Boyle Paradoxa Hydroftatica novis experimentis evicta: habetur Operum

Sedi.IV. qux Genevæ 1677. in 4to prod.

- - Experimeñta de Coloribus f. Operum Sect.IV.

- De Origine \& Virtacibus Gemmarum f. Operum in fine.

Micbal Boyms Florá STrnenfis. Viennail 656 fol.

Adam. Brand Relation du Voyage de Mr. Everh, Isbrand de l'Emper. de la Chine. Amftel. 1699. 8vo.

Anton. Mufa Braffavolus Examen omnium Simpliciom quorum ufus in pablicis eft

Officinis. Lugduni. 1544. 8 vó.

Elia Brenneri Thefaurus Nummorum Sveo. Gothorum XXX. annorum fpatio collecorum f.a Guftavo I. ad Carolum XII. Holmix I691. 4to.

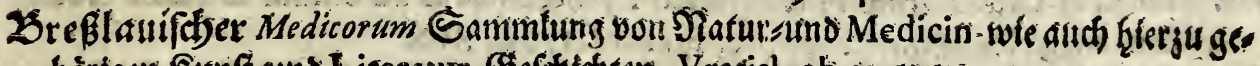

horigen Sunftuns Literatur. (S) efotchten, Vratisl. ab an.1717\% 4to.

Jac. Zrennings Drientalifde Silfet, Etraburg 1612. fol.

Fac. Breynii Prodromus fafcicali rariurum Plantarum Hollandix. Gedani 680 .

Fob. Pbil. Breynii Epiftola de Melonibus petrefactis montis Carmel. Lipl.1722. 4to,

Zufigefangene Briefe.

Eduard Broion ltinera inHungariam, Bulgariam, Aufriam, Carynthiam \& Carnioliam, cum variis Obfervationibus Naturalibus \& Politicis. Anglice 1673. 4to.

Franc. Erneft. Bruckmanni Hiftoria naturalis Oolithi f. Ovariorum pif́cium \& concharùm in faxa mutatarum. Helmftad. 1621. 4 to.

- de fabulofillumiz originis lapide Arachneolitho Epiftol Wolffenbütrel 1622. 4 to, 
- - de Vulva marina \& Concha Venerea. Brunfwig. I622. 4 to.

- - Specimen botanicum exhibens fungos fubterraneos, vulgo Tubera texræ. Helmftad. 1720. 4to:

Joh, Frid. Buddei Differt. an Alchemifte fint in Republica tolerandi. Hale Magd. 1702. 4 to.

Dapid. Sigifm. Bütneri Rudera diluvii teftes, 1 . Zetchen und Zeugen ber Suinoflutf̧, in=

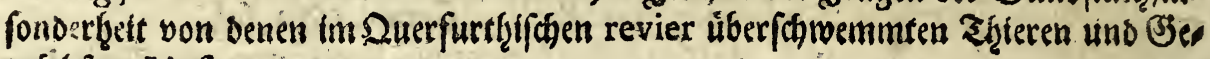
wáchfen. Lipfix 17io. 4 to.

- Coralliographia fubterranea, f.Diff. de Coralliis, in fpecie de Lapide corneo. Lipf.1714. 4to.

goh, Anton. Bumaldi Bibliotheca botanica $\mathrm{C}$. Herbariftaram Scriptorum promota Syhodia. Bonon. $16 \% 7$ in $16 \mathrm{mo}$.

Gilbert. Burneti Iter per Helvetiam in Italiam partesque quasdam Germanix \& Gallix, prod. Gallice Roterodami,edicio Germanica vero Lipfix i687. 12mo.

Tb. Burnetii Telluris Theoria facra; Orbis noftri originem \& mutariones generales, quas aut jam fubiit, aut olim fubiturus eft, complectens : Libri duo pofteriores de conflagratione mundi \& de futuro rerum ftatu. Londin. 1689.4 to.

Eernb. Caffi Mineralogia. Lugdun. 1636. fol.

Francifci Calceolarii Mufeum Veronenfe. Veronx 1625 . fol.

Guilielm. Camdeni Britannia. Anglic. Londin. 1695. fol.

Joacbim. Camerarii Patr, de Bolo Armenia \& Terra Lemnia Obfervat. Norimberg. $1583.8 \mathrm{vo.}$

Pbilip. Camerarii Horx lubcifiva. Francof. 1615.4 to.

70f. Campani Defcriptio novi Microfcopii. Romx 1686.

Maurit. Anton. Cappeler Prodromus Cry ftallographix. Lucern.1723.

Hier. Cardanius de Subtilitate. Norimberg. I550. fol.

70. . Sam. Carl Lapis Lydius Philofophico-Pyrotechnicus ad oflium foffilium Doci-

- nisfiam analycice demonitrandam. Francof. 1704.800.

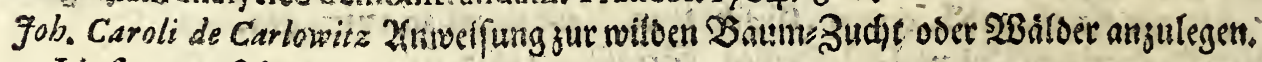

Lipfix I7l3. fol.

Fulii Cafferii Placentini Tabulx Anatomice LXXVIII. cum Dan. Bucretii Tabulis

XX. is, Adriani Spigelii Anatomia. Francof, ad Moen. $16,6.4$ to.

- - de Vocis Auditusque Organis Hiftoria Anatomica. Venet. I601. fol.

Petri Cafelli Hortus Mefranenfis 1640. 4 to.

Fob. Gottofr. Cave Difi. de Telo fulmineo. Lipf.r 706. $4^{\text {to. }}$

Fob. Bapt. de Cavelleriis omnium Puntificum Romanorum Icones a Sto Petro ad Cle-

mentem VIII. additis fingulorum infignibus. Romx I595. 8 vo.

Hich. Angeli Cánfic de la Chauffe Romanum Muleum five Thefaurus eruditx antiquiatis, Roma 1690. fol. -. Gens. 
Gemmx antiqua delineatx Italice Ronre an.1700. $410 \mathrm{cum} 200$. fig. $x n_{0}$. Moyjes Cbaras continuatio novorum experimentorum circa Viperas, una cum Difier. tat. de earum Veneno. Gallice, Parifiis 1671 . 8vo.

Dominici Cbabrai Stirpium Icones \& Sciagraphia. Gerrev. 1677. fol.

Gualtber, Cbarletoni Inquifitio Anatomico.Phyfica. Londin. 1665. 8vo.

Nicol. Cbevallier Hiftoire de Guillaume P.oy de Angleterre par Medailles. Amftelod. 1692. fol.

Job. Ciampini de incombuftibili Lino f. Lapide Amianto ejusque filandi modo. Roma 1691. 4 to.

Guil. Clarck Hittoria Naturalis Nitri. Lon'd, 1675.8 vo.

Gabriel Clauderus de Tinctura Univerfali. Altenb, 1678. 4to.

- - de Methodo Balfamandi. Altenb. 1679. 4to.

Caroli Cyffii Exoticorum Libri X. prod. ex officina Plantiniana, Antwerp. 1605. fol.

- - Rariorum Stirpium per Rannoniam, Auftriam \& vicinas Provincias.Antwerp, $1583.8 \mathrm{vo}$.

- - Rariorum Plantarum Hiftoria. Antvverp. 160r. fol.

Augerii Cluti Calfvee f. Differt. de Lapide Nephritico. Roftoch. 1627. I2mo.

Baptift. Codronobii de Chriftiana \& tuta medendi ratione. Bonon. 1629. 4 to.

Job. Henr. Cobaufen Lumen novum Phofphoris accenfum, i. Exercitatio Phyfico.

Chymica de Caufa lucis in Phofphoris tam naturalibus quam artificialibus.Amftel. 1717. $8 \mathrm{vo}$.

Fob. Combacbii Lib. de Homine. Marpurg. 1620. 8vo.

Comiers d' Ambrun l' Home artificiel Anemofcope ou Prophete phyfíque du changement des Temps, Infertas Mercurio Gallico, Menf. Mart.1683. pag.164.feqq.

- - - Traitté des Phofphores f. Comierii Tractatus de Phofphoris, cum fecrets ipforum compofitione; Exhibitus Mercurii Gallici Menf. Junio \& Jnlio an.I683. Iudov. de Comitibus Elucidatio Metallorum \& Metallicarum Naturx Opum. Colon. 1665. 8vo.

7ob. Commelini Rariorum Plantarum Horci Medici Amftelodamenfis Defcriptio \&

Iconés. Amftel.1697. fol.

- Catalogus Plantarum Indigenarum Hollandix. Amftel. 1683.

Caspar. Commelini Flora Malabarica, Lugd. Bat.1696.

Ludov. le Conte fieutiges Sina. Francof. 1699. $12 \mathrm{mo}$.

Herman. Conringii Differt. de Sale Nitro \& Alumine. Helmftad. 1678. 4to.

- - Differt. de Terris. Helmft.1678. 4to.

facob.Cornuti Canadenfum Plantarum aliarumque nondum editarum Hiftoria.Parif́

1635.420.

7ofepb. a Coffa de Natura Novi Orbis Lib.11. Colon. $1695.8 \mathrm{vo.}$ Cbrifloph. a Cofta Liber Aromatum, qui eft Caroli Clufi Exoticor.Libs. LX. Antvverp 3605 . fol. 
Casp. Crameri Collegiun Chy micum quinque Differtationibus editum a Jufto Vefti.

Francof. \& Lipf. 1688: 4to.

fob. Cunradi Crcilingii Differt. de Phoenomenis Laternx Magicx. Tubing. 1705. 4 to.

Ludov. Cbrifiani Crellii Difl. de Locultis non fine prodigio in Germania, Lipf. 1693. 4to.

Balth. Thom. Cretzfmars Minerologia Montis Gigantei. 1662. 4to.

Oswa aldi Crollii Bafilica Chymica. Genev.1658. $8 \mathrm{vo}$.

Fob. Andr. a Cruce Chirurgia univerfalis. Venet. 1596 . fol.

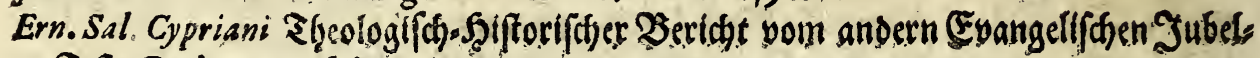

Seft. Gothæ1719.fol,

\section{D.}

Willbelm. Dampiers Scife umb oie Welt. ed. Germ. prod. Lipf. 1702. 8 vo.

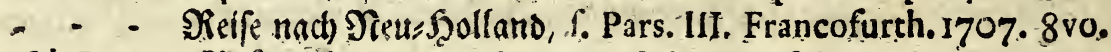
Ol. Dapperi 23 efódrelbung von Africa. Amltel. 1670. fol. - : Befdreibung von America. Amitel. 1673. fol. Dedu de $l$ 'Ame des Plantes, Effay de Phylique, Parif. 1682. 12mo. Anton. Deufingii Differt. de Unicornu \& Lap. Bezaar, Grœning. 16.59. I2mo. - Differt de Manna, Saccharo \& Monocerote, Groening. 1659. 12mo. Gotbofred. Dewerdeck Silefia Numifmatica, Jaurov. 1711. $4^{\text {to. }}$ Isbrand. de Diemerbroeck Opera Medica \& Anatc.nica. Ultraject. 1685 . fol.

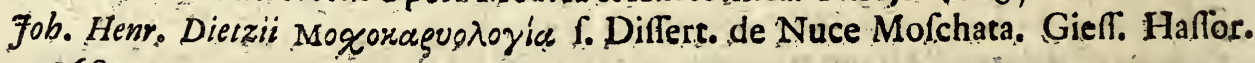
1681. 4 to.

Kenelm. Digbei Differt, de Planțarum Vegetatione, ex Anglico idiomat, in Lat. transl, Amitel.1663. $12 \mathrm{mo}$.

Mich. Deeringii de Medicina \& Medicis adverfus Jatromaftigas \& Pfeudiatrus Libr.II. Gief?. Heffor. I6II. 8vo.

- - de Calculo Renum Epift. Ulmx 1628. 4to. extat cum Gregor. Horfti Obr Medicinal. pag.4i8.

Hieron. Drexelii Aurifodina. Antvverp.1658. 16mo.

Francif. Drope brevis \& certa Methodus plantandi \& in ordinem difponendi arbores fructiferas. Oxoñi 1672 .

Ourdblsubtige $\$$ elt. Hamburg. 1704. $12 \mathrm{mo}$.

\section{E.}

Bónifacii Henrici Ebrenbergeri Differt. de Laternx Magicx augmento. Jenz I713.4to. Baltbaf. Ebrbart Diff. de Belemnitis Svevicis. Lugd. Batav. 1724.4te. Fob. Sigifm. Elsholtzii Obfervationes de Phofphoris. Berolin. I681. $4^{\text {to. }}$ Cbrificinus Encelius de Re Metallica, h. e. de origine, veritate \& nacura corporum Metallicorum, lapidum, gemmarum \& aliarum, qua ex fodinis eruuntur, rerum, ad Medicinæu ufum defervientium Libr. III. Francof. I557.8vo. 


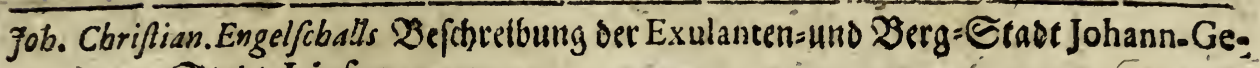
orgen, Strot. Lip $\int_{0} 1723.4$ to.

Epbemerides Nature Curioforum. prod. ab An. 1670.4 to.

Epipbanius Epilcopus de XII. gemmis in vefte Aaronis.Tiburi 1566.8vo.

Tbom.Eraffus de natura \& ortu lapidis fabulofi;reperitur inter ej.varia Opufcula.Fran cof. Isgo. fol.

Lazari Erckeri Aula fubserranea ed. novif. Francof. ad Mœen. 1703. fol.

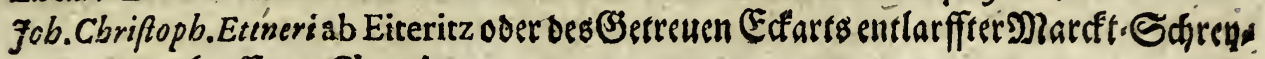

er und entlauffener Chymicus.

\section{F.}

Job. Matth. Faber de Pile marina Anatome, reperitur in Ephem. Natur. Curiofor.

Dec.II. An. X. pag. Yor. in fine.

Georg. Fabritii de Metallicis rebus; prod.cum Agricole de ortu \& caufisfubterraneis.'

Wittemb. 1612. 8vo.

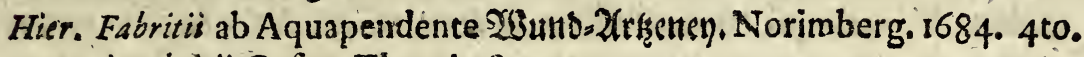

Samuel Fabritii Cofno Theoria Sacra.

Modeftini Sacblens Probfer = Buidjlein. Lipr, 1689. 8vo.

feg. Fetter der Sdheide. Siunft.

Fob. Bapt. Ferrarius Hefperidum fo de Malorum aureorum cultura \& ufu. Rom

1646. fol.

- de florum culeura. Rom. 1633. 4 to.

fidftelbergs ausfüfrelliche Befdoreibing. Lipf. 1716.4to.

Flore Theatrum. 1622, fol.

Tob. Forgeti artis fignate defignata fallacia. $1633.8 \mathrm{vo}$.

Pbil. Sylveftro du Four Traitez du Café, du Thé \& du Chocolate. Parif, 1685.12mo.

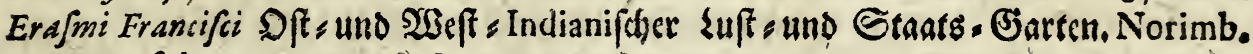
1668. fol.

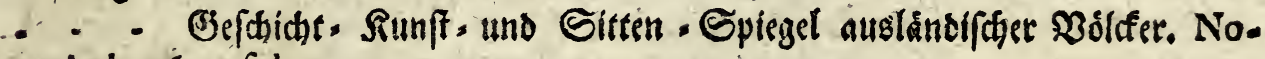
rimb. 1670 . fol.

Wolfg. Frantzii Hiftoria Animalium cum Commentariis \& Supplementis Obfervationum ex recentiori Hiftoria Naturali opera fob. Cypriani. Francof. \& Lipf. I7 72.410.

Caroli du Frefne Hifforia Byzantina c. Tom. II. C. Defcriptione urbis Cunftantino. politanx. Lut, Parif. 1680. fol.'

Tilemann Eriefe Minth: Spiegel.

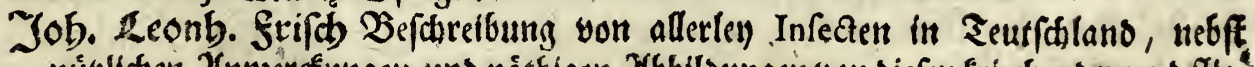

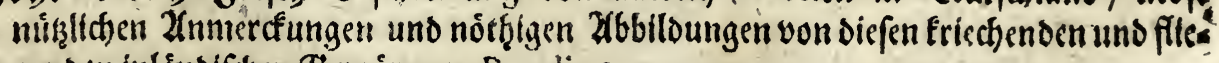
genden inlándif chen ङetwsirmen. Berolin.1720. 4.to.

Ant. Furetiere Dietionaire univerfel. Hagx Comit. \& Roterodam.1690, fol. 


\section{G.}

Jacobi Gaffarelli Curiofitates inauditx. Hamburg. 167.6 .

Thome Gage Dielfes Defchreibung nach Dleu= Spanien. Lipi. 1693.4to.

7ob. Ludov. Ganfii Hiftoria Coralliorum. Francof. 1630.12mo.

Cbriff. Fridr. Garmanni Oologia curiofa. Cygnex 1691. 4 to.

- - de Miraculis mortuorum. Dresd. \& Lipf. 1709. 4to.

foh. Daniel Geieri de montibus Conchiferis \& Glofopetris Alzeienfibus. Francof. 1687.410.

7ob. Gotbofr. Geilfufii de Terra figillata Laubacenfi, prod. una cum Joh. Goorg. Litbkneshis Metamorphofi in mineram ferri mutati ligni, Gieff. \& Francof. 1714. 8 vo.

Auli Gellii Noctes Atticx. Parif. I585. 8 vo.

Conrad. Gesneri Hiftor. Animalium Lib. V. qui eft de Serpentium Natura. Tiguri 1587. fol.

- Hiftor. Animal. qui eft de Pifcium \& Aquatilium Animantium natura. Francof.' 1604. fol.

- - de Rerum foffilium, Lapidum \& Gemmarum figuris. Tiguri is65. 8vo,

- - Hiftoria Infectorum Libellus, qui eft de Scorpione. Tiguri 1587. fol.

Guil. Gilberti de Magnete Magneticisque Corporibus Phyfrologia nova. Londin. 1600. fol.

Fob. Rudolpbi Glauberi Furnum novum Philofophicum. Pragx 1700. 8vo.

Laurent. Gobart Traat. Philofophicus de Baromerro, Amiftel.r7o j. 12 mo.

Seperinus Gabelius de Succino cum Gefneri Rer. fomil. Libr. Tiguri 1559.8 vo.

Joh. Gedartitus de Infectis in methodum redaclus cum nctularum additione opera

Marr. Lifteri Londin, $1685.8 \mathrm{vo}$.

Hubert. Goltzii Thefaurus rei antiquarix. Antwerp. 1644. \& 1655 . fol.

Gerard. Goris Mercuius Triumphator. Lugd. Bat. 1716.8vo.

Gottwaldianum Mufeum. Gedan. 1714. 8vo.

G. 7. Gravefandii Efrais de Perfpective, h. e. Tentamen Perfpectiva. Hagx Comir.

1711. $12 \mathrm{mo} 0$.

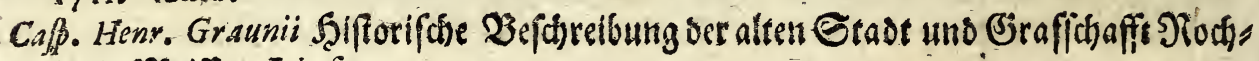

Uth in Meiffen. Lipf. i7719.4to.

Mar. Sibyll. Greffin nata Meranx Metamorphofis Infectorum Surinamenfium. Am. ftel, 1705 . fol.

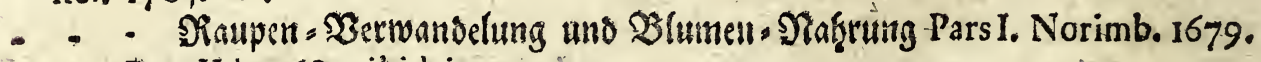
4to, Pars llda 1683. ibid. in 4 to.

Nehem. Grew Mufeum Societatis Regalis, Anglice. Londin. 1681. fol.

- - Anatomia Plantarum cum Idea Philofophicx Hiftorix de Plantis \& và. riis leetionibus aliis. Lond. 1682, fol, in Lingv. Latin, translata ext, in Ephem. -I Nat. Curriof. An. VIII. 
gob. Francifci Griendelii Micrographia nova, $f_{\text {. Nuva } \& \text { curiola variorum minuto- }}$ rum Corporum, fingularis cujusdam \& noviter ab Autore inventi Microfcopii ope adauctorum \& miranda magnitudine reprafentatorum Defcriptio, additis eor. figuris. Nórimb. 1687. 4to.

7ob. Facob. Groffers 23ajeler Chronica. Bafil. 1623. fol.

Fob. Grenevelt Differt. Lithologica variis Oblervationibus \& figuris illuftrata Lon. din. 1684. 8vo.

Herman. Grube de IEtu Tarantuix \& vi mufices in ejus curatione Conjecturx Phyfi. co-Medicx. Francof. 1679.8vo.-

Dan. Grützmanni Differt. de Avibus Paradifiacis harumque Rege. Jenæ 1667.4to. Andr. Gryphii de Mumia Vratislavienfi. 1662. 12mo.

Baldaffaris Timai von Guldenklee Opera Medico. Practica, cum Prxf, Rivini. Lipf,

1715.4 ro.

Dominici Guiticlmini Meditationes Philofophicx circa figuras Salium, Itálice. Bo. non. 1688.4 to.

- . Differtationes de Principio Sulphureo. Venet. 1710.8vo.

H.

Matb. Haly Magnetifmus magnus f. Contemplationes Metaphyficx \& Divine a con: fideratione Magnetis fubnatx. Lond. $1695.8 \mathrm{vo}$. Georg. Albert. Hambergeri Hidraulica. Jenæ 1698. 4to.

Job. Ludop. Hannemanni fcrúinium nigredinis pofterorum Cham f. Æthiopum. - Kiloni 1677.4 to.

- - Jafon f. Catalogus teftimoniorüm veritatis Metamorphofin metallorum ignobiliorum in auro nativo preftantius afferens. Kiloni I709. 4to.

Everh. Wilb. Happelii Theatrum exoticorum. Hamb. 1688. fol.

- - Relationes curiofx. Hamburg. 1684.4to.

Job. Matb. Hafii Differt, de Tubis Atentoreis. Lipfix 1719. 4to.

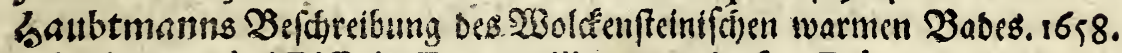

Gob. Fac. Harderi Diff. de \$gagropilis reper, in fine Ephem. Natur. Curiofor. Dec. II, An. I.

Pbil. Jacob. Hartmanni fuccincta Succini Pruffici Hiftoria \& Demonftratio. Berol. 1699. 4 to.

Guil. Harveji de Generatione Animal, Amftel, 16 క1. $12 \mathrm{mo}$.

Job. Paul. Hebenftreitii Differt. de Locuftis immenfo agmine aerem noftrum implenti-,

bus \& quid portendere putentur. Jenx 1693. $4^{\text {to. }}$

Mich. Heberer von Bretten Agyptiaca fervitus, ober $\mathfrak{D}$ efdorefbung feiner $D$ ren = jâtig, rigen Dienffbarfeit. Heidelberg. 1610.4to.

Caroli Heidani Thefaurus Grxcorum \& Romanorum Numifmatum, Infcriptionum, 
Marmorum \& Suppellectilis antiquaria ; Nec non Conchiliorum, Armorum Coralliorum, Mineralium, Gemmarum, \& Celaturarum plurimarumque rerum pretiofarum. Lugd. Batav. I2mo.

Ant. de Heide Anatome Mytuli. Amftel.1683.8vo.

Illdarici Heinfii Diff. de Alce. Jenx 168r. 4 to.

Job. Rapt. Ifelmontii Opera Francof.1682. 4 to.

Job. Frid. Helpetii Vitulus aureus quem mundus adorat \& orat, f. de rariffimo naturx miraculo transmutandi metalla. Amftel. $1667.8 \mathrm{vo}$.

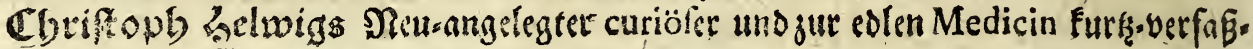
ter Sigier = Garten. I704.8vo.

Georg. Andr. Helwingii Lithographia Angerburica Pars 1. prod. Regiomont. r71\%. 4to, Pars altera Lipf. 1720.4 to.

Nic. Hennelii Silefiographia renovata. Vracisl.1704. 4 to.

Ludov. Hennepini Defcriprio Louifanæ Gall. Parif. 1683. I2mo.

Leonb. D.av. Hermanni Maslographia. Bregx I7II, 4 to.

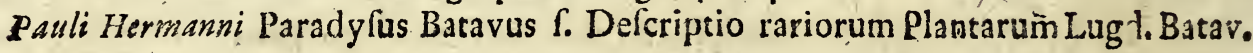
1705.4 to.

Francifc. Herandez Hiftoria Plancarum, Animalium \& Mineralium Mexicanorum cum

Commentar. Fabri \& Fabii.Romx 1651. fol.

Cbrif. Gottl. Hertelii Microfcopium noviter inventum. Lignitii 1712.4 to.

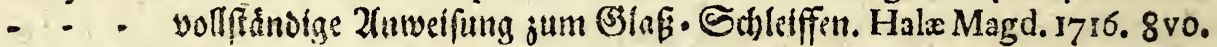

7ob. Ford. Hertodt Tartaro-Maftix Moravix. Viennx 1669. 8vo.

Cbriftiani Herzogs Mumiographia Medica : Ser $\mathfrak{V}$ athot Uon Agyptifđen Mumien. Gothx 1716. 8vo.

Guil. Fabritii Hildani Opera f. Obfervat. \& Curation. Chirurgicx Medic. Francof. 1646. fol.

Zifforifbe Remarguen ber neueften Gadben in Europa. Hamburg. ab An. 1699.. $1707.4 \% 0$.

Walf Heimbard von Hochbergs Georgica curiola f. Zublidyes Lnilo s und Felo = seben. Norimb. 1682.

Hacbletteri Differt. de Lapid. fulminari. Alcorff. 170 r. 4 to.

Trolff. Hoeferi Hercules Medic. f. Locorum communium Liber. Norimberg. 1575 . 4 to.

Frid. Hoffmanni Obfervationes Phyfico - Chymica felectiores. Halx Magdeburg: 1722. 4 to.

- - Dirt. de Terebinthina. Hal. Magd.1699.480.

- Differt. Hiftoriam Saçchari naturalem \& Medic. exhibens. Halæ Magd. I7. 410. 
Propempticon Inaugurale, de Pane groffiori Weftphalorum vulgo bon pour Nickel, annexum Differt. de Prudenti Medicamentorum applicatione in tempore. Halx Magdeb. $1695 \cdot 4$ to.

Difr. de Nitro, ejus Natura \& Ufu in Medicina. Halæ 1694.4 to.

Differt. de Carolinis Thermis. Halx Magd.1695. 4 to.

Wefdreibung des Salk̨= W3ercfs in . Salle. Halæ Magdeb. 1708. 4 to.

kob. Hoockii Micrographia. Londini 1669. fol.

Garzias ab Horto Aromatum \& Simplicium aliquot Medicamentorum apud Indos

nafcentium Hiftoria. Antwerp. 1579. 8vo.

Benedicz. Hopfferi Differt. de Chamæleontis victu aereo \& mirabili inedia. Túbing. 1681. 4 ro.

Job. Henr. Hottingeri Defcript. Montium glacialium Helvetix, rep. in Ephem. Nat.

Curiofor. Dec. III. An. IX. \& X. in Appendice.

Cbrifliani Hugerii Aftrofcopia compendiaria tubi obtici molimine liberata. Hagæ Comit. 1684. 4to.

- - Tr. de Lumine, in quo explicantur, qux ipfi in reflexione \& refractione Cryftalli Islandicx accidunt. Lugd. Batav. 1690. 4 to.

Levini Hulfii Series Imperatorum Romanoruma C. Julio Cæfare ad Rudolphum II. ex prif́cis recentibasque Numifmaribus. Francof. $1603.8 \mathrm{vo.}$

Oligeri facobai Mufeum Regium Danic. Haffnix 1696. föl.

Iudov. Frid. Jacobi Din. de Terris Medicatis Silefiacis. Erfordia 1706.4to.

rsbrant Ides Sieffe nach China ed. German. Francof. 1707.8vo.

Pauli fenifii Annxbergx Mifnix urbis Hiftoria. Drefdx 1605.410.

Caßp. Gotthold. Fent fchii Diff, de Gemmis. Lipfix 1706. 4 to.

Ferrandi Imperati Hiftoria Naturalis.Colon. \& Lipfia 1695.4 to.

Jo epbi Indi Navigationes. Bafil.1532. fol.

Job. Jonftoni Tavmatographia Naturalis. Amftel. 1633. $12 \mathrm{mo}$.

- - de Serpentib. Francof, ad Mœn. I653. fol.

- - de Pifcibus \& Cetis Libr. V. ibid. I649.fol.

- de Infectis Libr. III. ibid. 16\$3. fol.

- - de Exangvibus aquaticis Lib.IV.ibid. 1649.fol,

- de Quadrupedibus ibid.1652. fol.

- - de Arboribus Lib. X. ibid.1662. fol.

- Notitia regni Mineralis. Lipf. 166I, I2mo.

Fournal des Scapans, Parif, ab an. 1665.4 to.

Tbom.Ittigii Lucuhrationes Academicx de Montium Incendiis.Lipf. 1671.8vo,

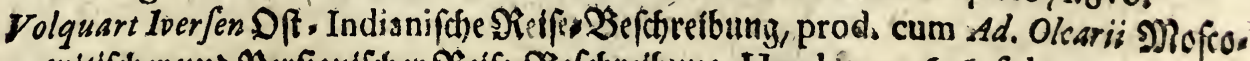

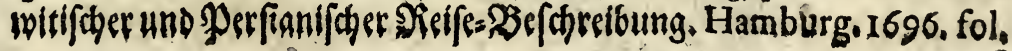




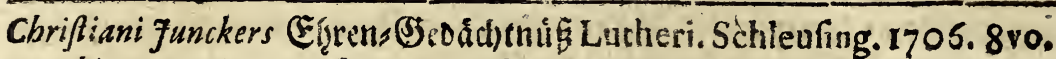
Joacbim. Jungii Doxolcopia Phyfica. Hamburg. $166_{2}$, 4to. K.

Engelbérti Kämpferi Amœnitatum Exotico-Politico-Phyfico-Medicarum. Fafcicul. V. Lemgovix 1712. 4to.

Dionyf. Kao Be efareibung des Ringfertf̧umb China, prod, una cum Ysbrand. Ides Pieffe nad China. Francof.1707.8vo.

Dav. Ketneri Praxis Metallica curiofa. Nordhuf, ryor. 8 vo.

- - Bergsund Salk=23ercf8=2Buch. Francof.1702. 8vo.

Dieteric. Herm. Ksmmericbii Differt, de Corona Boruflia Friderico Regi \& Electori a Deo data. Lipfix 170 or. 4 to.

Job. Kentmanni de Calculorum Genefi in corpore ac membris hominum. Tiguri s;6̧. 8vo.

- - Nomenclatura rerum foffilium. Tigur. $1565.8 \mathrm{vo.}$

Mart. Keryerus de Fermentatione. Wittemberg. 1663.4 to.

Frid. Gottl. Kettnerus de Mumiis Egyptiacis. Lip\}. 1703.8 vo.

Fob. Franc. Micbael Kbuon Dift, de Alumine. Altorf. I 75 . 4 to.

Atbanaf. Kircberi Turris Babel f. Archontologia, qua priforum poft diluvium hominum vita, mores rerumque geftarum magnitudo, fecundo Turris Babel defcribitur. Amftel.1679. fol,

- - Ars magna Lucis \& Umbræ. Roma 1646. fol,

- Mundus Subterraneus. Amftel.1665. fol.

- - Phonurgia nova, Campedon, 1673. fol.

Carol. Valent. Kirchmayers fiufus:23rann over Brablif̧cr 2 runquell. Prag. 1718.8 vo.

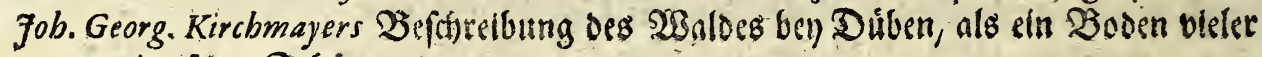
unteriroilden Sahinge 1692. 4 co.

- - Difr de Araneis. Vittemb. 4to.

- Differr. de Denarii Veter. mutatione, ito de adulterat. num. poena. Vittemb.1687. 4to.

- Differt. de Ignium miraculis locifque femper ardentibus fingulatim de Carbone foffili. Vitemb. 1693. 4to.

Emanuel. Koenigii Regnum Minerale. Bafil. 1686. 410.

- - Regnum Vegerabile. novif. editum Bafil. 1688. 4 to.

Foh. Cbrifoph. Koblbans Tractatus Opticus. Lipf.1663. 8ve.

Fob. Sopbronius Kozack de Sale Margaritarum. 1664. 4to.

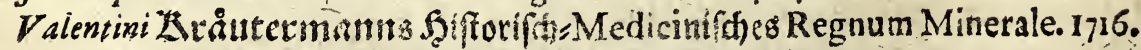

- - accurater Sdbeiber und Einftliber \$robirer. 1717.

Job. Kunckelii ars Vitraria experimentalis. Francof. 4 to.

Job. Chrift. Kundmanni 1. Aucoris Difl, de Regimine. Halie Magdeb. 1708. $4^{\text {to. }}$ 
266handlung vom Berfande Des Menfden vor uno nad dem falle. prima edir. prod. Budiffa 1716.8v0; 2da Vratislav, 1720. 8v0.

Conrad. Kbunratb Medulla deftillatorio \& Medica. Hamb.1638. 4to.

Friderici Küfneri Prodromus Agricolæ, Non.Agricolæ. in 4 to.

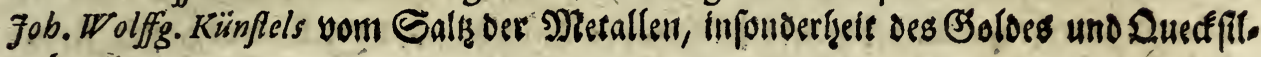
bers. 17 II. 4 to.

$\therefore$ L.

Friderici Lacbmindi Oryctographia Hildesheimenfis f. Admirandorum foffilium que in Tractu Hildesheimenfi reperiuntur. Hildesheimii 1669. 4to. fob. de Laët de Imperio Magni Mogolis f. India vera. Lugd. Batav.1636.16mo. - - Novus Orbis f. Americx utriusque Defcriptio. Lugd. Batav. 1633. fol. - . de Gemmis \& Lapidibus. Lugd. Batav. 1647. 8 vo.

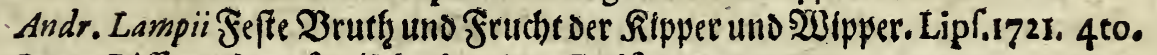
Lamy. Differtations fur l'Antimoine. Parif,1682.12mo. Cbriftian. Lange de Thermis Carolinis. Lipf.16 53 . 4to. Cbriftian (Bottlieb L anges Jiufug= B3rum. Hirfchberg.1720. 8vo. Cbriftiani fob.Langii Opera Medica Theoretico-Practica. Lipfiæ ro o4. fol. Carol. Nicol. Langii Hiftoria Lapidum figuratorum Helvetiz ejusque vicinix. Vene. tiis 1708 . 4 to.

- - Methodus Teftacea marina in fuas debitas clafes, genera \& fpecies diftrie buendi. Lucern 1722. 4to.

Fr. Tertius de Lanis Magifterium Naturæ \& Artis. Brixix 1684. fol. Fob. Lanzonus de Ballamatione Cadaverum. Genux 1692. $12 \mathrm{mo}$. Fob.Bapt. Latan Nouveaux Voyages aux Isles de l'Amerique. Parif.1622. 8vo. Guiliel. Laurembergii Hiftorica Defcriptio Ætitis. Roftoch. 1627. $12 \mathrm{mo}$. Francifc. Leguat ঐietfen nad) jweyen untewofgnten Dft. Sndifden Infult. Francof. 1709. 8 yo.

Antor. de Leeuwenboek Epiftol. ad Soc. Regiam Anglicam \& alios illuftres viros, feu Continuatiu mirandorum Arcanorum Naturx deteftorum.Lugd.Batav.1719.4to.

- Continuatio Epiftolar. ad Regiam Societ. Londinenfem datarum. Lugd. Bat.1689. $4^{\text {to. }}$

- - Anatomia f. Interiora rerum cum animatarum tam inanimatarum ope \& beneficio exquifitifimorum Microfcopiorum deteda variisque experimentis demonftrata. Lugd. Bat. 1708. 410.

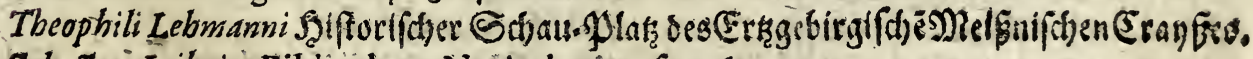
Fob. Fac. Leibnitz Bibliotheca Norimbergenfis. 1674 . 4 £o.

Lemery Traité de I' Antimoine. Parif. 1582. $12 \mathrm{mo}$. Lev. Lemnii de Occultorum Natura miraculis, Francof. $1628.12 \mathrm{mo.}$ Rgfini Lentiliz Mif́cellanea Medico.Practica tripartita. Ulmæ1698: 4 to. 
70b. Leonis Africani Africe Defcriptio. Lugd. Bat.163\%. 16mo.

Camilli Leonardi Speculum Lapidum. Pifauri $\mathrm{y}_{\mathrm{O}} \mathbf{2}, 4$ to.

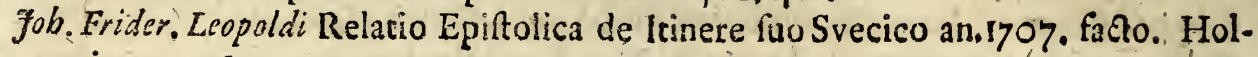
mix rzil. 8vo.

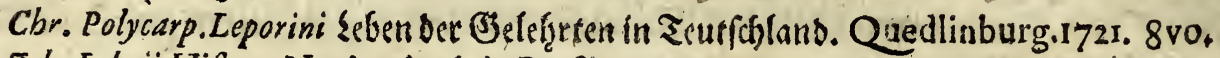
Foh. Lebrii Hiftor. Navigationis in Brafiliam. 1586. 8vo.

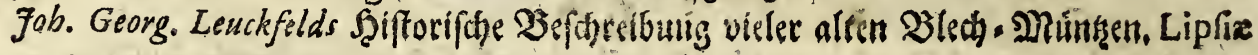

172 I. 4 to.

Andr. Libavii Singularia. Francof, ad Moen.160r. 8vo.

- Commentationes Metallici, Francof. 1597. 4to.

Foritunius Licetus de.Monftris. Amftel. 166;, 4to.

- - - Litheofphorus f. de Lapide Bononienfi, lucem in fe conceptam ab ambiente claro mox in tenebris mire confervante. Vtini 640.4 to.

Job. Georgii iebenewibts. Difcurfus de Diluvio maximo occafione inventi in mineram ferri murati ligni. Gieflx \& Francof, i 712. 8vo.

- - Dillert. Epiftolica de nonnullis Bracteatis Numnis Hafliacis. Helmitad. 1716. 4to.

30h. Hugon. Lintfcbotti Navigatio in Orientem. Francof.1599. fol.'

Lipfienfum Acta Eruditorum. Lipfix ab an.1682, 4to.

Martini Lifleri Hiftoria Animaliuin Anglix. Londin. 1678. 4 to.

- - Hiftoria Conchiliorum. Londini 168j. fol. c. figuris ab Anna \& Sufanna Lifteriis pict.

- - de Fontibus medicatis Anglix. Eboraci 1682. 8vo. \& Lipf.1684. Fob. Henr. Locbréri rariora Mufei Besleriani. 1716 . fol.

Mich. Frid. Lochneri Commentatio de Ananafa f. Nuce PineaIndica vulgo Pinhas. No: rimb. 1716.4 to.

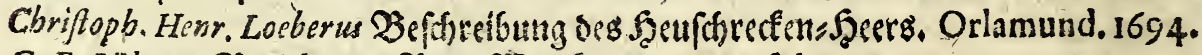
G. E. Löbneys $\mathfrak{B e r i t h t}$ von $\mathfrak{B e r g}=2 \mathcal{B}$ erten, an.1717. fol.

Joh. Lofelii Citrium prægnans. Regiomont.1645. 4 to.

Foh. Petr. Lotishii Tr. Medico. Phyfiologicus de Cafei nequitia. Francof.1643. 8vo.

Job. Lowiborp Tranfactiones \&: Colleaiones Philofophicx, usque ad finen an. 1700.

in Epitomen reda etx. Londin. 1705.4 to.

7ob. Luce Chronicon Silefix in $4^{\text {to. }}$

Jab. Fac. Luckii Sylloge Numilmarum elegant. Argentor.1620. fol.

Jobi Ludolf Hiftoria Ethiopica. Francof. ad Moen. 1691. fol.

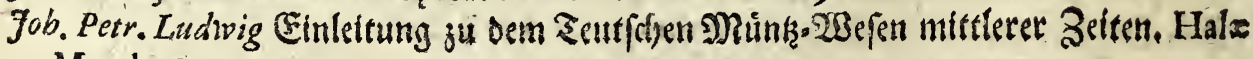

Magd. 1699. 8vo.

Edtaar. Luidii Lithopilacii Britannici Ichnographia. Lipfix 8 vo.

gob. Fac. Lungersbaufen Differtar, de Imicamentis Naturx. Jenxe 1698. 4 to. 
Fabii Columne Lynces Annotac. in Nardi Anton. Rechi res Médic. Nov. Hifpanix, reperitur in fine Franc. Hernandez. Romæ 16 I. fol.

\section{M.}

Job. Petr. Maffeji Hiftoriar. Indicarum Libr.XVI. Col. Agrip.I593. fol. Olai Magni Hiftoria Septentrionalis. Lugd. Batavor. 1645. I2mo. Sim. Majoli Dies Caniculares. Mogunt, $1607 \cdot 4$ to.

30b. Dan. Majoris 2Bevoltcêtteg Cymbrien.Ploenx 1692. fol.

- - dePlanta muiftrofa Gottorpienfi Slefvvig. I665. 4to.

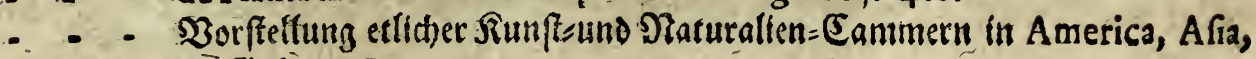
Africa, und Orainken Europx.

- - Differt. de Cancris \& Serpentib. petrefactis. Jenx 1664. 8 vo.

- . Differt. de Lacte Lunx. Kiloni 1667.4to.

_. Trast. de Marga Schlefvvig. 4 to.

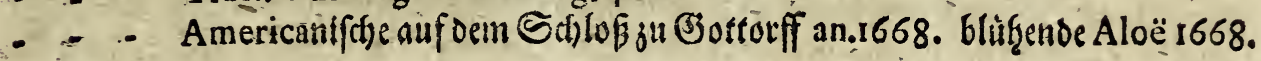
4to.

Marcelli Malpigbii Opera C. Anatome Plantarum. Londin. 1686. fol. 7ob. albr. von Whandelsloo Nieife.2Befarribung, prod. una cum Olearii Mofcos

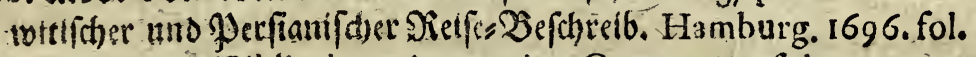

7ob. Jac. Mangeti Bibliotheca Anatomica. Genev.1685. fol:

- Bibliotheca Chemica curiofa. Genev. 1702. fol.

Foh. Caspar. Mangoldi Materix Medicx Idea nova. Bafil. 1715. 8 vo.

Marci MappiDiffert. de Rofa de Jericho. Argentorat.1700. 4 to.

Marbodei Opus de Gemmarum, lapidum pretioforum formis, natura ac viribus, cum

Ohfervat: Alardi. Colon.1539.

Georg. Marcgravii Hiftoria Brafil. prod. una cum Guil. Pifonis Hift. Nat. \& Med. Bra. fil Amftel.1698. fol.

Marci Marci Phil iophia vetus reftituta. Pragx 1662. 4to.

Mariotte Sirundelefren der Hydroftatick uno Hydraulick, ex Gallica lingva in Germa.

nic. transiar. a D. Joh. Chriltoph. Meinig. Lipfix r723. 8 vo.

Paul. Matb. ITTarpergers Rauffimaunso Magazm. Hamburg. 1708. 8vo.

Bartbol. Marradoni Dialogu de Chocolata. Sevilix 1618.

Ludov.Ferd.Comit, de Marfigli Phofphorus nineralisf: Lapis illuminabilis Bononienf.

Italice Lipf. $15984 \mathrm{tos}$.

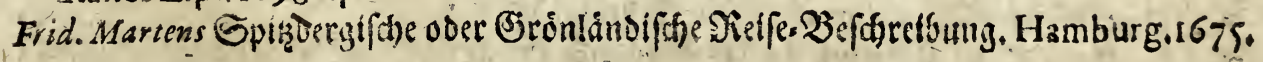

4 to.

Martiniere Siffe in die Mordiche Eandfhafietz. Hamb.1675. 4to.

Marini Martinii Novu Arias Sinenfis. Amftel.1655. fol.

UT.rens Ceutide Lliatertal. Cammer. Norimb.1587. 8 vo.

Chriftoph. Maskii Dirfert. de Metal fodinis Hartzgerodenf. 1687.4 to.

Znionii a Maffa Salis Áwatomia. Vratisl. 8ro.

$\mathrm{Y}$ y 
Foh. Maibrfii Sarepea. Nurimb. 1587. fol.

Petr. Andr. M thioli Commentar. in Diofcoridem. Venet. 1554 . fol.

Dortous de Mayran Differtat. fur la caufe de la Lumiere des Phofphores $\&$ de Nocallaques. Bordeaux 1717.8 vo.

Meáailles fur les principaux eveneni as du Regne de Louis!e Grand avec les explica. tions Hiftoriques. Opus hoc pretioffimum prod. Parif.1702. in 4 to maj. Hier. Megiferi Deliciz Ordinum Equeftrium. Foh. Hesr. Meibomii Differt. de Metallifodinis fylva Hercynix. Helmftad. 1580. 4 to.

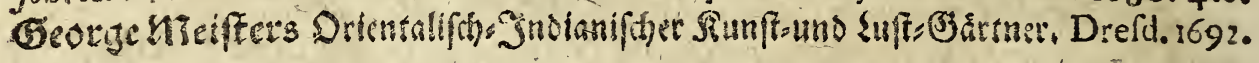
4 to.

Facobi a Melle Hiftoria Urnx fepulchralis Sarmaticx ad Georg. Wolff. We delium. Jsnxi 1679.450.

- - Epif. de Echinitis Wagricis ad Woodwardum. Lubec.1718 4.to.

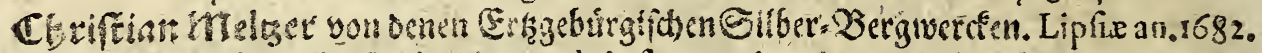
Apollonii Menabeni Traa. de Aice, \& de ipfus partium in re Medica facultacibus. Co: lon.rs8r. 8 vo.

Jvan Gonealez de Mcndoza Hiftoire du Grand Royaume de la Chine.

Menctrieriz Hiftoire de Roy Louis le Grand, par les Medailles, Emblemes, Devifes,

Jetrons, Infcriptions, ed, noviff. Parifiis l. potius ap. Batavos IGgr. fol,

Cbrifisan. Menzelii Lapis Bononienfis in obfcurc lucens, collatus cum Phofphoro Harmetico Chrifgiani Adolphi Balduini. Bilefeid. $1675.12 \mathrm{mo}$.

Math. Meriani Florilegium renovatum \& audum. Francof.1641. fol.

Job. Murfoi Achenx Batave. Lugd. Bacavir625. 4to.

Raymand. M ndereri Difquifitio de Chalcantho feu Vitriolo.Auguft. Vindel.1617.4to. 7oh. Frid. Miri Differt. de novo Phofphoro xthereo. Vitemb.I716. 4 to. Classd. du Molinet Hiftorix fummorum Pontificum a Martino V. ad Innocentiun XI.

per eorum Numifmata. Paril.1678, fol. c. fig.

- - le Cabinet de la Bibliotheque dé SainteGenevieve.Paris 1692 in fol. maj. Nic. Monardes de Lapide Bezaar, prod. una cum Clufai, Exoticor. Libris. Antwerp. s.605. fol.

Monconys curiöfe Stelfe Beffrralbung 1698. 4to.

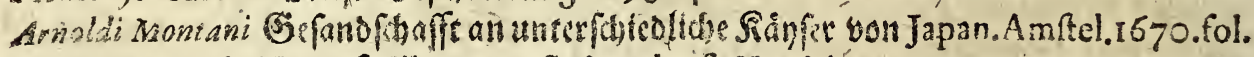
70h. Montani de Terra figillata prc. Strigonienfi. Vratistó 1610.4 to.

70b. Bapt. Montani Medicina univerfa. Francof. 1587. fol.

Jofept. Monti Catal, Rirpiuin agri Bononienfis Prodromus gramina ac ejusmodi affinia complectens. Bononix 1719.4 to.

Dan. Georg. Morhofi Epifol. de Metallorum tranfmutatione ad Langelottun, gux haberur in Volumine Difrert. Academicar. Hambufg. 1699.450.

Robert .Morifon Plantarum Umbelliferarum diftributio nova. Oxonii 1672. in fol. maj. fob. 
foh fac. Moferi. Hiftoria Numifmatica Caroli VI. Rom. Imperat, Aug. O, Max.1725. fol.

fos : Wuleni Numifmata Danorum. Haffixix 1670. 4 to.

1Foh. Muller: Ditfert. de Tarantulis. 16\%6. 4 to.

Job. Muys Padalirius redivivus. Lugd. Batav. $1586.12 \mathrm{mo}$.

Abr Muntingii de Vera antiquorum herba Britannica. Amfel. 168r. 4to.

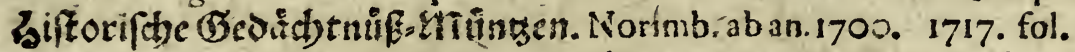

Gott Frid Mrlii, Memorabilia Saxonix fubterranex, Pars Ima Lipf,1709. 4to. IIda

Ibidem 1718.4 to.

N.

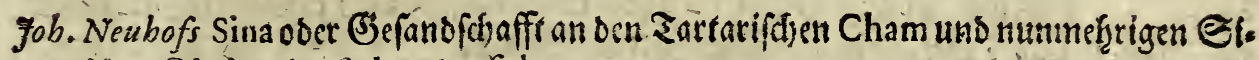
nifdon Sianfer, Amfteli1669. fol.

Cafp. Neumanni Biga Difficultatum Phyfico-Sacrarum de Gemmis Urim \& Thum. mim diatis, it, de cibo Samarix cbfeffx. Vratis!.170\% . 4to.

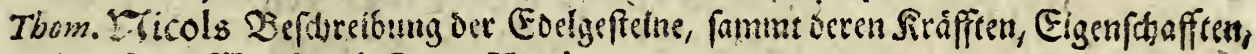

Preif uno SYerth. ed. Germ. Hamburg.1675. 8 vo.

Job. Eufeb. Nutrembergii Hiftor, Nature naxime peregrinx. Antwerp.1635. fol.

- . de miris \& miraculofis Naturis in terra Hebrais promiff. Antuverp.1635.

fol.

Anton. Nuckii Operationes \& Experimenta Chirurgica. Lugd. Bat.1692.870.

O.

Fob. Frid. Ochs Diff. de Sanguine Draconis. Altorff. 1712. 4 to.

Herr. Oldenburg:i Act Philoiophica Societ. Reg. in Anglia. Lipf.1675. 4to.

Adami Olearii Sottorptfhe Simft. Sanmer. Slefvig. 1674.4 to.

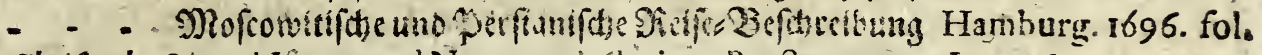
Cbrifoph. Oleari Ifagoge ad Nummophýlacium Broteatorum. Jenx 1694. 4 to. 3ob. Opffelbacbii $\mathfrak{B}$ ipper Gewinfe. Liprixe I6:1. 4to.

7ab. Cbrifloph. Ortlob de Prafagiis Lucuftaran incertis \& falfis. Lipfix 1713. 4 to. Wilh.d' Orville Caralogus varr een Uytmunten! Kabinec, beftande in Hoot ns, Scheipen en raare $Z c e G e v v a f f e n$, choone Agate, Carneclyne, Boom en andcre EdeieGefteentens. Amitel.1622: 8vo.

\section{$\mathrm{P}$.}

70b. Palatii gefta Potificum Romanorum. Venetiis $16870-1690$. fol.

Gudo Panirollus de rebus deperdisis. Francuf.1660. 4 to.

Marb. Parci Opera Parifis8z. fol.

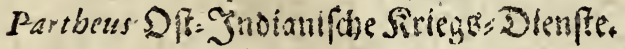

Carolus Patinus de Turfis. 1663.410.

$=$ : - Familix Romanx in antiquis Numilinatihus ab Urbe condita ad rempora 
D. Augufti ex Bibliotheca Fulvii Urfini cum adjunctis Antonii Augurfini Epifcopi llerdenfis. Parif $16 \% 3$. fol.

Pbilipp. Paiti f. Peu Praxis fubveniendi Parturientibus Gallice. Parif.1694. 8vo. Simon, Pasti Quadripartitum Botanicum. Francof. ad Moen.1708. 4 to.

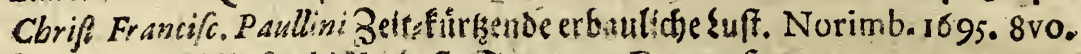
- - Philofophipa suftestunden. Francof 1707. 8vo.

- - Moxoraguoyea Фía f. Nucis Mofchatæ curiofa Defcriptio Hiftorico.Phyfico-Medica. Francof, \& Liplier $704.8 \mathrm{vo}$.

Fob, Nicol Pécblini Obfervationes Plisfico Medicx. Hamburg.169r. 4to.

- - de habita \& colore \&thiopum. Kilon.1677. 8vo.

- . - Theoph!us Bibaculus f. de Potu Thex Dialogus. Francof. 1684. 4to.

Cbriflian. Perfon Trab. vom Miod)likger Steins Maraf.

Petivers Gazophylaciam Narure \& Artis. Londin.

fob. Gearg. Pelsbofcri Tyrocinium Chymicum. Witteberg.

Gob. Conr. Psyeri Parerga Anatomica \& Medica. Amftel.1682. 8 vo.

Ibilippi a St. Trinitate Itinerarium India Orientalis. Lugdun. 1649.

Phil. Pigafetia Kegui Africani Defcriptio, olim ex Edoardi Lopez acroamatis Lingva

Itolica excerpta, nunc Latio fermone donata ab suguft. Cafjiodoro Reinio. Francof.

1598. fol.

Dé piles Cours de Peinture par principes. Parif.1708. 12 mo.

Math. Zatbar. Pillingii de B tumine \& Ligno bituninofo. Altenb.1674. 8vo.

Guilialm. Pifonis Hiftoria Narural. \& Medica Indix Ocsidentalis. Amftel.ı 658. fol.

Francif. placentic Mare Egèn redivivum f. Chorog aphia Archipelagi. Mutinx

1688.410.

Facobi Placestini de Barometro Difiert. II. Patavii $171 \mathrm{Ir}, 12 \mathrm{mo}$.

Gob. Za bar. Platneri Difr, de Generatione Metalorum. Lipfix 1697.4 to.

C. Plmii Hiftoria Naturalis.

Caroli Plumerii Defcriptio Plantarum Americx, una cum carum Iconibus, Gallice.

Lut Parif. I693. in fol. maj.

Rot. Ploot Hiftor. Natural. Oxford.

Leonb. Plukenet Phytographia. Pars Ima. Londin. 1691. 4to. Pars IIda ibidem 1692.

fol.

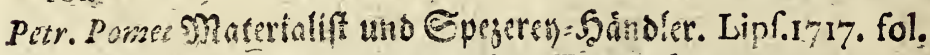

705. Bapifi Poyta Phytognomonica. Francof, 1608.8 vo.

Petr. Poters Pharmacopoea Spagirica. Colon. 1624. $12 \mathrm{mo}$.

Hennic. Pow Oblervationes Microfcopicx. Lond.isog.

Fob.Baptift. Ptolomai Philofophia mentis \& fenfuum Phyfic. particul.

$\mathrm{R}$.

7ob. Raji Metlodus Plantarum emendata \& aucta, Londini $703.8 \mathrm{vo.}$

- - de Difiolut. \& mutat. mundi ed. German. 
- Hiftor. Plantarum. Londin. ab An.1682.- 1688.Tom, III. prod.1704.fol. Bernb. Ramazzini Ep̣hemerides Bàrometricx Mutinenfes An.1694.una cum Difquifitione caufæafcenfus \& defcenfus in Torricelliana fiftula. Mutinx $1625.8 \times 0,-$ no. vifi edit: cum Controverfia quam habuic cum Günthero Schelbamero. Petar. 17io. I2mo.

ETeu-eroffnetes Ratititen Cabinet. Hamburg. 1707.8vo.

Tbiopbil. Raynaudus. de Cadaverum Incorruptibilitate. Aven. $1665.8 \mathrm{vo.}$ Adam.Recherbergii Differt. de Hermundurorum Metallurgia argentaria coer voinErk̨.

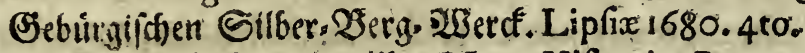

Nard. Ant. Recbi de A nimalibus Novæ Hifpanix. Romæ 16 1 1. fol.

Franc. Redi Experimenta circa res diverfas naturales, fpeciatim illas qux ex Indiis ad.

feruncur. Amftelodami 16́75. 12mo.

Gajp. a Rejes Campus Elyfius jucundarum Quæftionum. Francof. 1670. 4to.

Facob. Frid. Reimanni $\mathfrak{B e r f u c t}$ eitter Einleitung in oie Hiftoriam Literariam. Hala

Magd. 1708.-1713. 8vo.

Fob. Reiskii Commentatio Phyfica æque ac Hifforica de Gloflopetris Luneburgen-

fibus. Lipfix 1684. $4^{\text {to. }}$

马ifforifore Rernarquen der neueffen Endien in Ëuropa. Hamburg. ab An. 1699.:

$1707.4 \mathrm{tc}$.

Sinceri Renati Golocre Duclle ber Slafur in Gunft. Vratisl. 17Ir. 8vo.

Erbard. Reufibii Capita Deorum \& Illuftrium hominum in Gemmis, qux ftudio col-

legie Gob. Mart. Ebermayer. Francof. \& Lip., I7zr. fol.

Samuel, Reyberi Differt. doNunmis quibusdam ex metallo Chymico factis. Kiloni

1692. 4 to.

Henr. van Rbeede. Hortus Medicus Malabaricus, prod. XII. Tom, cum fig. Amftel.

$16-8$ - 1693 . fol.

Fob: Lut. Rbiem Difp, de Ebore foffili. Altorff. 1682. 4 to.

Godofr. Rhonii Epiftol. de Studio rei numarix Silefiaca \& exercitatio de Numis Epi-

fcopalibus Johannxis Vratislavienfibus. Vratisl. 1693.4to.

Vidi Riediini Linea Medicx. Augutt. Vindel. 1698.800.

Petr. Ripalieiz Obfervat Medico.Pacticz. Nemauf. 1683.

Auguft. Quirini Rivini Introductio generalis in ren Herbsriarn. Lipfix I690 fol.maj.

- - Ordo Plantarum qux funt flore itregulari tetrapetalo. Lipf. i6gi. fol.

- - Differeariones Medicx. Lipf. 1 710. 4 tó.

7ob. Auguft Ripinifil. Diff. de Terris Mediciralibus. Lipfix $1723.4 \mathrm{t}$.

De Rosbefort Defobreibung der Antillen. Infuln in America. ed. German. Francof. 1368. 12mio.

Baltbaf. Rasleri Speculum Metallurgix politifimx oner f̧ellspolitrer Borg= Epis gel. Dresdx 1700. fol. 
Guerner. Rolfinckii Differtationes Chymicx. Jen. 1679. 4to.

- Differtat. de Margáritis. Jenæ 1660. 4 to.

- - Difi. de Lapide Bezoardico. Jenx r675.4ro.

Guil. Rondeletii de Pifsibus marinis cum univerfa aquarilium Hiftoria \& de Infectis \& Zoophyr. Lugd. I $\$ 4$. in fol.

Henr. von Roonbuyfen Shiftorlfche Şeil = Runft, ed. Germari. pr. Norimb.1674.8vo. Dominici Ro/f3 Germme Veteres cum Explicatione Pauli Alexandri Maffei. Italic. Ro: mix 1707.410.

Olai. Rudbeckii Lapponia illuftrata, \& iter per Upplandiam, Geftriciam, Angermanniam, Bothniam, Finlandiam, 'Alandiam \&c. Upfalix 1701. 4to.

- - Atlantica.

Gacob. Rueffius de Conceptu \& Generatione hominis, Francof, ad Mœn. Ir88. 4to. Franc. Ruei de Gemíms, qui reperitur poft Levini Lemnii Herb، Bibl. Explicat.pag. 1.7. Tiguri 1665. 12mo.

Georg. Everb. Rumpbii Amboinfche Rariteit-Kàmer. Amftelod. 1705. fol. Frid. Ruyfcbii Thefaurus arrimalium primus. Amftelod. 1710,4 to.

\section{S.}

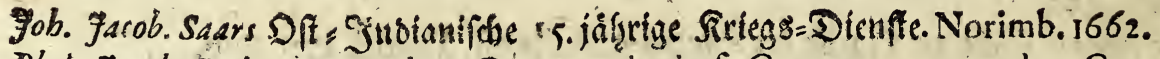
phel. Jacob. Sacbs a Lewenberm Gammarologia f. Gammarorum vulgo Cancrorum

Confideratio. Francof. \& Lipf. 1665.8 vo. Angeli Sale Opera Medico-Chymica. Francof. 16744 to.

Hippolyti Salviani Aquatilium Animantium Hiftoria. Romæ I 554. fol.

Jani Ant. Saraceni de Pefte Comment. Lugdun, 1589. 8 vo.

Jul. Cefar. Scaligeri de Subtilitate. Francof. 1612.8vo.

Foh, Scheffera Lapponia. Francof. 1673 4to.

Guntber. Cbrifoph. Scbslbameri de Nitro cum Veterum tum Noftrorum Commen.

tatio. Amftel. 1709. 8'vo.

- - - de Auditu Liber. Lugd. Batav. 1684.

Job. Valend. Scheid Dift cie Magnete. Argentor. 1683.4 to.

9ob. Adam. Scbleufingii letis sntoecftes Sibyrien oder Siewerien. An. 1690.

gob. Theod. Scbenckii Lithogenefis f. de Microcefni membris petrefactis. Jenx.

gob. Scbenckii Vol. Obfervationum Medicarum \& Monftrofsrum Volumen. Lugdua. 1643. fol.

70b. Facob.Scheucbzeri Hiftoria Naturalis Hel vetix oder Natur = Sclftorle Des Sdiwels ger =\{andeg, Pars I. prod. 3urtich 1716. 410, Pars IIda ibid. 77 17. 4to, lub Tir.Hydrographin Helvetice.

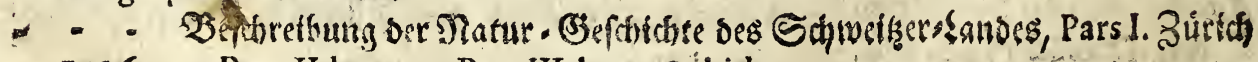
1706.4to, Pars IIda 1707. Pars IIItia 1708.ibid. 
- - Meteorologia \& Oryctographia Helvetica. Tiguri I7 18.4to.

$\therefore$ - Quxrelæ \& Vindicix Pif́ium. Tiguri 17 C-8.4to.

- Herbarium Diluvianum. Lagdi. Batav. 1723. fol.

- - Specimen Lithographix Hèvericx curiofx. Tiguri 1702.8vo.

- - OTPEভIФOITH $\Sigma$ Helveticus . Itinera Alpina tria. Londin. 1708. 4 to. fob. Scbeucbzeri Agroftographia f. Gi minum, Juncorum, Cyperorum, Cyperoidum iisque affininm Hiftoria. Tiguring 19.40.

Scbindleri geheimer Minth: Guardein umo Bిerg = Probierer. Francof. 1705.8 vo. Job. Andr. Sibmidii Diff. de Thermomerris. Jenz 1684. 4 to. Anton. Scbneebergeri de multiplici Salis Ufu. Cracov. 1562.8vo. Abrabam. a Scbonberg Zusfífįl. Berg.Information. Lipf. 1693. fol. Cbriftian. Andr. Scbangaft Difi, de morfu Tarantular. 1668.4to. Mart. Stbookius de Turfis. Groningx 1658.12mo. - - Diatriba de Averfatione Cafei. Grœening. 1664.12mo.

Stepban a Scbonevelde Ichthyologia \& Nomenclatura animalium, marinorum, fluviatilium, lacuftrarum, qux in Ducatibus Slefvvici, Holfatix \& Hamburgi occurrunt triviales. Hamburg. 1524.4 to.

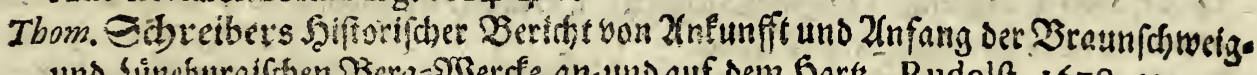

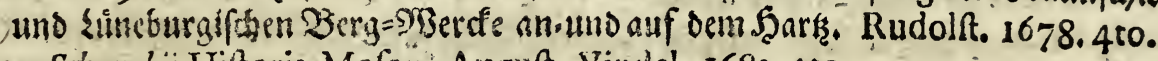

Lu6a Scbrceckii Hiftoria Mofcis. Auguft. Vindel. 1682.4to.

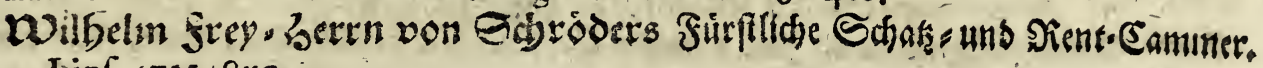

Lip?. $1721.18 \mathrm{ko}$.

Walth. Scbultzens Dft= Invifdse = Sieifen. Amftel. 1676. fol.

Georg. Nicol. Scburtzi T̃leurcingetictete Material - Sammer. Norimb. 1672. fol.

7ean. Scbwamerdam Hiftoire generale des Infeीes.1685.4to.

Job. Hénr. Scbuttei Ory tographia Jenenfis, Lipfix $1720.8 \mathrm{vo.}$

Ca/p. Scbrenckfeldti Catalogus Stirpium \& Fofilium Silefix. Lipfix 1600, 4to.

- - Befdreibung des f̧irfúberger 23adsb. Gorlitii 1607.8 vo.

7ob. Mich. Schwimmers Delicix Phyfico. Hurtenfes oder Phyficalifdes Barten.

23uक. Erfurt. 1917.800.

7ob. Sculceti Armamentarium Chirurgicum bipartitum. Francof. 1666. 4to.

Melcbior Sebizii Difi. de Lapide Lazuli.Argensorat.' 1668.4 to.

- - Diff. de Urinatoribus \& Urinandiarte. ibid.

- de cafu adolefcentis cujusclam Argentinenfis mirabili. Argentor. 1660. 4 to.

... de Conditura Cadaverum. Argentor. 4 ito.

7. W. Sengtrerdius de Tarantula, Lugd, Bat. $1668.12 \mathrm{mo}$.

Marc. Aurelius Sederinus do Viperx natura, venenu, medicina Demonftrationes \& Ex. perimenta. Petavii 1651. 4to. 


\section{$360 \quad$ CATALOGVS AVCTORVM}

Gob Henr. Seyfridic Medulla mirabilium Natura. Norim, $1694.8 \mathrm{vo.}$

Rob. Sibbald Scocia illuftrata, f. Prodromus Hiftorix Naturalis. Edimburg. 1684: - fol.

7oh. Bapt. Silvatici de Lapide Rezaar \& Unicornu.Venetiis 1605.4 to.

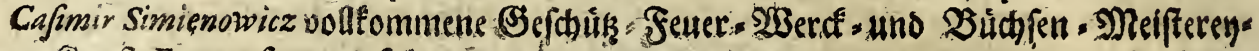
Siunft. Francof. 1676 . fol.

Job Sinapii Olsnographia. Lipf. \& Francof. $1707.8 v 0$.

Frader. Stare Experimenta \& Oblervationes crrca Lapidem Bezoardicum, una cum

Vindiciis Sacthari Anglice Londin. $1715.8 \mathrm{vo}$.

Job. Sloane Hiftoriaitineris in Infulas Maderam, Barbatam; NiviumSt.Chriftophori \&

Jamaicam. Anglice Londini : 707 . fol.

Fabianus Sommserus de Iventione, Defcriptione, Temperie, Viribus \& Ufu Thermarum Caroli IV. Imperatoris. Lipfixi6\$1 8vio.

Cbrift. Jacob. Speneri Differt de Ufibus Gemmarum fuperftitiofis. 4 to.

- Caralogus von Datur = uno אunft=gebildeten Seltenbetten in Regno A.

nimali Vegetabili \& Minerali Berol, 1718.8vo.

David. Spleiffii Oedipus Ofteolithologicus, I. Differt, de Cornibus \& Offibus foffilibus Canftadienfibus. Schąf hufx.

7ac. Sponii Voyage de Dalmatie, de Grece \& de Levant. Lugdun. 1678. $12 \mathrm{ma}$.

- Micellanea erudita antiquitatis. Lugdun. 1685. fol.

Otton. Sperlingii Epiftola ad Jac. a Mellen de Nummis bracteatis \& cavis. Lubecre 1700, 4 to.

Georg. Erneft. Stablii Differt. de Nova Pathologia Calculi Renum. Halx Magdeb. $170 \%, 4 \mathrm{ta}$.

- Differt. de Metallurgix Pyrotechnicx \& Docimafix Metall: fundamentis. Halx I700. 4 to.

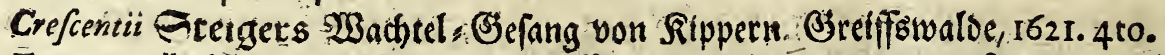
Franc. Stelluti Trattato del Legno foflile minerale nouvamente fcoperto, nel quale brevemente if accenna la varia \& mutabil natura di detto legno. Rom. 1637. fol. Extat cum Ephem. Nat. Curiof. a 7ob. Dan. Majore ex Italico in Latinum verio An.111.pag. 606. feqq.

Lus Stengliz Apologia adverius'Stibii Spongiam. Auguftx 1569.4to. Nicol. Stenonis Myologiz:fpecimen C. Mufculi Defcriptio geometrica cum Rajx Anatome. Fiorent 1667 . 4to. Extat etiam in Clerici \& Mangeti Bibliothec. Anatomica.

Cbriftian. Stieffi Epiftola de Urnis in Silefia Lignicenfibus \& Pilgrammsdorffenfibus. Lipfix 1704. 4to.

Laurent. Straugii Diff. de Ovo Gslli, 1670. 4to.

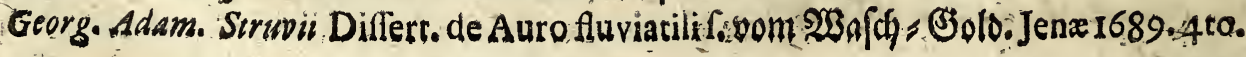


Job. Scurmii de Rofa Herishuntina. Lovanii 1608.8 vo. $0 ! r_{5}$

gob. Chriflopb. Stumii Collegium Experimentale. Norimb. I7or. 410.

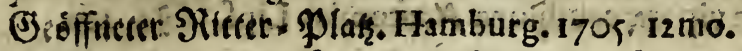

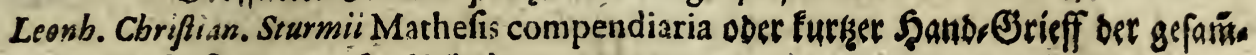
ten Mathefrs. Francof, ad Viadr. $1707.8 \mathrm{vo}$

\section{T.}

Otcon. Fabenit Hipporstes Chymicus. 1666 .

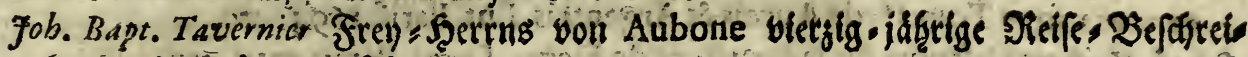

bung. Norimb: 168t. fol.

Doininici Tempefte Vité Summorum Pontificum a C. J. ad Clementem VII. Latino

Iiakicuque fermone breviter confcriptx, cum effigiebas eorum. Romx fol.

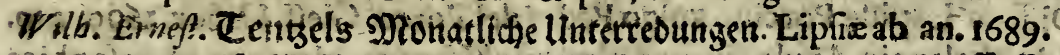

- Epiftola dé Sceleto Elephantino Tonna nuper effoffo. Jenze 1696. $8 \mathrm{vo.}$

Melch. Tbepenots Dft $=$ Gnbifdhe Selfen. Francof. ad Moen. 1693. 4 to.

Fob. Thiele Differt. de Minera Martis Solari f. Acidularum artificialium materia.

Witteberg. 1682.4to.

1. Theelogia Medica f. Differt de Ufu \& abufa potus calidi cum herba

Theé. Witteb. 1687.4 to.

Gob. Henr. Thiemrotbs Diflertatio fiftens Plantam ac fructum Ananas hujusque ufum

Medicum. Erford. 1723.4 to.

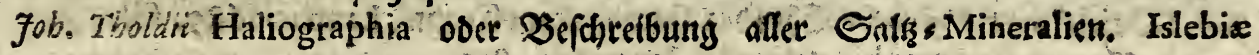

1703.800 .

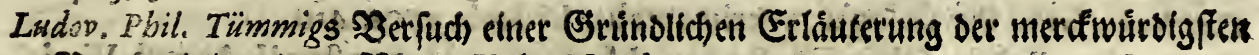

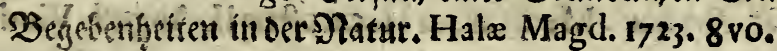

M.atth. Tilingii de Cinnabari. Francof. 1621.8 vo.

Tbom. Treteri Imperatorum Romanorum effigies. Romx. 1583. 8 vo.

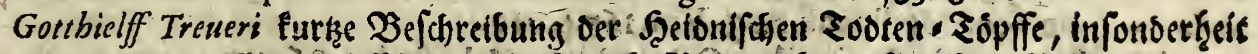

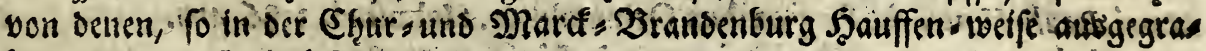

ben vorden. Norimb. 1688. 4 to.

-7ob. Phil. Treuneri Phœenomena Locuftarum precip. nuperrimarum. Jenæ 1693.4to. 7ob. Pitton Tournefort Elementa Botanices, f.Methodus cognofcendi Plantas. Galli:

ce Parif. 1694.8 vo.

- - Corollariumİntitutionum rei Herbarix. Parif. 1703.4to.

Memoires de Trevoux.

Job. Bapt. Triumfetti Obfervationes de Ortu ac Vegetatione Plantarum, cum nov2rum ftirpium Hiftoria. Romx 168 5. 4 to.

Georg: a Turre Hiftoria Plantarum. Petavii 1685. fol. 
Adalbcrti Tylkowsky Philofophia curiola f univeria Ariftotelis Philofophia juxta communes fententias expofrta. Olivæ $1680.8 \mathrm{vo}$

Edoard. Tyffonis Tr. de viperz caudifonx Anatomia. Lipf, 1684.4to.

U.

Gob. Vaillanz Numifnata Imperatorum Romanorúm praftantiora a Julio Cæláe ad

Poftumum \& Tyrannos Tom. I. de Romanis \&̈reis. Lutet. Parif, 1694. 4to.

- - Numifmata Imperatorum Romanorum preftantiora a Julio Cær. ad Tyrannos usque Tom.II. de A ureis \& Argenteis. Lut. Parif. 1694.4to. Sebaft. Vaillant Difcours fir la Strućture de Fleurs. Lugd. Batav. 1718.4to. Mi.b. Bernh. Valentini Mufeum Mufeorum Pars Ima Francof, ad Moen.17,04. fol. Pars IIda \& Illcia ibid. 1714. fol.

- - Difi de Lapíde Porcino valgo Pedra del Porco. Gieft. Haffor. 1699. 4to. Lud.Valotta de Phalangio A pulo, in quo pleraque hiftorice, pleraque philofophice de hoc infecto ejusque miro veneno enarransur ac difcutiuntur. Neapol. 1706. I2mo.

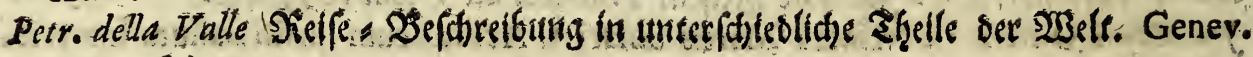
1674. fol.

De Vallemont Curiofitéz de la Nature \& de l’ Art fur la Vegetation. Parif. 8vo, qux

a Ferd. Ludov. a Bresler in Germanicum Idioma transl, prod. fub Titul, Des Sarn.

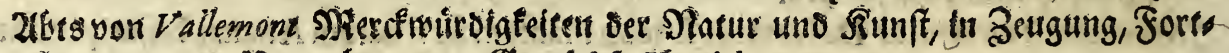

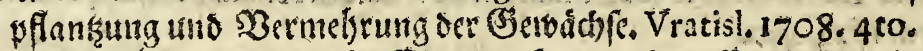

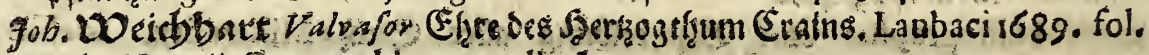
Bernb. Varenii Geographia generalis. Jenx 1693. 8vo.

Cbrifian, Vateri Phyfiologia experimentalis, Vitemb. 170r. 4:0.

Georg, Hier. Velfcbii Obfervact. Phy fico. Medicarum Hecatoftex Il, Auguft. Vindel.

1679.400

- de Agagropilis. Aug Vindel.1660.4to.

- de Vena MedinenfiAug. Vin 1674.4to.

Marci \&nuli Venet de Regionibus Orientalibus. Helmftad, 1586, 4to.

pbil. Verbeyen Anatomia humani corporis. Lipfia $1705.8 \mathrm{vo}$

Jof. du Verney Tr. de Auditus organo, ftructura \& ufu, rep. in Clerici \& Mangeti Bibliotheca Anatomica Part. III. pag 371. feorfim Gallice prod. Parif, fub Tit. Traité de l' Organe de $1^{8}$ Ouie. $1683.12 \mathrm{mo}$.

Francifo. Baconis de Verulamia Opera. Francofad. Moen,1665. fol.

fufti Veffi Dift. de Pollinciura. Erfurt. 1699.4to.

- de Lapide Bezoardico: Erfurr. 1707. 4to.

- de Antimonio. Erfurt. 1711. 4to.

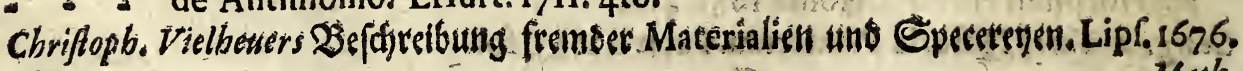
4to. Math. 
Matb. Unzeri Phyfiologis Salis. Halx Sax. 1624 4to.

- - . Tract. Medico-Chymicus de Sulphure. Hale 1629.

Gotbofred. Voigtii Curiofitates Phyficx. Lipf. 1698.8vo,

- - Phy ficalifher Zeit= Bertreiber, Lipf, 1694. $12 \mathrm{mo}$.

70b. Cbriftopb. Volckbammeri शlúrnbergtfdse Hefperides. Norimb. 1708. fol,

- - Continuario Nlirnbergifcher Hefperidum. Norimb. 1714. fol.

- - Beftreibung etlider fiemder (Betwadffe, reper, in Continuatione Hefperidum, pag. 208. feqq.

Georg. Anton. Volckmanni Silefia fubterranea. Lipi, 1720.4 to.

\section{W.}

Leonel Wafers Seife = Defdgreibung ber Americanifthén Eivo, Enge Darien, reperitur

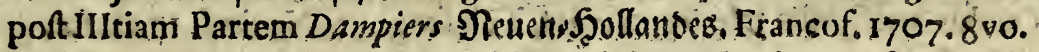

7ob. Cbriftop. Wagenfeiliz de S. R. I. libera civitate Noribergenfi. Altorf. 1697-4to, Godofred. Wagneri Diff. de Lapide fulminari. Vitemb. 1710.4 to.

Wagneri Hiftoria Naturalis. Helvetia curior,

Petri Cbriftiani Wagneri Differtat, de Lapidibus Judaicis. Halx Magdeb.1724. 4to. Cbrif. IW arlitzii Mufeum curiofum auctum. Witteberg.1702. 4to.

Georg. Wolff. Wedelii Exercitationum Medico. Philologicar, Sacrarum \& profana-

rum Dec. V. Jenx 1691. 4to,

- - Diff, de Serpentaria Virginiann, Jenx I7 10. 4to.

gob. Frid. Weidleri Exercitatio de Phofphoro Mercuriali, precipue eo, qui in Baro. metris lucet, \& ejus rationibus, Witemb. 1715. 4 to.

Martin. Wsindricbii Commentarius de Monftris, in quo effentia, caufe \& affectiones mirabilium animálium explicantur. Vratisl. 1595.8vo.

Cbrift. Weifens StaatsoGeographie. Lipfix 1709.8vo.

Georg. Wendii Examen Svecici lapidis, qui miris fuperbire figuris dicebatur. Thorunii 1701.4 to.

Cbrift. Wermutbi Catalogus Imperatorum Romanorum, Gothx 1702. 8 vo. Jacob. de Wilde Gemmx antiqux felectx. Amftel. 1703. 4 to.

Matb. Willens Tractat, de Salis Origine ejusque incremento, accremento \& decre. mento. Jenx 1686, 4to.

Cornel. Stalpart van der WWiel Centur, Obfervationum Medico - Chirurgico- Anatomicarum rariorum, Haga Comitis 1686.8vo.

Job. Wierus de Preftigiis Dxmonum. Bafil. 1583.4to.

7ob. Wigandi vera Hiftoria Succini Boruffici. Jenæ $1590.8 v 0$.

petr. Wolfart Hiftoria Naturalis Haftix inferioris. Caffel. 1719. fol. 


\section{CATAL. AVCTOR. ET LIBROR. ALLEGATORVM.}

facob. Wolffi Scrutinium Amuletorum. Jenæ.

Cbiftian. Wolffii Entbectung ber waf̧ren Lirfache yon ber wunberbaren $\mathfrak{B e r m e f ̧ r u n g ~}$ Des Ëetrendes. Hal. Sax. 1718. 4to.

70b. Woodivardi Specimen Geographix Phyficx. Tiguri s704. 8v́o.

Olai Wormii Mufeum f. Hiftoria rerum rariorum. Lugd. Batav. 1655. fol.

Job. Pauli Wurffbainii Salamandrologia. Norimb. 1683 .

\section{Z.}

Pauli Zaccbic 2uafiones Medico-legales. Francof, ad. Mœn. 1688 . fol. Zacuti $\mathrm{Tr}$. Calculos non gigni in fubftantia, fed cavitatibus renum. Lugd. Batav. $1638.12 \mathrm{mo}$.

fob. Zabnii Specula Phyfico-Mathematica:Norimb. 1702. fol.

- - Oculus artificialis teledioptricus f. Telefcopium. Norimb.1702. fol.

Mart. Zeileri Epiftolæ.

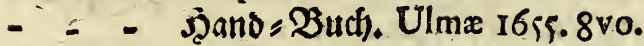

- - Topographia Ducatus Brunfvicenfis. Francof. $16\{3$, fol.

- - Itinerarium Magnæ Britannix.

- - Theatrum Tragicum.

Jab. Mar. Zonca de Viperis pro Trochifcis eligendis. Venet. 1605.4 to.

Joh. Zwelferi Pharmacopœja Regia. Norimberg. 1693. 4to.

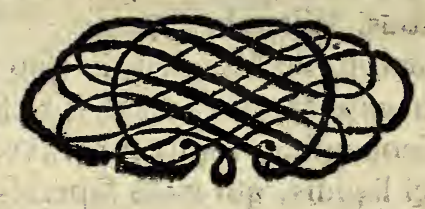




\section{$(0)$}

\% 

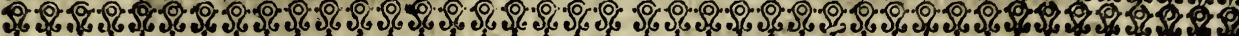

\section{INDEX RERVM.}

A.

Alveolus Luid. 208.

A bardxolx roftrum IIo.

1. Abelmofch 172 .

Abies marina 164 .

Abortus 9I.

Abri femen Asgyptiacum 160 。

Acajou 164.

Accipiter $3 \mathrm{HI}$.

Achates 180.

Acinus Peruanus 163.

Acus marina 97.

Adamas 178 .

Aggagropila I18.

Enex figurx vid. Tabula anez

Eris f. Cupri minerre 40.87.264-270.

Ithiops 9i.

Etites 206.207.

Ætito-Ammonites $20 \%$

Itito-Bucardites ibidem.

Etrito-Campoides ibid.

Etito-Geodes ibid.

Atrna 294.

Agrimenfor 321\%,

Ahoay 163 .

Alabaftrites 199.

Alcis pes 116 .

Algá Intybacea 166.

Aloès flores 170 .

Ex Aloë foliis linteum $31 \%$.

Aloë variolofa \& varicofa inf

Altaria 3.4. 13.19.

Alchea Agyptiaga

Aluminofa minera 290.29r.

Amethyftus 40. 178 .

Amygdali Regni Granatenfis $1640^{\circ}$

Amygdaloides 217.

Anacardium Brafilienfe 164 .

- - Orientale 165.

Ananafa 175.

Androdamas 178 .

Anifum ftellatum $1590^{\circ}$

Annulus 62.181. 315.

Anthracodendron 238.

Aphrofelinus lapis 203 .

Amaranthus faxeus $217:$

Ambrx globus 312 .

Amianthus 41. 198.

Ammochryfos 199.

Amuletum Rom. 310 .

Amygdali petrefacti $67^{\circ}$

Angvis 99.

Animalia petrefacta $67^{\circ}$

Antimonii Minere 87.278.280.

- Apocymum 175.

Aqva petrefacta $6 \% .216$.

Arachnites, Arachneolithus, Arachnoides

Lapis II 3.22\%。

Aranea Regni Sardinix I I 2.

- - Brafilienfís 39. 1 I 30

- - Exficcata II 3.227.

Arcus Tartaric. 46.

Arecx Fruclus 174 .

- - Lignum 1758 
Arena 199.

- conchifera 244.

Argenti Minerx 40.65.87.259.263.

Argyrites 199.

Arma 45.

Armamentarium $45 \cdot 46 \cdot\{2.63$.

Armadillus 95 .

Arfenicalis minera 279.280 .

Arum paluftre 172 .

Afellorum lapides I 13.

Afini Egyptiaci cornu 106.

Afpeftinus lapis vid. Amianthus,

Aftacus marinus 39.

Afphaltcum 293.

Aftería 208.

Afteriarum Matrix $23 \mathrm{I}$.

Aftroites 86.181.208.209.

Aftronomica inftrumenta 42.322 .

Atramentum Sinęnfe \& Japonenfé 3 I 3.

- - Indix Occidentalis ibid.

Aurantium hermaphroditum I 68 .

- - petrefactum 224.

Auri minerx 40.64.75.86.256-.259,

Aurum Chymicum 304 .

Auris marina I 25 :

B.

Baculus lit. Sinicis infer. 308 .

Badiana 159.

Balanorum Tefte 127.

Balanus Narbonenfis I.28,

Bambuina canna 160.

Ex B. Can. capfella 308 ,

Barometron 320.

Bafaltes 200.214.

Bafilifucus 94:

Belemnites 209.210.

Bellaria Tiburtina $2 \mathrm{I}$,

Beloculus I8z.

Bezoar Orientale roz.
Bezoar Occidentale 103.

- - Microcofmicum 104.

- - Suillum ro4.

- - Bovinum 105.

Bezoardici capri cornua I06.

Bibliotheca Elifabetana 22.

- Mar, Magdalenea 4r.

Bilmuthi Minera 279.284.

Bitumen 29r.

Bituminofum lignum 291 .

Boletus cervinus 173 .

Bolus Armenix co aliis 301.

Bunonienfis lapis 200.

Brontias'229. 230.

Bucardites 227.228.

Buccina I 46,

Buceros 228 .

Bufo Indix Orientalis 109.

- - caudatus IOO.

- - per vomitum ejectus ro8.

Bufonites 228.

Buglolfa, pifcis I 16 .

Cacao in nuce 166.

Cadmia 28 I.

Calcarius lapis 200.

Calcis Flos 200.

Calculus veficx 38.104.

- - Renum I05.

- Pulmonum ros.

- - Fellis 105.

- Mufculorum 106.

Calendarium Turcicum 307.

Calices vid. Balanorum tefitx.

Callimus 2 ro.

Camera obfcura 318 .

Campana i 3 .

- urinatoria 329 


\section{INDEX RERVM.}

Cancer petrefactus $6 \%$.

Cancellus in cochlea rox.

Cancrorum lapides 102。

Cancer Moluccanus ror.

- Brafilianas toz.

.. Marinus 10r. 102.

Caninus foetus III.

Canna Bambuina 160.

- Saccharifera ibid.

Cantharus 64 .

Capreoli cornua alba 106.

- - monftrofa ibid.

Capricornus infectum IIg.

Caphur vid. Afinus Egyptiacus。

Carbo foffilis 293.

Cardamomum maximum i6t。

Cardites 182.

Carina vide. Nautilus minor.

Carcharoduntes 233 .

Cariophyllorum arboris ramius 16

Cariophyllus miraculofus $16 \%$

Carniola vid. Sarḍa.

Carpionum lapis 119.

Carpolithus 21\%.

Cartilago terre vid. Ofteocolla.

Cafeus petrefactus 42.62 .210 .

- - peregrinus 122.

Cafláve vid. Panis Cuba Inful。

Caflia . Agyptiaca 159.

Cataphracta 46:

Cataphractus pifcis Izz.

Catena patibuli zio.

Cateñx plambex 308

Cati oculus 182.

Caviano 121.

Cedrí conus 166. . .

Cenchrites 217\%

Cerachates 181.

Cerafa botryformia: 161

Cerafi nucleus 316 .
Ceratites 228.

Ceraunias 211.230.

Cervinus porus 166.

Cervi tophus 64.

- lapis 122.

Cesbes bituminofus 294'

Chalcedonius 40.179.182.

Chama 128.

Chameleon Ir 4 .

- Amboinus íbid.

Charea 38 .

- incombuftibilís ex Asbefto 79.

Chela cancri marini rot.

305.306.

Chelex cancrorum monftrofia ror. IO2.

Chelidonii lapilli 228.

Chelonites 229.

Chemicum metallum 76.334.

Chirurgica inftrumenta 322.

Chryfammonites 247.

Chryfitis 179.183 .200 .

Chryfócolla 284 .

Chryfolithus 179.183 .

Cinnabarina mineræ $40.65 \cdot 282 \cdot .285$.

Cinnâmomi Medulla 170.

Ciftulæ Siniciè 308.

Citrus in citro 168 .

Citrium monftrofum ibid.

Clethrites $24 t_{0}$

Cobalti mínerx 87.284。

Cochlew 132 .

Cochlea c cancello st.

Cochlearia żt6.

Coecilia 99. 100.

Cocorium opera 313.

Colites 229.

Collare 316.

- . Turcícum 308.

Colocynthis Ægyptiaca 171. 
Columba marina 117 .

Columelli 2 Ir.

Colybri avis 39.

Conchæ 127.

- - Veneris 129.

- pétrefadx 66.75.243.

Conchilia 39.52 .68 .124 .132 .

Confetti de Tibuli 2ı.

Conus Pinus far. Indic. 164 :

- . Pinaftri maritimi ibid.

- - Abietis marina ibid

- Cedri 166

- 7. Laricis arboris 164.

Corallium $64.68 .21 \% \cdot 220_{0}+319$

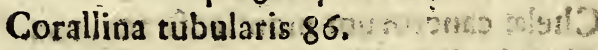

Corallinus arbor 68.165 .

Corallinus lapis 40 :

Cordylus si6.

Corium humagum 75

Cornu Ammonis 86.246.

Cornu Afini Egypr, yid. Afini Æg Corn.

Cornua Rupicapræ vid. Rupicapra coin.

- Capri Bezoardici vid. Bezoard.

Capr. cornd

- - Capreoli monftrofa vid. Ca. preoli corn. mon.

- - Capreoli alba vid.Capreoli corn. alba

Coronx ferpentum I0O. IOI.

Curfoides 183.

Cortex Maffoy vid. Mafloy cortex.

Cortex Aromaticus Ind. 170..

- - - Jubabxi7r.

- - Odoratus Indicus 175.

- - Flexilis fingularis 175.

Corvi Americani roftrum no.

Cos 200 .

Crabronum nidus II6.

Cranium 93.

Cremor Thermar. Carolinar. 200:
Crocodyius 39.

- - Terreftris Agypracus Ir4.

Crucifer lapis 183, 21.

CrucifixusSalvator ex murice 303.

- - - ebore 316.

- - . Cile cryftallino $31 \%$

Cryftallus 40.63.66.85.192\%-198.

Cucurbita amara 17 i.

- - Japoneafístizo.

- - lagenas referens 174:

Culter Turcicus $30 \%$

- - Mofcovicicus zio.

- - Sinenfis ibid.

- - Sacrificatorius 75 .

- - ad jocum factus 310.

Cuprefli arboris fruetus $164 . "$.

Cupri mineræ vid. Eris nineræ.

Cuprum camentatum $40.64 \cdot 212$,

Curia 22.

D.

Daciylis Idxus $2 \mathrm{iz}$.

Damarum pilx ir8.

- - cornua 106.

Datura Indorum 172.

Delineationes Mathematicx $5 \mathrm{I}$.

- - Pißorum 5 I. 53 .

Delphini caput 110.

Dendrachates 66.180.

Dendrita 68. 238.--240.

Dendroides 221.-223. it. 86.79.88.

Dens petrefactus 86 . I2I.

Diabecicus Crater 319.

Draco 94.115.

Draconis arboris Lignum I7I.

Dracontia $247^{\circ}$

E.

Echinus marinus $39.95 \cdot 96$

Echinometra 96.

Echinites 66.229.-123\%.

Echini capitulum 231. 


\section{INDEX RER VM.}

Echini Radiolum ibid.

Echin tmetri230.

Echini pedes 236

Elatites 240.

Enorchis 23ेr's

Enfis 46.316.

Entrochus 23r.

Equinus fcerus trr.

- - tophus 39.

Equina caudă fignum milit. Turcic. 30\%.

Erinacei foetus III.

Eruca II3. II4.

- - petrefáta $2 \xi 2$.

Excutia ventriculi $7 \% .30 \%$.

= - - Sinenfis 308 .

F.

Faba R. Virginix Is9.

- - Brafiliz ibid.

Faufel 174 .

Ferri Flos 40.223:

- - Minerx 69.86.87.212.276, -278 .

Fiftula 308.

Fiftularia 212.

Flabellum Chinenfe 63.308.

Florentinus lapis $6 \hat{j} .214$.

Flores 159.

- - Herbx Thex 170.

- Aloës i70.17 I.

- - Martis 223.

Fluores 192.

Foetus humanus $9 \mathrm{r}$.

- - canisus IIr.

- - equinus Irr.

- - erinacei III.

Folium ambulans 39.117 .

Fortitudinis exempla 314.338 .

Fungites 40.66 .86 .223 .240 .

Fungus Querni arbor. $17 \mathrm{r}$.

Funis pyrius Turcicus 307.

G.

Galadites 183.200:
Galdx Gummi vid. Gummi.

Gallix cornutx 172.

Gallus Guineenfis rig.

- Gamaicu vid. Variolites

Ganitri femen 173.

Geminze.40.65. 85.178.--192.

-... D. Stephani 89. .

- - figurate 64.65.180.-184.186.190.

... antiquxe 83.183.185.186.

Geodes 212.

Geographicus lapis I84.

Gladius 316.

Globus marmoreus 40.20 .

- Globularis lapis 68:213.

Globuli Turca:um precatorii 4r.316.

- - Pontificorum precaturii ibid.

Glofopetra 232.

- Glottis lapid. 233.

Gobio capitatus 1 19.

Goflipiam Turcicum 163 .

- - Javenfe ibid.

- - Silefiacum ibid.

Gramen 59.

- - topho incruftatum 240.:

Granatus 179.

Gryilotalpa 123.

Gryphites 247.

Gummi Gaidx 170.

1. - Kikekunemalo ibid

- - - de Lock ibid.

Gyprum 201.

Hæmachates 183.

Halcyoneum $255^{\circ}$

Hammites 234.

Helictropius 183.

Herbarium impreffum 38.

- - vivum 39.159.

Hiacynthus $66: 183$.

Hippocampus 95.97.

\section{H.}




\section{INDEX RERVM.}

Hippopotamus 39.

- - dens III.

Hirundo marina 94.

Horologium 52 .

Hortus 48 .

Hydraulicx machinz yid, Machine $\mathrm{Hy}$ -

Hyfterolithus 234 .

(draulicar

Hyfteroxylon 173 .

Hyftricis penna IO9.

-. - lapis 122.

-.. Pícis 123.1 I.

Jafpis I79. 183.184 .

Ichthyites $40.68 \cdot 88.235$

Ichthyodontes 228.233 .

Ichthyofpondyli 208 .

ICtis Brafilienfis 107 .

Jecco vid. Lacerca domeftica.

Indigo 174 .

Infula 6 .

Inftrumenta Mathèmatica 42.52 .85 .

- - Aftronomica 42.322.

- Chirurgicai322.

- Optica 75.317.318.

- - Mafica 322.2

- Pyrobolica ibid.

Jolith us 40.205 .

Iridis fcutell: 76.304 :

Ifidis Icuncula 63.77 .

Jubabx cortex vid. Cortex Jubaba:

Judaicus lapis 223.224 .

Juvencx tophus $12 \mathrm{I}$.

$$
\text { L. - . }
$$

Lacertus Cyprius I I4.

Lacerta volans II 5

- - domeftica f. Jecco II5:

- - Chalcidica II6.

- - Indix Orientalis I I5.

Lagenx ex cryftallo 305.

Lagenx inclufum opus artif, ibid:

Lanifera arbor 163 .
Lapis miraculofus 5 .

- numifmaticus, 213.

- D. Stephani ibid.

$\because-$ Lunaris 215.

Lapides-anthropomorphi 236.

Laqueus patibuli 310.

Laterna c. lampade 321 .

- Magica 318.

Lazaroli Italorum 17.2 .

Lazuli lapis $40.179 \cdot 184.185$.

Leucophthalmus 185 .

Libra vid. Statera.

Lignum Carabaccinum I 7 I.

- - Draconis arboris IZI.

- Cephaloides 173.

- Arecx I74.

- Foffile abiegnum 240

- Alni 24r.

- - Diebenfe ibid.

- . Bituminofum ibid.

Lithanthrax 293.

Lingula 116 .

Litheofphorus 200.

Lithoftrotior 214.

Lithoxylon 40.42 .66 .75 .241 .242 。

Lobus ex Virginia I 59.

- - Brafilianus ibid.

Lock, Gummi vid, Gummi deLock.

Locufte I I7 • I 18.

Locuftarum alx literatx 117 .

Ludus c. conchis Joponenf. 308 .

Lydius lapis 201 .

Lyncis ungula 116.

Lyncurius $185^{\circ} \mathrm{M}$.

Machinx Hydraulicx 46.47.

Magnes 20r.

Mantes vid. Folium ambulans.

Manucodiaca vid. Paridifiaca avise

Malaccenfis lapis 122.

Malachites $179.185^{\circ}$ 
Mandibulatapidea 2$\} 2$

Marcafita 40.

Marga faxatitis 302 .

Margarita 185 .

Margaritiferz conch 128. 129.130 .

Marmor 20r:

- - Florentinam 63. 214.

Maffoi cortex 170.

Mathematica inftumenta 42. 52.85 .

Mathematicx delineationnes $\delta \mathrm{r}$.

Mehenbetheñ 174 .

Melanteria 290.

Melitites 186.

Melocarduus I72.

Mica 199.

Micrographice feripture 38.43 .312 .

Microfcopium 317.318.

Milleporis 214 .

Mineralia $40.42 .75 \cdot 86 \cdot 87 \cdot 2790: 285$.

Mineræ aúri vid. Auri M.

- - Eris vid. Eeris M.

- Argenti vid, Argenti M.

- Antimonii vid. Antimónii M.

- - Cinnabarine v.CinnabarineM.

- Ferri vid. Ferri M.

- - Plumbi vid. Plumbi M.

- - Stanni vid Stanini M.

Monachus marinus IIx.

Monfrum 38.92 .

Möhument Frider.Carđin.\& Epifc. Vr, $\not$. - Francifi Ludovici Electolis Trevir. 8.

- - GodofrediEp. Ir.

- Henrici Ep. 10.

- - Precislai de Pogrella Ep. io.

- - Nankéri Ep. Io.

- Johannis IV.Ep.ibid.

- Petri II. Ep. ibid. Ingitsica

- - Rudolphi Ep ibia.

- Johan.V.Thurzonis Ep. ibid.
- - Aner. Jernin Ep. ibid.

- - Weiskopti Suffragan. Ir. -

- - Lifchii Suffragan. ur.

- - Canonicorum II.

- Henrici Ṕiitz.

- - Wenceslai Duc.Sagan. 18.

- - Anna Duc. 21.

- Henrici VI.Duc. Vratisl, 21.

$-\quad$ Kromayeriz13.

- Ribifchii r3.

- Cratonis a Kraftheim. ibid.

- - Wolffii i4.

- Arzatii 14.

Morochtus 203.

Mofchata nux vid. Myriftica nox.

Mofchifer folliculus roz.

Mumia Agyptiaca 42.120.

Murex 147.148.

Mus albusiis.

$\because \quad-\quad$ variegatus ibid.

- Norwegicus ibid.

- - marinus ibid.

Mufculites 24 \%

Muleus Áfricanus 169.

- Sf. petrofus ibia.

- petrefactus 67.242.

Mufetrm Retsmarianúm î.

$$
\begin{aligned}
& \text { - D Lanrex ibid. }
\end{aligned}
$$

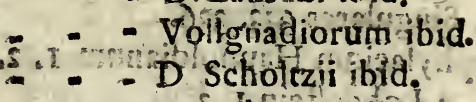

$$
\begin{aligned}
& \text { - _. Káfenbergeri ibid. } \\
& \text { - - Crufí ibid }
\end{aligned}
$$

Murrhina vafá 63.314.

Muficum avtomaton 42 . 
Myrifticą nux Bạntamenfis I60.

- - Malabarica 16I.

- - lapidea 224.

M) tulus 127.120 .

Narval pifcis cornu 106.

Natrix 98 .

Nautilus major 124 .

- - minor 124. 125.

- - petrefactus I.Nautilites 66,246 .

Nephriticus lapis 183. 247. 248 .

Nerita 156.

Nidus avicul, edulis nir.

- Pfittaci 112.

Nitri minere 289.

Nuculx Indice 163.306.

Numifmaticus lapis 213.

Nummi Grxci 29.69.70.75.78.

- Confulares29.45. 70.78.

- - Imperatorum Romanorum 3i. $35 \cdot 45.69: 70.71 .75 \cdot 81.309 .322$.

- - Bracteati 71. 75. 304 .

- Thaleri $71.74 .81 .324 .-33 \mathrm{I}$

- - Moderni $38.45 .52 .71 .74 .322 .-$

- - ex metallo Chemico 334.

324 .

- Exotici 2. 38.332.

- - Singulares 333.336 .

Nummophylacium Haunoldianum $I .2$.

- a Lohenifein I. t.

- - abHoftmannsvvaldau 1.2.

- a Reufch 2.

- Bibliothecs Elifabeth. 29.

- Biblioth. Mar. Magd. 45.

- Com. a Proskau sz.

- Hanckianum 69.

- Líbentantzianum 78.

Nux Palm $x$ coccifere $162 \%$

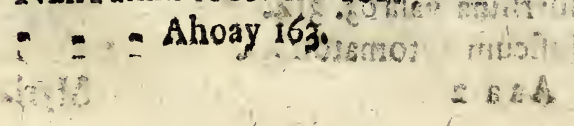

- - Juglans fingul. 170.

Obfidianus lapis 186. Oculi artificiales 320 . Odontopetra 232.252.253. Olivarìs lapis vid. Pirenes. Olyfantfande 126 . Ombrias 214. 230.

Oninius cortex 170 . Ony x 179. 186. 188 .

Opalus 179.188.

Oolithus 234.

Ophthalmici lapilli 2r4.

Opuntix fruclus 16 I.

Orbis maritimus fpinofus 123.

Organum pnevmaticum I5.

Ornithogloflum 232. Offa 93.94.

- petrefacta 66.86.252.-2540

- gigantea I2. $2\{2.253$.

Officula auditus 93.

- genitalia canis 120.

Ofteocollus 212.

Ofeocolla 224.225.226.

Oftraceus pifcis 39.

Oftrea 127.

Ovalis lapis 2r4.

Ovum in ovo 39.108.

- - petrefactum 67.

- toplo incruftatum 67.205 .

Ova monftrofaro7. 108.

- Parchalia Mofcovitica 75 .

- - Viperarum 100.

- - Scorpionum 10.

- Struthionis 107.

- Sepiarumiro.

Palatinm 49.

P.

Palmx Dactylifera ramus 162. - - fructusibid. $=2: \mathrm{Coc}^{2}$ 


\section{INDEX RERVM:}

- . Coccifere ramus ibid.

- ... frúctus major ibid.

- . - fruetus minor 163.

- . - fructus politusibid.

- - ex fructu poculum ibid.

Panis petrefactus 42.63 .

. . Cubx Infulx 169.

- Mexicanus ibid.

- ex Weftphalia vulgo Bon pour

Nickel. ibid.

- .. ex glandibus ibid.

- ex margaibid.

Pannus ex Apocymo 175.

- - fingularis 312.

Papilio 39. 123.313.

Papyrus incombuftibilis 75.305 .

Paradifiaca avis 109. eutabut cil 02 ?

Paranacare roz.

Paftinaca marina 98.

Patella 125.

Pavonis caput Iro.

- c cauda Alchymicorum 304.

Pectinites 248.

Pelicani roftrum no.

Pennx Galli Africani rig.

Pepita Indica $163_{3}$

Percx pifcis lapis 23. 6 .

Pes petrefactus 67 .

Phafeolus Ægyptiacus 160

Phofphorus 294.

- nativus 200 .

Picx Brafilienfis roftrum no.

Pifturx in recentialbario $8.9 \cdot 9.21 .23 \cdot 25$.

- - - veftute 12.

: : recentiores 6.13.21.43.49. 33 .

Piedro del Porco 63. 82. 88.

Pila marina 98 .

- - Atagnatilis $98 \%$

Pinna marina 127.
- fruticofa 166.

- maritima conus 164.

Pinaftrum 164.

Pinus fativæ conus 164.

- - conus lapideus $225^{\circ}$

Piper Brafilienfe $173^{\circ}$

- Athiopicum 174.

Pifa Indix Orientalis I 72.

Pifcis quadrangularis 1 I 6 .

- - - triangularis ibid.

- - cenutus 117.

Pifolithus $67 \cdot 86 \cdot 2,25 \cdot 226$.

Plumbi mineræ $65 \cdot 86 \cdot 87 \cdot 272 .-275$ ह

Pnigires 237.

Poculum ex nuce:Palma 163.355 .

- - cx argento Gramatis diftind. 30 .

Polyedrum 319.

Polygonum vitrum vid. Rolyedrum. $\pi$

Porcellain vid. Murrhina vafa.

Porcellana concha $I 52$.

Porus cervinus 166 .

Precatoriæ fphirula.4I. 3 I 6.

Prifmatriangulare 3.9

Prunum lagideuper $26 \%$.

Pfeudodamas 178 .

Pfeudocoallium vid. Corallium:

Pfoafites 2,6

Pugio Turciris 307.

- Romanus 3 IO

Punctularia 214.2 I $\{$.

Punicamala I I I.

Purpura I 5 I.

Pyrenes 226.

Pyrites 202.

Quercus marina I 65 .

- - veficularis I75.

$R$.

Radix cordaca $I 72$.

-, - miraculofa II. 63.

- - Serpentariz Virginianxi72. 
Raja pifcis 39.94.97.

Rana peregrina I09.

Ranxiceletus IO9.

Reliquix 5 .

Retepora.215:

Rhinocerotis avis cornu rog.

- - quadrupedis corhu 63 .

Ricini Americ. femen I73.

Rhodites vid. Rofoices.

Bofoites $18 \mathrm{I}$.

Roftrum a vis Rhinocerotis I09,

- . S Abardeole folicanir IO.

to - Corvi Americanit Y Y $0_{0 .}^{-}-$

- Pica Brafilienfís a ro.

Rosulatia 24 .

Rubinus I88.

Rubrica 302.

Rupicaprecornua rô6.

. DI $\hat{C} \cdot T$. S

Sabatili femen Imb.

Sabulofus lapis vid. Ofteocolla

Sacellum 3. 6.-2.1,3.20.2I.

Saccharifera canna 160.

Sagittx Tartaricx 46.310.

- - Turcice $30 \%$

Sal $40.75 \cdot 86.87 \cdot 288$.

- - ex Sale cryftallino ftatux $3 \mathrm{I}$.

Salamandra II 5 .

Salix monftrofa 68.

Sangvinalislapis 88 .

Sapphyrus I79. 188.

Sarda 179.188 189.

- alba 64 .

Sardonyx 40. $179 \cdot 180.789$.

Saxum 202.203.

Saxdution medulla 202.0 \&
Saxum Lisillum 203.

Scarabaus Ind. Orientalis I I x. -

- - Monoceros ibid.

- Lervinus ibid.

- $\quad$ - Bucerosibid.

- Aquaticusibid.

- - Piaus ibid.

Sceletus Abortus 91.

- - Partus monftrofi 92:-

- Teftudinis 98.

- Rañ 109.

Schapedarmtje 127 .

Sclopetum Turcicum 310.

Scolopendra 97

Scolopendrites 190.

Scoria 86.287 .288 .

Scorpio Javanus 39.

\section{- Ceilanicus 107.}

Scorpionum ova 107.

Scriptura exotica fingul. 38.43.63.37T.

Scriptorix pennx 316.

- 10 inftrumentum pro temperandis 317.

Sculpture vid. Tabula xneex.

Scyncus marimis 'I I 4 .

Secale Sicilianum 168 .

- - miraculofún ibid.

Selenites 215 .

Semen Sabariti i 70 .

- - Ganitri Ambonenfe 173.

- - Ricini Ámericani ibid.

Sepites 190.

Serpentaria Virginiana 72.

Serpens 92.

Serpentum exuviagg.

- ... perrefacta 127.

- - corone 100. Pof.

Serpentinus lapis 236.237 .

Serra pifcis v.Xiphia pifcis.

Sigillum Turcicum 189.308 
Sigillum Mofcoviticum 308.

Silex perforatus 215 .

Sipho 47.

Smaragdoprafius 180.190.

Smaragdus Orientalis 40.180.190.

Solea lingulata Ir 6 .

Solen 127.128.

Speculum caufticum 318.

- anamorphoticum $3 \mathrm{rg}$

Specularis lapis zoz.

Spongites 226.

Spondylus 125.-

Spondylolithi 208 .

Staladites 86.203.204:

Stalagmites 215 .

Stanni minerx $65.86 .87 \cdot 270.27 \mathrm{y}, 27 \mathrm{z}$.

Staterx fingulares 46.

- - Sinicx 308.

Stätux modern. 3.7.8.9.14.15.22.29.42\%

$43.61 .62 .75 \cdot 303 \cdot 35 \cdot 316$.

- - vecufte i3.21.

Stavrolithos vid. Crucifér lapis.

Stelechites 226.

Stella marinx 39.119.120.

- - Judaicx 215 .

Stellares lapides vid. Aftroitzo

Stentoreus tubus 3210.

Stigmites 214.

Strombi 14 r.

Sturio 119.

Sturionis ovula 122.

Stylus Vet. Ériptorius 309.

Suberis arboris fructus 175 .

Succinum 66.75,291-293.

Succini-Mater 29r.

Suffimentum Japonicum 308.

Suggeftus 6. I5.

Suillus lapis 203.

Sulphur 294-296.

$$
T \text {. }
$$

Tabaci capfellæ 3 I2, 313.
Tabaci fiftula Turcica $30 \%$

- - Sinenfis 308.

- - Tartarica ibid.

Tabernaculum 4 .

Tabulx ex argento \& metallo 4.10 .29 .

- ex Succino 313.

- pictx praftantifima $6.12 / 13$. $21 \cdot 22.43 \cdot 49 \cdot 53.61 \cdot 82.88 \cdot 3 \mathrm{IT}$

Tabula anamorphotica 311.319 .

- - Optica 318.

- - Sinica 308.

- - excera 28.

- - ex ebore 316 .

- - ex offe frpix 29.

- ex floribus I59.

- - ex feminibus I59.

Tabula xnex 26.29.43.51.52.61.84. 85.311 .313$.

Talcum 281.284 .

Tarantula Perfica-112.

- - ex Apulia ibid."

Talifman 335 .

Talpa 123.

- - Capenfis Ir8.

Tartarus 204.

Tedæ arboris conus 164 "

Telefcopium 318.

Tellina I 3:2.249.250.

Tellinites 249.250 .

Templum D. Johannis 2:

- - ad St. Crucem II.

- D. Virginis I2.

- D. Vincentii ig.

- - D. Elifabetx I3.

- - D. Mar. Magdalene I4.

- D. Barbarz I8.

- SS. JElu ig.

- D. Alberti 2 I.

D. Dorothex $2 \mathrm{r}^{\circ}$ 


\section{INDEX RERVM.}

Tempum S. Córporis Chrifti $2 x$.

- - S. S. Trinitatis ibid.

- - D. Claræ 2 I.

- D. Urfulx 2 I.

Terebinthin ramus 172 .

Terra figillata $40.86 .88 .296 \cdot 30 \mathrm{r}$.

- - foliaca Sicula 294.

Ex T Terasigillata, urceus, 314.

T.eftace marina vid. Conchylia, $i$ -

Teltudo 97.98.

- marina 39.

Thex flores 170 .

Thermometron 320.

Thracius lapis 190.

Thurus marinus $x 16$.

Topazius 63.66.180.190.

Tophus 204.205.

- Undulacus 216.

- Equi 39.

- Cervi 64.

- - Juvencx I2F.

- - Viculinas I2r.

Tormentum 45.321.

- Pnevmaticum 5z.

Tornatx res 62.306.307.

Trichices 205.

Triticum Sicilianum 168.

- - miraculofum ibid.

Trochifci Cypheorum 303 .

- . de Vipera ibid.

Trochitz 237.

Tubera terrx $17 \mathrm{r}$.

Tubularia 216.258.

Tubuli vermiculares 126.

Tubus opticus 318 .

Turbo 135 .

- - cylindroides 144 .

Turbinites f. Turbo petrefactus 86,250 .

Turcois 40.180. 190.

Turris I3.

Vaccinus lapis 215.
Vaniglix Gliqua $I 7 \mathrm{r}$.

Variolites 237.

Vafcula ex Achate I80.315.

- - Sinenfia 315.

- Japonia 3 I4.

- - Delphenfia 315.

- - ex Alabaftro ibid.

- - ex Lap. Serpentino 315.

Verdello 203 .

Vermicularis lapis $238.255^{\circ}$

- - Tubulus 127.238.

Vertebra lapictea 208.

Vefpertilio 1 IO.

Violacei odoris lapis vid. Jolithug.

Vipera 100.

Vitra antiqua 22. $30 \%$.

- rubinea 63.305.

- - c cinere humano 305 .

- - - tabaci, Ibid.

Vitrum Sinenfe 307.

Vitra tonantia $3 \mathbf{I 9}$.

Vitrex lacrymx ibid.

Virrum Antimonii 63.

Vitriolum lanuginofum $87^{\circ}$

Vitrioli Minerx 289.290.:

Vitulinus tophus $\mathbf{I} 2 \mathrm{r}$.

Umbilicus marinus 126 .

- - petrefactus $25 \mathrm{r}$.

Undulago 216.

Ungvis marinus 128.

Unicornu marinum 106.

- - foffile 254.

Unionum mater 128.

Urceus Perficus 63.

- - Turcicus 30\%.

- - ex Terra figillata 314.

Urnx fepulchrales 42,76,86.309.

Ufrixa 93.

Uva marina I 16 .

Vulpis Canadenfis ro7.

Xiphia pifcis 39.98 .

Xylofteum vid. Ofteocolla.

Zieatlinan 99.
Z. 


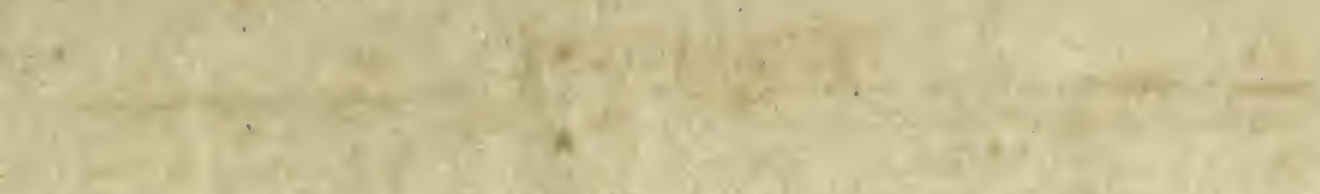

\section{ant}

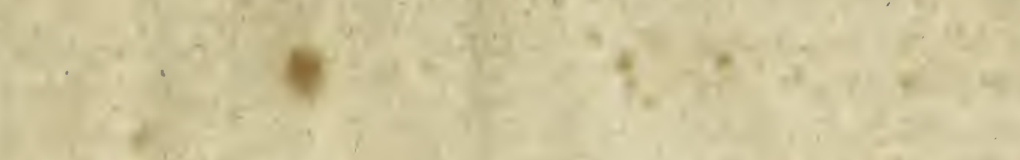

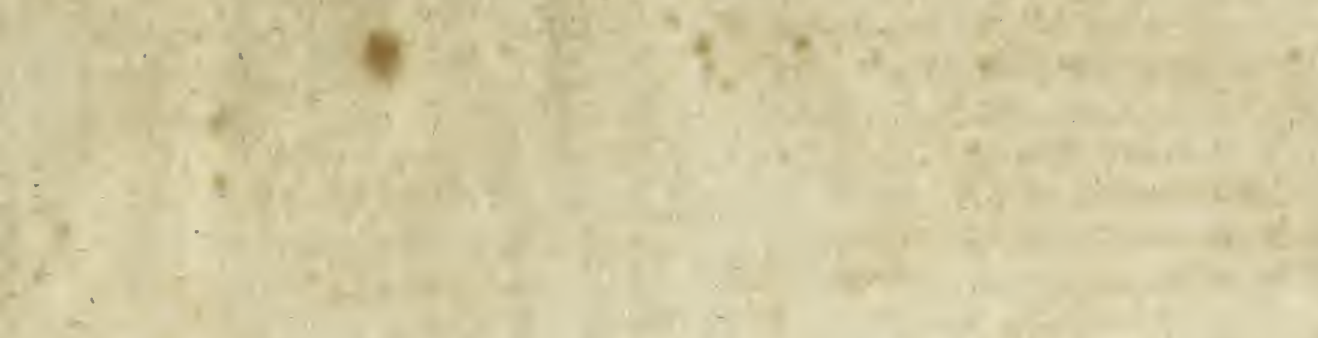

the

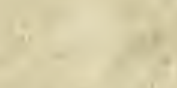

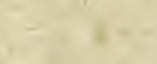

$=$

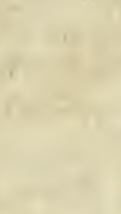

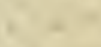

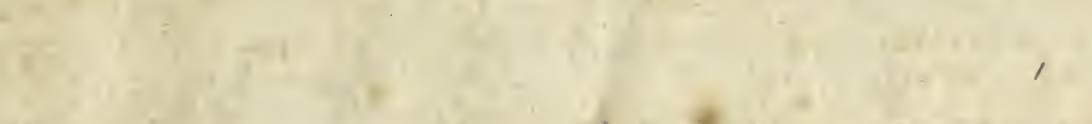

$+\infty$

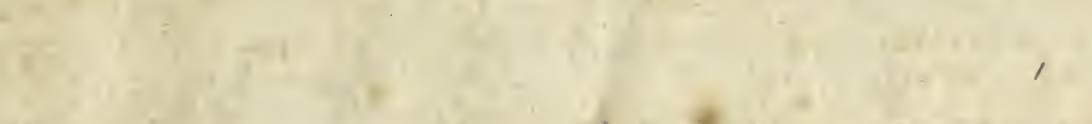

$=$
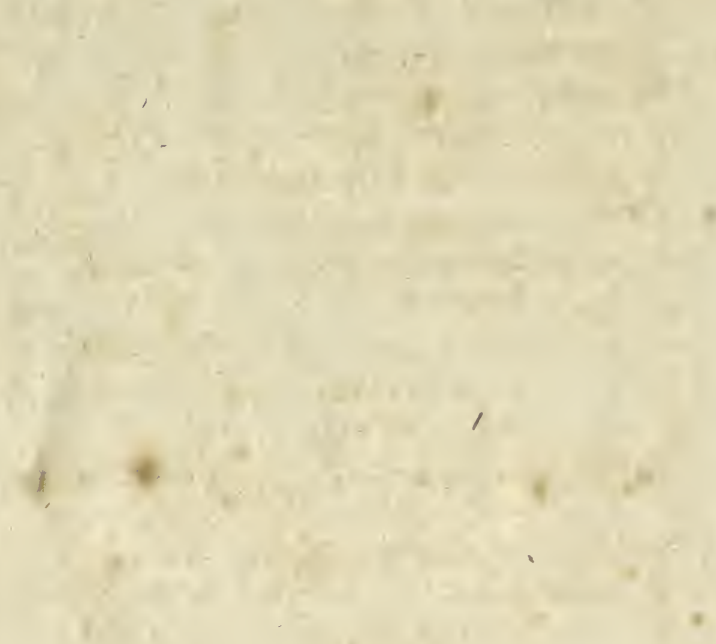

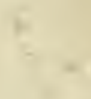

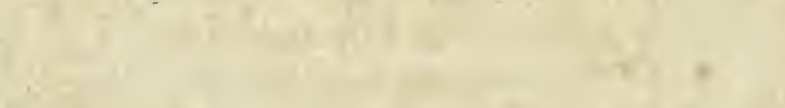



coles:

$$
\begin{aligned}
& x^{2+1}, A-Z, A a-Z Z, A a a^{4} \\
& B, a, L+d, 18 / 1 / 82
\end{aligned}
$$

$$
P
$$

$$
\text { SPECIAL } \begin{array}{r}
85-B \\
17.09
\end{array}
$$

THE d. PAUL GETTY CENTER LIBRARY 
4

2

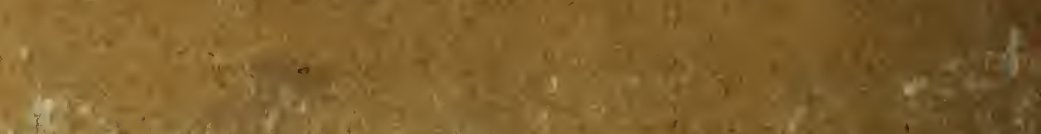

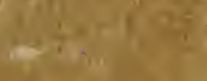

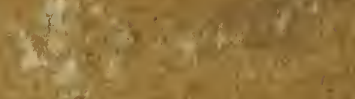

s.

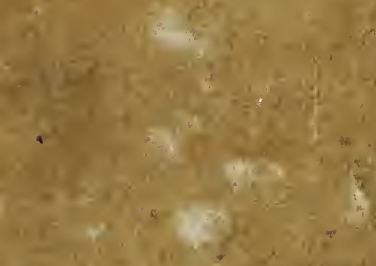

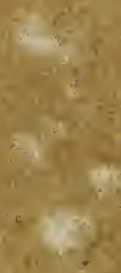

$+4$

it on

4

me

.

$x_{1}^{2}$

8

\section{$\left(\frac{1}{2}\right)$}

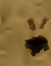

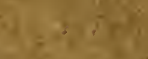

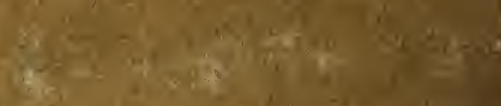

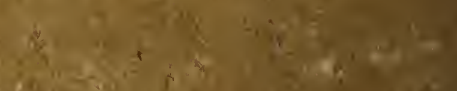

$3(x)$ 